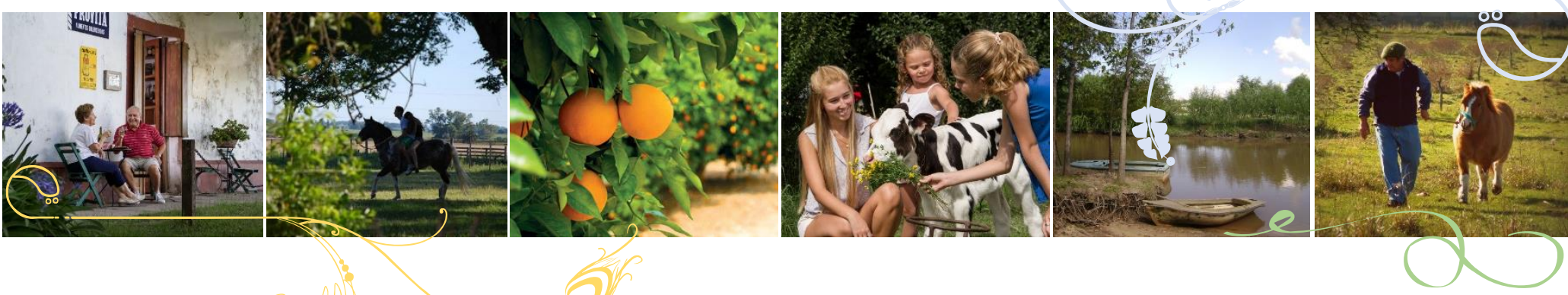

El turigmo rural y lag trangformacioneg de lof sigtemag productives familiareg del corredor del Uruguay. provincia de Entre Riof

Lic. Bernardita Zeballos

Trabajo de Tesis para ser presentado como requisito parcial para optar al Título de MAGISTER EN PROCESOS LOCALES DE INNOVACION Y DESARROLLO RURAL (PLIDER)

UNIVERSIDAD NACIONAL DE LA PLATA FACULTAD DE CIENCIAS AGRARIAS Y FORESTALES

DEPARTAMENTO DE DESARROLLO RURAL

CARRERA DE MAESTRIA

La Plata, Argentina

Noviembre de 2018 


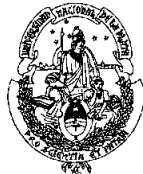

EL TURISMO RURAL Y LAS TRANSFORMACIONES DE LOS SISTEMAS PRODUCTIVOS FAMILIARES DEL CORREDOR DEL URUGUAY, PROVINCIA DE ENTRE RÍOS

Lic. Bernardita Zeballos

Director: Ing. Agr. MSc .Gustavo Larrañaga

Co-director: Dr. Pierre Gasselin Tutor: Dr. Marcelo Sili 

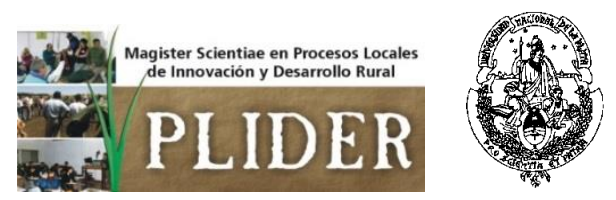

EL TURISMO RURAL Y LAS TRANSFORMACIONES DE LOS SISTEMAS

PRODUCTIVOS FAMILIARES DEL CORREDOR DEL URUGUAY, PROVINCIA DE ENTRE RÍOS

\title{
APROBADA POR
}

\author{
Dr. Roberto Bustos Cara
}

Ing. Agr. Guillermo M. Hang

Dra. Ada Graciela Nogar 


\section{AGRADECIMIENTOS}

A los pilares de mi vida, mis viejos, Hebe y Coqui, por su amor incondicional, su ejemplo y enseñanzas...

A Dante, la luz de mis ojos, por su apoyo eterno, por bancar semanas de cursado de maestría, los nervios y búsquedas de una madre inquieta...

A mi gran amor Lucas, por su hermosa compañía, por su escucha atenta y consuelo cuando la angustia me invadió, por su abrazo contenedor, por su infinito amor...

A mis compañeros y jefes de INTA que me dieron esta posibilidad de formación, en especial a Diana, Alejandro y Rubito que me acompañaron con su paciencia, consejos y cariño...

Al INTA, como institución y emblema, porque es a partir y a través de esta que puedo sentirme útil, que puedo ser un instrumento al servicio de otros...

A los docentes y compañeros de la maestría PLIDER, porque mi vida fue un antes y un después de ellos, de ese aula, de los aprendizajes y de cada experiencia y momento compartidos...

A Gustavo Larrañaga, Pierre Gasselin y Marcelo Sili por sus consejos, su generosidad y tiempo brindados a esta aprendiz durante todo el proceso de tesis...

A los informantes en territorio y las familias entrerrianas que abrieron sus vidas, que me permitieron bucear en su pasado, en sus luchas y sueños, para intentar comprender, descubrir, interpretar... un poco más...

A Dios, a la vida y a este espíritu aguerrido que se animó a surcar horizontes, atravesando barreras y muros para llegar a destino... 


\section{INDICE GENERAL}

RESUMEN

ABSTRACT

CAPÍTULO 1 - LA EMERGENCIA DEL TURISMO RURAL EN LA ACTIVIDAD

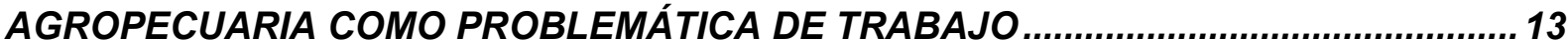

1.1 LA TRANSFORMACIÓN DEL SECTOR AGROPECUARIO COMO FACTOR CLAVE PARA EL IMPULSO

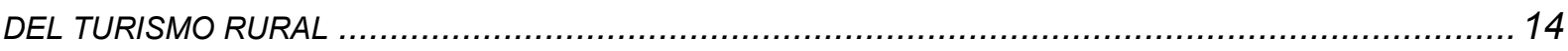

1.2 EL TURISMO RURAL EN ARGENTINA Y EL ROL DEL INTA EN SU PROMOCIÓN COMO ESTRATEGIA

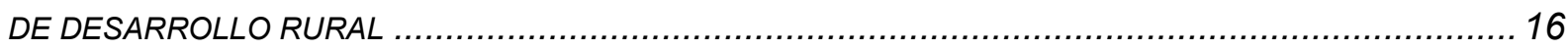

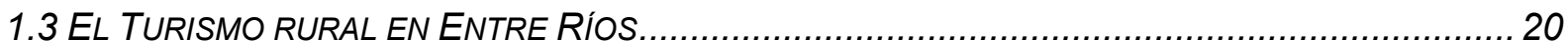

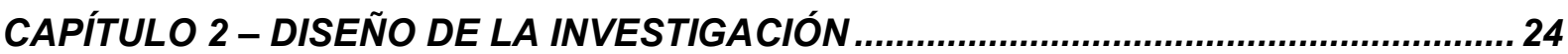

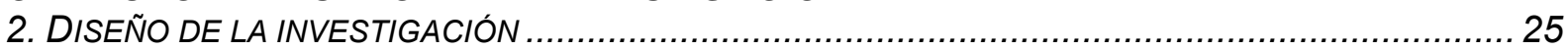

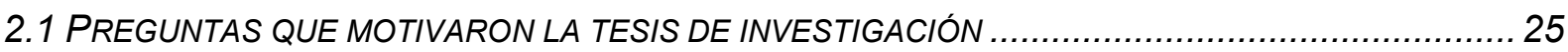

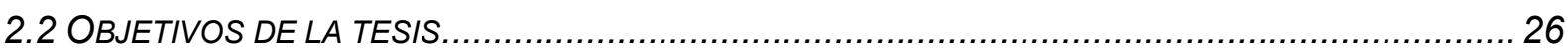

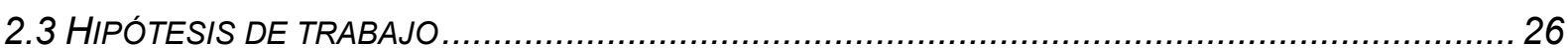

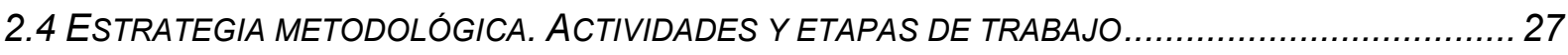

2.4.1 1era etapa: entrevistas exploratorias y elección de variables ..................................... 27

2.4.2 2da etapa: generación de preclasificación de emprendimientos de turismo rural del

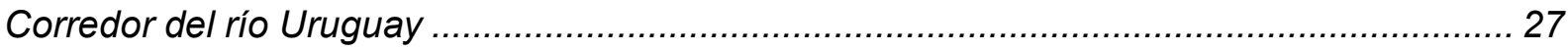

2.4.3 3era etapa: selección de casos y realización de entrevistas ...................................... 27

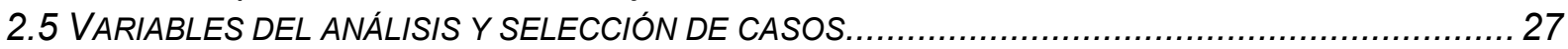

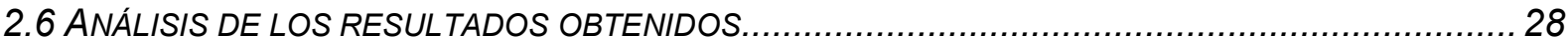

CAPÍTULO 3- EL MARCO CONCEPTUAL DE REFERENCIA PARA INTERPRETAR LAS TRANSFORMACIONES EN EL SISTEMA DE ACTIVIDADES FAMILIARES .....................31

3.1 LA FAMILIA RURAL, EJE VERTEBRAL DEL SISTEMA ...................................................... 32

3.2 LAS UNIDADES PRODUCTIVAS FAMILIARES COMO SISTEMAS DE ACTIVIDADES. EL SISTEMA DE ACTIVIDADES COMO MARCO CONCEPTUAL Y METODOLÓGICO............................................... 37

3.3 EL TURISMO RURAL COMO HERRAMIENTA DE VALORACIÓN TERRITORIAL Y ESTRATEGIA DE

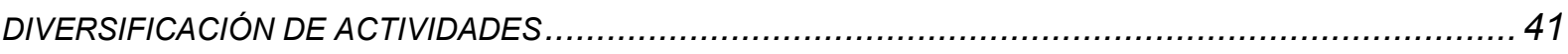

3.3.1 EL TURISMO COMO INSTRUMENTO DE TRANSFORMACIÓN Y VALORACIÓN DE LA IDENTIDAD

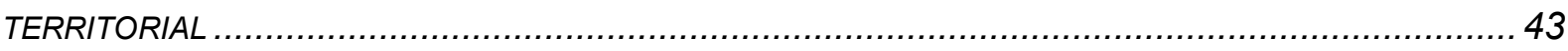

3.3.2 EL TURISMO RURAL COMO ESTRATEGIA DE DIVERSIFICACIÓN DE INGRESOS Y/O ACTIVIDADES

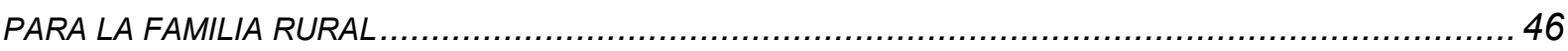

3.3.3 EL TURISMO RURAL EN EL ESPECTRO DE LA PLURIACTIVIDAD RURAL ............................. 46

CAPÍTULO 4- CARACTERIZACIÓN DE LA REGIÓN EN ESTUDIO: LA PROVINCIA DE ENTRE RÍOS Y EL CORREDOR DEL RÍO URUGUAY.................................................52

4.1 EL TERRITORIO PROVINCIAL................................................................................. 53

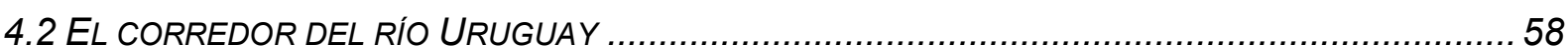

ANÁLISIS POR REGIONES DEL CORREDOR DEL RIO URUGUAY ………....................................59

4.2.1 La región norte del Corredor del Uruguay ................................................................6 60

4.2.1.1 Localización y características generales...................................................................6 60

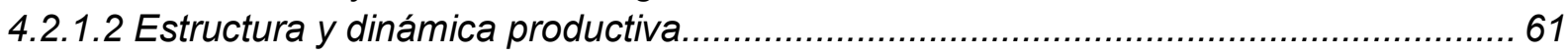

4.2.2 La región Centro del Corredor del Uruguay ............................................................... 63

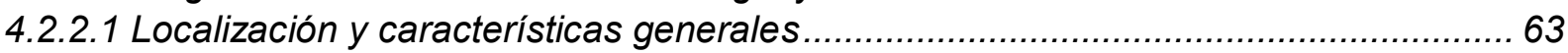

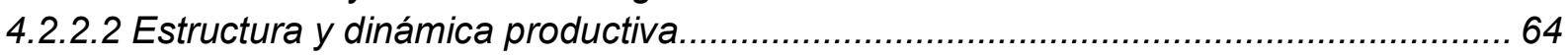

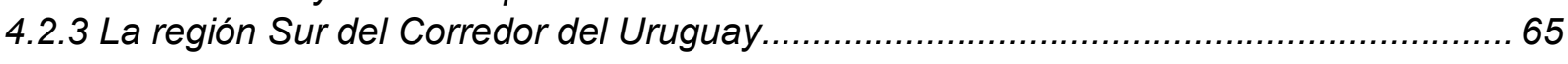




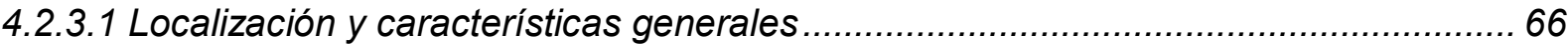

4.2.3.2 Estructura y dinámica productiva.

CAPÍTULO 5- EL TURISMO RURAL EN LA COSTA DEL RÍO URUGUAY. PRESENTACIÓN DE RESULTADOS Y DESCRIPCIÓN DE LOS CASOS.........................69

5.A RESULTADOS OBTENIDOS DE LA PRECARACTERIZACIÓN .................................................. 70

5.B ZONA NORTE. DESCRIPCIÓN DEL CONTEXTO, ASPECTOS ORGANIZATIVOS Y REGULATORIOS. 72

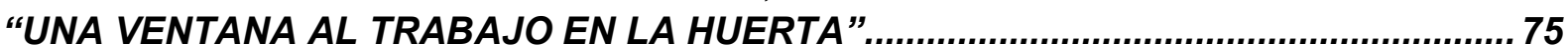

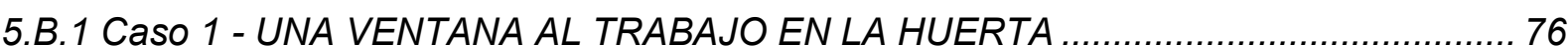

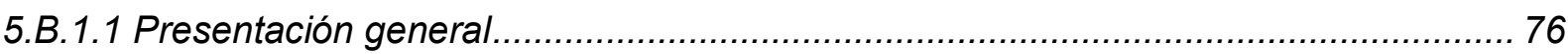

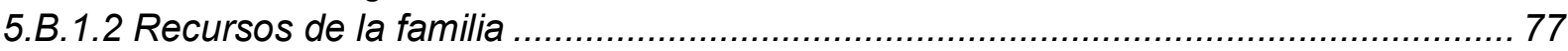

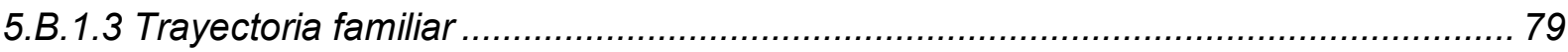

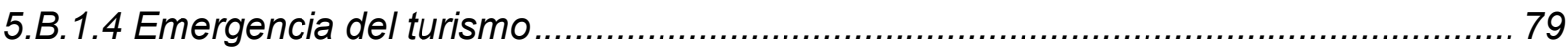

5.B.1.5 Objetivos, decisiones y estrategias puestas en marcha......................................... 79

5.B.1.6 Vinculación del sistema familia-explotación con la actividad de turismo rural........... 80

5.B.1.7 Impacto del turismo en el sistema productivo......................................................... 81

5.B.1.8 Impacto del turismo en la familia, en las personas y en sus estilos de vida.............. 81

5.B.1.9 Percepción del futuro en relación a los hijos y en relación a su resguardo de ingresos

“UN ALMACÉN QUE ES MÁS QUE DESPENSA”

5.B.2 CaSo 2 - UN ALMACÉN QUE ES MÁS QUE DESPENSA .................................... 87

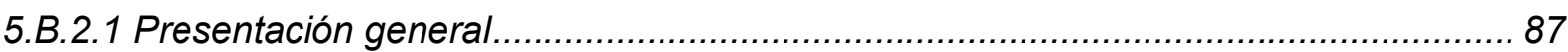

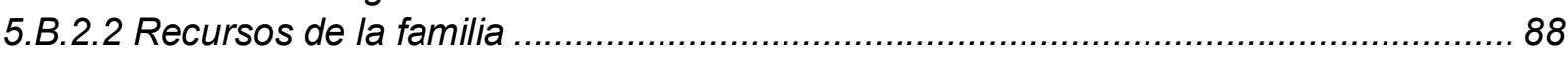

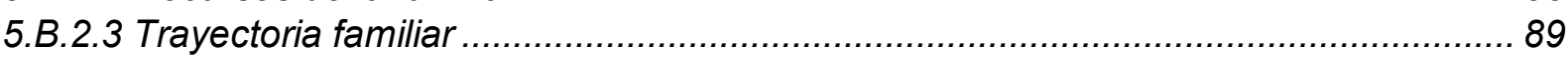

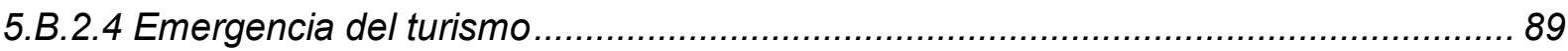

5.B.2.5 Objetivos, decisiones y estrategias puestas en marcha........................................ 89

5.B.2.6 Vinculación del sistema familia-explotación con la actividad de turismo rural............ 90

5.B.2.7 Impacto del turismo en el sistema productivo..................................................... 91

5.B.2.8 Impacto del turismo en la familia, en las personas y en sus estilos de vida ............. 92

5.B.2.9 Percepción del futuro en relación a los hijos y en relación a su resguardo de ingresos

“PATRIMONIO \& POLO, UNA COMBINACIÓN INTERNACIONAL”............................................ 96

5.B.3 Caso 3 - PATRIMONIO \& POLO, UNA COMBINACIÓN INTERNACIONAL ............... 97

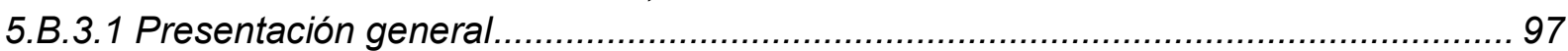

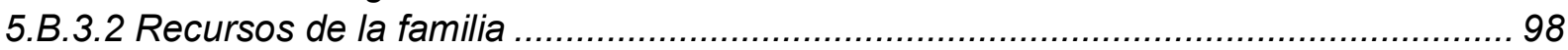

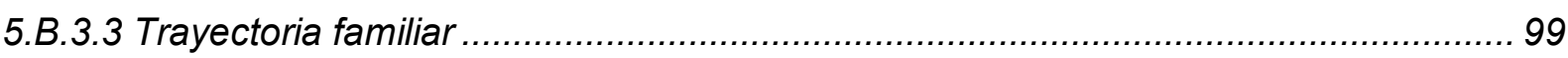

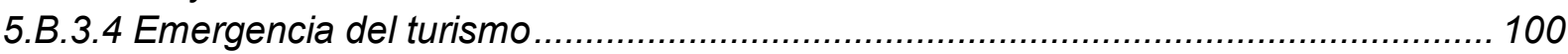

5.B.3.5 Objetivos, decisiones y estrategias puestas en marcha......................................... 101

5.B.3.6 Vinculación del sistema familia-explotación con la actividad de turismo rural.......... 102

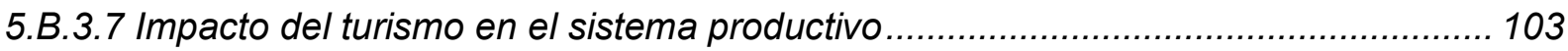

5.B.3.8 Impacto del turismo en la familia, en las personas y en sus estilos de vida............ 103

5.B.3.9 Percepción del futuro en relación a los hijos y en relación a su resguardo de ingresos

.

5.C ZONA CENTRO. DESCRIPCIÓN DEL CONTEXTO, ASPECTOS ORGANIZATIVOS Y

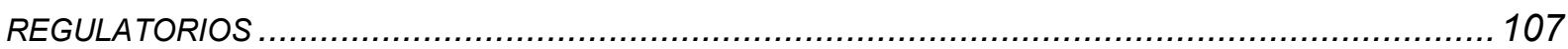

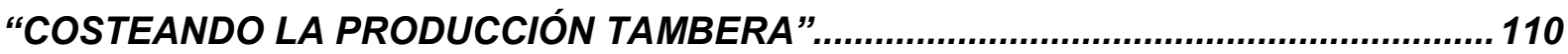

5.C.1 Caso 4- COSTEANDO LA PRODUCCIÓN TAMBERA......................................... 111

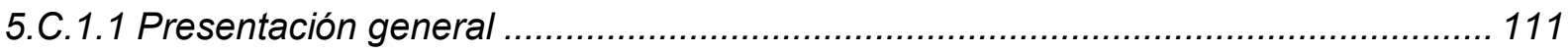

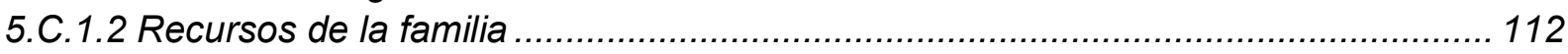

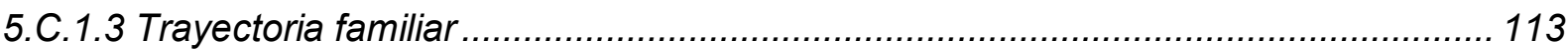

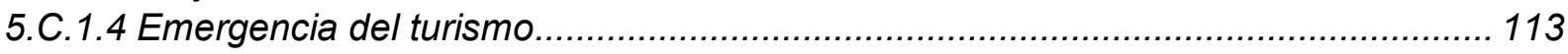


5.C.1.5 Objetivos, decisiones y estrategias puestas en marcha ..................................... 114

5.C.1.6 Vinculación del sistema familia-explotación con la actividad de turismo rural......... 115

5.C.1.7 Impacto del turismo en el sistema productivo...................................................... 116

5.C.1.8 Impacto del turismo en la familia, en las personas y en sus estilos de vida............ 119

5.C.1.9 Percepción del futuro en relación a los hijos y en relación a su resguardo de ingresos

“UN ESPACIO DONDE LUGAREÑOS Y TURISTAS SIGUEN HACIENDO HISTORIA".. 121

5.C.2 CaSO 5 - UN ESPACIO DONDE LUGAREÑOS Y TURISTAS SIGUEN HACIENDO

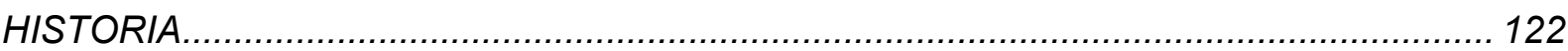

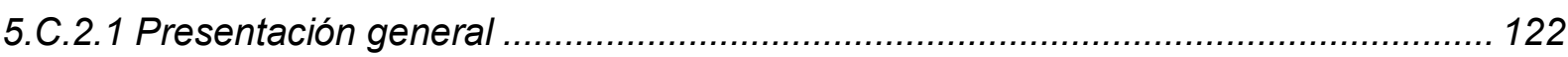

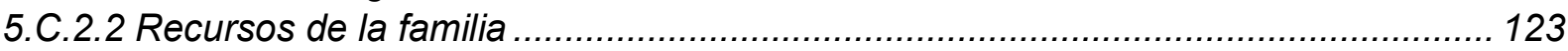

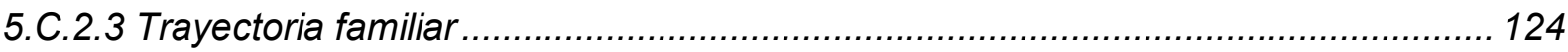

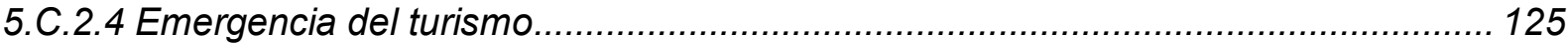

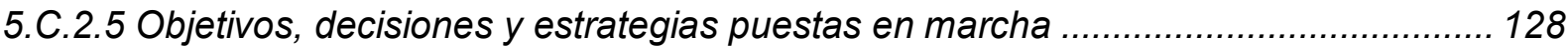

5.C.2.6 Vinculación del sistema familia-explotación con la actividad de turismo rural......... 128

5.C.2.7 Impacto del turismo en el sistema productivo...................................................... 129

5.C.2.8 Impacto del turismo en la familia, en las personas y en sus estilos de vida............ 130

5.C.2.9 Percepción del futuro en relación a los hijos y en relación a su resguardo de ingresos

“UN ALOJAMIENTO RURAL AL RESGUARDO DE LA HISTORIA"...............................133

5.C.3 Caso 6- UN ALOJAMIENTO RURAL AL RESGUARDO DE LA HISTORIA............... 134

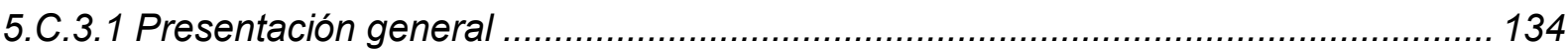

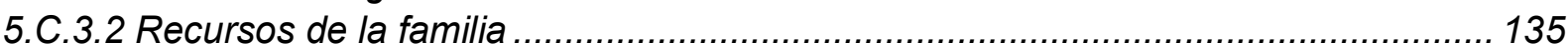

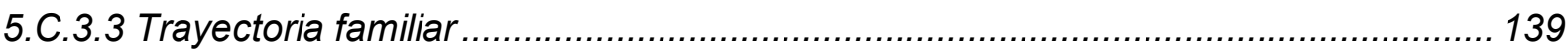

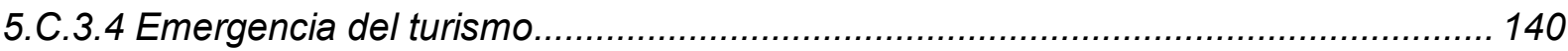

5.C.3.5 Objetivos, decisiones y estrategias puestas en marcha ..................................... 141

5.C.3.6 Vinculación del sistema familia-explotación con la actividad de turismo rural.......... 143

5.C.3.7 Impacto del turismo en el sistema productivo.................................................... 146

5.C.3.8 Impacto del turismo en la familia, en las personas y en sus estilos de vida............ 146

5.C.3.9 Percepción del futuro en relación a los hijos y en relación a su resguardo de ingresos

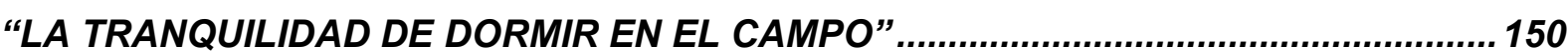

5.C.4 Caso 7- LA TRANQUILIDAD DE DORMIR EN EL CAMPO ................................. 151

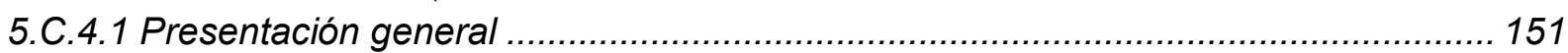

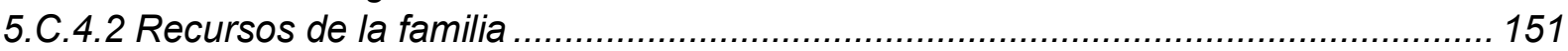

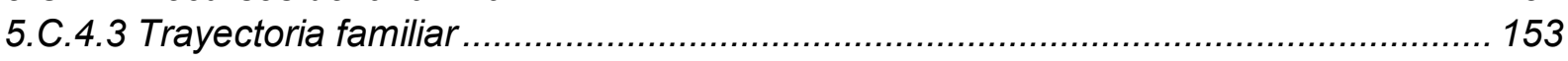

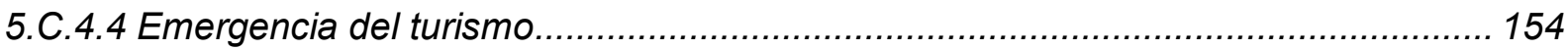

5.C.4.5 Objetivos, decisiones y estrategias puestas en marcha ....................................... 154

5.C.4.6 Vinculación del sistema familia-explotación con la actividad de turismo rural.......... 155

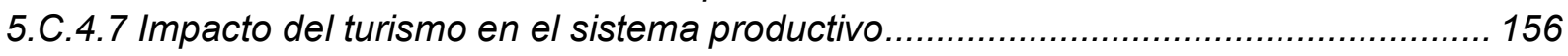

5.C.4.8 Impacto del turismo en la familia, en las personas y en sus estilos de vida............ 156

5.C.4.9 Percepción del futuro en relación a los hijos y en relación a su resguardo de ingresos

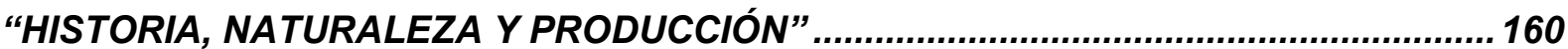

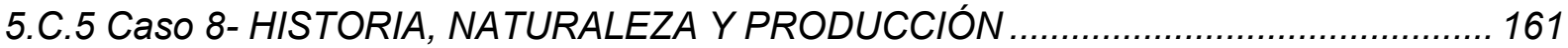

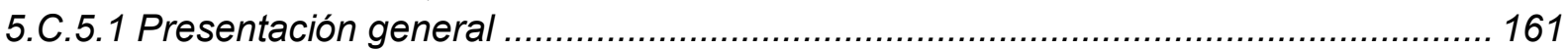

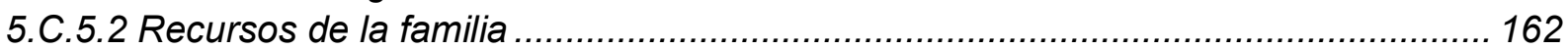

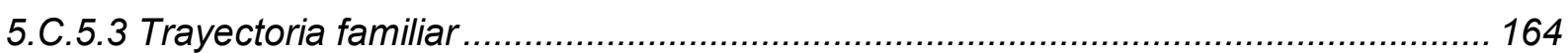

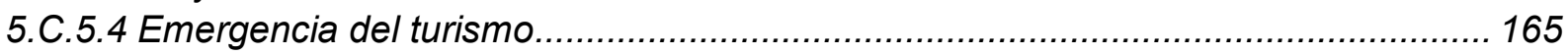

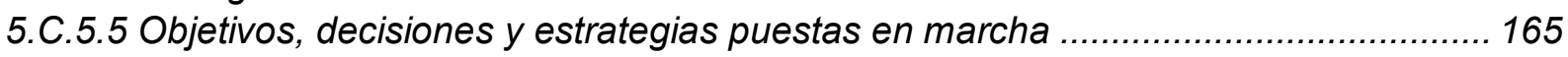

5.C.5.6 Vinculación del sistema familia-explotación con la actividad de turismo rural......... 166 
5.C.5.7 Impacto del turismo en el sistema productivo......................................................... 169

5.C.5.8 Impacto del turismo en la familia, en las personas y en sus estilos de vida............ 171

5.C.5.9 Percepción del futuro en relación a los hijos y en relación a su resguardo de ingresos

5.D ZONA SUR. DESCRIPCIÓN DEL CONTEXTO, ASPECTOS ORGANIZATIVOS Y REGULATORIOS... 173

5.D.1 CASO 9- SER ISLEÑO

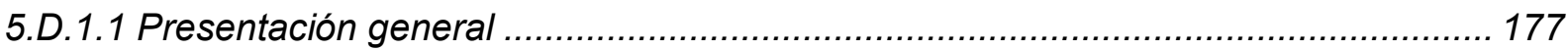

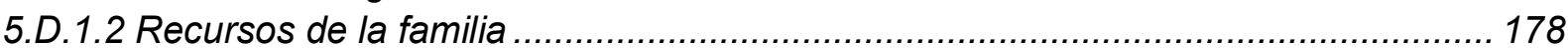

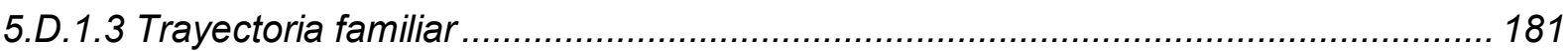

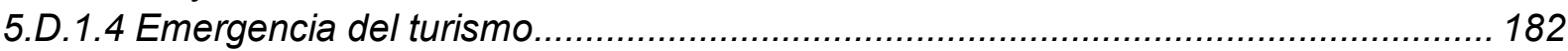

5.D.1.5 Objetivos, decisiones y estrategias puestas en marcha ....................................... 183

5.D.1.6 Vinculación del sistema familia-explotación con la actividad de turismo rural.......... 186

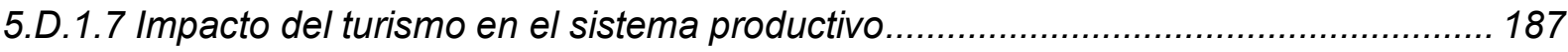

5.D.1.8 Impacto del turismo en la familia, en las personas y en sus estilos de vida............ 187

5.D.1.9 Percepción del futuro en relación a los hijos y en relación a su resguardo de ingresos

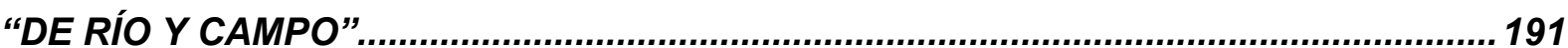

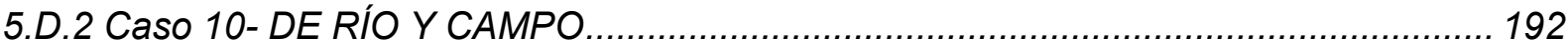

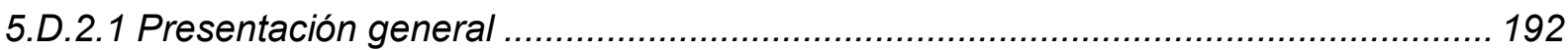

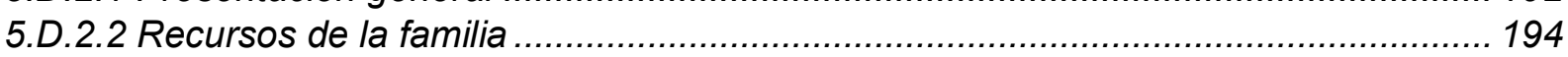

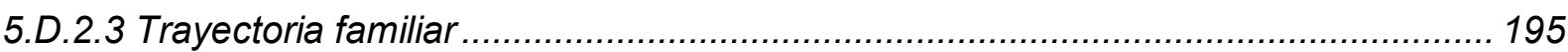

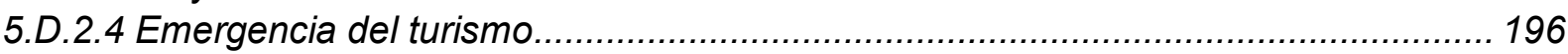

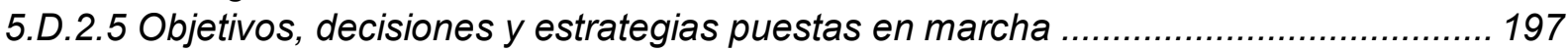

5.D.2.6 Vinculación del sistema familia-explotación con la actividad de turismo rural.......... 198

5.D.2.7 Impacto del turismo en el sistema productivo...................................................... 199

5.D.2.8 Impacto del turismo en la familia, en las personas y en sus estilos de vida............ 199

5.D.2.9 Percepción del futuro en relación a los hijos y en relación a su resguardo de ingresos

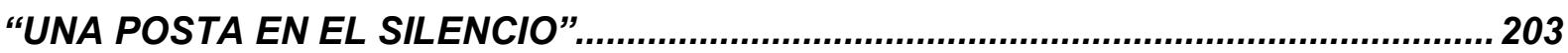

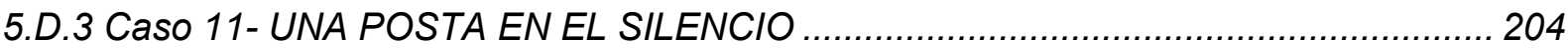

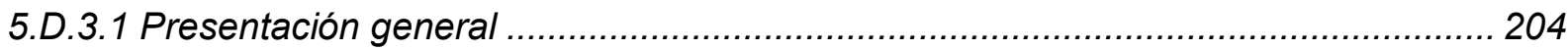

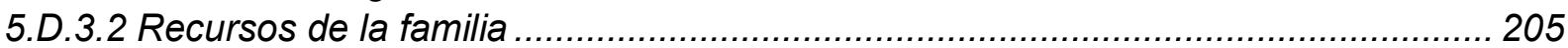

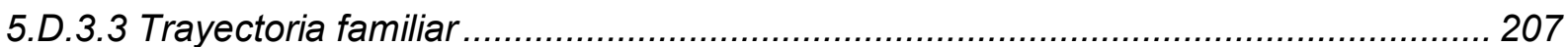

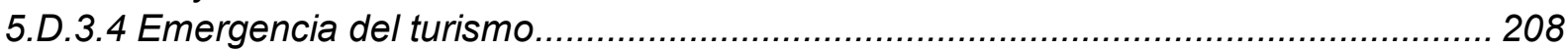

5.D.3.5 Objetivos, decisiones y estrategias puestas en marcha ...................................... 209

5.D.3.6 Vinculación del sistema familia-explotación con la actividad de turismo rural......... 211

5.D.3.7 Impacto del turismo en el sistema productivo........................................................ 212

5.D.3.8 Impacto del turismo en la familia, en las personas y en sus estilos de vida............ 212

5.D.3.9 Percepción del futuro en relación a los hijos y en relación a su resguardo de ingresos

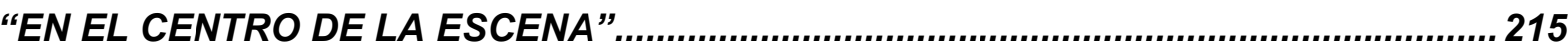

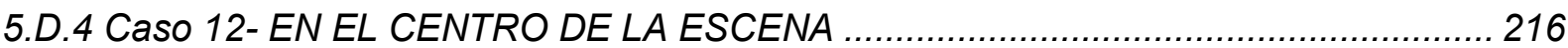

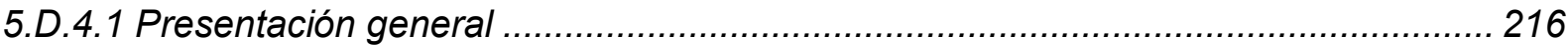

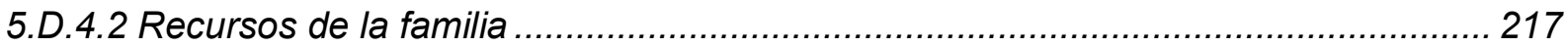

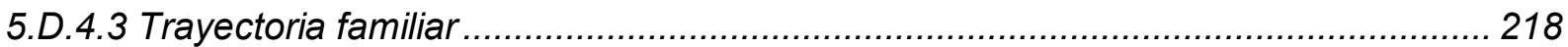

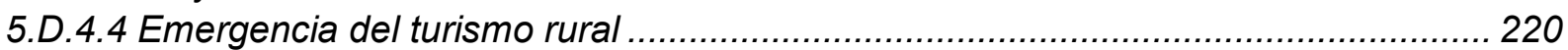

5.D.4.5 Objetivos, decisiones y estrategias puestas en marcha ....................................... 220

5.D.4.6 Vinculación del sistema familia-explotación con la actividad de turismo rural......... 222

5.D.4.7 Impacto del turismo en el sistema productivo.......................................................... 222

5.D.4.8 Impacto del turismo en la familia, en las personas y en sus estilos de vida............ 223 
5.D.4.9 Percepción del futuro en relación a los hijos y en relación a su resguardo de ingresos

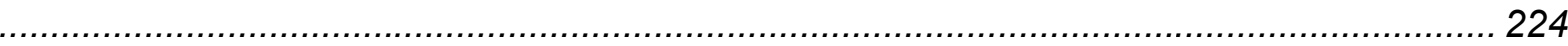

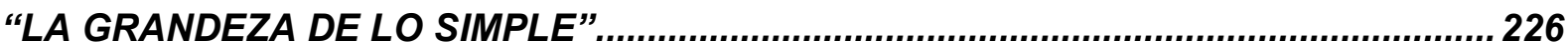

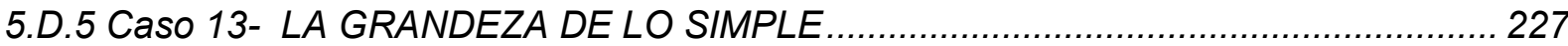

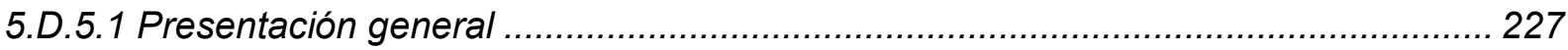

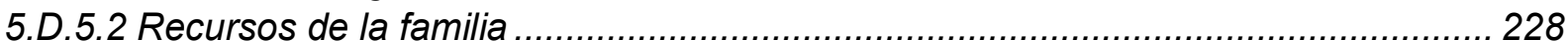

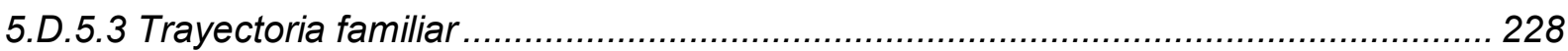

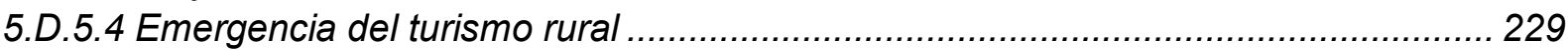

5.D.5.5 Objetivos, decisiones y estrategias puestas en marcha ...................................... 229

5.D.5.6 Vinculación del sistema familia-explotación con la actividad de turismo rural......... 231

5.D.5.7 Impacto del turismo en el sistema productivo..................................................... 231

5.D.5.8 Impacto del turismo en la familia, en las personas y en sus estilos de vida............ 232

5.D.5.9 Percepción del futuro en relación a los hijos y en relación a su resguardo de ingresos

\section{CAPÍTULO 6- FACTORES CLAVES QUE EXPLICAN LA ORGANIZACIÓN DEL TURISMO} EN LAS FAMILIAS AGROPECUARIAS.....................................................................234

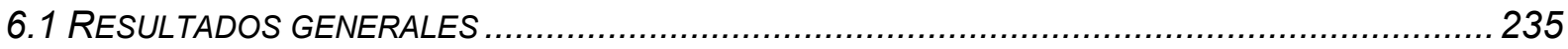

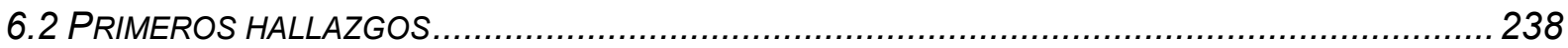

6.3 OBJETIVOS Y MOTIVACIONES EN TORNO A LA ACTIVIDAD TURÍSTICA EN LAS FAMILIAS

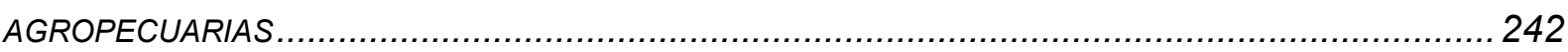

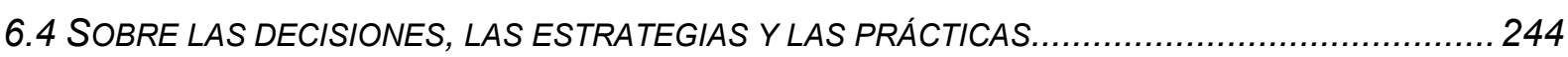

6.5 VARIACIONES EN LA RELACIÓN DE LOS SISTEMAS FAMILIA-EXPLOTACIÓN CON SU ENTORNO 246

6.6 LAS INTERACCIONES DEL SISTEMA DE ACTIVIDADES TURÍSTICAS Y AGROPECUARIAS ........... 248

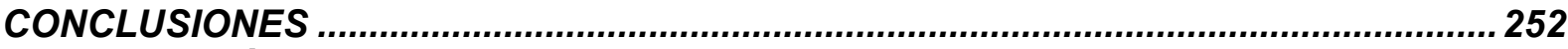

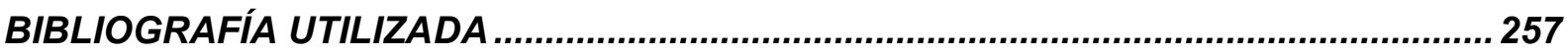

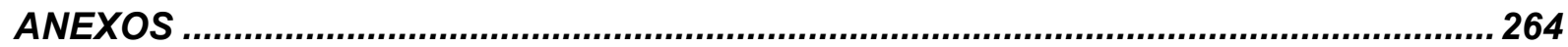

ANEXO 1- FORMATO DE CUESTIONARIO A INFORMANTES CLAVE TERRITORIALES PARA

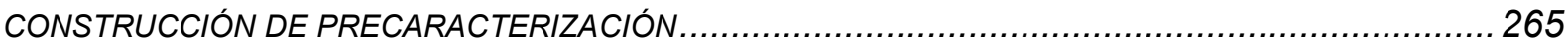

ANEXO 2- CUESTIONARIO BASE DE LA HERRAMIENTA PARA REALIZAR LAS ENTREVISTAS DE LOS

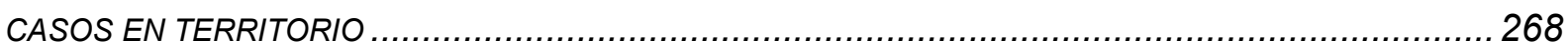

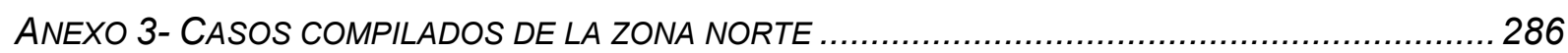

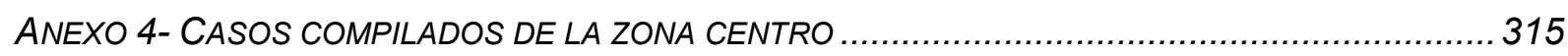

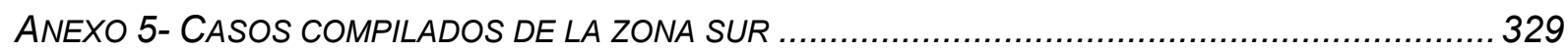

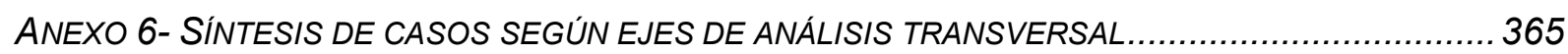

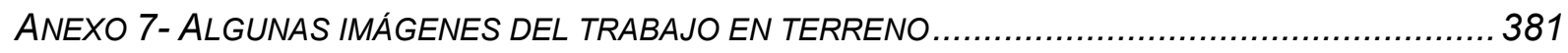

\section{INDICE DE ILUSTRACIONES Y TABLAS}

Ilustración 1- Espacios donde se concentra la mayor cantidad de emprendedores de turismo rural y se focaliza la intervención estatal. Fuente Mapa: Ministerio de Turismo de la provincia de Entre Ríos

llustración 2 Ubicación de Entre Ríos en el mapa nacional y departamentos de la provincia

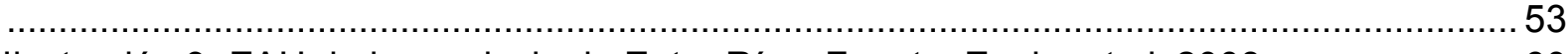

Ilustración 3- ZAH de la provincia de Entre Ríos. Fuente: Engler et al, 2008 ......................60

llustración 4- Localidades del departamento Colón. Fuente: García et al, 2006....................65

Ilustración 5- Esquema del sistema familia/explotación Caso 1 ........................................... 84

llustración 6- Esquema de interacciones de las actividades dentro del sistema Caso 1 ........85

Ilustración 7- Esquema del sistema familia/explotación Caso 2 .......................................... 94 
Ilustración 8- Esquema de interacciones de las actividades dentro del sistema Caso 2 ....... 95

Ilustración 9- Esquema del sistema familia/explotación Caso 3 ........................................ 105

Ilustración 10- Esquema de interacciones de las actividades dentro del sistema Caso 3.. 106

Ilustración 11- Esquema del sistema familia/explotación Caso 4 ...................................... 117

Ilustración 12- Esquema de interacciones de las actividades dentro del sistema Caso 4 ... 118

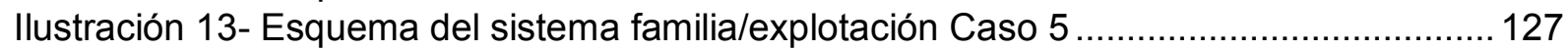

Ilustración 14- Esquema de interacciones de las actividades dentro del sistema Caso $5 \ldots 132$

Ilustración 15- Esquema del sistema familia/explotación Caso 6 .......................................142

Ilustración 16- Esquema de interacciones de las actividades dentro del sistema Caso 6 ... 145

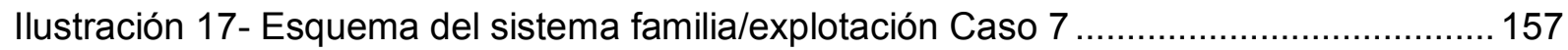

llustración 18- Esquema de interacciones de las actividades dentro del sistema Caso 7 ... 158

Ilustración 19- Esquema del sistema familia/explotación Caso 8 ........................................168

Ilustración 20- Esquema de interacciones de las actividades dentro del sistema Caso $8 \ldots 170$

Ilustración 21- Ubicación de la localidad. Fuente: Diario La Nación 8/3/2016 .................... 173

Ilustración 22- Esquema del sistema familia/explotación Caso 9 ....................................... 185

Ilustración 23- Esquema de interacciones de las actividades dentro del sistema Caso $9 \ldots 190$

Ilustración 24- Trayectoria de la familia Caso 10 ............................................................ 193

Ilustración 25- Esquema del sistema familia/explotación Caso 10 ....................................201

Ilustración 26- Esquema de interacciones de las actividades dentro del sistema Caso 10.202

Ilustración 27- Esquema del sistema familia/explotación Caso 11|...................................210

llustración 28- Esquema de interacciones de las actividades dentro del sistema Caso 11.214

Ilustración 29- Esquema del sistema familia/explotación Caso 12 ..................................... 221

Ilustración 30- Esquema de interacciones de las actividades dentro del sistema Caso 12.225

Ilustración 31- Esquema del sistema familia/explotación Caso 13 .....................................230

llustración 32- Esquema de interacciones de las actividades dentro del sistema Caso 13.233

Ilustración 33- Algunas de las dificultades de transitar por caminos rurales en días de lluvia

Ilustración 34- Conociendo y aprendiendo de la mano de los entrevistados. ......................381

Ilustración 35- Personajes de la colonia que se acercan a ayudar y curiosear..................... 381

Ilustración 36- Villa Paranacito a pocos días de una de las crecidas más importantes de la

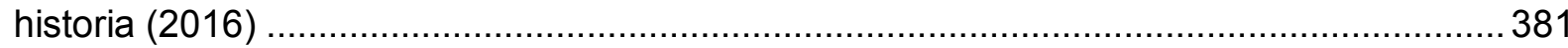

llustración 37 y 37 - Ingreso a la localidad de Villa Paranacito y entrada al pueblo, a pocos

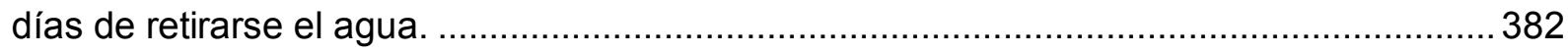

Tabla 1. Cantidad y superficie de EAPs por estrato de superficie Fuente: Engler et al, 2008.

Tabla 2. Cantidad de EAPs según organización social del trabajo Fuente: Engler et al,

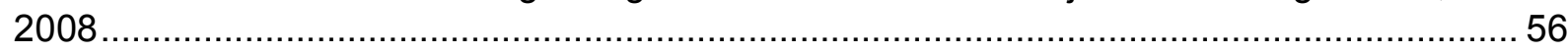

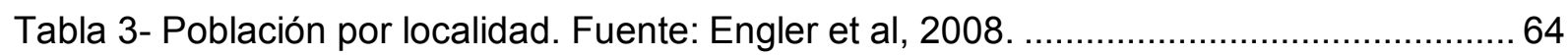

Tabla 4- Resumen orientación productiva de las zonas del Uruguay. ............................... 68 


\section{RESUMEN}

El campo argentino ha experimentado profundas trasformaciones en su historia, fundamentalmente en la década de 1990 a partir de la ejecución de políticas sociales y económicas derivadas del neoliberalismo. Como consecuencia de estas complejas transformaciones, empiezan a emerger actividades productivas alternativas como el turismo rural de la mano de familias rurales que reconvierten -parcial o totalmente- sus establecimientos productivos, incorporando una nueva estrategia de diversificación de ingresos como una manera viable de mantener sus unidades.

En la provincia de Entre Ríos, existe una red de familias rurales que deciden incorporar el turismo a sus actividades productivas, acompañadas por el Estado, a través de organismos como INTA, gobiernos locales y otros organismos provinciales y nacionales.

A partir de las inquietudes que movilizaron la investigación en torno a este proceso, el objetivo general fue comprender las transformaciones operadas al interior del sistema familia/ explotación y en vinculación al entorno, a partir de la incorporación del turismo como estrategia de diversificación de actividades e ingresos.

Para dar respuestas a interrogantes y objetivos, se realizó una precaracterización de emprendimientos de turismo rural del Corredor del río Uruguay, construido con el aporte de información y datos confidenciales de informantes territoriales.

Luego se definieron criterios de análisis para la selección de casos por zona. Se seleccionaron en total 13 casos a lo largo del Corredor.

La mayoría de éstos representan sistemas de actividades que incluyen el turismo en el espacio rural y son gestionados por familias rurales. Para enriquecer el estudio, también se incluyeron propuestas implementadas por personas que no son productores agropecuarios.

Para el abordaje de los casos, se desarrollaron entrevistas semiestructuradas ( 9 grupales y 1 entrevista individual) y se tomó como base principalmente el marco teórico y metodológico del Sistema de Actividades.

Algunas de las conclusiones que se desprenden del trabajo evidencian que los productores interesados en diversificar sus explotaciones a través del turismo, poseen un grado de capitalización que les ha permitido reinvertir en su propio predio. Además, que existen dos elementos que confluyen en la puesta en marcha del turismo por parte de estas familias entrerrianas.

En algunos casos se asocia a situaciones críticas que movilizan la necesidad de generar cambios al interior del sistema. En otros convergen aspectos asociados a la valorización de recursos y dinámicas territoriales que se visualizan como oportunidades para el desarrollo del turismo.

Si bien la riqueza explicativa está dada por las singularidades de los casos, se intentó elaborar patrones comunes en la trayectoria de estas experiencias para comprender de qué forma la actividad turística se relaciona con el resto de las actividades del sistema.

Algunos establecimientos que se abocan al turismo utilizan parte de su producción primaria como insumo para generar nuevos servicios en su predio, lo que agrega valor a la producción, existiendo una integración entre la actividad productiva y la turística. En el otro extremo, encontramos casos en los que la actividad turística no guarda ninguna relación con la actividad productiva, se desarrolla en otro espacio, aprovechando las características naturales o edilicias del mismo, pero no se integran los productos primarios los servicios brindados. Entre uno y otro esquema de integración se visualizan grados de integración diversos, en los que el turismo y producción comparten el uso del mismo espacio poniéndose en valor los recursos patrimoniales territoriales. 


\section{ABSTRACT}

The Argentine countryside has undergone profound transformations in its history, fundamentally in the 1990s, from the execution of social and economic policies derived from neoliberalism. As a consequence of these complex transformations, alternative productive activities such as rural tourism begin to emerge with the help of rural families that partially or totally reconvert their productive establishments, incorporating a new strategy of income diversification as a viable way of maintaining their units.

In the province of Entre Ríos, there is a network of rural families that decide to incorporate tourism into their productive activities, accompanied by the State, through organizations such as INTA, local governments and other provincial and national agencies.

Based on the concerns that mobilized the research around this process, the general objective was to understand the transformations that took place within the family / farm system and in relation to the environment, based on the incorporation of tourism as a strategy for diversifying activities and income.

To answer questions and objectives, a pre-characterization of rural tourism ventures was carried out in the Uruguay River Corridor, built with the contribution of information and confidential data from territorial informants.

Then, analysis criteria were defined for the selection of cases by area. A total of 13 cases were selected along the Corridor.

Most of these represent systems of activities that include tourism in rural areas and are managed by rural families. To enrich the study, proposals implemented by people who are not agricultural producers were also included.

To address the cases, semi-structured interviews were conducted ( 9 groups and 1 individual interview) and the theoretical and methodological framework of the Activity System was taken as a basis.

Some of the conclusions that emerge from the work show that producers interested in diversifying their farms through tourism, have a degree of capitalization that has allowed them to reinvest in their own land. In addition, there are two elements that come together in the implementation of tourism by these families.

In some cases, it is associated with critical situations that mobilize the need to generate changes within the system. In others converge aspects associated with the valorization of resources and territorial dynamics that are seen as opportunities for the development of tourism.

Although the explanatory richness is given by the singularities of the cases, an attempt was made to elaborate common patterns in the trajectory of these experiences in order to understand how the tourist activity is related to the rest of the activities of the system.

Some establishments that engage in tourism use part of their primary production as input to generate new services on their property, which adds value to production, there being an integration between productive and tourist activities. At the other extreme, we find cases in which the tourist activity does not have any relationship with the productive activity, it is developed in another space, taking advantage of the natural or building characteristics of it, but the primary products are not integrated with the services provided. Between one and the other integration scheme different degrees of integration are visualized, in which tourism and production share the use of the same space, valuing the territorial heritage resources. 
Capítulo 1 - La emergencia del turismo rural en la actividad agropecuaria como problemática de trabajo 


\subsection{La transformación del sector agropecuario como factor clave para el impulso del turismo rural}

El campo argentino, su paisaje, fisonomía y dinámicas, sus producciones, formas de producir han transitado un recorrido de profundas trasformaciones en la historia argentina, signados por el rumbo de las definiciones políticas de cada etapa particular.

Estas transformaciones que experimenta el medio rural en Argentina

"tienen impacto sobre la organización de los sistemas de producción de las familias rurales, su descomposición, las formas de persistencia y los cambios en ciertas fracciones de éstas, que transforman las características que teórica y empíricamente las definieran en los estudios rurales". (Cloquell, 2013).

Fundamentalmente en la década de 1990, la ejecución de políticas sociales y económicas derivadas del neoliberalismo imperante, trajo aparejada una serie de cambios que calaron hondo en el sistema agrario argentino.

Como principales consecuencias del deterioro, producto de los programas de ajuste estructural, flexibilización del mercado laboral, liberalización de los mercados, privatizaciones y desregulaciones, pueden mencionarse la disminución en número y tamaño de las explotaciones agropecuarias ${ }^{4}$, un profundo proceso de concentración de tierra en manos de pocos actores, pérdida de rentabilidad en las unidades de menor escala y la constitución de nuevos umbrales de sostenibilidad (Teubal y Rodríguez, 2001), intensificación de la capitalización en los procesos productivos y el incremento de los niveles de endeudamiento y del empleo no agrario entre los productores y sus familias, y una disminución del empleo rural". (Herner, 2010).

En palabras de Bochetto (2008),

"la vigencia del modelo económico neoliberal durante la década de los 90, acompañado por la crisis económica y social de principios de siglo profundizó las desigualdades del desarrollo, consolidó la exclusión, aceleró el desempleo, incrementó sustancialmente la pobreza, esparció la indigencia por todo el país, desarticuló la industria nacional y desintegró los espacios regionales. Colapsó en su conjunto el sistema económico y social, y en consecuencia, la estructura política del país".

Puede decirse que este escenario, del que el sector agrícola es protagonista, ha materializado dos modelos contrapuestos de desarrollo rural y de producción de alimentos.

El modelo dominante, el agro-exportador, de lógica neoliberal,

"que responde al lucro corporativo y la intensificación de la producción para la exportación... responsable de la creciente concentración de tierras, recursos, cadenas de producción y distribución de alimentos y otros productos agrícolas en manos de un número reducido de corporaciones". (Andrade, 2011).

Y en la vereda opuesta, por el contrario emerge el modelo de la agricultura familiar y soberanía alimentaria, que prioriza la producción local para el mercado interno, prácticas basadas en el conocimiento local. (Andrade, 2011).

Según la autora, aunque

\footnotetext{
1 Según el Censo Agropecuario del año 1988 había en la Argentina 421.221 explotaciones agropecuarias. El censo del año 2002 contabiliza luego de 14 años 333.000 explotaciones agropecuarias, es decir 88.221 explotaciones menos. Además de este proceso de concentración de la tierra, entre los años 1988 y el año 2002 cambia sustancialmente el uso de la tierra en el país, con un aumento significativo de 6 millones de has. en los cultivos anuales y con 300.000 has. más de bosques implantados. Por otro lado, disminuyeron notablemente las tierras forrajeras dedicadas a la ganadería, los bosques naturales, que fueron reemplazados por cultivos y las áreas no aptas que comenzaron a ser valorizadas para otros usos como cultivos y ganadería (Sili y Somoulou, 2011)
} 
"este modelo es potencialmente más productivo por unidad de superficie, más compatible con el medio ambiente, capaz de proporcionar una vida digna a las familias rurales (...) el modelo dominante neoliberal agro-exportador continúa empujando la agricultura familiar y campesina hacia la búsqueda de prácticas pluriactivas". (Andrade, 2011).

En este contexto, caracterizado por la preponderancia de un modelo capitalista "que desafía la persistencia de las estructuras familiares en el agro pampeano" (lorio y Mosciaro, 2013), los agricultores, campesinos y familias rurales deben repensar sus estrategias de producción para conservar su patrimonio, salvaguardar -o aumentar- sus capitales y amparar un estilo de vida que han construido históricamente, y que pretenden legar a las generaciones venideras no como una añoranza si no como el fruto real de una trayectoria vivida.

Las unidades productivas familiares han tenido que reestructurar tareas, reconfigurar 0 modificar patrones históricos e implementar estrategias que les permitan resguardar su capital y mantener su vida y trabajo en el medio rural.

"En el marco de un capitalismo globalizado, la reestructuración organizativa de los sistemas deja su impronta en el esquema estructural y funcional del espacio. Dicha transformación se ha basado en la necesidad de las explotaciones agropecuarias de reconvertirse para hacerse más competitivas frente a la crisis (...) Una vez más, ante la cambiante evolución de la economía sectorial y global, los productores recurren a estrategias adaptativas diversas que implican una nueva transformación socioproductiva y espacial, producto del agotamiento del modelo económico anterior". (Fernández y Ramos, 2000).

Este periodo de la historia argentina estuvo definido por un proceso de concentración económica y un conjunto de medidas políticas y económicas "que llevó en una década a la desaparición del $20 \%$ de los establecimientos agropecuarios existentes, afectando centralmente a pequeños y medianos productores". (Lattuada y Nogueira, 2011).

\section{Se implementaron}

"... medidas tendientes al desmantelamiento de las estructuras de intervención estatal en el sector agrícola y la desaparición de instrumentos como precios sostén, subsidios a la producción y créditos a tasas preferenciales (...) Las mencionadas transformaciones generaron un difícil contexto para la viabilidad de pequeños y medianos productores rurales, muchos de los cuales debieron abandonar sus explotaciones. Asimismo, la exacerbación de las asimetrías de poder, produjo una situación de creciente proletarización y/o expulsión de mano de obra asalariada, con el consecuente incremento de la pobreza rural. Una salida para estos actores la constituyeron estrategias como la pluriactividad o la multiocupación, ya sea en actividades agrícolas (extraprediales) o no agrícolas, cuya importancia presenta una tendencia creciente". (Pasciaroni et al, 2010).

Como consecuencia de estas complejas transformaciones, empiezan a emerger otro tipo de actividades productivas alternativas. Una de éstas ha sido el turismo rural de la mano de familias rurales que reconvierten -parcial o totalmente- sus establecimientos productivos, incorporando una nueva estrategia de diversificación de ingresos como una manera viable de mantener sus unidades.

Por un lado entonces es importante comprender la necesidad o capacidad de las familias rurales de poner en práctica cambios o estrategias diferentes para llevar adelante sus objetivos de producción o reproducción social. Y qué implican estos cambios al interior de sus familias, de su propia esencia, porque la mutación del territorio rural conlleva que la identidad de los productores se transforme. "Lo que significa ser un agricultor familiar se redefine". (Muzlera Klappenbach, 2007).

Pero además, estos sujetos viven, se desenvuelven, trabajan en un contexto de cambios que trasciende lo económico, ya que la complejidad de las transformaciones en la realidad rural está dada por las nuevas dinámicas de relación que se dan entre el campo y la ciudad, la emergencia de nuevos actores y actividades, el aumento de la movilidad espacial y 
sociocultural, la deslocalización de las relaciones sociales y económicas, y la disponibilidad de información y las nuevas tecnologías de transportes y comunicaciones. (Sili, 2007).

Este conjunto de factores definen los territorios rurales en la actualidad, que

"vuelven a aparecer como nuevos espacios estratégicos, ahora valorizados por la lógica de la globalización ${ }^{2}$. Lo "rural" emerge con fuerza, ya no sólo en tanto espacio alternativo para el desarrollo económico, sino como ámbito para la creación de procesos de desarrollo más diversificados y sustentables que permiten ayudar a resolver los problemas de congestión urbana y a superar los crecientes niveles de desigualdad y retraso en la gran mayoría de los países de América Latina". (Sili, 2007).

Para finalizar, se retoma una definición sobre la que luego se volverá respecto a esta idea de cambios, cambios que sufrió el escenario global, transformaciones del espacio agrario, de los sujetos y de sus propias representaciones.

"Las transformaciones que atravesó el agro argentino en las últimas décadas comprometieron todos los niveles posibles: escalas productivas, requisitos de capitalización, niveles de rentabilidad. Los cambios no han sido sólo de magnitud; más importante aún, se han redefinido relaciones básicas: las que estructuraban la constitución y la dinámica de la estructura agraria argentina en torno a la propiedad de la tierra". (Gras y Hernández, 2008).

Sobre este tema y la incidencia del turismo como dinamizador de los espacios rurales se volverá y profundizará más adelante.

\subsection{El turismo rural en Argentina y el rol del INTA en su promoción como estrategia de desarrollo rural}

Tal como se ha comentado en el apartado anterior, familias rurales argentinas, condicionadas por un contexto de profundos cambios y permanentes crisis, se vieron obligadas a buscar alternativas que posibiliten la continuidad de su vida y quehacer en el campo. Es así, como la actividad turística emerge como una opción válida.

En el caso de Argentina, si bien existen casos aislados y se han dado fundamentalmente en la zona patagónica de nuestro país (Grupo Estancias de Santa Cruz, por ejemplo), es a partir de la crisis del 2001 que se vislumbra un mayor crecimiento de estas experiencias.

"La crítica situación de una parte del sector agropecuario argentino fue lo que dio impulso al turismo rural, configurándose, en algunos casos, como la única manera viable de mantener sus establecimientos. La diversificación de la agricultura ha sido un patrón que se dio, principalmente, entre los productores de menor escala, quienes, precisamente por producir a menor escala, pierden competitividad para la producción de commodities. Se señala que la modificación de la función productiva tradicional entre las que se encuentra la incorporación de actividades no agrícolas y servicios, en muchos casos, surge debido a la necesidad de diversificación del riesgo y de generación de ingresos adicionales a los agrícolas". (Román y Cicolella, 2009).

En este contexto, comienzan a surgir experiencias asociativas de turismo rural ${ }^{3}$ apoyadas por INTA, posibilitando que estos grupos de productores rurales compartan con otros este nuevo

\footnotetext{
2 Sili (2007) hace referencia a la valorización de los territorios rurales pasadas cuatro décadas del proceso de modernización agraria de principios de siglo en el que las áreas rurales fueron espacios más marginales especialmente desde el punto de vista social y cultural. Sili plantea que en ese contexto la cultura rural, asociada a la tradición, costumbres y relaciones interpersonales fue reemplazada por otras formas de consumo y de tipo de relaciones más anónimas y deslocalizadas. Y que en la actualidad se da un proceso de revalorización territorial rural.

${ }^{3}$ En esta investigación se entiende al turismo rural, siguiendo a Scalise (2012) "El turismo rural es una actividad turístico - recreativa complementaria a las actividades agropecuarias tradicionales, desarrollada principalmente en emprendimientos, comunidades y pueblos rurales, gestionada por la población local respetando el medio ambiente y la cultura. Ofrece la oportunidad de compartir, vivenciar y conocer costumbres, actividades (productivas y
} 
desafío, delineen propuestas turísticas integrales que permitan complementar sus productos y servicios, vinculándose con las comunidades y constituyéndose como espacios de referencia y pertenencia.

De la primer experiencia en Santa Cruz en la década de 1990, en la actualidad se registran más de 112 experiencias en el país, que integran 1259 emprendedores y 45 organizaciones públicas y privadas. (Guastavino et al, 2012).

"El crecimiento del turismo en general y, en particular, el interés por la naturaleza y la cultura del campo son tendencias en crecimiento. El turismo rural constituye para el sector agropecuario y para las comunidades locales una oportunidad para la generación de empleo directo e indirecto que contribuye a evitar el éxodo rural; una alternativa para diversificar y ampliar los ingresos, disminuyendo así las desigualdades socioeconómicas; $y$ una forma de difundir y revalorizar las culturas, tradiciones, prácticas y saberes locales". (Arrúa Maidana, 2009).

La Facultad de Agronomía de la Universidad de Buenos Aires realizó en el año 2012 una encuesta a establecimientos de turismo rural del país. Los resultados de esta encuesta verifican que la actividad vivió un período de auge a partir de 1990, y que a partir del 2000 ha cobrado un mayor impulso. Es interesante mencionar lo que Dachary y Barrera (2012) manifiestan en torno al rol del Estado en este proceso.

"Este crecimiento de la actividad ha ido de la mano del impulso que diera el Estado a la actividad. Debe notarse que en la Argentina el Estado no ha otorgado financiamiento especial para el turismo rural y que se carece no ya de subsidios, sino de créditos a bajas tasas, por lo tanto el impulso del Estado ha consistido básicamente en difundir la actividad y en el apoyo a la formación de grupos asociativos. A éstos grupos les ha brindado asistencia técnica". (Dachary y Barrera, 2012).

En relación a lo anterior, uno de los organismos del estado nacional que mayor injerencia ha tenido sobre el desarrollo de la actividad ha sido el Instituto Nacional de Tecnología Agropecuaria (INTA).

EI INTA apoya el desarrollo del Turismo Rural desde la década de 1990. Sin embargo, es a partir de la implementación del Programa Federal de Apoyo al Desarrollo Rural Sustentable (PROFEDER), en el año 2004, que se comienza a registrar un crecimiento exponencial de este tipo de experiencias. Este Programa se enmarca en el Plan Estratégico Institucional 2005-2015, que orienta la actividad de la institución hacia el Desarrollo Territorial a partir de los objetivos de competitividad, salud ambiental y equidad social.

El enfoque territorial adoptado por la institución ha sido la base para integrar estrategias y herramientas otrora no tenidas en cuenta. Esta perspectiva "implica un abordaje integral del medio rural, con el cual es posible emprender acciones tanto en el plano económicoproductivo como en el sociocultural, el político institucional y el medioambiental". (Rozenblum et al, 2010).

A partir de este enfoque, INTA incorpora la noción del territorio

"como una construcción social de un espacio físico y simbólico caracterizado por la existencia de una base de recursos naturales específicos; determinadas relaciones sociales, instituciones y formas de organización; una identidad compartida, y ciertas formas de producción, intercambio y distribución del ingreso que hace que el entramado socioinstitucional local presente características únicas". (Rozenblum et al, 2010).

Y es así que germina el acompañamiento institucional al turismo rural como herramienta con capacidad para promover procesos de desarrollo territorial, movilizando y poniendo en valor los recursos endógenos de un territorio, y que

culturales) y experiencias del medio rural, promoviendo el respeto y la valoración del patrimonio natural y cultural" (Scalise, 2012). 
“...muestra su potencialidad como estrategia para favorecer la visualización de la identidad territorial de productos y servicios, para revalorizar la multidimensionalidad de un territorio (dimensiones económicoproductiva, sociocultural, políticoinstitucional y medioambiental), favoreciendo procesos de Desarrollo Local". (Guastavino et al, 2012).

Entonces, en la trama de este paradigma en el que se sustenta el accionar institucional y en el que actividades integrales como el turismo rural comienzan a ser abordadas, el PROFEDER, marco de trabajo, se propone como finalidad "contribuir a la promoción de la innovación tecnológica y organizacional, el desarrollo de las capacidades de todos los actores del sistema y el fortalecimiento de la competitividad sistémica regional y nacional en un ámbito de equidad social y sustentabilidad" 4 .

El programa cuenta con una serie de herramientas basadas en una metodología de trabajo participativa y grupal. Son los emprendedores participantes quienes elaboran junto con los técnicos los proyectos, los cuales deben tender a promover y/o iniciar procesos de desarrollo de sus territorios junto a organizaciones locales.

Como se mencionó anteriormente, un número importante de experiencias de turismo rural a lo largo y ancho del país, están vinculadas a los instrumentos PROFEDER (fundamentalmente al programa Cambio Rural). Son de base asociativa, nuclean y promueven la articulación e integración de grupos de productores, emprendedores e instituciones del sector.

Entre las acciones llevadas a cabo por el equipo de trabajo del INTA, se encuentran además del apoyo para la organización de grupos de productores agropecuarios que entre sus actividades agropecuarias contemplen al turismo rural, la promoción de asociaciones de emprendedores de turismo rural, la capacitación de productores, contribución en la articulación con fuentes de financiación y principalmente la asistencia técnica a través de los técnicos asesores y Agentes de Proyecto.

Ahora bien, como se ha comentado, el turismo rural es una actividad sumamente compleja que requiere el acompañamiento de una política sectorial integral, que contemple sus dinámicas, actores, funcionamiento y necesidades de manera específica. En este sentido, es importante destacar que el Estado, en sus diversas esferas y capacidades, ha dado señales concretas de atención a este sector en particular, más allá de la calidad en la ejecución en sí de sus instrumentos. No es el objetivo de este apartado hacer una descripción y análisis pormenorizados de estas herramientas si no proponer una aproximación global a la forma y dinámica del acompañamiento estatal al desarrollo de esta actividad.

En relación al Ministerio de Agricultura, Ganadería y Pesca de la Nación (actualmente Ministerio de Agroindustria), en el marco de este organismo se ejecutaron programas cuyos objetivos estaban vinculados directa e indirectamente al desarrollo del turismo rural. Los que más relación tuvieron con el impulso específico a la actividad fueron el área Rutas Alimentarias- luego Programa ValorAR- y el Proyecto Nacional de Turismo Rural (PRONATUR), sobre el que se volverá en los próximos párrafos. Las principales prestaciones de los programas ejecutados estuvieron focalizadas en fortalecimiento institucional mediante la realización de estudios, capacitaciones y asistencia técnica.

Por su parte, el Ministerio de Turismo de la Nación, ha elaborado de manera concertada con los actores del sistema a nivel regional y el apoyo del sector privado, el Plan Federal Estratégico de Turismo Sustentable (PFETS) que fija el rumbo de las políticas turísticas para la década 2006-2016 y fue actualizado al 2020. Este Plan establece las estrategias y políticas para el desarrollo turístico de Argentina y el Plan Operativo del Ministerio de Turismo de la Nación. Identifica y formula los programas y proyectos a nivel nacional y regional. Se ha

\footnotetext{
${ }^{4}$ En https://inta.gob.ar/documentos/profeder-programa-federal Última revisión: febrero de 2018.
} 
concebido como un proceso orientador y articulador de actuaciones, voluntades y recursos hacia un desarrollo turístico sustentable en el país.

Junto al PFETS se aprueba la Ley Nacional $n^{\circ} 25997^{5}$, para la cual el turismo es considerado actividad esencial para el desarrollo del país. Así lo manifiesta el artículo $n^{\circ} 1$ de la Ley, haciendo referencia al turismo como actividad socioeconómica estratégica y esencial para el desarrollo del país y prioritaria dentro de las políticas de Estado.

En relación a lo anterior, el PFETS contempla una serie de programas relacionados con el desarrollo del turismo rural, como el PROFODE - Programa de Fortalecimiento y Estímulo a Destinos Turísticos Emergentes ${ }^{6}$ y la RATRC - Red Argentina de Turismo Rural Comunitario $(\operatorname{RaTRC})^{7}$.

En los últimos años se implementó como marco para el desarrollo de estas actividades el programa TERRA (Turismo en Espacios Rurales de la República Argentina) que incluye todas las actividades y modalidades de turismo rural del país.

"El Turismo en Espacios Rurales es una línea de trabajo innovadora que se presenta como una política integradora, para contribuir, desde la gestión pública del turismo, a la diversificación de la oferta con una mayor equidad en la distribución de la riqueza y el bienestar de la población. Incorpora espacios que incluyen diferentes formatos turísticos (estancias, pueblos rurales, turismo comunitario, mundo del vino, agroturismo, experiencias asociativas), con puntos de contacto con otras modalidades turísticas, especialmente las que se concretan en los espacios naturales. La finalidad del Proyecto es lograr ofertas de turismo en los espacios rurales, organizadas y estructuradas, dotadas de viabilidad económica, social, ambiental, política y tecnológica, y respetuosas de las identidades locales". (Pelliza y Ercolani, 2013).

Respecto al Proyecto Nacional de Turismo Rural (PRONATUR) fue impulsado por el Ministerio de Agricultura, Ganadería y Pesca de la Nación en el marco del PROSAP, con la participación del Ministerio de Turismo de la Nación y del INTA.

"Tuvo como fin contribuir al desarrollo de los territorios rurales, promoviendo la diversificación económica mediante la incorporación del turismo a la actividad agropecuaria, y favorecer la expansión de la actividad en la Argentina, aumentando el volumen de producción turística y el ingreso de divisas, y priorizando la participación del sector privado nucleado en asociaciones y grupos de turismo rural. Su propósito fue lograr una masa crítica de productores de turismo rural en condiciones para ofrecer servicios de calidad, técnicamente factibles, económicamente viables y ambientalmente sostenibles. Este proceso se desarrolló asumiendo el compromiso y el trabajo articulado con los actores de la cadena de valor del turismo rural en la Argentina: pequeños y medianos productores rurales, asociaciones y grupos asociativos, comunidades rurales, artesanos, operadores turísticos, técnicos del sector y gobiernos provinciales y municipales". (Scalise, 2012).

Durante la ejecución de las actividades territoriales, entre 2008 y 2011, tuvo tres componentes fundamentales: la promoción, difusión y apoyo a la comercialización turística; la capacitación y asistencia técnica; y la transferencia de tecnología y el fortalecimiento institucional. E programa perteneció a la cartera de proyectos del PROSAP y fue financiado un $50 \%$ con recursos BID y un $50 \%$ con aporte local.

\footnotetext{
5 Sancionada el 16/12/2004, promulgada el 5/1/2005 y publicada en el Boletín Oficial el 7/1/2005. Datos de: www.derecho.uba.ar/institucional/ley-nacional-de-turismo-25997.pdf

6 EI PROFODE tiene como propósito fundamental disparar procesos de desarrollo en destinos turísticos emergentes. Su implementación se enmarca en la estrategia de redireccionamiento de flujos turísticos para el crecimiento equilibrado de la actividad en el territorio nacional, observando una clara correspondencia con otros programas y con las premisas del PFETS 2016. Parte de la construcción de un modelo local basado en la inclusión social y el desarrollo sustentable, el afianzamiento de la identidad local y la interculturalidad, el respeto por el patrimonio natural y cultural y la mejora de la calidad de vida de la población local.

${ }^{7}$ La RATRC nace en 2008 y es una iniciativa de la Dirección Nacional de Desarrollo Turístico de la SECTUR. Los destinatarios del proyecto son las comunidades campesinas y de pueblos originarios en ámbitos rurales que llevan adelante emprendimientos vinculados a la actividad turística, ya sean en un estado inicial o avanzado de gestión, construida sobre los pilares de la organización local.
} 
"En este proyecto se priorizó la formación y capacitación de los distintos actores de la cadena de valor (productores, artesanos, organizaciones, comunidades locales, funcionarios de gobierno, etc.) y también se incorporó el uso de tecnologías de información -base de datos, intercambio electrónico de datos, información a distancia, etc.- complementadas con materiales gráficos y una política de comunicación, como plataforma para el impulso a la actividad de turismo rural". (Román y Cicolella, 2009).

EI PRONATUR posibilitó la contratación de agentes de desarrollo por provincia, se realizaron visitas de intercambio entre experiencias del país, capacitaciones, se promovieron las propuestas a través de materiales de difusión y participación en ferias nacionales.

Una de las acciones más destacadas fue la asistencia técnica y la articulación con las experiencias asociativas de turismo rural, fuertemente vinculadas a grupos y proyectos PROFEDER/ INTA.

En algunas provincias como Entre Ríos, la implementación del Proyecto fue el puntapié inicial para la vinculación del Centro Regional Entre Ríos de INTA con la actividad. A partir de su ejecución se comenzó a promover la conformación de grupos de turismo rural, se generó una red de trabajo interinstitucional que al día de hoy funciona apoyando estas iniciativas y generando más actividades que incentiven el desarrollo del sector. Sobre el desarrollo de la actividad en esta provincia en particular se ahondará en la próxima sección.

Como consecuencia de este proceso de articulación interinstitucional dado a través del PRONATUR, surge en el año 2012 la Comisión Interministerial para el Desarrollo del Turismo con Inclusión Social en el Espacio Rural, conformada por técnicos y referentes de los Ministerios de Turismo, Desarrollo Social, Trabajo y Agricultura, Ganadería y Pesca de la Nación, convocados por un propósito común, que fue la generación de un espacio de trabajo para la gestión y organización de esta actividad en el orden nacional. En la actualidad, este órgano de gestión no está funcionando activamente. Tampoco se han dado a conocer desde el gobierno a cargo del estado nacional desde el 2015 a esta parte políticas específicas que promuevan el desarrollo del sector turístico rural.

Para finalizar este apartado puede decirse que los distintos procesos de desarrollo del turismo en el espacio rural han sido acompañados por una progresiva institucionalización dado el reconocimiento de su importancia como estrategia con potencialidad para favorecer la valorización de los recursos territoriales y la cultura rural, enraizando su identidad, por su capacidad transformadora de la realidad socio- económica de las familias rurales que obtiene ingresos económicos adicionales por los servicios prestados, por el movimiento económico y comercial que genera en las comunidades, por la generación de puestos de trabajo, el fortalecimiento del capital social y la generación de espacios de articulación y participación. (Guastavino et al, 2012)

A continuación, se presentarán los antecedentes del desarrollo del turismo rural en la provincia de Entre Ríos, escenario de análisis del objeto de estudio de la presente investigación.

\subsection{El Turismo rural en Entre Ríos}

En la provincia de Entre Ríos, desde el año 2009, se instituyó un trabajo de base territorial a partir del cual el Estado, a través de organismos como INTA, gobiernos locales y provincial, el Instituto Nacional de Tecnología Industrial (INTI), la Secretaría de Agricultura Familiar y otros organismos provinciales y nacionales, apoyaron y asistieron técnicamente a una red de familias rurales que deciden incorporar el turismo a sus actividades productivas.

Esta intervención institucional se focalizó básicamente en tres espacios provinciales correspondientes al corredor del río Uruguay, ubicado en el este provincial, con eje fundamentalmente en las localidades y zonas alrededor de Chajarí y Villa del Rosario; otro 
espacio en el centro este, coincidente con la microrregión turística Tierra de Palmares y una tercera zona en el sur de la provincia o Delta del Paraná.

Es dable destacar que el corredor del Río Uruguay es una de las zonas con mayor vocación turística en el mapa turístico provincial y nacional, atraviesa la provincia por su margen este, de norte a sur. Cruza seis departamentos provinciales y es franqueado por la Ruta Nacional $\mathrm{N}^{\circ} 14$, actualmente convertida en una amplia y ágil autovía, que dinamiza el flujo de turistas hacia toda la región, fundamentalmente los provenientes de Buenos Aires.

En próximos capítulos se retomará la descripción en detalle de esta zona de la provincia de Entre Ríos, sus características productivas y desde el punto de vista de la organización turística.

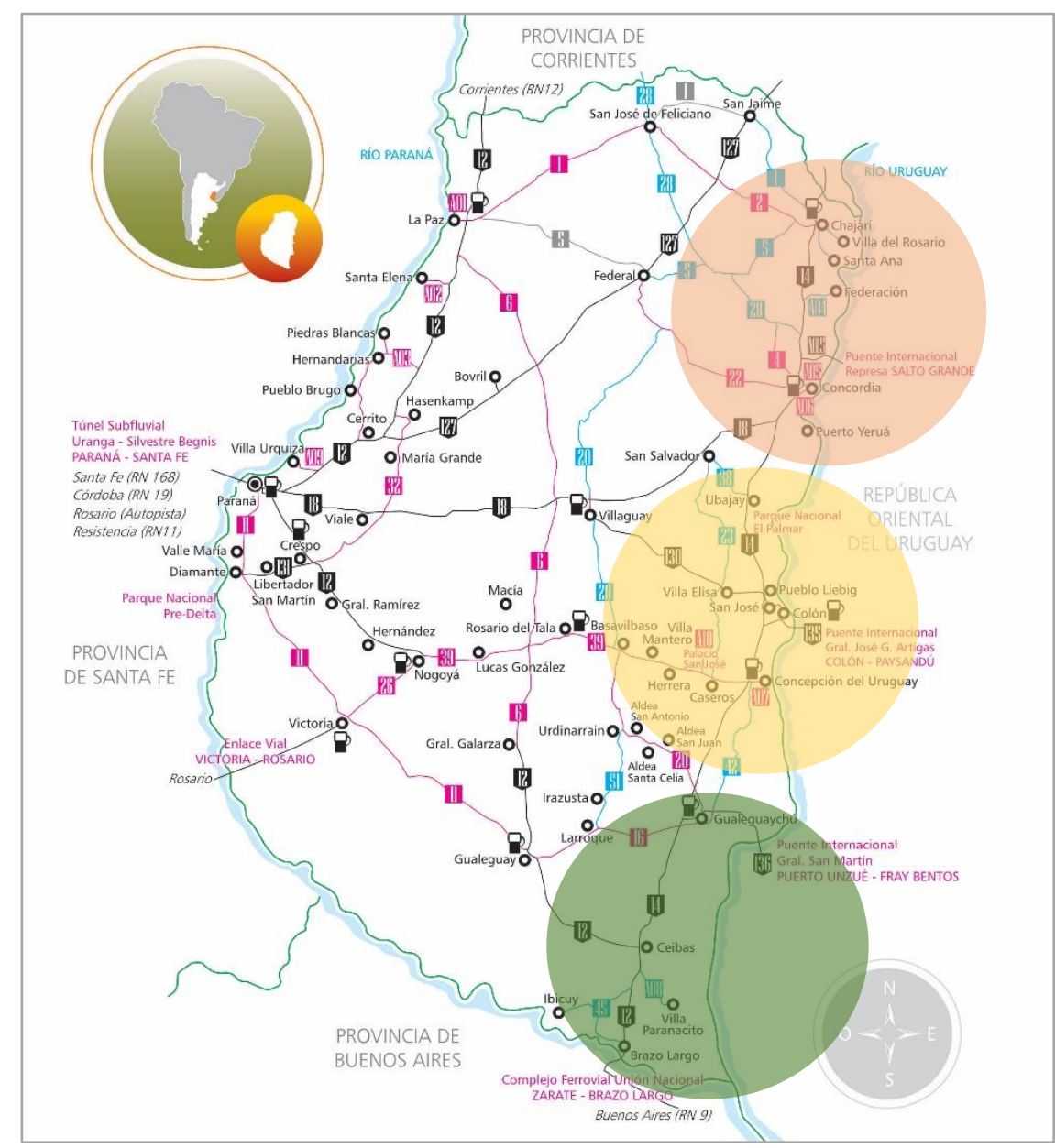

Ilustración 1- Espacios donde se concentra la mayor cantidad de emprendedores de turismo rural y se focaliza la intervención estatal. Fuente Mapa: Ministerio de Turismo de la provincia de Entre Ríos

Lo que es importante enfatizar ahora es que a grandes rasgos, cada una de estas zonas posee atributos identitarios diferentes que los distingue claramente del resto del territorio y un sistema de actores que la configuran de manera disímil.

En relación al desarrollo del turismo rural, sus trayectorias han sido diferentes, pero puede establecerse un factor en común que es la existencia de agrupaciones asociativas de productores rurales y otros actores de la comunidad, que han sido vertebrales en torno a la generación de proyectos colectivos, marcos de referencia, espacios de contención e 
intercambio de prácticas y saberes. Estos espacios grupales funcionaron bajo la figura programática de Cambio Rural, de la que ya se ha hecho mención con anterioridad.

Estas experiencias promueven como estrategia la integración de los actores para quienes, la forma de trabajo asociativo posibilita la complementariedad de los servicios o productos que cada uno presta, permitiendo la formación de propuestas turísticas más integradas a nivel local y microregional -en el caso de ofertas locales cercanas-.

En el corredor, desde el año 2010 a esta parte llegaron a funcionar diez grupos Cambio Rural.

Con base en estos espacios territoriales, en el año 2012 se diseñó un nuevo proyecto en el marco del PROFEDER -Programa Federal de Apoyo al Desarrollo Rural- que funciona en el marco de INTA, que conduce a integrar y consolidar una ruta temática de turismo rural de base asociativa, con identidad regional, con una activa participación de familias rurales, proceso que está en marcha aun en la actualidad.

Este proyecto se basa en las experiencias asociativas relacionadas al quehacer de INTA en articulación con los organismos provinciales, municipales, microregionales y actores estratégicos del sector. Este proyecto se ha planteado como objetivo contribuir al desarrollo territorial con identidad cultural de la zona, tomando como herramienta fundamental al turismo rural.

\begin{tabular}{|c|c|c|c|}
\hline Zona & Herramienta programática & Localidades vinculadas & $\begin{array}{l}\text { Periodo } \\
\text { aproximado de } \\
\text { funcionamiento }\end{array}$ \\
\hline \multirow[t]{2}{*}{ NORTE } & $\begin{array}{l}\text { Grupo Cambio Rural Aromas de } \\
\text { Azahares }\end{array}$ & Villa del Rosario & $2012-2015$ \\
\hline & $\begin{array}{l}\text { Grupo Cambio Rural II -Aromas } \\
\text { de Campo }\end{array}$ & Chajarí y Paraje Las 14 & $2015-2017$ \\
\hline \multirow[t]{7}{*}{ CENTRO } & $\begin{array}{l}\text { Grupo Cambio Rural Aire de las } \\
\text { colonias (Agroturismo río } \\
\text { Uruguay) }\end{array}$ & $\begin{array}{l}\text { Colón - San José y colonias de } \\
\text { la zona }\end{array}$ & $2009-2012$ \\
\hline & $\begin{array}{l}\text { Grupo Cambio Rural Uniendo } \\
\text { Colonias }\end{array}$ & $\begin{array}{l}\text { San José, Primero de Mayo y } \\
\text { colonias de la zona }\end{array}$ & 2011-2014 \\
\hline & $\begin{array}{l}\text { Grupo Cambio Rural } \\
\text { Agroturismo Villa Elisa }\end{array}$ & Villa Elisa y colonias de la zona & $2011-2013$ \\
\hline & $\begin{array}{l}\text { Cambio Rural II Agroturismo } \\
\text { Colón }\end{array}$ & Colón y colonias de la zona & \\
\hline & $\begin{array}{l}\text { Cambio Rural II Huellas del } \\
\text { Montiel (Villaguay) }\end{array}$ & Villaguay y Villa Dominguez & $2015-2018$ \\
\hline & $\begin{array}{l}\text { Cambio Rural II Feriantes Tierra } \\
\text { de Palmares }\end{array}$ & $\begin{array}{l}\text { Villa Elisa, Primero de Mayo, } \\
\text { San José, Colón y colonias de } \\
\text { la microrregión }\end{array}$ & $2015-2017$ \\
\hline & $\begin{array}{l}\text { Proyectos de Apoyo al } \\
\text { Desarrollo Local en Primero de } \\
\text { Mayo, Liebig, Santa Anita y } \\
\text { Colonia Elía. }\end{array}$ & $\begin{array}{l}\text { Primero de Mayo, Liebig, } \\
\text { Santa Anita y Colonia Elía }\end{array}$ & $\begin{array}{l}\text { Desde el } 2010 \\
\text { en adelante }\end{array}$ \\
\hline \multirow[t]{2}{*}{ SUR } & $\begin{array}{l}\text { Grupos Cambio Rural Turismo } \\
\text { Rural del Delta Entrerriano I y II }\end{array}$ & Villa Paranacito & $2009-2014$ \\
\hline & $\begin{array}{l}\text { Grupo CRII Paraíso isleño (nuez } \\
\text { pecán y turismo rural) }\end{array}$ & Villa Paranacito & $2014-2016$ \\
\hline
\end{tabular}


A partir del conocimiento que la autora posee del territorio y del proceso en marcha, al momento de generar el proyecto primigenio de esta tesis, se presentó una caracterización de los responsables de la oferta de productos o servicios de turismo rural. Se retoma esta caracterización para luego, en el transcurso de la investigación complejizarla y darle otros sentidos a la luz de los marcos conceptuales desplegados.

En el proceso de desarrollo de turismo rural en Entre Ríos, se distinguen:

Familias rurales que ofrecen la actividad turística dentro del predio/explotación.

Ejemplo: familia tambera que invita a los turistas a recorrer su predio y compartir tareas rurales que allí se realizan

- Familias rurales que ofrecen productos o servicios de turismo rural extra predial.

Ejemplo: familia rural que invierte en un campo cercano al predio donde realizan la actividad productiva principal (avicultura) y construye un par de cabañas en el espacio rural o brinda servicios de gastronomía en un restaurante de campo fuera de su predio.

- Artesanos, emprendedores, prestadores de servicios de turismo en el espacio rural que no se dedican a la actividad agropecuaria

Y se vinculan a éstos,

- Turistas, excursionistas, consumidores, es decir, personas que demandan este tipo de alternativa turística, en contacto con la cultura rural y la naturaleza vinculada al campo.

- Organismos públicos/técnicos vinculados a las distintas actividades productivas que se despliegan en el territorio.

- Las comunidades locales.

La presente investigación, se centró fundamentalmente la atención en las familias rurales que hayan incorporado la actividad turística al interior de sus emprendimientos o en forma extra predial, pero además se tendrán en cuenta otro tipo de actores que no se vinculan con la actividad pecuaria.

Para ello, se realizó una primera caracterización de las propuestas turísticas en el espacio rural tomando como base una serie de variables -definidas en relación a la pregunta central de investigación- y los datos obtenidos de encuestas a informantes territoriales.

La información producida entendemos ha sido de utilidad para la comprensión de una actividad productiva que tiene relativamente pocos años de desarrollo en el país y en la provincia, de la que se han realizado investigaciones en torno a sus implicancias en el desarrollo de los territorios pero con pocos antecedentes en torno al tema central de esta tesis, vinculado a las posibles transformaciones que la actividad turística opera sobre los sistemas productivos familiares. 


\section{Capítulo 2 - Diseño de la investigación}




\section{Diseño de la investigación}

A continuación se presentarán los elementos que integran el plan global de esta tesis de maestría.

El punto de partida es entender a la investigación

"como un proceso que involucra un conjunto de decisiones y prácticas (que a su vez conllevan la puesta en juego de instrumentos conceptuales y operativos) por las cuales conocemos -lo que puede significar describir, analizar, explicar, comprender o interpretar -algunas situaciones de interés cuya definición y delimitación (o construcción) forma parte de las decisiones apenas aludidas". (Marradi et al, 2007).

En este marco, el diseño se asemeja a una representación esquemática, un bosquejo, a la estructura a seguir "... ejerciendo el control de la misma a fin de encontrar resultados confiables y su relación con los interrogantes surgidos de la hipótesis". (Diccionario de la Investigación Científica, de Tamayo y Tamayo, 2005). ${ }^{8}$

La analogía más común del diseño metodológico de una investigación es la del diseño de una casa, y nada más cercano a este proceso, ya que a título personal, a la par que comenzaba a transitar el camino de la maestría (y por ende de esta tesis) también lo hacía en la construcción de la primera vivienda familiar, pues entonces este "conjunto de planos, dibujos de vistas, preselección de materiales, presupuestos, etcétera" (Marradi et al, 2007) que permiten guiar el proceso de construcción efectiva, en este caso, fue por partida doble.

\subsection{Preguntas que motivaron la tesis de investigación}

El espacio rural, además de ser el sustrato para la producción agropecuaria, es el sitio elegido por un número cada vez más significativo de turistas que, entre las diversas posibilidades y modalidades de viaje, deciden pasar sus días "en el campo", en contacto con la naturaleza, realizando o no tareas rurales, conociendo a la gente que vive en él, sus costumbres, sus tiempos, sus saberes. El espacio rural, con sus peculiaridades, ha sido revalorizado como lugar de disfrute y descanso para hombres y mujeres, generando a la vez una posibilidad de ingreso para prestadores oferentes de servicios turísticos en este medio, algunos de los cuales son productores agropecuarios.

En la provincia de Entre Ríos puntualmente, han pasado pocos años desde el inicio del proceso de integración de actividades de turismo rural en las familias agropecuarias (2010). Se presume que las nuevas actividades de turismo rural han favorecido el desarrollo de estas familias y que podrían haber operado reconfiguraciones en los núcleos familiares, diversificando la base económica de las unidades, aunque no se sabe ciertamente en qué medida.

Tampoco se tiene conocimientos sobre las implicancias que estas nuevas actividades de turismo rural han tenido sobre el resto de las actividades productivas de las familias, es decir, sobre sus actividades agropecuarias o sobre sus otras actividades de generación de ingresos (empleos no agropecuario por ejemplo), ni en cuanto a la dotación de recursos productivos del sistema familiar -a cuáles y cómo los afecta- pues en muchos casos la generación de actividades de turismo ha reducido el tiempo que las familias dedicaban a sus actividades agropecuarias o no agropecuarias que generaban también ingresos o les permitían generar otros circuitos productivos.

En este contexto, comprender cuál es la lógica de las familias que eligen diversificar sus actividades en el turismo rural y por qué optan por este tipo de actividad productiva, son algunas de las inquietudes que movilizan en forma recurrente la práctica profesional de esta autora como agente de INTA en el territorio entrerriano, partiendo de la base de que la

\footnotetext{
${ }^{8}$ En Batthyány y Cabrera (2011)
} 
actividad turística contempla otras reglas de juego, otras dimensiones y cambios trascendentales en el rol del emprendedor rural, que pasa de ser un productor a un oferente de servicios, y en el medio rural que de ser espacio de producción se reconfigura como espacio de consumo. ¿Por qué espacio de consumo? ¿Es que el campo deja de producir alimentos para producir "turismo"?

En el marco de la concepción y construcción de este trayecto de investigación científica, se presentaron preocupaciones en torno a preguntas como:

¿qué motivaciones llevan a los productores a optar por este tipo de estrategia de diversificación de ingresos?; ¿pueden estas familias reconfigurarse hasta el punto de abandonar sus actividades productivas de base para dedicarse en forma exclusiva al turismo?; ¿puede reemplazar el turismo al resto de las actividades del sistema?; ¿cuál es el peso de esta nueva actividad en la configuración económica del sistema?; ¿Poseen estos sistemas familia/ explotación una alta capacidad de adaptación?; ¿qué vinculación tienen estos sistemas con el entorno?; ¿Cuáles son las características del entorno que favorecen estas nuevas prácticas?

Teniendo en cuenta lo anterior, a partir de las inquietudes e interrogantes que movilizaron la investigación, la pregunta central planteada es:

¿Qué tipo de cambios y reconfiguraciones produce en el funcionamiento de las explotaciones familiares del Corredor del río Uruguay la introducción de la actividad

\subsection{Objetivos de la tesis} turística?

El objetivo general de esta investigación es comprender las transformaciones operadas al interior del sistema familia/ explotación y en vinculación al entorno, a partir de la incorporación del turismo como estrategia de diversificación de actividades e ingresos. En tanto los objetivos específicos son:

- Caracterizar el funcionamiento del sistema de actividad de las unidades productivas seleccionadas, desde una perspectiva global e histórica.

- Analizar los elementos constitutivos del sistema y las interacciones entre éstos y el sistema y el entorno, identificando las variaciones que se dan en la vinculación de los sistemas con el contexto.

- Identificar las tensiones, conflictos y sinergia que se dan al interior del sistema a partir de esta reconfiguración.

- Caracterizar las variaciones en el comportamiento de la familia a partir de las nuevas actividades turísticas en la explotación.

\subsection{Hipótesis de trabajo}

Las hipótesis que guían esta investigación reúnen los siguientes términos:

El turismo rural es una estrategia de pluriactividad que genera una nueva trayectoria biográfica en la unidad productiva familiar.

El turismo rural impacta sobre el resto de las actividades productivas del sistema, redefine las dinámicas familiares y el tradicional estilo de vida de las familias $y$ posiciona a la familia de una forma diferente frente al futuro, asegurando la continuidad de la explotación involucrando a los miembros más jóvenes en esta nueva actividad y/o instaurándose como caja de ahorro para el futuro. 


\subsection{Estrategia metodológica. Actividades y etapas de trabajo}

\subsubsection{1era etapa: entrevistas exploratorias y elección de variables}

Luego de realizar las primeras siete entrevistas exploratorias en dos de las zonas de estudio surgieron nuevas reflexiones para el análisis del objeto y se avanzó en la realización de la preclasificación de propuestas de turismo rural en la zona de estudio.

En esta primera etapa se desarrollaron entrevistas semiestructuradas a tres parejas de productores, tres entrevistas por separado a productor, productora e hija de familia (todos de la zona centro) y una entrevista a productora del sur.

A partir de las nuevas contribuciones que aportaron complejidad a la central del trabajo, se definieron las variables para la identificación del universo de análisis.

\subsubsection{2da etapa: generación de preclasificación de emprendimientos de turismo rural del Corredor del río Uruguay}

A partir de la identificación de las variables y con el aporte de información y datos confidenciales de 16 informantes territoriales (técnicos de INTA, de los Municipios locales, promotores asesores de los grupos Cambio Rural) se generó una preclasificación de los emprendimientos turísticos, en la cual se vertieron los datos de las 130 propuestas de turismo rural a lo largo del Corredor del Uruguay, zona seleccionada para el análisis.

Se relevaron los siete departamentos que integran el Corredor-. En la zona norte, Federación y Concordia; en el centro los departamentos San Salvador, Colón y C del Uruguay, y en el sur, Gualeguaychú e Islas del Ibicuy.

\subsubsection{3era etapa: selección de casos y realización de entrevistas}

Luego de realizar la primera preclasificación de propuestas o emprendimientos de turismo rural, se avanzó en una selección de éstos, que permita visualizar la heterogeneidad de historias y experiencias en el territorio.

Es importante mencionar que el estudio de casos no posee pretensión de representatividad estadística. Lo que se pretende con este abordaje metodológico es aportar riqueza explicativa, que posibilite generar elementos comprensivos de la realidad.

A partir de los resultados, se definieron los siguientes criterios de análisis tomados como base crítica para la selección de casos por zona.

Se seleccionaron en total 13 casos, 3 casos de la zona norte, 5 casos de la zona centro y 5 de la zona sur.

Se desarrollaron 9 entrevistas grupales (6 a la pareja de productores y 3 a la pareja y uno de los hijos más involucrados en la actividad) y 1entrevista individual (a un productor) en el periodo comprendido entre julio de 2016 y octubre de 2017.

\subsection{Variables del análisis y selección de casos}

El universo de las unidades de análisis ${ }^{9}$ de esta investigación entonces está dado por los Sistemas de Actividades (SA) que involucren la actividad turística en el espacio rural.

El primer elemento considerado para abordar este universo está dada por la discriminación de la gestión de los SA, ya que pueden estar a cargo y gestionados por productores agropecuarios u otras personas que no se dedican a la actividad rural.

\footnotetext{
9 "Son unidades de análisis porque se identifican con las unidades para las cuales cobran sentido las proposiciones teóricas, las hipótesis y el análisis correspondiente". (Batthyány y Cabrera, 2011)
} 
La siguiente variable utilizada es la orientación de los productos y servicios turísticos brindados:

$\checkmark$ SA que ofrecen alojamiento,

$\checkmark$ SA que ofrecen gastronomía, ya sea en forma de servicios y/o elaboración de alimentos para venta

$\checkmark$ SA que ofrecen actividades turísticas (recreativas, culturales, deportivas, tareas específicas rurales)

$\checkmark$ SA que combinación más de 1 categoría.

Luego, se definieron los siguientes elementos como base para construcción de la preclasificación:

- Forma social del trabajo ${ }^{10}$ : teniendo en cuenta si la mano de obra predominante en la explotación es familiar o con mayor cantidad de asalariados.

- Composición familiar ${ }^{11}$ : si la familia tiene o no tiene hijos. Y si éstos intervienen en alguna de las actividades productivas, son independientes del SA, son niños pequeños.

Procedencia de los productores: si son nacidos y/o criados, o residen en la zona hace más de 10 años, con la cual tienen una identificación territorial y cultural, o no.

- Pertenencia a redes o grupos sociales/ técnicos relacionados a las actividades productivas de la unidad (que incluye el turismo): es fundamental comprender la lógica de los actores en interdependencia y relación con su contexto, no de manera aislada. Es por ello que se determinó la pertenencia a redes o grupos sociales/ técnicos en los que se generen relaciones de intercambio material y/o simbólico con un grado de institucionalización, es decir, relativa estabilidad y permanencia. ${ }^{12}$

\subsection{Análisis de los resultados obtenidos}

Se procedió a hacer una desgrabación parcial de las entrevistas, pretendiendo rescatar los dichos significativos de los entrevistados y que colaboren a comprender su historia y el porqué de sus decisiones y prácticas. A tal fin se tomó como base el marco teórico y metodológico del Sistema de Actividades planteado por Pierre Gasselin y otros autores que se explicitan a lo largo de la investigación y se desarrolló un modelo que permitió volcar la información vertida por los entrevistados en una planilla de Excel. ${ }^{13}$

\footnotetext{
10 Siguiendo a Caracciolo de Basco y otros (1981) "la forma social del trabajo en las explotaciones es la variable determinante para considerar si un establecimiento es familiar o empresarial (...) Se define por la índole del factor trabajo en que se basa la explotación. Cuando ésta se halla centrada en el trabajo directo del productor y su familia -aunque se contraten también asalariados- la forma social de dicha unidad es familiar. Esta situación se da tanto en el tipo social familiar capitalizado como en el minifundista. Por el contrario, cuando la explotación está organizada en base al trabajo asalariado, reservándose el titular las funciones de supervisión y/o dirección, dicha forma social es asalariada y es lo que caracteriza al tipo social empresario (...)" (Caracciolo de Basco et al, 1981). ${ }^{11}$ Creemos que el análisis de la composición y dinámica familiar es un "elemento insoslayable a la hora de caracterizar a las familias productoras y analizar la resolución de coyunturas (diferenciando sus formas de consumo, ahorro o inversión de acuerdo a la etapa del ciclo vital) y la construcción de estrategias de más largo plazo". (López Castro, 2009).

Además, está directamente relacionado con el traspaso y continuidad de las explotaciones, elemento destacado de la hipótesis central de esta investigación. "Uno de los factores que la bibliografía destaca en los aspectos relativos a la toma de decisiones tiene que ver con la existencia de sucesores dentro del grupo familiar. En este sentido, diversos estudios han mostrado la importancia de este factor, por ejemplo, para lo que hace a la incorporación de medidas de manejo innovadoras o incluso para la inversión en tecnologías que propicien la continuidad de la actividad productiva". (Piñeiro y Cardeillac, 2010).

12 Siguiendo a Bourdieu (en Plascencia, 2005), en las redes sociales o grupos poseedores de capital social se da un intercambio de bienes materiales y simbólicos que presupone conocimiento y reconocimiento entre sus miembros, lo que permite fijar los límites del grupo. El capital social, según Putman referenciando a Coleman es productivo, y "hace posible el logro de ciertos fines que serían inalcanzables en su ausencia" (Millán y Gordon, 2005), puesto que la "estructura de la relación es un recurso para el actor, ya que le permite llevar a término sus metas e intereses a un menor costo". (Millán y Gordon, 2005). Por otra parte, en las redes circula información, se generan instancias de formación y capacitación que colaboran a incrementar el capital cultural de sus integrantes. ${ }_{13}$ Estos instrumentos pueden consultarse en la sección de anexo.
} 
En ésta se concentró la información ordenada por ejes de análisis:

\section{Caracterización general del sistema familia/ explotación}

1.A. Presentación general

1.B.Caracterización del SA Familia/ explotación según los recursos/ capitales (humanos, físicos, materiales, naturales, financieros y económicos, sociales, identitarios y territoriales)

\section{Trayectoria familiar}

\section{Objetivos familiares e incorporación del turismo}

3.A.Objetivos/motivaciones de la familia

3.B.Cómo y por qué incorporan el turismo

4. Funcionamiento del turismo dentro del sistema familia- explotación. (centrando la atención en aquellas dimensiones que sean fundamentales para explicar cómo el turismo se combina con el resto de las acividades del sistema)

4.A. Interacción producto: explica el flujo de materia prima de una actividad a otra.

4.B Interacción recursos: se explica a partir de la movilización de un mismo recurso para varias actividades.

4.C Interacción patrimonial: la implementación actividades simultáneas se dan en torno al valor intangible de un patrimonio

4.D Interacción temporal: explica los procesos de anticipación de un cambio que está por venir, del abandono o implementación de una nueva actividad

4.E. Interacción ingreso/ sentido del trabajo: la combinación de actividades permite asociar actividades fuertemente remuneradas con actividades que no son menos importantes pero proveen otro tipo de satisfacciones

4.F. Interacción ingreso/ sentido del trabajo: la combinación de actividades permite asociar actividades fuertemente remuneradas con actividades que no son menos importantes pero proveen otro tipo de satisfacciones

4.G Interacción ingreso: se da cuando 2 o más actividades aportan a los ingresos totales disponibles para la familia.

\section{Impacto del turismo en las dinámicas familiares y estilos de vida de la familia}

5.A. Impacto del turismo en las dinámicas familiares

5.B. Cambios personales y en los estilos de vida

\section{Posicionamiento frente al futuro}

6.A. Respecto a la sucesión y continuidad de la actividad por parte de los hijos

6.B. Respecto al futuro de la pareja de productores

Cabe subrayar que de cada caso se han destacado los aspectos centrales y sobresalientes que los mismos entrevistados han puesto de manifiesto a través de la diálogo, además de los hitos en su historia y trayectoria personal y familiar, que seguramente no son los únicos trascendentales.

Asimismo, se realiza una descripción de los recursos que no pretende ser minuciosa o detallada sino que procura revelar los elementos sustanciales para comprender lo mas integralmente posible la realidad del caso. Esto es importante acentuar porque cada historia y la forma en que fueron contadas, los tiempos que cada entrevistado otorgó a los diferentes temas y las derivaciones de éstos, fueron y son maravillosamente incomparables y únicos. $Y$ es en esa diversidad y complejidad dada por el tipo de herramienta -entrevistas semiestructuradas- y experiencias seleccionadas donde se sitúa la riqueza del objeto. 
"El relato, sea biográfico o autobiográfico, como el del testimonio que se confía a un investigador, propone acontecimientos que, sin desarrollarse todos y siempre en estricta sucesión cronológica (cualquiera que ha recogido historias de vida sabe que los testimonios pierden constantemente el hilo de la sucesión estrictamente cronológica), tienden o pretenden organizarse en secuencias ordenadas según relaciones inteligibles.

(...) se inspira siempre, al menos por una parte, en el deseo de dar sentido, dar razón, extraer una lógica a la vez retrospectiva y prospectiva, una consistencia y una constancia, estableciendo relaciones inteligibles, como las del efecto a la causa eficiente o final, entre los estados sucesivos, constituidos de este modo en etapas de un desarrollo necesario". (Bourdieu, 1989).

Luego, apuntando a un mayor nivel de interpretación que permitiese distinguir aquellos rasgos comunes entre los casos, y los que diferencian y particularizan las configuraciones al interior de los sistemas, se desarrolló una herramienta de síntesis con ejes transversales de análisis, instrumento que se adjunta en el anexo de la presente investigación. 
Capítulo 3- El marco conceptual de referencia para interpretar las transformaciones en el sistema de actividades familiares 
El eje de esta investigación está dado por el análisis de la familia en su sistema de actividades productivas y de generación de ingresos (que incorporan el turismo). Y cómo sus decisiones, en función de sus estrategias productivas y objetivos, modifican el funcionamiento de los otros elementos del sistema y las relaciones del sistema en su conjunto con el contexto, que condiciona y es condicionado por el propio sistema. Es por ello que los ejes a partir de los cuales se funda el marco teórico se construyen a partir de una aproximación conceptual sobre el turismo rural, su potencialidad como herramienta para contribuir a la dinamización de los territorios rurales, a partir de la movilización de sus recursos y sus decisiones en torno, y como estrategia de diversificación de ingresos de las familias rurales.

\subsection{La familia rural, eje vertebral del sistema}

Tal como se ha expuesto, el eje de esta tesis de investigación está dado por el análisis del comportamiento de los sistemas productivos familiares entrerrianos como sistemas de actividades que incluyen al turismo.

Por ello, se considera atinado precisar en primer lugar qué se entiende por productores agropecuarios familiares o sistemas de producción familiar. Teniendo en cuenta cómo estas unidades combinan los medios de producción (tierra, capital y trabajo) para llevar adelante los procesos productivos, se abre un grado de heterogeneidad de los sistemas productivos familiares.

"El grado de heterogeneidad de las unidades productivas contenidas bajo esta forma -dadas por las distintas combinaciones de tierra, capital y trabajo para llevar a cabo los procesos productivos- varía según la forma en que el capital se instala y domina la organización de los procesos productivos, con alto impacto sobre la capacidad de reproducción de las unidades familiares". (Cloquell, Propersi y Alabenesi, 2001).

Sobre esta cuestión y sobre la forma de denominar a este tipo social agrario ${ }^{14}$ existe un amplio volumen de conceptos y material en la historiografía agraria.

A los fines del presente trabajo, se parte de la definición de Chia (1995, en Tort y Román, 2005) quien expresa que

"toda explotación agrícola familiar cumple una función de producción, una función de consumo y una función de acumulación de patrimonio. La presencia simultánea de estas tres funciones en un mismo lugar (o individuo, familia) confiere a la explotación agrícola una lógica propia que puede denominarse lógica familiar de producción/reproducción. La reproducción del sistema familia-explotación consiste en preservar el patrimonio familiar incrementando en cada generación los medios de producción que permitirán, a la vez, asegurar un nivel de consumo aceptable para la familia y para la reproducción de los medios de producción". (Chía, 1995).

Asimismo, se retoma a Piñeiro (2004) quien explicita que el concepto de productor familiar es un término definido por las relaciones sociales de producción.

"Se entiende por una explotación de carácter familiar aquella en que se trabaja con mano de obra predominantemente de origen familiar. El trabajo familiar debe ser aplicado a una parcela de tierra en posesión (no necesariamente en propiedad) del grupo familiar. Podrá contratar mano de obra permanente o zafral pero siempre en cantidades menores al trabajo aportado por la familia. Si el trabajo contratado supera el trabajo aportado por la familia se entiende que ha dejado de ser una explotación familiar para convertirse en una explotación de carácter empresarial". (Piñeiro, 2004).

Siguiendo a Cloquell, Propersi y Albanesi (2011) se puede agregar que en este tipo social agrario, uno de los criterios fundamentales para considerar el carácter de producción familiar

\footnotetext{
14 Siguiendo a Basco y otros (1981) "se caracterizan y diferencian por la disponibilidad y magnitud de su dotación de recursos y por la forma de organización social del trabajo”. (Basco et al, 1981).
} 
es que la conducción, organización y toma de decisiones está en manos de miembros de la familia.

"Éstos supervisan las tareas que se realizan y el manejo de los mercados, aumentando en términos relativos las tareas administrativas, aun cuando haya incorporación de asalariados transitorios y o permanentes en la explotación, de acuerdo al ciclo de vida y/o las decisiones de dedicarse a otra actividad". (Cloquell, Propersi y Albanesi, 2011).

Tort y Román (2005) especifican dos criterios para diferenciar una explotación familiar de una empresaria. El primero se relaciona con la participación directa del titular y su familia en las labores del campo, lo que no impide la contratación de trabajadores permanentes y/o eventuales. El segundo se refiere a la responsabilidad directa del titular en la administración de la explotación (que incluye lo comercial y financiera además de lo estrictamente productivo y laboral) sin que exista un administrador contratado.

Retomando nuevamente a Piñeiro (2003) pueden distinguirse tres tipos de situaciones en la producción de tipo familiar.

\section{La del productor familiar capitalizado}

"es aquel que aun utilizando trabajo familiar predominantemente (pero contratando asalariados) consigue generar y guardar excedentes de un ciclo agrícola para el próximo. Por otro lado como suele reinvertir sus ganancias en maquinarias y otras mejoras tecnológicas que ahorran fuerza de trabajo, aunque la explotación crezca en tamaño y en producción, se sigue manejando la unidad productiva con trabajo familiar". (Piñeiro, 2003).

Este tipo social agrario puede saltar de la categoría familiar capitalizado a un empresario agropecuario cuando su grado de capitalización lo lleva a que la proporción de trabajo asalariado supera el aporte de la mano de obra familiar. Cittadini y otros (1990) reserva el concepto de empresa agropecuaria:

"para aquella unidad de producción basada en el trabajo asalariado, en la que el productor, en este caso empresario, tiene funciones de organización y dirección. Esta particular forma de organización social de la producción generalmente se corresponde con una disponibilidad de capital y recursos naturales para la cual puede ser válido considerar como criterio de decisión a la maximización de beneficio, entendido como tal a la retribución de todos los factores de producción". (Cittadini, Manchado y Mosciaro, 1990).

En el otro extremo de la figura de este productor familiar capitalizado se encuentra otro tipo de productor familiar, el semi-asalariado (Piñeiro, 2003), que

"por la escasa tierra que posee o por los bajos ingresos que percibe debe recurrir al empleo fuera del predio para completar sus ingresos. De esta manera uno o varios miembros de la familia trabajan en explotaciones vecinas o en empleos públicos o privados en una localidad vecina (...) Suele ocurrir que una menor dedicación de fuerza de trabajo a explotar la parcela familiar determina una menor producción y por lo tanto menores ingresos del predio, que deben ser por lo tanto reforzados por ingresos crecientes de fuera del predio que provienen de mayor trabajo extrapredial. Se entra así en una espiral que generalmente termina con la venta del predio o por lo menos con la total proletarización de la fuerza de trabajo quedando el predio solo como residencia de la familia. En ambos casos (por definición) ese grupo familiar deja de ser considerado como productor". (Piñeiro, 2003).

El autor menciona otro tipo de situación en la cual miembros del grupo familiar buscan trabajo fuera del predio, pero empleando formas de capital propio, por ejemplo prestando servicios a terceros siendo contratistas de maquinaria agrícola o realizando otro tipo de actividad dada por capital cultural adquirido "ya sea a través de estudios realizados como es el caso de maestros, técnicos, etc. (situación más frecuente en las nuevas generaciones que han podido capacitarse) o a través de habilidades adquiridas en el entrenamiento como trabajadores en el propio establecimiento familiar: tractoristas, alambradores, mecánicos, etc". (Piñeiro, 2003). 
Sobre esta última forma de organización del trabajo familiar, que el autor asocia a la estrategia de pluriactividad, se volverá en próximos párrafos.

En una categoría intermedia entre las dos tipologías mencionadas se encuentra al productor familiar

"que dedica todo el trabajo familiar a la explotación de su unidad productiva, pudiendo contratar algo de trabajo asalariado, pero siempre en menor proporción que el trabajo aportado por la familia y que percibe ingresos suficientes como para vivir pero no como para acumular capital. Es probablemente el tipo más frecuente". (Piñeiro, 2003).

Hamdan (1994) lo explicita en otro términos, manifestando que

"las explotaciones familiares (...) incluye a aquellas unidades que producen en condiciones de escasez de recursos productivos y en las cuales la forma de organización social del trabajo se caracteriza por ser básicamente familiar (...) las explotaciones empresariales son aquellas unidades de producción con una dotación adecuada de recursos productivos y en las cuales la mano de obra es preponderantemente asalariada, el productor tiene funciones de organización y dirección (...). El tercer tipo es el familiar capitalizado, al que se lo ubica como un caso intermedio entre el familiar y el empresarial. El trabajo es básicamente familiar pudiendo requerir de personal asalariado. Posee una dotación de factores que le permiten acumular excedentes, con un cierto grado de capitalización". (Hamdan, 1994).

Ahora bien, como explicita Chía (1995), la explotación familiar es unidad de producción, unidad de consumo y unidad de acumulación.

En este sentido,

"pueden estar en proceso de reproducción simple (es decir que no logran acumular excedentes), en proceso de descapitalización (que las llevará hacia la proletarizacion) o en proceso de reproducción ampliada cuando logran retener excedentes económicos a lo largo de varios años sucesivos". (Piñeiro, 2003).

Ahora bien, en sus contextos, cada productor construye, pone en marcha prácticas para modificar o sostener su realidad familiar, personal, productiva. Estas operaciones incluyen "actividades rutinarias, pre-reflexivas y también tomas de posición y acciones estratégicas, que pueden ser conceptualizadas como las formas en que los sujetos tratan de resolver sus problemas y organizar sus recursos dentro de los límites que enfrentan". (Craviotti y Palacios, 2012).

He de aquí que otro de los conceptos intrínsecamente relacionado es el de racionalidad y estrategia, vinculados directamente con las decisiones y respuestas que toman los actores, en los planos productivo y reproductivo, en cuanto al uso de los medios disponibles, al proyecto puesto en marcha, en un contexto dado y en el marco de una historia personal, familiar y colectiva.

Cada productor tiene sus objetivos y razones para hacer lo que hace y eso que hace es el producto de una determinada lógica de funcionamiento, que a su vez es producto de los recursos con los que cuenta, los condicionantes del entorno y su experiencia (Brossier, 1974 citado por Osty (1987). Por ello es fundamental "comprender las condiciones en que se desenvuelven los productores familiares y sus formas de manejo de recursos a partir de sus propios marcos de significado y disposiciones culturales". (Craviotti y Palacios, 2012).

En términos de Cittadini et al (1990), el término estrategia "se refiere al tipo de actividad, a la combinación de actividades y al modo como estas se realizan". En otras palabras, los tipos de actividades productivas y la manera en que se llevan a cabo.

Estas estrategias pueden mantenerse invariables o ser modificadas dados los cambios del contexto y al interior de la unidad productiva.

"En contextos históricos estables, las estrategias se mantienen estables, pero ante cambios en el contexto que afectan aspectos fundamentales de la organización de los recursos, antiguas estrategias 
dejan de servir y la familia deberá generar nuevas prácticas adaptadas a las situaciones que se van creando. La sensibilidad al contexto sin dudas provoca el desarrollo de estrategias en busca de conservar o incrementar el capital, de maximizar sus ingresos conforme a sus necesidades de reproducción". (Huinca, 2013).

¿Y qué medios, qué recursos se ponen en juego en estas decisiones y prácticas?

Cada sistema familia- explotación cuenta con distintas dotaciones de capital, de tal forma que sus estrategias, sus acciones, dependen de la estructura y volumen de cada uno de estos tipos de capital.

Siguiendo a De Nicola (2007), en Huinca (2013), puede decirse que las unidades familiares poseen tres especies distintas de capital (medios) que son el económico, el cultural y el social.

Teniendo en cuenta el capital económico, uno de los elementos más importantes es la propiedad de la tierra, en cantidad y calidad, que condiciona fuertemente el ingreso que la familia recibirá. (Huinca, 2013).

Piñeiro (2003) explicita que los productores familiares movilizan no solo capital patrimonial sino también capital social y capital cultural.

Por capital social se entiende la inserción local del agricultor y se expresa en el conjunto de relaciones que él mismo establece.

"Estos vínculos le sirven no solo para obtener información a través de la cual puede tomar mejores decisiones en la Unidad Productiva sino también le permite acceder a recursos que suelen ser repartidos por esos canales (por ejemplo cuando los vecinos de un paraje consiguen a través del dirigente político local que les arreglen el camino)". (Piñeiro, 2003).

Tomando a Putnam (1993) en Piñeiro (2004), el capital social está formado "fundamentalmente por el grado de confianza existente entre los actores sociales de una sociedad, las normas de comportamiento cívico practicadas y el nivel de asociatividad". (Putnam et al, 1993).

"Contribuye a crear un tejido social, una trama social más robusta y ésta tiene su impacto en la posibilidad de lograr un mayor desarrollo económico (...)

La asociatividad reúne esfuerzos dispersos, acumula capital disperso, aumenta la escala de las transacciones económicas, confiere mayor poder de compra o de venta y por lo tanto consigue mejores resultados económicos". (Piñeiro, 2004).

En otras palabras, Craviotti y Palacios (2012) explicitan que

"las relaciones interpersonales de las familias y su participación en organizaciones les facilita el acceso a otros recursos. Muchas veces este capital social está representado por la cantidad y calidad de la vida asociativa y la actitud de las personas hacia los demás". (Craviotti y Palacios, 2012).

Respecto al capital cultural,

"comprende los conocimientos y prácticas a las cuales el productor accede a través de su pertenencia familiar (...) Los conocimientos (y los conceptos equivocados) y las prácticas son principalmente transmitidos de padres a hijos, formando su capital cultural.

Es por ello también que la sucesión generacional tiene tanta importancia en las explotaciones familiares. El productor siente que él es el creador de su obra, la explotación familiar y desea transmitir todo lo que ella tiene y contiene, tanto en términos patrimoniales como sociales y culturales, a sus descendientes". (Piñeiro, 2003). 


\section{De ciclos y trayectorias}

Como se ha comentado, los procesos históricos por los que transitó la Argentina, fundamentalmente desde la década de 1990 a esta parte, han sido particularmente críticos para las familias rurales, que ponen en juego su capacidad de permanencia en la producción agropecuaria, poniendo en marcha estrategias que adquieren distintas versiones. (Cloquell, Propersi y Albanesi, 2011).

Parte de las estrategias que materializa la familia en su sistema (sistema familia-explotación), guarda estrecha relación con el ciclo de vida de la unidad, que a la vez determina un proyecto que Petit (1981) ${ }^{15}$ define como un conjunto de objetivos más o menos jerarquizados, no desprovistos de contradicciones y susceptible de evolución.

"De esta manera el sistema familia-explotación nace, crece, madura y envejece, desaparece o es retomado por otro individuo, dando lugar, en este último caso, a un nuevo ciclo de vida. Esta idea, se encuentra presente ya en los trabajos de Chayanov, donde articula el crecimiento de la explotación agropecuaria con la evolución familiar y se define en cuatros etapas: instalación, transición, crecimientoconsolidación y declinación". (Gange, Mosciaro y lorio, 2013).

Bennet (1982) en López Castro (2009) propone un modelo de las etapas por las que atraviesan las unidades agropecuarias que en el marco del objeto de esta tesis puede ser una herramienta para analizar las experiencias.

Las fases identificadas por el autor son:

1. de establecimiento

2. de desarrollo

3. de estabilidad

Las tres con variantes descendiente/decline, re-desarrollo por traspaso o estática.

"En la primera el objetivo central es acceder a la tierra, procurar la infraestructura productiva básica y vivienda para la familia. El mayor esfuerzo está concentrado en conseguir cierta estabilidad que permita la formación de una familia y una ocupación estable con ingresos suficientes.

La fase de desarrollo es la del mejoramiento y expansión de la explotación, a partir de las necesidades de la familia y las condiciones económicas generales. Se caracteriza por la búsqueda de mayor escala, mayor desarrollo de la infraestructura y la adquisición de maquinarias. El objetivo central es la acumulación de capital, en un esquema que permita ahorrar parte de los ingresos para contrarrestar las incertidumbres de la actividad. Esta es una fase recurrente: ocurre siempre que el operador tenga la necesidad o el deseo de expandirse.

Por último, la etapa de estabilidad, aunque suene contradictorio, es la más variable de todas y puede adquirir matices diferenciados. Ocurre cuando la familia considera cubiertas sus necesidades y la unidad produce a un nivel suficiente para solventar los gastos diarios e incluso permitir cierto nivel de ahorro. Se distinguen dentro de esta fase tres posibles características: estabilidad descendiente (puede tener causas variadas como deficiente base de recursos, pérdida de incentivo, desastres económicos y ambientales, etc); estabilidad con re-desarrollo por traspaso (se trata de un nuevo comienzo en nuevas manos, pero con una base de desarrollo anterior) y estabilidad estática (suele ser una fase pasajera, relacionada con el cansancio físico y/o falta de interés por parte del operador, que se refleja en la falta de voluntad para sostener la explotación)". (Bennet, 1982, en López Castro, 2009).

La primera analogía que viene a la mente al pensar en el ciclo de la vida de una persona, de una organización, es el de un camino, una línea, que en algunos casos puede ser más armónica, en otros presentar curvas peligrosas, zigzagueos permanentes. Lo cierto es que en retrospectiva todo guarda una razón, inconsciente a veces, pero coherente al fin.

Esta historia individual y familiar es la que intentamos descubrir a través de las entrevistas a los hombres y mujeres, eje de los casos seleccionados. $\mathrm{Y}$ a partir de éstas y sus relatos,

\footnotetext{
${ }^{15}$ En Gange, Mosciaro y lorio, 2013.
} 
intentar abordar su singularidad en el marco de procesos sociales, culturales e históricos determinados.

Si bien el objeto central de esta investigación no es estudiar las trayectorias, sí es fundamental su consideración, puesto que

"permite obtener informaciones biográficas y además posibilita una contextualización de los proceso, es decir, la ligazón entre la biografía individual y las características estructurales globales de la situación histórica vivida (...) La trayectoria se constituye en un proceso en el que se ponen de manifiesto las disposiciones y prácticas de los distintos actores". (Lera et al, 2007).

Ahora bien, dado que el enfoque con el que se analizarán las explotaciones productivas familiares y las configuraciones que se dan a partir de la introducción del turismo es el enfoque de sistemas, es que en el próximo apartado se profundizará en torno a esta temática.

\subsection{Las unidades productivas familiares como sistemas de actividades. El sistema de actividades como marco conceptual y metodológico}

En el marco de esta investigación, y tal como se ha esbozado en la hipótesis de trabajo, se entiende que el productor familiar que incorpora la actividad del turismo a su sistema productivo, modifica pautas, tiempos en la dedicación de las actividades, y que de alguna manera, ello trae aparejado algunas reconfiguraciones en el resto del sistema. Por ello es importante analizarlo en forma global, en el marco de una estrategia que el productor pone en marcha en torno a sus objetivos de producción y a la racionalidad que lo caracteriza.

Uno de los enfoques considerado más procedente en relación al objeto de esta tesis que ofrece elementos de análisis para explicar y abordar cómo opera el turismo al interior de los sistemas productivos, cómo se relaciona con el resto de las actividades que en éste se desarrollan y de qué manera impacta en el estilo de vida y dinámicas de la familias es el acuñado por Gasselin (2009) denominado sistema de actividades que junto a Bathfield (2013) lo retoman para explicar la flexibilidad y los procesos adaptativos de las actividades de los agricultores. De este marco conceptual y metodológico, que contempla otros elementos de análisis como los resortes de flexibilidad de los sistemas, la resiliencia, la capacidad de adaptación a los cambios, entre otros, se tomarán los conceptos considerados centrales para su aplicación y ajuste al objeto de esta investigación.

Estos autores proponen una mirada integradora del objeto de análisis seleccionado, que permite comprender los vínculos que el actor $^{16}$ establece con la combinación de todas sus actividades y su entorno (sectorial, territorial y político). Se parte del análisis del sistema familiar, no de las actividades en particular de alguno de sus miembros. ${ }^{17}$

Para Gasselin (2009) la intención de desarrollar estas herramientas es analizar la capacidad de los sistemas de actividades a mantenerse en contextos aleatorios y perturbados. Teniendo en cuenta esto, el sistema de actividades puede ser conceptualizado como

"un conjunto estructurado de actividades localizadas y en interacción implementadas por una entidad social dada, movilizando unos recursos disponibles con vistas a satisfacer los objetivos de la entidad social y permitir su mantenimiento en equilibrio dinámico en un entorno ecológico y social dado". (Gasselin, 2009).

\footnotetext{
${ }^{16} \mathrm{El}$ término actor es incorporado por los propios autores a su marco conceptual.

17 En el marco de esta investigación se tomarán en cuenta las actividades productivas y de generación de ingresos para la familia. Corresponden al tipo de actividades que Arendt (2009) incluye dentro de la órbita del trabajo. "Trabajo es la actividad que corresponde a lo natural de la exigencia del hombre, que no está inmerso en el constantemente repetido ciclo vital de la especie, ni cuya mortalidad queda compensada por dicho ciclo. El trabajo proporciona un artificial mundo de cosas, claramente distintas de todas las circunstancias naturales (...) La condición humana del trabajo es la mundanidad". (Arendt, 2009). De esta manera distingue al trabajo de la labor y la acción, las tres actividades fundamentales de la vida del hombre.
} 
Según los autores, examinar un objeto desde la óptica de los sistemas de actividad, exige "reconocer las propiedades emergentes que surgen a raíz de las interacciones que se establecen entre los componentes del sistema de actividad, en particular, entre los recursos, y entre el sistema y su entorno". (Gasselin y Bathfield, 2013).

A través del sistema de actividad se pretende reconocer la poliracionalidad del actor, es decir, el sentido dado al involucrarse a una actividad.

"Esta coherencia global se evidencia solo si se examina el conjunto de las actividades implementadas por la entidad social, agropecuarias o no". (Gasselin, 2009).

Para Gasselin (2009) los actores toman decisiones coherentes que se traducen en prácticas y estrategias, y presentan motivaciones que pueden explicarse en diferentes registros, y que pueden ser sinérgicas o estar en tensión ${ }^{18}$.

Lo importante en este punto es que "la comprensión de las prácticas y de las decisiones del actor supone haber caracterizado lo que él reconoce como valores producidos por las actividades y lo que él considera o no como recurso". (Gasselin y Bathfield, 2013).

Respecto a estos conceptos Paul et al (1995) parten del axioma de que el sistema de actividad se aplica al nivel de la familia. Es ésta la que moviliza los factores de la producción a fin de alcanzar los objetivos "de consumo, de capitalización, de transformación del aparato de producción; objetivos mismos que son determinados por la situación socioeconómica globalizante". (Paul et al, 1995).

Los autores plantean que en el fondo de la cuestión se encuentra la racionalidad de agricultor y de su familia ${ }^{19}$. En este sentido,

"lo que se trata de despejar son los objetivos estratégicos generales que conducen a la implementación del sistema de actividad y los subobjetivos asociados a cada una de las actividades que contiene a fin de comprender cómo el agricultor y su familia van a razonar, jerarquizar la asignación de los recursos de los que ellos disponen y, particularmente, el del trabajo familiar”. (Paul et al, 1995).

Otra cuestión trascendente para entender la lógica de los actores, en este caso, productores agropecuarios, es la interacción dado entre el sistema de actividades y el entorno. Y en este sentido, es cardinal vislumbrar lo planteado por los autores en términos de condicionamientos y libertad de acción del actor. Ellos esgrimen que "si bien el actor es un sujeto social producto de la Historia, también posee una historia personal y tiene la capacidad de actuar sobre su entorno". (Gasselin y Bathfield, 2013).

Este enfoque reconoce al entorno como contexto y a la vez producto de la actividad. Hacen referencia a los distintos niveles (internacionales, nacionales, regionales, locales) y dimensiones que confluyen a nivel de la entidad social. En su esquema de análisis se refieren a dimensiones de regulación, sectoriales y territoriales ${ }^{20}$ que condicionan los sistemas y son condicionadas por estos.

\footnotetext{
18 Para los autores estas motivaciones, que explican la poliracionalidad de los actores pueden ser económica, axiológica, relacional, identitaria, técnica, estética.

19 Bravo (1991) explica la definición de racionalidad tomando a Mingat et al (1985) esgrimiendo que "el principio de racionalidad no significa que un individuo haga la mejor elección posible, exactamente la misma que haría en su lugar un individuo mejor informado y dotado de un sistema de preferencias conforme a la finalidad de la especie humana. Se supone simplemente que él realiza la elección que le parece mejor de acuerdo a sus objetivos (que un observador puede juzgar irrazonables) y sus medios..."

20 En las dimensiones de regulación, se incluyen las políticas públicas y dispositivos o herramientas de apoyo, las relaciones de fuerza, las instituciones intervinientes. En las sectoriales se tienen en cuenta los actores y eslabones de la cadena de valor, entre otras cosas. $Y$ en la territorial, se incluyen cuestiones inherentes a la identidad del territorio, la organización social y política, las condiciones biofísicas y el ordenamiento territorial, entre otras posibles de mencionar.
} 
Otro de los puntos vertebrales de la teoría de los sistemas de actividades se relaciona con que los actores, que toman decisiones en base a sus propias representaciones ${ }^{2122}$, están condicionadas por el acceso y la disponibilidad de los recursos y contextos del territorio.

Estos recursos que los actores ponen en juego pueden ser categorizados como familia de recursos (Gasselin, 2009) ${ }^{23}$ internos o externos al sistema, humanos, naturales, materiales, financieros, informacionales, identitarios, sociales, territoriales, patrimoniales. Pueden variar según el momento histórico de la entidad o las fases del ciclo de vida, entre otras causas. (Gasselin y Bathfield, 2013).

En este marco, es necesario

"prestar especial atención a interacciones que lo cruzan, si se trata de interacciones entre actividades (productos, tiempo, espacio, ingresos, riesgo, significado, etc.), entre los recursos (competencia, complementariedades, sinergias, etc.), entre los diversos elementos de la decisión (motivaciones, representaciones, estrategias, etc.) o entre el sistema de actividades y su entorno político y normativo, territorial y sectorial". (Gasselin, Vaillant y Bathfield, 2015).

Ahora bien, Gasselin (2009) ${ }^{24}$ plantea un marco de análisis sintético sobre los tipos de relaciones funcionales que pueden darse entre los subsistemas que contribuyen a fundar la coherencia global del sistema.

Hace referencia entonces a:

1. Una interacción producto: que traduce la existencia de un flujo de materia "arriba" que abastece de un insumo o materia prima a una actividad "abajo". Por ejemplo, transferencia de fertilizantes entre el sistema ganadero y el cultivo. Hay productos que pasan de una actividad a otra y son considerados insumos por parte de una de las actividades.

2. Interacción recursos: se da alrededor de la movilización de un mismo recurso -que se encuentra en cantidad limitada - por varias actividades del sistema. Puede ser entendida para cada categoría de recurso:

2.a. Interacciones capital o recurso humano. En primer lugar, se pueden detectar interacciones trabajo, examinando en particular el reparto de las distintas tareas en las diferentes actividades en el tiempo, en el seno de la entidad social y la prioridad que se da a las operaciones, tareas, buscando discernir las tareas impostergables (obligatorias), de las postergables con algún tipo de costo (facultativas). También se dan las interacciones competencias, en las que el saber, saber hacer, son movilizados en una actividad permitiendo mejorarla o permitir la realización o implementación de otras actividades, por ejemplo, el saber manejar bien un tractor para campos propios es la base de la prestación de un servicio de terceros o de ser obrero agropecuario.

2.b. Interacciones capital o recurso físico: situaciones donde varias actividades movilizan el mismo medio de producción cuya duración de vida es plurianual (equipos, edificios, herramientas).

2.c. Interacciones recursos naturales: la existencia de una actividad permite desarrollar otra actividad vinculada con el uso de la tierra. Por ejemplo el desarrollo de una actividad inmobiliaria o alojamientos turísticos en parcelas que se han vuelto constructibles o puede ser también en términos de competencias, cuando las condiciones del suelo permiten una diversificación agrícola.

2.d Interacciones en torno al recurso o capital financiero: se traduce por las relaciones entre los ritmos y niveles de flujo de caja o entre los procesos de capitalización de las distintas actividades.

\footnotetext{
${ }^{21}$ El término representación es utilizado por los autores. No es objetivo de esta tesis ahondar en este marco conceptual.

22 "Estas representaciones se aplican a todos los niveles: sobre el propio actor, sus recursos, sus actividades, su entorno, sobre lo que él estima de las propiedades de su sistema de actividad". (Gasselin y Bathfield, 2013).

23 Documento de trabajo del autor actualizado al 19 de noviembre de 2009.

${ }^{24} \mathrm{La}$ traducción es propia, correspondiente a la lectura del documento de trabajo escrito en francés por el autor citado. Se tomaron también los apuntes de lo compartido con el autor en el trabajo en terreno (Entre Ríos, 2016)
} 
2.e. Interacciones capital o recurso social: dos o más actividades están vinculadas por las relaciones sociales que una o las dos suponen o permiten. Se puede dar a través de la movilización de redes técnicos profesionales cercanas. Un ejemplo puede ser un vitivinicultor que comercializa vinos de vecinos, utilizando la misma red de contactos para valorizar tanto su vino como el que vende de otros productores.

3. Interacciones patrimoniales: la realización de actividades están organizadas en torno al valor de un patrimonio tangible o inmaterial. Se da cuando la implementación simultánea de varias actividades se fundamenta en el valor de un patrimonio inmaterial, que puede ser paisajes, razas, variedades locales, patrimonio cultural y simbólico, patrimonio arquitectónico, culinario y gastronómico.

4. Interacciones espaciales: se da cuando las actividades que se desarrollan simultáneamente tienen una relación particular con el espacio, que condiciona las prácticas técnicas y organizacionales (organización multipolar de la familia, transporte para varias actividades, agua residual para piscicultura).

5. Interacciones temporales: cuando las prácticas están asociadas a la perspectiva de la evolución del sistema. Son los procesos de anticipación de un cambio que está por venir, del abandono o implementación de una nueva actividad.

6. Interacción riesgo: inseguridad relativa de las actividades que permite combinar actividades arriesgadas con otras más seguras (actividad asalariada por ejemplo), contribuyendo a aumentar la flexibilidad del sistema.

7. Interacción ingreso/ sentido del trabajo: la combinación de actividades permite asociar actividades fuertemente remuneradas con actividades que lo son menos pero proveen una satisfacción personal.

8. Interacciones ecológicas: situación que se da cuando una combinación de actividades permite o conduce a un mutualismo ecológico entre dichas actividades.

9. Interacciones ingreso: cuando dos o más actividades aportan o contribuyen al ingreso total disponible de la entidad social, consolidando un ingreso total que permite cubrir las necesidades y expectativas de la familia.

Estas interacciones no son exhaustivas ni exclusivas. No todo sistema de actividades tiene que presentar estas relaciones, pero en su búsqueda se encuentran elementos para explicar qué es lo que da coherencia a cada sistema. Como se verá más adelante, tomando como soporte esta línea metodológica ofrecida por Gasselin (2009) se abordarán los casos de esta investigación, intentando percibir de qué forma o cómo interactúa el turismo con el resto de las actividades productivas y/o de generación de ingresos de los sistemas seleccionados.

En relación a los tipos de interacciones mencionadas, Gasselin (2009) agrega que éstas pueden ser obligatorias o facultativas/opcionales, si la relación es una condición indispensable o no para la viabilidad de las actividades; competitivas o complementarias, cuando, como el nombre lo indica, se da una competencia por el uso de los recursos limitados del sistema o por el contrario, cuando el resultado de las actividades depende de cómo se valoriza el objeto de la relación funcional. Y por último, pueden ser simétricas o asimétricas, dependiendo de la reciprocidad o no de los productos.

Complementando lo planteado hasta el momento, otro autor tomado de base para la comprensión de los sistemas productivos es Osty $(1987)^{25}$, quien postula el concepto de familia-explotación como el conjunto constituido por la explotación, el agricultor y su familia.

El autor formula una serie de elementos a tener en cuenta que trasciende el funcionamiento en sí de las explotaciones incluyendo inseparablemente a la familia en relación a ésta. Propone tomar en cuenta la situación de la familia, la toma de decisiones, sus intervenciones,

\footnotetext{
${ }^{25}$ A pesar de ser un artículo publicado hace más de cuatro décadas (ya que se publicó primero en 1978 y luego en español en 1987) para la autora su lectura fue esclarecedora y sentó un punto de partida para la selección de artículos posteriores, coherentes con esta forma de entender los sistemas desde una lógica menos tecno o agrocentrista.
} 
ya que en cada explotación "una familia compromete trabajo, competencias, un patrimonio y también, como se sabe, una parte de su vida social”. (Osty, 1987).

Continúa el autor explicitando que

"la familia tiene un objetivo global que tiende a asegurar su permanencia bajo diversas condiciones. Este objetivo se relaciona con las prácticas patrimoniales, la educación de los hijos. Lo esencial aquí es que dicho proyecto dirige un objetivo estratégico, referente a la elaboración de un sistema de explotación considerado adecuado". (Osty, 1987).

Para finalizar con este apartado, se considera clarificador retomar una cita del autor citado anteriormente, quien manifiesta que

"la explotación agrícola es un conjunto organizado que no responde a criterios simples y uniformes de optimización; es a partir de la visión que los agricultores tienen de sus objetivos y de su situación que se puede comprender sus decisiones y necesidades". (Osty, 1987).

A la luz de lo expuesto, retomando los conceptos centrales y entendiendo la complejidad que impregna cada situación familiar, cada decisión tomada, se intentará desentrañar, comprender e interpretar, cómo los distintos sistemas (familia-explotación) se comportan al incluir la actividad turística. Elementos que serán explicitados en el capítulo $\mathrm{n}^{\circ} 4$ de esta investigación.

\subsection{El turismo rural como herramienta de valoración territorial y estrategia de diversificación de actividades}

Siguiendo a Posada (1999),

"dos son los elementos constitutivos del turismo rural que concitan la atención de los analistas. Por un lado, su pertenencia al espectro de la pluriactividad rural ${ }^{26}$; por otro lado, las mutaciones que origina en la conformación del espacio rural".

Es en esta dirección de pensamientos que se presentarán algunas referencias conceptuales que conciben al turismo rural desde el punto de vista de la familia, como una estrategia de diversificación de ingresos y/o actividades y en relación a la pluriactividad y desde el territorio, entendiéndolo como estrategia de revalorización de los recursos endógenos.

Antes de seguir avanzando en esta avenida de conceptos, es fundamental profundizar sobre el concepto de turismo rural en el marco de esta investigación

En la revisión bibliográfica de autores del orden internacional, latinoamericano y nacional se encuentra una diversidad de aportes a la temática del turismo rural, que puede ser comprendido y analizado desde diversos enfoques y tomando universos de estudio diferentes.

Algunos autores hacen referencia al turismo rural como estrategia para el desarrollo integral de las áreas rurales, siendo éste el enfoque que desarrolla INTA (Guastavino et al, 2012; Sili, 2007), aspecto vinculado también a la problemática y sus potenciales efectos inductores en el desarrollo local (Estrada, 2013).

El territorio rural es considerado ámbito para la creación de procesos de desarrollo más diversificados y sustentable, en los que se incluye el turismo rural y su revalorización como sustento de la identidad y cultura no uniformizada, postura adoptada por Sili (2007) y Nogar, $(2010,2011,2013)$.

\footnotetext{
${ }^{26}$ Sobre este concepto se volverá y profundizará en los próximos párrafos.
} 
Para Flores Ruiz y Barroso González (2011), el turismo es un importante dinamizador de los procesos de desarrollo rural y una de las actividades económicas con mayor potencial para generar nuevas fuentes de riqueza y empleo, y frenar el abandono de las zonas rurales.

Por otra parte, el turismo rural ha sido estudiado y analizado como agente para la reactivación económica de las áreas rurales deprimidas, para la rehabilitación del patrimonio socio- cultural y de la economía local (Bote Gómez, 1979, 1988).

Según Martinez y Monzonis (2000), la modalidad del turismo rural puede ser entendida, en este sentido, como una estrategia para mejorar las condiciones de vida de los pobladores. Genera ingresos complementarios, permite la incorporación de la mujer al trabajo remunerado y posibilita el enriquecimiento cultural de la población rural.

Siguiendo esta línea de comprensión del turismo como agente económico pueden mencionarse los aportes de Millán Vázquez de la Torre et al (2006) que partiendo del análisis del desarrollo y distribución de la renta en la zona de Priego de Córdoba (España) consideran la actividad como un instrumento para lograr el desarrollo de regiones donde existe un gran desequilibrio socioeconómico, en las que se precisa la necesidad de diversificar las rentas de sus explotaciones

Desde otro punto de vista, existen referencias al turismo rural como herramienta para identificar y valorizar los recursos territoriales "étnicos-culturales activables y patrimonializables". En esta línea pueden mencionarse los aportes de Bustos Cara (2004) y sus reseñas sobre la patrimonialización de recursos territoriales, las contribuciones teóricoprácticas de Champredonde et al (2007) en relación a la producción gastronómica típica de diferentes zonas de Argentina; y en este misma perfil, los pensamientos de Acámpora y Fonte (2008).

Las hay también en base al papel que juega el turismo en el rescate de la identidad cultural de los territorios y la participación activa de las comunidades. De esta manera, Ascanio (2004) refiere a la experiencia venezolana para poner en ejecución el primer programa de posadas turísticas en el medio rural, partiendo del criterio que el turismo comienza a tener éxito una vez que la comunidad de acogida participa en el mismo proceso de su desarrollo como comunidad.

"Una vez que toma conciencia de sus derechos y deberes; y logra consolidar su autoestima y su propia identidad, entonces los grupos familiares puede, de una manera integral, participar en el ritual que supone las relaciones interpersonales, con todos los visitantes temporales, sin temor de que sea vulnera do su hábitat en un sentido integral. Sin este primer paso, cualquier intento de una comunidad frágil de participar en los "paquetes turísticos", podría más bien ser objeto de un simple juego comercial que los atropelle". (Ascanio, 2004).

Murilo Flores (2007) por su parte, concibe a la identidad cultural como una estrategia de valorización productiva y analiza la capacidad local de las redes de actores de movilizarse a fin de producir un dinamismo innovador como elemento clave para la construcción del territorio con identidad cultural. Cuanto más grande la multiplicidad de los puntos de conexión de esas redes, mayor será el flujo de conocimiento e información que favorece la interacción, la articulación, la cooperación y el aprendizaje.

Para finalizar este apartado es sustancial manifestar que esta modalidad turística, dada la amplitud de actividades y servicios que comprende, ha sido denominada e identificada de diversas maneras. Es por ello que nos parece esclarecedor especificar que, en el marco de esta investigación, el turismo rural es entendido como

"una actividad turístico - recreativa complementaria a las actividades agropecuarias tradicionales, desarrollada principalmente en emprendimientos, comunidades y pueblos rurales, gestionada por la 
población local respetando el medio ambiente y la cultura. Ofrece la oportunidad de compartir, vivenciar y conocer costumbres, actividades (productivas y culturales) y experiencias del medio rural, promoviendo el respeto y la valoración del patrimonio natural y cultural”. (Scalise, 2012).

En esta concepción, la atención al visitante es fundamentalmente familiar y los sujetos de desarrollo son los pobladores locales.

Se concibe como una modalidad de turismo sustentable, no masivo, lo que algunos autores plantean como turismo alternativo, por ejemplo Nogar y Capristo (2010) basado en el intercambio cultural, respetuoso de las costumbres locales y que valoriza el cuidado del ambiente.

Para complementar lo anterior y en otros términos,

"se origina un proceso diferente al de la lógica fordista caracterizada por la masificación, un modelo complementario para algunos, contrapuesto para otros; pero claramente un tipo de turismo diferente que según las aproximaciones conceptuales es identificado como alternativo, ligado casi en su totalidad a las áreas rurales y naturales cuyo principal rector es la sostenibilidad de los recursos y la ponderación del saber local, lo auténtico y lo identitario territorial". (Nogar y Capristo, 2010).

En el marco de una sociedad en permanente cambio y búsqueda, surgen propuestas turísticas para dar respuesta a un segmento social con mayor conciencia ambiental y respeto por la diversidad cultural, que demanda viajes y actividades que generen el menor impacto negativo al ambiente y en contacto con la cultura "real", presentada de manera genuina.

Si este fenómeno se materializa y lleva adelante en los espacios rurales... ¿qué impacto genera en éstos? ¿Qué moviliza estos procesos?

\subsubsection{El turismo como instrumento de transformación y valoración de la identidad territorial}

"Los espacios rurales no sólo son el trasfondo sobre el cual ocurren cosas (producciones, actividades de ocio) sino que también ellos mismos se convirtieron en cosa consumible: el consumo de los espacios rurales como espacios en si". (Nogar, 2011).

Tal como se ha venido presentando en los capítulos introductorios, los territorios rurales han experimentado profundas transformaciones, muchas de las cuales responden a una lógica capitalista de acumulación y expansión. Pero también existen otras trayectorias que convergen en procesos de desarrollo más diversificados y sustentable, en los que se incluye el turismo rural y su revalorización como sustento de la identidad. (Sili, 2007).

Y si existen estos procesos de base local, en el que se ponen en valor los espacios rurales no sólo como medio productor de alimentos, es porque existe un colectivo social,

"otro espectro de actores, que revalorizan los recursos olvidados o desestimados por el proceso productivista/homogeneizador, poniendo en valor la singularidad de lo natural y de los saberes locales" (Nogar, 2020).

En este mundo salvaje ávido de poderes y ambiciones humanas desmedidas, que avanza contra todo lo que no responda a objetivos determinados, estos sujetos resguardan y le otorgan un valor personal a sus espacios, sus pequeños lugares en el mundo, sus prácticas, su historia, la historia de sus conquistas y fracasos, sus costumbres, y en ese darle un sentido como una forma de resistir, resguardan su identidad y la de sus territorios de una inercia global que viene de contramano.

En esta lucha, en esta forma de resguardar el pasado, el presente y el futuro, pareciese que poder mostrar a otros, contar o poner en palabras, colabora a mantener viva esa esencia y valores, "identidad como valor de referencia y comportamiento solidario, como conjunto de 
características que unen o diferencian (...) y que constituye un valor que da especificidad a los grupos humanos, y como la imagen, se construye y se produce" (Bustos Cara, 2001).

Tomando como referencia a este autor, puede explicitarse que

"el turismo impulsa y demanda procesos identitarios ya que es una actividad que necesita crear imágenes y representaciones, que nos enfrenta al otro, nos obliga a preguntarnos quiénes somos, ¿por qué estamos juntos como pueblo?, ¿qué nos emociona? Y sobre todo ¿qué nos mantiene unidos? El turista pregunta y es necesario mostrarle, descubrir los secretos que guarda nuestra propia sociedad". (Bustos Cara, 2001).

En los territorios rurales de hoy, reconfigurados como espacios multifuncionales ${ }^{27}$ en un mundo globalizado, el turismo puede entonces movilizar procesos identitarios de la mano de la valorización de los propios recursos y valores territoriales ${ }^{28}$ por parte de las comunidades locales y por parte de ese otro, el turista, que en este proceso genera a la vez posibilidades de ingresos económicos para los grupos anfitriones, a través del consumo de determinados productos y/o servicios.

Siguiendo a Posada (1999), Sarasa (2000) y Nogar (2010, 2011, 2013) esta idea de transformación del medio rural de espacio de producción a espacio de consumo, a espacio revalorizado, se relaciona a que además de ser el cimiento para la producción agropecuaria, es el sitio elegido por un número cada vez más significativo de turistas que, entre las diversas posibilidades y modalidades de viaje, deciden pasar sus días en el campo, en contacto con la naturaleza, compartiendo las tareas rurales, conociendo a partir de estas actividades a la gente que vive en él, sus costumbres, sus formas de trabajo, sus saberes.

\section{Como afirma Posada (1999)}

"el ámbito rural de fines de siglo se diferencia en mucho al que podíamos observar hace apenas unas décadas. No se trata sólo de cambios en los aspectos físicos o funcionales, sino que también enfrentamos unas mutaciones profundas en la manera de valorar a lo rural por parte de lo urbano, lo que conlleva a que aquel se modele (estructural y funcionalmente) en base a estas valoraciones. Una de las expresiones más acabadas de estas modificaciones son los cambios en la conceptualización del uso de lo rural: antes era un espacio para la producción, hoy es un espacio para el consumo. Pero no para el consumo de lo producido, sino para el consumo del espacio en sí. El turismo rural, en sus múltiples facetas, es un claro ejemplo de esto". (Posada, 1999).

El potencial de esta actividad puede explicarse no sólo desde el lado de la oferta, es decir, de la existencia de propuestas auténticas y legítimas que productores y prestadores de servicios ofrecen en este espacio rural en transformación, sino también del lado de la "demanda", ya que el turista de hoy, concebido como un consumidor posmoderno (Acámpora y Fonte, 2008) manifiesta ciertos estilos de consumo, en los cuales se prioriza la vivencia de experiencias genuinas, el contacto con las culturas locales "reales" y las producciones alimentarias típicas de cada zona, además de la defensa por la diversidad cultural y el cuidado al ambiente.

\section{Acorde a lo mencionado, a esto contribuyó}

\footnotetext{
27 "Por espacio rural multifuncional se entiende un espacio rural que genera renta y empleo; que protege el entorno físico y socio-cultural, la biodiversidad y el paisaje; que promueve la gestión equilibrada del territorio y que contribuye al desarrollo general comentado en el mantenimiento de valores culturales y una forma de vida que le son propias (Congreso Internacional sobre Comercio y Desarrollo Rural, 1998”, en Andrade (2011). Este concepto se utiliza para "superar la noción meramente productiva de alimentos y materias primas, apelando a dos dimensiones más de la actividad: sus funciones ambientales, referidas a la protección del medio ambiente, de los recursos naturales, los ecosistemas y los paisajes agrarios; y sus funciones territoriales, referidas a su valor para generar equilibrio territorial y conservar el tejido socioeconómico de los espacios rurales" (Andrade, 2011).

${ }^{28}$ Es el territorio "el lugar de creación de recursos específicos (...) el lugar de creación de la innovación que permite mantener una actividad económica a través de la valorización de la calidad de los productos. Es necesario valorizar al territorio como espacio de promoción, es decir portador de vectores simbólicos culturales e históricos que confieren a la producción un carácter específico" (Bustos Cara, 2001).
} 
"el desenvolvimiento de la vida urbana [que] generó en una gran parte de sus habitantes una sensación de agobio, de asfixia, de desnaturalización del medio y de la vida en sí misma... Los espacios rurales comenzaron a ser re-visitados conceptualmente, se los revalorizó; se los presentó como un repositorio de valores que la sociedad industrial olvidó o destruyó. Lo natural, lo auténtico, lo puro o lo personal serían algunos de los factores que sólo podrían hallarse en el medio rural... Como consecuencia del rescate de los valores rurales, lo rural pasa a ser un objeto de consumo por parte de la ciudad (primero, como consumo ideológico-cultural, después como consumo espacio-ocio)". (Nogar, 2008).

Bote Gómez (1979), autor español considerado clásico y base de las lecturas vinculadas a la actividad turística en el espacio rural, plantea la demanda de esta modalidad de propuestas en términos de necesidades (fisiológicas y psicológicas) sentidas por este tipo de turistas, ante la contaminada vida de las grandes ciudades: la búsqueda de aire puro y espacios libres, el descubrimiento y ejercicio de actividades creadoras y polivalentes de la vida rural frente al rutinario, frustrante y especializado hábitat urbano. Ante esta demanda de primera necesidad, es el espacio rural, refugio o reserva para satisfacer estas necesidades.

Siguiendo a Smith (1989), Béssiere (2000) y De la Rosa (2003), Fuller (2011) manifiesta que del lado de la demanda, esta variedad de turismo responde a la nostalgia por el mundo rural y la vida campesina que, en el imaginario de los habitantes urbanos, se han convertido en santuarios de las tradiciones y raíces perdidas: el refugio de una autenticidad que la vida urbana ha desvanecido. También es expresión de la diversificación y creciente sofisticación en los intereses de los viajeros que se han ido volviendo más exigentes con respecto a la calidad de la experiencia, especialmente en lo que concierne a la búsqueda de entornos naturales conservados y experiencias de contacto con la diversidad cultural.

\section{Costa Beber y Barreto (2007) esgrimen que}

"la demanda creciente por [esta actividad] se incorpora al amplio fenómeno de concienciación y reivindicación ecológica por el cual han pasado las sociedades altamente urbanizadas en las últimas décadas del siglo XX... En este contexto, se le atribuyen al medio rural nuevas funciones que según Cavaco (2001) son: el equilibrio territorial que compensa los efectos de despoblamiento provocados por la concentración urbana; el equilibrio biológico, mediante la conservación de los ecosistemas y de los procesos biológicos; producción de paisajes de calidad, abiertos y naturales; producción de recursos, en particular, de agua limpia, recurso cada vez más escaso; suministro de actividades, distracción y entretenimiento al aire libre; combate a la contaminación del aire, del agua y del suelo".

En esta misma línea, Sarasa (2000) pone de manifiesto que "lo rural", luego de un periodo de "abandono" experimenta una corriente de revalorización en sentido opuesto que lo "pone de moda", y que a su juicio responde a

"dos profundas razones, en primer lugar, al espíritu de conquista que siempre caracteriza a la sociedad urbana respecto del espacio que le rodea, adviértase que colmadas, o en vías de serlo, las áreas periurbanas a base de viviendas de todo tipo con funcionalidad residencial, ahora ponen los ojos en espacios más distantes donde encontrar el «escape» a la trepidante lucha cotidiana de la ciudad; en segundo lugar, es preciso reconocer que la cultura rural, tradicionalmente denostada pero presente en los genes de la mayor parte de la población urbana, aflora como un valor en alza y cada vez es mayor el número de personas que desean vivirla y hasta poseerla a modo de reivindicación ancestral". (Sarasa, 2000).

Es muy interesante lo planteado por Bustos Cara (2001) cuando esgrime que el turismo no es sólo una alternativa, una actividad económica para las comunidades anfitrionas sino que es especialmente un instrumento de transformación.

"Sobre todo porque nos involucra profundamente ya que al incorporar al turista, ese actor particular, extraño en la sociedad receptora, su impacto se manifiesta de muchas maneras. No es una mercancía, es un representante de otra sociedad, cargado de actitudes, información, subjetividad y es nuestro huésped, nos vemos obligados a interactuar con él. Nos saca de nuestro entorno conocido y nos 
enfrenta a otro, al otro. Nuestros hábitos son confrontados, expuestos, nuestros secretos puestos a consideración. Esta situación es aún más clara en situaciones de turismo alternativo, donde lo artesanal y vivencial es el producto". (Bustos Cara, 2001).

Desde el punto de vista del territorio, el turismo es consumidor, productor y transformador de espacios. (Bustos Cara, 2001).

"Es al mismo tiempo consumidor de territorio es decir, utilizador no sólo del espacio sino de las condiciones sociales que le dan sentido y es sobre ese territorio organizado y con sentido que impacta. Es una actividad creadora de imágenes y representaciones que impregna no solo a los agentes y la sociedad de que forman parte los usuarios (es decir el mercado), sino también a las sociedades receptoras". (Bustos Cara, 2001).

Es en este espacio, multifuncional, espacio de producción y consumo, en el que entran en contacto dos culturas diferentes, la del anfitrión y la del turista. $Y$ en este sentido,

"el contacto entre la cultura del visitante y la cultura del visitado conlleva un proceso de contradicciones, tensiones y cuestionamientos, pero que, de manera sincrónica o diacrónica provoca el fortalecimiento de la identidad y de la cultura de esos individuos, principalmente en la comunidad autóctona. Al mismo tiempo, esta interacción fortalece también la identidad del propio turista que, en la alteridad, se puede redescubrir". (Costa Beber y Barreto, 2007).

\subsubsection{El turismo rural como estrategia de diversificación de ingresos y/o actividades para la familia rural}

En el contexto que se señalaba, caracterizado por las profundas transformaciones en los territorios rurales, en los que principalmente los productores de menor escala deben repensar sus prácticas, el turismo rural puede ser comprendido como una tentativa de resistencia situada, de guardián del pasado, de la herencia y la tradición, pero también de reivindicación del presente, de una agricultura familiar que resiste y que busca alternativas de subsistencia y existencia, y de un estilo particular de ser y estar en el mundo.

Algunos autores como Nogar (2011), afirman que es una estrategia de adaptación que permite hacer frente a las exigencias del sistema y a las transformaciones que los espacios rurales han transitado en los últimos años. Surge como una estrategia innovadora-alternativa ${ }^{29}$ de los productores familiares, para reactivar las economías regionales y revalorizar las especificidades culturales propias de cada territorio, fortaleciendo la autoestima de los sujetos, quienes reivindican sus raíces, su estilo de vida, producciones locales y costumbres, reconocidas por un "otro" como bienes tangibles e intangibles de interés para su consumo.

Partiendo de estudios de caso vinculados a redes entre el turismo rural y las agroindustrias de base rural, Nogar (2013) explica que existen

"múltiples estrategias que pueden ser interpretadas en forma agregada como: i- aquellas de tipo productivista-agriculturista estructuradas desde lo sectorial, sostenidas en la incorporación de ciencia, la artificialización de los ciclos productivos y reproductivos; con el fin de maximizar los índices de productividad y de ganancia cortoplacista. Estas acciones se enmarcan en un contexto direccionado por el mercado externo en respuesta a una demanda estandarizada guiada por mecanismos macroeconómicos y ii- estrategias innovadoras-alternativas, las mismas encierran un cúmulo de acciones integradas a las productivas con el fin de estimular la diversificación, optimizar los recursos ociosos, resistir como productores activos y aumentar el valor añadido territorial; materializando así, flujos contrapuestos a los hegemónicos homogeneizantes". (Nogar, 2013).

En algunos casos, constituye una estrategia inclusiva ya que actúa como complemento de ingresos y optimización de la mano de obra familiar. (Nogar, 2010).

\footnotetext{
${ }^{29}$ Rogers (2003) define la innovación como una idea, práctica u objeto que el individuo percibe como nuevo, y que posteriormente (a través de un aprendizaje) podría adaptar o rechazar.
} 
Leonardi Bricalli (2005) siguiendo a Graziano da Silva, Vilarinho y Dale (2000), por otro lado, afirma que "el turismo puede ser considerado como una estrategia de diversificación productiva de las propiedades rurales que intentan generar ingresos no agrícolas para compensar la baja rentabilidad de sus negocios tradicionales".

Un valioso antecedente ha sido el de Francès y Méndez (2001) quienes entienden que "la familia agraria debe ser capaz de aprovechar los recursos endógenos de la explotación, generar sinergias y complementariedades entre las diversas actividades y con los actores externos para producir y ofrecer unos bienes y servicios, agrarios o no, novedosos que permitan aprovechar nichos de mercado" (Francès y Méndez, 2001).

En su estudio, definieron cuatro grandes grupos de diversificación, entre los cuales se contempla la producción y servicios no agrarios como los servicios de hospedaje y la realización de actividades de ocio/recreativas.

Tomando como base el estudio de 125 explotaciones agrarias catalanas, se analizan las razones, cambios e impactos que comporta la incorporación del turismo o actividades asociadas en las explotaciones agrarias, y cómo ello afecta a la estrategia de las familias, a sus ingresos y a sus proyectos futuros.

Algunas de las conclusiones más sobresalientes tienen que ver con que las razones económicas son, según señalan sus encuestados, la motivación principal para iniciar el turismo, actividad que permite aumentar el contacto social, la realización de metas personales y evita que los miembros de la familia trabajen fuera de la explotación, consideradas ventajas adicionales que supone la diversificación en turismo.

Las principales desventajas que comporta la diversificación turística tienen relación, según las autoras, con la variable tiempo, a partir del aumento del tiempo de trabajo y la consiguiente reducción del tiempo de ocio.

En línea con lo anterior, de Oliveira Santos et al (2012), en base a un estudio a partir del cual analizan la evolución de la renta, el empleo y los sueldos en propiedades rurales que ofrecen turismo rural en Brasil, consideran que "existen diversos motivos para que los propietarios rurales inicien actividades turísticas en sus propiedades; uno de los principales es la disminución de los ingresos provenientes de la agricultura".

Siguiendo a Criado et al (2003), esgrimen que la actividad turística en el espacio rural aumenta la renta, agrega valor y diversifica la actividad económica.

Diéguez Castrillón y otros (2009) por su lado, realizaron una completa investigación sobre el turismo rural como estrategia de diversificación en Galicia. Las autoras plantean, siguiendo a Ilbery (1998) que frente a la crisis del sector agrario, que ha reducido las oportunidades económicas de las comunidades rurales,

"las alternativas de negocio que las explotaciones agrarias tienen ante sí son diversas: la extensión del modelo industrial de producción agraria basado en productos tradicionales del campo, la utilización de los recursos agrarios para nuevos productos agrarios en la explotación (diversificación), la reorganización y utilización de los recursos agrarios en nuevos productos no agrarios en la explotación (diversificación estructural), la reorganización y utilización de recursos agrarios en empleo fuera de la explotación, el mantenimiento del modelo tradicional de producción agraria, la reducción de la actividad a un hobby o bien el abandono parcial o completo de la actividad agraria". (Diéguez-Castrillón et al, 2009).

Una de las alternativas consideradas no tradicionales (citan a Wilson et. al, 1991) para el desarrollo económico del campo es el turismo asociado a oportunidad de negocio. En el caso de España, existe un número importante de alojamientos en el espacio rural que combinan actividades agropecuarias y turísticas, ofreciendo a pequeña escala alojamiento de alta calidad y/o desarrollando actividades específicas para los visitantes. 
La combinación de actividades agrarias y turísticas se presenta como una opción dominante de diversificación de las explotaciones agrarias. "La actividad del turismo rural, como modalidad de diversificación estructural comienza a ser una importante vía en la búsqueda de nuevas fuentes de ingresos dentro y fuera de la explotación. Los agricultores comenzaron a emplear las construcciones y el campo para usos (industrial, de recreo o residencial)". (Diéguez-Castrillón et al, 2009).

Algunas de las conclusiones ponen en conocimiento que los principales motivos por los cuales los actores en la zona de estudio deciden diversificar sus actividades, se concretizan en el ámbito económico y social, destacándose:

- la generación de rentas que aseguren la supervivencia financiera como el motivo dominante.

- la posibilidad de sucesión futura para los miembros de la familia, en segundo lugar; Así, a través de la realización de nuevas actividades, se persigue la continuidad futura de las actividades agrarias.

- la elección sobre el estilo de vida (independencia, sociabilización con clientes, etc.) en tercer lugar. (Diéguez-Castrillón et al, 2009)

Además, mencionan como principales factores que confluyen en la puesta en práctica de estrategias de diversificación a:

- la búsqueda de generar ingresos continuos en el tiempo dadas las fluctuaciones en los ingresos agrarios;

- empleo para los miembros de la familia, ingresos adicionales, obteniendo un complemento a las rentas agrarias a través del turismo. "Normalmente las rentas agrarias se complementaban con trabajo fuera de la explotación. El turismo presenta como alternativa que estas rentas se generen en el seno de la misma". (DiéguezCastrillón et al, 2009).

- Cuestiones relacionadas al estilo de vida, ya que "las características de las tareas realizadas por los trabajadores en el tema del turismo son apetecibles para los individuos que deseen desarrollar competencias relacionadas con la sociabilización) (Diéguez-Castrillón et al, 2009), y al hobby.

- Mejora en el uso de los recursos, en relación a la optimización y utilización plena de los mismos.

- "Asegurar la continuación de la explotación agraria, involucrando en actividades turísticas a los miembros más jóvenes que puedan simultanear ambas actividades". (Diéguez-Castrillón et al, 2009).

Para estos autores se combinan diversos motivos para la incorporación del turismo como estrategia de diversificación, motivos de índole económica y social que

"pueden ser clasificados en motivaciones de racionalidad formal (aquellas estrictamente relacionadas con la racionalidad económica) y las motivaciones de la racionalidad substantiva (que van más allá de la estricta racionalidad económica y guardan relación con la visión del cambio social, las inquietudes morales, etc). En este sentido, los empresarios de turismo rural pueden verse influenciados no exclusivamente por la búsqueda de rendimiento económico, sino también por mantener las labores agrarias como medio de continuidad de las relaciones familiares (...)”. (Diéguez-Castrillón et al, 2009).

Desde otro punto de vista, Costa Beber y Barreto (2007) estudian los cambios socioculturales que se dan en los núcleos familiares autóctonos a partir de la introducción de la actividad del turismo rural en un establecimiento y analizan si el proceso de "turistificación" del establecimiento rural está ocasionando cambios en la familia anfitriona y de qué forma ellos lo corroboran. En este sentido, las autoras afirman que el turismo es un elemento capaz de generar cambios en la cultura de los anfitriones.

En el estudio de caso que toman, el turismo rural se convirtió en la principal fuente de ingresos. Hablan de la paradoja que el turismo rural enfrenta ya que el intercambio cultural intenso transforma la cultura rural, que es el propio atractivo de este tipo de turismo. La convivencia, 
que es la esencia de este tipo de propuestas, acaba por crear aislamiento dentro de la familia y entre ésta y su grupo social y familiar más amplio. Las autoras utilizan los siguientes términos

"El tipo de turismo realizado pone siempre a los turistas en contacto íntimo con los familiares. Esta nueva rutina altera la manera en que la familia se relaciona. Sin embargo, esta modificación conlleva una nueva manera de establecer la relación familiar, ahora con un nuevo elemento, el turista, que según los familiares, es responsable por los intercambios culturales". (Costa Beber y Barreto, 2007).

Además de lo anterior, el turismo posibilitó, a partir de convertirse en la principal fuente de ingresos, que la familia continúe viviendo en el campo.

\subsubsection{El turismo en el espectro de la pluriactividad rural}

Hasta el momento se mencionaron experiencias donde el turismo se presenta como una alternativa de diversificación de actividades productivas y de ingresos para las unidades de producción. Es nuestro interés profundizar en la comprensión de la actividad turística y su pertenencia al espectro de la pluriactividad, que permite a los productores rurales, complementar -o aumentar- sus ingresos, diversificando las actividades que realizan.

Siguiendo en este punto el pensamiento de Craviotti (2002), en un contexto de declinación de la agricultura como fuente de empleo y de la fase propiamente agrícola de la producción agroalimentaria, crece el peso de las ocupaciones no agrícolas de las familias rurales, que a través de un esquema de pluriactividad puede insertarse en múltiples ámbitos de actividad.

"En ciertas áreas se desdibujan las fronteras entre lo rural y lo urbano, y emergen nuevos usos para el espacio rural, que trascienden lo productivo agropecuario, y tienen como eje lo residencial y recreativo". (Craviotti, 2002).

Uno de estos ámbitos puede ser el turismo.

Concurren diversos diagnósticos en torno a los motivos que llevan a los productores a volcarse a otra actividad, que no solo se relacionan con el bajo retorno de la actividad agrícola principal o a los procesos de diversificación de las áreas donde estos se encuentran.

"Se ha discutido que el ejercicio de varias actividades por parte de los agricultores familiares no necesariamente constituyen una demostración de la precariedad o declinación de esta forma social". (Neiman, Berger y Neiman, 2013).

También estas decisiones puede estar relacionadas con situaciones de estabilidad económica o expansión patrimonial, o vincularse a factores sociales o búsquedas personales específicas.

Para los autores mencionados, la pluriactividad puede presentarse bajo tres formas diferentes:

1. Como una estrategia de agropecuaria expansión de la empresa (para adaptarse al modelo socio-productivo imperante)

2. Como una posibilidad de entrada a un proyecto individual de alguno de sus miembros

3. Como persistencia ante el riesgo de cierta salida de la actividad. (Neiman, Berger y Neiman, 2013).

Se entiende que la pluriactividad contribuye a los objetivos de producción de la unidad familiar. Incluso las tensiones o conflictos intergeneracionales pueden reducirse mediante el desarrollo de la pluriactividad "como estrategia de expansión y/o garantía de continuidad y traspaso de la gestión de la unidad y del patrimonio familiar". (Neiman, Berger y Neiman, 2013).

Siguiendo a Francés y Méndez (2001), que citan a Fuller (1990)

"se aboga por el término pluriactividad por su carácter expansivo, multidimensional e integrador. Este concepto engloba mayores razones/motivos para explicar por qué las explotaciones obtienen rentas de 
diferentes actividades. Estas razones no son exclusivamente derivadas de la pérdida de peso de la agricultura sino que dependen de otros factores como las oportunidades de trabajo fuera de la explotación, su estructura y los cambios en el ciclo de vida de sus miembros". (Fuller, 1990).

Las autoras contemplan una definición que resulta pertinente para esta investigación y se refieren a ésta como "la realización de múltiples actividades dentro de la explotación agraria con el objetivo de asegurar la viabilidad de la explotación en el tiempo y crear o mantener empleo". (Francés y Méndez, 2001).

En esta línea de pensamientos, los brasileros Sacco dos Anjos y Velleda Caldas (2007), en un trabajo en el que examinan la pluriactividad en explotaciones familiares del Sur de Brasil, desde nuestro punto de vista, aclara el concepto de pluriactividad, al afirmar que forma parte de las estrategias que adoptan los pequeños agricultores para garantizar la reproducción social de sus familias, desarrolladas mediante la combinación de diversas actividades (agrícolas y no agrícolas) realizadas dentro o fuera de las propias explotaciones.

Los autores aludidos plantean dos formas de pluriactividad: la agraria y la no agraria.

"La pluriactividad agraria tiene su anclaje en contextos económicos caracterizados por la existencia de escasas oportunidades laborales distintas de las que ofrece el sector agrario, de tal modo que son las actividades agrícolas o ganaderas la fuente casi exclusiva de ingreso de las familias rurales y el sostén de la dinámica de desarrollo territorial. En esos contextos, los pequeños agricultores y los miembros de su familia alternan las actividades en su explotación con las realizadas en otras explotaciones, bien como asalariados, bien como trabajadores autónomos. Una variante de este tipo de pluriactividad agraria sería la protagonizada por aquellos pequeños agricultores y su familia que, sin salir del marco de sus explotaciones, diversifican las actividades aprovechando los recursos naturales de su entorno y añadiendo nuevo valor a los productos agrícolas y ganaderos que obtienen en sus granjas familiares". (Sacco dos Anjos y Velleda Caldas, 2007).

En particular, esta definición responde a las circunstancias que definen a las familias rurales de Entre Ríos. Aquí pueden evidenciarse dos realidades diferentes: algunos productores optaron por introducir la actividad turística a sus predios, y en éstos coexisten las actividades a las que históricamente se han dedicado y la visita de turistas; y otros, pudiendo haber realizado alguna inversión, se hicieron dueños de algún predio en las proximidades de su explotación y generaron un nuevo circuito productivo- recreativo a partir de la incursión por el turismo rural. Tomando a los autores citados, estas dos opciones podrían ser contempladas como estrategias de pluriactividad de las familias rurales.

A las anteriores, se suman los conceptos de Piñeiro y Cardeillac, quienes consideran pluriactivos a

"aquellos hogares cuyos miembros residen en la tierra que poseen, en unidades de producción y reproducción, y que dedican parte de la fuerza de trabajo a actividades de carácter no agrícola, dentro o fuera del predio. Monoactivas serán aquellos hogares con iguales características pero que dedican toda la fuerza de trabajo familiar sólo a la producción que se realiza en el predio". (Piñeiro y Cardeillac, 2010).

Se cree entonces que la pluriactividad intensifica la capacidad de adaptación de los sistemas productivos familiares a los contextos económicos, sociales y familiares "dando como resultado situaciones de resistencia, expansivas o incluso de estabilidad en el tiempo hasta que se concrete el relevo generacional". (Neiman, Berger y Neiman, 2013).

En torno a lo anterior, siguiendo a Gasselin, Cloquell y Mosciario (2013) puede afirmarse que las respuestas que estos actores pueden dar, en el marco de las mutaciones dadas en el orden global en los últimos años, pueden adquirir intensidades y naturalezas diversas, que revisten desde reajustes simples a cambios profundos e irreversibles. 
Los autores se preguntan acerca del impacto que estas adaptaciones tienen sobre las dinámicas de los sistemas productivos, la identidad y la estructura agraria. En la misma línea de pensamientos, concluyen los autores que "adaptarse no tiene las mismas implicaciones según los tipos de actividades y producciones”. (Gasselin, Cloquell, Mosciario, 2013).

Como explicitan Gasselin y Bathfield (2013)

"la capacidad de una entidad (una finca, una organización, un territorio, una nación, el planeta...) para perdurar, para mantenerse en el tiempo, depende tanto de su eficacia conjugada en los ámbitos sociales, económicos y ambientales (a veces designada con el concepto de sostenibilidad) como de su capacidad para adaptarse a eventos y cambios a menudo imprevisibles".

En el marco de estas conceptualizaciones se profundizará y analizará fundamentalmente las trayectorias y motivaciones de las familias rurales entrerrianas que optaron por añadir el turismo a sus vidas y a su cotidianidad. 
Capítulo 4- Caracterización de la región en estudio: la provincia de Entre Ríos y el corredor del río Uruguay 


\subsection{El territorio provincial}

"Sobre los 75.759 kilómetros cuadrados que forman la superficie de la provincia de Entre Ríos se han establecido, de medio siglo a nuestros días, centenares de miles de habitantes de origen diverso. Italianos que traen de sus aldeas nativas la noción geométrica del surco y trazan la amelga con la perfección de un dibujo, andaluces que esparcen la canción mientras vigilan el arado, gallegos en quienes la recia línea del rostro céltico parece identificarse con los perfiles del terrón que castigan con la azada, vascos de duro temple y blando corazón, alemanes que copian con su apacible método y su cordura inalterable la vieja granja del Rin, eslavos de ojos perdidos en el horizonte que andan en el carro liso, judíos agobiados de antigüedad y en cuya siesta del sábado Jehová, como en el valle jordánico, bendice el florido trigal, se mezclan en aquellos 75.759 kilómetros cuadrados con la masa criolla bajo el cielo favorable, de un extremo a otro extremo, e integran ese conjunto de elementos tan heterogéneos y que constituye social y moralmente la definida familia y la fisonomía uniforme del hombre entrerriano". (Gerchunoff, 2015). ${ }^{30}$

La provincia de Entre Ríos presenta particularidades paisajísticas y ambientales, de infraestructura y de ubicación regional estratégica, que le imprimen características especiales para su desarrollo integral.

Se sitúa en la región mesopotámica, limita al norte con la provincia de Corrientes; al este con la República Oriental del Uruguay; al sur con la provincia de Buenos Aires, y al oeste con las provincias de Buenos Aires y Santa Fe. Posee una superficie total de $78.781 \mathrm{~km}^{2}$, que representa el 2,1\% del total nacional. (Consejo Federal de Inversiones, 2007) ${ }^{31}$

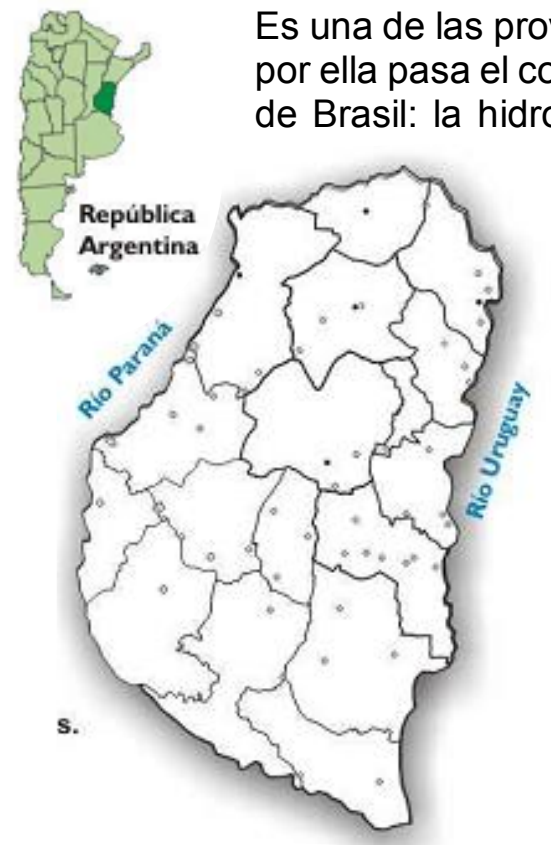

Ilustración 2 Ubicación de Entre

Ríos en el mapa nacional y

departamentos de la provincia

secundario alcanza el $77 \%$.

\footnotetext{
${ }^{30}$ La obra "Entre Ríos, mi país" de Alberto Gerchunoff (1884-1950) fue prologada y comentada por Leonardo Senkman y coordinado por Guillermo Mondejar

31 http://cfi.org.ar/wp-content/uploads/2007/07/entre rios.pdf Síntesis socioeconómica de la Provincia de Entre Ríos. Última revisión: 8/2/2018

32 En Plan Tecnológico Regional del Centro Regional Entre Ríos de INTA (2009-2012)

${ }^{33}$ Censo Nacional de Población de Viviendas y Hogares 2001
} 
- En el principal conglomerado urbano provincial (Paraná) el 50,9\% de la población económicamente activa (PEA) tiene estudios secundarios completos.

- La presencia de centros de estudios superiores y universidades es muy fuerte, contando Entre Ríos con 89 establecimientos de estudios superiores no universitarios y con 6 universidades públicas y privadas con el dictado de las más variadas disciplinas a las cuales asisten alrededor de 40.000 alumnos.

En base a datos de la Dirección de Estadísticas y Censos de Entre Ríos se aproxima el valor del Producto Bruto Geográfico (PBG) ${ }^{34}$ provincial en 49.694 millones de pesos en el 2012, un $2,2 \%$ del Producto Bruto Interno (PBI) de la Argentina.

La actividad primaria es la de mayor importancia en el aporte a la economía provincial, alcanzando el $24 \%$ del PBG. Le sigue el comercio con un $20 \%$ y la actividad industrial en un 9\%. (Bourdin et al, 2013).

Según el Ministerio de Economía de la Nación (2015) los principales complejos productivos provinciales son los avícola, cerealero (arroz), forestal, frutícola (citrícola), ganadero (bovino) y turismo. Y la población provincial ascendía en el 2014 a 1.308.290 (Ministerio de Economía y Finanzas Públicas de la Nación, 2015) ${ }^{35}$

"Se destacan su alta potencialidad agropecuaria, su ubicación en el mapa productivo de la región, su población geográficamente bien distribuida y el estado maduro de mecanismos asociativos, cooperativos y estatales de inversión como los Institutos Nacionales de Tecnología Agropecuaria (INTA) e Industrial (INTI) (...). En los hechos negativos, hay que destacar (...) el relativamente bajo desarrollo, dentro de la región centro, en actividades de alto valor agregado y su baja capacidad exportadora de este tipo de bienes y servicios". (Bourdin et al, 2013).

Su territorio se caracteriza por una marcada heterogeneidad en su topografía, suelos y vegetación. Posee uno de los suelos más fértiles del país, que sumado al clima predominantemente templado húmedo, lo convierten en tierras especiales para el desarrollo agropecuario.

"Según datos técnicos obtenidos por el Ministerio de Agricultura, Ganadería y Pesca de la Nación, desde el año 1994 al 2010, la superficie de Entre Ríos destinada a agricultura aumentó un 246\%, pasando de 595.000 ha a 2.050.000 a 2010". (Ministerio de Economía y Finanzas Públicas de la Nación, $2011)^{36}$.

A nivel nacional, Entre Ríos se ubica:

- en la 4ta posición en área sembrada con soja;

- 4ta en existencias vacunas;

- 1 era en producción de lino;

- $\quad 1$ era en producción y exportación de carne aviar;

1 era en área cultivada con naranjas y mandarinas;

- 2da provincia productora de arroz, después de Corrientes, aportando el $41 \%$ a la producción nacional y representando el $38 \%$ de la superficie sembrada en el territorio nacional.

- 4to lugar en el país en cuanto a superficie forestada

\footnotetext{
34 "Constituye la porción del Producto Bruto Interno del país atribuible a cada provincia. EI PBI es la medida básica de la actividad económica. Se calcula sumando el valor de los bienes y servicios finales producidos en la economía de un país en un momento determinado. El término "finales" se refiere a que se toman los valores de los productos terminados; no se computan a los insumos que se utilizaron para crear un bien. PBI Se refiere al valor del producto, la cualidad de bruto se relaciona con que se contabilizan todas las inversiones que se hacen en esa economía (sin distinguir inversiones nuevas de aquellas que son reposiciones) y la de interno se refiere a que se contabiliza todo el valor del producto generado dentro de la frontera del país". Definiciones de la UBA en http://www.agro.uba.ar/apuntes/definicion.htm Última revisión: 8/2/2018

${ }^{35} \mathrm{https://www.economia.gob.ar/peconomica/dnper/fichas} \mathrm{provinciales/Entre} \mathrm{Rios.pdf.Última} \mathrm{revisión:} \mathrm{8/2/2018}$

36 Informe Económico de la provincia de Entre Ríos. Ministerio de Economía, Hacienda y Finanzas. Junio 2011
} 
- 2do productor de salicáceas y el tercero de eucaliptos, representando el $50 \%$ de la industrialización del sector.

- La existencia total de cabezas es de aproximadamente 4.711 .050 (el 7\% del total nacional).

- Entre Ríos alcanzó el $47 \%$ de la producción nacional de pollos ocupando el primer lugar del país.

- En cuanto a la producción de huevos, Entre Ríos representa (con 129.119.167 docenas) el $20 \%$ de la producción nacional,

- Entre Ríos es la 4ta provincia en importancia en producción de leche, participando con el $3 \%$ en la producción total del país. (Ministerio de Economía y Finanzas Públicas de la Nación, 2011)

La orientación productiva predominante en el ámbito provincial, es la ganadería vacuna, representando los sistemas que dedican el $80 \%$ o más de su superficie a la ganadería el $72 \%$ de las EAPs y $68 \%$ de la superficie censada. Le siguen en importancia los orientados predominantemente a la agricultura con el $13 \%$ y $14 \%$ y los mixtos ganaderos agrícolas con el $8 \%$ y $10 \%$ del total de las EAPs y de la superficie, respectivamente.

Otro dato de interés es la tendencia creciente a la concentración de la propiedad y gestión de la tierra, que se aprecia si se comparan los datos de los dos últimos censos nacionales agropecuarios (1988 y 2002). "De ellos se desprende que desaparecen 5.555 EAP's en 14 años; por otro lado, se observa un aumento del tamaño medio del $29 \%$ de la superficie en hectáreas por EAP”. (Domínguez y Orsini, 2009).

"La especialización agrícola con énfasis en la producción de soja, en las últimas dos décadas, ha producido importantes cambios en las formas de tenencia de la tierra, lo que provocó la irrupción de nuevos actores sociales, así como nuevos conflictos; y por lo tanto, modificaciones en la estructura agraria en la zona pampeana y, especialmente, en la provincia de Entre Ríos. En este sentido, no es casual la virulencia del conflicto rural en la provincia de Entre Ríos, ya que además de otras cuestiones, las movilizaciones rurales, su profundidad y prolongación en el tiempo, tienen su correlato en el modelo productivo agropecuario que profundizó las diferencias entre las dos caras de una misma moneda: por un lado, la concentración del uso del suelo y el capital y, en el otro, la existencia de pequeñas explotaciones familiares descapitalizadas y con escasez de recursos". (Domínguez y Orsini, 2009).

Según el Censo Nacional Agropecuario (CNA) 2002, las EAPs de Entre Ríos ascendían a 21.577 (20\% menos que en el CNA 1988) y ocupaban 6.351 .514 ha, con una superficie media de 294 ha.

El $57 \%$ de las EAPs se ubicaban en el estrato de menos de 100 ha $(62 \%$ en el CNA $1988)$ y ocupaban el $8 \%(11 \%$ en el CNA 88$)$ de la superficie total; mientras que las EAPs de más de 500 ha, representaban el $12 \%$ (9\% en el CNA 88) de las unidades y el $70 \%$ de la superficie (el $62 \%$ en el CNA 88$)^{37}$.

\footnotetext{
37 INTA Plan de Tecnología Regional (PTR) 2009-2012.
} 


\begin{tabular}{|c|c|c|c|c|c|}
\hline \multirow{3}{*}{ Tamaño (ha) } & \multirow{2}{*}{\multicolumn{2}{|c|}{ EAPs }} & \multicolumn{3}{|l|}{ Superficie } \\
\hline & & & \multicolumn{2}{|l|}{ Total } & \multirow{2}{*}{\begin{tabular}{|l} 
Media \\
ha/EAF
\end{tabular}} \\
\hline & Casos & $\%$ & ha & $\%$ & \\
\hline Menos de 50 & 7.824 & 36 & 186.049 & 3 & 24 \\
\hline entre 50 y 99 & 4.471 & 21 & 312.096 & 5 & 70 \\
\hline entre 100 y 249 & 4.510 & 21 & 699.336 & 11 & 155 \\
\hline entre 250 y 499 & 2.077 & 10 & 727.589 & 11 & 350 \\
\hline entre 500 y 1199 & 1.595 & 7 & 1.206 .572 & 19 & 756 \\
\hline Más de 1200 & 1.100 & 5 & 3.219 .872 & 51 & 2.927 \\
\hline Total & 21.577 & 100 & 6.351 .514 & 100 & \\
\hline
\end{tabular}

Tabla 1. Cantidad y superficie de EAPs por estrato de superficie Fuente: Engler et al, 2008

La forma de organización del trabajo predominante de las EAPs provinciales, está basada en la utilización de mano de obra familiar ( $72 \%$ de las EAPs).

\begin{tabular}{|l|l|l|}
\hline \multirow{2}{*}{ Mano de Obra } & EAPs \\
\cline { 2 - 3 } & Casos & $\%$ \\
\hline Familiar & 15.537 & 72 \\
\hline No Familiar & 5.499 & 25 \\
\hline EAPs sin datos de Mano Obra & 541 & 3 \\
\hline Total & 21.577 & 100 \\
\hline
\end{tabular}

Tabla 2. Cantidad de EAPs según organización social del trabajo Fuente: Engler et al, 2008

En cuanto a la forma de tenencia de la tierra, el $71 \%$ de la superficie censada en 2002 estaba operada bajo el régimen de propiedad, el 18\% en arrendamiento y aparecería y el $5 \%$ bajo contratos accidentales.

Respecto al sector turístico provincial, es sustancial de incorporar a este análisis por su relación al objeto de estudio de esta investigación. Y el turismo se vincula inexorablemente con los aspectos ambientales y naturales, socioculturales, históricos y económicos que coadyuvan a su potencialidad.

"Las características territoriales de Entre Ríos, cercana a los principales mercados turísticos, tanto nacionales como limítrofes, posicionan a la provincia en una situación inmejorable para abordar el desafío del desarrollo integral a partir del turismo, integrando a las demás actividades económicas, culturales, recreativas y deportivas tomadas desde una perspectiva de compatibilidad y afinidad de oportunidades" (Plan Estratégico de Desarrollo Turístico Sustentable de Entre Ríos, PEDTS 2008).

"Desde los inicios del siglo XXI Entre Ríos alcanzó su máximo y sostenido nivel de desarrollo, tendiente a la consolidación de la actividad. En 2007, el gobierno provincial reconoció que la provincia está motorizada para el crecimiento turístico. En los últimos años, el turismo creció un $42 \%$ en arribo de turistas, representa una participación del $10 \%$ en el PBG provincial y 3 de cada 10 puestos de trabajo están directamente vinculados al turismo". (Wallingre, 2008).

En el Plan Estratégico de Desarrollo Turístico Sustentable de Entre Ríos 2020 (PEDTS) se postulan los productos turísticos con mayor jerarquía dentro del espectro de la oferta turística provincial.

Entre estos puede mencionarse el producto termal, que ha logrado posicionar a Entre Ríos en el mercado nacional, con su iniciación en Federación en 1997 hasta el último en el Perilago de Salto Grande en Concordia en 2010 y con 13 complejos funcionando en la actualidad. 
Por otro lado, las Playas, que han tomado mayor protagonismo a nivel nacional, notándose un desarrollo más importante en la costa del río Uruguay -por sus características propias- que la distinguen de las demás costas entrerrianas. Además, Entre Ríos, a través de los años se ha posicionado además como un destino donde la naturaleza está presente en cada una de las actividades que desarrolla el turista, habiendo una gran disponibilidad de recursos distribuidos en todo el territorio y que actualmente son ícono a nivel nacional como el Parque Nacional El Palmar y el Pre Delta.

También se mencionan el avistaje de aves como una de las ofertas incipientes y por el contrario la pesca deportiva, con un gran desarrollo; el golf y los carnavales, el turismo de reuniones, las fiestas tradicionales y la historia.

"En cuanto al Turismo Rural se encuentra una amplia oferta dentro del territorio provincial, siendo Entre Ríos un destino de excelencia y tradición a nivel nacional. Pero sin dudas es uno de los que presenta menor atención por parte de los distintos actores intervinientes, ya que existe una informalidad en la prestación del servicio al no estar disponible de forma sostenida y los prestadores no tomarlo como una actividad principal, sino complementaria a su fuente de ingreso. En la actualidad no se tiene un número cierto de la oferta, debido a la ausencia en la aplicación de las normas correspondientes a la regulación del turismo rural, la cual permitiría el registro de prestaciones específicas a este producto, y no actividades relacionadas que se consideran en la actualidad dentro de esta tipología". (PEDTS 2020).

Siguiendo con el documento rector de turismo en la provincia, respecto a la cantidad de alojamientos y cantidades de plazas, no se tiene un número exacto, ya que las registradas por la Secretaría de Turismo de la Provincia, según el Decreto de Alojamientos Turísticos № $117 / 10$ representan aproximadamente un $50 \%$ del total de las existentes. Las plazas hoteleras y parahoteleras se concentran principalmente en las localidades de Colón (14\%), Federación (12\%), Gualeguaychú (11\%), Paraná ( $9 \%$ ) y Concordia $(8 \%)$.

En cuanto a las tipologías de alojamientos, del total provincial el $45 \%$ corresponden a Apart Hotel y Bungalows, el $23 \%$ a Hoteles, el $14 \%$ a Camping, el $10 \%$ a Bed \& Breakfast, el $7 \%$ a Casas y Departamentos de Alquiler Turístico y el $1 \%$ a Albergues.

En relación a la demanda, el arribo de turistas a la provincia según su procedencia es de aproximadamente un $72 \%$ provenientes de Buenos Aires (Capital y provincia), un $11 \%$ corresponde a turistas entrerrianos, un $10 \%$ de la provincia de Santa $\mathrm{Fe}$, un $2 \%$ de la provincia de Córdoba y un $5 \%$ de otros destinos. Los grupos de turistas están conformados en un $30 \%$ por parejas y en segundo lugar por familias tipo. (PEDTS 2020).

El marco jurídico que regula a la actividad turística en la provincia está dado la Ley $N^{\circ} 9946$ "Régimen de Promoción del Desarrollo Turístico Sustentable", sancionada en el año 2009, cuyo texto determina el marco de actuación en el que se desenvuelve la actividad turística provincial.

"Esta Ley tiene como objeto el desarrollo integral del turismo y reconoce en el Estado Provincial la responsabilidad de fomentar la conservación, planificación, investigación y aprovechamiento de atractivos y recursos, resguardando su desarrollo sostenible y sustentable, y la optimización de la calidad. La orientación, facilitación, coordinación, ordenamiento, regulación, control, promoción de actividades y servicios; la formación y capacitación de los trabajadores y profesionales del turismo y el resguardo del turista en todo el ámbito del territorio provincial.

En su Artículo $2^{\circ}$ reconoce al turismo como política de estado, remarcando la importancia estratégica para el desarrollo turístico sustentable de todas aquellas actividades que coadyuven a la generación de empleo, resguardo del medioambiente, protección del patrimonio natural y cultural, diversificación de la oferta turística, aumento de la demanda, como así también la revalorización y preservación de la cultura local". (Plan Estratégico de Desarrollo Turístico Sustentable de Entre Ríos 2020).

Esta Ley instituye una serie de herramientas para el alcance de los objetivos y principios establecidos como el Plan Estratégico de Desarrollo Turístico Sustentable de Entre Ríos, el Fondo Provincial de Turismo y los incentivos de fomento turístico. 


\subsection{El corredor del río Uruguay}

Existe una zona de la provincia, que por su configuración socio-organizacional, estructura productiva y recursos naturales, presenta un particular dinamismo territorial, que, a los fines de esta investigación, es donde se focalizan los casos para su estudio. Se trata del Corredor del río Uruguay.

"Durante la década de 1980, surge con fuerza el concepto de "Corredores Turísticos", que se aplican en Entre Ríos a las áreas geográficas del río Paraná y el río Uruguay, y analógicamente a otras actividades que se desenvuelven a lo largo de rutas nacionales o provinciales de importancia.

Un "Corredor Turístico" se define como un eje vial que impone una ruta troncal a partir de la cual se disponen y ofrecen atractivos y servicios, tanto rurales como urbanos y que es transitado por un flujo relevante de viajeros, con o sin detención.

La misma conformación geo-turística de Entre Ríos ya señalada, definió con nitidez dos corredores. Uno correspondiente a la "costa" del río Uruguay, sobre el eje vial de las rutas nacionales 12 y 14, entre los segmentos comprendidos desde Brazo Largo a Ceibas para el primero y desde ésta hasta Mocoretá, para el segundo tramo. Se trata en síntesis de la porción sur del corredor turístico que une el mayor mercado emisor de viajeros de origen nacional (Capital Federal y Gran Buenos Aires) con el Parque Nacional Iguazú, cuyo atractivo primordial, las cataratas, se constituye en el más atrayente y motivador de los propulsores de viajes a nivel nacional". (Medina, 2010).

El área más dinámica está concentrada sobre el río Uruguay, reforzada por las obras de vinculación terrestre de los puentes Zárate-Brazo Largo; Puerto Unzué-Fray Bentos; ColónPaysandú y Concordia-Salto que comunican la provincia con el país vecino de Uruguay. (Consejo Federal de Inversiones, 2007).

Como su nombre lo indica, este espacio atraviesa la provincia por su margen este, de norte a sur. Cruza seis departamentos provinciales y es franqueado por la Ruta Nacional $\mathrm{N}^{0} 14$, actualmente convertida en una amplia y ágil autovía, que dinamiza el flujo de turistas hacia toda la región, fundamentalmente los provenientes de Buenos Aires.

En el Plan Tecnológico Regional del INTA Entre Ríos (2006), la costa del río Uruguay es caracterizada como

"un territorio más dinámico, dotado de mayores recursos estructurales (rutas, caminos y energía) en el que se destacan los sectores foresto-industrial, frutícola, avícola y turístico como generadores de crecimiento económico. También aquí se identifica la presencia de organizaciones educativas de nivel superior que constituyen una oferta de importancia regional" (INTA Centro Regional Entre Ríos, 2006).

"El este del territorio provincial, área lindante con el Río Uruguay, es dinámico dotado de importantes recursos estructurales y actividades productivas. Se destacan el sector foresto-industrial, la fruticultura, la avicultura y la industria frigorífica derivada, y el turismo como generadores de crecimiento económico". (Engler et al, 2008).

Siguiendo al Bourdin et al (2013)

"la región que más creció ha sido la de la Costa del Uruguay, que se expandió al 10,5\%, y Concordia, que se expandió en $8,1 \%$ en el curso de nueve años (...). No es raro porque la Costa del Uruguay, con su conexión a las vías fluviales y a los países vecinos de Uruguay y el sur de Brasil ha disfrutado, en la década que pasó, de grandes oportunidades para el desarrollo de negocios (y con ello de empleos, ingresos y progreso) gracias a la bonanza económica internacional que llegó al continente".

(Bourdin et al, 2013).

Por otro lado, el Corredor del río Uruguay es una de las zonas con mayor vocación turística en el mapa turístico provincial y nacional. Ha sido priorizado por el Plan Federal Estratégico de Turismo Sustentable de Argentina (PFETS 2016) para favorecer su desarrollo en la primera 
etapa del plan, lo cual indica a las claras su potencial desde el punto de vista productivoturístico.

"En la Región Litoral se destaca ante todo la enorme oportunidad de sus grandes y bellos ríos, que ya han motivado el Corredor del bajo Uruguay, de creciente consolidación como destino de sol y playa, cultura y termalismo, El clima subtropical, la vegetación exuberante y los múltiples usos de los ríos (navegación, pesca, deportes náuticos, puertos a recuperar) posibilitan la práctica del turismo durante todo el año." (PFETS, 2016). ${ }^{38}$

Avizorando el potencial turístico en relación al fuerte componente agropecuario y rural de la zona, el cada vez más creciente flujo de turistas interesados en desarrollar modalidades de viajes en relación con la naturaleza, la tranquilidad del campo y el contacto directo con las culturas locales, y la demanda concreta de familias rurales interesadas en diversificar sus actividades económicas a través del turismo, desde una red de instituciones se ponen en marcha una serie de herramientas y proyectos tendientes a promover el desarrollo del turismo rural.

En virtud de lo anterior, se comienzan a conformar grupos asociativos de productores y emprendedores rurales (bajo la figura de grupos Cambio Rural), articulados bajo el objetivo de trabajar juntos en propuestas integrales de turismo en el espacio rural.

Estas experiencias de base asociativa son una estrategia de y para la integración de los emprendedores, quienes comprenden que el asociativismo posibilita la complementariedad de los servicios que cada uno presta, permitiendo la formación de propuestas zonales o microregionales, que trascienden las ofertas particulares.

\section{Análisis por regiones del Corredor del río Uruguay}

El desarrollo del turismo rural, acompañado por una red de instituciones públicas, se ha focalizado básicamente en tres espacios del Corredor del río Uruguay: en la zona norte fundamentalmente en las localidades de Chajarí y Villa del Rosario, en la microrregión turística Tierra de Palmares, que incluye las localidades de Colón, San José, Villa Elisa, Ubajay, entre otras y en el sureste, en la cabecera del departamento Islas del lbicuy.

Paralelamente a esta situación, se observa la localización de propuestas turísticas en espacios periurbanos de las principales localidades del corredor, fundamentalmente vinculadas a servicios de alojamiento en cabañas y bungalows, que en algunos de los casos, se suman a los grupos Cambio Rural o se generan vinculaciones estratégicas específicas. No obstante lo anterior, a lo largo y ancho de esta zona se pueden encontrar otras propuestas turísticas en los espacios rurales que no han integrado experiencias asociativas o apoyadas por organismos públicos, detalle que se explicitará más adelante.

Cada una de las zonas a las que se hace referencia en párrafos anteriores, posee rasgos identitarios diferentes, vinculados a lo cultural, productivo y paisajístico que los distingue claramente del resto del territorio, y un sistema de actores que la configuran de manera disímil.

Estos espacios territoriales, identificados en el marco de este proceso como puntos focales donde se concentran las propuestas de turismo rural, son comunes con las grandes ecoregiones 39 "que presentan diferencias relativas entre sí, vinculadas a aspectos históricos,

\footnotetext{
38 Plan Federal Estratégico de Turismo Sustentable de Argentina 2016.

En https://issuu.com/desarrolloturistico/docs/62601937d6ab128caa848457650a4e98 Última revisión: 8/2/2018

39 "El enfoque ecorregional incluye conceptos que integran en un mismo espacio geográfico aspectos climáticos, geomorfológicos, hidrográficos, agroeconómicos, fitogeográficos, fisiográficos y las condiciones generales de uso de la tierra y valor ambiental. Las ecorregiones son, por lo tanto, espacios donde convergen intereses económicos, sociales, ambientales y culturales, que se relacionan a diferentes niveles en el espacio y el tiempo. Este enfoque
} 
culturales, económicos, sociales y ambientales" (Plan Tecnológico Regional INTA Entre Ríos 2009-2011 $)^{40}$ identificadas y caracterizadas por INTA como base para la generación de planes de desarrollo territorial.

Además, pueden ser igualadas con cuatro de las principales Zonas AgroEconómicas Homogéneas (ZAH) que pueden identificarse en la provincia.

El concepto de Zonas AgroEconómicas Homogéneas ayuda a comprender la diversidad de sistemas productivos sobre los que se sustenta la producción agropecuaria en nuestro país, ya que reconoce "las condiciones naturales, sociales, económico productivas e institucionales como primeras determinantes de la diversidad, sostenibilidad y competitividad de los sistemas de producción". (Engler et al, 2008).

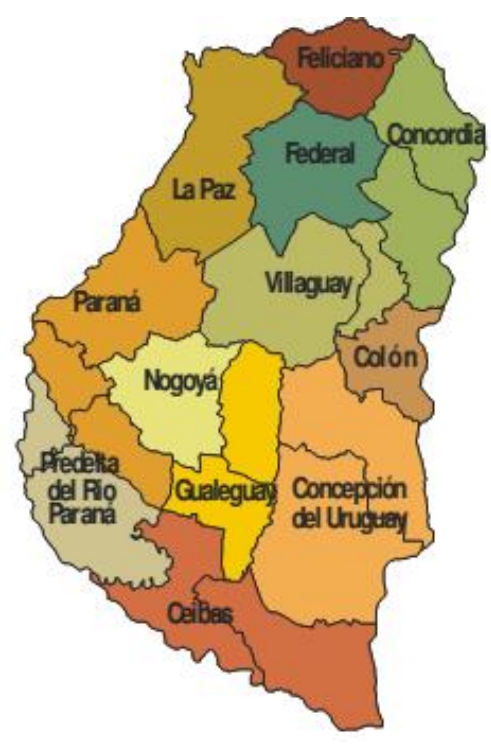

Ilustración 3- ZAH de la provincia de Entre Ríos. Fuente: Engler et al, 2008

Tomando como base este análisis y el de otras fuentes secundarias ${ }^{41}$ como proyectos territoriales y planes regionales de INTA, informes económicos de la provincia de Entre Ríos se sintetizan a continuación las principales características de los espacios territoriales definidos en la investigación.

\subsubsection{La región norte del Corredor del Uruguay}

\subsubsection{Localización y características generales}

Esta región comprende los departamentos de Concordia y Federación. El territorio abarca una superficie aproximada de 675.000 ha, lo que representa un $9 \%$ del total de la provincia. El

integra conceptos, niveles y dimensiones que permiten una mejor caracterización del espacio geográfico y por lo tanto una mayor precisión a la hora de diseñar estrategias de intervención institucionales en el ámbito de los territorios". (Plan Tecnológico Regional de INTA 2009-2011).

40 En https://inta.gob.ar/sites/default/files/script-tmp-plan tecnolgico regional 2009-2011 centro regional en.pdf 41 Plan Tecnológico Regional INTA Entre Ríos 2009-2011; Zonas Agro Económicas Homogéneas Entre Ríos. Descripción ambiental, socioeconómica y productiva. (Engler y otros, 2008). Proyectos Regionales con Enfoque Territorial: información ampliada del PRET Noreste; Fortalecimiento Institucional de la Provincia de Entre Ríos PROINDER - PREDER, 2008; Dirección General de Análisis y Programación Económica; Dirección de Análisis Fiscal, Ministerio de Economía, Hacienda y Finanzas de Entre Ríos, 2011. 
clima es subtropical sin estación seca con un promedio de precipitaciones anuales que supera los 1200 mm. (PRET Noreste INTA Entre Ríos, 2015) ${ }^{42}$.

Las principales vías de comunicación de esta zona son el puente internacional Salto Grande, la Ruta Nacional № 14 (en sentido norte sur); la № 18 (en sentido este - oeste) que vincula la zona con el departamento San Salvador y la No 127 (noreste - sureste) en el departamento Federación que une la zona con Federal al sureste y con la provincia de Corrientes al norte. También son de importancia las rutas provinciales $N^{\circ} 2,4$ y 22. (Engler et al, 2008).

En cuanto a la población, según datos del Censo Nacional del 2010, posee 269.849 habitantes, lo que representa un $21,8 \%$ del total provincial.

Referido a la organización administrativa, cuenta con 14 municipios y 22 juntas de gobierno. De éstas, Concordia es el principal centro poblacional (con 152.128 hab) y Federación se encuentra en el estrato de municipios con entre 10 mil y 20 mil habitantes). (PRET Noreste INTA Entre Ríos, 2015). Por otro lado, la ciudad de Chajarí, según el censo 2010 contaba con una población de 34.848 personas (INDEC, Censo Nacional de Población, Hogares y Viviendas 2010). ${ }^{43}$

La población residente en fracciones con EAPs es de 64.423 personas, que representa sólo el $30 \%$ de la población total de la zona. El $64 \%$ se encuentra en el departamento Concordia y el $36 \%$ restante en Federación. (Engler et al, 2008).

De la población total residente en fracciones con EAPs,

"el $68,1 \%$ de los hogares de esta zona, cubre sus necesidades básicas y el 35,6\% no presenta privaciones ni de recursos materiales corrientes ni patrimoniales. Esta última condición asciende al $49,2 \%$ cuando se consideran los hogares de la población con ocupación laboral y es del $43,4 \%$ en el caso de aquellos ocupados en el Sector $A^{44 "}$. (Engler et al, 2008).

\subsubsection{Estructura y dinámica productiva}

Se destacan los sectores foresto-industrial, frutícola, avícola y turístico como principales generadores de crecimiento económico. Otras actividades como la ganadería, la apicultura, horticultura y la producción de arroz contribuyen también en distintas formas a este crecimiento. (PRET Noreste INTA Entre Ríos, 2015).

Las principales producciones están relacionadas con la citricultura, la forestación y la ganadería de carne y ovinos. En esta zona se concentra el $98 \%$ de la superficie citrícola provincial con 47.225 ha en producción y el $43 \%$ de los bosques forestales implantados con 48.713 ha, siendo la principal especie el eucalipto y en segundo lugar el pino. (Censo Nacional Agropecuario 2002, en Engler et al, 2008).

En referencia a la citricultura, según el último relevamiento de 2004 de la Federación del Citrus de Entre Ríos (FeCiER) existía una superficie plantada cercana a las 41.977 ha y un número de productores de 1.792 (concentrados en los departamentos de Federación, Concordia y norte de Colón, con un 65\%, 33\% y $1 \%$ del área implantada). En la región se encuentran instalados 14 empaques de exportación y más de 370 de mercado interno (80\% del total del país) contando además con 4 industrias elaboradoras de jugo.

\footnotetext{
42 Proyecto Regional con Enfoque Territorial "Contribuir al desarrollo socio económico del noreste de Entre Ríos, en un marco de competitividad, salud ambiental y equidad social".

En línea en https://inta.gob.ar/proyectos/contribuir-al-desarrollo-socio-economico-del-noreste-de-entre-rios-en-unmarco-de-competitividad-salud-ambiental-y-equidad-social Última revisión: 8/2/2018

43 Población por áreas de gobierno local, año 2010. https://www.entrerios.gov.ar/dec/paginas/municipios.html

44 Según la Clasificación Nacional de Actividades Económicas (CLANAE) el Sector A incluye agricultura, ganadería, caza y silvicultura. (Engler et al, 2008).
} 
Se observa una disminución en el número de explotaciones en el departamento de Concordia y un incremento en el departamento de Federación, lo que evidencia un desplazamiento de la producción hacia el norte.

Se evidencia una especialización en naranjas y mandarinas. (PRET Noreste INTA Entre Ríos, 2015)

Respecto a la actividad foresto-industrial, como dato de contexto, se puede apreciar que en la provincia de Entre Ríos, la superficie forestada supera las 144.000 hectáreas ${ }^{45}$.

"Esta cuenca forestal está conformada fundamentalmente por especies de rápido crecimiento, eucaliptos y pinos principalmente, siendo la especie Eucalyptus grandis la que representa más del 80 $\%$ de la superficie forestal (...)Según el censo de 2002, la implantación forestal se desarrolla predominantemente en explotaciones medias (de 100 a 500 hectáreas) y en grandes (de más de 500 ) en los departamentos de Colón y Concordia, mientras que prevalece en unidades más pequeñas en Federación". (PRET Noreste INTA Entre Ríos, 2015).

Se observa en la región el desarrollo de un polo Foresto-Industrial conformado en su mayoría por PYMES. Estas industrias generan más de 600 puestos de trabajo de forma directa en la región. (PRET Noreste INTA Entre Ríos, 2015).

En el caso de la ganadería el stock ganadero de la región representa aproximadamente el $12 \%$ del provincial. (PRET Noreste INTA Entre Ríos, 2015).

Esta actividad concentra 533 productores en Concordia y 1191 en Federación.

"Esto demuestra que la ganadería complementa otras actividades como la fruticultura y la forestación. Es frecuente encontrar explotaciones que combinan la ganadería de cría y la forestación con eucalipto, sistema basado fundamentalmente en la introducción de ganado para reducir el material vegetal y evitar riesgos de incendios". (PRET Noreste INTA Entre Ríos, 2015).

Según datos de la Dirección General de Producción Animal de Entre Ríos 2007 (en Engler et al, 2008), las existencias ganaderas están compuestas por 447.854 cabezas de ganado bovino y 66.113 cabezas de ovinos, que representan respectivamente el $10 \%$ y $19 \%$ del total de existencias provinciales. En Federación se encuentran registrados 4 feed lots de pequeña escala.

En cuanto a apicultura, Entre Ríos se ubica entre las primeras provincias aportando anualmente unas 16.000 toneladas para la exportación. Un $90 \%$ de la miel producida se comercializa a granel en tambores de $330 \mathrm{~kg}$ a acopiadores zonales, cooperativas o firmas comerciales con destino a exportación, quedando sólo el 10\% para consumo interno.

Los destinos más frecuentes son Alemania, España, Inglaterra y Estados Unidos. Esta zona involucra el $27 \%$ de productores, el $26 \%$ de los apiarios, el $35 \%$ de las colmenas y en cuanto a la producción de miel, representa el $40 \%$ del total provincial. (PRET Noreste INTA Entre Ríos, 2015).

Respecto a la avicultura es la provincia de mayor importancia en la producción aviar. Junto con Buenos Aires producen casi la totalidad de la oferta nacional. En 2.008, el $47 \%$ de la faena total de pollos y $21 \%$ de los huevos producidos correspondieron a Entre Ríos, representando 25.530.940 aves faenadas y 1.074.127 cajones de huevos de 30 docenas. La actividad ha seguido un ritmo de crecimiento considerable y vinculado al territorio del proyecto, si bien tradicionalmente la zona de Colón ha sido muy importante y sigue siéndolo, no solo desde el punto de vista productivo sino también referido a la instalación de las plantas procesadoras, la actividad se ha expandido en los departamentos de Concordia y Federación,

\footnotetext{
45 Datos del Mapa Forestal elaborado por la Dirección de Producción Forestal del Ministerio de Agricultura de la Nación (2009) en PRET Noreste INTA Entre Ríos, 2015
} 
constituyéndose en una alternativa viable e interesante para el pequeño y mediano productor. (PRET Noreste INTA Entre Ríos, 2015).

La horticultura es una actividad intensiva que se encuentra presente en la región vinculada principalmente al pequeño y mediano productor. Si bien el potencial de crecimiento dado por las condiciones ecológicas favorables es muy alto, contrasta con las escasas y poco organizadas posibilidades de comercialización lo cual limita su desarrollo. (PRET Noreste INTA Entre Ríos, 2015).

Los cultivos anuales representan el $3 \%$ del total sembrado en la provincia. El $68 \%$ corresponde a oleaginosas y el $32 \%$ a cereales. Dentro de las oleaginosas, se destaca la soja con el $56 \%$ de la superficie y dentro de los cereales, el arroz. (Engler et al, 2008).

En referencia a este cultivo genera una agroindustria importante en la Provincia y en esta zona en particular ocupando el $19,2 \%$ del área sembrada, siendo ésta la segunda zona más importante en la producción de arroz participando con el 18,9\% de la superficie total de arroz de la provincia (campaña 2006/07). (Engler et al, 2008).

La zona se caracteriza por la concentración de unidades productivas en los estratos de menos de 100 ha que representan el $70 \%$ del total de EAPs y ocupan el $14 \%$ de la superficie total.

La superficie media del estrato inferior a 50 ha es de 27 ha, mientras que en el comprendido entre 50 ha y 99 el tamaño promedio es de 67 ha. Las EAPs del estrato de 500 ha o más, que representan el $8 \%$ del total, ocupan el $65 \%$ de la superficie total censada de esta zona y poseen una superficie media de 779 y 3026 ha, según se trate del estrato mayor o igual a 500 y menor a 1.200 ha o el de más de 1.200 ha. De acuerdo al número de EAPs, un alto porcentaje se encuentra exclusivamente bajo régimen de propiedad $(85 \%$ de las EAPs que ocupan el $74 \%$ de la superficie). La forma de tenencia combinada entre propiedad y arrendamiento no es relevante en cuanto a número de EAPs, pero ocupa el $17 \%$ de la superficie censada de la zona. El $10 \%$ de la superficie está bajo arrendamiento. Las EAPs que predominan en términos de cantidad son las orientadas predominantemente a la agricultura 0 a la ganadería; sin embargo las primeras de ellas ocupan el $16 \%$ de la superficie y las segundas el $69 \%$, lo que indica que las unidades productivas agrícolas son de menor escala que las ganaderas. (Engler et al, 2008).

\subsubsection{La región Centro del Corredor del Uruguay}

\subsubsection{Localización y características generales}

Corresponde a la ZAH Colón y comprende el departamento homónimo que ocupa el 3\% de la superficie total provincial.

La población residente en fracciones con EAPs es de 52.718 personas, el $100 \%$ de la población total de la zona. 


\begin{tabular}{|c|c|c|c|c|c|c|}
\hline \multirow[b]{2}{*}{ Departamento } & \multirow[b]{2}{*}{ Localidad/ Paraje } & \multirow[b]{2}{*}{$\begin{array}{c}\text { Población } \\
\text { Total }\end{array}$} & \multicolumn{4}{|c|}{ Población en fracciones con EAPs } \\
\hline & & & Varón & Mujer & Total & $\begin{array}{c}\text { Proporción } \\
\text { población } \\
\text { total }\end{array}$ \\
\hline \multirow{12}{*}{ Colón } & Colón & 19.288 & 9.262 & 10.026 & 19.288 & $100 \%$ \\
\hline & San José & 13.406 & 6.632 & 6.774 & 13.406 & $100 \%$ \\
\hline & Villa Elisa & 8.351 & 4.127 & 4.224 & 8.351 & $100 \%$ \\
\hline & Rural Dispersa * & 7.783 & 4.155 & 3.628 & 7.783 & $100 \%$ \\
\hline & Ubajay & 1.847 & 979 & 868 & 1.847 & $100 \%$ \\
\hline & Pueblo Liebig's & 632 & 305 & 327 & 632 & $100 \%$ \\
\hline & Arroyo Barú & 509 & 240 & 269 & 509 & $100 \%$ \\
\hline & La Clarita & 448 & 226 & 222 & 448 & $100 \%$ \\
\hline & Pueblo Cazes & 216 & 118 & 98 & 216 & $100 \%$ \\
\hline & Hocker & 91 & 45 & 46 & 91 & $100 \%$ \\
\hline & Hambis & 87 & 47 & 40 & 87 & $100 \%$ \\
\hline & Colonia Hugues & 60 & 34 & 26 & 60 & $100 \%$ \\
\hline \multicolumn{2}{|c|}{ Total ZAH Colón } & 52.718 & 26.170 & 26.548 & 52.718 & $100 \%$ \\
\hline
\end{tabular}

Tabla 3- Población por localidad. Fuente: Engler et al, 2008.

"El 95,4\% de la población residía dentro de la provincia de Entre Ríos al menos cinco años antes de la realización del CNPVyH2001. De los que habitaban anteriormente en otras provincias, sólo alcanzan cierta importancia los que lo hacían en Buenos Aires, representando éstos el $2,1 \%$ de los casos". (Engler et al, 2008).

El $88,2 \%$ de los hogares de esta zona cubre sus necesidades básicas y el $64,2 \%$ no presenta privaciones ni de recursos materiales corrientes ni patrimoniales. Esta última condición asciende al $77 \%$ cuando se consideran los hogares de la población con ocupación laboral y es del $64,7 \%$ en el caso de aquellos ocupados en el Sector A.

Las principales vías de comunicación son la Ruta Nacional $N^{\circ} 14$ que en sentido nortesur comunica a esta zona con los departamentos Concordia y Uruguay y la Ruta Provincial $N^{\circ} 130$, que en sentido este-oeste vincula a Colón con Villaguay. Además, se encuentra el puente internacional General Artigas que une Colón con Paysandú en la República Oriental del Uruguay.

\subsubsection{Estructura y dinámica productiva}

"Los pilares de la economía de la región son la actividad agropecuaria, la agroindustria, el sector de la madera, el sector metalúrgico y el turismo. La actividad pecuaria está orientada a la producción lechera principalmente. La ganadería extensiva sobre pasturas naturales representa una importante proporción de superficie ocupada y emplea buena parte de la mano de obra de la región.

El sector arrocero con su industria transformadora es también un importante generador de empleo. La producción de la zona es una de las más importantes del país, y está dedicada al consumo interno y a la exportación. Esta producción es desarrollada por pequeños y medianos productores con una fuerte identidad como productores arroceros que se nuclean en torno a la cooperativa que crearon a principios de siglo". (García, 2006). ${ }^{46}$

Otra actividad de importancia en la región es la producción avícola fundamentalmente de carne aviar que se concentra en el departamento de Colón que constituye una fuerte generadora de empleo y una fuente de ingresos para los pequeños productores que se dedican a la cría de pollos a través de la integración vertical con los frigoríficos.

46 Informe final. Sistematización de experiencias de desarrollo rural territorial en la Costa del Uruguay. Departamentos: Federación, Concordia Colón, Uruguay y Gualeguaychú. Fortalecimiento Institucional de la Provincia de Entre Ríos. PROINDER - PREDER. 
"En los últimos años, ha ganado mucha importancia la actividad turística. La construcción de las termas de Villa Elisa en el año 1999 dinamizó la actividad turística, y esta tuvo importantes repercusiones en la actividad hotelera y gastronómica, el mercado inmobiliario y la industria de la construcción. La actividad implica un importante movimiento de turistas durante todo el año que se intensifica en temporada alta. Las plazas se cubren por completo durante las vacaciones de invierno y verano, así como también los fines de semana largos". (García et al, 2006).

El uso del suelo se caracteriza por las actividades forestales y ganaderas, presentando 36.250 ha de forestación, principalmente con eucaliptos, lo que representa el $32 \%$ del total implantado en la provincia. Las existencias ganaderas ascienden a 206.648 cabezas, el $4 \%$ del total provincial. La ganadería ovina está representada por 4.523 cabezas, el 1,3\% del total provincial. La superficie agrícola es de 43.120 ha (solo el $2 \%$ de la superficie total provincial). La proporción entre oleaginosas y cereales es de $64 \%$ y $36 \%$ respectivamente, siendo los principales cultivos la soja con el $63 \%$ de participación en la superficie sembrada en la zona, el arroz con el $15 \%$ y el trigo con el $8 \%$. (Engler et al, 2008).

Las unidades productivas en los estratos de menos de 100 ha representan el $68 \%$ del total de EAPs y ocupan el $16 \%$ de la superficie total. La superficie media del estrato inferior a 50 ha es de23 ha, mientras que en el comprendido entre 50 y 99 la superficie promedio es de 69 ha. Las EAPs del estrato de 500 ha o más, que representan el $5 \%$ del total, ocupan el $51 \%$ de la superficie. El $71 \%$ de la superficie censada de la zona es operada bajo el régimen de propiedad y el $15 \%$ en arrendamiento o aparcería.

El $80 \%$ de las EAPs, con el $56 \%$ de la superficie censada zonal, son predominantemente ganaderas. Las EAPs con orientación agrícola representan el $10 \%$ de los casos y el $22 \%$ de la superficie.

En el $75 \%$ de los casos predominan las EAPs que utilizan mano de obra familiar y se distribuyen entre ganaderas en un $85 \%$ y agrícola en un $8 \%$. Las de tipo no familiar lo hacen en un $71 \%$ en las orientaciones ganaderas, $12 \%$ agrícola y $9 \%$ mixta ganadera agrícola.

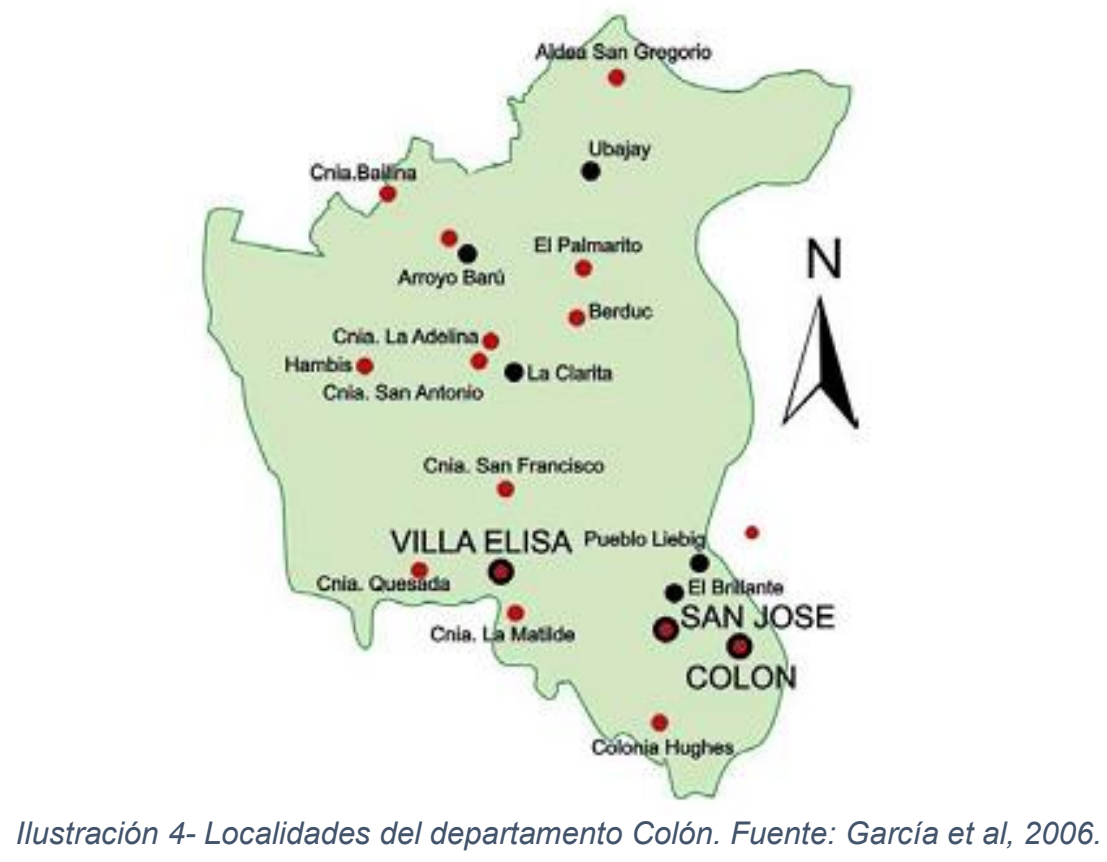

\subsubsection{La región Sur del Corredor del Uruguay}




\subsubsection{Localización y características generales}

El espacio del Delta Entrerriano, en el extremo sur, presenta un stock de recursos naturales de elevado valor ambiental pero con bajo desarrollo y fuertes dificultades en la ocupación tradicional del territorio por su configuración deltaica.

Esta región posee, en términos comparativos, elevados indicadores de NBI. Las actividades predominantes son la apícola, ganadera, forestal y pesquera. (INTA Plan de Tecnología Regional, 2006-2009). Corresponde a la ZAH CEIBAS en Engler et al (2008).

La zona en cuestión se ubica al sudeste de la provincia de Entre Ríos en el Delta inferior del río Paraná. Ocupa el $10 \%$ de la superficie total provincial y comprende la porción insular del departamento Gualeguay y el departamento Islas del Ibicuy en su totalidad.

Los suelos predominantes corresponden a los de un típico ambiente deltaico, donde es factible encontrarlos gran parte del año bajo agua, con una gran heterogeneidad espacial de suelos y sectores con contenidos importantes de sodio. La vegetación dominante está constituida por las praderas, estepas y pajonales de gramíneas. (Engler et al, 2008)

Esta zona tiene características muy particulares de producción. En el sector superior y medio predomina el uso ganadero extensivo y apicultura. En el inferior el uso mixto forestal-ganadero y Apicultura, en parte con implantación de praderas y verdeos de invierno en campos bajos, pastoreo estacional, forestación con salicáceas y apicultura sobre vegetación natural típica del Delta. (Engler et al, 2008).

La población residente en fracciones con presencia de EAPs asciende a 12.324 habitantes, el $65 \%$ de la población total de la zona (Tabla 8 ).

El 93\% de estas personas se encuentra en el departamento de Islas de lbicuy y el resto en Gualeguay.

Del total de habitantes en fracciones censales con EAPs, el $62,3 \%$ de los hogares, cubre sus necesidades básicas y el $35,2 \%$ no presenta privaciones ni de recursos materiales corrientes ni patrimoniales.

Esta zona alberga el puerto de lbicuy, situado a $3 \mathrm{~km}$ del eje de la hidrovía de los ríos ParanáParaguay. Es un puerto de aguas profundas destinado a cereales, carga general y combustibles. La zona se conecta con la provincia de Buenos Aires, por el río Paraná, a través del complejo ferro-vial Zárate- Brazo Largo. (Consejo Empresario de Entre Ríos, 2004).

En la zona existen pocas industrias y están relacionadas fundamentalmente con la producción forestal. Se encuentran registrados un aserradero, una fábrica de reciclado de cartón y un astillero naval. (Dirección de Estadística y Censos de Entre Ríos, 2005).

\subsubsection{Estructura y dinámica productiva}

De acuerdo al uso del suelo, la orientación productiva que predomina es la ganadería, representando el $52 \%$ de las EAPs y el $87 \%$ de la superficie. En segundo lugar, se encuentra la orientación agrícola, que representa el $45 \%$ de las EAPs y el $10 \%$ de la superficie total censada. Los sistemas predominantes son el agrícola forestal y el ganadero de bovinos de carne, que en conjunto representan el $80 \%$ de las EAPs y el $59 \%$ de la superficie censada de la zona.

En esta ZAH tienen gran relevancia las actividades apícolas, ganaderas con pastoreo estacional de recursos naturales, forestales y la pesca. La actividad forestal es la actividad de mayor importancia en la zona, representando el $16 \%$ de la superficie forestada provincial. 
En la zona se cultiva solo el $5 \%$ de la superficie total censada (según el Censo Nacional Agropecuario 2002) y de la superficie implantada, el $82 \%$ corresponde a la actividad forestal, principalmente montes de salicáceas, el $12 \%$ corresponde a agricultura, con participaciones similares de cereales y oleaginosas y el $6 \%$ se implanta con forrajeras.

Las existencias ganaderas corresponden prácticamente en su totalidad a ganado bovino de carne (extensiva, existiendo un solo feed lot de 2500 cabezas aproximadamente (Dirección General de Producción Animal de Entre Ríos, 2007). También existe ganado ovino pero en menor grado de importancia (Engler et al, 2008).

"Si bien existe una concentración de EAPs en estratos menores a 250 ha, la estructura agraria de esta zona se caracteriza por EAPs de mayor superficie que otras zonas de la provincia. En el estrato menor a 250 ha se encuentra el $64 \%$ del total de EAPs, que representan el $6 \%$ de la superficie total zonal. La superficie media del estrato de menos de 50 ha es de 22 ha; del estrato comprendido entre 50 a 99 ha es de 70 ha; y del estrato comprendido entre100 y 249 es de 157 ha". (Engler et al, 2008).

La propiedad como forma exclusiva de tenencia representa el $67 \%$ y $65 \%$ de la superficie y de las EAPs respectivamente. Asimismo, el $11 \%$ de la superficie corresponde a la combinación de tierra propia y arrendada. Igual valor también representa la forma de ocupación de hecho y con permiso.

\begin{tabular}{|c|c|c|}
\hline Zona norte & Zona centro & Zona sur \\
\hline $\begin{array}{l}\text { Principales producciones: } \\
\text { citricultura, forestación y la } \\
\text { ganadería de carne y ovinos. } \\
\text { Apicultura, horticultura y } \\
\text { producción de arroz, } \\
\text { actividades de importancia } \\
\text { menor: } \\
\text { La horticultura es una } \\
\text { actividad intensiva vinculada } \\
\text { principalmente al pequeño y } \\
\text { mediano productor. } \\
\text { Avicultura actividad } \\
\text { tradicional de la zona de } \\
\text { Colón ha sido que se ha } \\
\text { expandido en los } \\
\text { departamentos de Concordia } \\
\text { y Federación. }\end{array}$ & $\begin{array}{l}\text { Pilares de la economía de la } \\
\text { región: agroindustria, sector de } \\
\text { la madera, sector metalúrgico y } \\
\text { el turismo. } \\
\text { La actividad pecuaria orientada } \\
\text { a la producción lechera, } \\
\text { ganadería extensiva, sector } \\
\text { arrocero y producción avícola } \\
\text { fundamentalmente de carne } \\
\text { aviar. }\end{array}$ & $\begin{array}{l}\text { Actividades predominantes: } \\
\text { apícola, ganadera, forestal y } \\
\text { pesquera. } \\
\text { Suelos predominantes } \\
\text { corresponden a ambiente } \\
\text { deltaico. } \\
\text { Pocas industrias (relacionadas } \\
\text { con la producción forestal) La } \\
\text { actividad forestal es la de mayor } \\
\text { importancia en la zona, } \\
\text { representando el } 16 \% \text { de la } \\
\text { superficie forestada provincial. } \\
\text { Orientación productiva que } \\
\text { predomina es la ganadería, } \\
\text { representando el } 52 \% \text { de las } \\
\text { EAPs y el } 87 \% \text { de la superficie }\end{array}$ \\
\hline $\begin{array}{l}\text { La población residente en } \\
\text { fracciones con EAPs } \\
\text { representa sólo el } 30 \% \text { de la } \\
\text { población total. } \\
\text { Concentración de unidades } \\
\text { productivas en los estratos } \\
\text { de menos de } 100 \text { ha: } 70 \% \\
\text { del total de EAPs que } \\
\text { ocupan el } 14 \% \text { de la } \\
\text { superficie total. } \\
\text { Las EAPs del estrato de } 500 \\
\text { ha o más, representan el } 8 \% \\
\text { del total y ocupan el } 65 \% \text { de } \\
\text { la superficie total. } \\
85 \% \text { bajo régimen de } \\
\text { propiedad. }\end{array}$ & $\begin{array}{l}\text { Las unidades productivas en los } \\
\text { estratos de menos de } 100 \text { ha } \\
\text { representan el } 68 \% \text { del total de } \\
\text { EAPs y ocupan el } 16 \% \text { de la } \\
\text { superficie total. } 71 \% \text { bajo el } \\
\text { régimen de propiedad. } \\
\text { El } 80 \% \text { de las EAPs, con el } 56 \% \\
\text { de la superficie son } \\
\text { predominantemente ganaderas. } \\
\text { En el } 75 \% \text { de los casos } \\
\text { predominan las EAPs que } \\
\text { utilizan mano de obra familiar. }\end{array}$ & $\begin{array}{l}\text { La población residente en } \\
\text { fracciones con presencia de } \\
\text { EAPs asciende a } 12.324 \\
\text { habitantes, el } 65 \% \text { de la } \\
\text { población total de la zona (Tabla } \\
8 \text { ). } \\
\text { El } 93 \% \text { de estas personas se } \\
\text { encuentra en el departamento } \\
\text { de Islas de Ibicuy. Si bien existe } \\
\text { una concentración de EAPs en } \\
\text { estratos menores a } 250 \text { ha, la } \\
\text { estructura agraria de esta zona } \\
\text { se caracteriza por EAPs de } \\
\text { mayor superficie que otras } \\
\text { zonas de la provincia. En el } \\
\text { estrato menor a } 250 \text { ha se } \\
\text { encuentra el } 64 \% \text { del total de } \\
\text { EAPs, que representan el } 6 \% \text { de } \\
\text { la superficie total zonal. }\end{array}$ \\
\hline
\end{tabular}


Propiedad como forma exclusiva de tenencia: $67 \%$

Tabla 4- Resumen orientación productiva de las zonas del Uruguay. 


\section{Capítulo 5- El turismo rural en la costa del río Uruguay Presentación de resultados y descripción de los casos}


En el presente capitulo se presentarán por un lado los resultados del relevamiento y caracterización de las propuestas turísticas en el espacio rural, realizado a partir de encuestas a informantes calificados de cada territorio, de los cuales se seleccionaron los casos centrales de la investigación.

Luego, se describirán aspectos relacionados al desarrollo del turismo en los espacios rurales de cada zona específica como elementos para comprender las dimensiones territoriales del contexto en los que se insertan las experiencias, que luego son presentadas en apartados por zona norte, zona centro y sur.

\section{A Resultados obtenidos de la precaracterización}

Según el relevamiento de la oferta de propuestas de turismo rural de cada una de las zonas desarrollado a partir de la información de 16 referentes técnicos de Municipios, INTA y grupos Cambio Rural, se pueden encontrar 136 casos en los territorios. De éstos, no se logró obtener mayor información de 6, por lo que el universo de actores relevados es de 130.

De este universo, 48 son las propuestas gestionadas por productores agropecuarios, es decir un $37 \%$ del total, pero esa variable muta por zona, como el perfil de los actores y las actividades productivas de base.

En el capítulo de resultados $\left(n^{\circ} 6\right)$ se retomará el análisis de esta primera clasificación, exponiéndose en detalle el número de casos identificados y su relación con las variables escogidas. 
A modo de síntesis: ${ }^{47}$

\begin{tabular}{|c|c|c|c|c|c|c|c|c|c|c|c|c|}
\hline Zona & $\begin{array}{l}\text { Total } \\
\text { SA con } \\
\text { turismo } \\
\text { rural }\end{array}$ & $\begin{array}{l}\text { Gestión a } \\
\text { cargo de no } \\
\text { productores } \\
\text { agropecuarios }\end{array}$ & $\begin{array}{l}\text { Sin } \\
\text { datos }\end{array}$ & $\begin{array}{l}\text { Gestión a } \\
\text { cargo de } \\
\text { productores } \\
\text { agropecuarios }\end{array}$ & $\begin{array}{l}\text { Con más } \\
\text { mano de } \\
\text { obra } \\
\text { Familiar }\end{array}$ & $\begin{array}{l}\text { Con más } \\
\text { empleados }\end{array}$ & $\begin{array}{l}\text { Con hijos } \\
\text { involucrados } \\
\text { en el SA }\end{array}$ & $\begin{array}{l}\text { Sin hijos o } \\
\text { independientes } \\
\text { del SA }\end{array}$ & $\begin{array}{l}\text { Del } \\
\text { lugar }\end{array}$ & Foráneo & $\begin{array}{l}\text { Trabajo } \\
\text { en red }\end{array}$ & $\begin{array}{l}\text { Sin } \\
\text { trabajo } \\
\text { en } \\
\text { red }\end{array}$ \\
\hline Norte & 15 & 3 & 1 & 11 & 10 & 1 & 6 & 5 & 10 & 1 & 6 & 5 \\
\hline Centro & 55 & 35 & 1 & 20 & 14 & 6 & 13 & 7 & 20 & - & 15 & 5 \\
\hline Sur & 66 & 45 & 4 & 17 & 15 & 2 & 6 & 11 & 15 & 2 & 10 & 7 \\
\hline
\end{tabular}

${ }^{47}$ La sección marcada con la línea entre puntos corresponde sólo a los SA gestionados por productores agropecuarios. 


\section{B Zona norte. Descripción del contexto, aspectos organizativos y regulatorios}

Complementando lo presentado en el capítulo anterior, en el que la mirada se centró en los aspectos productivos, puede decirse que en la zona norte de la provincia las propuestas de turismo rural se concentran en dos localidades, Villa del Rosario y Chajarí, ubicadas a $11 \mathrm{~km}$. Villa del Rosario cuenta con una población aproximada de 4000 habitantes, se encuentra a $9 \mathrm{~km}$ del río Uruguay, cerca de la desembocadura del río Mocoretá y de la represa de Salto Grande y a 23 km al norte de la ciudad de Federación.

En esta localidad funcionó un Grupo Cambio Rural de Turismo Rural "Agrocitrícola Aromas de Azahares" (desde el 2012 al 2015) con una estrecha vinculación al área de turismo municipal, surgido a partir de una demanda de este organismo que procuró generar un espacio de trabajo y articulación para la integración de su principal producción -la citrícola- y sus productores al turismo.

Este grupo actualmente no cuenta con financiamiento del estado, pero funciona en la realidad con apoyo de la Dirección de Turismo Municipal y de la Agencia de Extensión Rural Chajarí de INTA, involucrada con el proceso desde sus inicios.

La mayoría de los emprendimientos están abocados a la producción citrícola, diversificando a través de actividades alternativas como granjas, producción ganadera, forestación. Otros, a la actividad ganadera y a la producción de nuez pecán.

A partir de este proceso, el municipio local trabaja en una marca de ciudad en torno a su perfil productivo y se autodenominan "El Pueblo de las Mandarinas". Además, empiezan a organizar en vacaciones de invierno la Fiesta de la Mandarina con una importante convocatoria regional, por cuanto es la zona de mayor producción y cantidad de variedades de este cítrico, pretendiendo posicionar a los productores orientados al turismo rural como "embajadores" de la localidad.

Chajarí es un municipio de escala mayor con una trayectoria en materia de turismo que se potencia a partir de la construcción del complejo termal municipal en el año 2001 principal motivador de viaje a la zona. Este se ubica sobre la Ruta Nacional $\mathrm{n}^{\circ} 14$, a $2 \mathrm{~km}$ del centro urbano.

Aquí también se conformó un Grupo Cambio Rural II, con apoyo del Municipio local, integrado por un número de productores rurales y prestadores turísticos próximos al paraje "Las 14", ubicado a pocos metros del complejo termal.

En el departamento Concordia en el año 2017 técnicos de la Agencia de Extensión Rural del INTA comenzaron a vincularse con el Ente Mixto de Turismo de Concordia y la Municipalidad local y la CAFESG (Comisión Administradora de los Fondos Especiales de Salto Grande) para trabajar en la temática del turismo y el desarrollo territorial.

Para entender el movimiento turístico que caracteriza esta particular zona del corredor del Uruguay es importante tener en cuenta la cantidad de visitantes a los complejos turísticos termales de las ciudades de Federación y Chajarí (a $51 \mathrm{~km}$ ) durante el año 2015 y 2016, que aunque no reflejan necesariamente el total de que llega a la visitantes que llega a la zona sí colabora a interpretar la realidad turística y su desarrollo regional.

En el año 2015 y 2016 ingresaron al complejo termal de Federación respectivamente 562.752 y 588.463 personas, Y en las termas de Chajarí, 141.541 personas en el 2015 y 138.194 en el 2016, es decir, más de medio millón de turistas en el año que se movilizan por esta región en particular. 
El potencial de la oferta de turismo rural en esta zona está dado por la actividad productiva en torno a la citricultura. Hasta el momento no cuenta con estatutos específicos que regulen la actividad, sólo las habilitaciones municipales y homologaciones turísticas provinciales.

"El extremo norte del corredor turístico del Uruguay puede considerarse vinculado al área con vocación turística identificada en el norte entrerriano y sur correntino caracterizada por una fuerte identidad producto de la conjunción en la producción de frutas (especialmente cítricos) y la colonización italiana de fines del siglo XIX y principios del XX. Esta situación le otorga un importante potencial vinculado al turismo rural, a las fiestas tradicionalistas y a la arquitectura vernácula que aún perdura". (Biasizo et al, s/f)

En esta zona funcionan, según los informantes clave, 15 experiencias de turismo rural. De éstas, el $73 \%$ son gestionadas por productores agropecuarios, de los cuales el $100 \%$ son de la zona, es decir prácticamente no hay actores extralocales integrados a esta modalidad en particular.

De ese total, el $91 \%$ es de gestión y mano de obra familiar.

En el $55 \%$ de los casos, los hijos están involucrados en el trabajo familiar.

De los 11 SA gestionados por productores:

- 3 ofrecen actividades

- 3 ofrecen servicios de gastronomía

- 5 combinan actividades

Del porcentaje de experiencias llevadas adelante por productores agropecuarios, el $55 \%$ pertenecen a redes formales de asociativismo (grupos cambio rural en su mayoría).

\begin{tabular}{|c|c|c|c|c|c|c|c|c|c|c|c|}
\hline $\begin{array}{l}\text { Total SA } \\
\text { con } \\
\text { turismo } \\
\text { rural }\end{array}$ & $\begin{array}{l}\text { Gestión a } \\
\text { cargo de } \\
\text { no } \\
\text { producto } \\
\text { res } \\
\text { agropecu } \\
\text { arios }\end{array}$ & $\begin{array}{l}\text { Sin } \\
\text { datos }\end{array}$ & $\begin{array}{l}\text { Gestión a } \\
\text { cargo de } \\
\text { productore } \\
\text { s } \\
\text { agropecuari } \\
\text { os }\end{array}$ & $\begin{array}{l}\text { Con más } \\
\text { mano de } \\
\text { obra } \\
\text { Familiar }\end{array}$ & $\begin{array}{l}\text { Con más } \\
\text { empleado } \\
\mathrm{s}\end{array}$ & $\begin{array}{l}\text { Con hijos } \\
\text { involucrado } \\
\text { s en el SA }\end{array}$ & $\begin{array}{l}\text { Sin hijos o } \\
\text { independient } \\
\text { es del SA }\end{array}$ & $\begin{array}{l}\text { Del } \\
\text { lugar }\end{array}$ & $\begin{array}{l}\text { Forá } \\
\text { neo }\end{array}$ & $\begin{array}{l}\text { Traba } \\
\text { jo en } \\
\text { red }\end{array}$ & $\begin{array}{l}\text { Sin } \\
\text { trabaj } \\
\text { o en } \\
\text { red }\end{array}$ \\
\hline 15 & 3 & 1 & 11 & 10 & 1 & 6 & 5 & 10 & 1 & 6 & 5 \\
\hline
\end{tabular}

Teniendo en cuenta lo anterior, los casos en esta zona se seleccionaron con los siguientes criterios:

1. Como la mayoría de los SA gestionados por productores agropecuarios son predominantemente familiares, se seleccionaron más casos de esta característica.

2. Una de las variables más importantes es la conformación de la familia con hijos a cargo que participen activamente del SA, por lo tanto se seleccionó un caso con hijos con mayor involucramiento en las actividades de generación de ingresos del sistema y otro en el que no intervengan.

3. Uno al menos debe tener experiencia asociativa.

4. Para profundizar el análisis e incrementar la diversidad y complejidad de la información obtenida en esta zona se eligió un SA cuya gestión no esté a cargo de productores agropecuarios y que integre o no redes asociativas.

\begin{tabular}{|l|l|l|l|l|}
\hline $\begin{array}{l}\text { Casos } \\
\text { zona } \\
\text { Norte }\end{array}$ & $\begin{array}{l}\text { Actividad } \\
\text { productiva }\end{array}$ & Categoría turística & Mano de obra & $\begin{array}{l}\text { Integración a } \\
\text { redes }\end{array}$ \\
\hline Caso 1 & $\begin{array}{l}\text { Horticultura- } \\
\text { citricultura- }\end{array}$ & $\begin{array}{l}\text { Combinan actividades } \\
\text { (alojamiento, }\end{array}$ & $\begin{array}{l}\text { Familiar con hijos } \\
\text { participantes }\end{array}$ & $\begin{array}{l}\text { Integran redes } \\
\text { asociativas }\end{array}$ \\
\hline
\end{tabular}




\begin{tabular}{|c|c|c|c|c|}
\hline & $\begin{array}{l}\text { actividades de } \\
\text { granja }\end{array}$ & $\begin{array}{l}\text { actividades dentro del } \\
\text { predio/ venta de } \\
\text { productos de la huerta }\end{array}$ & & \\
\hline Caso 2 & $\begin{array}{l}\text { Se dedican al } \\
\text { comercio. No son } \\
\text { productores } \\
\text { agropecuarios }\end{array}$ & $\begin{array}{l}\text { Gastronomía y } \\
\text { alojamiento }\end{array}$ & $\begin{array}{l}\text { Emprendimiento } \\
\text { familiar con hijos que } \\
\text { colaboran }\end{array}$ & $\begin{array}{l}\text { Integra redes } \\
\text { asociativas }\end{array}$ \\
\hline Caso 3 & $\begin{array}{l}\text { Productores } \\
\text { capitalizados con } \\
\text { perfil productivo y } \\
\text { comercial. }\end{array}$ & $\begin{array}{l}\text { Alojamiento y } \\
\text { actividades turísticas }\end{array}$ & $\begin{array}{l}\text { Con mayor mano de } \\
\text { obra asalariada. Los } \\
\text { hijos no participan de } \\
\text { la actividad } \\
\text { (estudiantes } \\
\text { universitarios y } \\
\text { secundario) }\end{array}$ & $\begin{array}{l}\text { No integra } \\
\text { redes } \\
\text { asociativas }\end{array}$ \\
\hline
\end{tabular}




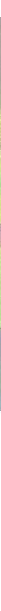

"Vimos que era necesario tener otro rubro porque la huerta, si bien es una entrada, un trabajo lindo, dependemos del tiempo, si llueve mucho, si llueve poco, si hay sequía, si hay helada, y en la época de verano es la época que menos trabajo en la huerta es la época fuerte del turismo, entonces pensamos en complementar ahí productivamente". (Analía, huerta Chajarí). 


\section{B.1 Caso 1 - UNA VENTANA AL TRABAJO EN LA HUERTA}

Este caso corresponde a un Sistema de Actividades llevado adelante por una familia de productores agropecuarios que integran el turismo a su actividad productiva, nacidos en la zona, con involucramiento activo de uno de los hijos en las actividades del sistema y con experiencia asociativa.

\section{B.1.1 Presentación general}

Familia integrada por la pareja de productores de 54 años con cuatro hijos de 25, 24, 17 y 9. Los dos mayores son varones y las menores mujeres.

Son productores hortícolas de Chajarí que hace aproximadamente dos años construyeron cuatro cabañas de madera en el predio donde poseen la huerta. Poseen 41 ha, 9 en producción y $4 / 5$ ha de citrus (heredadas del abuelo) pero no se les da cuidado, venden la fruta para jugo.

La chacra fue comprada por el abuelo del productor en el año 1957 y era citrícola en sus comienzos "pero daba apenas para vivir" (Carlos Huerta Chajarí). El productor comenzó la huerta en ese predio hace 40 años solo y luego se sumó una de sus hermanas y su familia. Actualmente, trabajan las dos familias y contratan a un empleado cuando es necesario carpir la tierra.

En el predio vive la familia, los abuelos (que ya no trabajan) y la familia de la hermana del productor. Se fueron capitalizando a partir de la producción hortícola. Crían algunos animales de granja (cerdos y vacas) para consumo familiar y para mostrarles a los turistas. "Cuando los

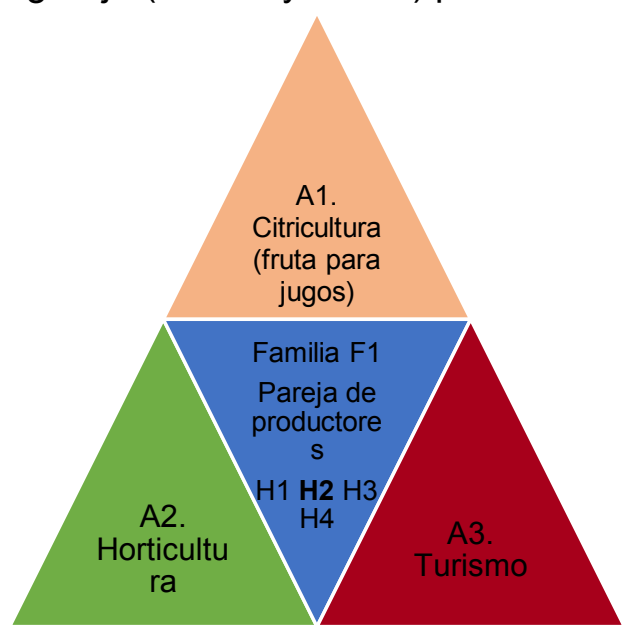
turistas quieren ven los animales se los lleva, ahora estamos poniendo 15 ovejas también". (Felipe, hijo Huerta Chajarí).

A los turistas ofrecen el alojamiento en el campo, la posibilidad de cosechar su propia verdura, recorrer los campos y se les regala frutas y verduras de estación durante los días de pernocte allí. No se les ofrece desayuno pero se les deja una canasta con naranjas de regalo.

La familia cuenta con tres actividades de generación de ingresos: citricultura (venta de frutas para jugo), horticultura y turismo. 


\section{B.1.2 Recursos de la familia ${ }^{48}$}

\begin{tabular}{|c|c|}
\hline & $\begin{array}{l}\text { Es un sistema netamente familiar. Trabajan la pareja de productores y uno de } \\
\text { los hijos, la hermana del productor, su esposo y una hija. Los hijos que estudian en } \\
\text { el nivel secundario se suman en sus ratos libres. } \\
\text { Todas las mañanas cosechan (todos) y por la tarde realizan el reparto. A los } \\
\text { animales los cuidan el hijo y el tío, dos veces al día les dan de comer sin demandar } \\
\text { mucho tiempo. A los cítricos no les dan importancia, la fruta se lleva a una fábrica } \\
\text { de jugos de la zona. } \\
\text { En turismo trabaja solamente la familia del productor y productora, con una } \\
\text { participación muy activa de uno de sus hijos. El otro que estudia en Concordia } \\
\text { se suma los fines de semana largos y vacaciones colaborando al igual que la hija } \\
\text { mayor que estudia en secundario. } \\
\text { Tienen repartidas las tareas al interior de la familia para organizar mejor los } \\
\text { tiempos entre las dos actividades: } \\
\text { "A los turistas los atendemos más mi marido y yo. Mi hijo está en la huerta". (Analia } \\
\text { Huerta Chajarí). } \\
\text { "Todos sabemos todo pero cada uno tiene su puesto. Lo que está bien } \\
\text { definido es: a la página y reservas la maneja mi papá. Limpian mamá y mi } \\
\text { hermana. Yo corto el patio y todo lo que es el parque" (Felipe, hijo Huerta } \\
\text { Chajarí). } \\
\text { "Si no está mi mamá y hay que limpiar una cabaña lo hacemos nosotros, si no está } \\
\text { mi papá y hay que contestar, lo sé hacer también, pero para que haya uno que } \\
\text { sepa bien cuántas cabañas están ocupadas, etc, nos organizamos asi". (Felipe, } \\
\text { hijo Huerta Chajarí). } \\
\text { Como al reparto lo realiza la pareja diariamente desde las } 16 \text { hs en adelante, si } \\
\text { llegan turistas los atiende el hijo. } \\
\text { Respecto a alguna tarea netamente femenina se refiere el productor: } \\
\text { "los toquecitos últimos, los detalles (decoración) son de ella (por la esposa). El } \\
\text { hombre es hombre". (Carlos Huerta Chajarí). "Me encanta hacerlo". (Analía Huerta } \\
\text { Chajarí). } \\
\text { La toma de decisiones se da en familia. "Se discute, sobre todo el tema del } \\
\text { turismo porque lo otro está encaminado. Hay discusiones pero todo arreglable". } \\
\text { (Carlos Huerta Chajari). }\end{array}$ \\
\hline $\begin{array}{l}\text { Recursos } \\
\text { físicos, } \\
\text { materiales } \\
\text { naturales }\end{array}$ & $\begin{array}{l}\text { Poseen } 41 \text { ha, } 9 \text { en producción y } 4 / 5 \text { ha de citrus. En su trayectoria han ido } \\
\text { invirtiendo en tecnología para el manejo de la huerta. } \\
\text { "Los tractores son viejos pero el tema riego por aspersión se empezó en el } 98 \text { y se } \\
\text { notó el cambio. Antes teníamos pero era desplazable de un lado para el otro, } \\
\text { después que pusimos los caños fijos bajo tierra fue un antes y un después". (Carlos } \\
\text { Huerta Chajarí). } \\
\text { Esta tecnología "facilitó el riego, la continuidad y nos permitió aumentar la } \\
\text { producción". (Carlos Huerta Chajarí). Se prepara la tierra con abono de pollo que } \\
\text { se compra y algo de fertilizante (nitrógeno o potasio). } \\
\text { La inversión en las cuatro cabañas de madera totalmente equipadas para seis } \\
\text { personas con las que cuentan se hizo a partir del ingreso de la huerta. }\end{array}$ \\
\hline & $\begin{array}{l}\text { La familia no ha pedido créditos en su haber. Todo lo construido lo han hecho } \\
\text { gracias al trabajo hortícola. } \\
\text { "Damos el paso seguro". (Analía Huerta Chajarí). } \\
\text { Según los entrevistados, el principal ingreso económico es la huerta. } \\
\text { "A hoy el ingreso es un } 90 \% \text { de la huerta, pero en verano un } 50 \text { y } 50 \text { ". (Felipe, hijo } \\
\text { Huerta Chajarí). } \\
\text { "No hay una cuenta exacta porque la luz por ejemplo que es uno de los gastos } \\
\text { principales está todo junto". (Analía Huerta Chajarí). }\end{array}$ \\
\hline
\end{tabular}

\footnotetext{
${ }^{48}$ En el cuadro se utilizan colores determinados para resaltar algunos conceptos que luego son recuperados en un esquema conceptual. Los recursos humanos son referidos en color rojo; los físicos, materiales y naturales en naranja; los recursos económicos en violeta; los sociales en azul y los recursos identitarios en verde.
} 


\begin{tabular}{|c|c|}
\hline $\begin{array}{l}\text { Recursos } \\
\text { sociales }\end{array}$ & $\begin{array}{l}\text { La familia utiliza sus redes sociales y de trabajo para dar a conocer la nueva } \\
\text { actividad que desarrollan en el predio, ya que son muy conocidos en la zona por } \\
\text { su producción hortícola. } \\
\text { A la vez han pertenecido a dos grupos Cambio Rural, uno hortícola y otro de } \\
\text { turismo, que además de ser un espacio de trabajo compartido, de formación y de } \\
\text { intercambio de conocimientos técnicos y experiencias es un ámbito social, de } \\
\text { encuentro y confianza. }\end{array}$ \\
\hline $\begin{array}{l}\text { Recursos } \\
\text { identitarios }\end{array}$ & $\begin{array}{l}\text { La familia demuestra sentir mucho orgullo por su trayectoria como productores } \\
\text { hortícolas, destacan que gracias a esa actividad se han capitalizado y logrado todo } \\
\text { lo que tienen. } \\
\text { "Cuando arrancamos con las cabañas yo les dije a los dos no descuidemos la } \\
\text { huerta porque eso es lo que nos dio todo lo que tenemos". (Analía Huerta Chajarí). } \\
\text { "Nosotros somos como somos, dice el hijo, si les gusta bien, y si no, no vendrán } \\
\text { más". } \\
\text { Al ser de la zona, haber nacidlo allí, les da un sentido de pertenencia al lugar } \\
\text { y un cariño por su terruño, que pretenden dar a conocer a través del turismo, } \\
\text { además de aquello a lo que se dedican y saben hacer históricamente: } \\
\text { "Mostrarle lo tuyo, lo que tenés, lo que hacés. A la gente le gusta que los lleves a } \\
\text { hacer lo que haces comunmente". (Felipe, hijo Huerta Chajarí). } \\
\text { "Hay dias que nosotros estamos cosechando y llega un turista con el hijo y la } \\
\text { cámara de fotos y se queda toda la mañana con nosotros, charlando, preguntando". } \\
\text { (Carlos Huerta Chajarí). } \\
\text { Cuando se les consultó qué tenían en común las familias de la zona que hacen } \\
\text { turismo, el hijo contestó: "Yo creo que lo económico no es lo que más pesa, a } \\
\text { lo mejor es que gusta recibir bien a la gente, que la gente se encariñe con el } \\
\text { lugar y vea nuestra forma de ser". (Felipe, hijo Huerta Chajarí). } \\
\text { "Si lo hacés solamente por dinero, no va". (Carlos Huerta Chajarí). }\end{array}$ \\
\hline $\begin{array}{l}\text { Recursos } \\
\text { territoriales }\end{array}$ & $\begin{array}{l}\text { Han integrado grupos cambio rural hortícola y de turismo rural. Destacan el rol } \\
\text { técnico y formativo de estas experiencias. } \\
\text { Respecto al grupo de turismo, } \\
\text { "A nosotros trabajar en el grupo nos ayudó para conocer la actividad, cómo } \\
\text { trabajar". (Carlos Huerta Chajarí). "El grupo de turismo nos sirvió más que el } \\
\text { hortícola porque uno ya venía organizado, se probaron algunas cosas". (Analía } \\
\text { Huerta Chajarí). } \\
\text { También les posibilitó una mayor interacción con otras familias de la zona. A } \\
1000 \text { metros de sus cabañas hay un prestador de turismo que integra también el } \\
\text { grupo y a pesar de ser vecinos hace años, no se conocían. Hoy con esta familia } \\
\text { tienen una relación muy cercana y de confianza. } \\
\text { "Los saludábamos pero no sabiamos ni cómo se llamaban". (Analía Huerta } \\
\text { Chajarí). } \\
\text { "Cuando ellos están llenos los mandan para acá, y cuando nosotros estamos llenos } \\
\text { los mandamos de un hombre que hizo dos cabañas de madera como las nuestras". } \\
\text { (Felipe, hijo Huerta Chajarí). } \\
\text { Han tenido el asesoramiento técnico de INTA. } \\
\text { "Si aparece alguna peste o algo, tenemos el asesoramiento del INTA, siempre los } \\
\text { buscamos". (Carlos Huerta Chajarí). } \\
\text { Es una familia que se relaciona mucho con otras familias del lugar. La gente de la } \\
\text { zona los reconoce y les envía gente. } \\
\text { "De la estación de servicio, del taller los mandan para acá". (Carlos Huerta Chajarí). } \\
\text { También tienen mucho contacto con la oficina de turismo de la municipalidad. } \\
\text { Este organismo conformó un grupo de whatsapp para ir chequeando la } \\
\text { disponibilidad de alojamiento, fundamentalmente los fines de semana largo. } \\
\text { "Una vez a la semana te preguntan si hubo gente, si no tienen folletería nos piden, } \\
\text { nos llaman que llevemos a termas". (Analía Huerta Chajarí). }\end{array}$ \\
\hline
\end{tabular}




\section{B.1.3 Trayectoria familiar}

La chacra de 41 ha fue adquirida por el abuelo paterno del productor en 1957. Era destinada a producción citrícola y tenía algunos animales para consumo familiar.

El productor comenzó con una huerta familiar, "y con lo que sobraba la llevaba a un negocio de Chajarí en bicicleta". (Carlos Huerta Chajarí).

"Cuando las hermanas vieron que la huertita empezó a dar, lo empezaron a ayudar. Así empezó la huerta y siguió creciendo hasta hoy que se cultivan 9/10 ha cuando arrancó con 20x20". (Analía Huerta Chajarí).

La pareja está casada hace 27 años, y desde ese momento viven allí, en el predio.

"Había una casa vieja, vivíamos todos ahí, después empezamos haciendo la casa, comprando herramientas, comprando vehículo, no había nada". (Analía Huerta Chajarí).

Se fueron capitalizando y creciendo en producción. Hace un año y medio construyeron las cuatro cabañas para turismo. El hijo mayor estudia fuera de la ciudad, el otro trabaja con ellos y las dos hijas aun van a la escuela. No han manifestado pasar por momentos críticos que hayan puesto en situación de riesgo la producción, sí fenómenos climáticos que la condicionan y determinan.

\section{B.1.4 Emergencia del turismo}

Hay tres cuestiones centrales que destacar en torno a los objetivos y motivaciones de la familia.

- Se incorpora el turismo como una alternativa de diversificación a la actividad central. "Por ahí vienen malos, dos o tres meses con la huerta y fuiste". (Carlos Huerta Chajarí).

- Fue pensada a futuro como una actividad a la que pudiesen dedicarse la pareja pero pensando también en la incorporación de los hijos.

"El tema de las cabañas surgió porque los dos hijos mayores son varones y en el campo cuando los varones no estudian, lo más normal es que se queden a trabajar en el campo, entonces hicimos las cabañas y hay trabajo para todos". (Analía Huerta Chajarí). "Nosotros ya tenemos 50 y pico y el trabajo de la huerta no es para viejos, esto es más para nuestro futuro". (Analía Huerta Chajarí).

- Se presenta un elemento de oportunidad que fue claramente vislumbrado por la familia: la existencia del complejo termal a 1000, 1200 metros del predio ha sido un estímulo para pensar en la actividad.

"El día que salió agua caliente en las termas Carlos (marido) dijo, cuando podamos vamos a hacer cabañas para alquilar. Y no va a pasar mucho que vamos a hacer un parque, entonces el día que podamos hacer una cabaña, los árboles ya van a estar grandes. Y salió al revés, hicimos las cabañas y después pusimos los árboles!". (Analía huerta Chajari).

\section{B.1.5 Objetivos, decisiones y estrategias puestas en marcha}

La familia actualmente tiene claridad respecto a su apuesta al turismo. Como proyecto a 5/6 años piensan construir más cabañas, un quincho, una piscina y una proveeduría para generar mayor rentabilidad y que un miembro de la familia se dedique exclusivamente a esta actividad.

La productora quedaría más a cargo del complejo de aquí a unos años, cuando logren avanzar con las inversiones mencionadas. Esto implicaría una mayor demanda de tiempo y atención, inversión, pero un ingreso más fuerte de la actividad al sistema.

"A futuro queremos tener 10 cabañas con una proveeduría, una pileta, todo instalado bien y que una persona se dedique solo a eso. Seguramente ella quede a cargo (Analía Huerta Chajarí)". (Carlos Huerta Chajarí)."Así es medio poco para llevar una persona a trabajar solo 
en las cabañas, son pocas las cabañas y por ahí tenés que estar allá, tenés que dedicarte". (Carlos Huerta Chajarí).

Piensan seguir sosteniendo la huerta pero sin grandes inversiones y cambios, porque es una actividad rentable, a la que están acostumbrados y que les agrada hacer. No es un trabajo "pesado" pero les insume tiempo de dedicación, por eso la productora quiere probar alternativas que le permitan ahorrar tiempo de trabajo en esta actividad.

"Suficiente con esto. A lo mejor a la huerta podemos poner algún invernáculo para reforzar o más tecnología u otra manera de trabajar, porque nosotros trabajamos así hace 30 años".

"El trabajo en la huerta siempre me gustó, y el reparto, los clientes que tengo son un espectáculo. Y gracias a Dios nos sobran clientes". (Carlos Huerta Chajarí).

"Quiero sacarme tiempo en la huerta, quiero probar hacer algún ensayo con otra técnica. A lo mejor tengo más costo pero más rinde o menos tiempo". (Analía Huerta Chajarí).

"No es un trabajo muy pesado pero requiere mucho tiempo". (Felipe, hijo Huerta Chajarí).

En turismo tienen la estrategia de manejarse con precios accesibles para hacer conocer el establecimiento. Les gusta el turismo, el contacto con la gente, se sienten valorados y reconocidos por incluir esta actividad.

"Nos manejamos con un precio bajo para dar a conocer el lugar, como promoción. Hoy tenemos esta prioridad, barato y que la gente nos conozca". (Felipe, hijo Huerta Chajarí).

"Es un público que elige esto, no es que a cualquier persona le va a gustar, ya viene sabiendo que es en el campo. Hay gente que quiere esto, tranquilidad, estar solos, no hacer fila para nada, es un público distinto". (Analía Huerta Chajarí).

\section{B.1.6 Vinculación del sistema familia-explotación con la actividad de turismo rural $^{49}$}

\begin{tabular}{|c|l|}
\hline $\begin{array}{c}\text { Interacción producto } \\
\text { Explica el flujo de materia } \\
\text { prima de una actividad a } \\
\text { otra. }\end{array}$ & $\begin{array}{l}\text { En este caso hay un flujo de materia prima de la producción } \\
\text { primaria al turismo, pero se le agrega otro valor, esto es, a los } \\
\text { turistas se les permite tener la experiencia de cosechar con los } \\
\text { productores, se les regala la verdura que van a utilizar en los días que } \\
\text { permanezcan alojados en las cabañas, se les regala naranjas. La } \\
\text { producción se integra a la actividad turística, es parte del } \\
\text { recorrido y de la esencia de las cabañas que tienen vista a la } \\
\text { huerta. }\end{array}$ \\
\hline $\begin{array}{c}\text { Interacción recursos } \\
\text { movilización de un mismo }\end{array}$ & $\begin{array}{l}\text { La mano de obra de las actividades productivas es netamente } \\
\text { familiar. Hay dos familias dedicadas a la huerta pero solo la familia } \\
\text { recurso para varias } \\
\text { actividades. } \\
\text { organización en el que si bien todos pueden hacer todo, están } \\
\text { definidos los roles y momentos para cada actividad. Entienden al } \\
\text { turismo como una actividad complementaria. } \\
\text { Lejos de haber competencia hay una interesante integración } \\
\text { espacial, ya que, aunque distantes, las cabañas están ubicadas con } \\
\text { vista a la huerta. Está delimitado el espacio que serán en un futuro } \\
\text { otros servicios para el turismo. }\end{array}$ \\
\hline
\end{tabular}

\footnotetext{
${ }^{49}$ En el siguiente cuadro se enfatizan algunos conceptos utilizando colores que luego serán adoptados en el esquema conceptual que explica las interacciones de la actividad turística con el resto de las actividades del sistema. Así, con naranja se remarca la interacción entre productos de las distintas actividades; con rojo y azul la interacción de los recursos humanos y sociales; con verde la interacción patrimonial; con gris, la temporal; con violeta claro la interacción dada entre el ingreso y el sentido dado al trabajo, y con violeta oscuro, la interacción entre los ingresos que aportan las actividades al sistema.
} 


\begin{tabular}{|c|c|}
\hline & $\begin{array}{l}\text { Respecto a lo social, los contactos de la familia por su actividad } \\
\text { hortícola y su vinculación con las familias de la zona, estimuladas } \\
\text { también por su trabajo asociativo, colaboran al desarrollo de la } \\
\text { actividad turística. }\end{array}$ \\
\hline $\begin{array}{l}\text { Interacción patrimonial } \\
\text { La implementación } \\
\text { actividades simultáneas se } \\
\text { dan en torno al valor } \\
\text { intangible de un patrimonio }\end{array}$ & $\begin{array}{l}\text { La actividad turística, más allá del servicio de alojamiento } \\
\text { prestado, se basa en la historia familiar, en sus experiencias y en } \\
\text { la tarea a la que se dedican históricamente. El fuerte y aquello que } \\
\text { distingue esta propuesta de otros alojamientos de la zona es el perfil } \\
\text { productivo del predio y el saber y trabajo de la familia. Esto, que es } \\
\text { reconocido por los turistas y otros vecinos, es un elemento que genera } \\
\text { orgullo a la familia y los estimula a seguir invirtiendo y apostando por } \\
\text { el turismo. }\end{array}$ \\
\hline $\begin{array}{l}\text { Interacción temporal } \\
\text { Explica los procesos de } \\
\text { anticipación de un cambio } \\
\text { que está por venir, del } \\
\text { abandono o } \\
\text { implementación de una } \\
\text { nueva actividad }\end{array}$ & $\begin{array}{l}\text { Se da claramente en este sistema ya que la actividad turística } \\
\text { complementa a la actividlad hortícola en la temporada en la que } \\
\text { esta requiere menor intensidad de trabajo. "Justo cuando la huerta } \\
\text { se pone más complicada que es verano, es el fuerte del turismo", } \\
\text { explica Carlos (huerta Chajarí). } \\
\text { También en esta familia se pudo observar la visión del potencial que } \\
\text { vieron en el turismo, apenas se comenzó a trabajar en el complejo } \\
\text { termal. Ellos vislumbraron el desarrollo de la actividad y proyectaron la } \\
\text { inversión. }\end{array}$ \\
\hline $\begin{array}{l}\text { Interacción ingresol } \\
\text { sentido del trabajo } \\
\text { La combinación de } \\
\text { actividades permite asociar } \\
\text { actividades fuertemente } \\
\text { remuneradas con } \\
\text { actividades que no son } \\
\text { menos importantes pero } \\
\text { proveen otro tipo de } \\
\text { satisfacciones }\end{array}$ & $\begin{array}{l}\text { En este caso, es muy clara la relación de las actividades por el } \\
\text { ingreso que significa el turismo en temporada baja de producción } \\
\text { hortícola. Pero el turismo además reporta otras satisfacciones, } \\
\text { relacionadas al reconocimiento del otro de las tareas que } \\
\text { desarrolla la familia y al amor puesto en cada detalle. A la productora } \\
\text { este tipo de actividad al parecer le agrada más y es la que quedaría } \\
\text { más a cargo cuando terminen de proyectar el complejo completo. }\end{array}$ \\
\hline $\begin{array}{c}\text { Interacción ingreso } \\
\text { Se da cuando } 2 \text { o más } \\
\text { actividades aportan a los } \\
\text { ingresos totales disponibles } \\
\text { para la familia. }\end{array}$ & $\begin{array}{l}\text { Aun es más importante el ingreso de la producción hortícola, pero } \\
\text { a futuro esperan que crezca la de turismo requiriendo una mayor } \\
\text { inversión. En temporada estival según dichos de los productores es } \\
50 \text { y } 50 \text {. }\end{array}$ \\
\hline
\end{tabular}

\section{B.1.7 Impacto del turismo en el sistema productivo}

Hay una integración de la actividad turística y productiva. Se complementan desde el punto de vista de ingresos y espacial. La huerta es la base del alojamiento.

Moviliza los mismos recursos humanos pero en el caso del turismo solamente interviene la familia de los productores centrales del caso, o sea que es una tarea exclusiva de ellos.

Son centrales los saberes de la familia, sus rasgos identitarios y el patrimonio intangible en torno a la producción hortícola, que a la vez se visualiza como central para la identificación de la propuesta turística.

El turismo impacta a la vez en el sistema productivo. "En tiempos de vacaciones hay que cultivar menos porque tenés que estar muy metido con el turismo". (Felipe hijo Huerta Chajarí).

\section{B.1.8 Impacto del turismo en la familia, en las personas y en sus estilos de vida}

- El turismo ha generado modificaciones en los tiempos de la familia pero se pueden organizar. Son más actividades en las cuales distribuir los tiempos. 
"Es un despelote organizado, porque viste nosotros con la huerta venimos trabajando a full, implementamos esto y es algo más, tenés que abandonar un poco la huerta o buscar otros tiempos". "7:30 empezamos a trabajar en la huerta hasta las 12. Cortamos y empezamos 13:30, 13:45. Y después hacemos el reparto. Ellos dejan la cosecha como a las 18 hs". (Carlos Huerta Chajarí). "Ahí voy corto el paso, igual si hay que cortar antes dejo la huerta y voy. (Felipe, hijo Huerta Chajarí). "Si hay turistas se trata de estar por ahi por si necesitan algo". (Carlos Huerta Chajarí).

"No nos levantamos ni un minuto antes ni un minuto después, a lo mejor nos acostamos más tarde porque en turismo por ejemplo a alguien se le ocurrió llegar a las 3 de la mañana y en vez de llegar a las 3 llegó a las 5. A esas cosas no las teníamos pero lo otro, no nos vamos a levantar antes porque si no terminás siendo esclavo del trabajo". (Analía Huerta Chajarí).

"Tratamos de seguir con lo que siempre se hizo, si ellos hacen deporte que lo sigan por ejemplo". (Analía Huerta Chajarí).

- Aunque el tiempo que le dedican al turismo es relativo, son conscientes de que su presencia y dedicación es el valor agregado que deja más conformes a los turistas.

"Depende de cómo lo atendés, si vos dejás que estén ahí nomás, pero si uno va le ofrece naranjas, verduras, cuanto más le ofrecés más tiempo te lleva". (Felipe, hijo Huerta Chajarí).

"A la gente le gusta que vos estés, que converses un rato, que les cuentes cómo vive la gente, que los lleves a recorrer la huerta, que coseches la verdura con ellos. Eso te demanda un poco de tiempo". (Analía Huerta Chajarí). "A la gente le gusta eso y va a volver por eso". (Felipe, hijo Huerta Chajarí).

- La incorporación del turismo impactó sobre los tiempos de ocio de la familia, salidas y vacaciones, aunque tienen claridad respecto a que es momentáneo.

"Dificultó algunos tiempos los fines de semana, la salida en familia, las vacaciones en familia". (Analía Huerta Chajarí).

"No podemos vacacionar en tiempos de vacaciones". (Felipe, hijo Huerta Chajarí)."Para nosotros era fundamental salir juntos, papá, mamá y los cuatro gurises". (Analía Huerta Chajari).

"Eso está cada vez más complicado porque uno está un día el otro está otro. Además vendimos la trafic, pero la idea es comprar algo para salir en familia. Saldremos en temporada baja que aquí no hay nadie o casi nadie". (Carlos Huerta Chajarí).

"Sabemos que lo vamos a recuperar en algún momento, no sabemos cuándo ni cómo, pero no nos desespera porque sabemos que es un tiempo. No sé cómo nos vamos a arreglar más adelante, a lo mejor viajemos no en familia, saldremos con las nenas y ellos aparte" (refiriéndose a los hijos varones). (Analía Huerta Chajarí). "Serán uno o dos años". (Carlos Huerta Chajarí).

- El turismo les aporta mayor apertura mental y cultural.

"A mí me encanta recibir gente, conversar con la gente" (Carlos Huerta Chajarí).

"Es como innovador para nosotros este trabajo. Te abre un montón la mente, eso de tener que trabajar en la huerta, con la tierra y venir a charlar con la gente y ver que la gente esté contenta, es lindo". (Analía Huerta Chajarí).

- Sienten reconocimiento por las tareas que dedican y eso refuerza su autoestima

"Es placentero abrir la páginas y ver que te están agradeciendo por la fruta que les dejaste que a nosotros no nos cuesta nada". (Analía Huerta Chajarí). 


\section{B.1.9 Percepción del futuro en relación a los hijos y en relación a su resguardo de ingresos \\ - Si bien visualizaron el turismo como una alternativa de futuro para los padres, piensan en un proyecto familiar, que involucre más a los hijos varones, según sus dichos.}

"A mí me gustaría que se queden en el campo". (Carlos Huerta Chajarí).

"Por ahora me imagino acá, me gustan las dos cosas, cuando te cansas de una vas a la otra. Si es por los ingresos me quedo con la huerta pero a una vista futura me quedo con las cabañas, es más tranquilo y si pensás en todas las cabañas listas, alquiladas es mejor (económicamente). Hasta ahora mis planes son quedarme acá y trabajar". (Felipe, hijo Huerta Chajarí).

"Todo es para ellos en definitiva". (Analía Huerta Chajarí).

- También es comprendido como una actividad que requiere menos esfuerzo físico para dedicarse la pareja a futuro.

"Nosotros pensamos que estamos envejeciendo y teníamos que tener algo un poco más aliviado, un poco más liviano. Pero como siempre se trabajó en familia, uno lo piensa para todos porque también si ellos se quedan a trabajar acá, bueno, ahí tenés dos cosas". (Analía Huerta Chajarí). 
Ilustración 5- Esquema del sistema familia/explotación Caso 1

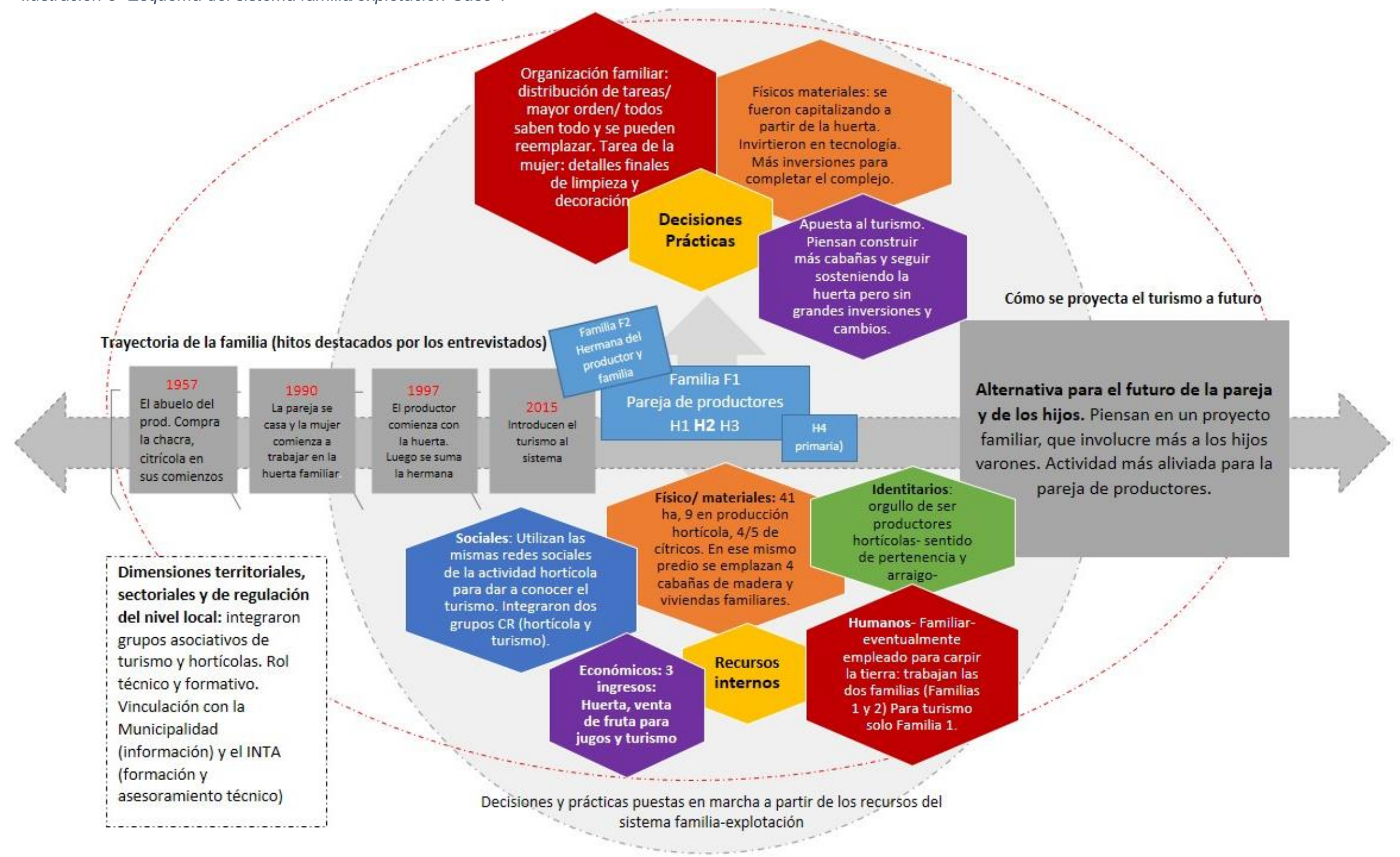


Ilustración 6- Esquema de interacciones de las actividades dentro del sistema Caso 1

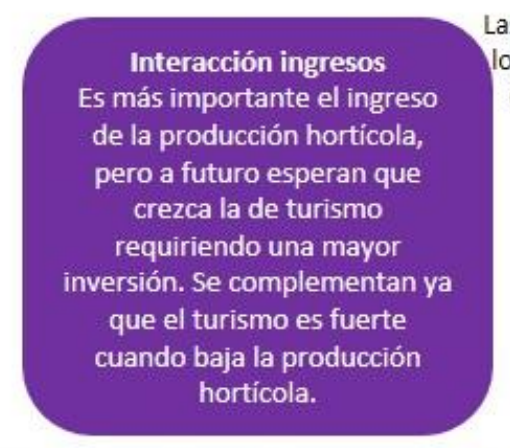

El símbolo + representa la importancia relativa del ingreso al sistema de cada actividad

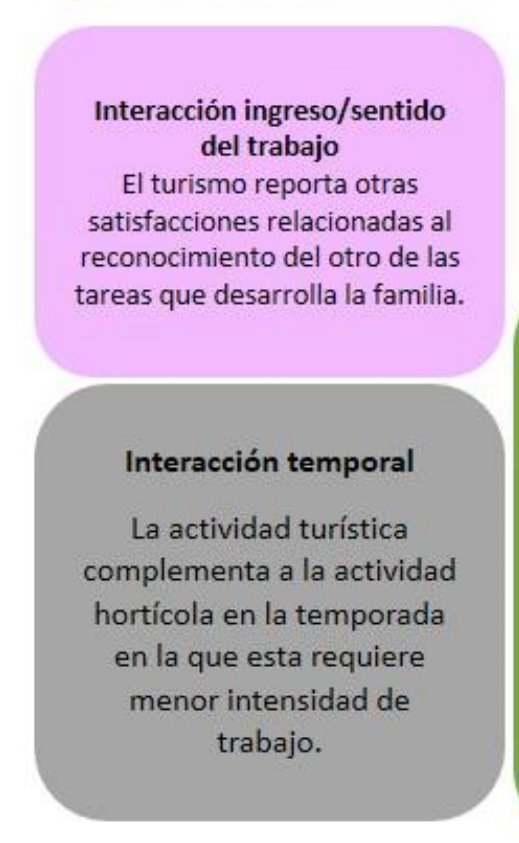

Las flechas del esquema central ejemplifican

stipos de interacción del sistema familiaexplotación, con sus respectivos colores
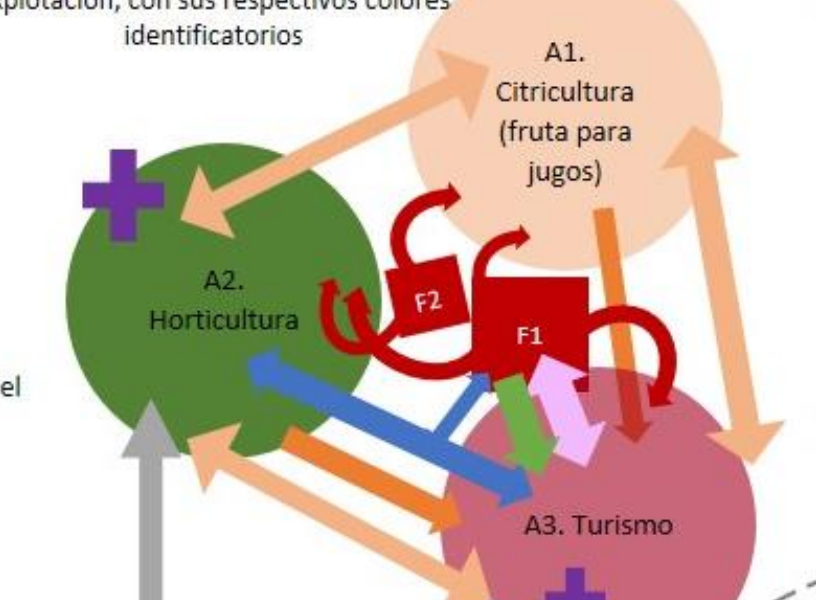

A3. Turismo

Interacción patrimonial Más allá del servicio de alojamiento prestado, se basa en la historia familiar, en sus experiencias y en la tarea a la que se dedican históricamente. El fuerte y aquello que distingue esta propuesta de otros alojamientos de la zona es el perfil productivo del predio y el saber y trabajo de la familia.

\section{Interacción de productos}

Flujo de materia prima de la producción primaria al turismo, pero se le agrega otro valor, esto es, a los turistas se les permite tener la experiencia de cosechar con los productores, se les regala la verdura que van a utilizar en los dias que permanezcan alojados en las cabañas, se les

$$
\text { regala naranjas. }
$$

\section{Integración espacial} Aunque distantes, las cabañas están ubicadas con vista a la huerta. Está delimitado el espacio que serán en un futuro otros servicios para el turismo.

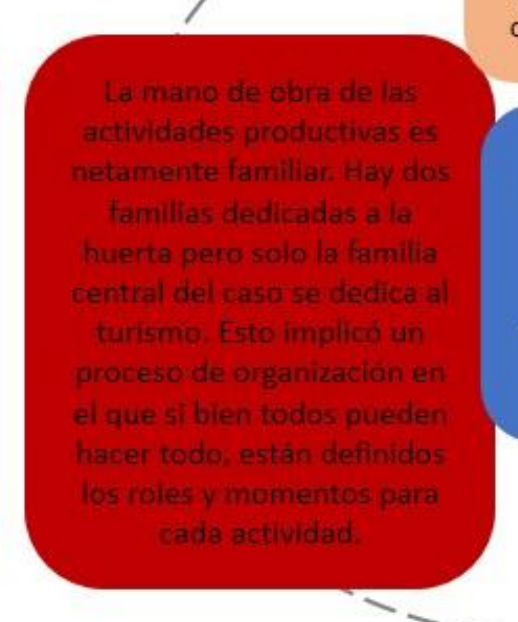
$-\ldots$

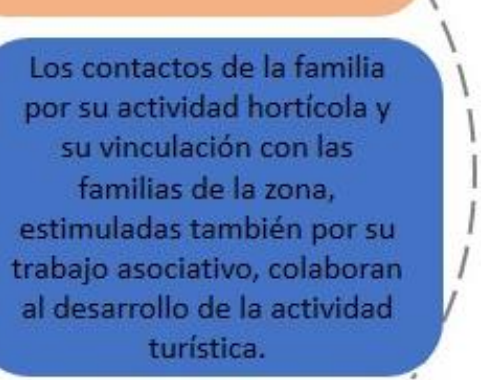

Tipo de interacciones entre recursos. Los colores utilizados responden al recurso movilizado (humano, en rojo; social, en azu; espacial, física, material en naranja claro) 


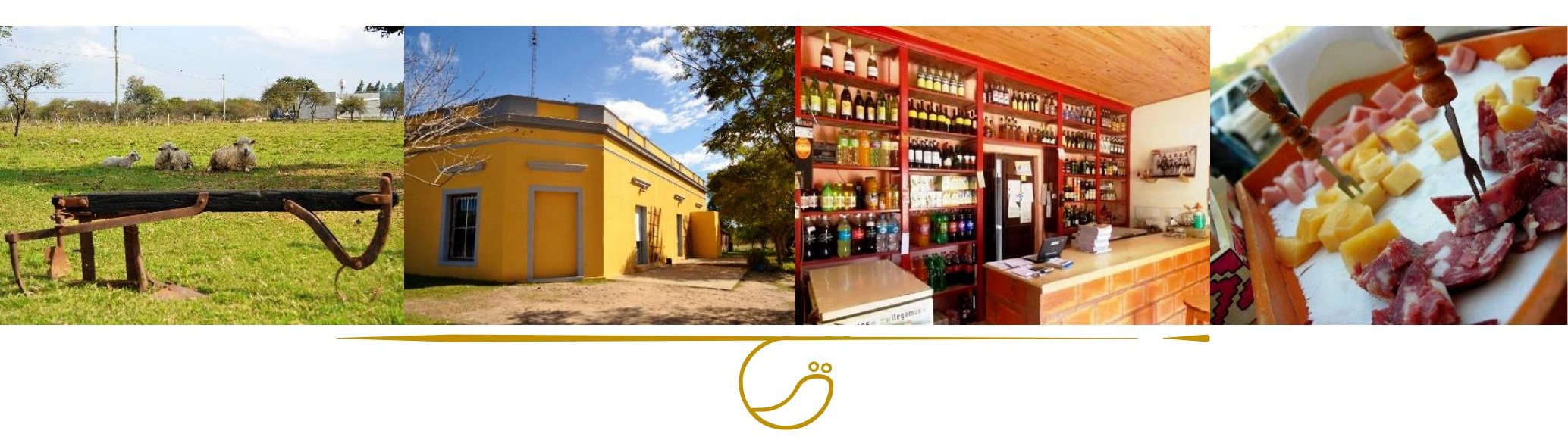

\section{"Un almacén que es más que despensa"}

"El turista viene y gasta, te compra lo que son los regionales, seguro te va a llevar salame, queso y miel porque sabe que es mercadería casera". (Juan, dueño del almacén). 


\section{B. 2 Caso 2 - UN ALMACÉN QUE ES MÁS QUE DESPENSA}

Este caso en particular representa un Sistema de Actividades cuya gestión no está a cargo de productores agropecuarios pero que ha integrado redes asociativas junto a otros representantes de la comunidad. En esta experiencia los hijos presentan un activo involucramiento en las actividades de generación de ingresos del sistema.

\section{B.2.1 Presentación general}

Pareja de comerciantes de 49 y 47 años con tres hijos (dos varones de 14 y 19 y una mujer de 21). Manejan un almacén de ramos generales que la familia paterna compró hace 45 años emplazado en un paraje en las afueras de Chajarí. Se ubica a 800 metros del complejo termal de Chajarí, atractivo muy fuerte en la zona y desde donde recomiendan la propuesta.

El almacén de campo funciona como una despensa, se venden productos de todo tipo además de productos regionales. Funciona también un bar en el que ofrecen picadas tanto para los lugareños como para turistas.

Se encuentra en un predio de 4 ha donde además se encuentra la vivienda familiar y una granja con animales. Tienen $25 / 30$ ovejas, vacas, $25 / 30$ gallinas, chajá y avestruces. Son para consumo familiar y a los huevos los venden en el almacén. Eventualmente venden algún cordero. En realidad los padres siempre tuvieron animales pero ellos no los toman como una actividad productiva que les genere un ingreso.

"Mi padre también tenía chanchos, hacía salames, mi madre ordeñaba. Cuando faltaron ellos no hicimos más, él era el que más sabía". (Juan, dueño del almacén).

Es un negocio netamente familiar. No venden productos de elaboración propia a excepción del pan y algún que otro producto de panificación que elabora el hijo del medio que estudia gastronomía. Los productos regionales (salame, miel, quesos, dulce de leche) los compran a productores de la colonia.

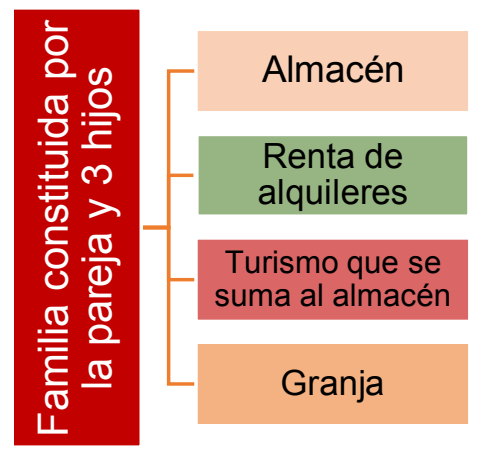

Abren todos los días con excepción del domingo, de $7: 30$ a $12: 15 / 30$ hs y de $15: 15$ a 21 hs. Los fines de semana largos son los que reciben más cantidad de turistas.

Como actividades de generación de ingresos se pueden mencionar: el almacén, el turismo que se incorpora al almacén y el alquiler mensual de departamentos. Además tienen animales para consumo propio que eventualmente pueden generar alguna venta en el almacén. 


\section{B.2.2 Recursos de la familia ${ }^{50}$}

\begin{tabular}{|c|c|}
\hline $\begin{array}{l}\text { Recursos } \\
\text { humanos }\end{array}$ & $\begin{array}{l}\text { En el almacén trabaja toda la familia, fundamentalmente la pareja. Los } 3 \\
\text { hijos colaboran, más los varones. Todos hacen todo, incluso comparten } \\
\text { las tareas domésticas. } \\
\text { "Lo que hay que hacer, se hace entre todos. Si hay que completar las } \\
\text { góndolas, despachar, tanto en la despensa como en el bar". (Juan, dueño del } \\
\text { almacén). } \\
\text { Una tarea específica del marido es hacer las compras, el contacto con los } \\
\text { proveedores, el resto se comparte. } \\
\text { No contratan empleados. Las decisiones se discuten en el seno de la } \\
\text { familia. }\end{array}$ \\
\hline $\begin{array}{l}\text { Recursos físicos } \\
\text { materiales y } \\
\text { naturales }\end{array}$ & $\begin{array}{l}\text { Construye ron } 2 \text { casas que en un principio fueron pensadas para turismo pero } \\
\text { como "no hicieron mucha propaganda". (Juan, dueño del almacén), las } \\
\text { terminaron alquilando mensualmente. Han ampliado el almacén, modernizado } \\
\text { e invierten en mercadería y en arreglos. }\end{array}$ \\
\hline $\begin{array}{l}\text { Recursos } \\
\text { económicos }\end{array}$ & $\begin{array}{l}\text { La familia vive del almacén. Han reinvertido en el mismo espacio } \\
\text { agrandándolo, construyendo un salón para separar el bar de la despensa, } \\
\text { modernizaron heladeras y aberturas. Con parte de las ganancias construyeron } \\
\text { dos inmuebles para alquiler. } \\
\text { El turismo implica un ingreso más, son nuevos clientes del almacén. } \\
\text { Aunque la mayoría de los clientes son de la colonia, funciona como la } \\
\text { despensa de la zona. } \\
\text { "La ganancia que te da es para vivir, no te da pata invertir mucho, por eso me } \\
\text { incliné por los departamentitos, ahora estoy arrancando otro". (Juan, dueño } \\
\text { del almacén). }\end{array}$ \\
\hline Recursos sociales & $\begin{array}{l}\text { Al conformar el grupo de turismo rural con otros prestadores de } \\
\text { alojamiento muy cercanos, han logrado una relación personal de } \\
\text { confianza y recomendación. Cuando eran vecinos no tenían tanta relación } \\
\text { como a partir de los grupos. Estos dueños de cabañas, cercanos, los } \\
\text { recomiendan a los turistas para sus compras. }\end{array}$ \\
\hline $\begin{array}{l}\text { Recursos } \\
\text { identitarios }\end{array}$ & $\begin{array}{l}\text { La posibilidad de narrar la historia del lugar refuerza la identidad familiar } \\
\text { y de la colonia. Además, genera orgullo por lo propio y por lo construido } \\
\text { históricamente. "Vienen y nos dicen uy mirá... estos almacenes no se ven } \\
\text { más! Esa gente, cuando son así te da gusto porque son gente dada y sencilla. } \\
\text { Nos da alegría". (Juan, dueño del almacén). } \\
\text { Ese reconocimiento es un estímulo. "Te dan ganas de seguir con lo que estás } \\
\text { haciendo". (María, dueña del almacén) "A la parte de la historia la cuenta mi } \\
\text { papá, si lo dejás puede estar una hora y pico conversando". (Pedro, hijo, } \\
\text { almacén Chajarí). } \\
\text { El haber nacido en el lugar les otorga un fuerte sentido de pertenencia y } \\
\text { amor por su lugar. "Nosotros vivimos y crecimos en el campo. Esto no es } \\
\text { campo campo porque está el pueblo cerca". (María, dueña del almacén). } \\
\text { "Para el que se crio acá, no hay mejor lugar que este. Por más de que la } \\
\text { ciudad sea linda y tenga todo lo que quieras, no es como el lugar en que } \\
\text { naciste y te criaste". (Juan, dueño del almacén). } \\
\text { "Los turistas ven que estamos tranquilos, cuántos vienen y nos dicen qué lindo } \\
\text { lugar, qué paz, cómo me gustaría tener una casita acá". (Juan, dueño del } \\
\text { almacén). }\end{array}$ \\
\hline $\begin{array}{l}\text { Recursos } \\
\text { territoriales }\end{array}$ & $\begin{array}{l}\text { Se da una importante vinculación con los vecinos y otros productores } \\
\text { de la colonia, dada por la actividad comercial a la que se dedican hace } \\
\text { tiempo. Además, compran hace años productos elaborados por gente de } \\
\text { la zona y dan garantía de la calidad y el sabor. } \\
\text { La cercanía a las termas y la ubicación privilegiada, a metros de la RN } 14 \\
\text { son elementos que han movilizado la incorporación de los turistas. }\end{array}$ \\
\hline
\end{tabular}

\footnotetext{
${ }^{50}$ En el cuadro se utilizan colores determinados para resaltar algunos conceptos que luego son recuperados en un esquema conceptual. Los recursos humanos son referidos en color rojo; los físicos, materiales y naturales en naranja; los recursos económicos en violeta; los sociales en azul y los recursos identitarios en verde.
} 


\begin{tabular}{|l|l|}
\hline & $\begin{array}{l}\text { Además, a partir de la integración de un segundo grupo Cambio Rural de } \\
\text { turismo, el vínculo con el municipio y con el complejo termal (que es } \\
\text { municipal) es más fluido. } \\
\text { "Los turistas vienen por el plano que les dan en las termas. Vienen a conocer, } \\
\text { algunos compran, otros vienen, miran y se van". (Juan, dueño del almacén). } \\
\text { El grupo Cambio Rural orientado al turismo rural que se conformó en la } \\
\text { zona fue un impulso para el desarrollo del turismo rural. }\end{array}$ \\
\hline
\end{tabular}

\section{B.2.3 Trayectoria familiar}

La pareja se conoce hace 30 años. Ella nació en Los Conquistadores, pero su abuela vivía en la zona y se fue a estudiar allí. El marido nació en la Colonia San Ramón, a $30 \mathrm{~km}$ del lugar. Hace 25 años que están casados. Los padres compraron el almacén hace $\mathbf{4 5}$ años y luego se lo heredaron a ellos.

En el 2004 se hace cargo la pareja del almacén.

En la trayectoria no manifiestan grandes crisis ni contratiempos, hablan de altibajos normales del comercio, épocas en las que les fue mejor y otras no tanto.

Abrieron al turismo en el 2012, cuando fueron convocados a integrar un primer grupo Cambio Rural de turismo rural con otros actores de Chajarí y Villa del Rosario.

Aproximadamente, en el 2013 construyen el primer departamento, a los dos años el segundo y están en vías de construir un tercero.

\section{B.2.4 Emergencia del turismo}

En este punto se dan una serie de elementos vinculados a las oportunidades que ofrece el desarrollo del turismo en la localidad. Por un lado, se encuentran ubicados estratégicamente, a unos metros del complejo termal y próximos a la RN 14. Las termas han sido uno de los principales factores que impulsó el turismo en esa zona.

"Las termas son lo principal, fue el factor inicial para el desarrollo". (Juan, dueño del almacén).

Además, en la zona se conformó un grupo Cambio Rural orientado al turismo rural que los entrevistados destacan como un punto de partida.

"Vino gente de termas y el técnico a hablarnos para incorporaron en el grupo. Y nosotros dijimos que sí". (Juan, dueño del almacén).

Por otro lado, la relación con la oficina de Turismo de la Municipalidad que los suma a la oferta turística de la zona incentiva la actividad.

"Los turistas vienen por el plano que les dan en las termas. Vienen a conocer, algunos compran, otros vienen, miran y se van". (Juan, dueño del almacén).

Y por último, el turismo significa nuevos clientes y más ventas para el almacén.

"Es un beneficio que te deja, para nosotros es positivo". (Juan, dueño del almacén).

\section{B.2.5 Objetivos, decisiones y estrategias puestas en marcha}

Para la pareja, el turismo hoy representa un ingreso más al generado por el almacén y no altera el ritmo familiar ni del negocio. Lo han incorporado de manera natural. 
No se vislumbra la idea de cerrar el negocio ni de hacer grandes cambios. Es lo que han hecho, saben hacer y más allá de algún altibajo económico, les permite vivir bien.

"Fuimos creciendo con el turismo, se vende un $40 \%$ más. Los fines de semana largo y semana santa hay mucho movimiento". (Juan, dueño del almacén).

"Hasta ahora nunca se pensó en cerrar, se trabajó regularmente". (Juan, dueño del almacén). "Hubo altibajos pero siempre se trabajó". (María, dueña del almacén).

La idea es que el hijo más pequeño termine la escuela secundaria y trabaje con ellos. La hija tiene un retraso y hace otro tipo de tareas.

Uno de los hijos está estudiando para ser chef. Los padres piensan que el lugar tiene potencial para trabajarlo desde el punto de vista gastronómico, además evalúan el costo de salir a alquilar o comprar un local en el centro de la ciudad. La limitante estaría dada, para ellos, por estar lejos del centro.

Piensan en seguir reinvirtiendo. El jefe de la familia proyecta además de mantener el almacén, la construcción de casas de alquiler, para generar un ingreso más.

"A mí me gustaría seguir haciendo casitas para alquilar. Me gustaría que esas casas sean más para turismo, más que para alquiler mensual porque el alquiler mensual te arruina las casas. No es lo mismo. El turista además viene y te compra acá, es un negocio que te dejaría lindo". (Juan, dueño del almacén).

Los fines de semana largo son los momentos de mayor flujo de clientes, lo que implica prever una serie de acciones estratégicas para la atención a los posibles turistas que circulen por la zona.

"Ya se sabe que los turistas andan, entonces nos tenemos que organizar con la mercadería, compramos más regionales". (Juan, dueño del almacén).

"Se mantiene el mismo horario y el almacén continúa funcionando con la misma lógica de atención, por orden de llegada. Ya es muy normal que un fin de semana venis a comprar y haya muchos turistas". (Pedro, hijo, almacén Chajarí).

\title{
5.B.2.6 Vinculación del sistema familia-explotación con la actividad de turismo rural ${ }^{51}$
}

\author{
Interacción producto \\ Explica el flujo de materia \\ prima de una actividad a \\ No se evidencia una interacción importante entre productos de \\ diferentes actividades. Puede mencionarse la venta en el almacén de \\ huevos de producción propia.
}

otra.

\footnotetext{
${ }^{51}$ En el siguiente cuadro se enfatizan algunos conceptos utilizando colores que luego serán adoptados en el esquema conceptual que explica las interacciones de la actividad turística con el resto de las actividades del sistema. Así, con naranja se remarca la interacción entre productos de las distintas actividades; con rojo y azul la interacción de los recursos humanos y sociales y con naranja claro entre recursos físicos, naturales y materiales; con verde la interacción patrimonial; con gris, la temporal; con violeta claro la interacción dada entre el ingreso y el sentido dado al trabajo, y con violeta oscuro, la interacción entre los ingresos que aportan las actividades al sistema.
} 


\begin{tabular}{|c|c|}
\hline $\begin{array}{l}\text { Interacción recursos } \\
\text { Se explica a partir de la } \\
\text { movilización de un mismo } \\
\text { recurso para varias } \\
\text { actividades. }\end{array}$ & $\begin{array}{l}\text { El capital humano familiar es el sustento de las tareas de generación } \\
\text { de ingresos. No hay contratación de mano de obra extra. } \\
\text { No hay tareas específicamente asignadas para los miembros de la } \\
\text { familia sino que todos comparten las tareas, incluso las domésticas. } \\
\text { El rol más determinante es el del padre como portador de la historia } \\
\text { del lugar y del almacén, la madre también interviene pero en menor } \\
\text { medida. } \\
\text { Existe una transmisión de los saberes en el manejo del almacén que } \\
\text { los padres enseñan a los hijos, fundamentalmente en lo que es la } \\
\text { organización, la venta y el manejo del bar. } \\
\text { Los recursos físicos y materiales que se utilizan para la actividad } \\
\text { comercial y turística son los mismos, ya que se realizan en el mismo } \\
\text { espacio. } \\
\text { No se evidencia competencia por su uso por el momento. } \\
\text { Desde el punto de vista económico, las ganancias permiten } \\
\text { mantener a la familia y realizar algunas inversiones. Respecto a lo } \\
\text { social, la vinculación con otros actores de turismo ha incentivado a } \\
\text { la familia a promover el almacén para este sector, incluso a incorporar } \\
\text { productos regionales y realizar picadas. } \\
\text { El intercambio social y cultural es uno de los principales aportes que } \\
\text { genera la incorporación de los turistas a la dinámica comercial del } \\
\text { almacén. }\end{array}$ \\
\hline $\begin{array}{l}\text { Interacción patrimonial } \\
\text { La implementación } \\
\text { actividades simultáneas se } \\
\text { dan en torno al valor } \\
\text { intangible de un patrimonio }\end{array}$ & $\begin{array}{l}\text { El patrimonio arquitectónico y cultural representado en el almacén } \\
\text { es la base de la propuesta que ofrecen en la que la visita a un } \\
\text { almacén de ramos generales se combina con la posibilidad de comprar } \\
\text { productos artesanales de la zona, compartir algunas picadas, conocer } \\
\text { más de la historia y el intercambio con lugareños. El turismo pone en } \\
\text { valor el espacio, el patrimonio. } \\
\text { El turismo refuerza su identidad, familiar y comunitaria. } \\
\text { El reconocimiento de la tradición, el esfuerzo por resguardar el patrimonio } \\
\text { y continuar con la tarea dada por la mirada de alguien externo a la colonia } \\
\text { es un impulso a continuar con la tarea. }\end{array}$ \\
\hline $\begin{array}{c}\text { Interacción temporal } \\
\text { Explica los procesos de } \\
\text { anticipación de un cambio } \\
\text { que está por venir, del } \\
\text { abandono o } \\
\text { implementación de una } \\
\text { nueva actividad }\end{array}$ & $\begin{array}{l}\text { La anticipación no es a largo plazo. La familia prevé que los fines de } \\
\text { semana largo o los picos de turismo en la zona pueden reportar un } \\
\text { ingreso extra importante. Hablan de un } 40 \% \text {. Se anticipan a esta situación } \\
\text { y toman decisiones en función de lo anterior. }\end{array}$ \\
\hline $\begin{array}{l}\text { Interacción ingresol } \\
\text { sentido del trabajo } \\
\text { La combinación de } \\
\text { actividades permite asociar } \\
\text { actividades fuertemente } \\
\text { remuneradas con } \\
\text { actividades que no son } \\
\text { menos importantes pero } \\
\text { proveen otro tipo de } \\
\text { satisfacciones }\end{array}$ & $\begin{array}{l}\text { En este caso lo económico es determinante. Y en este sentido el } \\
\text { turismo aporta más ganancias, más movimiento comercial en el almacén, } \\
\text { además de movilizar otros aspectos vinculados al reconocimiento } \\
\text { social de mantener abierto un almacén de colonia al público, de manera } \\
\text { regular, la posibilidad de generar nuevas vinculaciones y apertura cultural. }\end{array}$ \\
\hline $\begin{array}{l}\text { Interacción ingreso } \\
\text { Se da cuando } 2 \text { o más } \\
\text { actividades aportan a los } \\
\text { ingresos totales disponibles } \\
\text { para la familia. }\end{array}$ & $\begin{array}{l}\text { El ingreso económico para la vida de la familia está dada por el } \\
\text { almacén y el alquiler de los departamentos que les aporta un ingreso } \\
\text { fijo mensual. La integración del turismo aporta un } 40 \% \text { más de } \\
\text { ventas (en temporada). Las ganancias permiten cumplir las necesidades } \\
\text { y expectativas de la familia y reinvertir en departamentos para alquiler. }\end{array}$ \\
\hline
\end{tabular}

\section{B.2.7 Impacto del turismo en el sistema productivo}

En este caso, no se trata de un sistema productivo agropecuario sino uno de base comercial. 
El turismo colabora, no es indispensable para el desarrollo del resto de las actividades. No compite sino que complementa fundamentalmente en términos de ingresos.

\section{B.2.8 Impacto del turismo en la familia, en las personas y en sus estilos de vida}

- La incorporación del turismo no ha generado un impacto mayor en la familia. Lo incorporaron a la rutina.

"Para mí sigue todo igual, me gusta el turismo. No tuve que dejar de hacer nada. Lo incorporamos, hasta la misma gente del barrio se acostumbró a los turistas porque por ejemplo llegan al almacén y se sigue atendiendo por orden de llegada, no importa si es del lugar o turista. Fue algo que se fue dando y nos fuimos adaptando". (Pedro, hijo, almacén Chajarí).

- Mantienen el domingo para la familia, descansar y disfrutar. El domingo es sagrado. "El día domingo que tenemos libre tratamos de no incluir nada de eso. Nos quedamos en familia, salimos, vamos a comer". (María, dueña del almacén).

- Mayor apertura personal: según decir del hijo, los padres están más abiertos.

"No eran tan abiertos porque venía gente de acá nomás. Al venir gente de afuera que quiere conocer algo de sus vidas, del pasado, tuvieron que ir abriéndose de a poco. Eso es positivo. A la gente le interesa conocer la historia". (Pedro, hijo, almacén Chajarí).

- El turismo colabora con la transmisión de la historia familiar y local de generación en generación.

"A través del turismo empecé a conocer la historia del lugar, de mi papá. Antes no conocía mucho de la familia, no me había metido. A partir del turismo empecé a conocer quienes estaban acá, quiénes allá. Todo ese movimiento de la historia no la conocía". (Pedro, hijo, almacén Chajarí).

- Es una actividad que les gusta. Los complace el trato con los turistas, con gente que provenga de otros lugares.

"Hay turistas y turistas, gente y gente, hay algunos que son más calladitos". "El trato con la gente de afuera, conocer, escuchar porque escuchar también es importante". (María, dueña del almacén). "A mí me gusta conversar con ellos y más cuando son gente dada, que te hacen preguntas. A veces si no tengo gente que atender puedo seguir conversando un rato más". (Juan, dueño del almacén).

\section{B.2.9 Percepción del futuro en relación a los hijos y en relación a su resguardo de ingresos}

- La pareja vislumbra el turismo como un ingreso extra y a largo plazo como una actividad que pueden desarrollar los hijos.

"A medida que va pasando el tiempo te vas dando cuenta que es una entrada más y les va a quedar a ellos". (Juan, dueño del almacén).

"La idea es que sigan. No se sabe, pero entusiasmados por lo menos están". (María, dueña del almacén).

"Pienso que los hijos se van a quedar en el campo. Hasta ahora el proyecto de lo que se viene haciendo es para el más chico, el que quedaría en el almacén porque no le gusta estudiar". (Juan, dueño del almacén). 
- Pero también tienen en mente continuar con las actividades que hasta el momento desarrollan, incluso piensan en seguir invirtiendo. El capital es un resguardo para su futuro y a la vez queda para los hijos. También apuestan a seguir construyendo otras casas para alquilar y que puedan tener otro ingreso de las rentas.

"Si nos queda algún restito de plata lo que queda es mejorar el almacén o seguir haciendo cosas que te den en el futuro. A mí me gustaría seguir haciendo casitas para alquilar". (Juan, dueño del almacén).

"Pensamos seguir hasta que podamos". (María, dueña del almacén).

- La perspectiva de los jóvenes es la de irse, adquirir experiencia y volver.

Lo que manifiesta el hijo entrevistado es "llegar lo más lejos posible, viajar, y después de grande (adulto), volver acá al campo". "No me gusta mucho el campo, porque mi crie acá, pero siempre está la idea de volver". (Pedro, hijo, almacén Chajarí). 


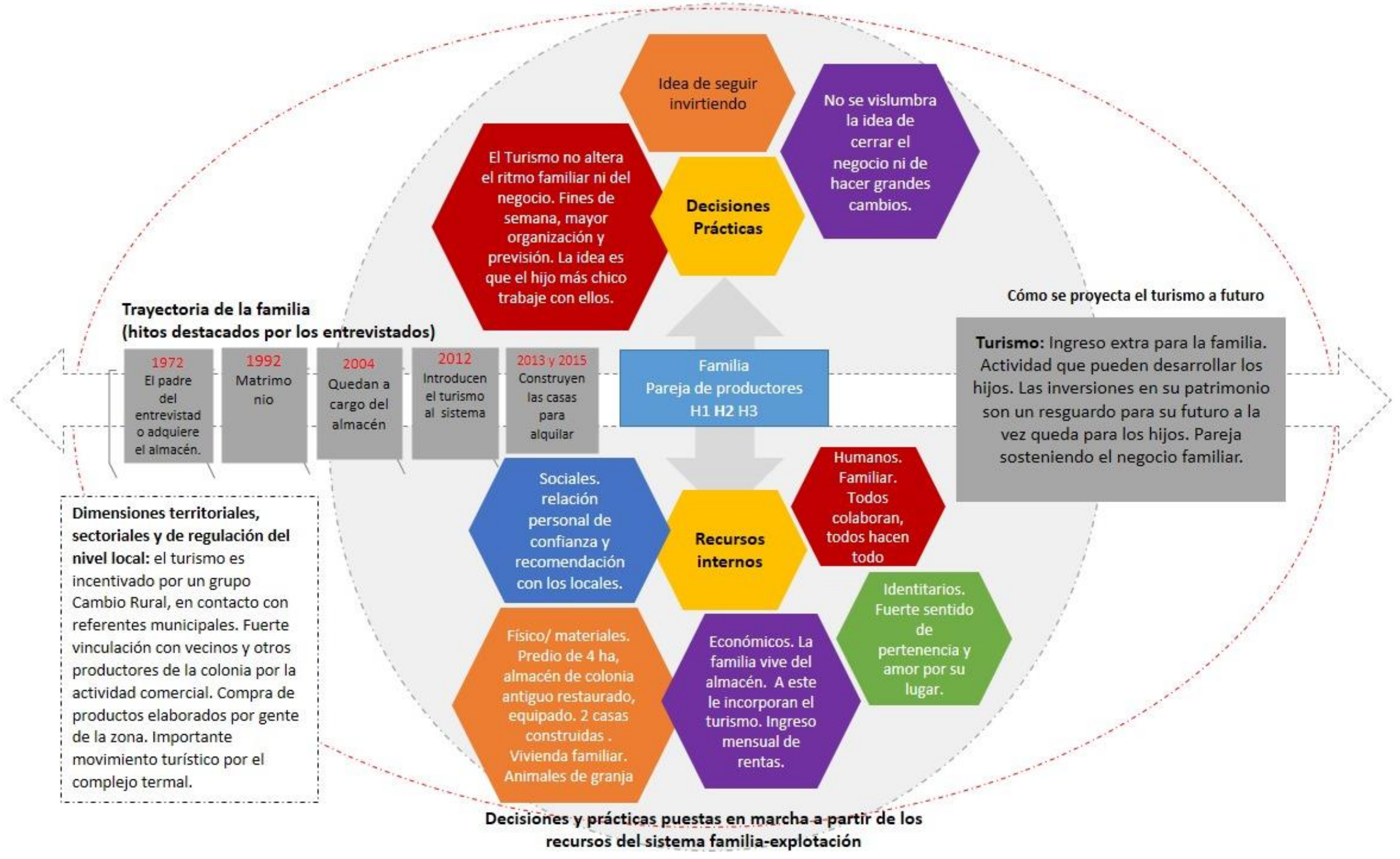




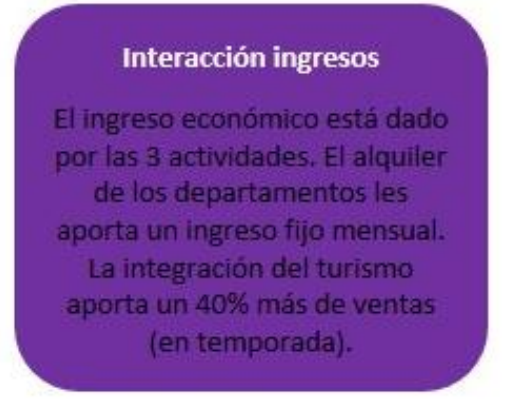

El símbolo + representa la importancia relativa de ingreso al sistema de cada actividad

Interacción ingreso/sentido
del trabajo
lo económico es
determinante. Pero además el
turismo moviliza otros
aspectos vinculados al
reconocimiento social de
mantener abierto un almacén
de colonia al público,, la
posibilidad de generar nuevas
vinculaciones y apertura
cultural.

\section{Interacción temporal}

La anticipación no es a

largo plazo. No es

determinante.

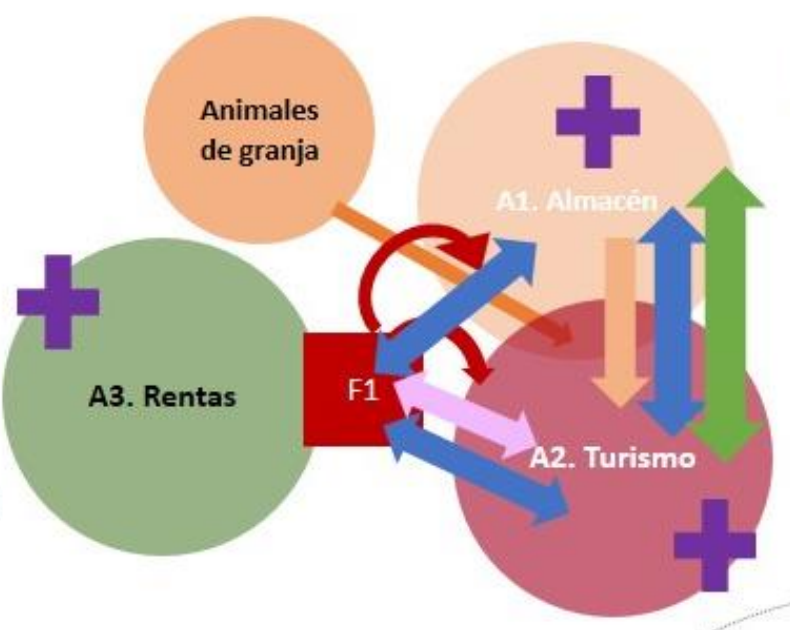

Las flechas del esquema central ejemplifican los tipos de interacción del sistema familia-explotación, con sus respectivos colores identificatorios

Interacción de productos No se evidencia una interacción importante entre productos de diferentes actividades. Sólo venta en el almacén de huevos de producción propia.

Recursos físicos y materiales que se utilizan para la actividad comercial y turística son los mismos, ya que se realizan en el mismo espacio. El almacén es la base del turismo.

\section{nteracción patrimonial} El patrimonio arquitectónico y cultural representado en el almacén es la base de la propuesta que ofrecen. El turismo pone en valor el espacio y el

patrimonio. Refuerza su identidad, familiar y comunitaria.

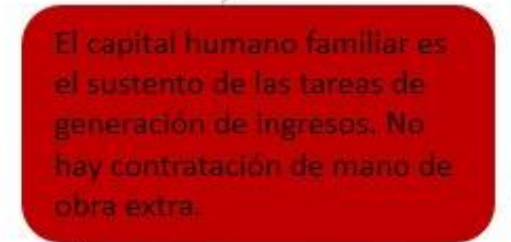

La vinculación con otros actores de turismo ha incentivado a la familia a promover el almacén para este sector. El intercambio social y cultural es uno de los principales aportes que

genera la incorporación de los turistas a la familia y a la
Tipo de interacciones entre recursos. Los colores utilizados responden al recurso movilizado (humano, en rojo; social, en azu;, espacial, física, material en naranja claro)

Ilustración 8- Esquema de interacciones de las actividades dentro del sistema Caso 2 


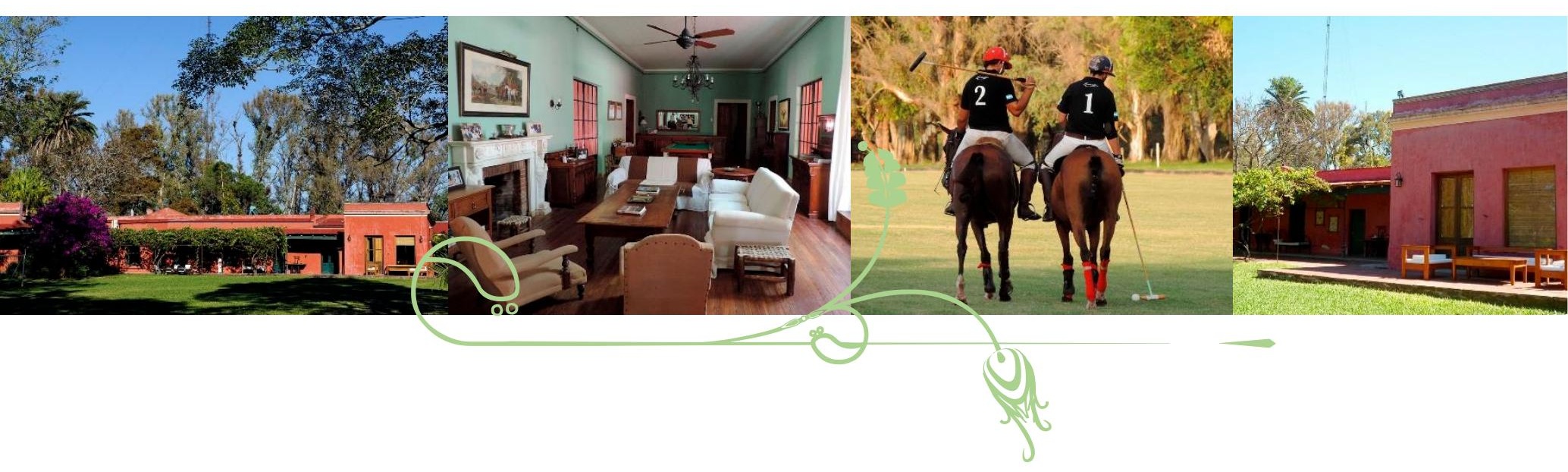

\section{"Patrimonio \& Polo, una combinación internacional"}

"Otros que han venido nos han dicho, a esto hay que demolerlo..." "Lo empezamos a poner lindo, a arreglar y nos encantaba invitar a amigos, a pasar tiempo con amigos acá. Mucha gente nos decía ¿por qué no hacen turismo? Y así empezamos, de a poco". (Carla, dueña de la estancia). 


\section{B.3 Caso 3 - PATRIMONIO \& POLO, UNA COMBINACIÓN INTERNACIONAL}

Esta experiencia fue seleccionada respondiendo a que es un Sistema de Actividades gestionado por productores agropecuarios familiares con una escala empresarial. Nacidos en la zona y cuyos hijos no tienen un involucramiento activo en las actividades de generación de ingresos del sistema puesto que son estudiantes (universitarios y nivel secundario).

\section{B.3.1 Presentación general}

Familia de una pareja de 49 años y tres hijos de 20, 19 y 17 años.

El entrevistado es productor agropecuario e ingeniero agrónomo egresado de la UBA. Ella se dedica a la familia y atención del turismo. Sus dos hijos estudian en Bs As (agronomía y veterinaria) y el tercero empezará allí también.

Poseen un casco de estancia de 1876 en las afueras de Chajarí que han recuperado para vivienda familiar y hace 6 años decidieron ofrecerla en el mercado como alojamiento de campo.

Son dueños de una empresa agropecuaria que posee una parte productiva y una comercial, con varias unidades de negocio.

El $50 \%$ de su producción se exporta.

Tienen producción ganadera (feed lot), agricultura y producción de arroz.

Poseen una empresa de insumos y servicios agropecuarios en Chajarí que se dedica a la comercialización en general, provisión de insumos, tecnología y agricultura de precisión en manejo de agua.

Cuentan con una industria arrocera que toma como insumos su producción.

El predio propio de la estancia cuenta con 400 ha. Alquilan unos 600 ha más que se explotan para ganadería. En este mismo espacio tienen cría de caballos de polo.

Respecto a esta última actividad, comenzó en el año 2004 con la compra de un plantel de yeguas pura sangre de carrera, cuentan con padrillos puros, infraestructura y personal idóneo, un club de polo, afiliado a la Asociación Argentina de Polo (AAP), dos canchas, pista de vareo, caballerizas, corrales y montureros a disposición de los socios.

Durante los fines de semana se llevan a cabo prácticas de polo y se realizan torneos.

Como la familia vive allí, tienen bien distribuida el sector para uso familiar y para turistas. La estancia cuenta con cinco habitaciones completamente equipadas y decoradas con excelente gusto y detalle, espacios de recreación y un amplio campo. Ofrecen cabalgatas, desayunos camperos, almuerzos de campo, paseos por el campo, pileta habilitada, bicicletas. Tienen dos modalidades de trabajo, reserva completa o solo alojamiento. También se alquila para eventos especiales.

"Tenemos dos sistemas, uno con todas las comidas y todo incluido o alojamiento con desayuno. Todo es a medida de la gente". (Carla, dueña de la estancia).

El polo como actividad también mueve un mercado turístico particular. 
"Hay también un turismo específico ligado al polo, nosotros criamos caballos, esto además es un club, se juega, hay torneos, se organizan eventos, clases para gente interesada". (Carlos, dueño de la estancia).
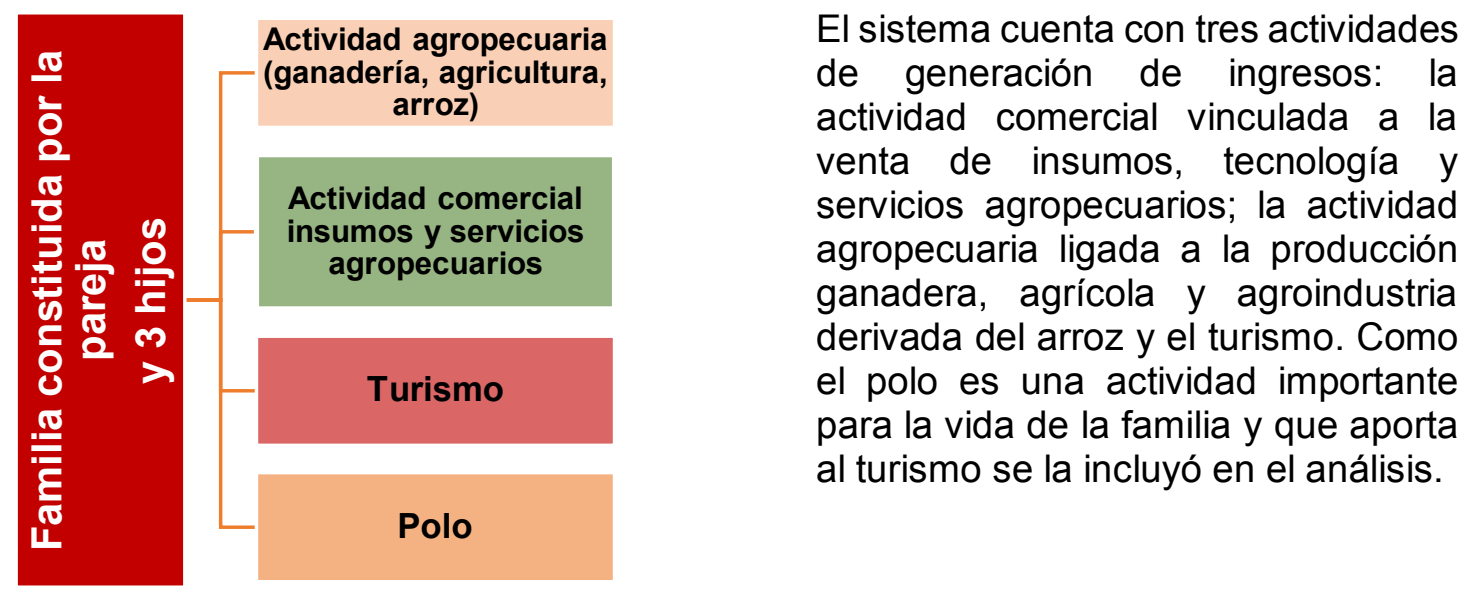

\section{B.3.2 Recursos de la familia 52}

\begin{tabular}{|c|c|}
\hline $\begin{array}{l}\text { Recursos } \\
\text { humanos }\end{array}$ & $\begin{array}{l}\text { Tienen seis empleados en el predio que se dedican a ganadería, mantenimiento y dos } \\
\text { a los caballos. Contratan más si es necesario. En total tienen } 35 \text { empleados si se incluye } \\
\text { la agroindustria y las otras unidades de negocio. El productor es el que realiza las } \\
\text { tareas de dirección y gestión en la empresa. } \\
\text { La más dedicada al turismo es la mujer. Ella se encarga de las reservas, de la logística, } \\
\text { la organización general. También elabora dulces para el consumo familiar y de los } \\
\text { turistas. } \\
\text { "Entre todos aportamos un poco, más allá de que cada uno se ocupa de los suyo. Cuando } \\
\text { hay turistas yo trato de cocinar a la noche". (Carlos, dueño de la estancia). "Tengo una } \\
\text { señora que viene cuando hay gente que es de acá y toda la vida trabajó con nosotros. El } \\
\text { también cocina, hace todo lo que es al disco, asados". (Carla, dueña de la estancia). } \\
\text { También trabaja el cuñado y se especializa en el tema de los caballos, es contratado part } \\
\text { time. }\end{array}$ \\
\hline $\begin{array}{l}\text { Recursos } \\
\text { físicos } \\
\text { materiales y } \\
\text { naturales }\end{array}$ & $\begin{array}{l}\text { Aunque en la charla, los entrevistados sólo hicieron referencia a las características del } \\
\text { predio de la estancia, se puede vislumbrar que este caso refiere a productores } \\
\text { empresariales. Solo en esta unidad de negocios cuentan con } 1000 \text { ha, ganado vacuno, } \\
\text { caballos de polo, yeguas pura sangre de carrera, padrillos puros, la propiedad de la } \\
\text { estancia, maquinaria, entre otros elementos a mencionar para describir los recursos con } \\
\text { los que cuenta. Poseen además dos canchas de polo, caballerizas, galpones de trabajo, } \\
\text { etc. Además tienen otros predios donde realizan agricultura y arroz, que integran la } \\
\text { agroindustria. }\end{array}$ \\
\hline $\begin{array}{l}\text { Recursos } \\
\text { económicos }\end{array}$ & $\begin{array}{l}\text { Los ingresos que sostienen el sistema están dados por las dos principales } \\
\text { actividades a las que se dedica, lo productivo (ganadería, agricultura y arroz) y lo } \\
\text { comercial (venta de insumos, asesoramiento en agricultura de precisión, etc). } \\
\text { Las actividades/unidades se complementan. } \\
\text { "Los márgenes comerciales son importantes, el volumen en lo productivo es menor pero } \\
\text { los márgenes son más importantes. Yo te diría que lo comercial y productivo están ahí. } \\
\text { El } 50 \% \text { de la facturación es exportación, lo que es industria es todo exportación. } \\
\text { Estamos diversificados pero todo en agro, } 100 \% \text { agro". (Carlos, dueño de la estancia). } \\
\text { El ingreso por turismo es menor al resto de las actividades pero ha tenido una } \\
\text { evolución. Se sostiene en parte con el resto de las actividades pero colabora } \\
\text { básicamente con el mantenimiento edilicio. }\end{array}$ \\
\hline
\end{tabular}

\footnotetext{
${ }^{52}$ En el cuadro se utilizan colores determinados para resaltar algunos conceptos que luego son recuperados en un esquema conceptual. Los recursos humanos son referidos en color rojo; los físicos, materiales y naturales en naranja; los recursos económicos en violeta; los sociales en azul y los recursos identitarios en verde.
} 


\begin{tabular}{|c|c|}
\hline $\begin{array}{l}\text { Recursos } \\
\text { sociales }\end{array}$ & $\begin{array}{l}\text { No trabajan en red con otros productores relacionados con turismo rural ni tampoco } \\
\text { integran redes técnicas. Sí tienen relación con instituciones del sector agropecuario } \\
\text { en general. } \\
\text { Lo social es muy fuerte en la familia, de hecho, la pareja plantea que su idea siempre fue } \\
\text { vivir en el campo y recibir amigos. Fueron ellos quienes los entusiasmaron para hacer } \\
\text { turismo. } \\
\text { Se evidencia un importante intercambio cultural con los turistas, que en su gran } \\
\text { mayoría son extranjeros. La idea que manejan es que los turistas se sientan como en } \\
\text { su propia casa, por lo que se dan y generan espacios para el diálogo y disfrute. Incluso } \\
\text { mencionan algunas familias que los han visitado en varias ocasiones y les traen regalos } \\
\text { a los hijos. "Se dan esas cosas, comés con ellos, a veces te cocinan ellos, hay un ámbito } \\
\text { de intercambio". (Carlos, dueño de la estancia). }\end{array}$ \\
\hline $\begin{array}{l}\text { Recursos } \\
\text { identitarios }\end{array}$ & $\begin{array}{l}\text { La particularidad del caso se relaciona a la esencia de la familia y el lugar. Todo indica } \\
\text { que imprimen a su propuesta de turismo aquellos aspectos y actividades que disfruta la } \\
\text { misma familia porque es la familia la que ama vivir en el campo y ha sido esta su opción. } \\
\text { Otra cuestión es que le dan vital importancia al cuidado del ambiente, a la producción } \\
\text { de alimentos saludables. A esto lo trasladan al turismo. } \\
\text { "Todo es casero. Todo es natural, la carne que comemos es producción de acá y a } \\
\text { pasto. La mayoría de la verdura es de la huerta. No se le echa nada. Nosotros } \\
\text { comemos esto". (Carlos, dueño de la estancia). } \\
\text { "El } 90 \% \text { de lo que consumimos lo producimos, es una cuestión cultural, toda la vida fue } \\
\text { así. Nosotros criamos ovejas así que hacemos todas las comidas que se te ocurran con } \\
\text { ovejas". (Carlos, dueño de la estancia). } \\
\text { El deporte, la cría de caballos de polo también se vincula con un gusto personal y } \\
\text { familiar, una actividad que desarrollan como deporte y comercialmente. } \\
\text { "Hay gente que ha venido por el polo, otra por turismo pero le gusta el polo. El polo } \\
\text { también le suma". (Carlos, dueño de la estancia). }\end{array}$ \\
\hline $\begin{array}{l}\text { Recursos } \\
\text { territoriales }\end{array}$ & $\begin{array}{l}\text { No tienen una activa relación con el municipio y otros actores del sector turístico } \\
\text { local u otras estancias de la provincia, sí en relación a las otras actividades } \\
\text { productivas. } \\
\text { "Hay buena relación con el municipio, nos han dado una mano, nos incluyeron en folletería } \\
\text { pero no es una actividad muy movida en ese sentido"(Carlos, dueño de la estancia). } \\
\text { "Hay voluntad de ambas partes para hacer actividades pero no nos enganchamos, no } \\
\text { tenemos el perfil de la mayoría. No es que no lo necesitemos, nos vendría bárbaro pero } \\
\text { quizás si no vienen ellos, yo no voy". (Carla, dueña de la estancia). } \\
\text { No trabajan en red con otros productores relacionados con turismo rural ni } \\
\text { tampoco integran redes técnicas. } \\
\text { La vinculación técnica, tecnológica y relacional se da por las otras actividades. } \\
\text { "Por el lado comercial, tenemos fuerte relación con la Bolsa de Cereales de Entre Ríos, } \\
\text { alguna relación con el INTA por el tema arroz pero no tenemos una vinculación técnica } \\
\text { mayor a esa, no estamos en un grupo CREA o de INTA". (Carlos, dueño de la estancia). } \\
\text { El preside la Cámara de la Industria Arrocera. } \\
\text { "Por turismo al principio estuvimos en RATTUR pero me resultó complicado" (Carla, } \\
\text { dueña de la estancia), por cuestiones internas a la organización. "Lo que más me } \\
\text { importaba era el tema del seguro. Me desvinculé y nunca más". (Carla, dueña de la } \\
\text { estancia). } \\
\text { "No hemos detectado una organización o institución proactiva respecto a esto, que genere } \\
\text { valor agregado a las cosas. Siempre fueron intenciones, está todo muy desperdigado". } \\
\text { (Carlos, dueño de la estancia). }\end{array}$ \\
\hline
\end{tabular}

\section{B.3.3 Trayectoria familiar}

La pareja es de Concordia. En 1996 comienzan su establecimiento en Chajarí, donde la familia de la mujer era originaria. Su abuela tenía un campo en la zona. Vivían en la ciudad pero con intenciones de irse a vivir al campo.

"La idea original era vivir en el campo". (Carlos, dueño de la estancia). 
Compran el casco de estancia en el año 2000 a un tío de la familia de la mujer.

"Esta estancia había sido originariamente de la familia que había quedado por división hasta que llegó a manos de un tío abuelo", relata el productor.

"El tío abuelo hizo todos los esfuerzos para que quede en la familia. En ese momento estaba muy abandonado, la parte de la estructura, edilicia". (Carlos, dueño de la estancia).

Mucha gente les insistía en demoler la casona y construir algo moderno y nuevo.

"Otros que han venido nos han dicho, a esto hay que demolerlo". (Carla, dueña de la estancia).

Se fue haciendo la reparación con muchos esfuerzo porque es una construcción muy antigua, que data de 1876.

"Es difícil mantenerlo, es mucho esfuerzo, mucho tiempo y mucha plata". (Carla, dueña de la estancia).

En el año 2004 compran un plantel de yeguas pura sangre de carrera para la cría de caballos de polo.

"Lo empezamos a poner lindo, a arreglar y nos encantaba invitar a amigos, a pasar tiempo con amigos acá. Mucha gente nos decía por qué no hacen turismo acá? Y así empezamos, de a poco". (Carla, dueña de la estancia).

Hace 6 años aproximadamente arrancaron con turismo, actividad en la que fueron creciendo paulatinamente.

"Al principio era de boca en boca, hace un par de años empezamos con la página web y empezamos con booking, ahora se va conociendo más". (Carla, dueña de la estancia)

"Al principio teníamos un poco de miedo porque vienen a tu casa pero ya está..." (Carlos, dueño de la estancia).

Tuvieron un período de expansión en turismo, fundamentalmente extranjero:

"Venían sin que los llamen, prácticamente todo el turismo que teníamos era extranjero. Después se planchó más el de afuera un poco por el tipo de cambio y otro porque no había una buena visualización afuera en el tema de turismo. Ahora estamos como lanzando un poco de vuelta, más masivo y nos gusta la idea". (Carlos, dueño de la estancia).

\section{B.3.4 Emergencia del turismo}

- El turismo surge a partir del potencial del casco de estancia como alojamiento, su entorno, estética, dimensiones. También es entendido como una inversión a futuro, aunque en la actualidad colabore al mantenimiento del edificio y estructura.

"Hoy se mantiene con las otras actividades, es como la inversión en vivienda, y de hecho ha generado ingresos, le da cierta movilidad". (Carlos, dueño de la estancia).

"Yo creo que $L V$ sin el proyecto de turismo en el tiempo no tiene sustento porque es real, esto se va agravando más el costo de estructura y nosotros lo que al menos pretendemos es ir arreglando de a poco y que se pague con el mismo valor, sino estás permanentemente subsidiando un elefante blanco que algún día te voltea". (Carlos, dueño de la estancia).

"Tampoco es que las actividades son super rentables y podés subsidiar una casa con toda esta estructura". (Carlos, dueño de la estancia).

- El turismo colabora con la conservación del patrimonio familiar.

"El turismo es interesantísimo, primero porque arraiga, segundo porque mantiene la historia y además lo que está generando es un poco de desarrollo en el lugar". (Carlos, dueño de la estancia). 
"No hay manera de subvencionar mucho la casa, sí o sí si queremos tener esto bien mantenido y lindo hay que mantener la impronta del turismo". (Carlos, dueño de la estancia).

- Se continúa en esta actividad porque hay una demanda turística interesada: existe un perfil del mercado más que nada el extranjero de aprender sobre el campo argentino y compartir las costumbres rurales. Les interesa la tranquilidad del lugar, degustar comidas típicas argentinas.

"Lo importante es el concepto de turismo que nosotros hacemos, de que la persona que viene se sienta como en su casa, es muy abierto y a la vez muy exclusivo". (Carlos, dueño de la estancia).

"Los extranjeros se interesan mucho por la producción, se sientan a comer y te preguntan de todo, quieren saber todo. A muchos les apasiona, ven desde su óptica cosas que nosotros damos por hecho". (Carlos, dueño de la estancia).

\section{B.3.5 Objetivos, decisiones y estrategias puestas en marcha}

La idea de la pareja es continuar con el desarrollo de la actividad con mayor profesionalismo y dedicación. Apuestan al crecimiento de la actividad y en ir agregando servicios vinculados con la producción local. Los entrevistados consideran al turismo como una alternativa para sostener y conservar el patrimonio. El mismo productor destaca que el campo va a seguir funcionando con o sin la estancia, pero al haber interés y arraigo piensan en esta actividad como estrategia para seguir salvaguardando la propiedad.

"Arrancamos como familia y produciendo pero la idea es, a medida que los chicos se van recibiendo y nos vamos quedando más libres es darle mayor importancia a lo que es turismo y eventos, sobre todo lo que se pueda hacer a partir del turismo rural. Acá no solo se aloja, se les da la comida, se hacen cabalgatas, varias actividades. El turismo tiene para crecer muchísimo y atrás de la gente que viene hay otros servicios que se pueden ir incorporando.

Hay mil cosas". (Carlos, dueño de la estancia).

"Otro tema que me interesa es el desarrollo de valor agregado a través del turismo. Ves cómo en Europa si vas a un viñedo hacen el vino y te lo venden ahí. Ese tema es para asociarlo al turismo, hacés tus dulces, los vendés al turismo, ligado al tipo de producción local". (Carlos, dueño de la estancia).

"Creemos que vamos bien con turismo, que se va a mover, que tiene mucho futuro". (Carla, dueña de la estancia).

En este caso se destaca la preocupación por el ambiente, por lo natural, por un estilo de vida personal y familiar ligado al consumo de alimentos sanos y en contacto con la naturaleza y el campo, idea que trasladan al turismo.

"Nosotros acá que tenemos el proyecto de turismo no tenemos ninguna actividad contaminante. El concepto que vendemos sin venderlo es que venís a un lugar auténtico y natural, acá nos podemos dar el lujo de eso". (Carlos, dueño de la estancia).

"Yo ni loca fumigo algo que nosotros comemos, que es lo mismo que consume el turista".

(Carla, dueña de la estancia). 


\section{B.3.6 Vinculación del sistema familia-explotación con la actividad de turismo rural ${ }^{53}$}

\begin{tabular}{|c|c|}
\hline $\begin{array}{c}\text { Interacción producto } \\
\text { Explica el flujo de materia } \\
\text { prima de una actividad a } \\
\text { otra. }\end{array}$ & $\begin{array}{l}\text { Con respecto a la relación de la actividad turística con los productos } \\
\text { del resto de las actividades puede decirse que hay una integración } \\
\text { de los insumos de la producción primaria para el consumo } \\
\text { familiar y como servicio gastronómico que se brinda al turismo } \\
\text { (Productos de la huerta, carne vacuna y ovina de producción propia) }\end{array}$ \\
\hline $\begin{array}{l}\text { Interacción recursos } \\
\text { Se explica a partir de la } \\
\text { movilización de un mismo } \\
\text { recurso para varias } \\
\text { actividades. }\end{array}$ & $\begin{array}{l}\text { En el predio de la estancia cuentan con empleados que desarrollan } \\
\text { diversas actividades. En cuanto a los miembros de la familia, la más } \\
\text { dedicada a la logística y organización de la actividad turística es } \\
\text { la productora, quien además elabora dulces y conservas para el } \\
\text { consumo. El productor está más dedicado al resto de las actividades } \\
\text { productivas y comerciales, pero se suma a la propuesta turística } \\
\text { cocinando y compartiendo con los turistas. } \\
\text { El conocimiento, experiencia y saber de los productores en } \\
\text { relación a su actividad, al sector turístico dado por su interés y } \\
\text { posibilidad de viajar, idiosincracia e intereses particulares como el } \\
\text { deporte, la alimentación sana, el cuidado del ambiente y del patrimonio } \\
\text { le imprimen calidad y calidez humana a la propuesta turística. } \\
\text { En cuanto a los recursos naturales y el uso de la tierra, parte de las } \\
\text { actividades productivas que no requieren uso de agroquímicos se } \\
\text { desarrollan en el predio de la estancia, donde a la vez vive la } \\
\text { familia. Esto ha sido remarcado fuertemente en la entrevista. Además, } \\
\text { poseen otros predios donde generan otras actividades productivas. } \\
\text { Es importante destacar que se diferencian los sectores de uso } \\
\text { exclusivo familiar y abierto al turismo, lo que promueve y propicia } \\
\text { la intimidad de la familia y de los turistas. Además se da una } \\
\text { distribución de las actividades productivas en el predio de la } \\
\text { estancia de tal forma que sea ordenada y que permita el disfrute } \\
\text { de Ios turistas y el quehacer rural a la vez. }\end{array}$ \\
\hline $\begin{array}{l}\text { Interacción patrimonial } \\
\text { La implementación } \\
\text { actividades simultáneas se } \\
\text { dan en torno al valor } \\
\text { intangible de un patrimonio }\end{array}$ & $\begin{array}{l}\text { La implementación de la actividad turística se basa y surge a } \\
\text { partir del potencial del casco histórico de la estancia. Esto es lo } \\
\text { que le da sustento. A esto se suma el mobiliario antiguo reciclado y los } \\
\text { objetos de valor histórico que agregan valor y estética a la propuesta, } \\
\text { pero además es lo que colabora a su mantenimiento, en el } \\
\text { presente y fundamentalmente a futuro. }\end{array}$ \\
\hline $\begin{array}{l}\text { Interacción temporal } \\
\text { Explica los procesos de } \\
\text { anticipación de un cambio } \\
\text { que está por venir, del } \\
\text { abandono o } \\
\text { implementación de una } \\
\text { nueva actividad }\end{array}$ & $\begin{array}{l}\text { La incorporación del turismo no está solo pensada en términos de } \\
\text { necesidades actuales, porque es una actividad que suma, que no } \\
\text { genera grandes complicaciones ni alteraciones al ritmo de la familia, } \\
\text { sino y fundamentalmente como estrategia a futuro. En esto, la pareja } \\
\text { se anticipa a un tiempo en el que la familia se achique, los hijos no } \\
\text { vivan más con ellos y tengan que seguir manteniendo la casona. } \\
\text { "Esto, si no fuera por el turismo rural, tarde o temprano no tiene } \\
\text { sustento. Si esto no tiene un proyecto de turismo rural atrás tarde } \\
\text { o temprano termina por desaparecer, lo que es el patrimonio". } \\
\text { (Carlos, dueño de la estancia). }\end{array}$ \\
\hline
\end{tabular}

\footnotetext{
${ }^{53}$ En el siguiente cuadro se enfatizan algunos conceptos utilizando colores que luego serán adoptados en el esquema conceptual que explica las interacciones de la actividad turística con el resto de las actividades del sistema. Así, con naranja se remarca la interacción entre productos de las distintas actividades; con rojo y azul la interacción de los recursos humanos y sociales y con naranja claro entre recursos físicos, naturales y materiales; con verde la interacción patrimonial; con gris, la temporal; con violeta claro la interacción dada entre el ingreso y el sentido dado al trabajo, y con violeta oscuro, la interacción entre los ingresos que aportan las actividades al sistema.
} 


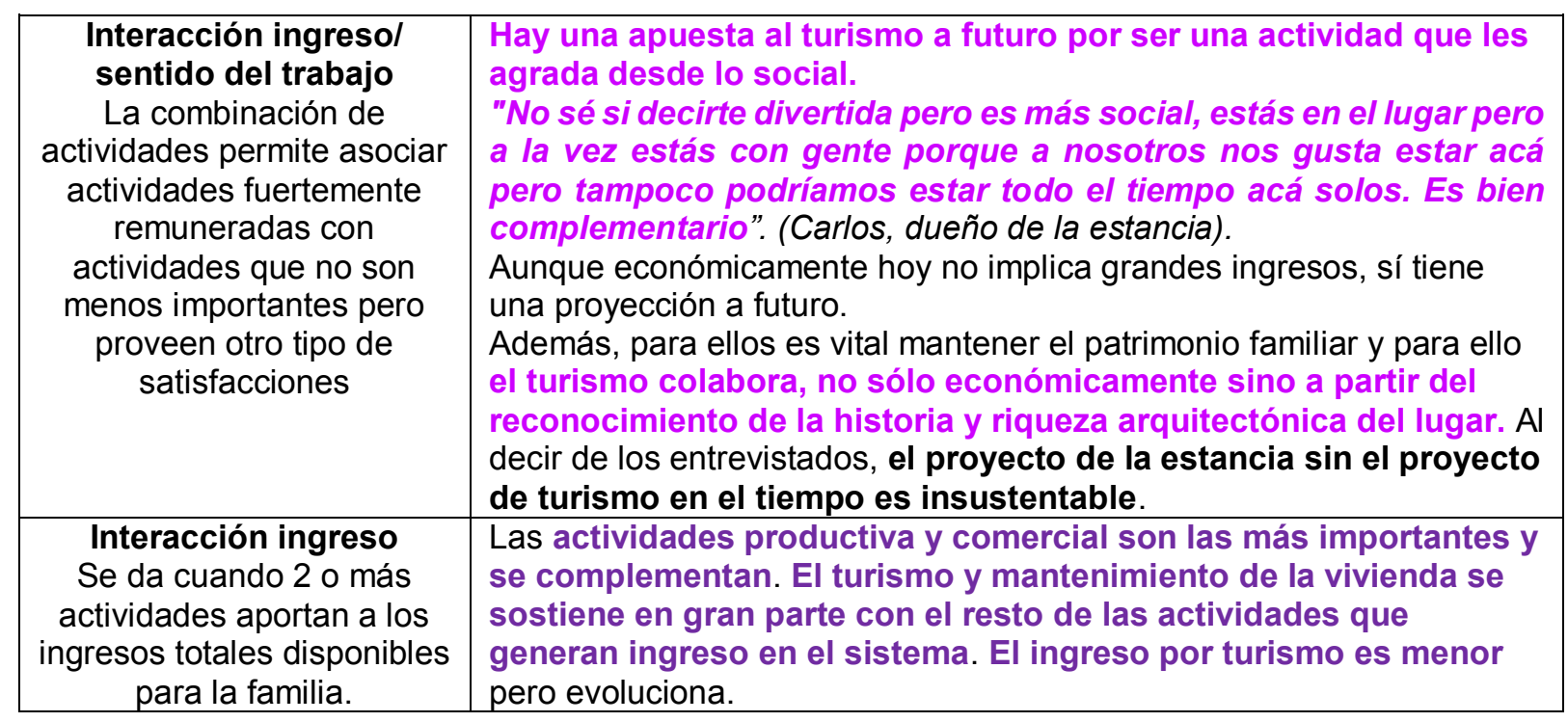

\section{B.3.7 Impacto del turismo en el sistema productivo}

La actividad turística no impacta en términos de modificar el resto de las actividades productivas del sistema.

Se utilizan insumos de la producción para brindar comidas al turismo, lo cual le agrega valor a la producción primaria y un plus a la propuesta turística en términos de ofrecer comida casera, elaborada artesanalmente con productos frescos y saludables.

El turismo además complementa económicamente al resto de las actividades, colabora al mantenimiento del patrimonio, aporta a la familia una actividad que les agrada hacer y es una actividad a la que la pareja piensa dedicarse en un futuro.

"El campo seguirá produciendo pero desde ese lado el turismo es interesantísimo, primero porque arraiga, segundo porque mantiene la historia y además lo que está generando es un poco de desarrollo en el lugar". (Carlos, dueño de la estancia).

\section{B.3.8 Impacto del turismo en la familia, en las personas y en sus estilos de vida}

- La familia vive en la estancia. Tienen una parte que es exclusivamente vivienda familiar y otra social, para el turismo. Están en contacto con los turistas, los reciben con la intención de que se sientan en su casa. Los hijos también se relacionan con los turistas. El hijo más grande fue a una escuela rural cerca de allí, pero luego los tres fueron a un colegio privado en Chajarí. Están ubicados a 20/25 minutos de la ciudad.

"Nos hemos organizado bien, té diría que ninguno se imagina viviendo de otra manera, es más, nuestros chicos estudian uno veterinaria y el otro agronomía". (Carlos, dueño de la estancia).

- Incorporaron el turismo de manera natural. Les gusta la actividad y la vida que llevan haciendo lo que hacen.

"El lugar donde tenemos lo que más nos gusta es acá. Ni siquiera hacemos agricultura. Me parece que el turismo ayuda un poco a querer hacer un ambiente lindo, amigable, te arraiga, te obliga a estar ordenado y te hace mirar las cosas de otra manera. Ha venido gente acá que justamente valora que no haya nada arado, que sea todo campo". (Carlos, dueño de la estancia). 
- El principal cambio está dado por la apertura cultural y posibilidad de educación (no formal) de los hijos.

"Los chicos son muy abiertos. El hecho de recibir gente de afuera los hizo muy abiertos. Suma muchísimo en esto del tema de los chicos, les hizo abrir mucho la cabeza, sino imaginate que los chicos viven en el campo y no es tan fácil. A eso lo veo como un punto muy importante. Los educa sí o sí". (Carlos, dueño de la estancia).

- Destacan lo interesante del intercambio con personas de otros países.

"Es como que vayas a otro país, te sientes con ellos y te cuenten cómo viven, qué hacen. Ellos vienen y te cuentan. Te vas cultivando, mirás las cosas de ellos con la perspectiva de ellos, es distinto a cuando viajas vos". (Carlos, dueño de la estancia).

\section{B.3.9 Percepción del futuro en relación a los hijos y en relación a su resguardo de ingresos}

El turismo es una actividad a la que la pareja piensa dedicarse exclusivamente en su retiro de la actividad agropecuaria. Hay dos cuestiones que emergen; primero, que es una actividad que les gusta hacer y segundo que colabora a mantener el lugar, los gastos de mantenimiento y de estructura, más en un periodo en el que los hijos se van yendo del hogar y les queda una casa de grandes dimensiones solo para la pareja.

"Qué disfrutamos hoy acá, que estamos activos. Algún día ya no te da para hacer todas las actividades que hoy hacemos y a la vez querés quedarte en el lugar... Es muy claro el tema de desarrollar algo a largo plazo que incluya deporte y turismo. Siempre lo tuve como algo que tiene un potencial bárbaro y nos gusta". (Carlos, dueño de la estancia).

"Ahora que ellos ya se están yendo, creo que es una buena manera de mantener esto. No hay manera de subvencionar mucho la casa. Sí o sí si queremos tener esto bien mantenido y lindo hay que mantener la impronta del turismo". (Carla, dueña de la estancia).

"Algún día tengo ganas de que los chicos se empiecen a ocupar de sus cosas y tener el lugar, tener la casa es realmente una actividad que me atrae, desde lo social nos atrae, conocer gente, recibir gente. Además yo creo que LV sin el proyecto de turismo en el tiempo no tiene sustento... "(Carlos, dueño de la estancia).

Si bien no se profundiza sobre el tema sucesional, hay un interés de la pareja por mantener el patrimonio familiar que perteneció a la familia de la esposa. No les da lo mismo que pase a manos que no sean de la misma familia. Se evidencia un sentido de pertenencia a ese espacio, incluso manifiestan que los hijos no estarían de acuerdo con vender la estancia.

"Tienen mucho arraigo. Nosotros por ahí en broma les decimos ahora que son más grandes vamos a vender todo y viajar. Y ellos dicen no, todo menos $L V$. No sólo se criaron acá, ellos han hecho todo acá, es su lugar". (Carlos, dueño de la estancia).

"No es menor cuando hablamos de recursos, el turismo no es la más importante pero porque tampoco no es la actividad a la que más tiempo y recursos le hemos dado. Pero sí creemos que es un desarrollo a futuro. También hay un tema sucesional acá". (Carlos, dueño de la estancia). 
Ilustración 9- Esquema del sistema familia/explotación Caso 3

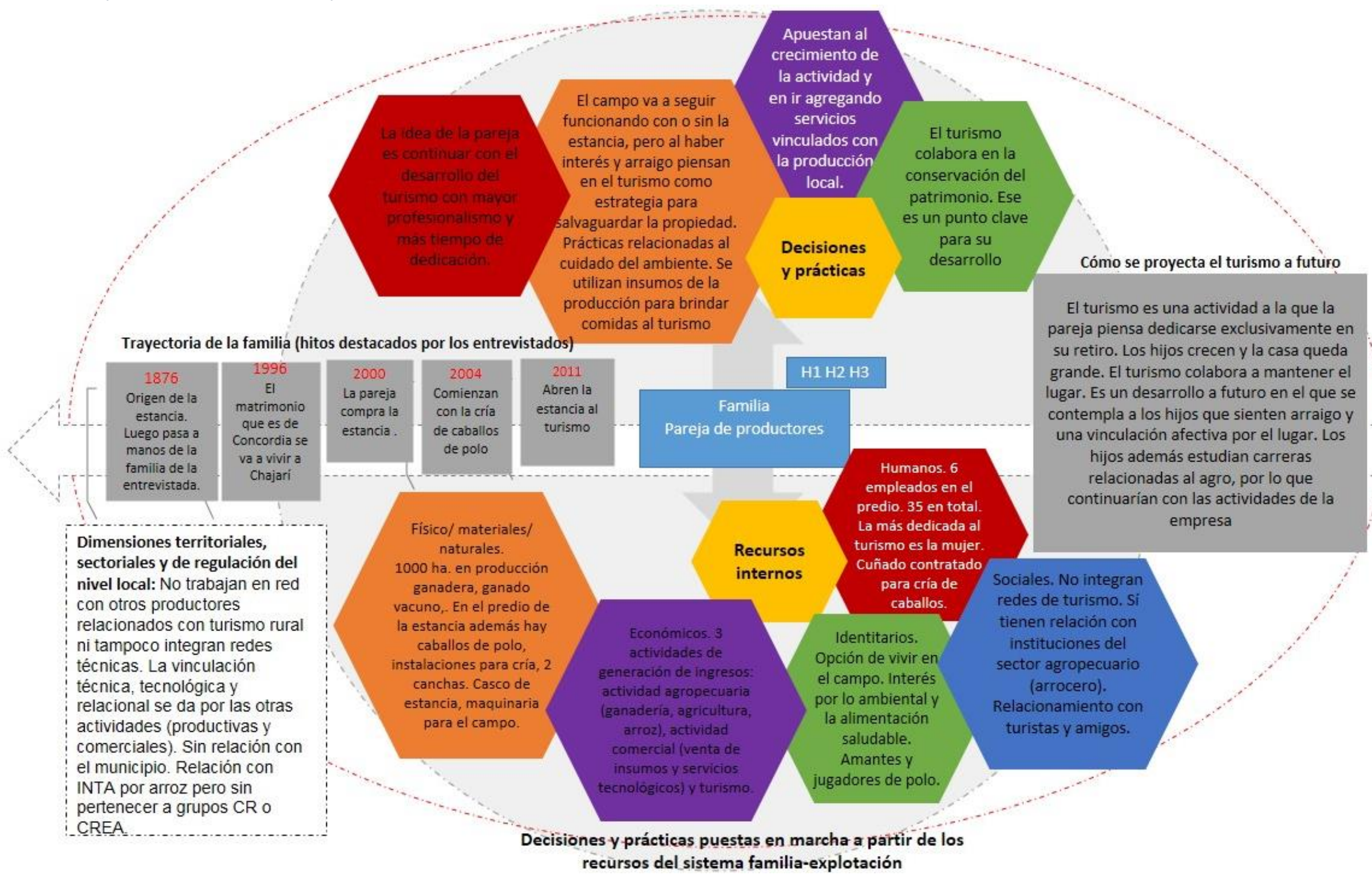


Las flechas del esquema central ejemplifican los tipos de interacción del sistema familiaexplotación, con sus respectivos colores identificatorios

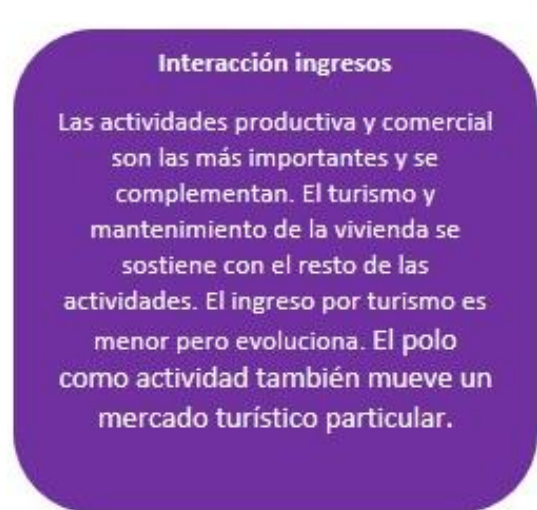

El símbolo + representa la importancia relativa del ingreso al sistema de cada actividad

Interacción ingreso/sentido del

$$
\text { trabajo }
$$

Aunque económicamente hoy no implica grandes ingresos, sí tiene una proyección a futuro, agrada desde lo social y colabora a mantener el

patrimonio familiar, idea vital para la familia. El polo es una actividad a la que se dedica profesionalmente la familia y que además les agrada.

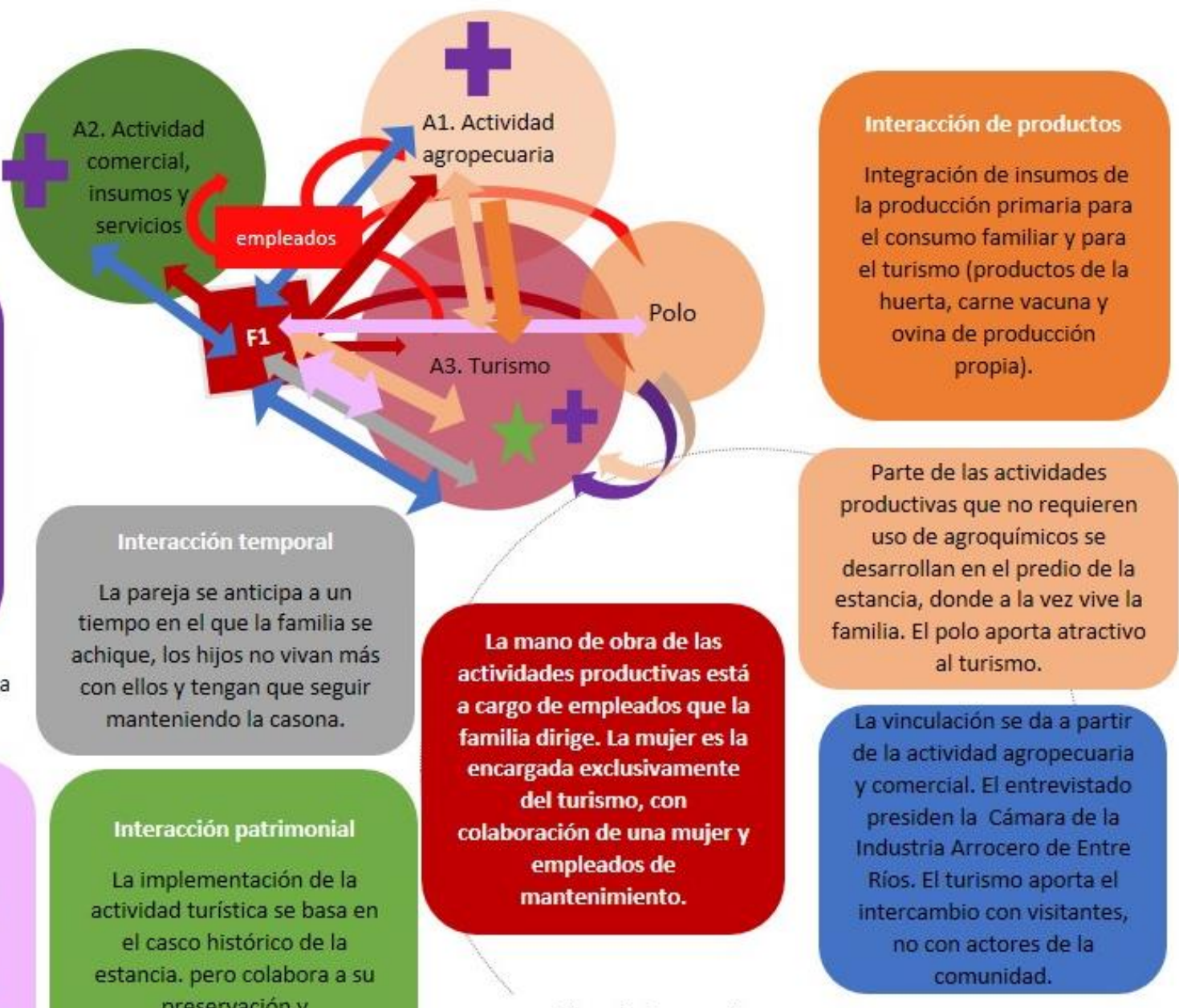

Tipo de interacciones entre recursos. Los colores utilizados responden al recurso movilizado (humano, en rojo; social, en azu; espacial, física, material en naranja claro) 


\section{C Zona centro. Descripción del contexto, aspectos organizativos y regulatorios}

La mayor parte de las propuestas de turismo rural de esta zona se ubican en la microrregión Tierra de Palmares llamada así por poseer una de las reservas ecológicas más importantes del país, el Parque Nacional El Palmar. Las localidades que la integran son Colón, San José, Villa Elisa, Liebig, Primero de Mayo, Hoker y Ubajay.

Puede definirse como una microrregión turística de jerarquía en la provincia por la diversidad de atractivos y su creciente demanda turística, y como una mancomunidad de municipios, que en la década de 1990 comienza a articular acciones para la resolución de problemas comunes.

Si bien esta micro región fue concebida por los municipios de la zona para dar respuestas a problemáticas de manera integral, uno de los principales ejes de articulación ha sido -y es- el turismo. En este contexto, el turismo rural es un espacio de trabajo en común, un punto de encuentro en la visión del desarrollo territorial que promueve la integración y complementariedad de los sectores productivos, agropecuarios y turísticos.

Las áreas de turismo de las municipalidades de San José, Villa Elisa y Colón, Liebig, Primero de Mayo y Hoker son los actores más comprometidos con esta temática. Han tenido y siguen teniendo una activa y comprometida vinculación con los grupos, proyectos, emprendedores y empresarios del sector. Para estos municipios, el turismo rural se presenta como alternativa turística complementaria a los principales atractivos, que fortalece y amplía el producto turístico del destino, contribuyendo al rescate y revalorización de la cultura e identidad rural. Además, la posibilidad de trabajar con productores y emprendedores rurales, les brinda la oportunidad de ampliar la cobertura de su acción política.

Si bien durante algunos períodos las diferencias políticas partidarias han influido negativamente en la articulación, en general, a la hora de gestionar fondos y dar vuelo a la región, los Intendentes y equipos técnicos trabajan en conjunto y con una alta capacidad de gestión.

Más allá de sus diversos procesos de altas y baja en el trabajo articulado, es una zona modelo de desarrollo mancomunado en la provincia y el país.

En la microregión funcionaron tres Grupos Cambio Rural de Turismo Rural ("Agroturismo Río Uruguay" (Colón - San José y colonias de la zona), "Uniendo Colonias" (San José, Primero de Mayo y colonias de la zona), y "Agroturismo Villa Elisa" (Villa Elisa y colonias de la zona). Además se integró un grupo Cambio Rural II de Valor Agregado en Origen que nucleaba a feriantes de la zona.

Por otro lado se pusieron en marcha Proyectos de Apoyo al Desarrollo Local de INTA en pueblos rurales como Primero de Mayo y Liebig que integran la oferta de atractivos rurales de este espacio.

Los proyectos arriba mencionados fueron integrados por productores agropecuarios en articulación con otros actores del territorio, situados alrededor de las ciudades de Colón, San José y Villa Elisa. Estos procesos de trabajo asociativo tuvieron su periodo de funcionamiento formal dado por la herramienta programática, estando no activos en la actualidad.

A partir del trabajo de estos proyectos se intentó conjugar la especificidad de los valores culturales históricos con la puesta en valor de las producciones de la zona, como el arroz, la nuez pecán, los frutos del yatay, generando propuestas innovadoras que vinculan el pasado, a través de recetas y relatos, el presente productivo y la creatividad de sus emprendedores. 
Otros actores que se sumaron al proceso fueron la CAFESG (Comisión Administradora para el Fondo Especial de Salto Grande), la Secretaría de Agricultura Familiar y el Instituto Superior de Turismo que funciona en Colón.

La CAFESG es la encargada de administrar el fondo formado por los aportes provenientes del excedente derivado de la explotación del Complejo Hidroeléctrico de Salto Grande, cuya área de influencia incluye los departamentos de Feliciano, Federal, Federación, Concordia, San Salvador, Colón, Villaguay y Uruguay.

En este marco funcionó un Programa Fortalecimiento del Turismo en los Gobiernos Locales con el objetivo de consolidar la actividad turística en pequeñas comunas y municipios emergentes de la región. Mediante acciones concretas de fortalecimiento, se estimula el proceso de desarrollo de las localidades que por sus características naturales, culturales y/o servicios, presentan potencialidad para atraer turistas.

Con respecto a la Secretaría de Agricultura Familiar se sumó activamente al proceso en torno al acompañamiento de los pequeños productores rurales a través de una serie de proyectos para consolidar el funcionamiento del espacio de ferias, habilitación de productos artesanales y la comunicación integral de las propuestas de turismo rural.

El Instituto Superior República Oriental del Uruguay de Colón, que posee la Tecnicatura en Turismo y Gestión de Servicios y funciona en Colón en articulación con estudiantes y docentes puso en marcha dispositivos de investigación para conocer con mayor profundidad el perfil de los turistas que eligen propuestas de turismo rural en la zona.

Uno de los avances que evidencian el compromiso del Instituto con el desarrollo del turismo rural ha sido la presentación ante el Consejo General de Educación en el Nivel Superior un proyecto para la realización de una especialización de 2 años en turismo rural en el marco del funcionamiento del establecimiento, lo que habla a las claras de su potencialidad para el desarrollo de competencias en futuros profesionales del turismo, que podrán acompañar con un conocimiento más cabal e integral a los emprendedores de la zona.

En cuanto al Ministerio de Turismo de la provincia, puede decirse que la vinculación de este actor ha atravesado diferentes etapas dadas por la orientación de la política pública puesta en marcha y acciones priorizadas. Durante muchos años desde se acompañó a emprendedores a ferias de promoción, apoyando además, la generación de circuitos y paquetes de comercialización. Por otro lado, en el Plan Estratégico de Turismo de la provincia, construido durante esos años de manera participativa, y orientado, entre otras cosas, al ordenamiento territorial, el turismo rural tenía una presencia vital, al menos para los actores directamente involucrados. En los últimos años este organismo manifestó interés por el sector del turismo rural, poniendo en marcha una serie de acciones de difusión y promoción de la modalidad.

\section{Caracterización de las propuestas de turismo rural de la zona centro}

El 36\% de las propuestas está gestionada por productores. De ese total, el $70 \%$ es familiar. En el $65 \%$ de los SA los hijos están involucrados en el trabajo familiar. El 100\% de los productores son de la zona. El $75 \%$ pertenecen a redes formales de asociativismo.

De los 20 SA gestionados por productores:

- 4 son alojamientos

- 1 ofrecen actividades

- 1 ofrecen servicios de gastronomía

- 14 combinan actividades- $70 \%$ 


\begin{tabular}{|l|l|l|l|l|l|l|l|l|l|l|}
\hline $\begin{array}{l}\text { Total } \\
\text { SA con } \\
\text { turismo } \\
\text { rural }\end{array}$ & $\begin{array}{l}\text { Gestión a } \\
\text { cargo de no } \\
\text { productores } \\
\text { agropecuarios }\end{array}$ & $\begin{array}{l}\text { Sin } \\
\text { datos }\end{array}$ & $\begin{array}{l}\text { Gestión a } \\
\text { cargo de } \\
\text { productores } \\
\text { agropecuarios }\end{array}$ & $\begin{array}{l}\text { Con } \\
\text { más } \\
\text { mano } \\
\text { de obra } \\
\text { Familiar }\end{array}$ & $\begin{array}{l}\text { Con más } \\
\text { empleados }\end{array}$ & $\begin{array}{l}\text { Con hijos } \\
\text { involucrados } \\
\text { en el SA }\end{array}$ & $\begin{array}{l}\text { Sin hijos o } \\
\text { independientes } \\
\text { del SA }\end{array}$ & $\begin{array}{l}\text { Del } \\
\text { lugar }\end{array}$ & $\begin{array}{l}\text { Foráneo } \\
\text { Trabajo } \\
\text { en red }\end{array}$ \\
\hline 55 & 35 & $\begin{array}{l}\text { Sin } \\
\text { trabajo } \\
\text { en } \\
\text { red }\end{array}$ \\
\hline
\end{tabular}

\section{Casos de la zona centro}

Los criterios utilizados para la elección de los casos fueron:

1. Aunque la mayoría de los SA gestionados por productores agropecuarios son predominantemente familiares, se seleccionaron actores de esta tipología pero también algún representante de actores con un perfil más empresarial, que también existen en la zona.

2. Una de las variables más importantes es la conformación de la familia con hijos a cargo que participen activamente del SA, por lo tanto se seleccionaron casos con hijos y otro en el que no intervengan, por ser pequeños o por no tener sucesión familiar.

3. Uno al menos no debe tener experiencia asociativa.

4. Para profundizar el análisis e incrementar la diversidad y complejidad de la información obtenida en esta zona se eligió un SA cuya gestión no esté a cargo de productores agropecuarios.

\begin{tabular}{|c|c|c|c|c|}
\hline $\begin{array}{l}\text { Casos zona } \\
\text { Centro }\end{array}$ & Actividad productiva & Categoría turística & Mano de obra & $\begin{array}{l}\text { Integración a } \\
\text { redes }\end{array}$ \\
\hline Caso 4 & $\begin{array}{l}\text { Tambo/ agricultura/ } \\
\text { actividades de granja y } \\
\text { huerta }\end{array}$ & $\begin{array}{l}\text { Combina } \\
\text { actividades y } \\
\text { gastronomía }\end{array}$ & $\begin{array}{l}\text { Familiar con hijos } \\
\text { participando } \\
\text { activamente en la } \\
\text { producción }\end{array}$ & $\begin{array}{l}\text { Integra redes } \\
\text { asociativas }\end{array}$ \\
\hline Caso 5 & $\begin{array}{l}\text { Avicultura, ganadería y } \\
\text { camión. }\end{array}$ & $\begin{array}{l}\text { Actividades y } \\
\text { gastronomía }\end{array}$ & $\begin{array}{l}\text { Es de gestión } \\
\text { familiar pero tienen } \\
\text { empleados. Mayor } \\
\text { capitalización. Uno } \\
\text { de los hijos } \\
\text { involucrado } \\
\text { directamente con } \\
\text { la ganadería. }\end{array}$ & $\begin{array}{l}\text { Integra redes } \\
\text { asociativas }\end{array}$ \\
\hline Caso 6 & Ganadería/ avicultura & Alojamiento & $\begin{array}{l}\text { Familiar } \\
\text { capitalizados, con } \\
\text { empleados y con } \\
\text { una hija trabajando } \\
\text { en la actividad }\end{array}$ & $\begin{array}{l}\text { Integran } \\
\text { redes } \\
\text { asociativas }\end{array}$ \\
\hline Caso 7 & $\begin{array}{l}\text { No son productores. } \\
\text { Son una familia de } \\
\text { Villa Elisa que } \\
\text { invierten en un campo } \\
\text { que tenía una casa de } \\
\text { campo, tipo tapera. La } \\
\text { arreglaron y alquilan a } \\
\text { turismo. Parte del } \\
\text { campo lo arrendan. }\end{array}$ & Alojamiento & $\begin{array}{l}\text { Familiar. Los hijos } \\
\text { están } \\
\text { indirectamente } \\
\text { relacionados con la } \\
\text { actividad turística o } \\
\text { con proyectos. }\end{array}$ & $\begin{array}{l}\text { Integraron un } \\
\text { grupo } \\
\text { Cambio } \\
\text { Rural. }\end{array}$ \\
\hline Caso 8 & Tambo/quesería & $\begin{array}{l}\text { Combinan } \\
\text { actividades y } \\
\text { gastronomía. }\end{array}$ & $\begin{array}{l}\text { Combinan mano } \\
\text { de obra familiar } \\
\text { con empleados. } \\
\text { Tienen hijos } \\
\text { pequeños, en edad } \\
\text { escolar. }\end{array}$ & $\begin{array}{l}\text { No integran } \\
\text { redes }\end{array}$ \\
\hline
\end{tabular}




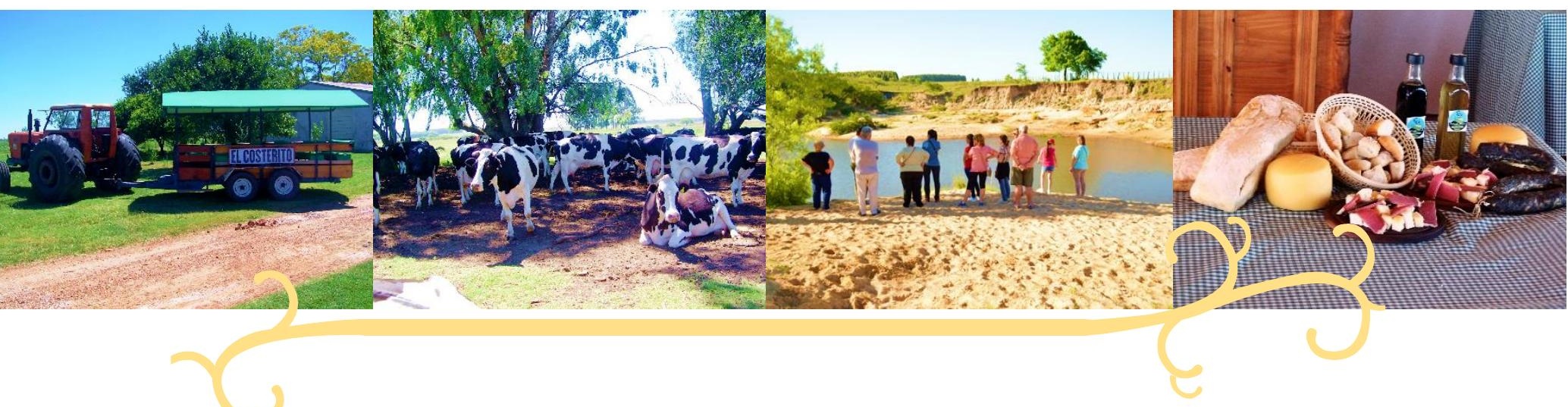

\section{"Costeando la producción tambera"}

"Lo que intenté es buscar otra fuente para decir: dejo el tambo, hago el animal de color (que es el 20\% del trabajo del tambo) y turismo". (Eduardo, productor zona centro). 


\section{C.1 Caso 4- COSTEANDO LA PRODUCCIÓN TAMBERA}

Esta experiencia se seleccionó respondiendo a que es una familia originaria de la zona, que su gestión y mano de obra es netamente familiar, con una activa participación de los hijos en el trabajo en la explotación. Además, han integrado experiencias asociativas junto a otras familias de la zona.

\section{C.1.1 Presentación general}

Familia conformada por una pareja de 47 y 41 años y dos hijos, una mujer de 21 y un joven de16 años. La hija del matrimonio tiene un bebé de 2 años.

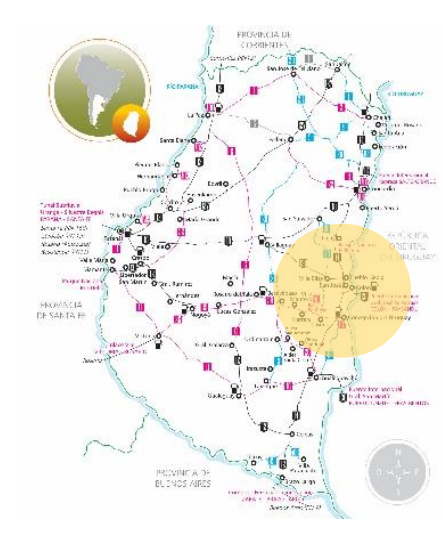

Son productores tamberos familiares ubicados en Hoker, centro rural ubicada a $12 \mathrm{~km}$ de la ciudad de Villa Elisa y a $30 \mathrm{~km}$ de la ciudad de Colón.

Cuentan con un predio de 81 ha, 29 son propias y arriendan 52. De esas, 22 son campo para el pastoreo, las otras 30 son para todo tipo de actividad.

Hace 3 años incorporaron el turismo a su predio. Pusieron en marcha una propuesta de turismo rural a partir de la cual ofrecen almuerzos y meriendas en un local que construyeron ellos especialmente. Ofrecen también una excursión guiada por el productor, en un carro tirado a tractor, con capacidad para 17 personas. En el recorrido se muestra el trabajo en el campo y se llega a un arroyo (Arroyo Mármol) y se visita un viejo puente ferroviario. Al turismo abren los fines de semana y feriados. La mayoría de los productos y alimentos que ofrecen al turismo son elaborados por ellos. La carne que sirven es de su producción, al igual que el chorizo parrillero que elaboran ellos. Solo un $20 \%$ del total de verduras que utilizan para las ensaladas son compradas a productores vecinos. Utilizan las frutas para los budines. A la elaboración del pan la hace la productora. Procesan los chorizos secos cuando hacen las carneadas de invierno, que también ponen a la venta del turismo.

Paulatinamente además, se están reconvirtiendo al animal de cría, actividad en la que incursionan hace tres años. Venden los novillos de un año y medio a carnicerías de la zona, aunque guardan carne para los asados que brindan a los turistas durante los fines de semana.

El tambo tiene 40/42 vacas de tipo Holando Argentino, de las cuales 32 se encuentran en ordeñe con una producción de 300/350 I por día, 10 I por vaca. Producen una leche económica, a sabiendas de que es baja la producción, estrategia que responde a la lentitud de los pagos y el bajo precio de la leche cruda. Poseen un toro (Pampa negro).

Ordeñan de manera mecánica dos veces al día, con una máquina de cuatro bajadas, con la que arrancaron hace casi 2 décadas. Compraron una más grande (de seis bajadas) cuando pensaban llegar a 100 vacas, pero no la utilizaron.

En su predio producen el silaje de maíz y además compran alimento. La leche se vende a la Cooperativa COTAPA (Cooperativa Tamberos de Paraná) desde hace $7 / 8$ años con un pago a 120 días aproximadamente y a un precio muy bajo. De la parte sanitaria se encarga un veterinario.

Hace 3 años empezaron con la ganadería de cría. Hasta ahora van reservando, comprando y cambiando vientres de Holando Argentino por vacas de color (Pampa Negro/ Pampa Colorado) para hacer vientres de animales de color. Venden novillos de menos de 1 año y medio (380/400 k) a carnicerías de San José o Colón. Tratan de quedarse con alguna manta de asado para ofrecer al turismo que llega al predio durante los fines de semana. 
Tienen huerta, árboles frutales y una granja con animales. Su destino es el autoconsumo y a partir del turismo se incorporan como un atractivo y producen alimentos a partir de estos. Tienen $5 / 6$ colmenas. La miel es para la venta y para endulzar los productos que elaboran para el
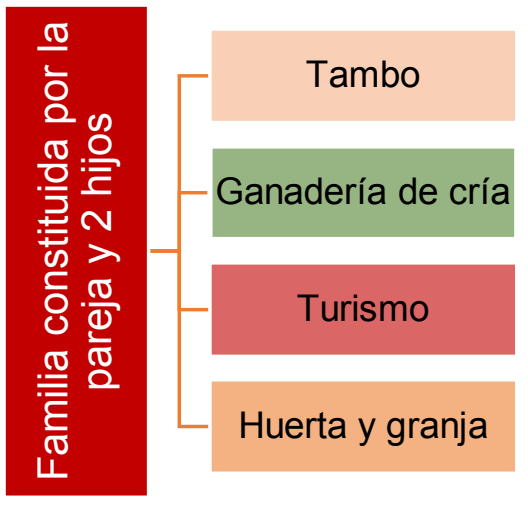
turismo.

Actualmente cuentan con tres actividades productivas que generan ingresos a la familia: el tambo, el animal de cría y el turismo. Se incorpora al análisis la huerta y granja por su integración al resto de las actividades.

\section{C.1.2 Recursos de la familia ${ }^{54}$}

\begin{tabular}{|c|c|}
\hline $\begin{array}{l}\text { Recursos } \\
\text { humanos }\end{array}$ & $\begin{array}{l}\text { Son productores familiares, no cuentan con empleados sino que se dedican los } \\
\text { integrantes de la familia al trabajo en el campo }\end{array}$ \\
\hline $\begin{array}{l}\text { Recursos } \\
\text { físicos, } \\
\text { materiales y } \\
\text { naturales }\end{array}$ & $\begin{array}{l}\text { Poseen un predio de } 29 \text { ha y arriendan } 52 \text {. Poseen su vivienda familiar, una que } \\
\text { cedieron a la hija que vive con su pequeña. Tienen } 40 / 42 \text { vacas de tipo Holando } \\
\text { Argentino, un toro, bajada mecánica. Construyeron un salón para brindar los } \\
\text { almuerzos y fabricaron también un carro que se ensambla con el tractor para hacer } \\
\text { las visitas. Poseen una huerta en la que producen verduras para autoconsumo y para } \\
\text { abastecer al turismo; alrededor de } 30 \text { árboles frutales, plantaciones de frutillas y } \\
\text { zanahorias. Cuentan además con un vivero con plantas aromáticas, cactus (para la venta, } \\
\text { en macetas de barro). Cuentan con una granja de animales con vizcachas, terneros, } \\
\text { conejos, chanchos (4/5), gallinitas, perdices, cordero, patos. El predio además cuenta con } \\
\text { recursos naturales como un arroyo con agua de vertiente, restos volcánicos, un antiguo } \\
\text { puente ferroviario, que integran y enriquecen la propuesta turística. }\end{array}$ \\
\hline $\begin{array}{l}\text { Recu } \\
\text { econ }\end{array}$ & $\begin{array}{l}\text { Manejan sus ingresos como una caja única, en la que el tambo representa el ingreso } \\
\text { más sólido y estable. No llevan un registro sistemático de su flujo de ingresos y egresos. } \\
\text { La familia integra los ingresos de las tres actividades aunque la actividad que más le } \\
\text { genera es el tambo. } \\
\text { "Sacamos de uno y lo metemos en el otro". (Eduardo, productor zona centro). } \\
\text { "Lo sólido es el tambito: hay que venir a buscar bebidas a Villa Elisa, paga el tambito; la } \\
\text { comida de las vacas se paga con cheques a la liquidación de la leche". (Eduardo, } \\
\text { productor zona centro). } \\
\text { "Al ser sólido el tambito, las otras actividades dan". (Eduardo, productor zona centro). }\end{array}$ \\
\hline $\begin{array}{l}\text { Recursos } \\
\text { sociales }\end{array}$ & $\begin{array}{l}\text { Se vinculan con la oficina de turismo de Villa Elisa, integran un grupo Cambio Rural } \\
\text { y el proyecto de la Ruta de Turismo Rural del Corredor del Río Uruguay. Se } \\
\text { relacionan con otros productores, articulación que potencia los intercambios, } \\
\text { aprendizajes y comunicación de su propuesta turística. } \\
\text { "Nos cruzamos con otros productores en ferias, cursos". } \\
\text { "Entre INTA y Villa Elisa nacimos nosotros". (Eduardo, productor zona centro). } \\
\text { "A través del grupo de INTA empezamos a aprender de turismo" (Eduardo, productor zona } \\
\text { centro). "Con los compañeros de turismo (otros productores) nos mandamos gente (más } \\
\text { con Miel Dorada, Olguita y Silvia" (integrantes del grupo Cambio Rural). "Y además a los } \\
\text { de Villa Paranacito y Villa del Rosario" (integrantes de la Red de la Ruta del Turismo } \\
\text { Rural). (Eduardo, productor zona centro). }\end{array}$ \\
\hline
\end{tabular}

\footnotetext{
${ }^{54}$ En el cuadro se utilizan colores determinados para resaltar algunos conceptos que luego son recuperados en un esquema conceptual. Los recursos humanos son referidos en color rojo; los físicos, materiales y naturales en naranja; los recursos económicos en violeta; los sociales en azul y los recursos identitarios en verde.
} 


\begin{tabular}{|l|l|}
\hline $\begin{array}{l}\text { Recursos } \\
\text { identitarios }\end{array}$ & $\begin{array}{l}\text { La razón de ser del turismo es el tambo, no sólo desde el punto de vista de la } \\
\text { producción de materia prima para los productos que elaboran para los visitantes, sino } \\
\text { también desde una mirada identitaria. El tambo, además de ser la actividad económica } \\
\text { más "sólida", es la que más los representa como familia, por su historia en la } \\
\text { actividad, por su origen y por las características que le imprimen como familia que a su } \\
\text { vez viene de familias tamberas. }\end{array}$ \\
$\begin{array}{l}\text { Recursos } \\
\text { territoriales }\end{array}$ & $\begin{array}{l}\text { El emprendimiento se localiza en el centro de una de las micoregiones más turísticas de } \\
\text { la provincia, a pocos kilómetros de uno de los principales destinos turísticos del país } \\
\text { (Colón). La misma familia considera que tiene más proyección el turismo que las } \\
\text { actividades del tambo. }\end{array}$ \\
\hline
\end{tabular}

\section{C.1.3 Trayectoria familiar}

Ambos productores nacieron en la zona, y ambos provienen de familias tamberas.

Comenzaron con su tambo hace 19 años a partir de la venta de 15 ha del terreno por parte de un familiar del productor, adonde fueron a vivir a los cinco años de casados.

Luego, reciben en herencia otra cantidad de hectáreas con la que llegan al arroyo Mármol, eje del atractivo de turismo rural.

En su trayectoria como productores tamberos han sufrido tres grandes crisis, producto de la caída de las grandes empresas a las que entregaban su leche cruda -1998/1999- 2003 y fines del 2015.

En los 2000, producto de la situación de crisis económica e institucional del país, que repercutió directamente en el sector, comenzaron a hacer queso de colonia, actividad a la que se dedicaron de tres a cinco años.

Como productores tamberos vienen retrocediendo en la producción. Hace tres años atrás estaban ordeñando 70/75 vacas y con intenciones de llegar a 100 (para lo cual hicieron inversiones) pero a partir de la crisis de las industrias lácteas en el país, el bajo precio de la leche y el pago diferido de la misma, han decidido achicarse y lentamente pasar al animal de cría.

También hace tres años, la familia construyó el local que fueron armando bajo directrices de accesibilidad (baños accesibles, rampas). Construyeron también un acoplado al que paulatinamente fueron agregando techo, rampa para personas con discapacidad, que ofrecen a los turistas para hacer un recorrido por el predio y hasta un arroyo cercano.

\section{C.1.4 Emergencia del turismo}

El turismo se incorpora como una alternativa de diversificación de los ingresos, en el marco de un proceso de reconversión productiva (paso de tambo a animal de cría) y turismo.

Al parecer hay algunos elementos determinantes en estas decisiones:

- La edad de los productores y la trayectoria de los mismos vinculados a un trabajo de gran esfuerzo físico han sido un factor decisivo en esta transformación. El turismo representaría un trabajo menos sacrificado y más placentero.

"No da mi esqueleto". (Eduardo, productor zona centro).

"Tengo 47 años y 27 de tambo". (Eduardo, productor zona centro).

"Tambo y turismo son dos cosas distintas: por el tema de mi rodilla sé que lo tengo que dejar. Hace 27 años que ordeño. Sé que si sigo ordeñando así con mi rodilla, en 50 6 años no voy a poder caminar más". (Eduardo, productor zona centro).

Para la productora, el turismo les representa una vida con más salud a futuro.

“...más bienestar a la salud de uno. Nosotros que ya tenemos varios años de tambo, el turismo es algo más tranquilo, más liviano. Mi marido ya está cansado de madrugadas, de lluvias, de frío... con esto (el turismo) te guardás más en la casa para preparar las cosas para el fin de semana". (Ana, productora zona centro). 
- Las recurrentes crisis en el sector lechero del país.

"Venimos de por demás castigados, esto no se va a dejar (el tambo) pero se van cayendo las expectativas que uno tiene".

"Entonces nos vamos al animal de cría, al engorde, seguimos haciendo lo que es turismo". (Eduardo, productor zona centro).

- Los atractivos paisajísticos, naturales y el patrimonio histórico que se destacan en su predio (un arroyo con agua de vertiente, restos volcánicos, un antiguo puente ferroviario) que incentivaron la búsqueda de un nuevo rumbo a través del turismo.

- La necesidad de generar alternativas para sus hijos.

"Buscando que los chicos se queden en la colonia, porque no está quedando más nadie". "La gente grande se va cerca de un hijo o de un doctor porque van quedando viejitos. Y la gente que se va a estudiar no vuelve más". (Eduardo, productor zona centro).

- Ubicación estratégica en una de las microregiones de la provincia con mayor flujo de turistas.

\section{C.1.5 Objetivos, decisiones y estrategias puestas en marcha}

Ante contextos de alta incertidumbre y volatilidad como es el sector tambero en Argentina, la familia busca incorporar otras actividades económicas, que colaboren y posibiliten su permanencia en el campo, actividades que son pensadas asimismo como una posibilidad de empleo y continuidad de los hijos en la actividad y en la colonia.

A partir de los ingresos del tambo se mantienen las otras actividades, pero a la vez no se puede dejar ninguna actividad, ya que todas generan un ingreso económico.

"No podemos dejar ninguna actividad, pero la idea es achicar el tambito lo más que se pueda". (Eduardo, productor zona centro).

Para esto tomaron una serie de acciones estratégicas:

1. El turismo es un canal de comercialización de los productos que elaboran con la materia prima que brinda su campo (huerta, frutales, granja), que de otra manera serían para autoconsumo solamente.

2. Elaboran todos los productos que ofrecen al turismo con una alta calidad, lo que les da confianza en sus servicios. Intentan comprar insumos para el turismo lo menos posible.

3. No tienen empleados. Es empleo familiar, y todos hacen todo.

4. Elaboran una leche económica. Son conscientes de que es bajo el rendimiento "pero es la única forma de hacer una leche económica". "Por lo rápido que nos pagan tampoco nos desesperamos por hacer leche". "Si no cobramos, no queremos invertir. La leche se levanta con dinero, con más alimento, con más silaje, con más alfalfa". (Eduardo, productor zona centro).

Un aspecto interesante es que esta diversificación productiva también está pensada como una manera de continuar con el tambo, aunque implique una reducción. Aunque podría pensarse que el turismo está desplazando esta actividad productiva principal, se nutre de ésta, y es la actividad que más los representa. 
Sus objetivos productivos son: reducir el tambo a 7/10 vacas, 100 is de leche a día para autoconsumo y para el turismo), cambio por animales de cría. Aun no tienen determinado si van a hacer recría.

Pretenden seguir apostando por el turismo y continuar con las tres actividades haciéndose cargo a nivel familiar, sin contratar empleados. Para poder sostener este sistema deben organizarse de una manera óptima. Así, la distribución de tareas se da de una manera organizada y coordinada, tanto para las tareas que desarrollan durante la semana, que mayoritariamente están asignadas a la alimentación y cuidado de los animales y mantenimiento del predio, como las del fin de semana, que dedican un $80 \%$ a la preparación del asado, comidas, visitas guiadas y atención al turista. Las mujeres se dedican al aseo de la casa, atención a animales de granja, alimentan a los terneros y producen alimentos.

\section{C.1.6 Vinculación del sistema familia-explotación con la actividad de turismo rural $^{55}$}

\begin{tabular}{|c|c|}
\hline $\begin{array}{c}\text { Interacción producto } \\
\text { Explica el flujo de materia } \\
\text { prima de una actividad a } \\
\text { otra. }\end{array}$ & $\begin{array}{l}\text { Los productos de la producción primaria son insumos para la } \\
\text { elaboración de los alimentos que sustentan una segunda actividad } \\
\text { como es el turismo: carne y chorizo para el asado, verduras para } \\
\text { ensaladas, frutas para budines y meriendas. Este circuito de materia } \\
\text { prima (Producción primaria) productos elaborados (turismo) } \\
\text { colabora a la sustentabilidad del proyecto familiar. } \\
\text { Se da también entre la agricultura y ganadería ya que ellos mismos } \\
\text { producen el maíz que alimenta a los animales de cría. }\end{array}$ \\
\hline $\begin{array}{l}\text { Interacción recursos } \\
\text { Se explica a partir de la } \\
\text { movilización de un mismo } \\
\text { recurso para varias } \\
\text { actividades. }\end{array}$ & $\begin{array}{l}\text { El capital humano familiar es la base del trabajo de todas las } \\
\text { actividades. } \\
\text { El turismo viabiliza una reorganización de tareas potenciando las } \\
\text { capacidades y gustos personales de los miembros de la familia. } \\
\text { Aunque "todos sepan hacer todo" y "todos hagan todo", hay tareas que } \\
\text { corresponden -por empatía y capacidad de trabajo- a cada uno ellos. } \\
\text { (Productor: ordeñe y asado; productora: granja y cocina; hija: granja y } \\
\text { ayudante en cocina; hijo: manejo de maquinaria, mozo y ayudante en } \\
\text { parrilla; yerno: ayudante en ordeñe, mozo y ayudante en parrilla). } \\
\text { Por otro lado, la base de las propuestas de turismo rural está dada } \\
\text { por el saber y saber hacer de la familia, sus valores, y aquellos } \\
\text { aspectos que la identifican con el entorno. } \\
\text { Tareas impostergables: El ordeñe y la comida a los novillos (se dan en } \\
\text { horas fijas, con turistas también). } \\
\text { Físico: se utilizan equipamientos para varias actividades del } \\
\text { sistema, por ejemplo el tractor, utilizado por las actividades típicas del } \\
\text { campo, es el motor de "El Costerito", una de las patas de la mesa de la } \\
\text { propuesta de turismo rural. Esto muestra a las claras la creatividad y la } \\
\text { eficiencia en el uso de los recursos de la familia. } \\
\text { Respecto a lo social, a diferencia de las otras actividades económicas } \\
\text { de la familia, el turismo vincula a la familia con las comunidades de } \\
\text { la zona, con referentes municipales, técnicos y con otros } \\
\text { productores posibilitando mayores oportunidades de intercambio } \\
\text { de experiencias y aprendizajes, en los que los productores dan y } \\
\text { reciben, son transmisores de sus propias experiencias y conocimientos, } \\
\text { en los que lo central es su saber, saber hacer y su ser. }\end{array}$ \\
\hline
\end{tabular}

\footnotetext{
${ }^{55}$ En el siguiente cuadro se enfatizan algunos conceptos utilizando colores que luego serán adoptados en el esquema conceptual que explica las interacciones de la actividad turística con el resto de las actividades del sistema. Así, con naranja se remarca la interacción entre productos de las distintas actividades; con rojo y azul la interacción de los recursos humanos y sociales y con naranja claro entre recursos físicos, naturales y materiales; con verde la interacción patrimonial; con gris, la temporal; con violeta claro la interacción dada entre el ingreso y el sentido dado al trabajo, y con violeta oscuro, la interacción entre los ingresos que aportan las actividades al sistema.
} 


\begin{tabular}{|c|c|}
\hline $\begin{array}{l}\text { Interacción patrimonial } \\
\text { La implementación } \\
\text { actividades simultáneas se } \\
\text { dan en torno al valor } \\
\text { intangible de un patrimonio }\end{array}$ & $\begin{array}{l}\text { La propuesta turística se basa en dos pilares: el patrimonio natural y } \\
\text { paisajístico que se encuentran dentro del predio y que a la vez son } \\
\text { utilizados como espacios de ocio de la misma familia; y la tarea rural } \\
\text { que desarrolla la familia, son sus saberes, experiencias y forma de } \\
\text { transmitirla a los turistas, que a la vez tiene la posibilidad de participar } \\
\text { de la actividad. }\end{array}$ \\
\hline $\begin{array}{l}\text { Interacción temporal } \\
\text { Explica los procesos de } \\
\text { anticipación de un cambio } \\
\text { que está por venir, del } \\
\text { abandono o implementación } \\
\text { de una nueva actividad }\end{array}$ & $\begin{array}{l}\text { El turismo se integra al sistema como una alternativa de trabajo a } \\
\text { futuro concretamente para la pareja de productores. La estrategia } \\
\text { es que paulatinamente se vaya convirtiendo en su actividad } \\
\text { principal para los próximos años, dado el desgaste físico que } \\
\text { caracteriza la actividad tambera y que, dada la edad del productor y su } \\
\text { mala salud, pareciese imposible de continuar. Esta decisión implica } \\
\text { transformaciones y un esfuerzo mayor en el presente, pero pensando } \\
\text { en una mayor calidad de vida a futuro. }\end{array}$ \\
\hline $\begin{array}{l}\text { Interacción ingresol } \\
\text { sentido del trabajo } \\
\text { La combinación de } \\
\text { actividades permite asociar } \\
\text { actividades fuertemente } \\
\text { remuneradas con actividades } \\
\text { que no son menos } \\
\text { importantes pero proveen } \\
\text { otro tipo de satisfacciones }\end{array}$ & $\begin{array}{l}\text { Además de los ingresos económicos, aporta a la familia otro tipo de } \\
\text { "ganancias", vinculadas con satisfacciones personales y aportes a la } \\
\text { salud de los miembros de la familia; refuerza la autoestima } \\
\text { personal y es un vehículo para reforzar la identidad y su propia idea } \\
\text { de quiénes son, de dónde vienen, que hacen y por qué hacen lo que } \\
\text { hacen. }\end{array}$ \\
\hline $\begin{array}{c}\text { Interacción ingreso } \\
\text { Se da cuando } 2 \text { o más } \\
\text { actividades aportan a los } \\
\text { ingresos totales disponibles } \\
\text { para la familia. }\end{array}$ & $\begin{array}{l}\text { Desde el punto de vista económico-financiero, el turismo ha sido } \\
\text { capitalizado y sigue siendo en su mayoría financiado por la } \\
\text { actividad tambera. No obstante, se piensa que en un futuro, va a tener } \\
\text { otro rendimiento económico, en el marco de una estrategia productiva } \\
\text { global. La familia integra los ingresos de las tres actividades y el } \\
\text { tambo es el más sólido y estable. El turismo complementa los } \\
\text { ingresos familiares y es pensada como una actividad económica que } \\
\text { genera más ingresos que egresos (por el nivel de sinergia entre } \\
\text { actividades y productos) a una caja única. }\end{array}$ \\
\hline
\end{tabular}

\section{C.1.7 Impacto del turismo en el sistema productivo}

Como se mencionó, el turismo surge como una alternativa de diversificación de los ingresos de esta familia tambera que ha sufrido el impacto de varias crisis del sector lechero y la caída en el precio de la leche. Al parecer, el sistema seguiría funcionando esté o no la actividad turística, aunque su integración colabora al engranaje de los productos de las diversas actividades más aun teniendo en cuenta que es decisión de los productores ir retrayendo la actividad tambera. El turismo se convierte en un mercado para la canalización de los productos primarios generados en la finca, dando más autonomía al sistema.

El turismo compite al interior del sistema, en términos del uso de la fuerza de trabajo porque es la familia la responsable de la gestión y ejecución de las actividades. No obstante, con una buena organización en la distribución del tiempo de tareas diarias y semanalmente, no agrega en sí una dificultad difícil de sortear, si se respetan los tiempos de las tareas impostergables (ordeñe, alimentación, tiempos del asado para el turista). 


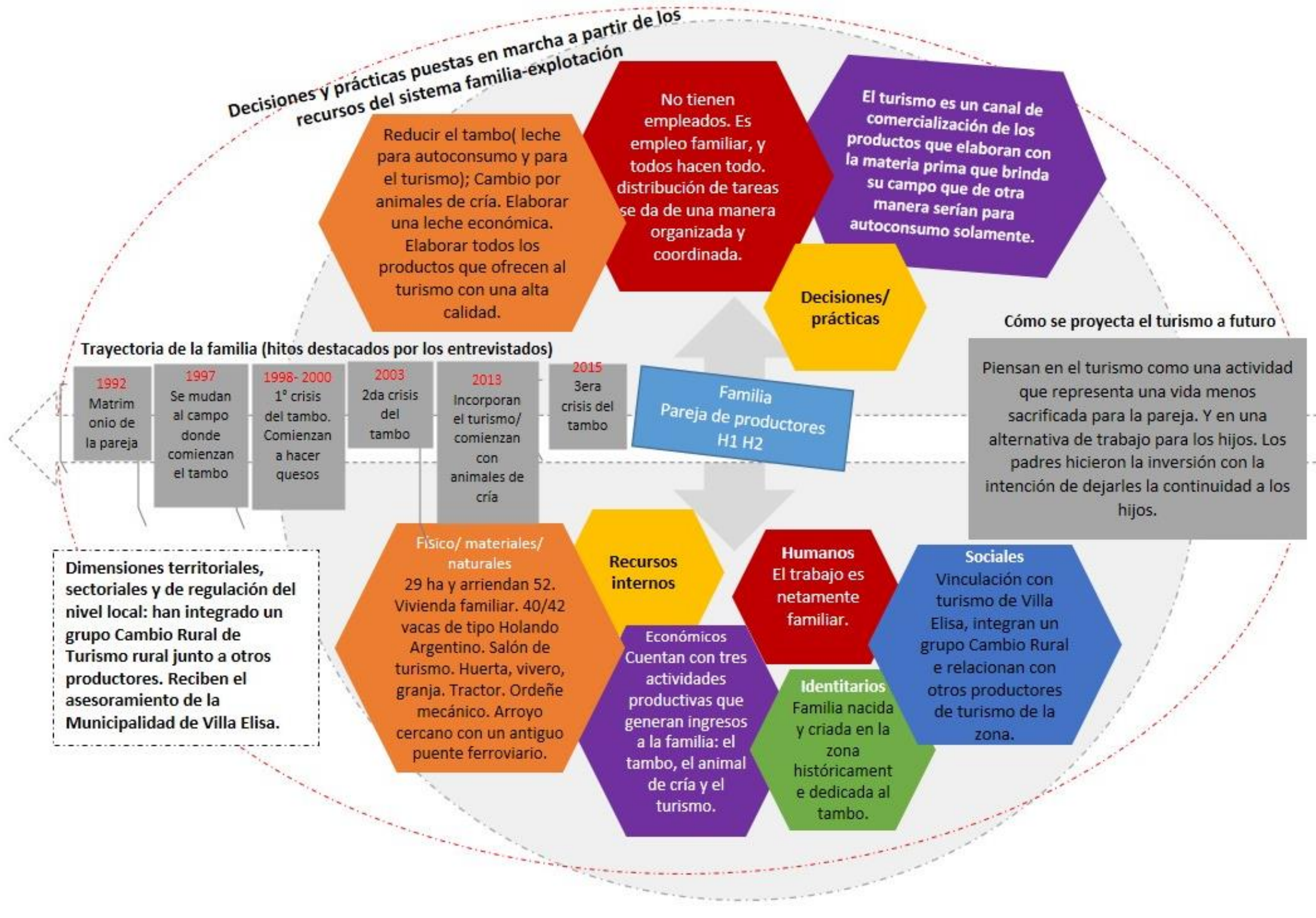


Interacción ingresos

La familia integra los ingresos de las tres actividades y el tambo es $\mathrm{el}$ más sólido y estable. El turismo complementa los ingresos farniliares.

El símbolo + representa la importancia relativa del ingreso al sistema de cada actividad

Interacción ingreso/sentido del trabajo

Además de los ingresos económicos, aporta a la familia otro tipo de "ganancias", vinculadas con satisfacciones personales $y$ aportes a la salud de los miembros de la familia

Interacción temporal
Idea de convertir al turismo
en la actividad principal del
sistema. Esta decisión
implica transformaciones y
un esfuerzo mayor en el
presente, pero pensando en
una mayor calidad de vida a
futuro.

Ilustración 12- Esquema de interacciones de las actividades dentro del sistema Caso 4

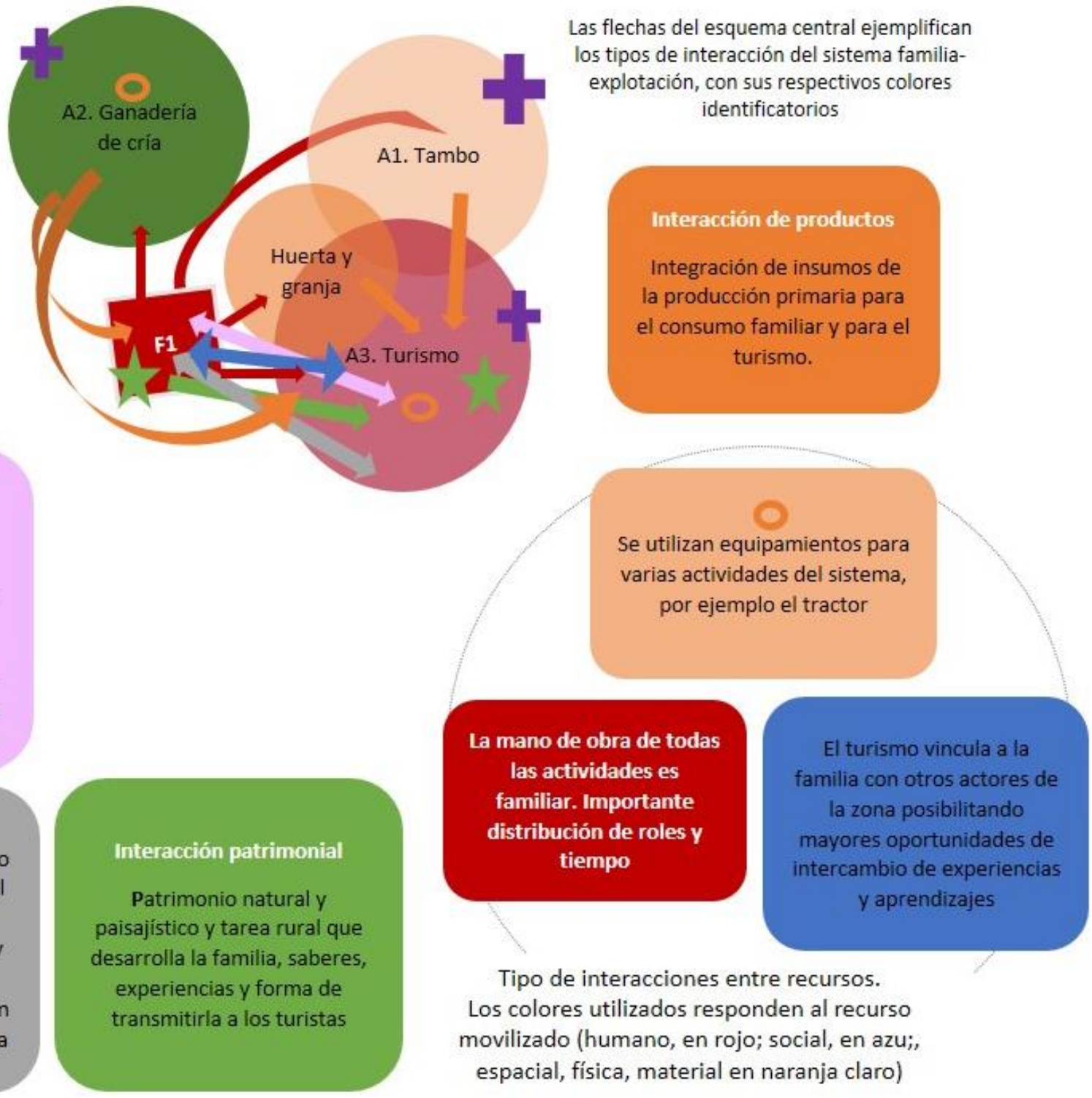

Tipo de interacciones entre recursos.

Los colores utilizados responden al recurso movilizado (humano, en rojo; social, en azu; espacial, física, material en naranja claro) 


\section{C.1.8 Impacto del turismo en la familia, en las personas y en sus estilos de vida}

- La integración de la actividad turística al interior de la unidad productiva aporta complejidad fundamentalmente desde el punto de vista de la redistribución de tareas y organización del tiempo de los miembros de la familia.

"A las 7 arrancamos con las tareas de la casa, huerta y jardín. Dormimos la siesta. En verano limpiamos y ordenamos más afuera. Los fines de semana, lo primero que se hace es el pan. 10:30 en el molde, 11 hs prende el horno para que 12:30/13 hs esté listo". (Ana, productora zona centro).

- Pero por otro lado les aporta nuevos y diferentes aprendizajes que brinda el contacto con los turistas, afianza aquellos aspectos que definen y caracterizan a la familia y refuerza su imagen como productores tamberos, sencillos, trabajadores, con una forma de vivir y trabajar, en familia, nacida y criada en la zona, conocedora del lugar y de las prácticas culturales que identifican el territorio.

- Funcionan como un engranaje en el cual cada uno sabe lo que tiene que hacer y cuándo: a las 5:30 hs el productor hace el ordeñe; por la mañana temprano las mujeres alistan todo para atender a los turistas al mediodía (limpieza, elaboración del pan, lavado y preparación de ensaladas); el productor comienza con el trabajo en la parrilla; los 2 varones (hijo y yerno) mantienen la parrilla mientras el productor hace la visita guiada (a las 12 hs); a las 15 hs paran la parrilla, el hombre hace una nueva visita y la mujer queda a cargo del local. Los dos varones preparan los animales para que a las $17 \mathrm{hs}$ hagan el segundo ordeñe. Mientras tanto son mozos.

"A las 12 les contamos cómo hacemos el ordeñe, a las 17 hs les mostramos" (cómo se da leche a los terneros, cómo se ordeña)". (Eduardo, productor zona centro).

- De los 7 días de la semana, 2 son destinados al turismo, aunque en temporada alta, son 4. Por día del fin de semana el $80 \%$ es dedicado al turismo. Durante la semana, la mayor parte del tiempo se dedica a las actividades con animales.

- Momentos de tensión: el estrés se da cuando llega mucha gente al predio durante los fines de semana y más cuando no hacen reserva para el asado. No obstante, aun en los momentos de mayor tareas y visitas- que implican una cierta tensión y temor a que el servicio no sea de la calidad que ellos esperan brindar, se organizan en sus tareas para cumplimentar los tiempos. Según ellos, "se ponen nerviosos" porque hacen todo en el momento.

"Cuando tenés 15 personas es todo tranquilo, más fácil. Cuando hay más de 25 es más difícil". (Eduardo, productor zona centro).

"El domingo tuvimos 32 personas. El carrito tiene hasta 17 personas, por tanto hicimos 2 salidas". (Eduardo, productor zona centro).

(Mientras el productor hacía el recorrido, el hijo buscó al segundo grupo que volvió a las 17:30 hs, hora en la cual el otro varón estaba dedicado al tambo)

- Se consideran exigentes, son una familia aguerrida, que han construido su capital con esfuerzo y tesón.

"Los dos venimos de familias de bajos recursos". (Ana, productora zona centro).

- Otro de los momentos más complejos es cuando llueve durante los fines de semana. En esta circunstancia se complejiza el trabajo con los animales pero a la vez se alivia el turismo porque el turista no llega al campo. Las tareas se complican cuando 
la gente no reserva para el almuerzo. Hay tensión porque cuando tienen más gente de la prevista se demoran en el servicio y eso les disgusta. Tareas impostergables: El ordeñe y la comida a los novillos (se dan en horas fijas, con turistas también).

\section{C.1.9 Percepción del futuro en relación a los hijos y en relación a su resguardo de ingresos}

La idea de la familia es vivir del turismo, que paulatinamente se vaya convirtiendo en su actividad principal para los próximos años, dado el desgaste físico que caracteriza la actividad tambera y que, dada la edad del productor y su mala salud, pareciese imposible de continuar; dedicar el trabajo de la semana a la elaboración de productos (quesos, escabeches, nueces) para vender al turismo que se recibe durante los fines de semana.

"Con el tiempo me gustaría, en parte a los animales que siempre van a estar, pero de trabajar para el turismo. Trabajar y vivir de eso". (Eduardo, productor zona centro).

A la propuesta desean agregar venta de artesanías y souvenirs, que responde a un anhelo personal del productor.

"Mi gran ilusión es trabajar con la madera, me gustaría algún día tener una mini carpintería para poder hacer recuerdos, platos, adornos..." (Eduardo, productor zona centro).

Esta familia ha decidido que los hijos no continúen con su estudio secundario, en principio porque se les hacía pesado desde el punto de vista económico. También afectan las experiencias personales de los padres en esta decisión, bien porque han tenido que despegarse de sus familias de jóvenes y porque entienden que es muy dificultoso finalizar la escuela. Y además pone a las claras una lógica -y necesidad- de trabajo con mano de obra familiar, y de "garantía" de continuidad del patrimonio familiar en manos de los hijos.

"Se tienen que ir para hacer el secundario... es bravo para una persona del campo ir a un internado". (Eduardo, productor zona centro).

"El hijo dijo que quiere estudiar para poner un taller "se lo apoyará si así lo deciden pero no creo que se vayan". (Eduardo, productor zona centro).

"No sé si es una deuda que nos va a quedar pendiente o no porque en general los chicos de la colonia empezaron todos a estudiar y no llegó ninguno". "Hace 7/8 años atrás no estábamos en condiciones de viajar $17 \mathrm{~km}$ de ida y vuelta y $17 \mathrm{~km}$ de vuelta, ida y vuelta, por razones de tiempo, de costo, de vehículo". (Eduardo, productor zona centro).

Piensan en el turismo además como "un horizonte para ellos", para los hijos. Los padres hicieron la inversión primera, con la intención de dejarles la continuidad a los hijos.

"Ellos sabrán el día de mañana si lo van a seguir o no. Techo no tiene esto, se podría ir ampliando con bungalows, con pileta, con más paseos, con más parques". (Eduardo, productor zona centro). 


\section{C. 2 Caso 5 - UN ESPACIO DONDE LUGAREÑOS Y TURISTAS SIGUEN HACIENDO HISTORIA}

En este caso en particular el eje está dado por un sistema productivo familiar más capitalizado, llevado adelante por una familia que nació en la zona, con uno de sus hijos muy involucrado con las actividades productivas del sistema y con experiencia en integración de redes asociativas de trabajo.

\section{C.2.1 Presentación general}

Familia integrada por la pareja de 65 años de edad aproximadamente- y tres hijos adultos, dos con sus propias familias. Viven y realizan sus actividades en Colonia EI Carmen, muy próxima a Villa Elisa. Históricamente se dedican a la producción avícola de gallinas y heredaron un antiguo almacén de campo que funciona para los lugareños y desde el 2010 abren al turismo.

Las actividades que generan ingreso económico a la familia son cinco: avicultura, ganadería, fábrica de alimentos, almacén de campo y turismo.

El productor, que fue camionero durante 60 años, está a cargo de la actividad avícola y del reparto de huevos. La productora y una socia, del almacén. Sólo uno de sus hijos, que es veterinario, está relacionado con las actividades productivas de la familia y se dedica a la ganadería.

Además es docente de la escuela agrotécnica de la colonia y posee un camión, con el cual hace trabajos a terceros. La hija es técnica en turismo y trabaja en el complejo termal desde sus inicios y el hijo del medio también es técnico en turismo pero tiene su camión propio y a este rubro se dedica.

El almacén de ramos generales de 1907 se encuentra en un predio de 12 ha. Abre de lunes a sábado desde las 8 hs hasta el mediodía, y luego por la tarde hasta las 19:30 hs. Además de la presentación de la historia del lugar se ofrecen picadas y meriendas. Funciona como almacén al público y además se venden productos regionales elaborados en la zona. Son propietarios de 180 ha que fueron comprando para la actividad ganadera. Y alquilan unas 150 ha más.

Respecto a la actividad avícola tienen dos empleados y cuentan con 10 mil gallinas ponedoras, situadas en tres galpones. Comercializan los huevos en Concordia, adonde el productor viaja todas las semanas. Las gallinas tienen un año y medio de postura.

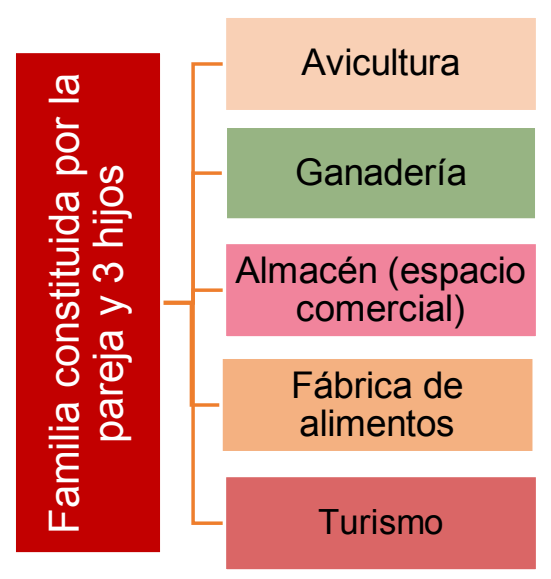

En ganadería hacen el ciclo completo, cría, recría e invernada. Se vende a frigoríficos de la zona. Cuentan con 300 cabezas de ganado. Se cultivan pasturas, se hacen rollos, silo picado y alimento balanceado con cereal comprado. Se abona con cama de pollo.

Para la fábrica de alimentos, un laboratorio les brinda asesoramiento y compran los núcleos. Venden una parte de sus cereales y alimento fabricado. Producen 40 toneladas para uso propio y 10 para la venta. 


\section{C.2.2 Recursos de la familia ${ }^{56}$}

\begin{tabular}{|c|c|}
\hline Recursos humanos & $\begin{array}{l}\text { En relación con la unidad productiva trabajan el productor, la productora, una } \\
\text { socia, el hijo, tienen un empleado para la ganadería y dos para avicultura. } \\
\text { El hijo tiene un sueldo y un porcentaje de lo que se produce. El productor se dedica } \\
\text { a las gallinas y al reparto. Una vez a la semana viaja a hacer el reparto. } \\
\text { Respecto a la toma de decisiones, en ganadería el manejo es a criterio del hijo. } \\
\text { "Consulta pero el manejo es suyo. Siempre estamos en contacto en las } \\
\text { decisiones y sabemos qué es lo que hace". (Jorge, productor y dueño almacén de } \\
\text { ramos generales). } \\
\text { En avicultura el productor gestiona pero en consulta con el hijo. } \\
\text { La productora y socia/empleada son responsables además de la parte } \\
\text { administrativa. Producen algunas conservas, dulces y mantienen la limpieza del } \\
\text { almacén. }\end{array}$ \\
\hline $\begin{array}{lr}\text { Recursos } & \text { físicos, } \\
\text { materiales } & y \\
\text { naturales } & \end{array}$ & $\begin{array}{l}\text { Han sufrido una crisis importante pero han logrado mantener su patrimonio. } \\
\text { Hoy están capitalizados. Aunque el almacén no implica un ingreso importante, } \\
\text { colabora con el mantenimiento del patrimonio. Poseen galpones donde crían a las } \\
\text { ponedoras, silo y máquina para fabricar el alimento. Poseen un almacén de más } \\
\text { de } 100 \text { años, } 180 \text { ha propias, } 150 \text { arrendadas, } 10 \text { mil gallinas ponedoras, } 300 \\
\text { cabezas de vacunos, } 2 \text { galpones, silo y máquina para producción de alimento. }\end{array}$ \\
\hline $\begin{array}{l}\text { Rec } \\
\text { ecor }\end{array}$ & $\begin{array}{l}\text { Manejan como caja única las cuentas de las diversas actividades. } \\
\text { El Almacén no implica un ingreso importante. Las otras actividades son el } \\
\text { principal sustento. } \\
\text { "Si hacés un balance se te cae la estantería". (Jorge, productor y dueño almacén } \\
\text { de ramos generales). } \\
\text { "Es un conjunto de cosas. Con la avicultura, la ganadería, que vendés algo } \\
\text { de cereales, de molido o algo de balanceado, hacés girar la rueda". (Jorge, } \\
\text { productor y dueño almacén de ramos generales). } \\
\text { "Viene un cliente a buscar el huevo, te lleva el alimento, pero te compra la galletita. } \\
\text { Son varias patas" (Irma, dueña almacén de ramos generales). } \\
\text { "Yo para comer tengo, a mí lo que me interesaba era toda la otra parte, esto de } \\
\text { ponerlo en valor, de las charlas, poder disfrutarlo en una palabra". "Digamos que } \\
\text { con esto comés, te entretenés y comés, pero a nosotros las otras actividades } \\
\text { nos generan más ingresos". (Irma, dueña almacén de ramos generales). }\end{array}$ \\
\hline Recursos sociales & $\begin{array}{l}\text { Se genera un vínculo muy especial con los turistas que llegan al almacén. } \\
\text { Algunas familias han vuelto más de } 10 \text { veces. Muchos visitantes les regalan } \\
\text { objetos que integran el patrimonio del museo. } \\
\text { "Cuando vienen y vamos mostrando se van mezclando con muchos recuerdos, } \\
\text { con muchas emociones". (Irma, dueña almacén de ramos generales). } \\
\text { Tienen una activa relación con las familias de la zona. } \\
\text { "Acá somos } 6 / 7 \text { familias, da cuenta de que somos una familia grande, nos damos } \\
\text { mucha bolilla, nos llevamos bien, es una familia grande, estamos muy } \\
\text { acompañados". (Irma, dueña almacén de ramos generales). }\end{array}$ \\
\hline $\begin{array}{l}\text { Recu } \\
\text { ident }\end{array}$ & $\begin{array}{l}\text { La propuesta turística se basa en la esencia de un almacén de campo, en el } \\
\text { hecho de que sigue funcionando como espacio de comercialización y } \\
\text { encuentro de la gente del lugar, a los que se suman los turistas en sus visitas. } \\
\text { "Seguimos con el sistema del almacén porque si no nos convertíamos en } \\
\text { restaurante de campo y eso es más fácil de encontrar. En cambio, la esencia del } \\
\text { almacén de campo es lo que se ha ido perdiendo". (Irma, dueña almacén de } \\
\text { ramos generales). } \\
\text { Intentan dar a conocer las costumbres del hombre de campo de antaño, sus } \\
\text { herramientas y estilo de vida. } \\
\text { "Vamos poniendo lo viejo con lo nuevo. Sobre la heladera por ejemplo hay } \\
\text { bebidas que ya no están a la venta. Tratamos de comparar cómo era en otro }\end{array}$ \\
\hline
\end{tabular}

\footnotetext{
${ }^{56}$ En el cuadro se utilizan colores determinados para resaltar algunos conceptos que luego son recuperados en un esquema conceptual. Los recursos humanos son referidos en color rojo; los físicos, materiales y naturales en naranja; los recursos económicos en violeta; los sociales en azul y los recursos identitarios en verde.
} 


\begin{tabular}{|c|c|}
\hline & $\begin{array}{l}\text { tiempo y cómo es ahora". "Se acuerdan de cuando el baño estaba afuera a partir } \\
\text { de la pelela". (Irma, dueña almacén de ramos generales). } \\
\text { El almacén posibilita la convivencia de lugareños y turistas, y esa es una } \\
\text { particularidad que le otorga autenticidad. La gente del lugar con sus historias } \\
\text { también forma parte del patrimonio del lugar. } \\
\text { "A los lugareños no les molesta el turismo. Eso es lo lindo, ese era el gran } \\
\text { desafío, que vengan los turistas pero también los lugareños, lograr eso. Hay un } \\
\text { paisano que se instala en aquel rincón y les dice si quieren me pueden sacar una } \\
\text { foto". (Irma, dueña almacén de ramos generales). } \\
\text { "Nosotros somos auténticos, somos esto. Y yo creo que el turista lo valora, que } \\
\text { estamos dando algo que es auténtico también, lo que tenemos, y el buen trato, } \\
\text { sentir que del otro lado hay un ser humano, que estas son las cosas que se han } \\
\text { perdido mucho, el dedicarle un ratito de tiempo. Yo creo que eso es lo más } \\
\text { valioso que le entregamos". (Irma, dueña almacén de ramos generales). }\end{array}$ \\
\hline $\begin{array}{l}\text { Recursos } \\
\text { territoriales }\end{array}$ & $\begin{array}{l}\text { En el almacén venden productos elaborados por productores de la zona. } \\
\text { "Vendemos todos los productos que hace la gente del lugar, por ejemplo hay una } \\
\text { escuela agrotécnica, a la que nosotros vendemos todos los productos que } \\
\text { hacen". "Hacemos la economía de lo cercano y lo lejano como para favorecer } \\
\text { nosotros primero a la gente del lugar". (Irma, dueña almacén de ramos } \\
\text { generales). } \\
\text { Poseen un fuerte vínculo con la colonia: nacieron en la zona, se criaron allí, } \\
\text { criaron a sus hijos. La productora fue la primer presidente de la Escuela } \\
\text { Agrotécnica de la colonia, y dos de sus hijos son egresados del establecimiento. } \\
\text { Están ubicados estratégicamente a } 15 \mathrm{~km} \text { de la ciudad de Villa Elisa, ciudad } \\
\text { pujante y con un complejo termal muy visitado en la zona. Reciben asistencia } \\
\text { técnica y acompañamiento de la oficina de turismo de ese municipio. Además, } \\
\text { desde el municipio y desde Termas recomiendan el almacén. } \\
\text { "Dejamos folletos, propagandas ahí y el boca a boca tiene muchísimo que ver". } \\
\text { (Jorge, productor y dueño almacén de ramos generales). Se vinculan también } \\
\text { con los municipios de la zona acercando folletería a las ciudades de San José } \\
\text { y Colón. } \\
\text { "Yo me encargo de que tengan folletería", expresa la productora. }\end{array}$ \\
\hline
\end{tabular}

\section{C.2.3 Trayectoria familiar}

Los productores son nacidos en la zona. Ella de una colonia ubicada a $\mathbf{2 0} \mathbf{~ k m}$ de donde se sitúa el almacén y viven. El almacén es de 1907, fecha en la que llega el tren. El abuelo del productor es el que comienza la sociedad. En aquella época había tres almacenes en la colonia. En 1909 el abuelo queda con el 33\% y en 1919 con el 100\%. Se convierte en único dueño.

El predio siempre fueron 12 ha. Hasta el 2010 funcionó solo como almacén de campo. La familia del productor lo hereda y luego ellos se hacen cargo en el año 2004 cuando se disuelve la sociedad con los hermanos.

Los entrevistados han vivido muchos procesos en su historia y en el haber del almacén, uno de ellos es la migración del campo a la ciudad que impactó en la dinámica del comercio.

"Hasta el año 60/61 se trabajaba un montón. Llegó a haber 120 clientes, abarcaba un radio de $20 / 30 \mathrm{~km}$ porque ya se habían cerrado otros almacenes. Este funcionaba como acopio de aves, acopio de huevos, de cereales, pero a partir de esa fecha se vino una ola que me parece que la gente grande se empezó a ir al pueblo, porque veía que la juventud migraba a otro lado. Acá las parcelas son todas chiquitas, de 25 ha, pero había 70/80". (Jorge, productor y dueño almacén de ramos generales).

"No había luz, faltó comunicación, el camino era grave. Además, la mamá se iba con los chicos que estudiaban y ya no volvía". (Jorge, productor y dueño almacén de ramos generales). 
La familia nunca cerró el almacén. Estuvo abierto al público desde sus orígenes.

La productora comenta que en 2015 se inundaron y producto del agua se cayó una pared del sótano, donde se hace una visita.

"En ese momento mi marido había viajado con mis hijos, entonces yo dije lo cierro y me quedo tranquila. Y cuando llegó el momento dije 'no, nosotros nos llenamos la boca diciendo que nunca se cerró, yo no lo voy a cerrar'. Pusimos el mostrador tapando y atendimos por una sola puerta, pero no cerramos".

"Cuestión de orgullo", dice el productor.

Comienzan con la avicultura en la década de 1960, continuando con la producción familiar (padre del productor). Hacían producción integrada pero tuvieron un problema financiero y no continuaron.

"No se pudo reponer, nos costó mucho pero logramos salvar el patrimonio". "Nosotros siempre hicimos avicultura, producción de parrillero y huevos. Con el pollo allá en el 2001/2002 dejamos". (Jorge, productor y dueño almacén de ramos generales).

"Y si no, nos dejaba a nosotros, todavía nos quedan manchas de esa época". (Irma, dueña almacén de ramos generales). "Con avicultura de ponedora seguimos en menor escala y el hijo veterinario nos empuja a tener algo de hacienda. Eso nos Ileva a diversificar". (Jorge, productor y dueño almacén de ramos generales).

Hace 20 años que hacen ganadería.

Él fue camionero hasta el 2000/2001. Sufrieron la crisis del 2001 que afectó fundamentalmente la producción avícola. Les llevó 15 años pagar las deudas para salvar el campo.

"Decayó todo. Esto se fue todo abajo, entonces nos planteamos ¿seguimos o lo cerramos y nos vamos? Pero también irte adónde, si estaba todo el mundo igual. Si resistimos a esa época, hoy por hoy estamos chochos". (Jorge, productor y dueño almacén de ramos generales).

Se fueron reduciendo en la parte de la producción avícola. Eran una sociedad con los hermanos del productor, desde el 1972. Cuando se disuelve y quedan solos, se retrae.

"Yo fui 32 años a Buenos Aires con huevos, la mayoría de producción propia. Acopiábamos 500/ 600 cajones por semana. Después se terminó la integración". Con el mismo camión que llevaba los huevos a Bs As iba a Córdoba o Rosario y buscaba cereales para hacer el alimento de las gallinas y la hacienda. Hoy producen ellos el alimento y venden a otros particulares. Uno de los hijos continúa con esta forma de trabajo con el camión. El otro hijo solo hace transporte para terceros. Transporta cereales más que nada a Rosario, también lleva implementos para cría de cerdos, arma la vuelta completa. Ellos ya son rancho aparte". (Jorge, productor y dueño almacén de ramos generales).

Cuando se hicieron cargo del almacén tuvieron que trabajar mucho para darle vida nuevamente. "Nosotros encontramos un almacén totalmente despoblado. En 10 años lo dimos vuelta. Hoy tenemos más de 3000 visitas al año". (Irma, dueña almacén de ramos generales).

\section{C.2.4 Emergencia del turismo}

El turismo se presenta como una alternativa para generar un ingreso extra, colabora al mantenimiento del edificio, y fundamentalmente, es una oportunidad para permanecer viviendo en el campo, en su lugar de siempre, estando en contacto con otras personas, lugareños y turistas.

Entienden que el turismo les aporta una oportunidad para seguir viviendo en el campo pero más relacionados.

"Ver que había otras posibilidades que permitían que nos quedáramos en el campo. Pero también por ejemplo él toda la vida viajó, no le gusta la vida monótona. Nos gusta estar 
relacionados, intercambiar y esto del turismo lo permitió". (Irma, dueña almacén de ramos generales).

"Se vuelve interesante desde toda la gente que viene hasta lo que vas intercambiando. A mi marido le encanta, ustedes ven que parece que no dice nada pero cuando viene gente se hace el ratito para charlar, les arma los cuentos, las anécdotas que las tiene él más que yo". (Irma, dueña almacén de ramos generales).

Los entrevistados destacan el impulso del Municipio de Villa Elisa para sumar esta alternativa y el potencial que tiene el lugar en sí mismo.

"Los chicos de turismo nos entusiasmaron". (Irma, dueña almacén de ramos generales).

Además, la posibilidad de valorar y preservar el patrimonio (tangible e intangible) y que eso genere un ingreso económico.

"Empezamos a valorarlo, a darnos cuenta que no había otro, a mirar con otros ojos qué era lo que teníamos". (Irma, dueña almacén de ramos generales). 


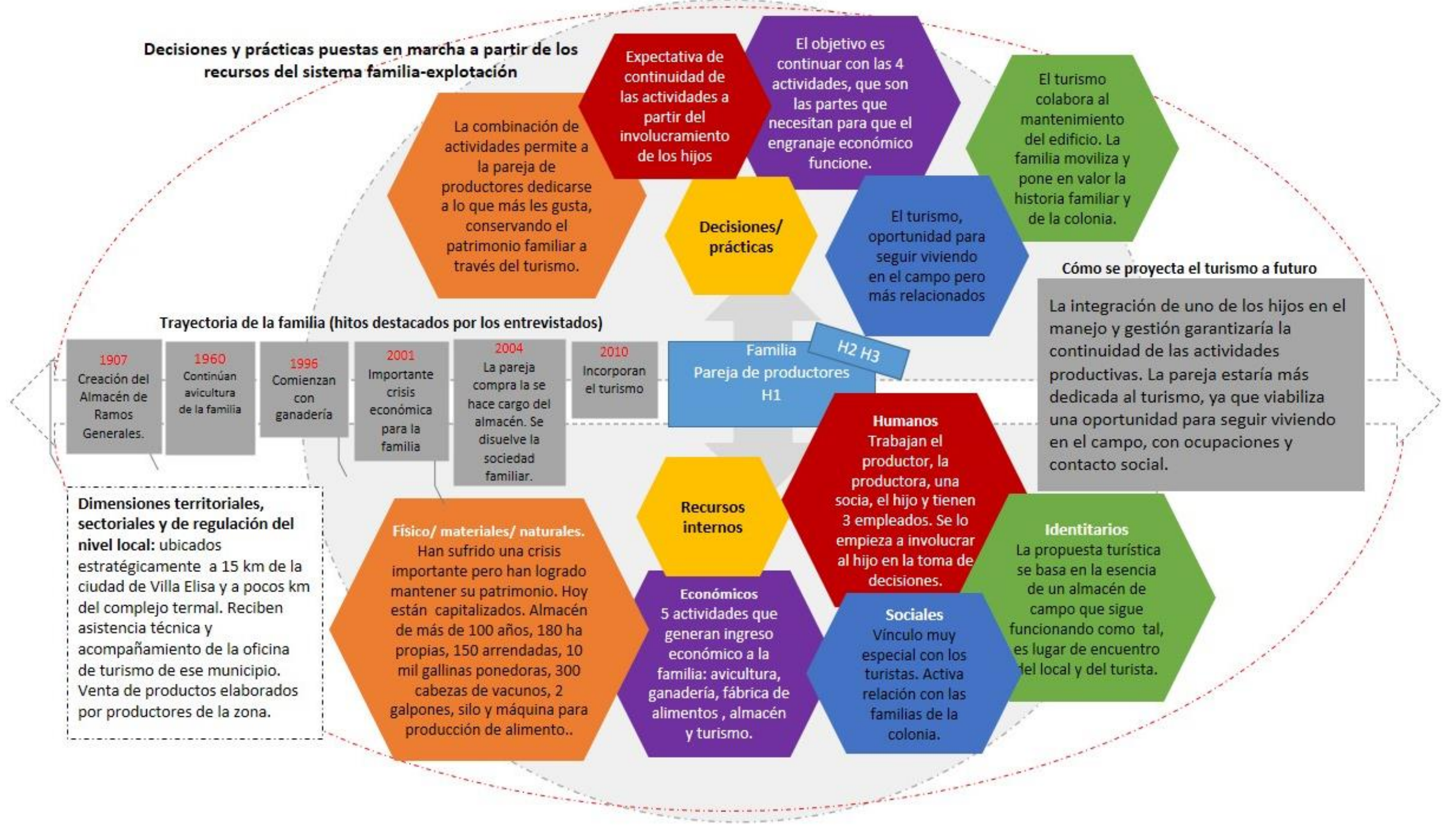




\section{C.2.5 Objetivos, decisiones y estrategias puestas en marcha}

A la altura del ciclo de vida familiar, la combinación de actividades permite a la pareja de productores dedicarse a lo que más les gusta, incluso mantener el patrimonio familiar que es el almacén, a través de la puesta en funcionamiento de la propuesta turística.

El turismo reporta una serie de satisfacciones que son vitales para la pareja de productores, fundamentalmente relacionados al bienestar personal y a lo vincular. Sin el patrimonio no sería una propuesta viable.

Se desprende de las entrevistas que el objetivo de la familia es continuar con todas las actividades, que son las partes que necesitan para que el engranaje económico funcione. Tienen empleados para la ganadería y la avicultura.

Existe una expectativa de continuidad de las actividades a partir del involucramiento de los hijos, fundamentalmente de uno de ellos.

Están pensando en modernizar la granja.

Tienen aceitado el esquema de la fábrica de alimentos y el almacén seguiría a cargo de la productora y su socia. El almacén les estaría aportando más satisfacciones personales y de vinculación que económica pero al compensarse con el resto de las actividades, no habría nada que alterar.

\section{C.2.6 Vinculación del sistema familia-explotación con la actividad de turismo rural $^{57}$}

\begin{tabular}{|c|l|}
\hline $\begin{array}{c}\text { Interacción producto } \\
\text { Explica el flujo de materia } \\
\text { prima de una actividad a } \\
\text { otra. }\end{array}$ & $\begin{array}{l}\text { En este caso, si bien el sistema funciona como una cadena según } \\
\text { los mismos productores (cultivan pasturas y se hacen rollos para } \\
\text { alimentar los animales, producen el alimento balanceado para las } \\
\text { gallinas, con la cama del pollo se fertiliza el campo donde se siembra, } \\
\text { no se contempla integración de los productos de las actividades } \\
\text { productivas como insumos de la actividad turística. }\end{array}$ \\
$\begin{array}{c}\text { Interacción recursos } \\
\text { movilización de un mismo }\end{array}$ & $\begin{array}{c}\text { En este caso se combina mano de obra familiar con asalariada. } \\
\text { recurso para varias } \\
\text { actividades. }\end{array}$ \\
$\begin{array}{c}\text { Están bien divididas las funciones de los miembros de la familia y } \\
\text { cada actividad tiene a la vez empleados. } \\
\text { El productor se dedica a la avicultura y al reparto y cuenta con } 1 \\
\text { empleado. La productora y 1 socia/empleada atienden el almacén y son } \\
\text { responsables además de la parte administrativa. Además producen } \\
\text { algunas conservas, dulces y mantienen la limpieza del almacén. } \\
\text { El hijo y 2 empleados se hacen cargo de la ganadería. } \\
\text { Para la fábrica de alimentos compran los núcleos y en la máquina se } \\
\text { elabora el alimento, que atienden padre o hijo una vez por semana } \\
\text { según el resto de las actividades. } \\
\text { La tarea que más requiere presencia es la avicultura. En el caso de que } \\
\text { la pareja deba viajar, se aseguran de que uno de los hijos quede a cargo } \\
\text { de esa actividad. } \\
\text { Es fundamental el conocimiento específico que tiene la pareja de } \\
\text { productores de la historia del lugar, la familia y la colonia, son los } \\
\text { portadores de la historia, lo que los convierte en pieza clave para } \\
\text { el desarrollo de la actividad turística. }\end{array}$ \\
\hline
\end{tabular}

57 En el siguiente cuadro se enfatizan algunos conceptos utilizando colores que luego serán adoptados en el esquema conceptual que explica las interacciones de la actividad turística con el resto de las actividades del sistema. Así, con naranja se remarca la interacción entre productos de las distintas actividades; con rojo y azul la interacción de los recursos humanos y sociales y con naranja claro entre recursos físicos, naturales y materiales; con verde la interacción patrimonial; con gris, la temporal; con violeta claro la interacción dada entre el ingreso y el sentido dado al trabajo, y con violeta oscuro, la interacción entre los ingresos que aportan las actividades al sistema. 


\begin{tabular}{|c|c|}
\hline & $\begin{array}{l}\text { La principal movilización se da en el almacén de campo, que } \\
\text { además de almacén de venta para la colonia fue abierto al turismo, } \\
\text { con la posibilidad de hacer meriendas o almorzar, con base en la historia } \\
\text { y dinámica particular del lugar. Natural-tierra: tienen organizadas las } \\
\text { actividades en predios separados, campos propios y arrendados. No } \\
\text { hay competencia por el uso porque cada actividad se realiza en } \\
\text { predios diferentes. } \\
\text { Respecto al capital económico, aunque han sufrido un proceso de } \\
\text { retracción en la avicultura, han diversificado sus actividades productivas } \\
\text { e invertido para recapitalizarse. } \\
\text { En lo social, el turismo ha reforzado el vínculo con las familias de la } \\
\text { colonia, se revalorizan los productos elaborados por gente de la } \\
\text { zona que se venden en el almacén, y a través de estos sus saberes. } \\
\text { El almacén posibilita además la convivencia de lugareños y turistas, y } \\
\text { esa es una particularidad que le otorga autenticidad. }\end{array}$ \\
\hline $\begin{array}{l}\text { Interacción patrimonial } \\
\text { La implementación } \\
\text { actividades simultáneas se } \\
\text { dan en torno al valor } \\
\text { intangible de un patrimonio }\end{array}$ & $\begin{array}{l}\text { La implementación de la actividad turística no solo se basa en el } \\
\text { patrimonio tangible, en el almacén de más de } 100 \text { años y sus objetos, } \\
\text { sino y fundamentalmente es a partir de la movilización y puesta en } \\
\text { valor de historias, sucesos, costumbres de las épocas, de la } \\
\text { herencia cultural de la familia y familias de la colonia. Es un rasgo } \\
\text { muy fuerte en el sistema. }\end{array}$ \\
\hline $\begin{array}{l}\text { Interacción temporal } \\
\text { Explica los procesos de } \\
\text { anticipación de un cambio } \\
\text { que está por venir, del } \\
\text { abandono o implementación } \\
\text { de una nueva actividad. }\end{array}$ & No es trascendente en el sistema. \\
\hline $\begin{array}{c}\text { Interacción ingresol } \\
\text { sentido del trabajo } \\
\text { La combinación de } \\
\text { actividades permite asociar } \\
\text { actividades fuertemente } \\
\text { remuneradas con actividades } \\
\text { que no son menos } \\
\text { importantes pero proveen } \\
\text { otro tipo de satisfacciones }\end{array}$ & $\begin{array}{l}\text { La combinación de las actividades permite sostener la propuesta } \\
\text { turística del almacén que genera más satisfacciones que ingresos. } \\
\text { "Las pocas ganancias del almacén son más satisfacciones que } \\
\text { ganancias". (Irma, dueña almacén de ramos generales). } \\
\text { "Yo no sé qué es más rentable, si el contacto con la gente y la } \\
\text { tranquilidad que la plata que va y viene". (Jorge, productor y dueño } \\
\text { almacén de ramos generales) }\end{array}$ \\
\hline $\begin{array}{c}\text { Interacción ingreso } \\
\text { Se da cuando } 2 \text { o más } \\
\text { actividades aportan a los } \\
\text { ingresos totales disponibles } \\
\text { para la familia. }\end{array}$ & $\begin{array}{l}\text { Las actividades en su conjunto contribuyen al ingreso total que } \\
\text { permite cumplir las necesidades y expectativas de la familia. }\end{array}$ \\
\hline
\end{tabular}

\section{C.2.7 Impacto del turismo en el sistema productivo}

El turismo no modifica el resto de las actividades fundamentalmente porque tienen bien divididas las tareas y roles en cada una de estas. No hay competencia al interior del sistema.

El turismo es complementario desde los ingresos y tienen bien diferenciadas las actividades en el uso de los recursos.

Sí es importante el aporte que genera desde la movilización de otros capitales que no es el económico: lo relacional y vincular, el reconocimiento de los turistas por el resguardo del edificio y los objetos y por el afable trato de la dueña y socia, la contribución a mantener viva la historia familiar, la historia de la colonia, sus usos y costumbres, sus formas de trabajo y los tipos de producción, entre otras cuestiones. 


\section{C.2.8 Impacto del turismo en la familia, en las personas y en sus estilos de vida}

- La productora es una persona muy abierta y sociable que disfruta del turismo más que de otras actividades administrativas que desempeña.

"Antes de turismo yo era como la secretaria del negocio, banco, contador, todas esas cosas lindas (ironiza). Y después como nos achicamos, quedamos solos porque era una sociedad, ya se trabaja de otra forma, más tranquilo. Lo sigo haciendo ahora pero lo hago de otra manera. Menos dedicación a eso y te permite más hacer esto de turismo". (Irma, dueña almacén de ramos generales).

- El turismo les brinda una oportunidad para seguir viviendo en el campo, con ocupaciones y contacto social.

"Yo no me hubiera quedado en el campo sin una actividad interesante por mi manera de ser. No me gusta la vida triste, monótona, me gusta disfrutarla de alguna manera, haciendo algo que te guste, que te haga crecer. Y si no encontraba nada que me guste acá y que me entretenga, yo creo que no me hubiera quedado. Esto del turismo son desafíos constantes, desde ir encontrando objetos antiguos, atender a la gente". (Irma, dueña almacén de ramos generales).

"El turismo nos aporta un montón de cosas como el contacto con la otra gente, yo veo que es tan interesante, los del sur, los del norte... son cosas muy distintas. Vas intercambiando ideas, cosas, te preguntan cosas como hacemos nosotros cuando viajamos. El turista busca conocer la historia, la historia del almacén de ramos generales". (Jorge, productor y dueño almacén de ramos generales).

- Tienen como dinámica familiar que todos los años realizan algún viaje. Se organizan para ello y tiene que quedar alguno de los hijos a cargo de la avicultura que demanda tiempo todos los días. Esto no ha cambiado a partir del turismo.

- Desde otro punto de vista, el turismo genera alteración de horarios y rutinas pero fundamentalmente en las temporadas de más turismo en la zona. Es tolerable.

"Yo hoy por ejemplo almorcé a las 15:30 hs, esas cosas así, pero son vacaciones de julio, son unos días. No es que te cambió la vida para tanto, cambió un poco". (Irma, dueña almacén de ramos generales).

"No hay momentos de gran tensión, salvo vacaciones de julio o fines de semana largo. En turismo el pico es en julio. Nos organizamos para contratar la menor cantidad de gente posible porque es cuando menos te rinde". (Irma, dueña almacén de ramos generales).

- Además, la atención al turista está supedita al disfrute y tiempo de intimidad de la familia. Los días de semana cierran al mediodía y luego abren a la tarde. Y los domingos no abren.

"Priorizamos la familia. El hecho de no recibir gente el domingo es para que yo me pueda dedicar a los nietos, que no me crezcan" (Irma, dueña almacén de ramos generales).

\section{C.2.9 Percepción del futuro en relación a los hijos y en relación a su resguardo de ingresos}

Es una actividad que ya desarrolla la familia y todo indicaría que a ella se van a dedicar, fundamentalmente la productora, aunque el productor también ha demostrado interés por el intercambio social y cultural que se da en el espacio. 
El desarrollo de las distintas actividades productivas y la integración de uno de los hijos en el manejo y gestión, permite a la pareja de productores dedicarse a lo que más les gusta, incluso mantener el patrimonio familiar que es el almacén, a través de la puesta en funcionamiento de la propuesta turística.

No se irían a vivir a otro lugar.

"El nació acá, tiene toda su vida acá. Hay un refrán que dice "a loro viejo no se le cambia la jaula". Lo llevas a este hombre a una ciudad y qué hace". (Irma, dueña almacén de ramos generales).

Si bien los hijos no trabajan en el almacén están muy vinculados afectivamente y aparentemente la pareja tiene esperanzas de que continúe en la familia.

"El día que se cayó la pared estaban los tres acá. Se vinieron los tres a darnos ánimo, a apuntalarnos. Y los nietos también. Vienen y les encanta contar la historia". (Irma, dueña almacén de ramos generales).

"Cuando les pregunto si piensan si van a seguir con el almacén me dicen que no saben".

"Lo que sea mejor para ellos. Yo pienso que esto tiene mucha fuerza, mucho valor, valor afectivo, pero no vas a hipotecar el futuro de nadie por esto porque no podés. Será lo que deba ser. El abuelo hace noventa y pico de años que murió, fijate si él iba a pensar que su almacén iba a ser esto". (Irma, dueña almacén de ramos generales).

Con respecto a la sucesión, todo indica que queda en mano de uno de sus hijos. La productora dice que no le gustaría "transmitírselo", sino que él lo elija, no imponérselo.

"Posiblemente (el hijo) es el que tome las riendas dentro de un tiempo. Ya se lo va consultando, tira ideas nuevas". (Jorge, productor y dueño almacén de ramos generales).

"Surgen cosas, hay que esperar, mientras tanto lo estamos disfrutando nosotros". (Irma, dueña almacén de ramos generales).

Se evidencia en la familia un importante afecto por la colonia y el patrimonio familiar:

"Ninguno de los hijos estuvo de acuerdo con cerrar e irnos. Hoy por hoy estoy seguro que ninguno estaría de acuerdo". (Jorge, productor y dueño almacén de ramos generales). 


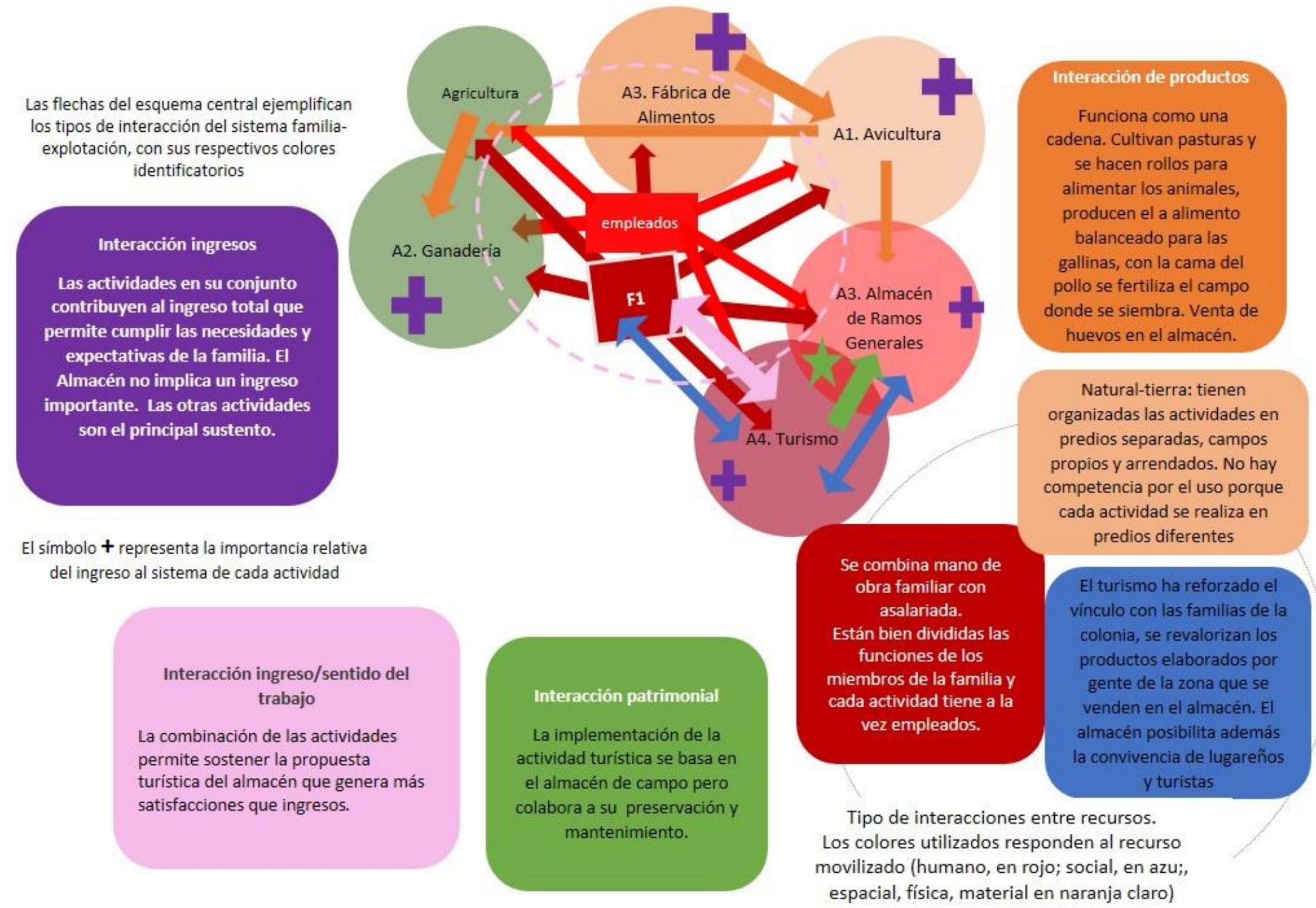

Ilustración 14- Esquema de interacciones de las actividades dentro del sistema Caso 5 


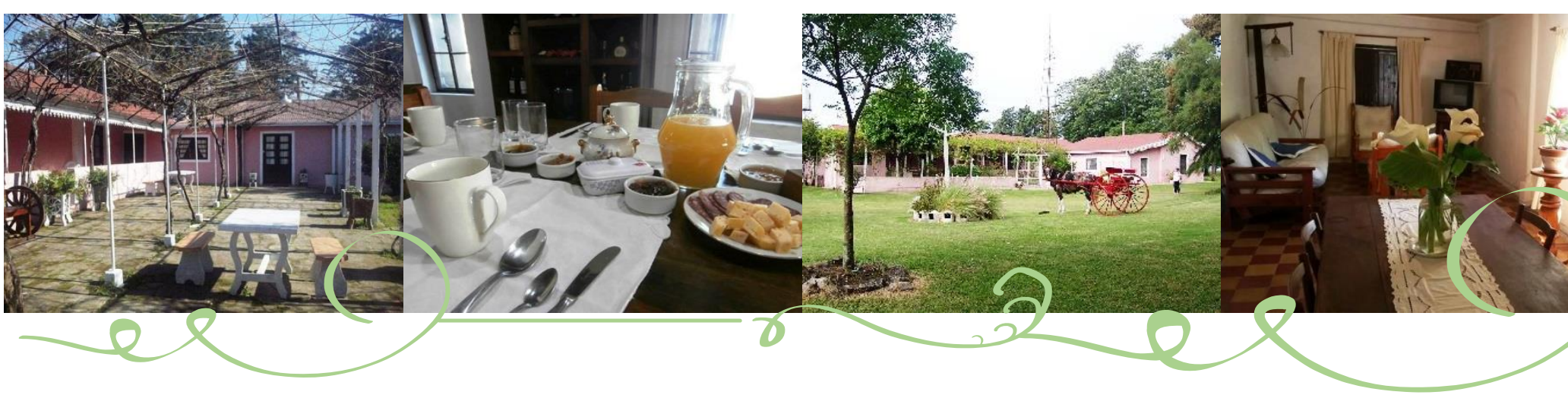

\section{"Un alojamiento rural al resguardo de la historia"}

"Hace 4 años no era lo mismo que hoy, es muy distinto, hoy la gente lo pide. A mí al principio me costó entender por qué la gente iba a querer venir al campo y cómo lo iban a elegir, pero gracias a toda la tecnología que hay, de ver en internet, hoy lo compruebo que sí, que la gente lo elige... por la tranquilidad, por muchas cosas que uno al tenerlos no lo valora. Unos chicos me decian "ay las estrellas!" y como yo las veo todas las noches no me llaman la atención". (Carmen, productora y responsable del alojamiento rural). 


\section{C.3 Caso 6- UN ALOJAMIENTO RURAL AL RESGUARDO DE LA HISTORIA}

Esta experiencia se caracteriza por ser un sistema productivo familiar capitalizado, cuya familia nació en la zona, con uno de sus hijos muy involucrado en la actividad turística y con experiencia en integración de redes asociativas de trabajo.

\section{C.3.1 Presentación general}

El sistema en cuestión se ubica en "Colonia Nueva al sur", en el departamento Colón de la provincia de Entre Ríos.

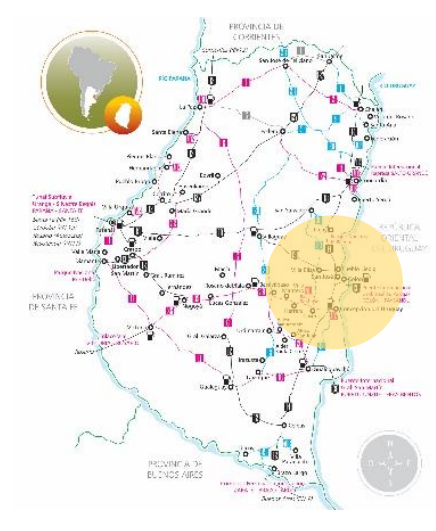

La familia está integrada por el matrimonio (54 años) y cuatro hijos (30, 28, 23 y 17 años). Los dos mayores han formado sus familias y no están estrictamente vinculados a la explotación familiar.

Se trata de un sistema agropecuario diversificado, que además de las actividades agropecuarias que históricamente desarrollan, esto es, ganadería de cría y avicultura de postura, incorporaron la actividad turística a través de la apertura de un alojamiento de campo, actividad que desarrollan desde el año 2012.

Son propietarios de 100 ha y alquilan lotes pequeños en la zona para el pastoreo de los animales. Actualmente, cuentan con 300 cabezas de ganado bovino, 130 madres y cinco toros. Realizan cría y engorde a campo con suplementación con rollos de alfalfa, que producen también, y alimento balanceado con granos de maíz, cafretillo de arroz y soja. Parte de estos insumos -que también se utilizan para la alimentación de las gallinas- se siembran y otra parte se compra porque no les alcanza para el ciclo completo. Poseen 30 ha de agricultura, en las que rotan cultivos -trigo, soja y maíz- utilizando siembra directa. Para la ganadería hacen siembra de praderas diversificadas, y una porción de alfalfa únicamente (30 ha), estrategia que han implementado hace un año y medio. Poseen parte de la maquinaria (para desmalezar y limpieza) y otra parte deben contratarla (enrolladora).

Se trabaja con un solo frigorífico y venden directamente a carniceros de la zona.

La avicultura se desarrolla en un predio a $5 \mathrm{kms}$ de donde se localiza el alojamiento turístico, en el que se ubica la casa familiar. En éste se encuentra la granja con 12 mil gallinas de postura. Poseen dos galpones, uno para la cría y otro para la postura. Para alimentar las gallinas se utiliza balanceado con granos de maíz, soja, harina de carne y núcleos.

Como se ha mencionado, los productores incorporaron la agricultura para suplir estos insumos, pero parte deben adquirirlos por fuera del sistema (vacunas, vitaminas, reposición de pollitos).

La venta de huevos es directa a minoristas y mayoristas -supermercados y despensas de Colón, San José y Concepción del Uruguay. 


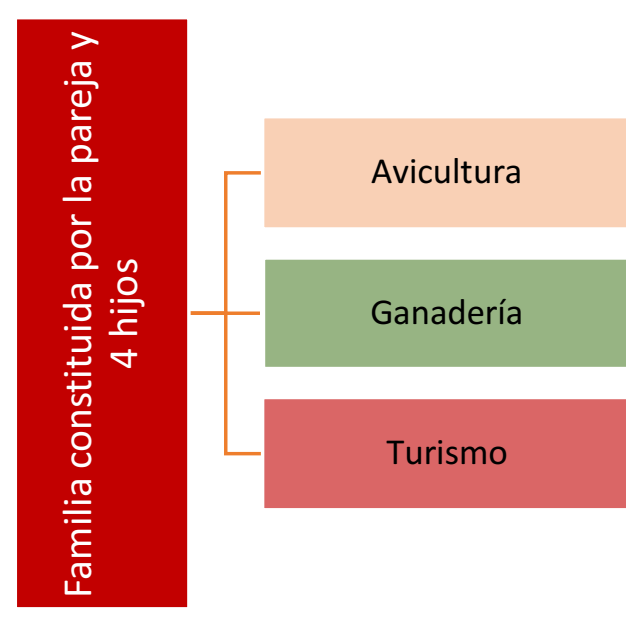

El turismo se añade al sistema en el año 2006/2007 por necesidad de contar con campos para pastorear en época de sequíapero se pone en funcionamiento como alojamiento en el año 2012.

El alojamiento se brinda en una casona antigua (construida en el año 1909) originariamente habitada por una familia de origen suizo (del Cantón de Vallais) que se dedicaban a la avicultura y la producción de quesos. Con el correr de los años y el fallecimiento del primer propietario, se fueron vendiendo campos y solo quedaron unas pocas hectáreas alrededor de la propiedad.

Específicamente, el predio donde se ubica la casona es de 20 ha -18 ha dedicadas a la ganadería y 2 ha al turismo -casona y predio para los paseos en caballos y sulkys.

Ofrecen actividades recreativas como bicicletas y cañas de pescar, ya que a 1000 metros de la casa se encuentra un arroyo, que aunque no está dentro del predio y es de un vecino, se ofrece como alternativa de entretenimiento y descanso. También comparten las tareas rurales a las que se dedican, invitando a los turistas a compartir fundamentalmente las relacionadas a la ganadería (yerra, enlazar terneros, curaciones).

Las épocas del año con mayor afluencia de turistas son de diciembre hasta Semana Santa, vacaciones de invierno y fines de semana largos.

No hay gran capacidad de carga, porque el alojamiento es pequeño, posee cuatro habitaciones con una capacidad de 17 a 20 plazas.

\section{C.3.2 Recursos de la familia ${ }^{58}$}

\begin{tabular}{|l|l|}
\hline Recursos \\
humanos & $\begin{array}{l}\text { Cuentan con mano de obra familiar y empleados. } \\
\text { Si bien todos los días la familia organiza su rutina de trabajo en función de las } \\
\text { actividades impostergables y la llegada de los turistas, hay roles que están } \\
\text { claramente asignados. } \\
\text { El productor se dedica a la ganadería; la productora a la atención al turista y la } \\
\text { avicultura (producción y comercialización). Los dos hijos menores están } \\
\text { relacionados con la unidad productiva: uno de ellos, más activamente en la } \\
\text { atención al turista, las reservas y comunicación del emprendimiento, además } \\
\text { trabaja en la oficina de turismo de una municipalidad de la zona; el más joven } \\
\text { colabora en las actividades agropecuarias y en el mantenimiento del predio de } \\
\text { la casona. Cuentan además con dos empleados permanentes para el trabajo } \\
\text { en la granja avícola y el mantenimiento de los campos para la ganadería. } \\
\text { Tiempos y distribución de roles: género - es indistinto. } \\
\text { Respecto a las competencias, los productores toda su vida han vivido en el campo y } \\
\text { han aprendido los oficios de sus padres, y con ellos han trabajado también. Enseñan } \\
\text { su saber a empleados e hijos. Hay intercambio de opiniones con la hija respecto a } \\
\text { decisiones en la casona, que aporta una mirada más técnica. } \\
\text { Los padres apuestan a la profesionalización de las actividades productivas a través } \\
\text { de la formación profesional de sus hijos menores. “Está bueno que toda la familia } \\
\text { trabaje en turismo rural. No tiene por qué ser uno u otro que trabaje atendiendo a la } \\
\text { gente” (Roberto, productor y responsable de alojamiento rural) }\end{array}$ \\
\hline
\end{tabular}

\footnotetext{
${ }^{58}$ En el cuadro se utilizan colores determinados para resaltar algunos conceptos que luego son recuperados en un esquema conceptual. Los recursos humanos son referidos en color rojo; los físicos, materiales y naturales en naranja; los recursos económicos en violeta; los sociales en azul y los recursos identitarios en verde.
} 


\begin{tabular}{|c|c|}
\hline & \\
\hline $\begin{array}{l}\text { Recursos físicos, } \\
\text { materiales y } \\
\text { naturales }\end{array}$ & $\begin{array}{l}\text { Suele reinvertir sus ganancias en maquinarias y otras mejoras tecnológicas } \\
\text { que ahorran fuerza de trabajo. Poseen parte de la maquinaria (para desmalezar y } \\
\text { limpieza) y otra parte deben contratarla (enrolladora). Poseen dos galpones, uno } \\
\text { para la cría y otro para la postura. En uno de sus predios cuentan con una casona } \\
\text { de más de } 100 \text { años, que ha sido restaurada como alojamiento rural. Los campos } \\
\text { son muy ricos en biodiversidad. Poseen montes de reparo de especies típicas de la } \\
\text { zona (Espinillos, Ñandubay, Cincina, Talas) donde abundan diferentes especies de } \\
\text { aves, insectos y roedores (cuices, comadrejas), zorros, entre otras especies. A } 1 \mathrm{~km} \\
\text { del predio donde se haya la casona, y en el mismo predio donde se ubica la vivienda } \\
\text { familiar, hay arroyos, ecosistema de peces y diversidad de plantas y animales } \\
\text { acuáticos. }\end{array}$ \\
\hline $\begin{array}{l}\text { Recursos } \\
\text { económicos }\end{array}$ & 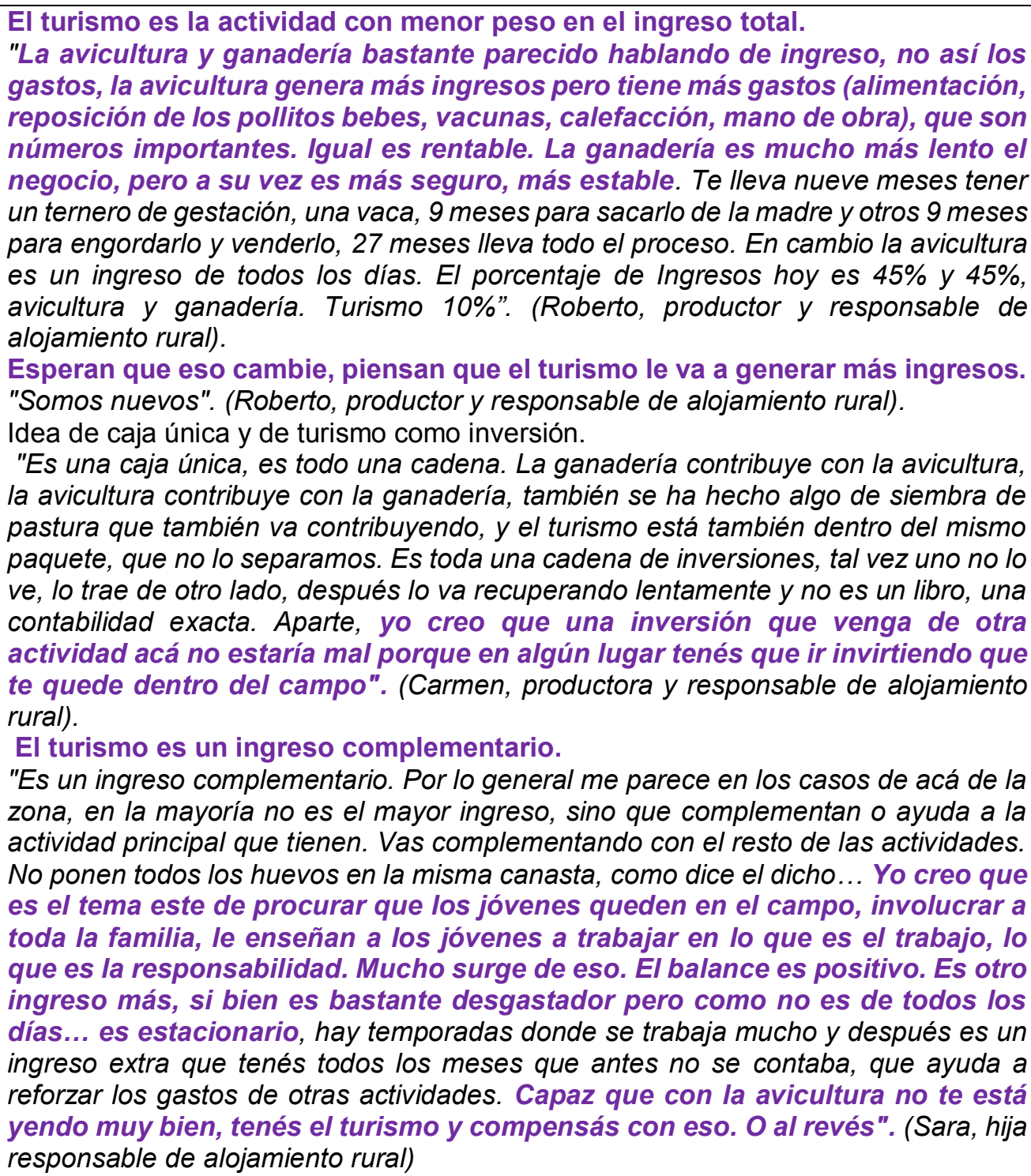 \\
\hline Recursos sociales & $\begin{array}{l}\text { Integración técnica y generación de redes. Integran grupos asociativos (Cambio } \\
\text { Rural) de ganadería y turismo rural. } \\
\text { A través del turismo venden productos que fabrican vecinos y compañeros de } \\
\text { los grupos (dulces, masas, panificación, salames). Además recomiendan } \\
\text { alternativas de turismo de otros emprendimientos rurales. Se vinculan con los } \\
\text { municipios de la microrregión Tierra de Palmares, INTA y otros organismos del } \\
\text { sector. }\end{array}$ \\
\hline
\end{tabular}


"Después de que se compra la casa, a los 2 años, arrancó el INTA con el tema de los grupos cambio rural de turismo rural, y fue ahí que la técnica conoce a papi, porque papi ya formaba parte de los grupos cambio rural de los ganaderos. A través de eso le comentó que tenía una casa como para hacer algo y empezó a surgir lo de turismo rural. Empezamos a participar del grupo de turismo, pero sin estar trabajando con la casa, era como un proyecto todavía muy a futuro y sin saber bien qué hacer. Después yo hice el curso en la UBA y todos los que conocían la casa iban tirando ideas de lo que se podía hacer y demás, y fue cuando decidimos hacer el alojamiento". (Sara, hija responsable de alojamiento rural).

Rol técnico de los municipios y del INTA: "es una gran ayuda. Los municipios ven una alternativa para cuando no es verano, no están las playas, en el invierno por ejemplo, es una salida de decir adonde los mandamos a los turistas... el día que llueve, un día van a las termas.... Se ve como una alternativa para los destinos". (Roberto, productor y responsable de alojamiento rural).

"Comenzamos con el INTA, con el apoyo de ellos y la información dentro. Fue la principal ayuda e información. Ahí surgió el turismo rural, las reuniones, las enseñanzas y las propuestas y el estudio del lugar. Eso fue lo más importante que si no no estaríamos... Dentro del rubro se trata de ir a las reuniones, de vincularse, de tener experiencias de qué es lo que hace uno y qué es lo que hace el otro, como ser ahora incorporar los dulces de una chica vecina que se los vende en el alojamiento, ella está muy contenta y a nosotros también nos sirve. Después están todos lo que son los productos de la zona también. Creo que es importante dentro de la zona". "Cada vez se está agrupando más la gente que permite, que está bueno también como productor vender los productos del otro, que te manden gente, que la gente vaya por chacinados a un lado, y por otra cosa a otro, que lo mandes a conocer a otro lado o tener el dulce que hace un vecino o un colega, y creo que habría que intensificarlo más. Que cada uno tuviera que tener el producto del otro en cada alojamiento o visita de turismo, saber qué ofrece, que productos tiene el otro". (Roberto, productor y responsable de alojamiento rural)

Reconocimiento social de la comunidad.

"Cuando arrancamos éramos "Ios locos estos que van a hacer turismo", quién va a venir al campo a hacer turismo? Decían. Al turismo rural lo veían muy lejos. Y después les llamaba mucho la atención a los vecinos, "mirá cuántos autos hay, cuántos autos van para Victoria del Campo". (Carmen, productora y responsable de alojamiento rural)

"Los vecinos de la zona son ganaderos más que nada y avicultores de pollo. Tratamos de sumarlos. Los dulces que ponemos en el desayuno y para la venta son de una vecina de cerquita del alojamiento, tenemos otro vecino que hace carne, chorizo de campo así que le compramos a él o le recomendamos a los turistas si quieren ir a comprar. Hay otra vecina que hace masas dulces y ese tipo de cosas, así que cuando tenemos fines de semana largos o vacaciones de invierno, o sea que sabemos que vamos a tener gente, le compramos como para la venta" (Carmen, productora y responsable de alojamiento rural)

Intercambio cultural con turistas. Se destaca lo vincular.

"Es super rico, por el intercambio de la gente, te permite eso. Estás en contacto con gente que viene de toda la Argentina y conocés otras culturas, otras formas de vida, es super enriquecedor". (Sara, hija responsable de alojamiento rural).

"El turismo, en la parte vínculos, es mucho más fuerte que las otras. En la ganadería hay vínculos, en la avicultura también, pero es distinto". (Carmen, productora y responsable de alojamiento rural)

"La gente viene a desenchufarse y a contarnos sus cosas. En su trabajo o en las cosas diarias de ellos uno ve que ni tiempo tienen de dialogar con alguien. Es algo que nos agradece la gente, el tiempo que nosotros les dedicamos. Para ellos es importante el tiempo que uno le dedica, en la atención, en conversar, en explicarles, en contarles la historia de la casa, de nosotros. Y agradece mucho". "Nos ha cambiado el trabajo. Creo que está bueno de que nos lleguen los turistas, y en el caso mío, por ejemplo no sabemos si es obrero, si es juez... un diputado, si es doctor (que han venido mucho)... por ahí te llega la gente y no sabés con qué tipo de gente 


\begin{tabular}{|c|c|}
\hline & $\begin{array}{l}\text { estás tratando. Realmente para nosotros es un halago y un orgullo... de que hayan } \\
\text { pasado por el lugar". (Roberto, productor y responsable de alojamiento rural). }\end{array}$ \\
\hline $\begin{array}{l}\text { Recursos } \\
\text { identitarios }\end{array}$ & $\begin{array}{l}\text { El turismo permite rescatar la tradición oral y la historia familiar, que son a la } \\
\text { vez esencia del atractivo turístico. } \\
\text { "Yo creo que es amor al campo, a transmitir lo que uno vivió, a transmitir una } \\
\text { cultura porque si no a mí me ocurriría contarles a los turistas qué es lo que } \\
\text { hacían mis abuelos. Es amor a contar lo que vivieron, lo que hicieron, valorar } \\
\text { su sacrificio y poderlo transmitir, como me gusta escuchar las historias de } \\
\text { otras culturas, de otras familias. Sí, creo que es amor, porque si no no me } \\
\text { acordaría de los abuelos cuando hacemos los cuentos, cómo trabajaban, los } \\
\text { desayunos que se levantaban temprano para ir a arar. Creo que es amor al campo } \\
\text { y a la zona, recordar lo que ellos hicieron. A veces uno no mira el pasado, pero lo } \\
\text { tenemos siempre presente. Lo que hacían los abuelos es lo que hoy podemos contar } \\
\text { y ver el sacrifico que tuvieron. Si hoy no lo seguimos contando no nos vamos a } \\
\text { acordar...". Parece que llega un momento de la vida en que uno hace un click para } \\
\text { acordarse de lo que hicieron los abuelos, los padres, uno recuerda dentro de la } \\
\text { infancia cómo era de sacrificado y la falta de tecnología" (Carmen, productora y } \\
\text { responsable de alojamiento rural). } \\
\text { "Ofrecemos el alojamiento, con la historia de la casa, porque no es un } \\
\text { alojamiento común. Ya desde la estructura de la casa traemos la historia de los } \\
\text { abuelos, no el servicio de los abuelos porque dentro de eso tenemos la tecnología } \\
\text { de hoy en dia". (Carmen, productora y responsable de alojamiento rural). }\end{array}$ \\
\hline $\begin{array}{l}\text { Recursos } \\
\text { territoriales }\end{array}$ & 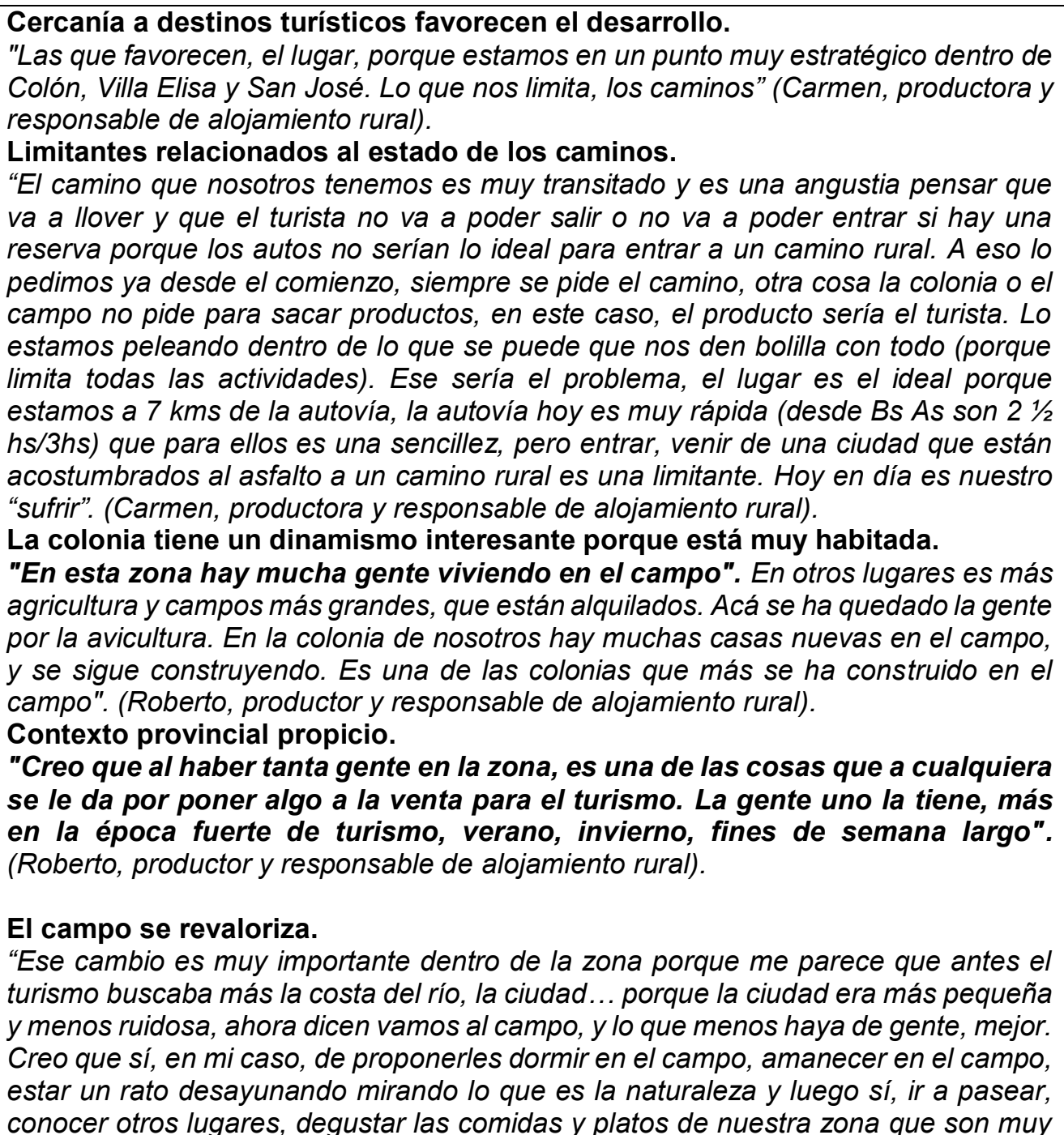 \\
\hline
\end{tabular}


ricas, y después volver al campo. Esa es la propuesta ideal". (Carmen, productora y responsable de alojamiento rural).

\section{C.3.3 Trayectoria familiar}

El matrimonio de productores nació y vivió toda la vida en la zona.

"Somos nacidos, criados, siempre vivimos acá en el campo, en la zona, los dos somos vecinos, las dos familias, mi familia y la de los papás de mi marido, vecinos de años. De los abuelos, de los inmigrantes, ya vienen siendo una generación que creció acá". (Carmen, productora y responsable de alojamiento rural).

Cuando emprenden su proyecto familiar, centran sus actividades productivas en la ganadería de cría y posteriormente la avicultura de postura (hace 28 años). La actividad turística es la más reciente. Cuando se casaron se dedicaron a la gallina de postura, actividad que continúan hasta el día de hoy. La ganadería siempre presente desde los padres en ambas familias. Forma parte de una de las actividades que desarrollan también hoy.

Siempre hicieron avicultura. Alrededor de 1992 dejaron la cría de pollo parrillero y se integraron, pero por poco tiempo porque empezó una enfermedad ("cabeza hinchada") que se atribuía a las granjas que combinaban parrilleros y de postura. Se prohibieron este tipo de granjas combinadas. Siguieron con la de postura, crecieron en esta actividad, construyendo galpones.

En el periodo 1990/1995 les fue bien. "De tener una hiperinflación a un dólar estable, fue bueno. En los 90 que hubo estabilidad, igual la ganancia era "muy chiquita". (Roberto, productor y responsable de alojamiento rural). Mencionan como crítica la enfermedad y las nuevas normativas que prohibían la combinación de granjas.

Vivieron los cambios de la avicultura. Relatan que "cuando antes había productores particulares, se compraba y criaba el pollito bebé, alimentos en bolsa, y se hacía la venta por su lado. Ahora se da la integración, desaparecieron los productores chicos por las crisis de la avicultura". Destacan que ahora también "hay crisis pero a otra escala". ". (Roberto, productor y responsable de alojamiento rural).

"A la avicultura ya la teníamos incorporada porque esta zona fue muy de avicultura en pollo y ya con mis padres nosotros ya vivimos la avicultura criando pollo, después surge que se van agrandado las empresas y como éramos pequeños productores, desaparece el productor pequeño de pollo, y ahí empezamos con la gallina para ser dueños de un emprendimiento propio, después vos tenes el de pollo que se integra que ya viene a ser como empleado. Para seguir siendo dueños de nuestro negocio pasamos a la gallina. Los años te van haciendo aprender como todo, como es, y ahí lo manejamos directamente. También somos vendedores directos al público, del productor al comerciante, sin intermediarios, también por una razón del momento, de cómo surge, no porque lo hayamos buscado sino que se presentó porque venían antes a buscar el huevo a la granja los camiones desde Buenos Aires, y eso se fue cortando porque era poca cantidad, por el centro, porque no se podía estacionar el camión, etc, y automáticamente nos fuimos buscando otros mercados acá en la zona para hacerlo directo". (Carmen, productora y responsable de alojamiento rural).

En 2000/2001 hubo un periodo de sequía con más de seis meses con poca lluvia. Fue un año muy difícil para la ganadería y la agricultura.

En todos estos años experimentaron un proceso de capitalización: lentamente pudieron comprar "algunos pedacitos de tierra" para desarrollar la ganadería.

"Cuando yo era chica recuerdo cómo mis padres trabajaban en el campo progresando con mucho esfuerzo. Eso lo fuimos aplicando desde chicos en la familia viniendo de los abuelos 
que ya tenían campo. Yo me caso en los 80 , era muy jovencita también trabajando en el campo y buscando progresar en el campo, queriendo hacer, siempre en la tarea del campo, nunca se nos ocurrió salir del campo. Hoy me doy cuenta lo que se pudo lograr en esos 30 años, 35 años en el campo que trabajamos juntos. Tuvimos crisis, cambios de gobierno, mucho más sacrificado, a veces tal vez no tanto, pero siempre con esfuerzos. Años de más progreso, años de menos pero gracias a Dios para adelante, despacito, para adelante". (Carmen, productora y responsable de alojamiento rural).

En el 2007 compran el campo con la casa y luego de pensar en el proyecto deciden convertirla en un alojamiento que abren al público en el año 2012.

\section{C.3.4 Emergencia del turismo}

- En el año 2007, afectados por una sequía, la familia decide alquilar campos cercanos para el pastoreo del ganado. Les ofrecen la compra de un campo de 20 ha que incluía una casona de más de 100 años, que había quedado deteriorada por el abandono y reparto de las tierras originales. Su origen estaba vinculado a una familia de colonos suizos radicados en tierras entrerrianas desde principios del siglo XX.

"En el año 2006/7 por una sequía importante-ajustados con el pasto-sale la compra por buscar un alquiler de campo para llevar los animales a otro lugar que estaba haciendo falta. Sale lo de la casona" (Roberto, productor y responsable de alojamiento rural).

"No fue fácil tampoco". Había financiaciones para comprar y además vendieron un campo más alejado, que no tenía luz" (Roberto, productor y responsable de alojamiento rural).

- Mirada empresarial. El productor lo vio como "un gran negocio, desde el primer momento".

"En ese momento nadie pensaba en turismo rural" (Roberto, productor y responsable de alojamiento rural). Pasan cuatro años hasta que la compran. Forman parte de un grupo ganadero desde el 2000, estando en ese grupo se enteran de la convocatoria de turismo rural. Luego entran al grupo de turismo rural (2009). 2010 se empieza a restaurar. Se decide hacer cuatro habitaciones con baños privados.

"Fue bastante fácil dentro de todo, no se hicieron grandes reformas a la casa. Arrancamos así sin experiencia, sin nada, sin tener página de internet solamente amigos que nos empezaban a mandar gente" (Roberto, productor y responsable de alojamiento rural). Abren en el año 2012.

- Destacan la compra de la casona "como una gran oportunidad, y que abrió la alternativa de turismo. Que vino por la sequía, fue el destino! Luis es el innovador. Cuando fue todo esto de la sequía él salió a consultar, sin preguntarme porque si no yo le hubiera dicho "nooo, déjalo, vamos a hacer otra cosa". Y surgió lo de la casona. Yo creo que es una inversión" (Carmen, productora y responsable de alojamiento rural)

"Daba pena dejar caer la casa por todo lo que había, entonces ahí se comienza a revertir esto, pero era más una inversión en ese momento, y hoy, todos los días pienso que es una inversión, que es un logro, es así" (Carmen, productora y responsable de alojamiento rural)

- Opción de futuro para los jóvenes pero también alternativa de agrado para los padres.

"Cuando Victoria termina su secundaria no tenía ninguna vocación a seguir estudiando qué. Y ahí yo tenía la visión de que el turismo es el fuerte nuestro acá en la zona... Aparte tenía la experiencia de mi mamá, que tiene departamentos en Colón que siempre alquiló, y sin estudio, sin conocimiento lo fue llevando, y yo le decía, eso, con estudio, sabiendo, con la experiencia de ser técnicos en turismo, me parecía que era una profesión ideal para ella. Por suerte a ella le gustó y arrancamos ahí, y desde ahí entonces viene el turismo a nuestra familia. Luego 
aparece la compra de este terreno con la casa antigua que yo no la quería refaccionar porque me parecía que era una locura...

Acá parecía cuando nosotros comenzamos con esto, que no era el momento. Otra persona hubiera hecho otra inversión, en un galpón de pollo, parecía descabellado en ese momento". (Carmen, productora y responsable de alojamiento rural).

- Herramienta que permitió poner en valor el campo, la forma de ser y vivir allí. "Hay algo de amor al campo, a transmitir lo que uno vivió... Es amor a contar lo que vivieron, lo que hicieron, valorar su sacrificio y poderlo transmitir, como me gusta escuchar las historias de otras culturas, de otras familias". (Carmen, productora y responsable de alojamiento rural).

\section{C.3.5 Objetivos, decisiones y estrategias puestas en marcha}

La familia decide continuar con las actividades del sistema, si es necesario contratando empleados, no para turismo porque entienden que en esta actividad deben estar ellos. "El turismo rural es una entrada más de dinero, si bien todavía no estamos a full todavía porque "somos nuevos". (Carmen, productora y responsable de alojamiento rural).

En el caso de necesitar piensan tomar algún empleado más pero para la avicultura, no para el turismo "porque es muy importante que sea personalizado. El resto, lo demás, hay trabajos que se pueden hacer con personal "si bien el patrón es el patrón", son cosas que se pueden lograr. Dejar algunas de las actividades no es mi idea" (Roberto, productor y responsable de alojamiento rural).

Mayor integración de las actividades con el turismo. Su idea es incorporar la granja al turismo (llevar a la gente a ver las gallinas, juntar los huevos) o la de llevar al turista a ver a los animales (enlazar un ternero, curar bicheras, yerra). "Para ellos es toda una novedad. Por la parte de atractivos creo que la ganadería es un atractivo más y que fuera la parte de avicultura incorporarla". (Roberto, productor y responsable de alojamiento rural).

"El turismo apareció sin pensarlo, y se agregó una cosa más. Uno no lo buscó. En lo demás, Estela es una de las que quiere dejar la avicultura. "Si fuera por ella quedarían pocas gallinas!". Para mí es una entrada importante, si bien genera su tiempo y todo, si fuera ella quedarían pocas gallinas". (Roberto, productor y responsable de alojamiento rural).

\section{Apuestan por el turismo. Piensan que el turismo rural tiene futuro como actividad.}

"La gente busca cada vez más lugares así, el estrés de las grandes ciudades hace que la gente busque lugares tranquilos. Eso es algo que me hace pensar que tiene futuro. Para mí es el tipo de turismo que se viene "por lo mal que está la gente... por el estrés..." aparte en 2 o 3 horas con las autovías desde Bs As o Rosario que es de donde viene la mayoría) están acá, se quedan 2 o 3 días ellos logran desenchufarse... logran bajar el ritmo". (Carmen, productora y responsable de alojamiento rural).

"Yo creo que va a tomar fuerza el emprendimiento. Lo imagino más desarrollado, con más servicios, como un lugar renombrado, pero creo que las otras actividades van a seguir existiendo". (Sara, hija responsable de alojamiento rural). 


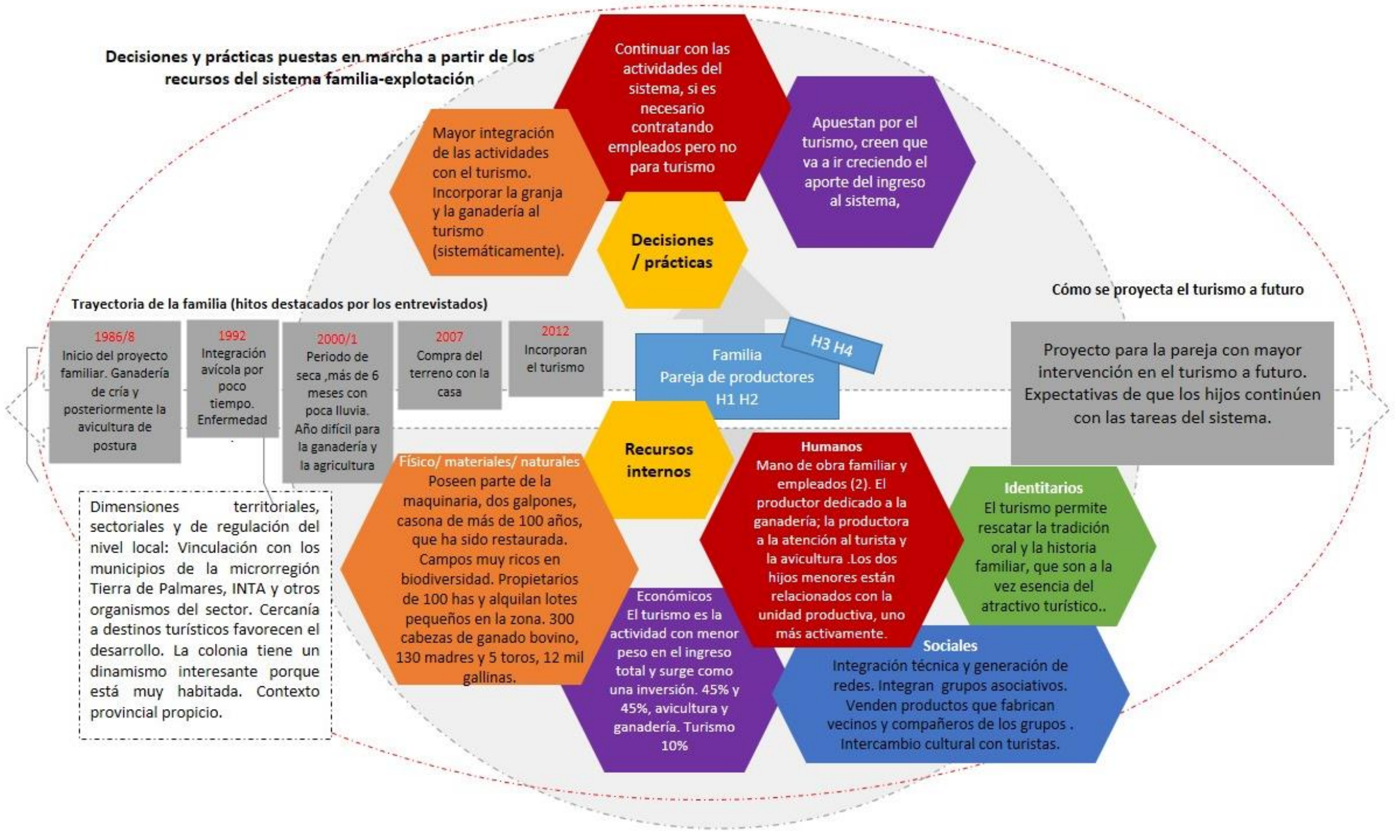




\section{C.3.6 Vinculación del sistema familia-explotación con la actividad de turismo rural ${ }^{59}$}

\begin{tabular}{|c|c|}
\hline $\begin{array}{c}\text { Interacción producto } \\
\text { Explica el flujo de materia } \\
\text { prima de una actividad a } \\
\text { otra. }\end{array}$ & $\begin{array}{l}\text { No se evidencia integración de los productos de las actividades } \\
\text { productivas como insumos de la actividad turística. Sí se da } \\
\text { entre ganadería, agricultura y avicultura ya que producen los } \\
\text { rollos de alfalfa, soja, trigo y maiz para el engorde de la hacienda. } \\
\text { Además, utilizan la cama de pollo para fertilizar el campo. } \\
\text { Eventualmente, utilizan huevos de su producción para preparar } \\
\text { alguna comida a pedido de los turistas. }\end{array}$ \\
\hline $\begin{array}{l}\text { Interacción recursos } \\
\text { Se explica a partir de la } \\
\text { movilización de un mismo } \\
\text { recurso para varias } \\
\text { actividades. }\end{array}$ & 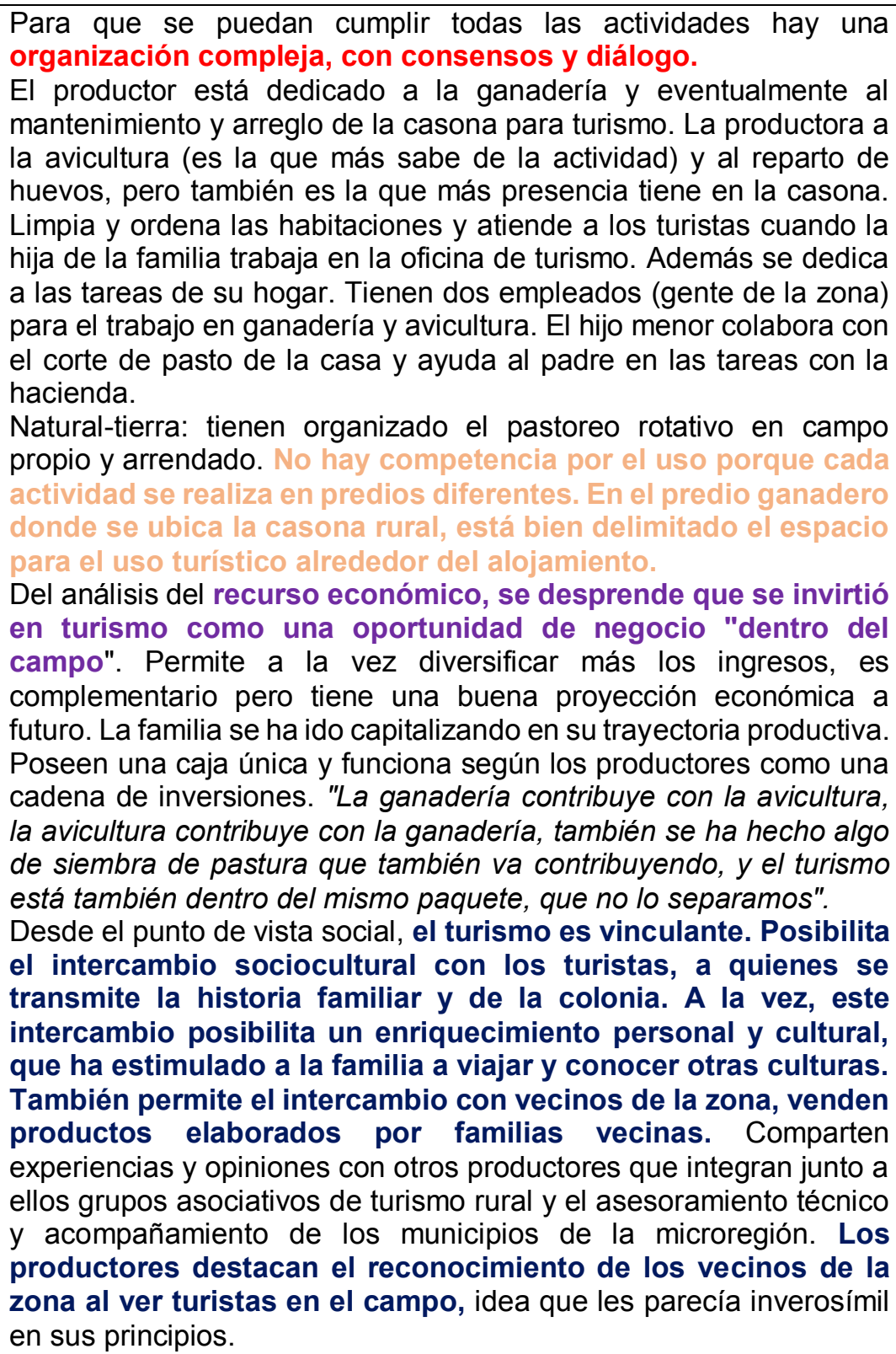 \\
\hline
\end{tabular}

${ }^{59}$ En el siguiente cuadro se enfatizan algunos conceptos utilizando colores que luego serán adoptados en el esquema conceptual que explica las interacciones de la actividad turística con el resto de las actividades del sistema. Así, con naranja se remarca la interacción entre productos de las distintas actividades; con rojo y azul la interacción de los recursos humanos y sociales y con naranja claro entre recursos físicos, naturales y materiales; con verde la interacción patrimonial; con gris, la temporal; con violeta claro la interacción dada entre el ingreso y el sentido dado al trabajo, y con violeta oscuro, la interacción entre los ingresos que aportan las actividades al sistema. 


\begin{tabular}{|c|c|}
\hline $\begin{array}{l}\text { Interacción patrimonial } \\
\text { La implementación } \\
\text { actividades simultáneas se } \\
\text { dan en torno al valor } \\
\text { intangible de un patrimonio }\end{array}$ & $\begin{array}{l}\text { La propuesta turística se basa en el patrimonio arquitectónico e } \\
\text { infraestructura que brinda la casona antigua de campo. Además } \\
\text { de ser atractiva a la vista, cuenta con espacios y detalles que } \\
\text { evidencian la historia y un estilo propio de las primeras familias } \\
\text { colonas que arribaron a la zona. La familia se interesó y estudió la } \\
\text { vida de la familia, con mucho esfuerzo recuperó los espacios, } \\
\text { recuperaron muebles y objetos de antaño para recrear lo más } \\
\text { posible la casa familiar como era originalmente. } \\
\text { Además del patrimonio tangible, la tradición oral, el transmitir la } \\
\text { historia familiar, cómo vivían y trabajaban sus abuelos y cómo } \\
\text { fue modificándose la vida en el campo ha sido destacado por } \\
\text { los productores como vital. El patrimonio paisajístico y el entorno } \\
\text { rural natural integran el atractivo de la propuesta. }\end{array}$ \\
\hline $\begin{array}{l}\text { Interacción temporal } \\
\text { Explica los procesos de } \\
\text { anticipación de un cambio } \\
\text { que está por venir, del } \\
\text { abandono o implementación } \\
\text { de una nueva actividad }\end{array}$ & $\begin{array}{l}\text { La pareja invierte en turismo porque vislumbran en la actividad } \\
\text { una alternativa con proyección a futuro y más placentera, } \\
\text { menos desgastante físicamente y más agradable por el intercambio } \\
\text { con los turistas y la gente. Existe una expectativa de arraigo de los } \\
\text { hijos al campo a partir de la continuidad de las actividades que se } \\
\text { desarrollan, fundamentalmente ganadería (con cabañas) y turismo. } \\
\text { También surge de las entrevistas la idea de la pareja de } \\
\text { productores de dedicarse más al turismo a futuro. }\end{array}$ \\
\hline $\begin{array}{l}\text { Interacción ingresol } \\
\text { sentido del trabajo } \\
\text { La combinación de } \\
\text { actividades permite asociar } \\
\text { actividades fuertemente } \\
\text { remuneradas con actividades } \\
\text { que no son menos } \\
\text { importantes pero proveen } \\
\text { otro tipo de satisfacciones }\end{array}$ & $\begin{array}{l}\text { El turismo es comprendido como una inversión, como una } \\
\text { oportunidad de negocio y genera ingresos, no tan importantes } \\
\text { como el resto de las actividades pero con proyección a mejorar en } \\
\text { un futuro. Además de lo económico moviliza otros sentidos, } \\
\text { que permiten poner en valor la historia personal, familiar y del } \\
\text { territorio. } \\
\text { Moviliza a la vez el reconocimiento de los vecinos de la zona y } \\
\text { la propia comunidad lo que refuerza la autoestima familiar y } \\
\text { visión innovadora de los productores. }\end{array}$ \\
\hline $\begin{array}{c}\text { Interacción ingreso } \\
\text { Se da cuando } 2 \text { o más } \\
\text { actividades aportan a los } \\
\text { ingresos totales disponibles } \\
\text { para la familia. }\end{array}$ & $\begin{array}{l}\text { El turismo es una actividad con menor peso en el ingreso total } \\
\text { ( } 10 \% \text { aproximadamente, respecto a la ganadería y avicultura, a } \\
\text { las que corresponde un } 45 \% \text { y } 45 \% \text { según dichos del productor). } \\
\text { Las actividades se complementan y equilibran: la avicultura } \\
\text { genera un ingreso diario con la venta de huevos y la ganadería } \\
\text { es más lenta ( } 27 \text { meses el proceso), pero más segura. Se } \\
\text { organizan con la idea de una caja única y en cadena. }\end{array}$ \\
\hline
\end{tabular}


Ilustración 16- Esquema de interacciones de las actividades dentro del sistema Caso 6

Las flechas del esquema central ejemplifican los tipos de interacción del sistema familiaexplotación, con sus respectivos colores identificatorios

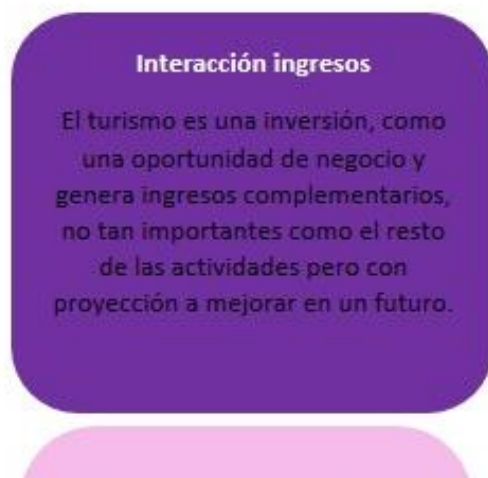

Interacción ingreso/sentido del trabajo

Además del aporte

económico pone en valor la

historia personal, familiar $y$

del territorio. oviliza a la vez

el reconocimiento de los

vecinos de la zona y la propia

comunidad

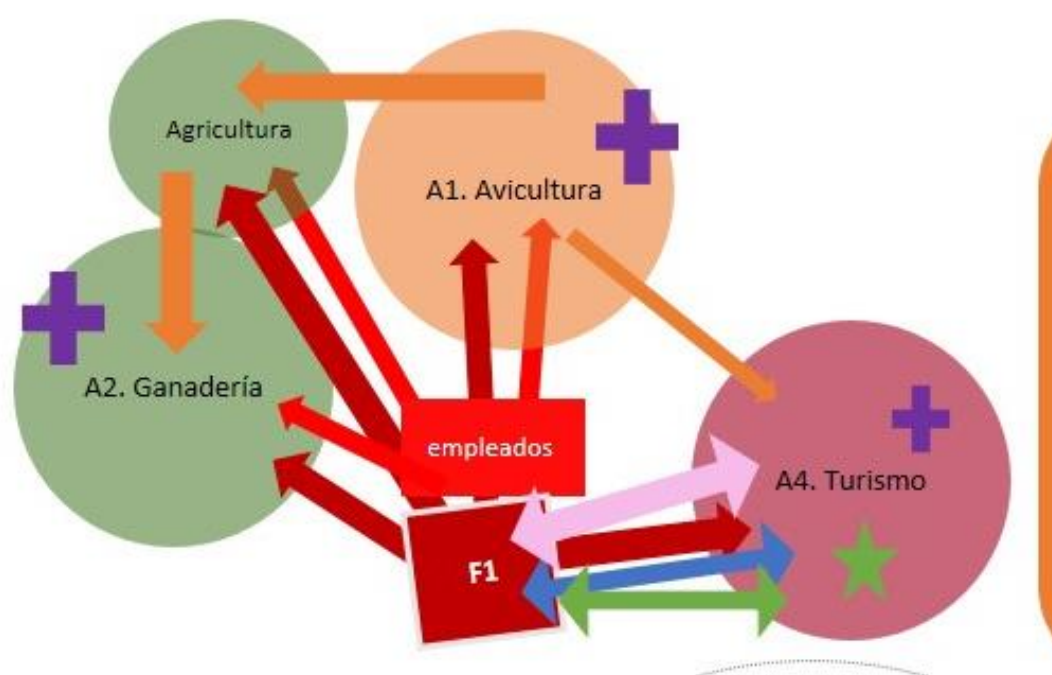

Interacción de productos

Funciona como una cadena. Producen los rollos de alfalfa, soja, trigo y maíz para el engorde de la hacienda. Además, utilizan la cama de pollo para fertilizar el campo.

No hay integración de los productos de las actividades productivas como insumos de la actividad turística. Ocasionalmente usan huevos de su producción para preparar alguna comida a pedido de los turistas.
El símbolo + representa la importancia relativa del ingreso al sistema de cada actividad

Interacción patrimonial

La propuesta turistica se basa en el patrimonio arquitectónico e infraestructura que brinda la casona antigua de campo. Revaloriza la historia familiar y de la colonia. Transmisión oral de la familia.
No hay competencia por el uso porque cada actividad se realiza en predios diferentes. En el predio

ganadero donde se ubica la casona rural, está bien delimitado el

espacio para el uso turístico alrededor del alojamiento

(venta de productos elaborados por familias vecinas.). Intercambio con otros productores que integran grupos asociativos de turismo rural.

Tipo de interacciones entre recursos.

Los colores utilizados responden al recurso movilizado (humano, en rojo; social, en azu; espacial, física, material en naranja claro)

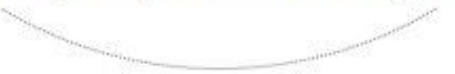




\section{C.3.7 Impacto del turismo en el sistema productivo}

Para entender la sustentabilidad del sistema es clave el tipo de relación que se da entre las distintas actividades productivas: se aprecia una relación de complementariedad y obligatoriedad en las relaciones funcionales de las tres actividades principales (agricultura, ganadería y avicultura). Se maneja el sistema de forma integrada y esto le da mayor autonomía. Los productos de una actividad son insumo para otra.

No sucede lo mismo con el turismo. No se vislumbra una interdependencia con el resto de las actividades, no hay competencia, pero cumple otras funciones dentro del sistema: genera ingresos complementarios, los ingresos permiten mantener el patrimonio (si no existiese el patrimonio sería muy difícil la puesta en marcha de una propuesta turística con lo cual hay un lazo de obligatoriedad entre patrimonio y turismo). Moviliza otro tipo de capitales relacionados a la valorización de la historia personal, familiar, los recursos paisajísticos, culturales y territoriales, es una opción para el futuro de los padres y una alternativa más para el futuro de los hijos.

\section{C.3.8 Impacto del turismo en la familia, en las personas y en sus estilos de vida}

- La incorporación de turismo complejizó las tareas y hay actividades de ocio que han dejado de practicarse. También genera reclamos en el resto de los miembros de la familia que no integran la unidad económica. Los tiempos son ajustados, más en temporada alta de turismo. Se requiere de mayor organización para cumplir con todas las actividades.

"Se modificó muchísimo mi ritmo de vida. Porque yo me vengo a trabajar a la oficina y cuando yo me vengo a trabajar, mi mamá va al alojamiento, y cuando yo salgo, mi mamá vuelve para la casa a hacer las actividades cotidianas suyas. A veces incluso se queda todo el día en el alojamiento trabajando. Entonces nos vamos rotando para ir cubriendo para que los turistas no queden solos. Pero aparte las veces que tenemos gente yo me voy a instalar allá. Si bien todos hacemos un poco de todo y colaboramos entre todos, mi papá está más con el tema de ganadería, la parte de avicultura la maneja más mi mamá. Y yo estoy con el turismo, y a la vez ellos dos me ayudan a mí. Mi hermano, el más chico, está estudiando en Colón, y mis otras hermanas ya están casadas y tienen sus familias, una vive en Colón y la otra en Villa Elisa. No participan de estas actividades". (Sara, hija responsable de alojamiento rural).

"Cuando tenemos gente los fines de semana largos olvídate porque mis hermanas empiezan "ay mamá qué estás todo el día allá, que no te vimos, que te cansás, que estás todo el día trabajando..."A ella le gusta... se cansa, trabaja, por ahí más de la cuenta de lo que debería, pero porque le gusta, se pone a arreglar las plantas, habla con la gente..." (Sara, hija responsable de alojamiento rural).

- El turismo implicó un cambio de vida y espacio de aprendizaje e intercambio.

"Significó un cambio de vida para la edad nuestra, para la edad mía. Aparte creo que a mi marido también le gusta todo lo que es el dialogo, las experiencias, las historias de vida, es muy lindo, es como una distracción dentro de lo que es nuestro rubro y un aprendizaje, porque de una zona ganadera distinta él pregunta cómo es la ganadería allá, cómo es la avicultura, cómo es el clima... es una zona de aprendizajes, de intercambio de culturas, de experiencias que también las podemos aplicar. También es nuestro lugar, que el departamento de Colón es muy turístico, y no estaba mal quedar fuera de ese círculo turístico que es muy importante y que progresa muy rápido. Son varias cosas dentro del paquete". (Carmen, productora y responsable de alojamiento rural). 
"El cambio me gustó. Porque lo otro... ya me acordaba de la edad que tenía y los años que lo venía haciendo y es como monótono... nunca dije un trabajo me aburre ni nada pero es como monótono. Para mi edad, ya el trabajo de andar subiendo y bajando huevos a la camioneta ya no da, yo decía, esto tiene que cambiar, esto tiene que cambiar... porque mi edad no lo va a permitir. Y en esto de que me gusta el diálogo, me gusta todo eso (que no se puede negar) en el turismo me vino una oportunidad especial". (Carmen, productora y responsable de alojamiento rural).

"Nunca salí cinco veces de vacaciones en seis meses. Esto es nuevo para mí. Pero a partir del turismo es algo que estoy anexando. Lo aprendí y me gustó. A mi marido no le gusta salir porque no probó! Es un dulce del que no abrió el frasco y no sabe degustarlo así que cuando abra el frasco pobre de él. Viajar... Ese era un sueño del futuro. Ese fue mi primer ideal, adonde Victoria tenga que viajar yo me engancho. Era un ideal de la vida que tenía guardadito cuando llegue esta edad. Dentro del trabajo que había hecho, de lo que la vida me acompañó que junté ahorros, poder disfrutar de esa forma. Es un cambio que me está generando y recién comienza! Ese es el sueño". (Carmen, productora y responsable de alojamiento rural).

"Creo que a nosotros se nos dieron muchas oportunidades, muchas condiciones: el estudio de Victoria, el lugar que nos tocó y tal vez, una forma nueva de salir de la estructura que teníamos en la vida, esto fue desestructurante, porque es una cosa que descompagina lo otro, en el sentido de que es totalmente diferente. Porque vos te imaginas al ganadero, con las vacas, al productor que vende los huevos, con su venta y no te lo imaginas en el turismo. Es como salir a pasear dentro de tu casa trabajando. Te da dinero, y le da otro sentido". (Carmen, productora y responsable de alojamiento rural).

"Creo que se fue dando solo el cambio... no se lo pregunto, pero se quedó... el cambio ya está. La familia se transformó en otra cosa, totalmente. Creo que va a ser positivo. Primero chocó muy fuerte, como que no gustaba, ese cambio como que les fue rotundo, no encontrar a mamá en el lugar donde tenía que estar, que para ellos era lo normal. Y ahora despacito, lo que son mis nietos ya lo tienen incorporado, ya les gusta venir". (Carmen, productora y responsable de alojamiento rural).

"No existen tiempos de ocio. Lamentablemente. Eso es lo que quiero anexar, no el ocio, pero sí por ejemplo comer un asado, que los nenes paseen en caballo. Ese sería el momento de disfrute. Antes del turismo íbamos a pasear a la costanera a Colón, por ejemplo, a eso ahora no lo hago" (Carmen, productora y responsable de alojamiento rural).

- Operó cambios en el rol y tiempos de la mujer.

"Sí, ha cambiado, totalmente. Van mis vecinos, mi hermana y me dicen "no te encontramos más acá" (por su casa), "no me cambié de domicilio, estoy en el alojamiento". Fue un cambio muy importante porque yo me puse la camiseta, más yo, porque Victoria con el tema de su estudio, su trabajo está trayendo todas las experiencias y la compartimos, pero como que las horas libres que hay que tomar, las tomo yo, me hice dueña de las horas libres para el turismo. Antes me dedicaba más a mi casa y a estar más dentro de controlar o de ayudar dentro lo que es la avicultura. En la ganadería participaba poco, pero en la avicultura era más la presente. Ahora dejé esa presencia, la tuve que delegar más a los empleados para ponerme más en el alojamiento, porque acá en el turismo... una que me gusta más, un cambio, otra, me parece que la presencia del dueño es más importante... en todos los emprendimientos, en lo otro también es importante el dueño pero con los años que tengo, con la experiencia como que lo puedo manejar más mandando al empleado. Específicamente, en la crianza de una pollita es muy especializado, hay que estar, ver si tomó agua, las vacunas, todo lo que hay que hacer. Después también el control de la postura, cómo están, cuánto ponen, mirar dentro de la granja, los resultados de lo que vos estás haciendo, si lo estás haciendo bien o no. Ya eso lo tuve que dejar... pregunto pero no lo puedo hacer más, es imposible. A esas horas las trasladé acá (alojamiento) a venir acá". (Carmen, productora y responsable de alojamiento rural). 
- Es una actividad que brinda oportunidades en relación a la formación y salida laboral para los jóvenes.

"Antes cuando era más chica sí me involucraba con el resto de las actividades. Ahora muy poco. Ayudaba si había que encerrar animales para cargar, juntar el huevo, clasificarlos. Sigo ayudando pero menos. Yo además trabajo en el área de turismo en la Municipalidad de San José. Empecé en el 2010 haciendo el curso de la UBA (postgrado de turismo rural), después hice otro curso de gestión turística, y en el 2012 arranqué con la carrera (tecnicatura en turismo)". (Sara, hija responsable de alojamiento rural).

\section{C.3.9 Percepción del futuro en relación a los hijos y en relación a su resguardo de ingresos}

\section{- Proyecto para la pareja con mayor intervención en el futuro}

"Tal vez instalarme más aquí (alojamiento). Es como un hobbies. Uno de los mini proyectos es en el galpón hacer un salón de juego (pin pong, metegol, como para que la gente, o a la noche, o el día que llueva tener un entretenimiento más). Pensar en un comedor, algo gastronómico, lo ven como algo rentable, pero sería ya tomar algo de personal. Si bien hay gente que pegunta y pide, hay gente que le gusta hacer sus asados, sería algo importante económicamente pero desde lo laboral sería más complicado". (Roberto, productor y responsable de alojamiento rural).

"Creo que con el tiempo se van a ir organizando mejor, creo que igual mis papás van a seguir trabajando pero en algún momento van a tener que pensar en jubilarse, dejar de trabajar tanto! Y ahí me los imagino más en el alojamiento, porque es como más liviano el trabajo, no es tanto físico el trabajo sino más el estar" (Sara, hija responsable de alojamiento rural).

- Los productores tienen expectativas de que los hijos continúen con las tareas del sistema.

"Sí, tengo expectativas, porque eso siempre se los digo fundamentalmente a los que no están, o sea la mayor que está en la ciudad, le digo que el día de mañana cuando tenga mi edad, o antes, sea ella la que pueda seguir continuando este emprendimiento. Pueden ser los nietos. Al hijo más chico le gusta el campo pero también le gusta el estudio, sueña con ser ingeniero, primero dijo que quería ser arquitecto, el padre se quería morir porque él pensaba que iba a ser agrónomo, y bueno, le digo yo, vamos a ver... el campo a él le gusta, aparte el nació con mucha diferencia, con mucha más tecnología, ama lo que es la tecnología para el campo. En ganadería el progreso en todo lo que es cabañas... nosotros hicimos los pasos con los abuelos, los pasos nuestros, los pasos de nuestros padres como fueron y veo que miro para atrás en el pasado cómo progresó todo eso, así que pienso que el sí, que él va a llegar con más tecnología y más progreso en el campo. Muy distinto porque con mucha más tecnología. Y si lo puede incorporar con estudio, mejor. Las dos cosas me parece que están bien ensambladas, el campo y el estudio, que traiga para aplicarlo. Pienso que sí, que van a continuar". (Carmen, productora y responsable de alojamiento rural).

- Por un lado esperan que sigan con todas las actividades del campo "que uno logró hacer con tanto sacrificio toda la vida". Creen que sería indignante que lo vendieran y se dediquen a otra cosa.

"Bueno, uno hace lo que a uno le gusta, pero creo que sería muy bueno que sigan con todo lo que uno ha logrado. El tema de la Avicultura sería lo primero que se dejaría... porque es un poco desgastante, es un trabajo de todos los días, no hay sábados, no hay domingos, no hay feriados". (Roberto, productor y responsable de alojamiento rural).

"Pienso que A. (el hijo más chico) es el que se va a quedar con la actividad agropecuaria y tal vez V. (la hija) con la parte de turismo. Hay cosas que hago porque me gustan a mí, 
Dios quiera que sigan, yo creo que es una alternativa de trabajo para el futuro". (Roberto, productor y responsable de alojamiento rural). 


\section{C.4 Caso 7- LA TRANQUILIDAD DE DORMIR EN EL CAMPO}

Este sistema de actividad responde a la variable de no ser administrado por productores agropecuarios. Se trata de una familia de trabajadores de la ciudad de Villa Elisa que pusieron en funcionamiento un alojamiento en el espacio rural. Han integrado experiencias asociativas de turismo rural y sus hijos están indirectamente vinculados con la actividad turística.

\section{C.4.1 Presentación general}

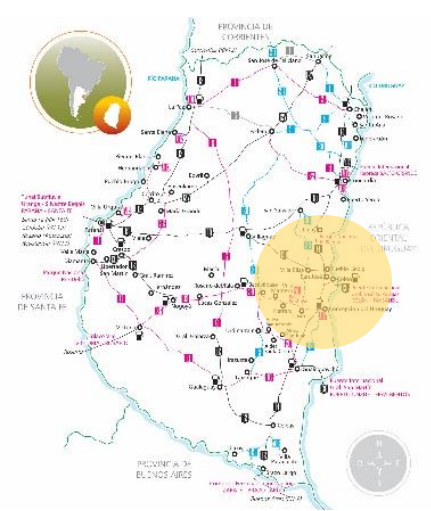

Esta experiencia se centra en una familia constituida por una pareja de aproximadamente 60 años, con hijos adultos con sus respectivas familias. Uno de sus hijos falleció en el año 2009. Viven en la ciudad de Villa Elisa, allí tienen una fábrica de aberturas y en el año 2002 compran un campo de $8^{1 / 2}$ ha con una casa que recuperaron y reconstruyeron para turismo.

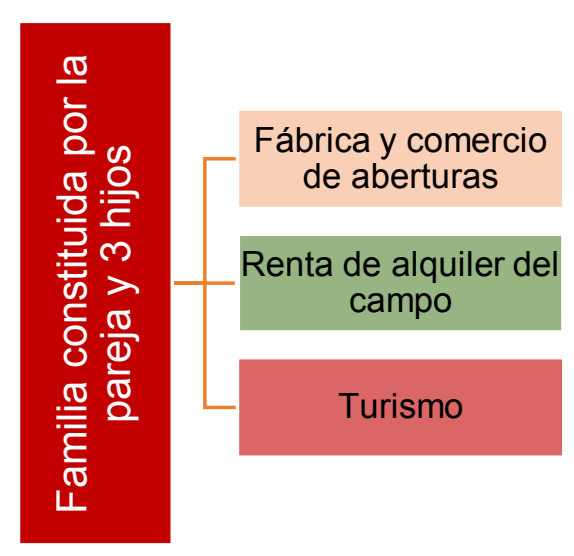

En el año 2009/2010 se presentaron a una convocatoria de Empretec $^{60}$ con un proyecto de alojamiento en ese espacio y con cabañas totalmente equipadas con energías renovables (solar y eólica).

Por algunos inconvenientes solo pudieron habilitar el alojamiento en la casa de campo.

Arriendan parte del predio a un productor ganadero. El marido se jubiló hace unos meses y está realizando los trámites para realizar el cambio de titularidad en la fábrica y dejarla en manos de uno de sus hijos.

Actualmente la familia vive de la fábrica y venta de aberturas, el alquiler del campo y el ingreso del turismo.

\section{C.4.2 Recursos de la familia ${ }^{61}$}

\begin{tabular}{|l|l|}
\hline Recursos humanos & $\begin{array}{l}\text { El emprendimiento turístico y la fábrica son atendidos por la familia. El } \\
\text { padre e hijo trabajan juntos en la fábrica. La madre se encarga de la parte } \\
\text { administrativa. En la actividad turística ella maneja las páginas y reservas, el } \\
\text { marido es "el jardinero", realiza el mantenimiento y ella y el hijo y su esposa la } \\
\text { limpian para alquilar. }\end{array}$ \\
\hline $\begin{array}{l}\text { Recursos físicos, } \\
\text { materiales y } \\
\text { naturales }\end{array}$ & $\begin{array}{l}\text { Para comprar el predio del campo y la casona hicieron una especie de } \\
\text { intercambio por la que en ese momento era su vivienda familiar. }\end{array}$ \\
\hline
\end{tabular}

\footnotetext{
60 La Fundación EMPRETEC nace en Argentina en el año 1988. A través de esta, las Naciones Unidas ofrece un programa integral de formación de capacidades empresariales, brinda asistencia a empresarios y emprendedores para mejorar sus posibilidades de éxito. Fuente: http://empretec.org.ar/FundacionEmpretec.php?pagina=institucional Última consulta 5/2/2018

${ }^{61}$ En el cuadro se utilizan colores determinados para resaltar algunos conceptos que luego son recuperados en un esquema conceptual. Los recursos humanos son referidos en color rojo; los físicos, materiales y naturales en naranja; los recursos económicos en violeta; los sociales en azul y los recursos identitarios en verde.
} 


\begin{tabular}{|c|c|}
\hline & $\begin{array}{l}\text { Cuentan con el campo de } 81 / 2 \text { ha, la casona y están construyendo un } \\
\text { galpón en el parque industrial para continuar y fortalecer la fábrica de } \\
\text { aberturas. Construyeron sobre el galpón donde fabrican las aberturas y allí } \\
\text { viven. El alojamiento fue en parte financiado por un crédito al que se } \\
\text { presentaron (con una tasa muy subsidiada) pero han tenido que invertir mucho } \\
\text { dinero y mucho tiempo de la familia para habilitar el alojamiento. }\end{array}$ \\
\hline $\begin{array}{l}\text { Recursos } \\
\text { económicos }\end{array}$ & $\begin{array}{l}\text { La familia cuenta actualmente con tres actividades de generación de } \\
\text { ingresos: la venta de aberturas, el alojamiento y el alquiler del campo. El } \\
\text { turismo hoy no les reporta grandes ingresos aunque ven que hay mayor } \\
\text { movimiento en los últimos tiempos. La ganancia por turismo, que es } \\
\text { mínima, se va reinvirtiendo, colabora al mantenimiento del alojamiento, pago } \\
\text { de impuestos y luz. } \\
\text { "Es mínimo el ingreso por turismo pero este es el primer año que enero se } \\
\text { alquiló durante todo el mes". (Jorge, dueño de alojamiento). } \\
\text { "Se usa para mantener el capital". (María, dueña de alojamiento). }\end{array}$ \\
\hline Recursos sociales & $\begin{array}{l}\text { No se consideran una familia sociable, no tienen mucha relación con los } \\
\text { turistas. Quedan a disposición pero tampoco quieren "invadir". Tampoco } \\
\text { están } 100 \% \text { dedicados, entonces no están todo el tiempo en el lugar } \\
\text { como para establecer una relación de más intercambio con los } \\
\text { pasajeros. } \\
\text { Fueron integrantes de un grupo de turismo rural y gracias a ello conocieron a } \\
\text { una de las vecinas del campo, que también tiene una casona en alquiler a } \\
\text { través de esa experiencia asociativa. } \\
\text { "Era rico el intercambio de experiencias". (Jorge, dueño de alojamiento). } \\
\text { No han creado muchos vínculos a partir del turismo. } \\
\text { "No hemos creado muchos vínculos porque en } 5 / 6 \text { años que estamos tampoco } \\
\text { ha pasado tanta gente". (María, dueña de alojamiento). }\end{array}$ \\
\hline Recursos identitarios & $\begin{array}{l}\text { Una de las dimensiones que identifica a esta familia es su vocación por } \\
\text { el cuidado del ambiente, por generar actividades sustentables, } \\
\text { amigables con la naturaleza. El proyecto turístico nació con esa vocación, } \\
\text { las actividades que pretendían desarrollar iban por una línea de producción } \\
\text { orgánica. Hicieron varias denuncias por fumigaciones en la zona. "Recién } \\
\text { ahora las leyes te protegen un poco" (María, dueña de alojamiento). "Se } \\
\text { invirtió mucho en árboles y se quemaron porque se fumiga a la vuelta". (Jorge, } \\
\text { dueño de alojamiento). }\end{array}$ \\
\hline $\begin{array}{l}\text { Recursos } \\
\text { territoriales }\end{array}$ & $\begin{array}{l}\text { Tienen una muy buena vinculación con técnicos de la oficina de turismo } \\
\text { municipal. } \\
\text { "Los chicos de turismo nos ayudaron mucho, siempre se ocupan, están muy } \\
\text { atentos". (María, dueña de alojamiento). "Nos acompañaron desde armar la } \\
\text { página, nos invitan a capacitaciones, siempre avisan, nos llaman". (Jorge, } \\
\text { dueño de alojamiento). } \\
\text { "El grupo de la gente de turismo pone mucho para salir adelante, tratan de } \\
\text { solucionar todo, de encontrarle una solución al problema que podés tener, vos } \\
\text { los llamás y los tipos están". (Jorge, dueño de alojamiento). } \\
\text { Tienen la práctica de recomendar otros establecimientos de turismo rural } \\
\text { de la zona. "Hay una carpeta en el alojamiento con folletos de todos los } \\
\text { emprendimientos de la zona" (Entrevistado). En los comienzos regulaban sus } \\
\text { precios en comparación a otros alojamientos de la zona. Desde que } \\
\text { empezaron a trabajar con Booking les exigen un precio internacional, en } \\
\text { dólares. "Cobramos } 80 \text { dólares a la pareja". (María, dueña de alojamiento). } \\
\text { Destacan el impulso al desarrollo turístico dado por las termas. } \\
\text { "Acá fuertes son los fines de semana largos en la zona, vienen por las termas" } \\
\text { (María, dueña de alojamiento). "Algunos vienen para conocer la zona, Colón, } \\
\text { el palacio, San José, el Parque Nacional". (Jorge, dueño de alojamiento). }\end{array}$ \\
\hline
\end{tabular}




\section{C.4.3 Trayectoria familiar}

La mujer de la pareja es de Villa Elisa, sus padres continúan siendo productores ganaderos y siguen viviendo en el campo. Él es oriundo de Villaguay.

Se conocen hace más de 40 años, desde cuando eran jóvenes. Estudiaron en Rosario. Ella no se alcanzó a recibir de farmaceútica. Él iba a estudiar ingeniería pero no finalizó, trabajó para mantenerse allí.

"Fue en la época mala del país, en la dictadura. Las cosas no se dieron y tuve que trabajar para mantenerme en ese momento muy difícil" (Jorge, dueño de alojamiento).

Por lo que comenta el entrevistado vivió algunos momentos complejos en esa época aun sin pertenecer a ningún movimiento ni espacio político. En aquel momento, ella se volvió a Villaguay estudió magisterio y trabajó en una escuela rural. Jorge se volvió a trabajar a Villaguay, trabajó en Chaco y Corrientes. Después se fue a San Lorenzo a la casa de un tío a buscar trabajo.Y consiguió. Es técnico mecánico. En 1979 entró a trabaja en SOMISA.

"Cuando nos casamos (1981) nos fuimos a vivir a San Nicolás por el trabajo de él. Allá estuvimos 12 años hasta que se acató al retiro voluntario en el 1992 y nos vinimos". (María, dueña de alojamiento).

"Habíamos planificado tres cosas; o poner una librería mayorista en Concepción del Uruguay o una fábrica o una tornería -yo soy tornero- acá. Esto era de mis suegros, un galpón viejo que se caía, se lo alquilamos". (Jorge, dueño de alojamiento).

"El galpón era un pedazo, nos instalamos en el fondo en un minidepartamento con los cuatro chicos". (María, dueña de alojamiento).

Ese mismo año abrieron la fábrica y no cerraron hasta ahora. Luego se construyeron su casa.

En el 2002, hicieron el cambio de su casa por un campo que tenía una casona abandonada. "El sueño de él siempre fue tener una chacra" (María, dueña de alojamiento Hicieron el cambio sin saber lo deteriorada que estaba la vivienda, tuvieron que prácticamente tirarla abajo y remodelarla. En un principio la idea del campo era cultivar aromáticas, tener pollos orgánicos. Pero no se fueron dando las cosas.

"La compramos en parte por una situación personal difícil que estaba atravesando la dueña y un deseo personal, pero una persona cuerda no lo hace!". (Jorge, dueño de alojamiento).

En ese momento no pensaban en turismo. "Era para tener un campo y sin demasiada proyección". (María, dueña de alojamiento).

Era difícil concretar lo productivo porque ellos estaban dedicados a la fábrica. Con los hijos durante los fines de semana se dedicaron a reconstruir la casa.

Sufrieron cinco grandes crisis de la mano de la historia económica del país. La del 2000/2001 fue muy fuerte. "Esta crisis (actual) nos agarró sin deudas, en las otras estábamos creciendo". (Jorge, dueño de alojamiento).

En el 2009 fallece uno de los hijos y esto moviliza la necesidad de concentrarse en alguna otra actividad. Es por esto en parte que surge la idea del alojamiento en el campo.

"Hace 2 o 3 años atrás estuvimos a punto de venderlo, hubo gente que lo quiso comprar. Cuando les dije a mis hijos me dijeron 'rompiste tanto que querías tener el campo y ahora lo querés vender?".(Jorge, dueño de alojamiento).

"Se opusieron los hijos". (María, dueña de alojamiento). 


\section{C.4.4 Emergencia del turismo}

En el 2002 se les dio la posibilidad de comprar un campo con una casona que pensaban trabajar con sus dos hijos, cultivar aromáticas, hacer huerta y producción de pollo orgánico. No pudieron avanzar en este camino.

"La compramos como una inversión y para disfrutarla nosotros los fines de semana" (María, dueña de alojamiento).

En el año 2009 fallece uno de sus hijos, y quizás motivados por esta situación personal empezaron a pensar en un proyecto turístico para desarrollar allí.

"Tal vez en parte lo del turismo surgió como un escape, una alternativa para estar ocupados en otra cosa" (María, dueña de alojamiento).

"Un desahogo". (Jorge, dueño de alojamiento).

La esposa e hija (que es técnica en gestión de pymes) presentaron un proyecto en la fundación Empretec y quedó seleccionado. Ganaron un crédito para hacer toda la construcción pero tuvo mucha demora y luego tuvieron un inconveniente con el vendedor de la madera.

"Habíamos sacado un crédito muy subsidiado y nos demoraron como un año". (María, dueña de alojamiento).

La idea era hacer un complejo con cabañas sustentable. Se decidió habilitar la casa. Para ello fue vital el impulso de los técnicos de la oficina de turismo.

"Ella conocía a la gente de turismo, los invitamos a comer un asado y les encantó el lugar". (Jorge, dueño de alojamiento).

"Ellos nos incentivaron, no había casas de campo en Villa Elisa salvo la de Lucía que está cerca". (Jorge, dueño de alojamiento).

En el 2013 arrancaron con el turismo.

La hija al final no pudo concretar el proyecto turístico ni involucrarse con la actividad ya que ingresó a trabajar en otro lugar y tuvo familia.

\section{C.4.5 Objetivos, decisiones y estrategias puestas en marcha}

Actualmente la prioridad es finalizar la construcción del galpón en el área industrial. La idea de la pareja es ceder la fábrica a mano de uno de sus hijos y ellos continuar con el emprendimiento turístico "sin enloquecernos, a disfrutar la familia y al disfrute personal". (María, dueña de alojamiento).

"Yo creo que ya cumplí mi ciclo, estoy para acompañar. Quiero ahora disfrutar, poder salir a pasear. Quiero dedicarme a varias cosas que no hice en mi vida por no darme permisos, por traer el dinero a la casa. Me gusta tallar, pintar, hago artesanías, muebles". (Jorge, dueño de alojamiento).

"Y por eso se va a ir para el campo". (María, dueña de alojamiento).

Hoy están evaluando el negocio familiar ya que quieren diversificar. Están analizando el mercado y pensando de qué manera pueden diversificar la oferta de productos (en relación a la fábrica de aberturas) puesto que hay mucha competencia.

Respecto al turismo, proyectan continuar, seguir invirtiendo y piensan en algunas alternativas para el complejo. Les gustaría construir las cabañas algún día, así "podés tener más gente, que valga la pena poder incorporar más servicios. Otras de las ideas es hacer paseos por la colonia en un camioncito $4 \times 4$ pero sin desesperarnos, ir haciendo sin desesperación". (María, dueña de alojamiento). 
Ven el alojamiento en el campo como una alternativa. "No dejarlo caer y si le podemos ir agregado cosas hacerlo, porque lo vamos usando nosotros también" (Jorge, dueño de alojamiento).

\section{C.4.6 Vinculación del sistema familia-explotación con la actividad de turismo rural $^{62}$}

\begin{tabular}{|c|c|}
\hline $\begin{array}{l}\text { Interacción producto } \\
\text { Explica el flujo de materia } \\
\text { prima de una actividad a } \\
\text { otra. }\end{array}$ & $\begin{array}{l}\text { No se da una integración de la actividad turística con el resto de } \\
\text { las actividades del sistema. Son actividades diferentes, que } \\
\text { complementan los ingresos familiares. }\end{array}$ \\
\hline $\begin{array}{l}\text { Interacción recursos } \\
\text { Se explica a partir de la } \\
\text { movilización de un mismo } \\
\text { recurso para varias } \\
\text { actividades. }\end{array}$ & $\begin{array}{l}\text { No hay relación de la actividad turística con las actividades } \\
\text { productivas que se desarrollan en el campo que alquilan. Son } \\
\text { espacios diferentes y no se combinan ni comunican. } \\
\text { Los recursos que se movilizan son el capital humano familiar, que } \\
\text { se distribuye entre las dos actividades, los saberes y conocimientos } \\
\text { de la familia sobre todo en lo que es construcción. }\end{array}$ \\
\hline $\begin{array}{l}\text { Interacción temporal } \\
\text { Explica los procesos de } \\
\text { anticipación de un cambio } \\
\text { que está por venir, del } \\
\text { abandono o implementación } \\
\text { de una nueva actividad }\end{array}$ & $\begin{array}{l}\text { No pareciera destacarse alguna movilización temporal entre las } \\
\text { actividades, solo que la familia se dedica al turismo } \\
\text { fundamentalmente los fines de semana, no generando una gran } \\
\text { tensión que genere incompatibilidad con la fábrica de aberturas. }\end{array}$ \\
\hline $\begin{array}{l}\text { Interacción ingresol } \\
\text { sentido del trabajo } \\
\text { La combinación de } \\
\text { actividades permite asociar } \\
\text { actividades fuertemente } \\
\text { remuneradas con actividades } \\
\text { que no son menos } \\
\text { importantes pero proveen } \\
\text { otro tipo de satisfacciones }\end{array}$ & $\begin{array}{l}\text { La familia actualmente prioriza el ingreso dado por las actividades que } \\
\text { otro tipo de satisfacciones. Incluso, la familia disfruta el lugar cuando } \\
\text { no hay turismo los fines de semana. } \\
\text { "En este momento priorizamos el ingreso porque se necesita". (Jorge, } \\
\text { dueño de alojamiento). } \\
\text { El objetivo es económico pero aporta a un objetivo mayor que tiene } \\
\text { que ver con el disfrute familiar. "Lo poco que nos va sobrando lo } \\
\text { estamos guardando para irnos de vacaciones en familia y poder } \\
\text { disfrutar. Eso y tratar de mantener la casa". (Jorge, dueño de } \\
\text { alojamiento). }\end{array}$ \\
\hline $\begin{array}{l}\text { Interacción ingreso } \\
\text { Se da cuando } 2 \text { o más } \\
\text { actividades aportan a los } \\
\text { ingresos totales disponibles } \\
\text { para la familia. }\end{array}$ & $\begin{array}{l}\text { Aunque no genere un ingreso importante, es una actividad que } \\
\text { crece. } \\
\text { "Cada vez hay más demanda de gente que quiere lugares aislados } \\
\text { como el campo, porque el campo es ideal para desconectarse". } \\
\text { (María, dueña de alojamiento). } \\
\text { "Si es por ingresos esto no es lo más rentable. Para hacerlo más } \\
\text { rentable le tendríamos que dedicar mucho más tiempo. No } \\
\text { podemos estar en las dos partes, si está mucho allá abandonás } \\
\text { acá". (María, dueña de alojamiento). }\end{array}$ \\
\hline
\end{tabular}

${ }^{62}$ En el siguiente cuadro se enfatizan algunos conceptos utilizando colores que luego serán adoptados en el esquema conceptual que explica las interacciones de la actividad turística con el resto de las actividades del sistema. Así, con naranja se remarca la interacción entre productos de las distintas actividades; con rojo y azul la interacción de los recursos humanos y sociales y con naranja claro entre recursos físicos, naturales y materiales; con verde la interacción patrimonial; con gris, la temporal; con violeta claro la interacción dada entre el ingreso y el sentido dado al trabajo, y con violeta oscuro, la interacción entre los ingresos que aportan las actividades al sistema. 


\section{C.4.7 Impacto del turismo en el sistema productivo}

En este caso el turismo aparece como una actividad complementaria, que no compite con las otras en términos de movilización de recursos. No interactúa con el resto de las actividades.

Hoy es funcional a un ingreso que colabora al mantenimiento del espacio y no hay una dedicación full time de ningún miembro de la familia.

\section{C.4.8 Impacto del turismo en la familia, en las personas y en sus estilos de vida}

- Al no ser la actividad central del sistema, el tiempo que le dedican al turismo durante la semana prácticamente no compite con sus tiempos en la fábrica. No ha generado tensión porque la dinámica que tienen es con reserva.

"Por lo general se alquila los fines de semana largos, entonces nos organizamos con tiempo, porque solamente nos manejamos con reservas. Yo de otra forma no trabajo". (María, dueña de alojamiento).

- El turismo genera preocupación y nervios en una situación concreta: cuando llueve, porque tienen un tramo de camino que se hace intransitable.

"Este fin de semana está alquilado y mañana llueve y yo ya me pongo loco, quiero tener todo perfecto". (Jorge, dueño de alojamiento).

"A lo mejor somos nosotros los que nos hacemos problema porque los turistas está chochos, nos dicen 'si tenemos algún problema los llamamos". (María, dueña de alojamiento).

- El turismo les demanda tiempo y sienten que eso los esclaviza. Sienten que tienen que estar cerca por cualquier problema que puedan tener los turistas, que no se pueden ir de la ciudad.

"Nos demanda que estemos, nos quita que por ejemplo podamos viajar un fin de semana largo que antes nos tomábamos para nosotros. De alguna manera te esclaviza. Es un lugar que está cerquita pero aislado". (María, dueña de alojamiento). "Es un trabajo extra. Los fines de semana no podemos disponer con libertad". (Jorge, dueño de alojamiento). 
Decisiones y prácticas puestas en marcha a partir de los recursos del sistema familia-explotación

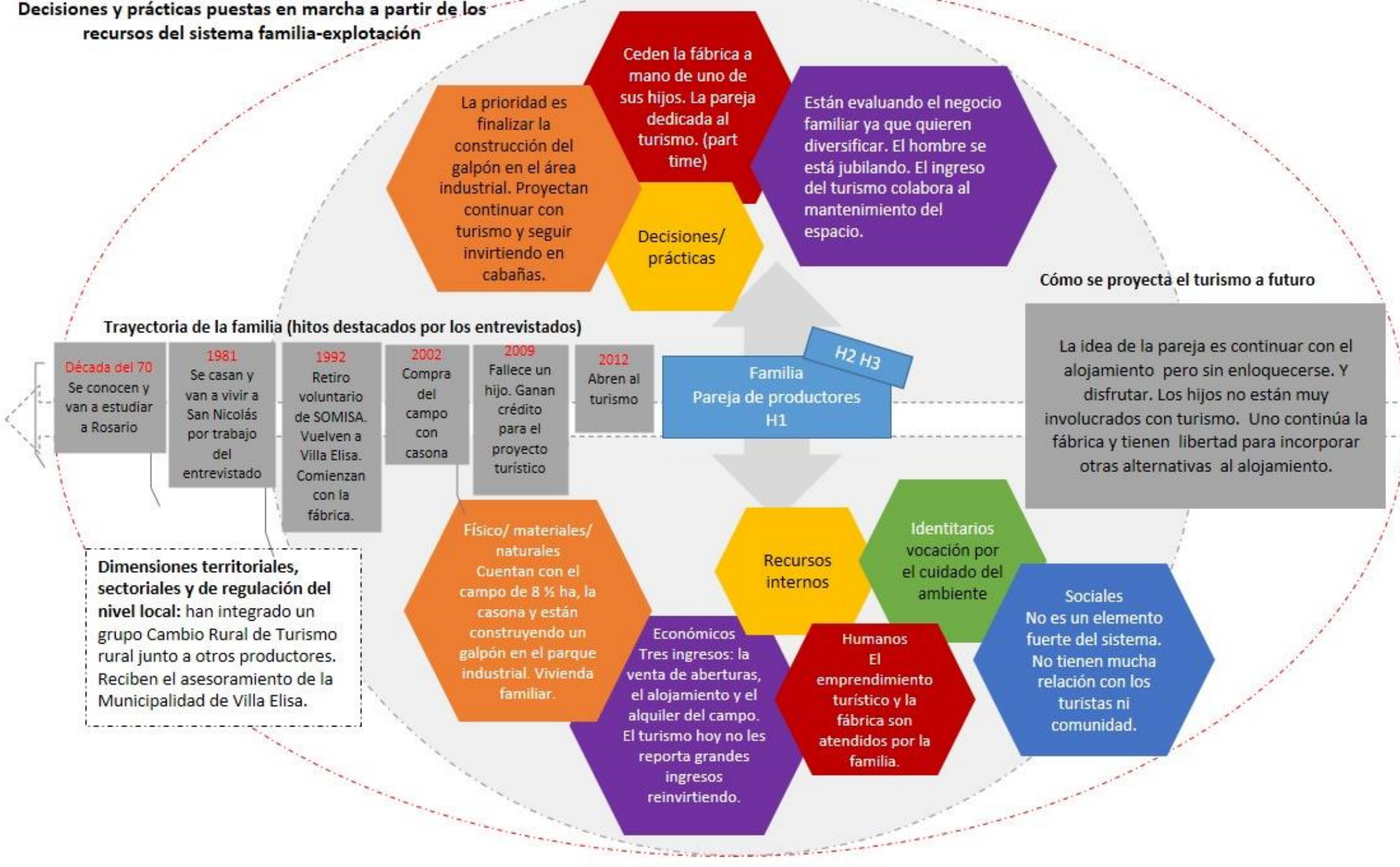




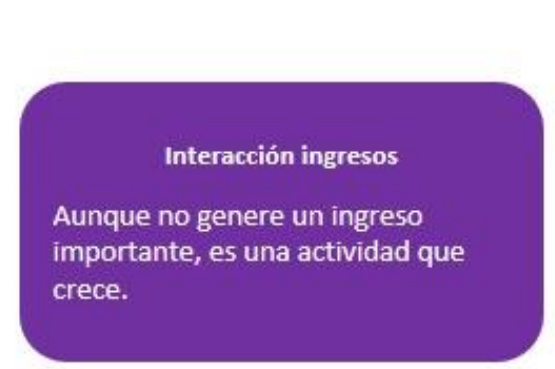

El símbolo + representa la importancia relativa del ingreso al sistema de cada actividad

Interacción ingreso/sentido del trabajo

La familia actualmente prioriza el ingreso dado por las actividades que otro tipo de satisfacciones. Incluso, la familia disfruta el lugar cuando no hay turismo los fines de semana.

Interacción temporal

la familia se dedica al turismo fundamentalmente los fines de semana, no generando una gran tensión que genere

incompatibilidad con la fábrica de aberturas.
Las flechas del esquema central ejemplifican los tipos de interacción del sistema familia-explotación, con sus respectivos colores identificatorios

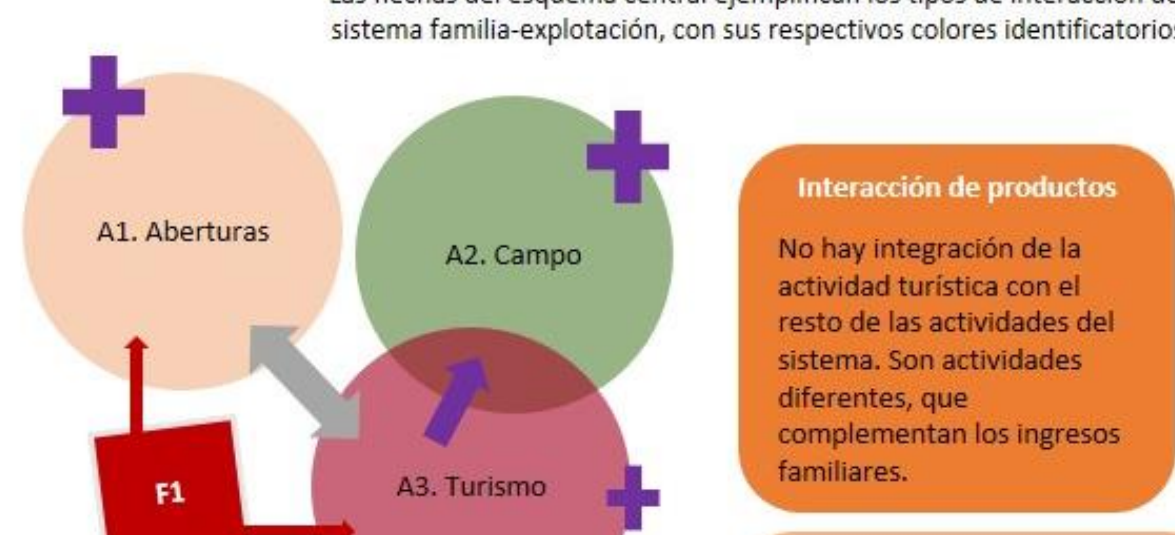

No hay relación de la actividad turistica con las actividades productivas que se desarrollan en el campo que alquilan. Son espacios diferentes y no se combinan ni comunican.

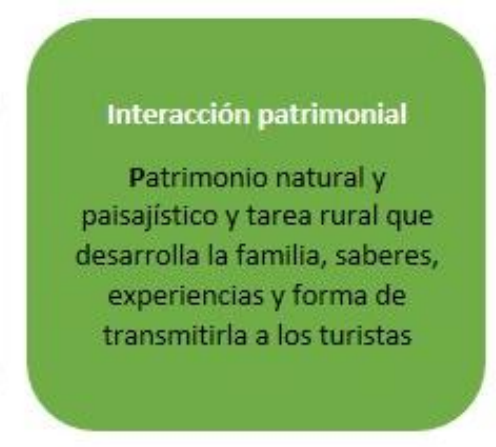

Los recursos que movilizan es el capital humano familiar,

que se distribuye entre las dos

actividades.

Tipo de interacciones entre recursos. Los colores utilizados responden al recurso movilizado (humano, en rojo; social, en azu; espacial, física, material en naranja claro)

Ilustración 18- Esquema de interacciones de las actividades dentro del sistema Caso 7 


\section{C.4.9 Percepción del futuro en relación a los hijos y en relación a su resguardo de ingresos}

- La idea de la pareja es continuar con el alojamiento "un par de años más, 4 o 5 años más, pero medio light, sin enloquecernos". (Jorge, dueño de alojamiento).

"Es grande la casa, a veces vamos el día entero para ponerla en orden y no nos alcanza". (María, dueña de alojamiento).

"El tema es que estamos viejitos. Nosotros ahora queremos disfrutar. Yo seguir disfrutando de los nietos, quiero empezar a viajar, tuvimos una época que pudimos viajar pero después las otras crisis nos agarraron mal". (Jorge, dueño de alojamiento).

- Si bien no hay total claridad respecto al rumbo que va a tomar el proyecto turístico, los hijos se opusieron a la venta del campo y casona. Hoy también la disfruta la familia como casa quinta. Hay líneas de proyectos en los cuales están involucrados los hijos pero hasta ahora no se han concretado. El que hoy está trabajando con el padre en la fábrica, es el que va a continuar con ese actividad, de hecho están tramitando el cambio de titularidad. Este hijo y su esposa son los más involucrados.

"Siguen la fábrica y si quieren hacer algo allá lo pueden hacer". (Jorge, dueño de alojamiento).

- Siempre ronda la idea de vender pero también el afecto y el esfuerzo puesto hace que cueste el desapego.

"Si yo estoy cansado no tengo problema, si la tengo que vender la vendo". (Jorge, dueño de alojamiento).

"Cuesta desprenderse porque uno puso mucho y dentro de todo es lindo". (María, dueña de alojamiento). "Lo emocional no tiene valor porque si le tuvieras que poner precio al tiempo que estuvimos ahí". (Jorge, dueño de alojamiento).

- En él es más firme la idea de ir a vivir al campo, en la mujer no. Ella vivió en el campo y piensa que es muy desgastante. "Me deprimiría vivir todo el tiempo en el campo, es muy aislado". (María, dueña de alojamiento).

"Mirá que la charlo pero no". (Jorge, dueño de alojamiento). 


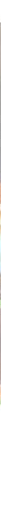

\section{"Historia, naturaleza y producción"}

"Nosotros atendemos desde las 9 de la mañana hasta que oscurece. A la picada la hacemos en cualquier momento". (Ana, tambo, granja y turismo).

"Un fin de semana largo hablás de 6000 personas". (Pedro, responsable granja y turismo). 


\section{C.5 Caso 8- HISTORIA, NATURALEZA Y PRODUCCIÓN}

En este caso lo central es que el manejo del sistema de actividades es implementado por una familia de productores tamberos-queseros, que fueron capitalizándose en el proceso, contando hoy con mano de obra familiar y empleados. Además, no han integrado espacios de trabajo asociativo y tienen dos hijos muy pequeños, en edad escolar.

\section{C.5.1 Presentación general}

El presente caso tiene como central a una pareja de 42 años y 36 años (hombre y mujer respectivamente) con dos niñas de 11 y 9 años.

El productor y su primo heredaron un campo de 60 ha de sus padres, en Colón, en el que se emplaza una casa histórica, donde funcionó la administración de la primer colonia de la zona.

Al comienzo se dedicaron al tambo, luego le agregaron la producción de quesos y con posterioridad añadieron el turismo. Comenzaron con la actividad del tambo hace 20 años, hace ocho años con la producción de quesos y hace cinco con turismo.

En ordeñe hay 25 vacas con un promedio de 400 Its al día. El ordeñe es mecánico con seis bajadas. Elaboran entre 90 y 95 quesos por día por la mañana. La responsable de la producción de quesos es la mujer. Comenzaron elaborando en su propia casa, con un crédito compraron una quesería y luego construyeron la fábrica de quesos. El ordeñe se desarrolla dos veces al día. A la mañana se lleva a los animales a pastorear a la pradera, al mediodía se las trae "y si hay silo se les da silo".

Araron una parte del campo para hacer silo maíz para alimentar la hacienda. Hicieron 6 ha de maíz y ya las ocuparon.

El campo cuenta con una casa construida en el año 1857. Allí residió Alejo Peyret, administrador, comisario y Jefe de Registro y organizador de las tierras de la Colonia San José. La familia puso en valor el patrimonio de la primera administración realizando una visita guiada. Además en el predio hay una granja con 400 animales de 30 especies que se puede visitar libremente. La granja no se trabaja productivamente, los animales son para vista del turismo. Ofrecen gastronomía, siendo la picada el fuerte del menú. Reciben a turistas de forma espontánea y grupos de jubilados y contingentes estudiantiles.

En turismo no tienen horario ni cobran entrada al predio.

"Nosotros atendemos desde las 9 de la mañana hasta que oscurece. A la picada la hacemos en cualquier momento". (Ana, tambo, granja y turismo). Un fin de semana largo hablás de 6000 personas". (Pedro, responsable granja y turismo).

Hace cuatro años comenzaron a realizar peñas en temporada de verano, durante los meses de enero y febrero. Son para 700 personas, no se cobra entrada, se toman reservas.

"A las 2 de la tarde sacamos tablones, mesas de casa, mesas del vecino, de donde sea, porque a esa hora ya no tenemos más lugar, ya se hicieron todas las reservas". (Ana, tambo, granja y turismo). 


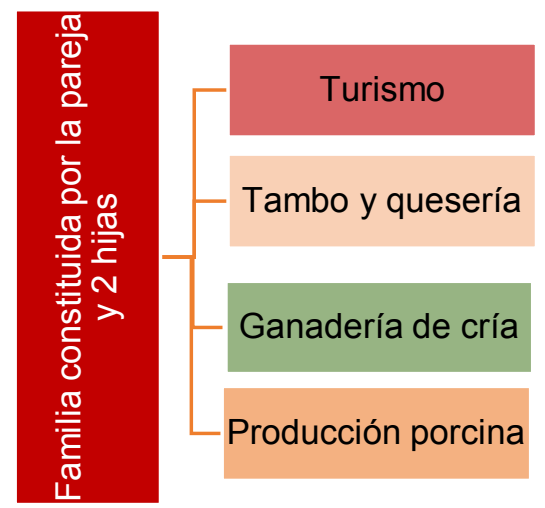

los vendemos". (Pedro, responsable granja y turismo).

\section{C.5.2 Recursos de la familia ${ }^{63}$}

\begin{tabular}{|c|c|}
\hline $\begin{array}{l}\text { Recursos } \\
\text { humanos }\end{array}$ & $\begin{array}{l}\text { Combina mano de obra familiar y empleados (una tambera y dos empleados fijos) } \\
\text { Trabajan el productor, la productora y el socio (primo). } \\
\text { Tienen una rutina durante la semana y otra para los fines de semana. La productora y } \\
\text { una señora elaboran el queso y preparan las picadas que venden al turista durante los } \\
\text { fines de semana. Durante la semana ella atiende al turismo y el productor y el primo con } \\
\text { otros empleados se dedican a lo productivo. } \\
\text { Todos atienden a los turistas, productor, productora y el primo. Durante los fines } \\
\text { de semana se suma el padre del productor que es profesor de historia. Realiza las } \\
\text { visitas y da las charlas en la casa. El primo y el productor atienden al turista. } \\
\text { "Yo me desenvuelvo mejor en la cocina y ellos atienden, me gusta más" (Ana, tambo, } \\
\text { granja y turismo). } \\
\text { "A veces hacemos bondiolas pero capaz que tenés que hacer } 1000 \text { para ese fin de } \\
\text { semana". (Pedro, responsable granja y turismo). } \\
\text { "Todos sabemos hacer quesos, si ella se tiene que ir (la esposa) todos podemos hacer, } \\
\text { que es lo más difícil". (Pedro, responsable granja y turismo). } \\
\text { Hay tareas que no se delegan, por ejemplo, no delegan la elaboración de la picada } \\
\text { y la atención al público. } \\
\text { Son una familia muy emprendedora, año a año van generando propuestas nuevas. } \\
\text { "Yo soy el que tiro las ideas, tengo las ideas en la cabeza para hacer de aquí a un tiempo } \\
\text { pero a veces lo económico no te da". (Pedro, responsable granja y turismo). }\end{array}$ \\
\hline $\begin{array}{l}\text { Recursos } \\
\text { físicos, } \\
\text { materiales y } \\
\text { naturales }\end{array}$ & $\begin{array}{l}\text { Para iniciar con la quesería pidieron un crédito a CAFESG, pero a la hora de comprar les } \\
\text { faltó dinero porque demoró mucho la entrega del dinero. Primero construyeron la } \\
\text { quesería, luego la vivienda familiar. Fueron capitalizándose año a año a partir del } \\
\text { turismo. } \\
\text { "Las primeras personas que venían a visitarnos les decíamos qué queriamos hacer y hoy } \\
\text { esa gente nos dicen pensábamos que estaban locos, pero ya lo hiciste!" (Ana, tambo, } \\
\text { granja y turismo). "Después construimos el quincho, pero sin las paredes y después los } \\
\text { baños". (Pedro, responsable granja y turismo). "A los corrales los cambiamos tres veces } \\
\text { hasta que hicimos los que están ahora". (Pedro, responsable granja y turismo). } \\
\text { En el predio del campo hay una zona que no ha sido desmontada y que conduce a un } \\
\text { arroyo donde hay agua de vertiente, vegetación con especies nativas de monte. Piensan } \\
\text { que en algún momento esa parte se puede añadir para realizar paseos y caminatas. }\end{array}$ \\
\hline
\end{tabular}

\footnotetext{
${ }^{63}$ En el cuadro se utilizan colores determinados para resaltar algunos conceptos que luego son recuperados en un esquema conceptual. Los recursos humanos son referidos en color rojo; los físicos, materiales y naturales en naranja; los recursos económicos en violeta; los sociales en azul y los recursos identitarios en verde.
}

Recientemente incorporaron producción de lechones. Tienen 20 madres y venden lechones todo el año, aproximadamente 750 .

Actualmente están limpiando otra parte del monte para hacer animales de cría.

"Antes a los terneros los vendíamos, ahora criamos y vendemos novillos 2 veces al año. Vamos a un tambo cerca de San Miguel, compramos terneros guachos y criamos. Entonces juntas 30/40 terneros de $200 \mathrm{~kg}$ y 


\begin{tabular}{|c|c|}
\hline $\begin{array}{l}\text { Recursos } \\
\text { económicos }\end{array}$ & $\begin{array}{l}\text { El principal ingreso del sistema actualmente proviene del turismo. Los turistas no } \\
\text { pagan entrada al predio pero ganan por la venta de las picadas que ofrecen con productos } \\
\text { de elaboración propia y los que compran a otros productores. Compran dulces, } \\
\text { escabeches, miel, salames a } 10 \text { productores de la zona. Elaboran quesos y bondiolas } \\
\text { para los fines de semana largos. } \\
\text { "El ingreso más grande que tenemos es la picada. Después cuando prueban se llevan las } \\
\text { cosas". (Pedro, responsable granja y turismo). } \\
\text { Hay una estacionalidad bien marcada con temporadas altas y bajas. "Abril y mayo es } \\
\text { malísimo en turismo. Semana Santa el año pasado y este llovió y fue desastroso para } \\
\text { todos iguales (porque acá cuando anda gente anda para todos). Nosotros tenemos la } \\
\text { suerte de que durante los fines de semana viene gente de la región, de Concordia, } \\
\text { Concepción del Uruguay, Gualeguaychú". (Pedro, responsable granja y turismo). } \\
\text { "El problema nuestro es cuando llueve, nos llueve cuatro fines de semana seguidos y vos } \\
\text { tenés que pagarle igual a los empleados, tenés que pagar los impuestos, la luz, y no te } \\
\text { entra nadie, y ahí no tenemos ingresos". (Pedro, responsable granja y turismo). "Las } \\
\text { épocas de malaria son abril y mayo, ya sabés, ahora ya sabés que no tenés que agarrar } \\
\text { ninguna deuda para esa época. Y nos damos cuenta que cada vez viene más gente". } \\
\text { (Pedro, responsable granja y turismo). } \\
\text { Se fueron capitalizando gracias al turismo. Van realizando inversiones todos los } \\
\text { años. "Nos vamos adaptando a las circunstancias, a la plata que entra. Sabemos que } \\
\text { ahora en octubre tenemos } 30 \text { excursiones y bueno, vos sabes que podés traer albañiles, } \\
\text { estamos por agrandar la cocina porque en verano hacemos peñas los jueves de noche, } \\
\text { para } 700 \text { personas". (Pedro, responsable granja y turismo). } \\
\text { No llevan registro, va todo a la misma caja. }\end{array}$ \\
\hline $\begin{array}{l}\text { Recursos } \\
\text { sociales }\end{array}$ & $\begin{array}{l}\text { Se genera un vínculo muy especial con los turistas. } \\
\text { "Nadie los atiende como los atendés vos. Viene gente que vino como hace cuatro años y } \\
\text { te abrazan, te dan un beso, hay gente que se pone a llorar". (Pedro, responsable granja } \\
\text { y turismo). } \\
\text { "Un } 80 \% \text { de la gente que viene te dice, me manda uno que es re conocido tuyo, uno medio } \\
\text { gordito. Yo les digo ah sí, y es un turista que vino. Así gente que nos manda gente, que } \\
\text { nos ha traído cosas de regalo, millones! aparte del que menos te esperás". (Pedro, } \\
\text { responsable granja y turismo). "Hay gente que ya somos amigos. Cuando vamos a Bs As } \\
\text { algunos te dicen no viniste a mi casa, y se enojan si no vas!". (Pedro, responsable granja } \\
\text { y turismo). } \\
\text { Hay un reconocimiento del trabajo y el progreso del lugar por parte de la comunidad } \\
\text { local, la oficina de turismo y los mismos visitantes. } \\
\text { "La mayoría de la gente que viene es por boca a boca". (Pedro, responsable granja y } \\
\text { turismo) }\end{array}$ \\
\hline $\begin{array}{l}\text { Recursos } \\
\text { identitarios }\end{array}$ & $\begin{array}{l}\text { Tienen claridad respecto a quiénes son y qué hacen. Son auténticos. } \\
\text { "Por ahí de turismo nos recomiendan que nos vistamos todos de gauchos, y nosotros no } \\
\text { lo sentimos, no nos sentimos cómodos, aparte a la gente lo que más le gusta es cómo la } \\
\text { tratás". (Pedro, responsable granja y turismo). } \\
\text { Se evidencia arraigo, amor a la historia y resguardo del patrimonio familiar. } \\
\text { "Al campo lo compró mi abuelo y nunca quiso vender el campo. También lo cuidamos por } \\
\text { mis abuelos. Y nos damos cuenta que la casa tiene valor histórico, fue lo primero que se } \\
\text { hizo en la zona, capaz que vas adentro y por ahí anduvo Urquiza. Por eso lo que } \\
\text { queremos hacer es darle más valor, hacer algo lindo". (Pedro, responsable granja y } \\
\text { turismo). }\end{array}$ \\
\hline $\begin{array}{l}\text { Recursos } \\
\text { territoriales }\end{array}$ & $\begin{array}{l}\text { La dinámica turística de la zona es muy favorable al desarrollo del turismo. } \\
\text { "Tenemos la suerte de estar entre San José y Colón. De San José estamos a } 20 \text { cuadras". } \\
\text { (Ana, tambo, granja y turismo). } \\
\text { "Aparte los dueños de los bungalows se han portado re bien con nosotros, el } 80 \% \text { de los } \\
\text { bungalows nos recomiendan. Por ejemplo llega un turista antes de la hora que tiene que } \\
\text { ingresar y les dicen, vayan a la granjita a desayunar, es barato y es lindo". (Pedro, } \\
\text { responsable granja y turismo). } \\
\text { Poseen un vínculo muy estrecho con la Municipalidad de San José. }\end{array}$ \\
\hline
\end{tabular}




\begin{tabular}{|l|l|}
\hline "El Municipio de San José nos da bolilla, el de Colón no. Para pagar impuestos somos de \\
Colón pero como atractivo somos de San José". (Ana, tambo, granja y turismo). \\
"Pero el $80 \%$ de los turistas vienen de Colón, están parando allá". (Pedro, responsable \\
granja y turismo). \\
No integran redes asociativas. \\
"No podemos ir a reuniones, son en horarios que estamos trabajando, no podemos salir". \\
(Ana, tambo, granja y turismo). "Capaz que un día de semana son las 11 y no hay nadie \\
y a las 12:30 tenés 15 autos y tenés que hacer picadas". (Pedro, responsable granja y \\
turismo).
\end{tabular}

\section{C.5.3 Trayectoria familiar}

El y la productora son nacidos y criados en la zona. Se casaron en el 2005.

El productor entrevistado y el primo heredan este campo que había comprado su abuelo, hace 54 años. El campo luego queda abandonado. De manos del abuelo pasó a su padre y su tío. "Y ellos nos regalaron el campo a nosotros. Lo único que existía era la casa y un galpón, donde ahora está la quesería. Hace 20 años me metí con el tambo, no tenía ni idea de lo que era el tambo. Gracias a Dios me llevó a tener todo esto. Empecé porque no quería estudiar ni nada" En el 2008 compran una quesería. "Y viste como es el tambo, si entregás la leche te va un año bien y tres mal entonces después compramos lo que era una quesería en San Anselmo". Empezamos con una olla a hacer quesos porque no pagaban nada la leche". (Pedro, responsable granja y turismo).

Comenzaron vendiendo los quesos en Colón. En el año 2010 hubo una creciente importante.

"Y ahí, por accidente porque no había actividad, no había playas, empezaron a venir acá. Y empezamos a vender los quesos a la gente que venía y así surgió lo del turismo". (Pedro, responsable granja y turismo).

En ese momento la Dirección de Turismo de la Municipalidad los impulsó a seguir trabajando en turismo. El INTI también los asesoró. En el 2010/11 hicieron la quesería actual.

"En el 2012 hicimos la inauguración de la casa como museo. En aquel momento nosotros vivíamos en la casa. Empezamos todo desorganizado, pero el fuerte de turismo empezó en el 2013/2014 y nos tuvimos que venir acá". (Pedro, responsable granja y turismo).

La familia en ese entonces había arreglado una casa en San José pero nunca se instalaron, vivían en la casa histórica. Luego construyeron su vivienda a unos metros, en el mismo predio. Hasta ese momento "se nos complicaba, como la casa es histórica mostrábamos el sótano, pero vivíamos también ahí, era un lío. No era museo toda la casa. Esto hasta el 2013. Y llegó un momento en que no podíamos más porque venía mucha gente". (Pedro, responsable granja y turismo). "Las nenas tenían 1 y 3 años. Sacábamos todo lo del comedor y lo llevábamos a la pieza donde estábamos nosotros, entonces mostrábamos el sótano y el comedor. El hacía las visitas y las nenas abrían la puerta para ir al baño! La gente entendía, se reían porque eran chiquitas". (Ana, tambo, granja y turismo). "Elaborábamos queso en la casa y los sábados yo me iba a vender a Colón". (Ana, tambo, granja y turismo).

Con la puesta en marcha del museo los ayudó el padre del productor que es profesor de historia, y una historiadora local muy reconocida (Celia Berna). "Creció mucho, primero no queríamos de la vergüenza mostrar lo que teníamos". (Pedro, responsable granja y turismo). Según ellos, el mejor año de trabajo fue el 2017. 


\section{C.5.4 Emergencia del turismo}

Incorporaron el turismo como una alternativa económica ligado a la oportunidad que le brinda la zona y su ubicación estratégica.

"Como una alternativa, por la cantidad de turistas que vienen, tenemos el Molino Forclaz cerca, es una zona turística y eso es una ventaja". (Pedro, responsable granja y turismo).

\section{C.5.5 Objetivos, decisiones y estrategias puestas en marcha}

Su objetivo es fortalecer la oferta de servicios que le ofrecen al turista, no agregar más servicios. Mejorar también la puesta en funcionamiento del museo en la casona.

"Ahora estamos haciendo una fabriquita de salames. Vamos haciendo según lo que va entrando, ahora queremos reformar la granja, estamos comprando unos loritos. En algún momento pensamos en hacer del quincho una parrilla pero tampoco queremos agrandarnos para enloquecernos". (Pedro, responsable granja y turismo).

"Decidimos no abrir la parrilla y fortalecer la picada, hacerla mejor". (Ana, tambo, granja y turismo).

"El año que viene queremos hacer la peña en invierno, agrandar el salón para 200 personas (ahora es para 130). Hacerla una vez por mes en invierno". (Pedro, responsable granja y turismo).

"Va todo aparejado de lo económico, para hacer cosas hay un montón, pero no nos queremos enloquecer". (Pedro, responsable granja y turismo).

"Ahora la idea es desarmarlo entero, nos van a ayudar la gente del Museo de San José. Queremos hacer luces y sonido, algo diferente". (Pedro, responsable granja y turismo).

En el verano desarrollan peñas. Esta estrategia fue implementada porque baja la afluencia de turistas.

"Se trabaja menos, trabajamos pero no es la locura porque hace mucho calor, entonces la gente viene de mañana o de tardecita, pero con las peñas cubrimos". (Pedro, responsable granja y turismo).

El fuerte de las excursiones es de septiembre a noviembre. Se hace por reserva y se les ofrece almuerzo o merienda con chocolatada y tortas fritas con dulce de leche. Trabajan también con grupos de jubilados.

Tienen una estrategia de precios que los hace muy accesibles.

"Son muy accesibles, los hacemos bien populares, una picada para cuatro, que comen los cuatro te sale $\$ 250$, con $\$ 190$ comen dos personas con una gaseosa grande". "Yo la voy peleando de no aumentar, los trato de aguantar hasta que me doy cuenta que es muy barato"(Pedro, responsable granja y turismo). No se comparan con otros lugares: "yo me voy manejando en base a la plata que me va entrando, lo que puedo hacer". (Pedro, responsable granja y turismo).

\section{Apuestan también a la producción de ganadería de cría.}

"Hoy dependemos del turismo, por ahí 2 veces al año te dan un empujón los terneros. Lo que queremos hacer es tener más terneros de cría. Queremos tener Aberdeen Angus. Podés tener dos ventas de 60, por eso estamos limpiando el campo que está sucio. Aparte agarra valor el campo, lo estamos limpiando. El día de mañana se puede hacer un paseo en carro, hay agua de vertiente, hay 70/80 pinos, es muy lindo". (Pedro, responsable granja y turismo). 


\section{C.5.6 Vinculación del sistema familia-explotación con la actividad de turismo rural $^{64}$}

\begin{tabular}{|c|c|}
\hline $\begin{array}{c}\text { Interacción producto } \\
\text { Explica el flujo de materia } \\
\text { prima de una actividad a otra. }\end{array}$ & $\begin{array}{l}\text { En esta experiencia se vislumbra una fuerte integración de la } \\
\text { producción primaria a la actividad turística. Primero decidieron } \\
\text { elaborar quesos por el poco ingreso que percibían vendiendo la leche. El } \\
\text { turismo alentó un segundo proceso de agregado de valor del queso, } \\
\text { elaborando picadas para la venta. A la vez, a partir de la venta de las } \\
\text { picadas, venden los quesos. } \\
\text { Por otro lado, utilizan maíz de su propia producción para alimentar a los } \\
\text { animales. }\end{array}$ \\
\hline $\begin{array}{l}\text { Interacción recursos } \\
\text { Se explica a partir de la } \\
\text { movilización de un mismo } \\
\text { recurso para varias } \\
\text { actividades. }\end{array}$ & $\begin{array}{l}\text { Los principales recursos que se movilizan en común para las } \\
\text { actividades son: la mano de obra que es familiar y a la vez tienen } \\
\text { tres empleados. } \\
\text { En este sentido, el turismo aportó complejidad pero se distribuyen las } \\
\text { tareas relacionadas al turismo entre el productor, la productora y el socio. } \\
\text { Hay dinámicas de distribución de roles y tiempos durante las } \\
\text { semanas y los fines de semana o fines de semana largos. Suelen } \\
\text { contratar algún empleado para hacer de mozo durante las peñas y fines } \\
\text { de semana largos, que es cuando reciben mayor cantidad de gente. Hay } \\
\text { tareas que no delegan como la atención al turista y la elaboración de } \\
\text { picadas. } \\
\text { Hay una movilización de recursos físicos y materiales en común, ya } \\
\text { que también en los límites del espacio del campo las familias han } \\
\text { construido sus viviendas familiares y en el predio combinan la actividad } \\
\text { turística con la producción tambera, la elaboración de quesos } \\
\text { artesanales, la ganadería de cría, y la producción de lechones, agricultura } \\
\text { para alimentar los animales y pasturas. } \\
\text { En este caso, los recursos económicos provenientes del turismo } \\
\text { están financiando la diversificación de actividades y la } \\
\text { capitalización familiar. La familia se ha ido capitalizando gracias al } \\
\text { turismo. Invierten las ganancias de esta actividad -y venta de terneros- } \\
\text { principalmente en mejorar y ampliar la infraestructura con la que cuentan, } \\
\text { poniendo en valor a la vez el campo. } \\
\text { Manejan sus ingresos como caja única }\end{array}$ \\
\hline $\begin{array}{c}\text { Interacción patrimonial } \\
\text { La implementación actividades } \\
\text { simultáneas se dan en torno al } \\
\text { valor intangible de un } \\
\text { patrimonio }\end{array}$ & $\begin{array}{l}\text { La propuesta turística tiene un fuerte contenido histórico y de } \\
\text { naturaleza, ligada a los dos atractivos del lugar. Combinan el } \\
\text { patrimonio de la casona donde funcionó la primera administración y } \\
\text { donde habitó uno de los responsables de la organización de los colonos } \\
\text { en esas tierras, con la posibilidad de disfrutar en un entorno campestre, } \\
\text { rodeados de animales y naturaleza prístina. También es fundamental el } \\
\text { rol del padre del productor que es profesor de historia, y el } \\
\text { conocimiento que ha podido transmitir a su familia que es } \\
\text { compartido con los turistas que visitan el lugar. A partir de esta } \\
\text { combinación de actividades turísticas logran dar respuestas a diversas } \\
\text { demandas y segmentos, tanto a estudiantes, familias y gente mayor con } \\
\text { diferentes intereses y gustos. }\end{array}$ \\
\hline
\end{tabular}

\footnotetext{
${ }^{64}$ En el siguiente cuadro se enfatizan algunos conceptos utilizando colores que luego serán adoptados en el esquema conceptual que explica las interacciones de la actividad turística con el resto de las actividades del sistema. Así, con naranja se remarca la interacción entre productos de las distintas actividades; con rojo y azul la interacción de los recursos humanos y sociales y con naranja claro entre recursos físicos, naturales y materiales; con verde la interacción patrimonial; con gris, la temporal; con violeta claro la interacción dada entre el ingreso y el sentido dado al trabajo, y con violeta oscuro, la interacción entre los ingresos que aportan las actividades al sistema.
} 


\begin{tabular}{|c|l|c|}
\hline $\begin{array}{c}\text { Interacción temporal } \\
\text { Explica los procesos de } \\
\text { anticipación de un cambio que } \\
\text { está por venir, del abandono o } \\
\text { implementación de una nueva } \\
\text { actividad }\end{array}$ & $\begin{array}{l}\text { En este caso hay una interesante puesta en marcha de estrategias } \\
\text { ligadas a la temporalidad de la actividad turística. Por un lado, se } \\
\text { continúan diversificando productivamente y desde lo turístico buscan } \\
\text { equilibrar los ingresos que son disímiles durante el año. Hay dos meses } \\
\text { que son temporada baja, abril y mayo. En ese periodo no toman deudas } \\
\text { ni hacen una fuerte movilización de recursos económicos. Generaron } \\
\text { peñas durante el verano teniendo en cuenta que los momentos de mayor } \\
\text { movimiento de turistas se dan a la tardecita, noche. Los fines de semana } \\
\text { apuntan a un turismo regional y los fines de semana largos y vacaciones } \\
\text { de invierno al turista que circula por la zona. Desde septiembre a } \\
\text { noviembre trabajan con grupos de jubilados y excursiones de estudiantes. }\end{array}$ \\
$\begin{array}{c}\text { Interacción ingresol sentido } \\
\text { del trabajo }\end{array}$ & $\begin{array}{l}\text { Al parecer, la combinación de actividades en esta experiencia se da } \\
\text { motivada por lo económico, para diversificarse. Pero a la vez, el } \\
\text { turismo genera satisfacciones que van más allá de lo económico, que el } \\
\text { permite asociar actividades } \\
\text { resto no presenta, como el reconocimiento de la comunidad, el vínculo } \\
\text { fuertemente remuneradas con } \\
\text { actividades que no son menos } \\
\text { importantes pero proveen otro } \\
\text { tipo de satisfacciones }\end{array}$ & $\begin{array}{l}\text { que los mismos productores destacan a algunos como "amigos". Y el } \\
\text { contacto social. }\end{array}$ \\
\hline $\begin{array}{c}\text { Interacción ingreso } \\
\text { Se da cuando } 2 \text { o más } \\
\text { actividades aportan a los } \\
\text { ingresos totales disponibles } \\
\text { para la familia. }\end{array}$ & $\begin{array}{l}\text { Este caso presenta una combinación de actividades que genera } \\
\text { ingresos, aunque la principal sea el turismo. El tambo es la base de } \\
\text { la producción de quesos que a la vez es insumo para el turismo, producen } \\
\text { lechones que también venden y ganadería de cría que están buscando } \\
\text { fortalecer. }\end{array}$ \\
\hline
\end{tabular}




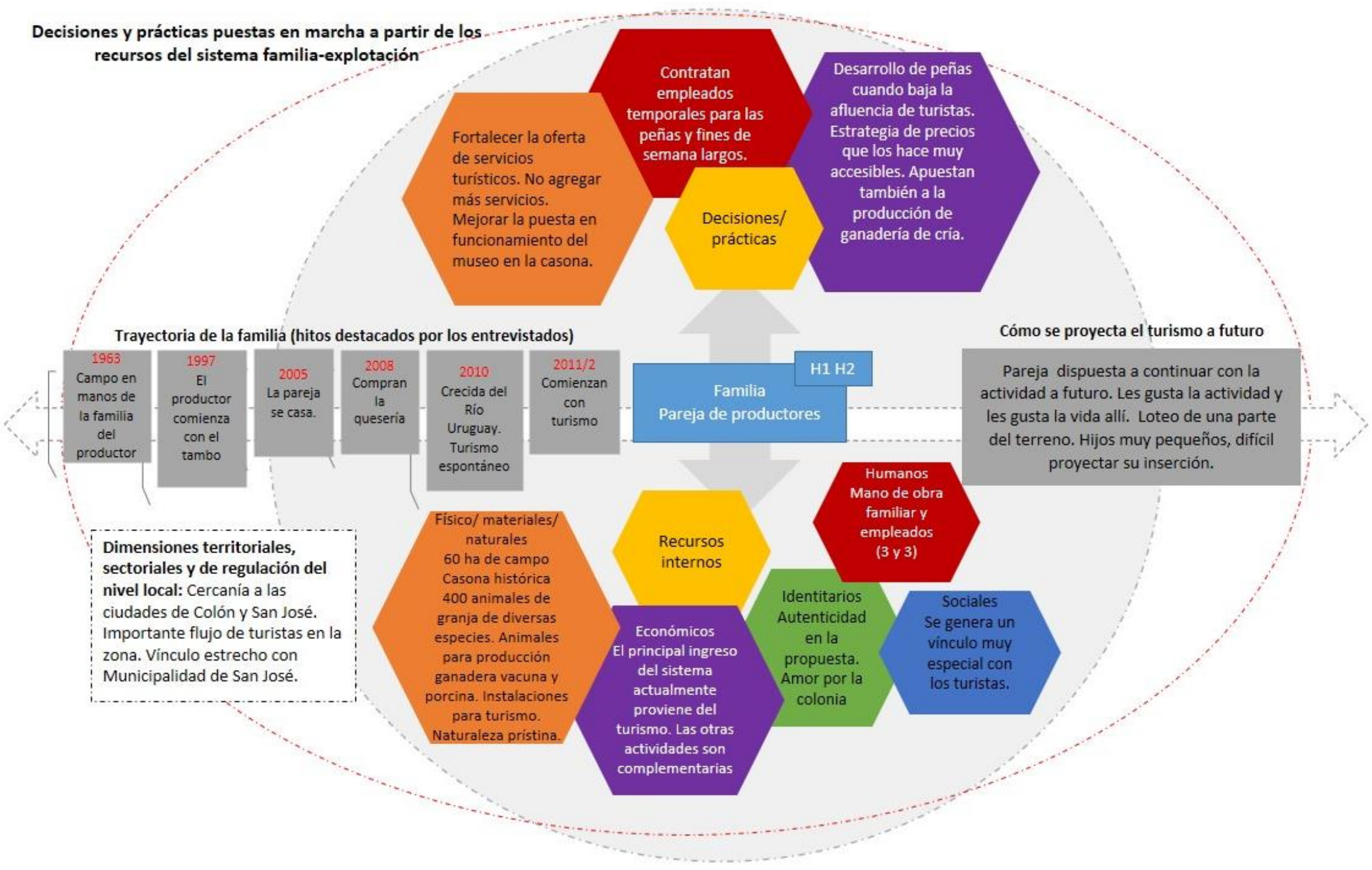




\section{C.5.7 Impacto del turismo en el sistema productivo}

En este caso, la familia se fue reconvirtiendo. De ser productores tamberos pasaron a producir quesos para la venta directa al público. Luego, a partir de la incorporación del turismo, el resto de las actividades y los tiempos de trabajo comenzaron a girar en torno a la actividad turística, hoy la más importante en términos de ingresos, satisfacciones personales y proyección a futuro.

No obstante, con el correr de los años se fueron diversificando productivamente, añadiendo cría de terneros y producción de lechones, generando una cadena entre agricultura, la producción de pasturas y ganadería. ¿Sería insustentable el sistema sin el turismo? Aparentemente sí, tal como se presenta, más dada la cercanía del predio a dos ciudades turísticas como Colón y San José, y a un monumento histórico muy visitado en la zona como el Molino Forclaz.

A partir de un mayor ingreso de gente y de añadir comidas, los productores redujeron la producción de quesos pero mejoraron el ingreso económico dando valor a su producción a través de la elaboración de picadas. Antes del turismo producían más cantidad de quesos.

"Antes produciamos más que ahora a la mañana y a la tarde, íbamos a comprar leche, pero tampoco era vida. Eso nos llevaba a hacer cosas. Después empezaron a venir las excursiones, compramos unos fardos y los atendimos a los nenes ahí, les servimos la merienda". (Ana, tambo, granja y turismo). "Estamos re contentos con como fuimos creciendo, no esperábamos esto". (Pedro, responsable granja y turismo).

Solamente producen queso por la mañana.

"Al principio cuando empezamos con turismo hacíamos a la mañana y a la tarde, hacíamos más litros, 1000 Its, comprábamos leche, pero ahora hacemos 400, porque no te da el tiempo, no tenés vida. Imaginate que a las 8 tirábamos la leche, terminábamos 11:45, sacábamos los trapos, teníamos que prensar, y volvés a tirar la leche a las 5 de la tarde, terminábamos a la 1 de la mañana". (Ana, tambo, granja y turismo).

A ese ingreso lo suplen con turismo. "Antes no hacíamos picada, nada, hacíamos el recorrido por la granja y les vendíamos los quesos y algún salame". (Pedro, responsable granja y turismo).

Esta familia está en un momento de crecimiento personal, familiar y en el establecimiento.

Piensan en diversas alternativas para incorporar a futuro pero siguen apostando a fortalecer las actividades que hoy desarrollan, turística y productivamente. En este caso, pareciera que lo patrimonial no es lo más fuerte, o que el turismo pudiese existir sin el eje histórico, ya que en el marco del turismo también están diversificados. 
Ilustración 20- Esquema de interacciones de las actividades dentro del sistema Caso 8

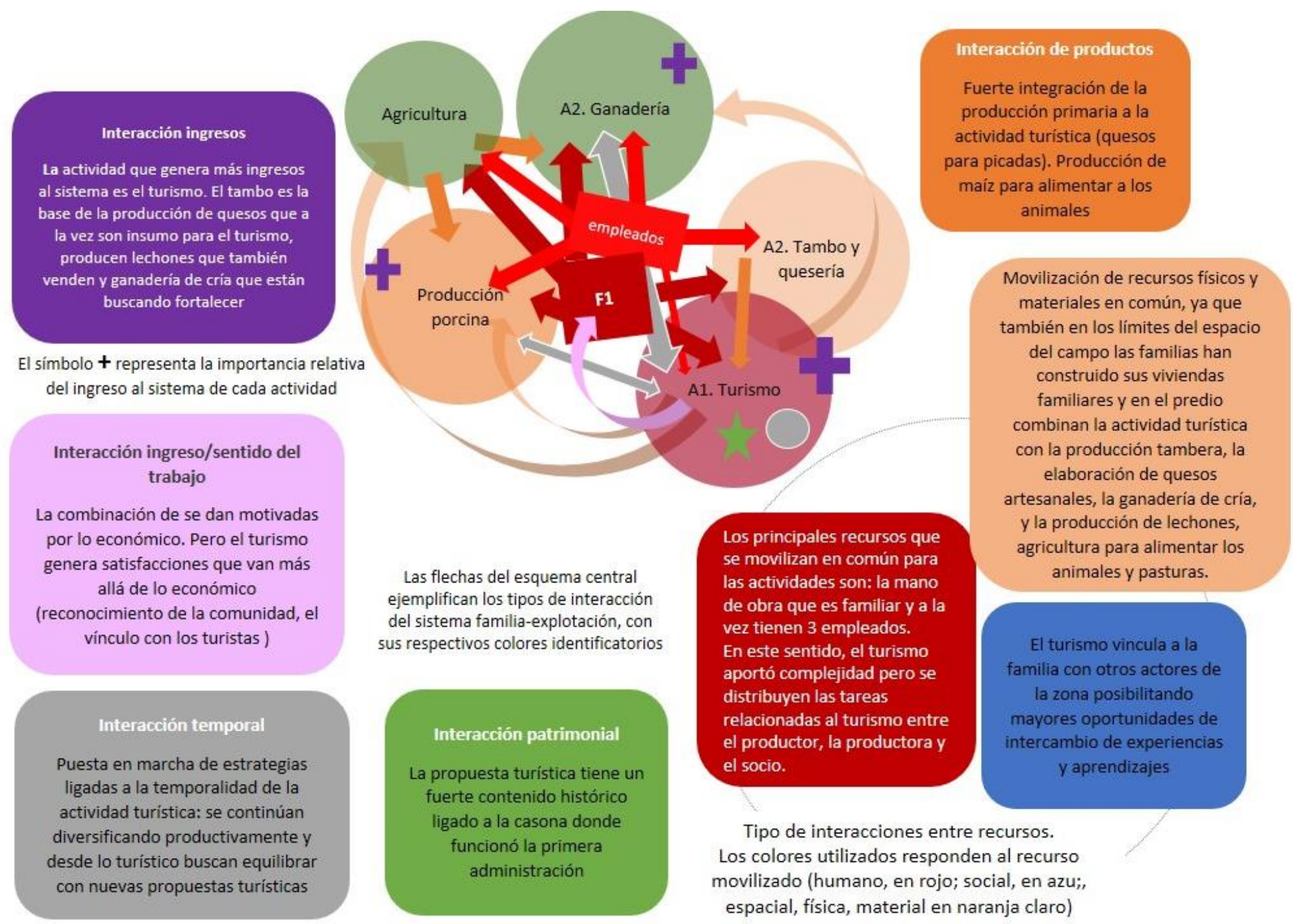




\title{
5.C.5.8 Impacto del turismo en la familia, en las personas y en sus estilos de vida
}

\author{
Hay momentos de nervios y gran tensión, sobre todo los fines de semana largos y \\ cuando organizan las peñas.
}

"A veces nos enloquecemos. Somos dos en la cocina, él atiende en el mostrador y el primo y otra chica hacen de mozos". (Ana, tambo, granja y turismo). "Yo me enloquezco. Un fin de semana largo teníamos 30 pedidos y en el bolsillo tenía otros 30 pedidos. Capaz que la demora es de 20 minutos, es rápido, y mi primo es una luz de mozo, y tenemos una chica que es una fenómeno, te atienden 120 mesas ellos dos. Entonces yo anoto a lo mejor "rubia remera gris" porque no puedo poner números en las mesas, las corren! Vienen y me dicen, mirá que vos me dijiste 20 minutos y van 22, y yo ya me empiezo a rascar la cabeza. Es una locura pero no hay forma, no les podés decir que no. Te dicen me recomendaron la picada, me vine hasta acá". (Pedro, responsable granja y turismo).

Se modificó mucho el ritmo de la familia. La familia necesita un tiempo para el descanso.

A partir del turismo, "nos tomamos un domingo por medio hace un año. Por ahí nos vamos, yo tengo campeonatos de padel y nos vamos el fin de semana. Necesitás tiempo libre para la familia porque te das cuenta que te pasan los años y tenés que vivir". (Pedro, responsable granja y turismo).

El turismo les da mayor apertura, más contacto.

"Yo por ejemplo para hablar con las personas, te relacionas mucho más. Si tenés producción te peleas con una vaca, porque vos estás ordeñando, te pagan poco, vivís rabioso, acá nosotros tenemos la suerte de que la gente viene buena onda. Esa es la gran diferencia que tenés, que tenés mucho más contacto". (Ana, tambo, granja y turismo).

\section{Reconocimiento que estimula a la familia.}

"El $90 \%$ de la gente te dice, yo vine cuando no tenían nada, qué espectacular todo. Eso es lindo". (Pedro, responsable granja y turismo).

Para la productora el turismo significa "trabajo, trabajo y trabajo, pero me gusta". (Ana, tambo, granja y turismo).

"Yo tomo todo positivo al turismo, porque digo que el turista es el que nos da de comer". (Pedro, responsable granja y turismo). "Las nenas se adaptaron, a la más chiquita le gusta el campo, interactúa con los turistas, me ayuda, junta la mesa, a la más grande no le gusta". (Ana, tambo, granja y turismo).

\section{C.5.9 Percepción del futuro en relación a los hijos y en relación a su resguardo de ingresos}

La pareja demuestra estar muy dispuesta a continuar con la actividad a futuro. Les gusta la actividad y les gusta la vida allí.

"Queremos seguir con esto, nos gusta lo que hacemos. Por ahí nos enloquecemos y rabiamos pero nos gusta. Es lindo, a mí me gusta personalmente". (Ana, tambo, granja y turismo).

No se ha mencionado si vivirían en otro lugar pero eligieron construir su hogar allí, teniendo posibilidades de realizarlo en la ciudad.

"A mí me encanta, podríamos vivir en San José porque vamos todos los días, capaz que estamos hasta las 11 de la noche, pero querés volver". (Pedro, responsable granja y turismo). 
En las entrevistas no se profundizó mucho sobre el futuro y las dinámicas de sucesión porque las hijas son muy pequeñas.

Al parecer una de las hijas presenta un perfil más ligado al turismo y es la que más colabora con los padres actualmente en tareas sencillas. Presenta interés por aprender y escuchar las visitas en la casona, le gusta atender a los turistas, a los niños y es más sociable. La niña mayor es más intelectual, reservada y según los padres no demuestra interés por las actividades que desarrolla la familia.

No obstante son muy pequeñas y es muy difícil proyectar su inserción al sistema.

Lo que sí queda claro es que el patrimonio y capital del campo es importante y que incluso existe la posibilidad a futuro de lotearlo, resguardando el espacio turístico.

"El día de mañana hablamos con mi primo de guardar 5/6 ha para esto y el resto lotearlo porque vos acá de una ha sacás 15/20 lotes". (Pedro, responsable granja y turismo). 


\section{D Zona Sur. Descripción del contexto, aspectos organizativos y regulatorios}

Los casos seleccionados para esta investigación se localizan en el departamento Islas del Ibicuy, en el sur provincial, concretamente en Villa Paranacito.

Villa Paranacito se ubica en la zona de confluencia de los ríos Paraná y Uruguay, en el corazón del delta entrerriano. Si bien no existe constancia de fundación del pueblo, tiene como fecha de fundación oficial la fecha conocida más antigua de actividad en el lugar, el 25 de mayo de 1906.

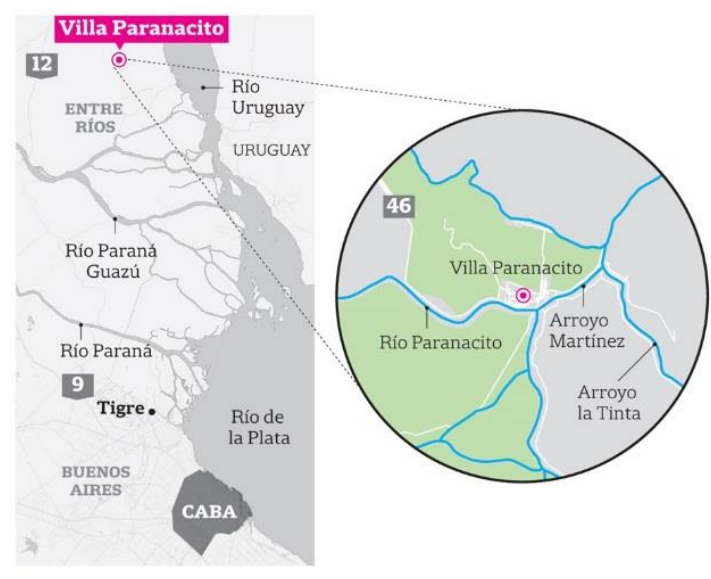

Ilustración 21- Ubicación de la localidad. Fuente: Diario La Nación 8/3/2016

Tal como han destacado los entrevistados fue colonizado por inmigrantes de Europa central y oriental, además de criollos.

De la mano de la colonización europea comenzó el auge de la forestación y la actividad frutícola en la isla.

En el libro Río abajo, de un autor local, se destacan sucesos y anécdotas de los primeros habitantes de las islas que a la vez describen con una crudeza y nivel de detalle maravilloso, la naturaleza y dinámica de la zona.

"Los primeros europeos que llegaron a las Islas del Ibicuy fueron los italianos que vinieron, a fines del siglo pasado, para hacer carbón de leña (...) pero la verdadera colonización de los europeos que constituyen casi la totalidad de los plantadores aquí, comenzó recién, según parece en el año 1895”. (Garra, 1994).

"Con el correr del tiempo, el arroyo se fue poblando con extranjeros que traían un extraño tesón para lograr un fin de riqueza a que él no aspiraba ni comprendía. Quintas nuevas aparecieron por doquier en las costas antes desiertas; plantaciones cada vez mayores variaron el paisaje". (Garra, 1994).

Desde la época colonial, se extraía madera para diversos usos y se fabricaba carbón vegetal fundamentalmente para Buenos Aires, y en menor proporción también para el país vecino en la costa oriental del río Uruguay. ${ }^{65}$

Hasta mediados de la década de 1930 solo se podía acceder a la ciudad por medio de embarcaciones.

Las décadas de 1940 y 1950 representan, según uno de los entrevistados,"una época floreciente de la isla en términos de actividad productiva y también de turismo. Había mucho turismo en esa zona, en el delta en general había muchas hosterías a las que se arribaba en lancha. Antes del boom de Mar del Plata, el Delta de Tigre con el Tigre Hotel era el lugar de veraneo de toda la gente de zona norte y Buenos Aires, después con las rutas el lugar de verano fue Mar del Plata. Acá en el medio de una actividad productiva fenomenal con la fruta y la forestación, era un combo que se hacía, hubo gente que vino, sobre todo muchos inmigrantes que hicieron hosterías con turismo de buen nivel. Era un delta que tenía 18/20 mil personas distribuidas dentro de las islas o sea que la actividad terrestre que hoy conocemos no existía. La organización del delta estaba en los arroyos, distinta a la forma normal de un pueblo como vos estás acostumbrado en cualquier lugar. En el medio de esa actividad se armaron 16 escuelas dentro del delta, clubes, hay banco desde el 1935 o sea que algo pasó acá como para que hubiera banco. Había tres servicios diarios de lancha, desde San Fernando y Campana que recorrían el delta, y esas grandes lanchas pasajeras llevaban correspondencia, llevaban de todo. Y traían turismo. Esto era Islas del Ibicuy, Villa Paranacito era el centro". (Enrique, producción y alojamiento en el delta).

\footnotetext{
65 http://heraldicaargentina.com.ar/3-ER-VillaParanacito.htm Última revisión: marzo 2018
} 
Pero como se ha comentado en el capítulo anterior,

"las crecientes limitan fuertemente el asentamiento poblacional y las producciones y sus manejos. Los humedales y los sistemas que se desarrollan sobre ellos, tienen el riesgo del régimen hidrológico que les da inestabilidad". (INTA, PRET Contribución al fortalecimiento del desarrollo del Delta Entrerriano). ${ }^{66}$

La actividad forestal y frutícola comienza a decaer, afectadas fundamentalmente por las crecidas de los ríos y la baja del precio de los productos derivados, y muchos productores se inclinan hacia la ganadería en zona de islas.

Respecto a la organización de la actividad turística, no existen organizaciones intermedias o privadas que nucleen a los prestadores turísticos.

Un intento de generar un espacio de trabajo asociativo y común fue la creación de dos grupos cambio rural orientados al turismo en el espacio rural a partir del año 2009. Se generaron diversas actividades en las que participaron sus integrantes, como visitas de intercambio, participación en ferias de promoción, generación de circuitos de turismo orientados a la naturaleza y a conocer las tareas de las familias en una zona muy particular, que combina ruralidad y delta. Estas agrupaciones finalizaron su periodo de funcionamiento y no lograron dar un paso más hacia la integración de una asociación o cámara. En el 2014, de la mano de la Cooperativa del Delta se delineó un nuevo grupo Cambio Rural que nucleó a prestadores de turismo y a productores pecaneros, con el fin de asociar ambas actividades, destacando esta producción y dando valor agregado a través de la venta de productos elaborados por mujeres de la zona, realizando visitas y circuitos en la isla. Este grupo finalizó en el año 2016 por inconvenientes particulares, pero uno de las actividades centrales que se comenzó a realizar a partir de éste, la feria isleña, continúa desarrollándose.

El $25 \%$ de las propuestas de turismo rural está gestionada por productores. De ese total, el $88 \%$ es familiar. En el $35 \%$ de los SA los hijos están involucrados en el trabajo familiar. El $88 \%$ de los productores son de la zona. El 59\% pertenecen a redes formales de asociativismo.

De los 17 SA gestionados por productores:

- 4 son alojamientos

- 6 ofrecen actividades

- 5 ofrecen servicios de gastronomía

- 2 combinan actividades

\begin{tabular}{|l|l|l|l|l|l|l|l|l|l|l|l|}
\hline $\begin{array}{l}\text { Total } \\
\text { SA con } \\
\text { turismo } \\
\text { rural }\end{array}$ & $\begin{array}{l}\text { Gestión a } \\
\text { cargo de no } \\
\text { productores } \\
\text { agropecuarios }\end{array}$ & $\begin{array}{l}\text { Sin } \\
\text { datos }\end{array}$ & $\begin{array}{l}\text { Gestión a } \\
\text { cargo de } \\
\text { productores } \\
\text { agropecuarios }\end{array}$ & $\begin{array}{l}\text { Con } \\
\text { más } \\
\text { mano } \\
\text { de obra } \\
\text { Familiar }\end{array}$ & $\begin{array}{l}\text { Con más } \\
\text { empleados }\end{array}$ & $\begin{array}{l}\text { Con hijos } \\
\text { involucrados } \\
\text { en el SA }\end{array}$ & $\begin{array}{l}\text { Sin hijos o } \\
\text { independientes } \\
\text { del SA }\end{array}$ & $\begin{array}{l}\text { Del } \\
\text { lugar }\end{array}$ & Foráneo & $\begin{array}{l}\text { Trabajo } \\
\text { en red }\end{array}$ & $\begin{array}{l}\text { Sin } \\
\text { trabajo } \\
\text { en } \\
\text { red }\end{array}$ \\
\hline 66 & 45 & 4 & 17 & 15 & 2 & 6 & 11 & 15 & 2 & 10 & 7 \\
\hline
\end{tabular}

\section{Casos de la zona sur}

Los criterios utilizados para la elección de los casos fueron:

1. Como la mayoría de los SA gestionados por productores agropecuarios son predominantemente familiares, se seleccionaron actores de esta tipología.

\footnotetext{
${ }^{66} \mathrm{https}$ ://inta.gob.ar/proyectos/contribucion-al-fortalecimiento-del-desarrollo-del-delta-entrerriano Última revisión: marzo 2018

66 http://www.mininterior.gov.ar/municipios/masinfo.php?municipio=ERI064 Última revisión: marzo 2018
} 
2. Una de las variables más importantes es la conformación de la familia con hijos a cargo que participen activamente del SA, por lo tanto se seleccionará un caso con hijos y otro en el que no intervengan, por ser pequeños o por no tener sucesión familiar.

3. Para profundizar el análisis e incrementar la diversidad y complejidad de la información obtenida en esta zona se eligió un SA cuya gestión no esté a cargo de productores agropecuarios y que sea un actor extralocal.

\begin{tabular}{|l|l|l|l|l|}
\hline $\begin{array}{l}\text { Casos } \\
\text { zona sur }\end{array}$ & Actividad productiva & Categoría turística & Mano de obra & $\begin{array}{l}\text { Integración a } \\
\text { redes }\end{array}$ \\
\hline Caso 9 & $\begin{array}{l}\text { Forestación (en } \\
\text { disminución) } \\
\text { Ganadería }\end{array}$ & Alojamiento & $\begin{array}{l}\text { Productores familiares } \\
\text { capitalizados. Mano de } \\
\text { obra netamente familiar. } \\
\text { Con hijos que se integran a } \\
\text { la actividad }\end{array}$ & $\begin{array}{l}\text { Integra redes } \\
\text { asociativas }\end{array}$ \\
\hline Caso 10 & $\begin{array}{l}\text { Pescadores } \\
\text { comerciales (actividad } \\
\text { que ya no realizan). } \\
\text { En país de origen } \\
\text { producción tambera } \\
\text { quesera. Extralocal. }\end{array}$ & Gastronomía & $\begin{array}{l}\text { Mano de obra familiar con } \\
\text { hijos chicos en edad } \\
\text { escolar. }\end{array}$ & $\begin{array}{l}\text { No integra } \\
\text { redes } \\
\text { asociativas }\end{array}$ \\
\hline Caso 11 & $\begin{array}{l}\text { Vajividad forestal. } \\
\text { actividad }\end{array}$ & Alojamiento & $\begin{array}{l}\text { Productores familiares } \\
\text { capitalizados. Con } \\
\text { empleados transitorios. } \\
\text { Hijos independientes del } \\
\text { sistema }\end{array}$ & $\begin{array}{l}\text { Integra redes } \\
\text { asociativas }\end{array}$ \\
\hline Caso 12 & $\begin{array}{l}\text { Fueron productores } \\
\text { ganaderos hasta el } \\
\text { 2016 }\end{array}$ & Alojamiento & $\begin{array}{l}\text { Mano de obra familiar } \\
\text { (empleados transitorios). } \\
\text { Hijo adolescente que no se } \\
\text { vincula al sistema }\end{array}$ & $\begin{array}{l}\text { Integra redes } \\
\text { asociativas }\end{array}$ \\
\hline Caso 13 & $\begin{array}{l}\text { Fue productor } \\
\text { forestal. Vendió parte } \\
\text { de sus campos, } \\
\text { realizó un camping. } \\
\text { Además es empleado. }\end{array}$ & $\begin{array}{l}\text { Combina } \\
\text { alojamiento y } \\
\text { gastronomía. }\end{array}$ & $\begin{array}{l}\text { Mano de obra familiar. } \\
\text { Hijos independientes }\end{array}$ & $\begin{array}{l}\text { No integra } \\
\text { redes } \\
\text { asociativas }\end{array}$ \\
\hline
\end{tabular}




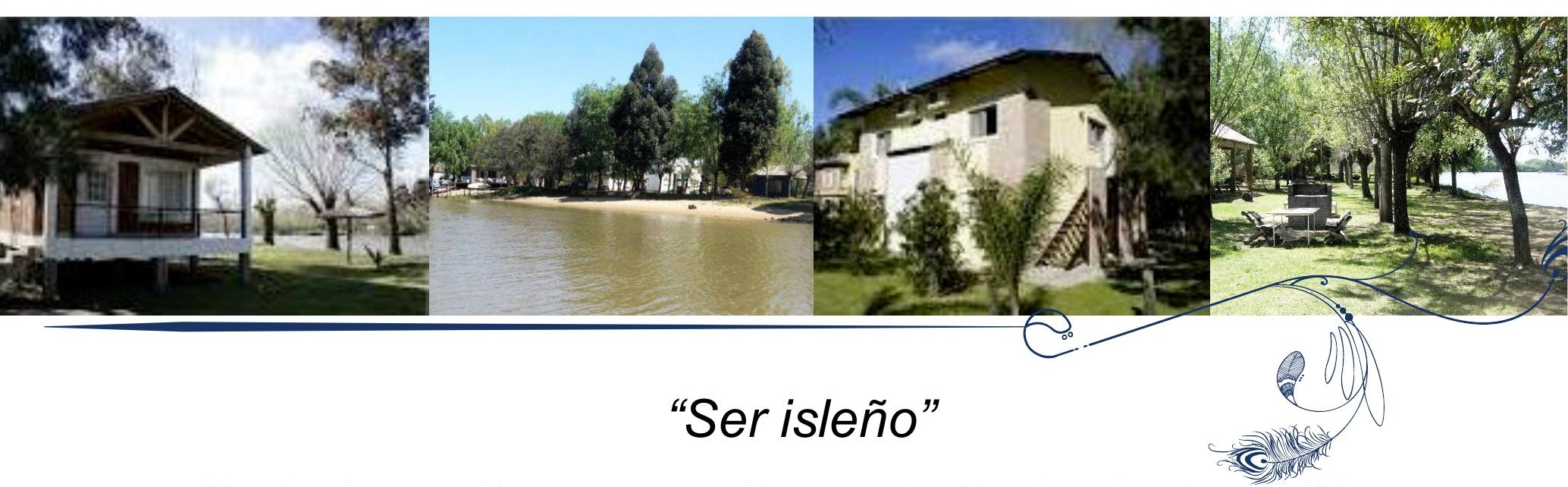

"Cuando no hay agua, el ingreso que genera el turismo en el pueblo es impresionante, es muchísimo.

Un fin de semana con turismo es totalmente diferente al que llovió y no entró ninguno. En todo el pueblo se nota, si viene gente es otro movimiento, se vende más". (Susana, producción y alojamiento en Villa Paranacito). 


\section{D.1 Caso 9- SER ISLEÑO}

Sistema de actividad implementado por una familia de productores agropecuarios de tradición forestal, a la que van incorporando nuevas actividades. El trabajo es netamente familiar, con dos de sus hijos incroporándose a la producción. Han integrado redes asociativas y espacios de quehacer institucional local.

\section{D.1.1 Presentación general}

La familia del presente caso es de Villa Paranacito, está integrada por la pareja de padres de 50 años y cuatro hijos. Los dos hijos varones actualmente están trabajando con ellos, uno es ingeniero electrónico y el otro a punto de recibirse de agrónomo. Tienen una hija contadora y la más chica estudia turismo rural en la UBA y es chef. Tienen 27, 25,23 y 21 años.

Cuentan con varias actividades de generación de ingresos: la actividad forestal (que está retrayendo), realizan tablas y tirantería con aserradero propio, brindan servicios a terceros con maquinaria propia, cuentan con un complejo de bungalows y hace algunos años se están dedicando a la producción ganadera.

Históricamente esta familia se ha dedicado a la actividad forestal pero hoy no están renovando sus plantaciones. En la isla cuentan con un predio de $\mathbf{3 4 0}$ ha.

"Éramos forestales, seguimos trabajando lo que nos queda pero no volvemos a plantar. Teníamos 200 ha en producción, quedarán 60 ha. Hace como 6 años hicimos la última plantación". (Mario, producción y alojamiento en Villa Paranacito).
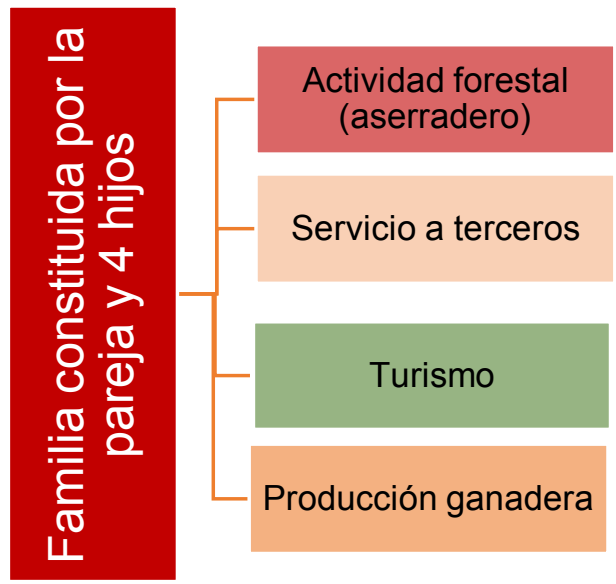

Tienen un aserradero móvil y además, con las máquinas que fueron comprando para mejorar, endicar y levantar su campo en la isla, comenzaron a hacer trabajos a terceros, no sólo en Villa Paranacito sino en otras localidades de la zona. Actualmente es uno de sus principales ingresos.

"Lo del aserradero es muy chico. Vendemos la producción de por ejemplo eucalipto colorado que acá es una madera que no se trabaja. La trabajamos nosotros, vendemos tirantería, tablas, se vende localmente". (Mario, producción y alojamiento en Villa Paranacito).

Con el turismo comenzaron en 1996. Este complejo se ubica a la vera del río Villa Paranacito, cuentan con 8 bungalows de diferente capacidad. En un tiempo ofrecían salidas de pesca y paseos en lancha pero lo abandonaron en el 2000.

"Por un lado crecimos en cantidad de bungalows pero reducimos actividades. Mi esposo antes hacía salidas de pesca embarcada, cuando le quedaba un tiempo libre. El trabajaba toda la semana en el monte y los fines de semana hacía las salidas, incluso después compramos otra embarcación y llamábamos a un guía. En el 2000/2001 lo dejamos. No tenía ni 1 día libre, los sábados se levantaba a las 4 de la mañana y a las 7 salían. Nosotros vendíamos carnadas, artículos de pesca. Lo hacés un tiempo, ganás plata pero después uno se cansa. Como 5 años 
lo hicimos. Y yo hacía paseos en lancha. Yo era la que recibía, atendía, limpiaba y después hacía paseos de una hora. Los dejaba a los chicos a cargo, que eran chicos". (Susana, producción y alojamiento en Villa Paranacito).

Hace aproximadamente 8 años comenzaron a incorporar ganadería, primero con el objetivo de mantener limpio el campo y para autoconsumo pero actualmente apostando productivamente a esta actividad, con la integración de uno de sus hijos, estudiante avanzado de agronomía.

"Hay algo de animales que en un principio se tenían para autoconsumo y para mantener limpio el campo por el tema de los incendios y para que sea más fácil recorrer, pero uno ve que es más atractivo eso desarrollarlo desde el punto de vista de la rentabilidad". (Mario, producción y alojamiento en Villa Paranacito).

"Cría pero siempre ajustando al ciclo de las crecientes. Ahora tenemos 40 animales. Pero hay cosas que no tenemos definido, no tenemos parámetros aun (de destete, qué porcentaje de preñez se obtiene) como para decir con este número podemos vivir de la ganadería". (Rubén, hijo, producción y alojamiento en Villa Paranacito).

"Teníamos ganas de meternos con ganadería porque si hay creciente, arrendás algún campo y llevás los animales y podés seguir con eso". (Mario, producción y alojamiento en Villa Paranacito).

\section{Los hijos además tienen una carpintería.}

"Con mi hermano empezamos una carpintería y ahí hacemos otros trabajos, construir muebles, estamos viendo si en un futuro no podemos hacer cabañas también, y muebles pero no sólo con la madera que producimos nosotros sino también compramos". (Rubén, hijo, producción y alojamiento en Villa Paranacito

En este caso, como en otros sistemas ubicados en el Delta, las condiciones ambientales marcan y condicionan las decisiones de las familias, además de las producciones y actividades a las que se dedican. Estos aspectos se podrán ir percibiendo a medida que se vaya presentando la experiencia.

\section{D.1.2 Recursos de la familia ${ }^{67}$}

\begin{tabular}{|l|l|}
\hline $\begin{array}{l}\text { Recursos } \\
\text { humanos }\end{array}$ & $\begin{array}{l}\text { El sistema se basa en la mano de obra familiar y la organización y distribución de } \\
\text { las tareas se da para mantener el sistema bajo esta modalidad de trabajo. En el tema } \\
\text { forestal y servicio a terceros, ocasionalmente contratan jornaleros. El marido está más } \\
\text { dedicado a la actividad forestal y el servicio, la mujer al turismo, dos de los hijos se están } \\
\text { sumando al sistema a partir la carpintería y el agrónomo vinculado a la gastronomía. La } \\
\text { hija menor que estudia turismo rural, aporta ideas y proyectos a la parte turística. } \\
\text { En turismo "siempre nos mantuvimos sin empleados, eso te Ileva a que nunca parás, } \\
\text { estás todos los días a full". "Yo lo hago con gusto, a mi esposo no le gusta atender, a } \\
\text { eso lo hago yo. Le gusta que esté todo en orden, eso sí, pero no el trato directo con la } \\
\text { gente. A él le gusta la actividad tranquila del campo, y a mí lo contrario, me gusta el trato } \\
\text { con la gente". (Susana, producción y alojamiento en Villa Paranacito). } \\
\text { "La parte comercial la maneja ella, nosotros hacemos todo el mantenimiento, la } \\
\text { construcción. Cuando ella no está lo podemos hacer nosotros. Como no cerramos nunca, } \\
\text { siempre alguien queda (Mario, producción y alojamiento en Villa Paranacito). }\end{array}$ \\
\hline
\end{tabular}

\footnotetext{
${ }^{67}$ En el cuadro se utilizan colores determinados para resaltar algunos conceptos que luego son recuperados en un esquema conceptual. Los recursos humanos son referidos en color rojo; los físicos, materiales y naturales en naranja; los recursos económicos en violeta; los sociales en azul y los recursos identitarios en verde.
} 


\begin{tabular}{|c|c|}
\hline & $\begin{array}{l}\text { Respecto a la toma de decisiones, "En general nosotros hablamos todo, todo lo que } \\
\text { hacemos en lo productivo lo hacemos en conjunto (con los hijos), menos la parte turística". } \\
\text { (Mario, producción y alojamiento en Villa Paranacito). }\end{array}$ \\
\hline $\begin{array}{l}\text { Recursos } \\
\text { físicos, } \\
\text { materiales y } \\
\text { naturales }\end{array}$ & $\begin{array}{l}\text { "Cuando uno pudo decir tengo para comer, entonces invertí en maquinarias". (Mario, } \\
\text { producción y alojamiento en Villa Paranacito). } \\
\text { Es una familia que está capitalizada, cuentan con el predio donde se ubica el } \\
\text { complejo turístico y la vivienda familiar y la quinta forestal en la isla, donde apuntan } \\
\text { a la ganadería. Allí también tienen una casa que en un tiempo alquilaron para } \\
\text { turismo, y hoy está más desmejorada por la última creciente. Comentan que el turismo } \\
\text { surgió por la venta de un barco que el esposo heredó y luego fueron invirtiendo en turismo } \\
\text { a partir de la venta de la madera. "Con el tema de la creciente (del 98) nadie trabajaba. } \\
\text { Había demanda de madera pero nadie cortaba por las condiciones de la creciente. Y } \\
\text { bueno, mi esposo cortaba sobre pontones, cortaba hasta donde se podía, era todo } \\
\text { incómodo pero eso te permitía vivir porque eran muchos meses sin ingresos y se pagaba } \\
\text { bien". (Susana, producción y alojamiento en Villa Paranacito). } \\
\text { Han hecho inversiones importantes para mejorar la calidad y accesibilidad de sus predios. } \\
\text { "Se ha invertido en un dique para que no esté constantemente inundado porque las } \\
\text { crecientes vienen cada vez más seguidas. Llegó a comprar una retroexcavadora y } \\
\text { empezamos a hacer un dique para tratar de preservar la plantación con un sistema de } \\
\text { compuertas para que el agua no entre en el campo si hay una creciente "normal". } \\
\text { (Susana, producción y alojamiento en Villa Paranacito). } \\
\text { Las crecientes imprimen el rumbo de las decisiones personales y familiares. }\end{array}$ \\
\hline $\begin{array}{l}\text { Recursos } \\
\text { económicos }\end{array}$ & $\begin{array}{l}\text { Según los entrevistados tienen dos ingresos importantes: el turismo y el servicio a } \\
\text { terceros. } \\
\text { "La forestación es lo que más aporta, no sólo la forestación sino el servicio que él hace a } \\
\text { terceros, en eso se gana. Eso es lo que posibilitó el ingreso mayor porque en la quinta } \\
\text { vos invertís, invertís, invertís y el día que querés cortar tenés } 1000 \text { problemas. Lo que } \\
\text { más sirve es el servicio, manteniendo lo propio. Es el ingreso mayor". (Mario, } \\
\text { producción y alojamiento en Villa Paranacito). } \\
\text { "El servicio a terceros te permite la inversión. Lo que se gana se invierte en las dos } \\
\text { actividades". (Susana, producción y alojamiento en Villa Paranacito). } \\
\text { "Yo hago trabajos a terceros con las máquinas que tenemos, esa entrada también es } \\
\text { importa. Eso y el turismo están más o menos equilibradas". (Mario, producción y } \\
\text { alojamiento en Villa Paranacito). } \\
\text { "Mezclamos todo, por ahí él saca mucho de un trabajo decimos bueno, vamos a hacer } \\
\text { una cabaña". (Susana, producción y alojamiento en Villa Paranacito). }\end{array}$ \\
\hline $\begin{array}{l}\operatorname{Re} \\
\text { soc }\end{array}$ & $\begin{array}{l}\text { Son una familia que históricamente ha integrado redes y están muy vinculados a } \\
\text { actividades de la comunidad. } \\
\text { Integran Federación Agraria desde el } 2008 \text {. Forman parte de la Cooperativa que primero } \\
\text { era forestal y luego fueron incluyendo otras actividades productivas como la producción } \\
\text { de nuez pecán. } \\
\text { "Yo ingresé al grupo pecanero hace } 4 \text { años, empezamos con un grupo Cambio Rural. } \\
\text { Hay muchos productores forestales que tenían árboles de pecán, que los abuelos habían } \\
\text { plantado. Hoy son otro ingreso más para la familia. Yo estoy en el grupo pero no vendo } \\
\text { nada, ayudo en la comercialzación, estoy en las ferias, se hace todo ad honorem para } \\
\text { sacar el grupo de la cooperativa adelante". (Susana, producción y alojamiento en Villa } \\
\text { Paranacito). } \\
\text { También ella integra la comisión de la Biblioteca Popular desde sus inicios. } \\
\text { Respecto a lo social que ofrece el turismo, destacan que muchos de sus amigos } \\
\text { datan de sus inicios en turismo, que la mayoría de los turistas vuelven muchas veces } \\
\text { y se genera un vínculo estrecho. }\end{array}$ \\
\hline $\begin{array}{l}\text { Recursos } \\
\text { identitarios }\end{array}$ & $\begin{array}{l}\text { Uno de los rasgos que más distingue a esta familia es el sentido de pertenencia al lugar, } \\
\text { el vínculo afectivo, por la historia familiar, que los une a esas tierras. } \\
\text { Por otro lado es muy notoria la noción del trabajo mancomunado, la integración y } \\
\text { colaboración en actividades comunitarias. } \\
\text { "Por mi formación o lo que sea, creo que es muy importante agruparse, poderse } \\
\text { ayudar mutuamente y no importa si tenés beneficios personales porque ayudás a } \\
\text { la comunidad entera. También estoy en la biblioteca popular desde que se fundó. Estoy } \\
\text { en distintas actividades. No sirve el aislado, no se logra nada. Uno solo no llega a nada y }\end{array}$ \\
\hline
\end{tabular}




\begin{tabular}{|c|c|}
\hline & $\begin{array}{l}\text { la comunidad no crecer. El ejemplo que tuvimos: cuando se empezó a formar esta zona } \\
\text { de islas (no Villa Paranacito) había una cooperativa eléctrica, acá en la isla tenían la luz } \\
\text { antes que en Bs As, había cooperativa de agua potable. Se hacía todo a partir de la unión } \\
\text { de la gente, por eso prosperó". (Susana, producción y alojamiento en Villa Paranacito). } \\
\text { "Yo estoy muy metida con lo de la cooperativa porque al insertarse lo del pecán se } \\
\text { inserta más la mujer. Ahora se cumplen dos años de la feria isleña que también surge } \\
\text { por la necesidad de vender la nuez y la miel al turista, y a su vez agregarle más personas, } \\
\text { mujeres que hacen artesanías, cestería, cerámica. Son como } 14 \text { mujeres. Yo participo } \\
\text { ayudando, no vendo, ayudo a cómo presentar las cosas, los stands. Son personas que } \\
\text { necesitan ánimo porque no se valoran así mismos, al estar en la isla son también muy } \\
\text { retraídas. Yo les aporto en eso y apoyo moral". (Susana, producción y alojamiento en Villa } \\
\text { Paranacito). }\end{array}$ \\
\hline $\begin{array}{l}\text { Recursos } \\
\text { territoriales }\end{array}$ & 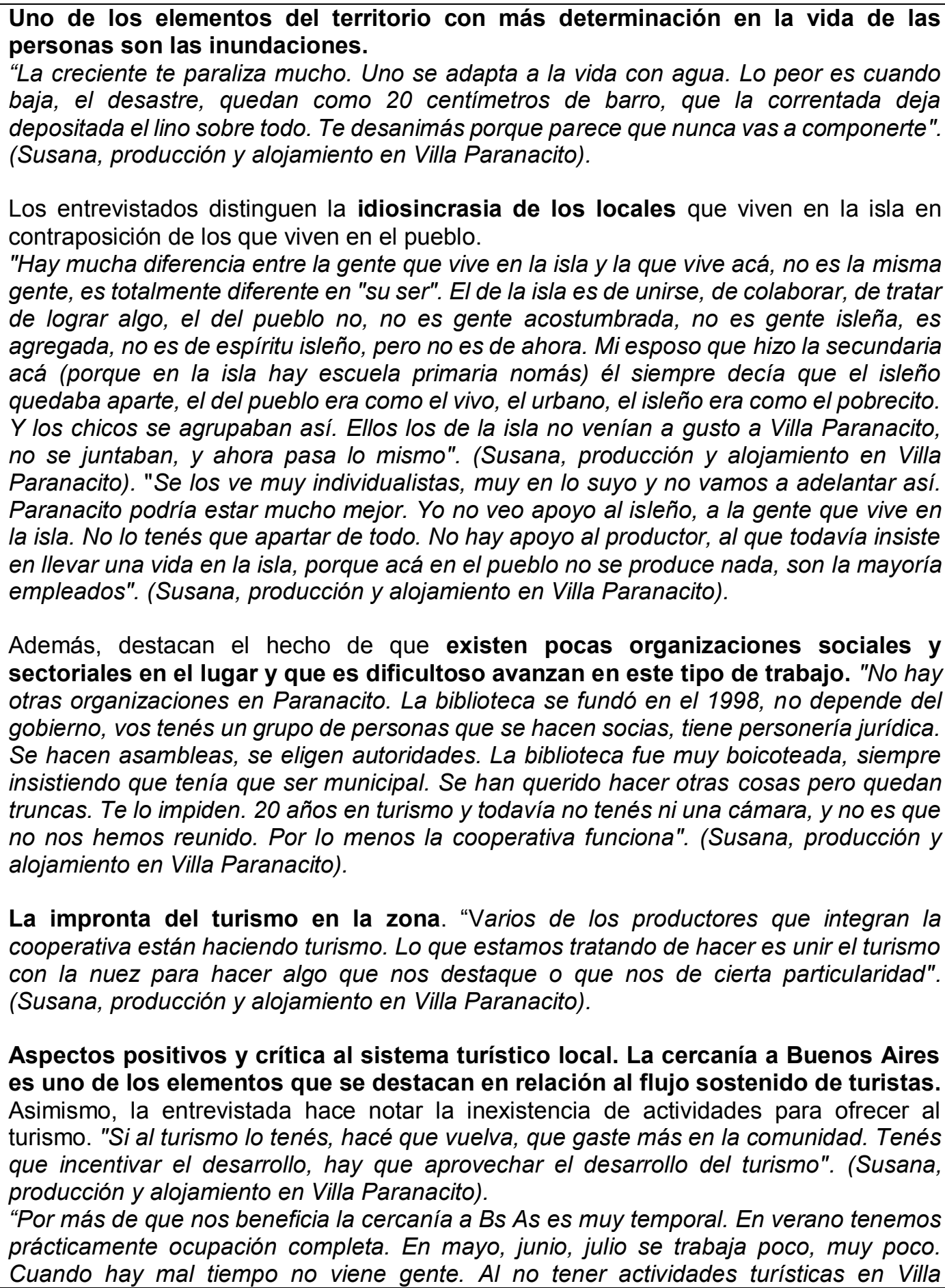 \\
\hline
\end{tabular}


Paranacito la gente viene 2 o 3 días nomás”. (Susana, producción y alojamiento en Villa Paranacito).

\section{Destacan el trabajo en red con asesoramiento de INTA.}

"Trabajamos con el INTA para presentar un proyecto para mejorar la infraestructura de la feria, unificar todos los puestos. También se había pensado en ofrecer circuitos para recorrer las plantaciones, cosechar y después cerrar con la venta de algún producto. Brenda lo quería hacer en casa, hacer un circuito, llevarlos en lancha a la quinta, hacer un recorrido y ofrecer un té, un café con alguna torta de pecán y volver en lancha". (Susana, producción y alojamiento en Villa Paranacito).

\section{D.1.3 Trayectoria familiar}

La historia familiar narrada por los protagonistas se sitúa en la isla. Y también en este caso, como en muchos otros, la dinámica de la isla va marcando la historia familiar.

Tanto la familia del marido como la de ella son de la zona. La familia del entrevistado se instaló en Brazo Chico y la de la entrevistada tenía una pensión en Brazo Largo.

"Mi abuelo vino después de la primera guerra mundial. El empezó con la forestación y con frutales (tenía 2 ha) y un almacén. Después siguió mi papá con el almacén y la parte forestal y como parte principal. Y después seguimos nosotros, el almacén dejó de funcionar". (Mario, producción y alojamiento en Villa Paranacito).

"Cada arroyo era como un barrio", narra la entrevistada, "Brazo Chico tenía más inmigración dinamarquesa, Brazo Largo era de alemanes, suizos, austríacos. Mis padres y los padres de mi esposo se conocían de joven. Todos los inmigrantes comenzaron a dedicarse a la actividad forestal (sauce y álamo) y en aquella época, el cítrico también era fuerte, eran plantaciones de cítricos que iban al Mercado de Frutos de Tigre. Las crecientes se ve que no eran tan fuertes porque los cítricos aguantaban. Todos se dedicaban a esta actividad, eran productores chicos que veían la necesidad de unirse para vender sus productos, por eso la cooperativa de productores tiene más de 78 años. El europeo quería educación para sus hijos y los del vecino, eran muchos chicos. Empezó un sistema de educación privada que después pasa a manos del estado. Había mucho progreso porque el inmigrante trabajaba su tierra pero también hacía cosas para la comunidad, por ejemplo, hacían canales hechos a pala entre todos". (Susana, producción y alojamiento en Villa Paranacito).

"La actividad forestal empieza con los inmigrantes europeos, comienza a crecer la zona. La creación de la organización del pueblo es mucho posterior. Acá era más que nada campo. Después se empiezan a instalar turcos, españoles, italianos y se empiezan a hacer otro tipo de actividades, más comercial". (Susana, producción y alojamiento en Villa Paranacito).

"Yo me crié en Bs As, nací allá por más de que toda las vacaciones obligado era venir acá. Estudié en una escuela alemana y después administración de empresas alemanas. Me vine a vivir acá cuando me casé en 1987. Vivimos en la isla muchos años". (Susana, producción y alojamiento en Villa Paranacito).

"El abuelo de mi esposo empezó con forestación pero también tenían un almacén de ramos generales, todos se surtían de ahí, combustible, las primeras máquinas, alimentos... empezó a adquirir más tierras, a hacer más producción y empiezan a vender a Bs As que había más aserraderos y necesitaban más producción, que se traslada en barcos. Mi suegro se hace de un barco, era épocas muy buenas, la madera valía mucho. Estos barcos se cargaban a pulso. Todo eso sufrió una transformación muy grande". (Susana, producción y alojamiento en Villa Paranacito). 
El marido hereda el barco, lo utilizan mucho tiempo y luego lo venden. Con ese dinero compran las tierras en el pueblo donde ahora funciona el complejo turístico y vive la familia.

"Al barco lo tuvimos bastante tiempo hasta que llegó una tecnificación mayor que fue en los 80 y pico que se empezó a poner pluma. El barco se armó para cargar 90 toneladas, se alarga. Después lo vendimos. Con ese capital en 1995 compramos la tierra que está en VP donde está el complejo y dijimos vamos a hacer otra cosa. Vamos a volcarnos al rubro turístico. Desde que compramos se modificó mucho porque había una parte de bañado. Lo que se vendían eran en total como 16 ha de las cuales 1 era utilizable. Todo el resto ahora estamos haciendo una inversión importante para aprovecharla, está entre la ruta y otro arroyo. Cuando compramos acá estuvimos un año rellenando porque era muy bajo el terreno, ahí vivíamos en la isla, todavía nuestro domicilio está ahí. En la isla teníamos básicamente forestación, solo forestación. Al barco lo utilizábamos para hacer fletes, transportábamos nuestra madera y la de otros".

En 1996 arrancan con el turismo, comienzan arreglando una construcción vieja existente. Empiezan con cuatro módulos. "Había un piso arriba y otro abajo. Cuando veníamos ocupábamos uno y el resto lo alquilábamos. El equipamiento y todo eso lo hicimos con un trato con un corralón, era un trueque, cambiábamos madera por material de construcción. Le compramos todos los muebles, era la única manera de hacernos de algo. Así empezamos con esas primeras cabañas. Después le agregamos el camping. La gente que venía a VP en un principio era como muy tipo pescador y requería pocas instalaciones. Desde el inicio, yo teniendo chicos apunté a un turismo familiar, nuestro equipamiento fue siempre para la familia". (Susana, producción y alojamiento en Villa Paranacito).

"Estábamos iniciando todo bien y en el 98 vino un agua peor que esta (2016), todavía más meses que esta. Todo lo que habíamos empezado...

Subimos todo, teníamos poquito, el agua pasó la altura de la toma de la luz. Cortamos todo y nos quedamos en la isla también inundados. Allá bajó antes que acá, primero acomodamos allá y después acá. El parque había quedado mal, habiamos plantado un montón de árboles que se secaron. Fue muy deprimente, pero bueno, arrancamos de nuevo. Fue un golpe duro porque recién estábamos arrancando. Después hicimos el quincho, otra cabaña más, parrillas en alto. Allá en la isla es como que se está más organizados para las crecientes, de por sí tenés movimiento en lancha, escuela había, pasaba la lancha escuela, nuestra casa se inundó toda pero teníamos dos piecitas en alto y un baño y ahí estábamos los 6 . La vida continúa, hay que lavar ropa por ejemplo, entonces mi marido me hizo una base afuera para lavar ropa, después me hizo una terracita. Para colgar la ropa lo hacía desde el bote. Con los chicos en ese momento jugábamos mucho a juegos de mesa. Después vino el invierno, un frío hacía, pusimos una salamandra en el pasillito. La cuestión era que esté la familia junta, yo me podría haber ido a Bs As que estaban mis padres, pero separar la familia no. Estuvimos como 8 meses, fue duro". (Susana, producción y alojamiento en Villa Paranacito).

Hace algunos años comenzaron a incorporar la ganadería, primero para limpiar los campos forestados, en un sistema silvopastoril.

\section{D.1.4 Emergencia del turismo}

El turismo surge asociado a una necesidad de diversificar, como una actividad complementaria. Cada vez se fue haciendo más importante en el sistema, sumado a la baja del precio de la madera y condiciones ambientales que perjudican al productor forestal.

"Con el turismo arrancamos en el 1996. Arrancó como complemento, primero empezó mi hermano con algo de turismo. Ellos empezaron a construir y ahí surge la idea de por qué no 
hacíamos algo nosotros. Surgió como para hacer algo más. Y después cambió. Ahora lo del turismo es lo primero". (Mario, producción y alojamiento en Villa Paranacito).

"Nosotros plantábamos 20 ha y al año lográbamos 18. Todo el tiempo era invertir, invertir y no lográs. Los ciclos del agua de las crecientes se fueron acortando, cada vez la tenemos más cerca. Y después la edad. Uno es mayor. Cuando uno es joven todo te parece que todo lo podés revertir. Cuando te vas poniendo viejo, vas cambiando". (Mario, producción y alojamiento en Villa Paranacito).

"Nosotros, la idea de la vida antes era forestar. No pensábamos otra cosa y después te vas dando cuenta que con eso no lográs. Si vos no vivís de eso es distinto porque vos decís dentro de 12 años voy a cosechar lo que plantás hoy". (Mario, producción y alojamiento en Villa Paranacito).

\section{D.1.5 Objetivos, decisiones y estrategias puestas en marcha}

- Actividad forestal en retraimiento. Les implica una gran inversión que no les genera tanta rentabilidad. Su sostenimiento está más asociada a la tradición.

"Forestadores quedan muy pocos, la madera no vale mucho. Los valores los fija papel prensa, se han fundido la mayoría de los aserraderos. Vino toda una consecuencia lógica del progreso, se reemplazó la madera por el plástico".

"La semana pasada recorrimos la quinta y ya me dijo que no va a volver a plantar, son ciclos de 10 años si todo va bien, para tener una madera de corte, pero una creciente así te seca, te impide que lleguen a desarrollarse. No tiene ganas de seguir, aparte por la edad, ya tenemos más de 50. Esta forestación se va a seguir cuidando, lo que se pueda cortar se va a cortar pero se requiere mucha inversión para plantar". (Susana, producción y alojamiento en Villa Paranacito).

"La forestación está más relacionada a la tradición que a la inversión". (Rubén, hijo, producción y alojamiento en Villa Paranacito).

- Piensan apostar a la ganadería como alternativa de diversificación de manera progresiva. Van invirtiendo de a poco, pero lo ven "como una forma de ahorro"

"Pensamos algo ganadero, probar con eso, hay que ver si funciona. Pensábamos hacer algo de cría, es una prueba porque hay que empezar a aprender de vuelta". (Mario, producción y alojamiento en Villa Paranacito).

"La idea es, teniendo el campo acá, no abandonarlo. Qué se puede producir para aprovecharlo porque es una zona endicada, que es una inversión muy grande, y ya a las crecientes chicas, los repuntes, ya con eso tenemos con qué atajarlos". (Rubén, hijo, producción y alojamiento en Villa Paranacito).

"Tampoco es que abordamos las actividades de forma brusca. No decimos vamos a hacer ganadería y compramos 500 madres. Siempre es de a poquito y nos vamos repartiendo con otras cosas y siempre organizándonos y viendo cómo marcha". (Rubén, hijo, producción y alojamiento en Villa Paranacito). "Siempre con el esquema de tener varias actividades diferentes, cosa de que uno sabe si falla algo, uno tiene de donde sostenerse, siempre hay una salida laboral aunque falle la otra". (Rubén, hijo, producción y alojamiento en Villa Paranacito).

Tienen 40 animales y "compramos 40 más, van 20 en enero, 20 en abril y así vamos a seguir despacito a ver qué pasa". (Mario, producción y alojamiento en Villa Paranacito).

- Respecto a las actividades comunitarias que desarrolla la entrevistada, las va a seguir haciendo. 
- En referencia al turismo, la hija menor es la que más aporta ideas y proyectos. Invirtió en kayaks para ofrecer actividades, pero según la entrevistada "los ofrezco si está ella". De otra manera le genera complicaciones. 
Ilustración 22- Esquema del sistema familia/explotación Caso 9

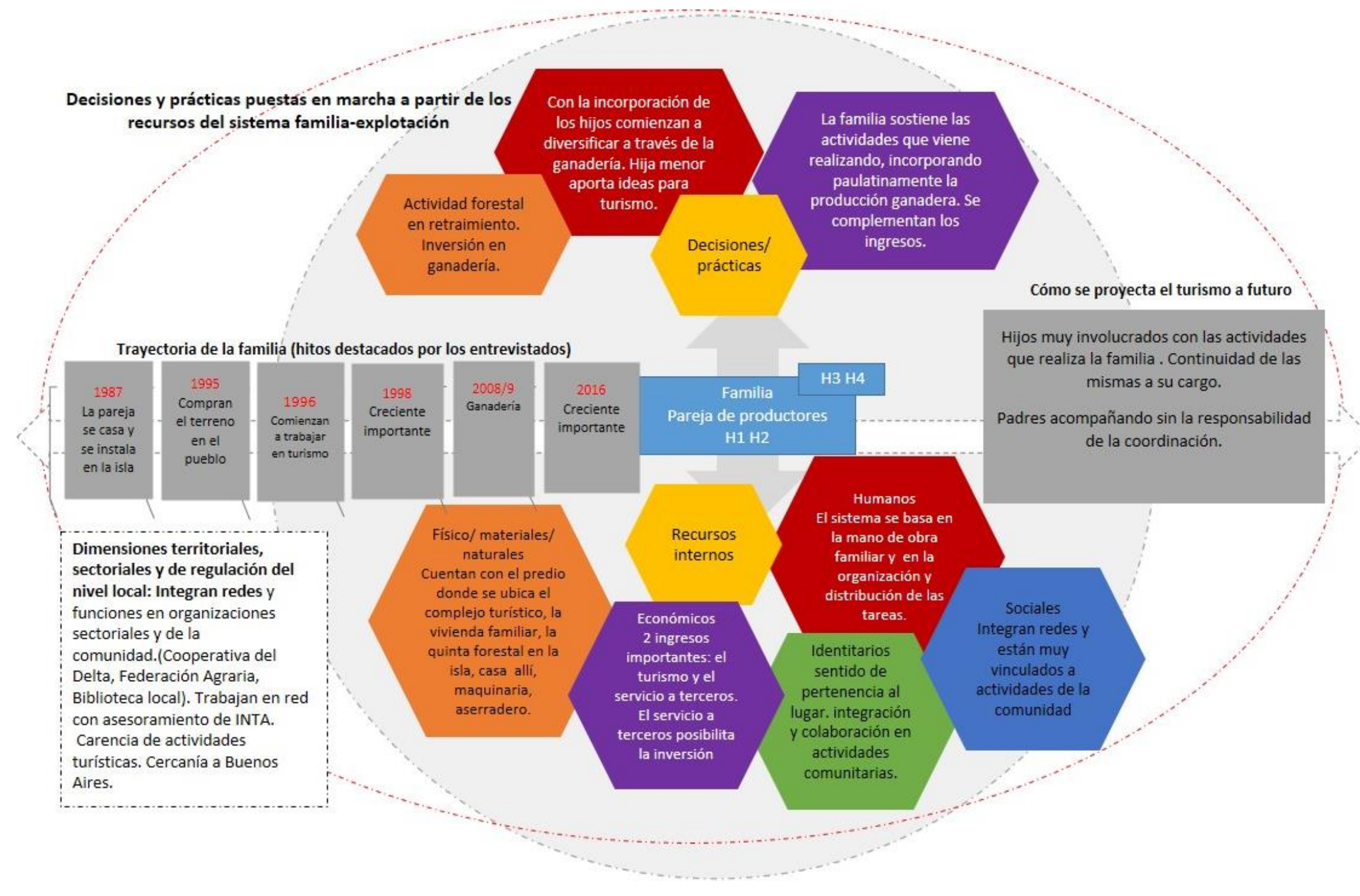




\section{D.1.6 Vinculación del sistema familia-explotación con la actividad de turismo rural ${ }^{68}$}

\begin{tabular}{|c|c|}
\hline $\begin{array}{c}\text { Interacción producto } \\
\text { Explica el flujo de materia } \\
\text { prima de una actividad a } \\
\text { otra. }\end{array}$ & $\begin{array}{l}\text { Si bien la vinculación más importante entre las actividades es la } \\
\text { económica. No hay una integración importante. Su } \\
\text { complementariedad se vislumbra el uso de las propias maderas para } \\
\text { la construcción de decks y estructuras dentro del predio del turismo. } \\
\text { "El hace sus propias tablas. Tratamos de auto proveernos de esas } \\
\text { cosas". (Susana, producción y alojamiento en Villa Paranacito). } \\
\text { La carpintería de los hijos se nutre de los materiales de la forestación } \\
\text { y realizan muebles para venta al público y para equipar las cabañas. }\end{array}$ \\
\hline $\begin{array}{l}\text { Interacción recursos } \\
\text { Se explica a partir de la } \\
\text { movilización de un mismo } \\
\text { recurso para varias } \\
\text { actividades. }\end{array}$ & $\begin{array}{l}\text { En este caso, la fuerza del trabajo es familiar, que se organiza para } \\
\text { cumplimentar con las tareas de las distintas actividades. } \\
\text { Se ve un uso compartido de las maquinarias que fueron } \\
\text { adquiridas para hacer mejoras en el campo y también se ofrecen } \\
\text { como servicios a terceros. } \\
\text { Cuentan con un tractor, una guía cargadora, el año pasado compró un } \\
\text { aserradero móvil. } \\
\text { Con esos recursos que fueron utilizados primeramente para mejorar } \\
\text { los campos propios, hacen trabajos de desmonte, canales, desagües, } \\
\text { diques, a terceros. } \\
\text { En turismo, el capital social de la familia, nacida y criada allí es } \\
\text { puesto en juego para que los visitantes conozcan de manera genuina } \\
\text { la esencia y estilo de vida de los isleños y lugareños. }\end{array}$ \\
\hline $\begin{array}{l}\text { Interacción patrimonial } \\
\text { La implementación } \\
\text { actividades simultáneas se } \\
\text { dan en torno al valor } \\
\text { intangible de un patrimonio }\end{array}$ & $\begin{array}{l}\text { En este caso la actividad forestal no se abandonó por un apego a } \\
\text { las tradiciones, al patrimonio familiar, al saber que transmitieron los } \\
\text { abuelos, que continuaron los padres, continúan los entrevistados y } \\
\text { piensan continuar los hijos. También el turismo es un motor para } \\
\text { poner en valor el patrimonio intangible que rodea al "ser isleño". }\end{array}$ \\
\hline $\begin{array}{l}\text { Interacción temporal } \\
\text { Explica los procesos de } \\
\text { anticipación de un cambio } \\
\text { que está por venir, del } \\
\text { abandono o } \\
\text { implementación de una } \\
\text { nueva actividad }\end{array}$ & $\begin{array}{l}\text { En la lógica de los productores el tema de las crecientes hace que } \\
\text { estén por ejemplo previendo reservas, o pensando en mover animales } \\
\text { a la zona alta o a otro campo. } \\
\text { Los ciclos de las crecientes condicionan los procesos de } \\
\text { anticipación, el retraimiento de la actividad forestal, y las diferentes } \\
\text { inversiones que se van realizando, además del ánimo de la familia y } \\
\text { sus expectativas a futuro. }\end{array}$ \\
\hline $\begin{array}{l}\text { Interacción ingresol } \\
\text { sentido del trabajo } \\
\text { La combinación de } \\
\text { actividades permite asociar } \\
\text { actividades fuertemente } \\
\text { remuneradas con } \\
\text { actividades que no son } \\
\text { menos importantes pero } \\
\text { proveen otro tipo de } \\
\text { satisfacciones }\end{array}$ & $\begin{array}{l}\text { Hay un involucramiento en actividades relacionadas con la } \\
\text { comunidad, que no generan ingresos pero que les otorga } \\
\text { satisfacciones personales y sentido político. } \\
\text { "Por ahí descuido las actividades propias por las que hago afuera. Me } \\
\text { han reclamado mucho pero me da satisfacción. Cuando hay que } \\
\text { trabajar, trabajo, pero por ahí descuido de mi actividad personal, por } \\
\text { ahí me disperso pero siempre lo he hecho así y mal no me fue. Igual, } \\
\text { creo que sirve, a la larga, para que todo el entorno crezca hay que ser } \\
\text { así". (Susana, producción y alojamiento en Villa Paranacito). } \\
\text { El esposo encuentra satisfacciones en la actividad forestal, que } \\
\text { además es un patrimonio familiar. }\end{array}$ \\
\hline
\end{tabular}

${ }^{68}$ En el siguiente cuadro se enfatizan algunos conceptos utilizando colores que luego serán adoptados en el esquema conceptual que explica las interacciones de la actividad turística con el resto de las actividades del sistema. Así, con naranja se remarca la interacción entre productos de las distintas actividades; con rojo y azul la interacción de los recursos humanos y sociales y con naranja claro entre recursos físicos, naturales y materiales; con verde la interacción patrimonial; con gris, la temporal; con violeta claro la interacción dada entre el ingreso y el sentido dado al trabajo, y con violeta oscuro, la interacción entre los ingresos que aportan las actividades al sistema. 


\begin{tabular}{|c|c|}
\hline $\begin{array}{c}\text { Interacción ingreso } \\
\text { Se da cuando } 2 \text { o más } \\
\text { actividades aportan a los } \\
\text { ingresos totales disponibles } \\
\text { para la familia. }\end{array}$ & $\begin{array}{l}\text { La familia expresó que no se puede vivir exclusivamente de la } \\
\text { actividad forestal, fundamentalmente por el bajo precio de la madera } \\
\text { y porque las plantaciones están muy condicionadas por las crecientes. } \\
\text { Por ello surge el turismo, como una actividad complementaria que } \\
\text { hoy genera uno de los ingresos más importantes y estables. El } \\
\text { ingreso por los servicios que brinda el sistema también son } \\
\text { importantes, se equilibran. } \\
\text { "El turismo es un ingreso más seguro, más constante. Es un ingreso } \\
\text { fijo, teniendo la estructura, uno lo tiene que hacer trabajar } \\
\text { simplemente. (Mario, producción y alojamiento en Villa Paranacito). } \\
\text { "Es constante porque la cercanía a Buenos Aires hace que casitodos } \\
\text { los fines de semana haya turistas". (Rubén, hijo, producción y } \\
\text { alojamiento en Villa Paranacito). } \\
\text { "De la madera no es una actividad de la cual se pudiese vivir } \\
\text { exclusivamente". (Mario, producción y alojamiento en Villa } \\
\text { Paranacito). }\end{array}$ \\
\hline
\end{tabular}

\section{D.1.7 Impacto del turismo en el sistema productivo}

Esta familia, tradicionalmente dedicada a la producción forestal en su trayectoria fue incorporando otro tipo de actividades a su sistema que le permitan diversificar los ingresos y dispersar los riesgos. Primero el turismo, luego la prestación de servicios con máquinas propias, el aserradero móvil, la carpintería de los hijos, la ganadería.

No se puede afirmar que la incorporación del turismo fue la condición sine qua non para la retracción de la actividad forestal, ya que impactan otros factores que se han mencionado, como la caída del precio de la madera, el cierre de aserraderos en la zona, las crecientes, que perjudican el normal crecimiento de los árboles y la accesibilidad a los predios. Pero sí es claro que aporta un ingreso estable, importante para garantizar la calidad de vida de la familia y que, dada la principal ventaja que tiene la zona, que es su cercanía a la provincia de Buenos Aires, puede seguir desarrollándose y creciendo más.

\section{D.1.8 Impacto del turismo en la familia, en las personas y en sus estilos de vida}

- La familia hace más de dos décadas que se dedican al turismo. Ya lo tienen incorporado a sus tiempos y roles. La llegada y necesidades planteadas por los turistas son las que marcan y diferencian la rutina.

"Es como que tenés asumido todo. Si tenés mucho trabajo, trabajás todos los días y tratas de cumplir con todas las cosas. Acá lo que tiene prioridad es el turismo porque la persona que viene quiere estar bien y encontrar todo en condiciones. Vos al campo si lo dejás un día no sería tan grave". (Mario, producción y alojamiento en Villa Paranacito).

"Estamos bien organizados con las actividades. Acá vamos bien con todo pero tenés que trabajar todos los días, no es fácil decir corto, me voy. todos los días es hacer algo, es como la vida del campo". (Mario, producción y alojamiento en Villa Paranacito). 
"No te cambia mucho la vida. La vida en el campo puede ser más tranquila que acá. Acá muchas veces tenés que salir apurado a hacer las cosas, en el campo no, en el campo lo manejás distinto. No hay quien te apure, acá se rompe algo a las 10 de la noche y lo tenés que arreglar". (Mario, producción y alojamiento en Villa Paranacito).

- El turismo es una actividad que agrada a la familia y se esgrime como una herramienta para dar a conocer el lugar, la idiosincracia del lugareño, su historia y paisaje.

"El tema del turismo me gusta mucho. Te permite mostrar lo que uno tiene, cómo uno vive, las particularidades de la gente de la zona a la gente que eligió Villa Paranacito, que viene con una apertura porque justamente quiere absorber de las personas, de los locales.

Uno también trata de hacerles un panorama para que se enamoren del lugar. A mí el trato con la gente me gusta mucho, yo disfruto, aparte la gente que viene es re buena, incluso uno traba amistades. Muchos de mis amigos actuales datan de los inicios del turismo mío, los chicos jugaban juntos, van creciendo, se una situación particular porque acá es un turismo más familiar". (Susana, producción y alojamiento en Villa Paranacito).

"Tenés la gente que viene una vez y no vuelve porque no le gustó. Y tenés la de siempre, porque a varios de los que estamos en turismo nos pasa esto de tener clientes que son los mismos, que se repiten". (Susana, producción y alojamiento en Villa Paranacito).

\section{D.1.9 Percepción del futuro en relación a los hijos y en relación a su resguardo de ingresos}

Los hijos están muy involucrados con las actividades que realiza la familia y se evidencia una clara continuidad de las mismas en sus manos.

"Por el momento pensamos quedarnos. A uno le gusta el lugar y tiene más facilidades para trabajar acá, conocés más el lugar por haberte criado, ya sabés como manejarte" (Rubén, hijo, producción y alojamiento en Villa Paranacito).

"Uno intenta seguir con lo que se venía haciendo, no perder las producciones o lo que uno siempre aprendió a hacer de chico. Pero viendo de incorporar, tanto mi hermano como yo, ir haciendo algo de la actividad privada en el ámbito profesional pero no como actividad principal y no abandonar todo lo otro". (Rubén, hijo, producción y alojamiento en Villa Paranacito).

"El agrónomo es el más entusiasta con el tema de la forestación y la ganadería. Yo pienso que él va a seguir con esto, a él es al que más le gusta ir a Brazo Chico. La que hace turismo rural estudió gastronomía y ahí metiéndose en eso dijo voy a estudiar turismo rural, que es una carrera bastante nueva. Su intención era ya insertarse con el tema de las cabañas, venía con muchas ideas. Ella dice que nosotros no tenemos ninguna actividad, vamos a poner bicicletas, canotaje. Ella me está diseñando una web con cosas nuevas, me manda proyectos. Mi otro hijo me está rediseñando el parque porque se secó todo, es como empezar de nuevo tratando de mejorar todo (...) El que estudió ingeniería eléctrica sueña con dejar de ser empleado, dejar la empresa, inclusive la idea del aserradero portátil fue de él. El piensa volver, hacer algo tipo de mecanización". (Susana, producción y alojamiento en Villa Paranacito).

Lo que surgió claramente en la entrevista es que la pareja es amante de su lugar y que a pesar de las circunstancias dramáticas que vivieron en las crecientes más importantes de la historia del lugar, no se irían a vivir a otra parte. 
"Al final uno se queda, cuando viene el agua lo pensás, pensas en irte, pero al final uno se queda". (Susana, producción y alojamiento en Villa Paranacito).

Su idea es que los hijos se vayan haciendo más cargo de las actividades y ellos puedan acompañar, sin la responsabilidad de la coordinación.

"La idea de los chicos es venirse a vivir acá. Brenda seguiría con las cabañas, la idea es pasarle esto. Tiene la base hecha. vamos a seguir trabajando pero tanto mi esposo como yo pensamos pasarle la posta a ellos. Uno los acompañará, pero si Brenda asume todo el tema este, que para eso estudió, mi idea es pasarle todo". (Susana, producción y alojamiento en Villa Paranacito). 
Ilustración 23- Esquema de interacciones de las actividades dentro del sistema Caso 9

Las flechas del esquema central ejemplifican los tipos de interacción del sistema familia-

explotación, con sus respectivos colores identificatorios

\section{Interacción ingresos}

La familia integra los ingresos

de todas las actividades.

Turismo y servicios son los

ingresos más importantes y estables.

El símbolo + representa la importancia relativa del ingreso al sistema de cada actividad

$$
\begin{gathered}
\text { Interacción ingreso/sentido } \\
\text { del trabajo } \\
\text { Involucramiento en actividades } \\
\text { relacionadas con la comunidad, } \\
\text { que no generan ingresos pero } \\
\text { que les otorga muchas } \\
\text { satisfacciones personales y } \\
\text { sentido político. }
\end{gathered}
$$

\section{Interacción temporal}

Los ciclos de las crecientes condicionan los procesos de anticipación en todas las actividades.

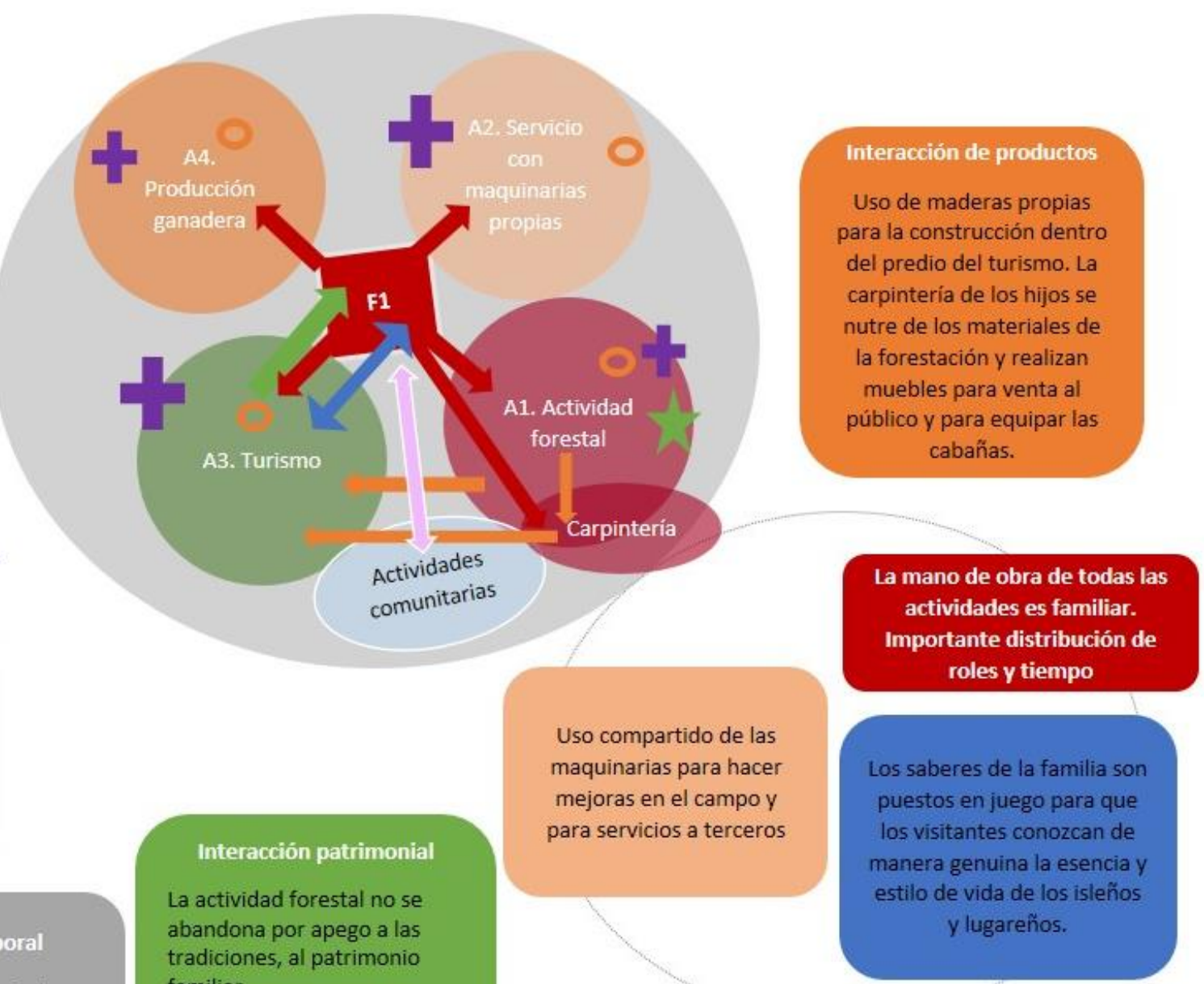

Tipo de interacciones entre recursos.

El turismo es un motor para poner en valor el patrimonio intangible que rodea al "ser isleño". os colores utilizados responden al recurso

movilizado (humano, en rojo; social, en azu; espacial, física, material en naranja claro 


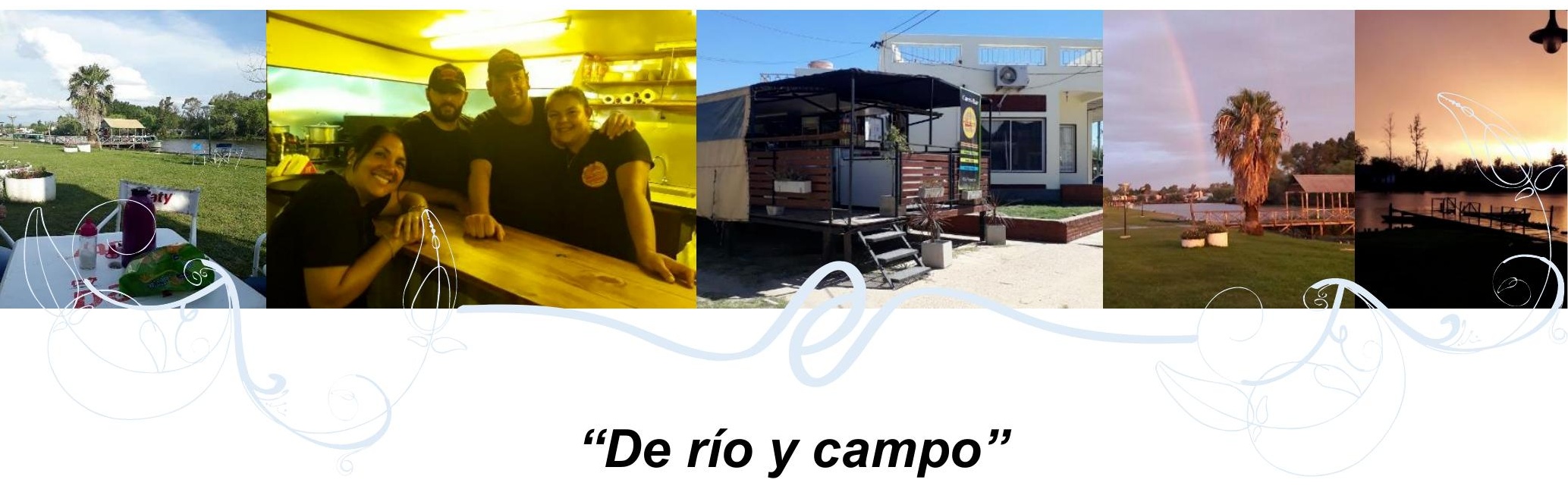

"Es mucho más sacrificada la vida del pescador. Ahora estamos bastante más tranquilos, el río es complicado. Se gana bien cuando el pescado sale pero arriesgas mucho, incluso la vida". (Sergio, pesca y gastronomía). 


\section{D.2 Caso 10- DE RÍO Y CAMPO}

Este caso representa al único sistema familia-explotación de origen extra-local. En esta experiencia, el entrevistado es de origen uruguayo, productor tambero quesero en su país de origen, luego pescador comercial. A partir de esta actividad conoce a su esposa y hace 10 años se radica en Argentina. Dejan la actividad comercial para dedicarse a la gastronomía para lugareños y turistas. El trabajo es familiar, con un empleado. Sus hijos están en edad escolar y no han integrados grupos de trabajo técnico con otros referentes del sector.

\section{D.2.1 Presentación general}

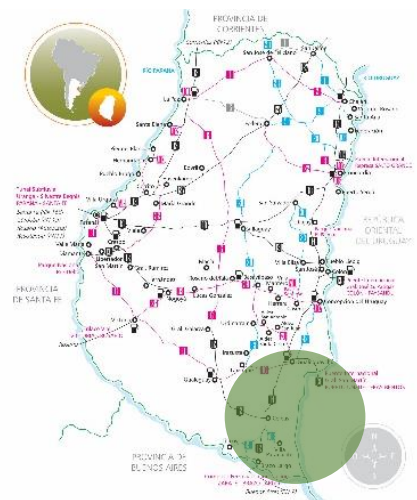

Este sistema tiene como familia a una pareja de 38 años él y 31 ella, con una hija del primer matrimonio de la mujer y un niño de 9 años en común.

Él es uruguayo y ella nacida en Villa Paranacito. Se conocieron en el río ya que ambos son pescadores comerciales, él de la costa uruguaya, ella del lado argentino. Además, él y su familia son productores tamberos queseros en Uruguay.

Este es un caso muy particular porque la actividad del tambo y quesería no es en Argentina, no es una actividad que genere ingresos a la familia pero parte de las decisiones que se tomaron están en relación directa a su desarrollo. Si bien el entrevistado no trabaja diariamente en la producción, está relacionado desde la toma de decisiones familiares.

"La actividad mía de toda la vida fue el campo: tambo y quesería toda la vida. La quesería cumplió 40 años y yo tengo 38. Mi viejo sigue con la actividad en un predio chico, de 55 ha". (Sergio, pesca y gastronomía).

La familia posee este predio lindero al río Uruguay, entre Nueva Palmira y Dolores. En el año 2000 por una crisis económica tuvieron que cerrar el tambo y quesería, pero continuaron con ganado de carne y comenzaron a trabajar en la pesca comercial en el río Uruguay.

El entrevistado continúa relacionado con la producción agropecuaria de su familia en Uruguay, aunque no esté diariamente en el campo.

"No trabajo allá pero siempre estoy con mi padre en lo que son las ideas, nos estamos consultando todo el día lo que es siembra, pasturas, compra de animales, se compran vaquillonas todos los años, terneros. Hoy ya se está con 51 vacas y 1320 litros, 25 I promedio por vaca. Se ordeña dos veces al día y se elaboran quesos 2 veces al día". (Sergio, pesca y gastronomía).

Producen queso cáscara colorada que en Uruguay se llama queso de colonia que es similar al queso Mar del Plata.

"Estuvimos 12 años sin producir esa calidad de queso. Hace dos años logramos el permiso de exportación". (Sergio, pesca y gastronomía).

Venden un queso de muy buena calidad. "No tenés competencia en el mercado. Allá pasa lo mismo que en Argentina: la leche vale muy poco entonces hay momentos en que muchos lecheros se mandan a hacer quesos para valorizar la leche. Te saturan el mercado". (Sergio, pesca y gastronomía).

El padre además utiliza el suero para producir chanchos o terneros. Tiene entre 150/200 lechones. Utilizan el sistema de feed lot "para la vaquillona que está por parir". Producen el silo maíz. 
El objetivo de diversificar a través de la pesca siempre fue recuperar el tambo y la quesería. La actividad tuvo un buen desempeño desde el 2003 y con esos ingresos lograron reactivar el campo. La mujer seguía pescando del lado argentino.

En el 2007 decide radicarse en Villa Paranacito para formar su familia y continúa con la pesca él desde el lado argentino y su padre del uruguayo.

La pareja continúa con la pesca hasta el 2015 y en ese momento dejan la actividad. Por esos años comienzan a elaborar y vender comidas caseras desde su propia casa, para contrarrestar la caída de la producción pesquera en invierno.

En el 2014 deciden emprender un establecimiento gastronómico del estilo food truck, es decir un carrito fijo donde se elaboran y venden diversos menú. Comenzaron con un carro más pequeño, prestado, y luego lograron construir el que tienen actualmente, completamente instalado.

Es hasta el día de hoy que se dedican exclusivamente a la gastronomía, han logrado capitalizarse y atienden tanto a turistas como lugareños. Fueron diversificando sus propuestas de platos, adaptándose a la clientela local y visitantes. Ofrecen desde comidas rápidas, bebidas, hasta platos más elaborados como pastas o guisos.

Dejaron la actividad pesquera para dedicarse exclusivamente a la gastronomía y el turismo. Hoy están dedicados al $100 \%$.

En este caso, si bien actualmente solo concurre una actividad de generación de ingresos, la gastronomía, se sumarán al análisis la actividad agropecuaria desarrollada en Uruguay por la familia del entrevistado y la pesca comercial (desarrollada por la pareja primero en forma individual y luego como familia) con el objeto de comprender la relación entre éstas.

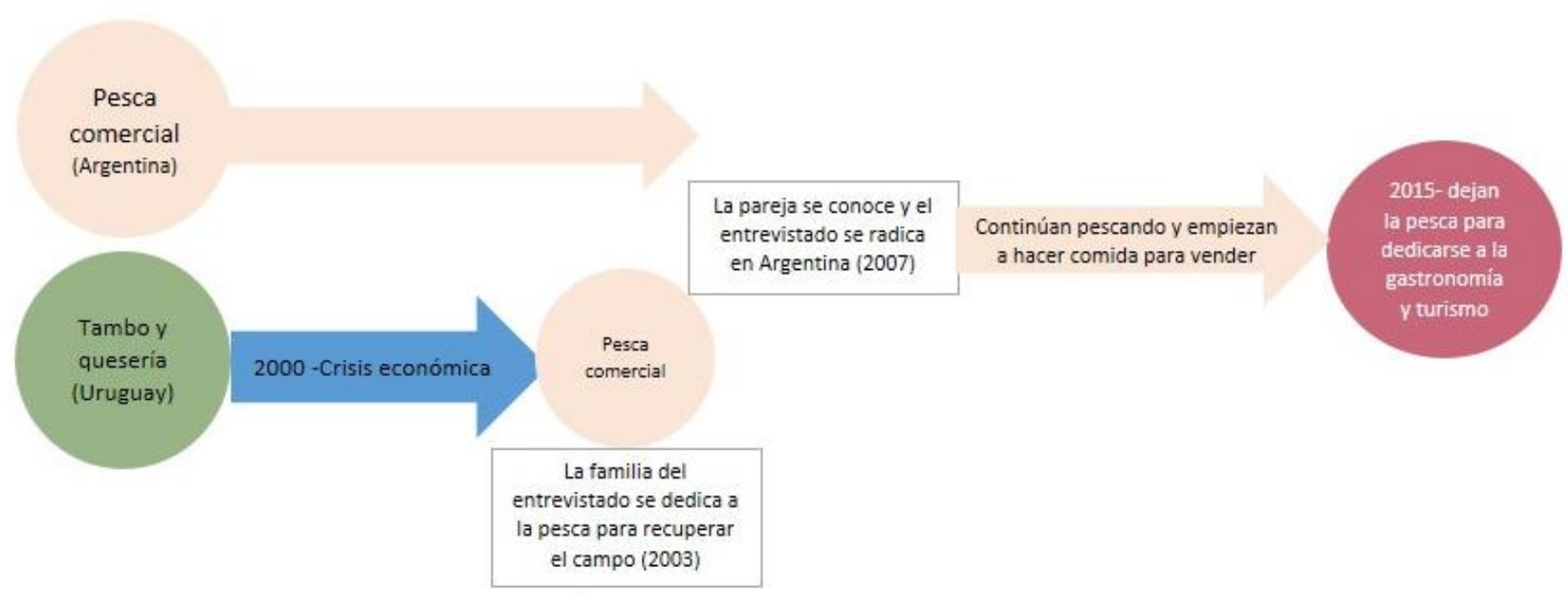




\section{D.2.2 Recursos de la familia ${ }^{69}$}

\begin{tabular}{|c|c|}
\hline $\begin{array}{l}\text { Recursos } \\
\text { humanos }\end{array}$ & $\begin{array}{l}\text { Actualmente la única actividad de generación de ingresos es la gastronómica. } \\
\text { En esta trabaja la pareja y un empleado. Por el momento es un trabajo muy intensivo, } \\
\text { con jornadas de más de } 12 / 13 \text { hs durante el año y en verano, que es temporada alta } \\
\text { turística, más de } 18 \text { hs. Abren a las } 11 \text { de la mañana y trabajan de corrido hasta la noche. } \\
\text { Ella se retira antes del carrito para estar con los hijos. } \\
\text { "Vamos, hacemos tarea, comemos y se acuesta temprano porque a la mañana tiene la } \\
\text { lancha para ir a la escuela". (Tamara, pesca y gastronomía). } \\
\text { Trabajan todos los días juntos y los dos hacen las mismas tareas. } \\
\text { Tuvieron que aprender y fueron mejorando el menú, adaptándose al público local y } \\
\text { turistas. Ellos destacan que cocinan con los mismos criterios que en su propio hogar, con } \\
\text { limpieza, calidad y buen sabor. } \\
\text { "La idea de arrancar con esto fue como si estuviéramos cocinando en casa, porque a uno } \\
\text { le gusta comer bien, y eso hemos tratado de volcarlo a los clientes, y con eso hemos } \\
\text { andado bien" .(Sergio, pesca y gastronomía). }\end{array}$ \\
\hline $\begin{array}{l}\text { os } \\
\text { ales y } \\
\text { les }\end{array}$ & $\begin{array}{l}\text { La familia del entrevistado ha logrado capitalizarse a partir de la pesca. De hecho } \\
\text { la gastronomía/turismo se forjó también a partir de la ganancia de esta actividad. } \\
\text { Para construir el carrito vendieron una embarcación, más la venta que en la época de la } \\
\text { inundación fue buena. "La inundación es una desgracia porque le pasa a todo el mundo. } \\
\text { A nosotros nos favoreció porque estábamos arriba del cerro. Se trabajó más que nunca. } \\
\text { Se compró todo nuevo". (Sergio, pesca y gastronomía). } \\
\text { Las ganancias se reinvierten en mercadería fundamentalmente. Tienen varios } \\
\text { freezers en el carrito y en el hogar donde stockean mercadería. }\end{array}$ \\
\hline & $\begin{array}{l}\text { Hoy el único ingreso con que cuenta la familia es la gastronomía pero apuestan a su } \\
\text { sostenibilidad en el tiempo a pesar de las dificultades. } \\
\text { "Está complicado los últimos meses pero venimos zafando. Los impuestos y la luz han } \\
\text { subido bastante". (Sergio, pesca y gastronomía). } \\
\text { Ellos destacan que es una actividad que genera ingresos todos los días. Esta } \\
\text { característica, más orden y organización en los gastos y reservas de insumos le dan } \\
\text { tranquilidad y sustentabilidad en el tiempo. } \\
\text { "Con la gente del pueblo trabajas todos los días, los precios son bastante accesibles } \\
\text { porque uno se tiene que acomodar al lugar donde vive. Trabajas todos los días, algo } \\
\text { laburás". (Sergio, pesca y gastronomía). "Creo que es uno el que tiene que emprolijar los } \\
\text { gastos fijos. Yo lo hice toda la vida en el campo y acá pasa lo mismo. No endeudarse, si } \\
\text { no tenés deudas la vas acomodando, si no tenés créditos o no malgastas la plata. Gracias } \\
\text { a Dios si vas a mi casa tenés } 40 \text { mil pesos en gaseosas, hay } 3 \text { freezers llenos de } \\
\text { mercadería, eso te da tranquilidad. No tenés dinero en el bolsillo pero la tenés invertida". } \\
\text { (Sergio, pesca y gastronomía). }\end{array}$ \\
\hline & $\begin{array}{l}\text { A partir de esta nueva actividad de la gastronomía la pareja está en permanente } \\
\text { contacto con la gente de la localidad y turistas que visitan el pueblo, más la } \\
\text { entrevistada que muchos años vivió en la isla y no tenía tanto intercambio social. }\end{array}$ \\
\hline & $\begin{array}{l}\text { Hay algunos rasgos claros que definen a esta pareja, que tiene que ver con sus orígenes } \\
\text { y estilo de vida elegida. } \\
\text { Él es un hombre de campo y río, que decidió comenzar una actividad diferente a la que } \\
\text { venía desarrollando para cambiar su presente dos veces. Primero para salvar el campo } \\
\text { de la familia en Uruguay, segundo para tener una vida diferente con su nueva familia en } \\
\text { Argentina, lo que lo define como un hombre emprendedor y sumamente trabajador. En } \\
\text { ambos casos, el valor de la familia ha sido central. } \\
\text { Ella una mujer nacida y criada en la isla, con una vida alejada de las grandes urbes, que } \\
\text { también se adaptó a las circunstancias y que tuvo que salir a pescar -con el riesgo y el } \\
\text { sacrificio que implica- para vivir y mantener a su hija. }\end{array}$ \\
\hline & $\begin{array}{l}\text { /illa Paranacito tiene una dinámica particular, social y natural. La vida de las personas, } \\
\text { as actividades comerciales, el turismo, de alguna manera está condicionada por el agua, } \\
\text { us crecientes y sudestadas. }\end{array}$ \\
\hline
\end{tabular}

${ }^{69}$ En el cuadro se utilizan colores determinados para resaltar algunos conceptos que luego son recuperados en un esquema conceptual. Los recursos humanos son referidos en color rojo; los físicos, materiales y naturales en naranja; los recursos económicos en violeta; los sociales en azul y los recursos identitarios en verde. 


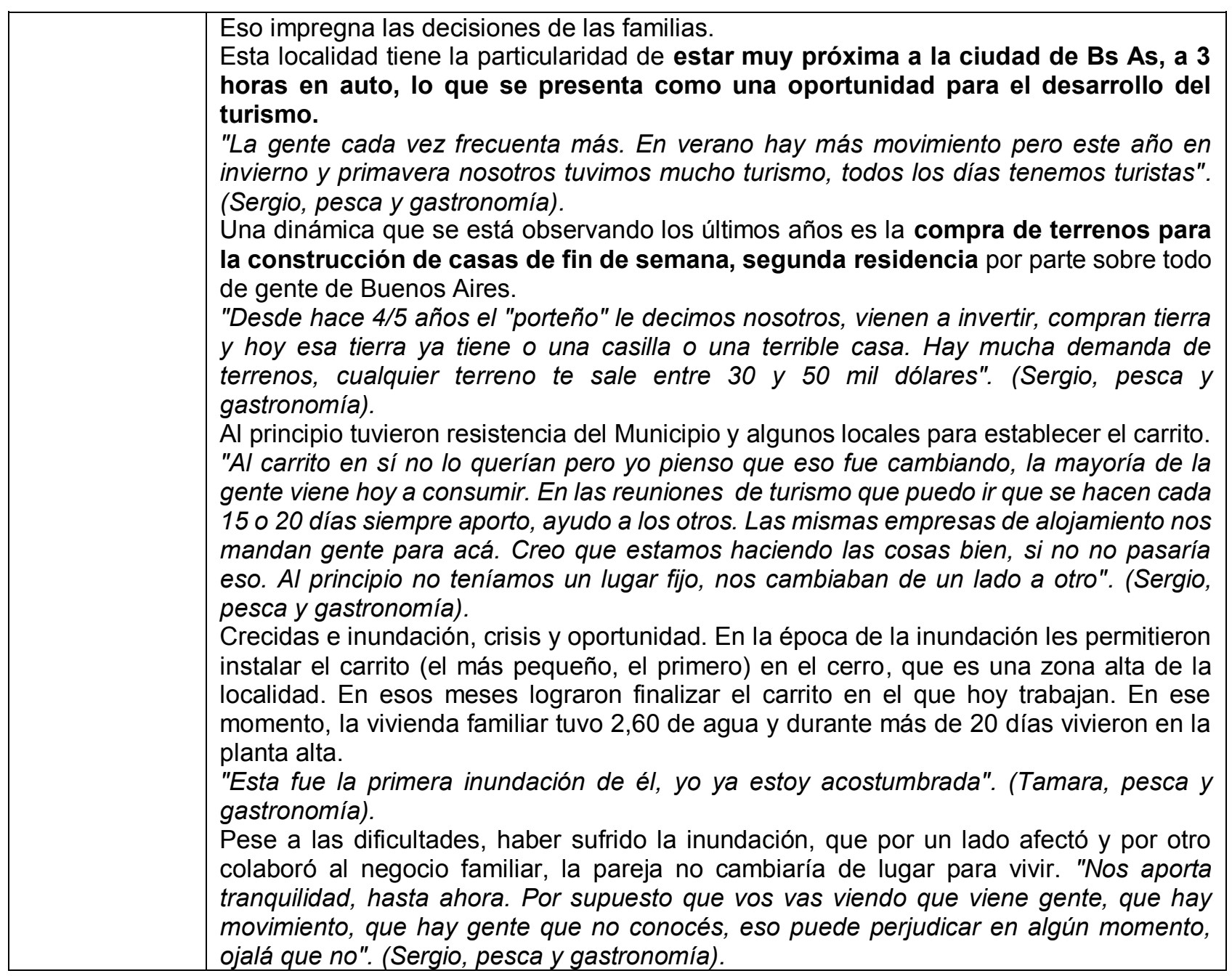

\section{D.2.3 Trayectoria familiar}

El entrevistado comenta que toda su vida estuvo dedicado al campo ya que colaboraba con el padre en el tambo quesería que tiene 40 años de existencia. En los 2000 les fue "muy mal" y tuvieron que cerrar el establecimiento quesero pero continuaron con ganadería de carne. En esa época el entrevistado comenzó la actividad pesquera "para ayudar a la empresa. Con la pesca se pagaron algunas deudas que estábamos complicados".

"En el 2003 el pescado empezó a valer muchísimo dinero. En Uruguay empezó a haber mucha demanda de sábalo desde la parte brasilera y Uruguay le empezó a vender a Nigeria y otros países africanos y a un precio terrible. El $60 \%$ del pescado fresco se vende a Brasil y el $40 \%$ a 8 países". (Sergio, pesca y gastronomía).

Ellos trabajaban todo el día y lo obtenido se vendía a acopiadores. La mujer también era pescadora del lado argentino.

"El padre de mi primera hija era pescador, yo empecé a trabajar con él cuando ella era chiquita, tenía meses. Después la familia fracasó y yo seguí trabajando con mi cuñado. Yo tenía que mantenerla a ella, todo era por ella. Mi familia me ayudaba a cuidarla". (Tamara, pesca y gastronomía).

La entrevistada nació y vivió hasta hace 10 años en la isla. Su padre "siempre trabajó en el monte". 
La pareja se conoce trabajando. "El río es compartido y hay pescadores argentinos y uruguayos, en ese interín a los pescadores argentinos se le complican las exportaciones y empiezan a llevar pescado para allá. Nos conocemos todos porque andamos todo el día en el agua. Ahí fue cuando la conocí a ella que pescaba con el cuñado, la misma actividad. Lo que es desde Paranacito que es el kilómetro 0 del río hasta el km 40 hay 138 pescadores, entre argentinos y uruguayos. En un tramo corto conviven muchas familias". (Sergio, pesca y gastronomía).

La pareja logró capitalizarse en la pesca, ya que las condiciones para la venta eran óptimas y la demanda de pescado estaba en alza.

"Nos fue recontra bien, y cuando empezamos a andar bien empezamos a comprar ganado lechero de vuelta porque en el tambo nos remataron las vacas, nos remataron la quesería". (Sergio, pesca y gastronomía). Hasta ese momento tenían 130 cabezas. "Es un predio chico pero se trabaja muy intensivo, con mucha reserva, mucho alfalfa, silo maíz". (Sergio, pesca y gastronomía). "Se fue comprando ternerada de vuelta con la idea del da de mañana arrancar la actividad quesera". "Trabajamos juntos hasta el 2007 que yo quedo embarazada" (Tamara, pesca y gastronomía) "En el 2007 decido venirme para Paranacito después que la conocí a ella y yo seguir con la actividad pesquera desde este lado, ya con el DNI de acá pero trabajando a la par de mi viejo ayudándonos unos a otros tratando de armar el predio allá". (Sergio, pesca y gastronomía).

\section{El objetivo siempre fue recuperar la actividad tambera.}

"Ahí nos abrimos, él siguió por su lado con 4 embarcaciones en Uruguay y yo con dos en Argentina. Tenía una embarcación y al año una más". (Sergio, pesca y gastronomía).

"Del 2008 hasta el 2012 ya llegamos a tener un rodeo de 30 y pico de vacas y las usábamos como nodrizas porque no había máquina para ordeñar, no estaba la quesería armada, entonces se compraban terneros en los campos cercanos y se tenían 3/4 terneros por vaca y se juntaban dos veces al día. En el 2012 fue que empezamos con el ordeñe a máquina, ya con la quesería instalada, y desde esa fecha hasta ahora se sigue" (Sergio, pesca y gastronomía).

\section{En abril de 2015 dejaron la pesca.}

"Hay pocos compradores de pescado y hay 68 familias como patrones de embarcaciones, a eso lo tenés que multiplicar por 3 o 4 que son los que trabajan por embarcación. A fines del 2014 vivían 277 pescadores artesanales en Villa Paranacito. Nosotros dejamos en el 2015 por no tener mercado. El $70 \%$ de los pescadores acá en Paranacito se dedicó a otra cosa, madera, algunos están cuidando animales en estancias, que la inundación perjudicó mucho". (Sergio, pesca y gastronomía).

"En julio del 2014 arrancamos con la comida antes de que se cortara lo del pescado. Arrancamos con un carrito más chico que nos prestaron y haciendo panchos y hamburguesas. No sabiamos ni hacer hamburguesas. Habíamos arrancado en casa haciendo torta frita, empanadas, churros y hacíamos reparto, pedidos. La idea era abrir los fines de semana pero nos salía más caro así el impuesto municipal. Hoy hace 3 años que estamos, y vendemos hasta pasta. En invierno hacemos buseca, guisos, nos adaptamos a la gente del pueblo, al turismo". (Sergio, pesca y gastronomía).

\section{D.2.4 Emergencia del turismo}

Incorporan el turismo de la mano de la gastronomía, para complementar los ingresos de la pesca, pero luego se convirtió en su actividad central.

"Como la pesca es fuerte en verano, en invierno nos quedábamos medio pelados. Todo el peso que se juntaba en verano era para sobrevivir en invierno. O bien te endeudabas y salías a flote en verano, así que había que hacer algo en invierno cuando no había pesca". (Tamara, pesca y gastronomía). 
"No había mucha opción". (Tamara, pesca y gastronomía).

"Lo que saldría para hacer se iba a hacer. Yo tenía la opción de volverme a Uruguay a seguir con el campo, pero elegí la familia, no iba a volverme". (Sergio, pesca y gastronomía).

El cambio de la actividad pesquera al turismo les da más estabilidad y tranquilidad desde lo económico y es menos riesgoso "porque eso es todos los días y algo entra. Con la actividad pesquera dependes mucho del clima, hoy podés estar sacando mucho pescado pero se levanta un viento y tenés que parar, te podés ir a pique en el río. Esos son los riesgos que tenés en el río". (Sergio, pesca y gastronomía).

\section{D.2.5 Objetivos, decisiones y estrategias puestas en marcha}

\section{- Apuestan a la gastronomía y el turismo.}

Piensan seguir capitalizándose a través de la compra de insumos, de mercadería que es su forma de ahorrar y lo que les da más tranquilidad pensando en el futuro.

"Para mí el turismo no va a parar de crecer, por lo que ando viendo año a año hay cada vez más gente de afuera en el río. Y al pescador eso le viene en contra porque el desarrollo del turismo genera mucho movimiento en el río, mucho alboroto y el pescado no está tranquilos" (Sergio, pesca y gastronomía).

"Invertir más en esto no creo, esto nos salió mucha guita más lo que hay en casa de infraestructura (freezer, heladera). Uno tiene que tener mucha mercadería". (Sergio, pesca y gastronomía).

"Si seguís invirtiendo acá pasas a otro nivel, tenés que poner más gente, ya después te estás obligando a trabajar con un presupuesto fijo que te armaste. No da para complicarse tanto". (Sergio, pesca y gastronomía).

"Yo la tengo clara de que de acá en adelante uno va a trabajar más que menos, por más de que se nota que en el pueblo falta plata. Vos tenés un gran porcentaje de gente que antes salía mucho más lejos a gastar plata, hoy salen más cerca". (Sergio, pesca y gastronomía).

"Y además hay que hacer las cosas bien para vender, trabajar con buena calidad, ser muy higiénico, muy prolijo. Mucha gente de afuera nos recalca eso, que somos muy prolijos". (Sergio, pesca y gastronomía).

- En pesca no tienen pensado continuar a corto plazo al menos la pareja. Cuentan con el capital, que no quieren vender, para una posible integración de miembros de la familia.

"Están las embarcaciones, está todo, y está un hermano de ella y mi sobrino. No lo quisimos vender porque no me armo nunca más de eso. Una de las embarcaciones vale 500 mil pesos, y si le echas las herramientas para salir a pescar te sale 120 mil pesos más. Si la vendiamos podríamos haber terminado la casa, pero no me hago nunca más de esas cosas. Hoy se hace algo de flete, algún viaje de pesca, mi sobrino viene todos los días a la escuela. Es mejor que el motor esté andando y no parado". (Sergio, pesca y gastronomía).

- Se les consultó si les interesaba hacer otro tipo de actividad vinculado al turismo y no se sienten motivados.

"Las salidas de pesca están muy controladas, tenés que abrir como otra empresa y las embarcaciones no tienen los mismos permisos. No podés hacer las dos cosas". (Sergio, pesca y gastronomía). Además, el entrevistado manifestó no gustarle la pesca deportiva, con caña. 


\section{D.2.6 Vinculación del sistema familia-explotación con la actividad de turismo rural ${ }^{70}$}

\begin{tabular}{|c|c|}
\hline $\begin{array}{l}\text { Interacción producto } \\
\text { Explica el flujo de materia } \\
\text { prima de una actividad a } \\
\text { otra. }\end{array}$ & $\begin{array}{l}\text { No hay integración de la actividad gastronómica/turística con el } \\
\text { resto de las actividades, no se utilizan insumos de otras } \\
\text { actividades en ésta. } \\
\text { Puede verse una mayor integración en la actividad tambera/ quesera en } \\
\text { Uruguay pero no guarda relación tampoco con las desarrolladas en } \\
\text { Argentina. }\end{array}$ \\
\hline $\begin{array}{l}\text { Interacción recursos } \\
\text { Se explica a partir de la } \\
\text { movilización de un mismo } \\
\text { recurso para varias } \\
\text { actividades. }\end{array}$ & $\begin{array}{l}\text { Este sistema actualmente contempla una sola actividad. Los recursos } \\
\text { humanos son la pareja y un empleado. El entrevistado si bien no } \\
\text { trabaja diariamente en la producción tambera y quesera, tiene una } \\
\text { relación directa en la toma de decisiones y manejo de la actividad. } \\
\text { Si bien cuentan con recursos materiales (lanchas, equipamiento de } \\
\text { pesca) y los conocimientos relacionados a la pesca, no se están } \\
\text { poniendo en uso de forma regular, salvo algún que otro flete que pueda } \\
\text { surgir. } \\
\text { Los recursos materiales con los que cuenta hoy la actividad } \\
\text { gastronómica son producto de las ganancias de la actividadl } \\
\text { pesquera. Y gracias a esta actividad también se pudo reactivar el } \\
\text { tambo y quesería en Uruguay. }\end{array}$ \\
\hline $\begin{array}{l}\text { Interacción patrimonial } \\
\text { La implementación } \\
\text { actividades simultáneas } \\
\text { se dan en torno al valor } \\
\text { intangible de un } \\
\quad \text { patrimonio }\end{array}$ & $\begin{array}{l}\text { En este caso, el patrimonio intangible está vinculado a la historia y estilo } \\
\text { de vida de la pareja, a los cambios y motivaciones, que es lo que los ha } \\
\text { impulsado a torcer la dirección del timón para cambiar su estilo de vida } \\
\text { y volcar sus saberes, habilidades, competencias y ganas de aprender } \\
\text { en una nueva actividad de servicios. Pero no es trascendental en este } \\
\text { sistema. }\end{array}$ \\
\hline $\begin{array}{l}\text { Interacción temporal } \\
\text { Explica los procesos de } \\
\text { anticipación de un cambio } \\
\text { que está por venir, del } \\
\text { abandono o } \\
\text { implementación de una } \\
\text { nueva actividad }\end{array}$ & $\begin{array}{l}\text { La familia supo aprovechar o adaptarse a un momento de crisis en la } \\
\text { actividad pesquera para generar otra actividad que genere } \\
\text { ingresos en épocas en las que la pesca estaba en baja. } \\
\text { Así comenzaron preparando alimentos en el hogar. Luego pensaron en } \\
\text { una alterativa innovadora para el lugar como es el estilo food truck. }\end{array}$ \\
\hline $\begin{array}{l}\text { Interacción ingreso/ } \\
\text { sentido del trabajo } \\
\text { La combinación de } \\
\text { actividades permite } \\
\text { asociar actividades } \\
\text { fuertemente remuneradas } \\
\text { con actividades que no } \\
\text { son menos importantes } \\
\text { pero proveen otro tipo de } \\
\text { satisfacciones }\end{array}$ & $\begin{array}{l}\text { La actividad gastronómica/ turismo genera ingresos que permiten } \\
\text { garantizar la vida de la familia y reinvertir, pero fundamentalmente } \\
\text { implica un menor desgaste físico que la pesca, condición que ha } \\
\text { sido determinante para dejar esta actividad y dedicarse a la } \\
\text { gastronomía. }\end{array}$ \\
\hline $\begin{array}{l}\text { Interacción ingreso } \\
\text { Se da cuando } 2 \text { o más } \\
\text { actividades aportan a los } \\
\text { ingresos totales } \\
\text { disponibles para la } \\
\text { familia. }\end{array}$ & $\begin{array}{l}\text { Hoy el sistema cuenta con un único ingreso pero: 1. tiene capital de } \\
\text { resguardo, 2. tienen reserva en mercadería e invierten en ésta. }\end{array}$ \\
\hline
\end{tabular}

\footnotetext{
70 En el siguiente cuadro se enfatizan algunos conceptos utilizando colores que luego serán adoptados en el esquema conceptual que explica las interacciones de la actividad turística con el resto de las actividades del sistema. Así, con naranja se remarca la interacción entre productos de las distintas actividades; con rojo y azul la interacción de los recursos humanos y sociales y con naranja claro entre recursos físicos, naturales y materiales; con verde la interacción patrimonial; con gris, la temporal; con violeta claro la interacción dada entre el ingreso y el sentido dado al trabajo, y con violeta oscuro, la interacción entre los ingresos que aportan las actividades al sistema.
} 


\section{D.2.7 Impacto del turismo en el sistema productivo}

Hoy el sistema contempla una sola actividad de generación de ingresos que es la gastronomía/turismo. Esta ha ido desplazando la actividad pesquera que fue durante años el principal sostén de la familia. Durante un corto plazo, la familia combinó ambas actividades pero luego la abandonaron para dedicarse exclusivamente a la actual.

\section{D.2.8 Impacto del turismo en la familia, en las personas y en sus estilos de vida}

- Las largas jornadas de trabajo tienen su impacto en un desgaste de la pareja y a nivel familiar. La necesidad de generar ingresos para seguir capitalizando el negocio y garantizar la vida de la familia hace que tengan que estar abiertos 12 o 13 horas.

"El descuido a los niños, a eso sí lo he notado mucho, de parte de los dos. Eso se nota más porque los niños crecen". (Sergio, pesca y gastronomía).

- Aunque los entrevistados dicen que "el cuerpo nos pasa factura" respecto a las jornadas tan intensas de trabajo, nada se equipara en agotador y riesgoso a la tarea de la pesca en el río. El cambio pasa por una mejora en la calidad de vida.

"Nosotros trabajábamos todos los días, todo el día, no había horario, llegábamos a andar 21 horas en el río. Se laburaba todos los días, hacíamos ranchadas en cualquier lado, terminabas muerto. si te ponés a hablar de la pesca. te deja desecho, los riesgos que hay". (Sergio, pesca y gastronomía).

"Yo iba y venía, pero no tenés horario para volver, para comer, son horas al sol, horas al frío, mojados". (Tamara, pesca y gastronomía).

"Volver al río no, yo estoy desecho de la cintura, sufro un montón, no es fácil, cuando sos joven es una cosa, es muy castigador". (Sergio, pesca y gastronomía).

La entrevistada hace referencia al desgaste físico, a los problemas de salud que trae aparejado el trabajo en el río.

"La lama (el verdín del pescado) te llaga todas las manos, te deja a carne viva las manos. la cintura, las rodillas, cortes en las piernas". (Tamara, pesca y gastronomía).

- El turismo les aporta mayor interacción social, sobre todo a la mujer que solo hace 10 años vive en el pueblo.

"El turismo es otra cosa, a veces llegan, les buscás conversación de alguna manera, intentás entablar una charla con ellos. La gente de afuera viene, se sienta y están acostumbrados a que los atiendan. Nosotros no tenemos mozos así que cocinamos y hacemos de mozos y esto de estar todo el tiempo amables, yo soy más cerrada pero después te acostumbrás. A la clientela uno ya la tiene así que ya la conocés, ya sabés, ya charlas". (Tamara, pesca y gastronomía).

"En mi caso, yo allá en el Uruguay, el 90\% del queso que se producía ya en el 94 yo decía "lo bolicheaba", hacía comercio, 300 ventas al comercio, ahí tenía más contacto con la gente, en ese sentido tenía más dialogo. En el caso de ella se tuvo más que hacer". (Sergio, pesca y gastronomía).

\section{D.2.9 Percepción del futuro en relación a los hijos y en relación a su resguardo de ingresos}

A futuro ellos se ven trabajando en la actividad gastronómica pero más tranquilos. 
"Esto pero trabajarlo más tranqui porque nos desgasta mucho y a veces hasta conflictos en casa tenemos. Laburamos tres años buenos, ahora tomarlo más tranqui. Logramos armar esto. Y después trabajar un poco más para disfrutar uno". (Sergio, pesca y gastronomía).

"Necesitamos tener más momento de familia". (Tamara, pesca y gastronomía).

Aunque no hay una referencia directa al futuro vinculado a los hijos y las actividades de la familia, todo indica que el hijo menor es el que demuestra mayor empatía con las actividades productivas de la familia.

"La idea de la nena mayor es irse a estudiar afuera. Y para trabajar el día de mañana no sé tampoco. El nene tiene 9 años y es el que está esperando terminar las clases para irse al campo, allá a Uruguay". (Sergio, pesca y gastronomía).

"Son sus vacaciones, el viernes termina las clases y marcha, él se va para allá, la nena no". (Tamara, pesca y gastronomía). 
Ilustración 25- Esquema del sistema familia/explotación Caso 10

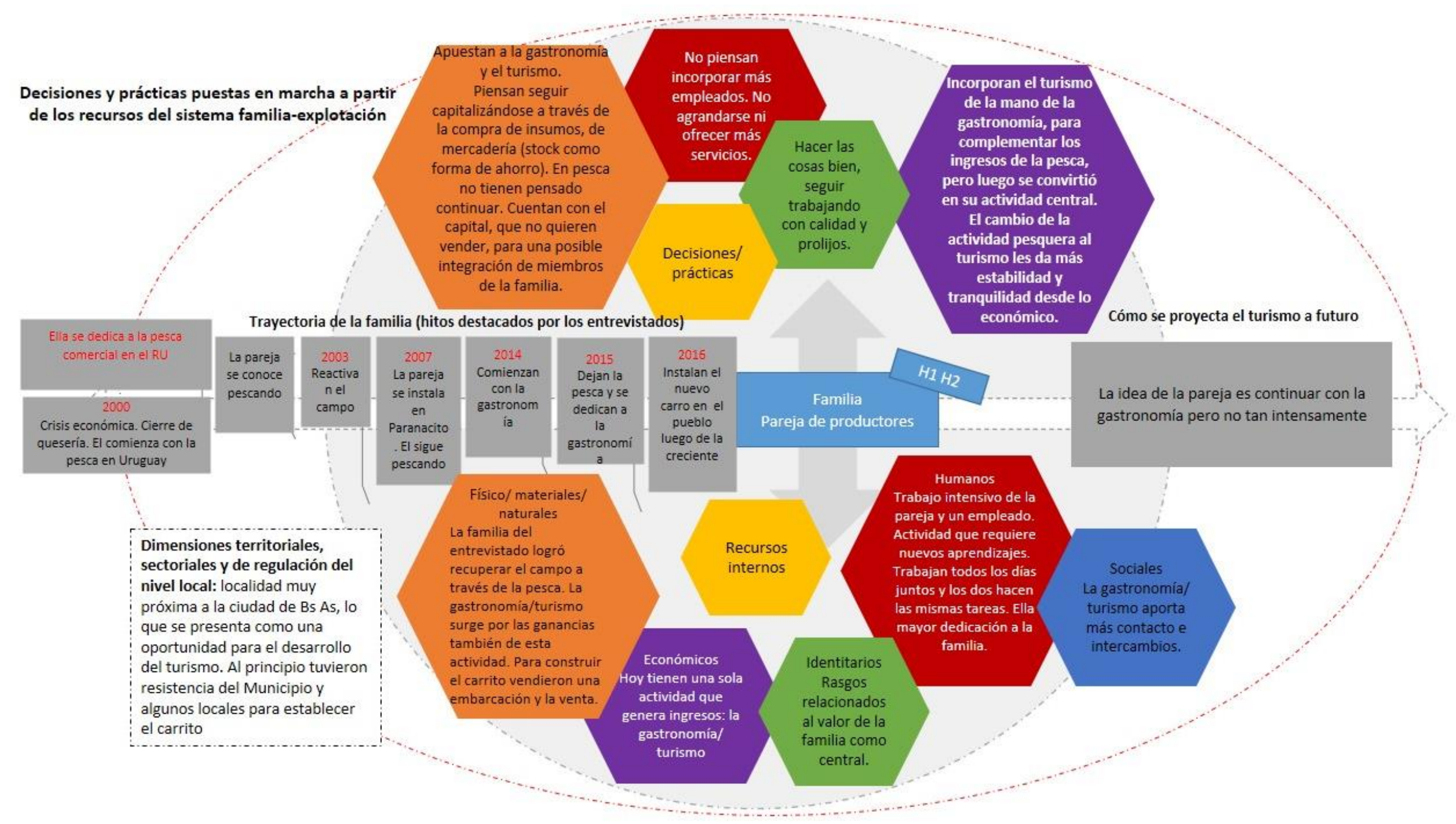


Las flechas del esquema central ejemplifican los tipos de interacción del sistema familiaexplotación, con sus respectivos colores identificatorios

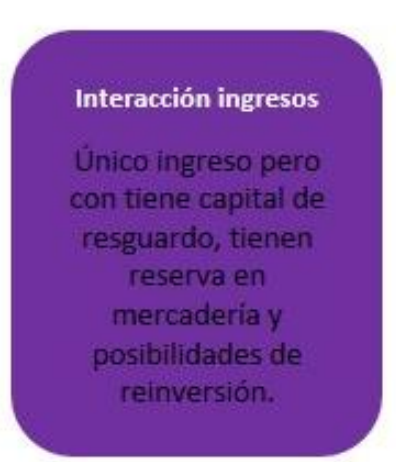

El símbolo + representa la importancia relativa del ingreso al sistema de cada actividad

Interacción ingreso/sentido de trabajo

La actividad gastronómica/ turismo genera ingresos que permiten garantizar la vida de la familia y reinvertir, pero fundamentalmente implica un menor desgaste físico que la pesca, condición que ha sido determinante para dejar esta actividad y dedicarse a la gastronomía.

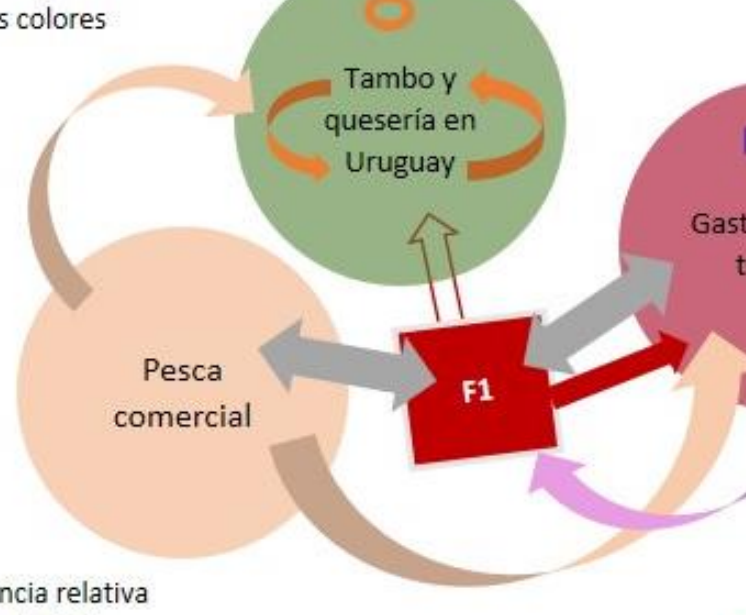




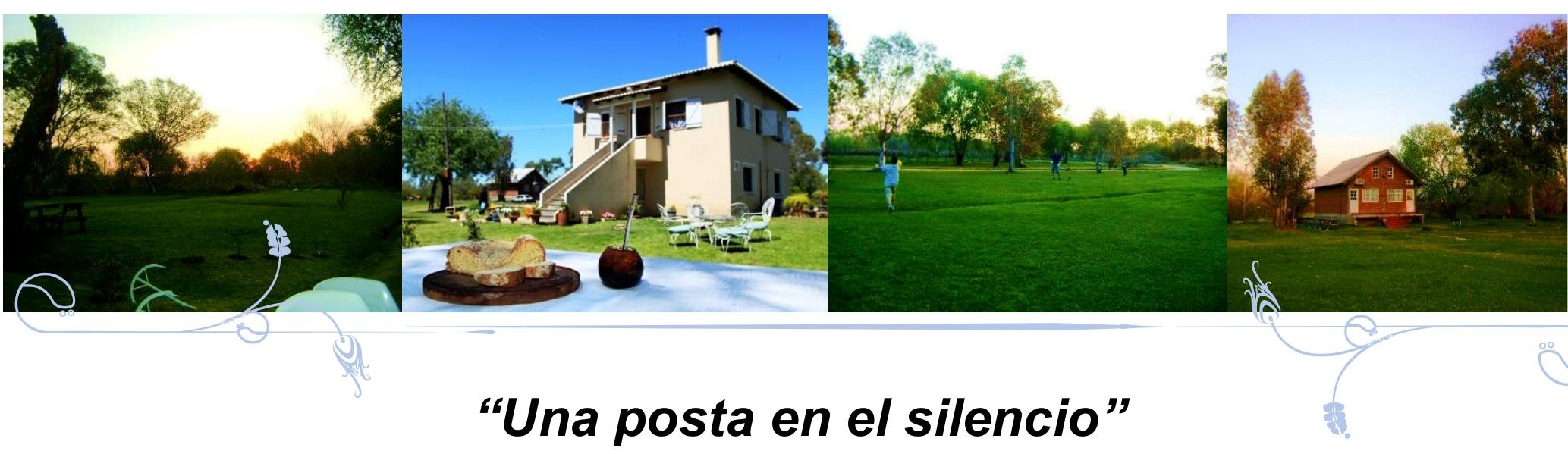

"El turismo surge como una cosa aleatoria a lo que teníamos. Arrancamos trabajando fuerte en el 2005 cuando empezamos con un bungalow. Alquilábamos esta casa y nos íbamos a vivir a Villa Paranacito, teníamos la casa paterna de ella. Después yo venía y algunos días me encontraba con gente acampando acá y les decía amablemente que no era camping, pero venían por el lugar tan lindo. En una creciente, como la casa tenía agua, empezamos a alquilar para camping con un baño abajo, para pasar el día. Después sí vimos que el camping era un buen servicio y sirve también". (Enrique, producción y alojamiento en el delta). 


\section{D.3 Caso 11- UNA POSTA EN EL SILENCIO}

En esta experiencia se evidencia un sistema llevado adelante por una familia que se dedicó a la producción forestal y luego a la comercial y gastronómica. El entrevistado nació en la isla y toda su historia familiar está allí. En la década de 1990 emprenden su propuesta de alojamiento turístico. Están capitalizados. La mano de obra es familiar, sobre todo la pareja, y contratan empleados en forma transitoria. Han tenido una activa vida política e integraron experiencias asociativas relacionadas al turismo.

\section{D.3.1 Presentación general}

Sistema que tiene por familia a una pareja de 61 años él y 59 ella, con 3 hijos (38, 35 y 20). Los dos más grandes tienen sus actividades y familia, la menor estudia en La Plata.

La pareja cuenta con un complejo de 4 bungalows y camping para 40/50 personas lindero al Arroyo Sagastume en Villa Paranacito en un predio de 2 ha. Además tienen una tienda de ropa en el pueblo y hacen servicios de catering en eventos.

Por otro lado, cuentan en otro campo en una isla con un predio de 20 ha. Allí poseen una casa para 12 personas en alquiler.

Una parte de este terreno se ha loteado para la venta y otra la arrendan para ganadería.

Allí todavía poseen una plantación de árboles para sacar madera.

"Algo de forestación nos queda, algo le sacamos. En el caso mío yo tengo una parte en Arroyo Las Tintas, unas 20 ha que por ahí arrendo para vacas y hay alguito de forestación. En ese predio hice un proyecto medio náutico adelante, que eso fue lo que posibilitó mejorar, hacer buenos baños. Vendimos lotes y eso nos dio un respiro porque el turismo es muy lindo pero tenés que invertir y no siempre se está en condiciones de acceder a los créditos". (Enrique, producción y alojamiento en el delta).

Comenzaron a trabajar en turismo como un complemento al trabajo en la tienda.

Tienen 3 bungalows con capacidad para 4 personas cada uno y otro para 2 pasajeros y un amplio sector de camping. La pareja posee su vivienda familia en el mismo predio donde se desarrolla el turismo.

\section{La familia del entrevistado era productora forestal y frutícola. La actividad frutícola se abandonó y luego se fue retrayendo la forestal por varias condiciones del contexto.}

"Tenemos algunos destellos de la actividad. Lo que pasó es que el porcentaje de la tierra acá en el Delta es de pequeños productores. Las unidades económicas para 20/30 ha en la forestación empezaron a ser inviables, además de que los precios no acompañaban los requerimientos de la evolución de las demandas familiares. La gente empezó a vivir mejor y empezó a requerir que los chicos estudiaran por ejemplo. Antes las familias producían lo que consumían, tenían desde su fruta, su vaca, su leche, su cerdo que carneaban, la huerta. Era gente que no necesitaba prácticamente nada y de repente se encontraba con el ahorro de la forestación que la plantaba y esperaba 11, 12 años. Ahí tenés las versiones de que con 2 ha que cortaban por año vivían, en el contexto de esas economías". (Enrique, producción y alojamiento en el delta). 
Respecto al catering, ellos cotizan a los clientes el servicio que puede incluir alquiler de mesas y sillas, el servicio de mozos y la comida.

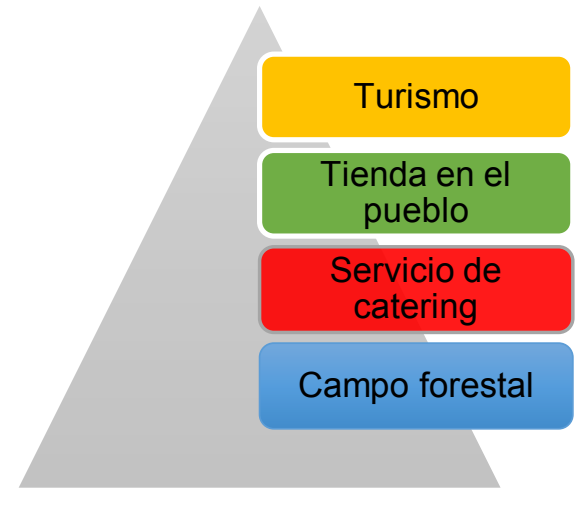
A modo de síntesis entonces, la familia cuenta con diversas actividades de generación de ingresos: el turismo, la tienda en el pueblo, el servicio de catering y los múltiples usos del campo otrora forestal en la isla (venta de terrenos y alquiler para ganadería).

\section{D.3.2 Recursos de la familia ${ }^{71}$}

\begin{tabular}{|c|c|}
\hline Recursos humanos & $\begin{array}{l}\text { Los principales recursos humanos del sistema son la pareja. } \\
\text { Para el trabajo en turismo, él es el que maneja las reservas y la atención al turista } \\
\text { en general. Ella se encarga de los detalles, de la limpieza de los bungalows y de } \\
\text { que todo esté "impecable". Además contratan personal de limpieza y de } \\
\text { mantenimiento, pero no de forma estable. } \\
\text { "En turismo no tenemos a nadie fijo, contratamos a gente esporádicamente, es } \\
\text { muy irregular. Contratamos generalmente para la limpieza de los bungalows a } \\
\text { gente que se dedica a eso, cobran por hora y lo hacemos, ella está en la parte } \\
\text { estética, decoración, de las plantas, que el bungalow esté impecable". (Enrique, } \\
\text { producción y alojamiento en el delta). } \\
\text { A la mujer también le gusta el cuidado del jardín. La responsable de la tienda } \\
\text { es principalmente ella. Si tienen reserva de bungalows ella se queda por la } \\
\text { mañana a prepararlo y él se va a la tienda, donde además tienen una empleada } \\
\text { y luego se vuelven a rotar. "De lunes a sábado atendemos la tienda, si hay que } \\
\text { limpiar algún bungalow yo me quedo y él va a la tienda con la chica, cuando se } \\
\text { termina todo acá yo marcho a la tienda y él vuelve, y asi". (Irma, producción y } \\
\text { alojamiento en el delta). } \\
\text { En el servicio de catering, el entrevistado es el encargado de la logística } \\
\text { general y la mujer con otras } 3,4 \text { señoras preparan la comida. Toman gente } \\
\text { para el servicio de mozos para cada evento. } \\
\text { La atención al turista es indelegable. } \\
\text { "Al turismo no lo delegamos, no es fácil, yo soy un fanático de controlar el buen } \\
\text { ambiente y soy celoso de que se vayan contentos. La gente vuelve por los } \\
\text { detalles, la tranquilidad y el ambiente familiar. En el camping tenés que estar } \\
\text { mucho encima, nosotros hacemos un ambiente familiar y de descanso, eso } \\
\text { requiere de la percepción de que sí y que no, no es discriminar pero tenés que } \\
\text { tener cuidado". "Yo creo que en turismo un gran porcentaje es el prestadory cómo } \\
\text { atiende al que viene". (Enrique, producción y alojamiento en el delta). }\end{array}$ \\
\hline $\begin{array}{l}\text { Recursos físicos, } \\
\text { materiales y naturales }\end{array}$ & $\begin{array}{l}\text { En una parte del campo de } 20 \text { ha que poseen en otra zona de la isla hicieron } \\
\text { un loteo. Con la venta de esos terrenos ampliaron y mejoraron el complejo } \\
\text { turístico. } \\
\text { Tenían } 27 \text { ha de las cuales el padre le había regalado una parte y él compró lo } \\
\text { otro. Todavía tiene lotes para vender allí. } \\
\text { Y con el predio de } 11 \text { ha que lindan al complejo tienen el proyecto de hacer otro } \\
\text { loteo, a futuro. El predio donde se ubican los bungalows y el camping tiene } 2 \text { ha. } \\
\text { Además, la mujer es dueña de la tienda en el pueblo, que proviene de línea } \\
\text { familiar. }\end{array}$ \\
\hline
\end{tabular}

\footnotetext{
${ }^{71}$ En el cuadro se utilizan colores determinados para resaltar algunos conceptos que luego son recuperados en un esquema conceptual. Los recursos humanos son referidos en color rojo; los físicos, materiales y naturales en naranja; los recursos económicos en violeta; los sociales en azul y los recursos identitarios en verde.
} 


\begin{tabular}{|c|c|}
\hline Recursos económicos & $\begin{array}{l}\text { Los principales ingresos están dados por el turismo y la venta en la tienda } \\
\text { en el pueblo que se complementan dada la marcada estacionalidad del } \\
\text { turismo. } \\
\text { "Nosotros tenemos divididas las cosas, cuando está floja una cosa tenemos la } \\
\text { otra. De septiembre en adelante trabajamos bien con turismo y la tienda empieza } \\
\text { a aliviarse, la preparamos para el invierno que es cuando cae el turismo y levanta } \\
\text { la tienda". (Enrique, producción y alojamiento en el delta). } \\
\text { El catering colabora, pero no es tan estable el ingreso. Respecto a la forestación, } \\
\text { "sacamos madera de lo que había, y en los campos esos que se están } \\
\text { quedando sin madera apuntan a la ganadería. Los arrendamos porque la } \\
\text { forestación grande permite que haya vacas abajo. Quedan } 7 / 8 \text { ha de árboles, muy } \\
\text { poco. Cuando tenés algo que cortar contratás a alguien y lo saca hasta la costa } \\
\text { del río, ahi lo llevan a papel prensa la mayoría". (Enrique, producción y } \\
\text { alojamiento en el delta). } \\
\text { Los entrevistados manifiestan que tienen altos gastos fijos de servicios y por } \\
\text { la hija que estudia afuera. } \\
\text { "No vivimos mal, vivimos bien, pero eso implica un enganche muy } \\
\text { particular". (Enrique, producción y alojamiento en el delta). }\end{array}$ \\
\hline Recursos sociales & $\begin{array}{l}\text { No se profundizó en la entrevista sobre este aspecto pero por dichos del } \\
\text { entrevistado, él es muy sociable, le gusta interactuar con los turistas, ha formado } \\
\text { parte de espacios políticos, liderado procesos de transformación local, ocupado } \\
\text { cargos públicos e integrado redes de trabajo asociativo en turismo, con cuyos } \\
\text { integrantes continúa en contacto. }\end{array}$ \\
\hline Recursos identitarios & $\begin{array}{l}\text { Hay elementos que identifican a la familia y su vínculo con la comunidad. Son una } \\
\text { familia emprendedora y sumamente trabajadora, comprometida y que } \\
\text { participó activamente de la construcción y crecimiento del lugar, desde } \\
\text { diferentes roles. } \\
\text { "Nosotros estamos convencidos de que el que soluciona algo o deja de solucionar } \\
\text { es cada uno con su propio esfuerzo. Partís de eso. El único artífice de lo que sos, } \\
\text { sos vos. Podés tener circunstancias de mala suerte, una creciente esas cosas, } \\
\text { pero a lo largo de la vida es la garra que vos le pongas. Y en ese sentido, sí, } \\
\text { somos emprendedores". (Enrique, producción y alojamiento en el delta). } \\
\text { Además, el haberse criado en la isla les da una particularidad como isleños, } \\
\text { un amor por su lugar que permite contrarrestar las limitaciones y } \\
\text { coyunturas varias que presenta el ambiente y la misma sociedad. }\end{array}$ \\
\hline
\end{tabular}

Recursos territoriales

Al igual que en otros casos, la idiosincrasia, las decisiones de las familias están definidas por la dinámica particular del lugar, y en este sentido, el agua, con sus picos y crecientes es central.

"En la última creciente fuimos verduleros porque estuvimos 8 meses sin trabajar el año pasado, ni tienda ni turismo. Yo iba al mercado de Escobar, traía verdura con la camioneta hasta el Sagastume y de ahí la cargábamos arriba de la lancha y la vendíamos... El gran afectado de las crecientes es el que se las arregla solo, porque el que tiene un sueldo mal que mal sigue viviendo del sueldo, y el indigente. Paranacito tuvo una avalancha de donaciones. A nosotros no nos perdonaron ni los impuestos. Los gastos fijos los seguís teniendo, yo tengo una hija estudiando afuera. Todo un drama". (Enrique, producción y alojamiento en el delta). "Con la creciente esto era un caos, teníamos dos metros de agua". (Irma, producción y alojamiento en el delta).

Tienen una visión sobre el turismo en el pueblo. Así como destacan las ventajas de estar en un lugar cercano al principal centro emisor de turistas como es Buenos Aires remarcan las limitantes del pueblo.

"El isleño es muy particular, celoso de su lugar, muy aislado. Esta irrupción del foráneo, del "porteño" tiene algunos que lo aceptan y otros que no". (Enrique, producción y alojamiento en el delta).

"Nos faltan servicios, falta gastronomía, y aparte qué puede hacer la familia, el hombre pesca y el resto? Esas cosas para mí se van dando de a poco, va 
mejorando Villa Paranacito, hay servicios que hace un tiempo atrás no se ofrecían". (Enrique, producción y alojamiento en el delta).

Esta familia ha integrado grupos de turismo y siguen manteniendo relación con otros referentes del turismo.

"Hicimos un intercambio con turismo en Tigre. Y esas cosas para qué sirvieron? Nos dimos cuenta que lo que teníamos servía y era tan bueno como aquello para hacer turismo porque nosotros teníamos algún grado de... esto servirá para hacer turismo? Si bien yo tenía fe, no sabía si era una locura mía". (Enrique, producción y alojamiento en el delta).

"Ahora es por wapp, es fantástico, tenemos un grupo de turismo que todo el tiempo se está chequeando quién tiene lugar, se dice tengo lugar para 3, una familia de 4 busca alojarse. Eso que nosotros intentamos hacer con reuniones, lo solucionó el wapp". (habla de la coordinación). Esto lo centraliza la Dirección de Turismo de la Municipalidad, con la misma dinámica se coordinan las salidas en lancha, los guías de pesca. Esto es realmente una satisfacción porque el turismo funciona así, el que se encapsula y se hace una isla no funciona". (Enrique, producción y alojamiento en el delta).

\section{D.3.3 Trayectoria familiar}

"Nosotros tenemos la vida aquí".

Así comienza el diálogo sobre la historia familiar del entrevistado que se mezcla inevitablemente con la dinámica e historia de la isla.

"Siempre estuve relacionado con el campo, con la producción. Mis abuelos vinieron de Europa, de pasarla muy mal por la posguerra, para ellos acá era todo divino. El abuelo llegó en 1906. Los padres de ella llegaron en el 40/50 en una época floreciente de la isla en términos de actividad productiva y también de turismo". (Enrique, producción y alojamiento en el delta).

"En 1984 se crea el departamento Islas, se crea para atender una zona especial del delta que no tenía nada que ver con Gualeguaychú". (Enrique, producción y alojamiento en el delta).

En ese momento el entrevistado formaba parte del grupo político que ganó las elecciones en el 83 y trabajaron para crear el departamento.

"Hicimos alguna presentación porque entendíamos que nuestra idiosincracia, nuestra forma de vida no tenía nada que ver con una ciudad "normal" de la provincia. Esto era diferente. Incluso los reclamos eran distintos. Cuando ibas a pedir presupuesto para una lancha para que los chicos vayan a la escuela, no te entendían". (Enrique, producción y alojamiento en el delta).

"Yo participé en política, estuve en la actividad pública, en las dos primeras intendencias de la democracia como concejal, secretario de gobierno y en una etapa fui diputado provincial. Cuando volví, volví pobrísimo. Eran otras épocas. Recibimos la intendencia arriba de un barco porque estaba recién creada y estaba la creciente. La intendencia no tenía ni donde funcionar. Éramos nosotros, un par de palas y unas carretillas". El entrevistado destaca la pasión que sentían por el trabajo en la comunidad, cómo trabajaban juntos todos los políticos más allá de las banderas políticas. Era como la comisión de un club". (Enrique, producción y alojamiento en el delta).

La creciente del 83 según el entrevistado marca un antes y un después en la isla.

"Después de la creciente del 83 se produce un fenómeno, se empieza a despoblar el delta interior y se empieza a concentrar mucha gente en los servicios del pueblo, en Paranacito, fenómeno que se da también en otros lugares. Se empieza a incrementar la actividad ganadera porque al abandonarse un poco la actividad forestal empezaron a quedar campos que, manejando el agua, se transforman en campos ganaderos y en los lugares 
donde empiezan a llegar caminos que antes no llegaban (por ejemplo acá) se empieza a visualizar la posibilidad del turismo. Se empieza a ver la necesidad de abrir caminos donde antes se llegaba solo con lancha. En ese momento se habían perdido los servicios de lancha que te comentaba porque al despoblarse el delta interior dejaron de funcionar. No había gente en el delta". (Enrique, producción y alojamiento en el delta).

“Con nuestra familia yo estuve hasta los 80 , con la actividad forestal. Después de los 80 nosotros nos volcamos un poco más a la parte del comercio, sin llegar a abandonar del todo porque siempre algo de madera tenemos". (Enrique, producción y alojamiento en el delta).

De 1996 al 2001 trabajaron en dos parrillas ubicadas en la ruta. Además, tuvieron la concesión del Club Isleño donde iniciaron el servicio de catering que todavía desarrollan.

Luego de la creciente de 1983 le compraron el terreno a un hermano ("que en la creciente del 83 se acobardó y se fue..." y a fines de 1990 comenzaron a hacer el primer bungalow.

El fuerte del turismo se da a partir del 2005 y en esos años espontáneamente la gente acampaba en el predio, modalidad que luego incorporan y funciona hasta la actualidad. A la tienda la abren "hace más de 10 años, antes de eso yo era ama de casa". (Irma, producción $y$ alojamiento en el delta).

\section{D.3.4 Emergencia del turismo}

Puede decirse que múltiples causas colaboran a la incorporación de la actividad turística al sistema.

- El turismo surge como una actividad complementaria a la que desarrollaban.

"El turismo fue una cosa paso a paso, incipiente, como una cosa aleatoria a lo que hacíamos. Es un complemento, no es para todos, no todos tienen la vocación del servicio turístico, yo tengo la convicción de que es el futuro de la zona". (Enrique, producción y alojamiento en el delta).

- Tenían la visión de que era una actividad con futuro.

"Tenía la visión de que era una actividad que podía ayudar, yo era el loco del turismo. Visión de. a qué nos quedamos? El tema era a qué nos quedamos, y yo vi que esto podía ser". "A mí siempre me gustó, siempre tuve la idea del turismo, primero porque a mí me gusta lo social, segundo porque la venía venir. Ya cuando estaba en el municipio, dábamos una mano a gente porque yo decía que el que pudiera brindar una pieza, un baño y algo de costa podía tener un ingreso extra que le permitiera quedarse. Yo les decía, vos hacelo que en algún momento se va a dar. Vos te encontrabas de repente que esa actividad decaída de la forestación o la fruta, y te encontrabas en una coyuntura que no sabías qué hacer y que posiblemente tenías que migrar. El turismo, esto te daba una esperanza". (Enrique, producción y alojamiento en el delta).

- La incorporación del turismo además obedece a la caída de las otras actividades.

"Hoy con 20/30 ha no podés vivir, la madera te puede ayudar pero no vivís. Los precios de la madera no son buenos, hoy a un productor forestal no le quedan ni $\$ 500$ por una tonelada de madera". (Enrique, producción y alojamiento en el delta).

- La cercanía a Buenos Aires para el entrevistado es un punto a favor para el desarrollo del turismo.

"Nosotros tenemos mercado de 13/14 millones de personas a 2 horas. Y creo que no es menor lo que le podemos ofrecer si les damos infraestructura y servicios. Alguien que sale a las 6 de Buenos Aires, a las 8, 8:30 ya está acá. El ámbito de tranquilidad, de verde y de cercanía a nosotros nos da una ventaja". (Enrique, producción y alojamiento en el delta). 


\section{D.3.5 Objetivos, decisiones y estrategias puestas en marcha}

Al día de hoy la pareja trabaja intensamente en las tres actividades que requieren su presencia y mano de obra: la tienda, el turismo y el servicio de catering. Pero el límite temporal de esta organización es "hasta que la hija termine de estudiar en La Plata". (Irma, producción y alojamiento en el delta).

\section{Apuestan al turismo y a futuro, aparentemente la idea es dejar la tienda.}

Respecto a lo productivo tienen "la idea no es seguir plantando árboles. Dentro de la actividad productiva yo estoy más cerca de irme a la parte ganadera que a la forestal, si tendría que salir para eso. Antiguamente en casa tenían vacas, pero porque tenía otra explicación, era por los fuegos. Las quintas estaban forestadas $1000 \mathrm{~m}$ desde la costa, y en el fondo había albardones, que son la parte más alta. En esos albardones se tenían vacas porque adonde hay vacas está limpio. A vos te permitía que si alguien prendía fuego no se te metía el fuego en la parte forestada. Y la ganadería a partir de las lecheras que también servían. Si cambiaran las políticas de gobierno, volvería a hacer frutales. Yo creo que esas unidades económicas que no sirven para la forestación, hoy si esto cambiara y hubiera coherencia en algunas políticas se podría volver al tema de las frutas, con el manejo de aguas y con los diques. 20 ha de frutas es una cosa diferente a 20 ha de forestación". (Enrique, producción y alojamiento en el delta).

"Yo creo que hay bisagras y estas son bisagras en la historia. Ahora están llegando los caminos adentro de la isla, las balsas, entonces por ejemplo en una isla como la 9 que yo tengo el lugar que me permitió e loteo, te permite que salir con un camión y eso te posibilitaría hacer otro tipo de actividades". (Enrique, producción y alojamiento en el delta).

No piensan diversificar las propuestas de turismo. "A mí me gusta la gastronomía pero cada cosa que le agregás a la actividad es una tortura, es más tiempo y estamos solos. Es complicado sumarle algo". (Enrique, producción y alojamiento en el delta).

\section{Los entrevistados creen en el Delta y cree en el turismo.}

"Yo soy un optimista, el delta tiene futuro, tiene futuro turístico, hablan de una conexión con Nueva Palmira que le va a dar un manijazo grande". (Enrique, producción y alojamiento en el delta).

No pensaron en irse pero ella manifiesta ciertas dudas ahora que "están solos" y que la creciente afectó tanto. "Dentro de unos años pienso a lo mejor en comprar alguna casa o departamento en Gualeguaychú, cosa de si viene el agua ella se pueda instalar ahí. A nosotros no nos sorprenden las crecientes pero aun con toda la experiencia no pensábamos que esta iba a ser tan grande, nos comimos el garrón. Yo siempre soy optimista de que vamos a andar mejor. Ella se irá a alguna casa o con la hija hasta que baje el agua". (Enrique, producción y alojamiento en el delta).

Tienen una reserva de capital con unos lotes para vender en las hectáreas de la isla. Le quedarían 13/14 lotes de $500 \mathrm{~m} 2$. Tienen el proyecto para hacer otro loteo a futuro en el predio de 11 ha lindero al complejo, un canal central navegable y terrenos con salida a ese canal. 
Ilustración 27- Esquema del sistema familia/explotación Caso 11

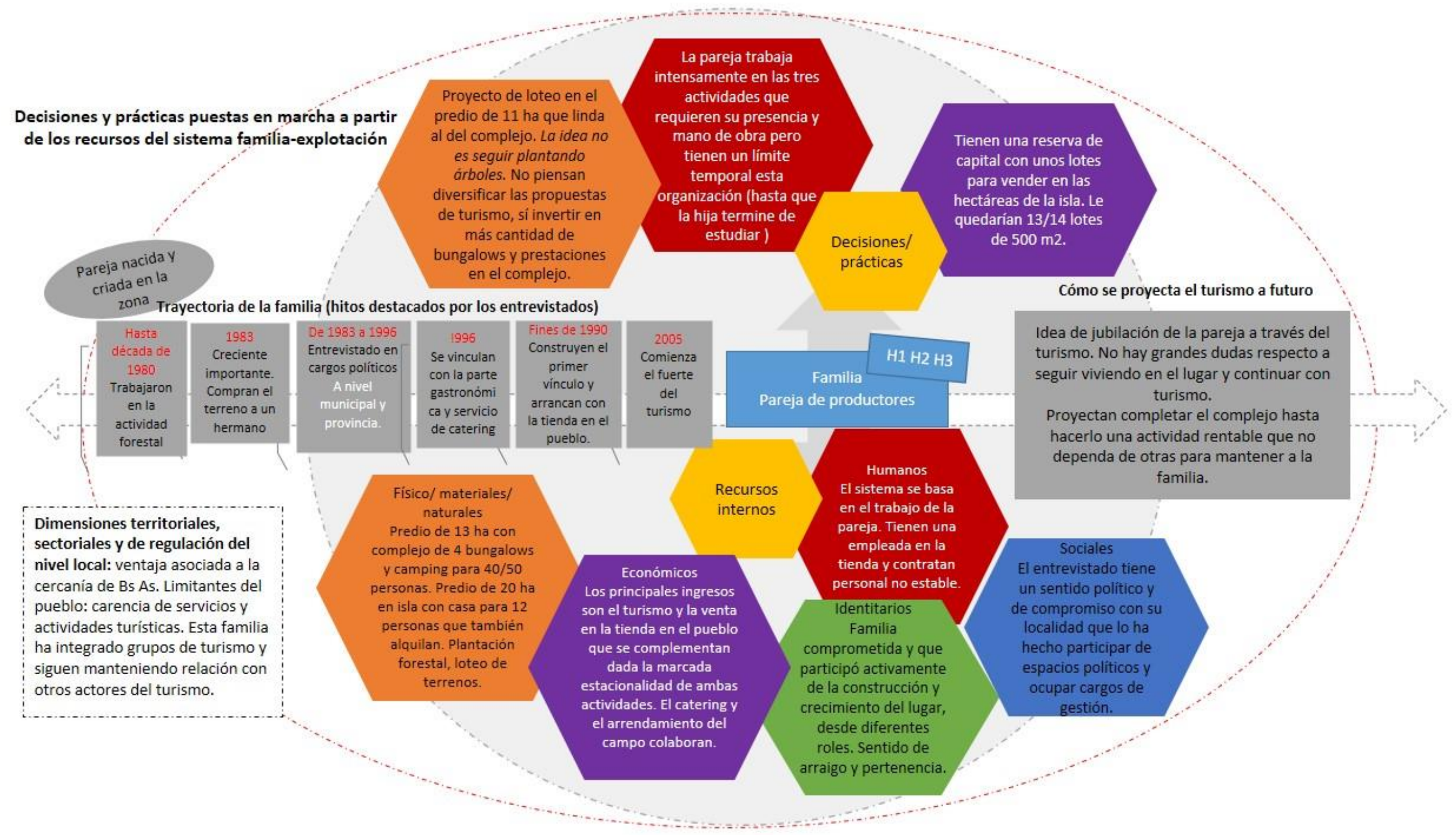




\section{D.3.6 Vinculación del sistema familia-explotación con la actividad de turismo rural $^{72}$}

\begin{tabular}{|c|c|}
\hline $\begin{array}{c}\text { Interacción producto } \\
\text { Explica el flujo de materia } \\
\text { prima de una actividad a } \\
\text { otra. }\end{array}$ & $\begin{array}{l}\text { No hay integración de productos de las diversas actividades que } \\
\text { desarrolla la familia. }\end{array}$ \\
\hline $\begin{array}{l}\text { Interacción recursos } \\
\text { Se explica a partir de la } \\
\text { movilización de un mismo } \\
\text { recurso para varias } \\
\text { actividades. }\end{array}$ & $\begin{array}{l}\text { La pareja es la base de todo el sistema, más la contratación de } \\
\text { recursos para tareas específicas en momentos concretos. La } \\
\text { única empleada fija es la que está en la tienda de ropa. Hoy sostienen } \\
\text { estas actividades gestionando sus tiempos, recursos y tomando } \\
\text { decisiones que les permitan seguir combinando las actividades para } \\
\text { obtener el ingreso necesario que sustente su vida y sobre todo } \\
\text { garantice el estudio de la hija menor. } \\
\text { En referencia a lo espacial, hay dos predios y en estos se generan la } \\
\text { actividad turística, la venta de lotes, lo que queda de la actividad } \\
\text { forestal y lo que se arrenda para ganadería. Como no están plantando } \\
\text { árboles para seguir con la actividad forestal se da un complemento } \\
\text { entre ésta y la ganadería, en término de uso de recursos. } \\
\text { Los ingresos dados por la venta de lotes han permitido invertir, } \\
\text { ampliando y mejorando la infraestructura turística. }\end{array}$ \\
\hline $\begin{array}{l}\text { Interacción patrimonial } \\
\text { La implementación } \\
\text { actividades simultáneas se } \\
\text { dan en torno al valor } \\
\text { intangible de un patrimonio }\end{array}$ & $\begin{array}{l}\text { Lo más trascendente es la vinculación con los recursos } \\
\text { patrimoniales (naturales e idiosincrasia) del territorio que son la } \\
\text { base de la oferta turística y de la forma de ser y hacer las actividades } \\
\text { de la familia. }\end{array}$ \\
\hline $\begin{array}{c}\text { Interacción temporal } \\
\text { Explica los procesos de } \\
\text { anticipación de un cambio } \\
\text { que está por venir, del } \\
\text { abandono o implementación } \\
\text { de una nueva actividad }\end{array}$ & $\begin{array}{l}\text { El turismo surge como una alternativa a la tienda, ya que está } \\
\text { muy marcada la estacionalidad de ambas. Cuando hay actividad } \\
\text { turística en alza, en el verano, bajan las ventas en la tienda, y } \\
\text { viceversa, lo que permite concentrar los esfuerzos y organizar los } \\
\text { tiempos familiares. } \\
\text { En este sistema se ve cómo la visión del productor respecto al } \\
\text { desarrollo de la actividad turística, sumado a la caída de la } \\
\text { actividad forestal dados los precios de la madera hicieron que sumen } \\
\text { el turismo a su sistema, actividad que hoy está fortalecida. Esta } \\
\text { capacidad de anticipación del productor también se evidencia en } \\
\text { la toma de decisión de lotear un predio en una isla a la que solo se } \\
\text { podía acceder en lancha que gracias a las obras tiene acceso } \\
\text { terrestre. } \\
\text { La venta de estos lotes fue el capital para invertir en turismo y es una } \\
\text { reserva para el futuro de la familia. }\end{array}$ \\
\hline $\begin{array}{c}\text { Interacción ingreso/ } \\
\text { sentido del trabajo } \\
\text { La combinación de } \\
\text { actividades permite asociar } \\
\text { actividades fuertemente } \\
\text { remuneradas con actividades } \\
\text { que no son menos } \\
\text { importantes pero proveen } \\
\text { otro tipo de satisfacciones }\end{array}$ & $\begin{array}{l}\text { Actualmente el funcionamiento de todas las actividades colaboran al } \\
\text { equilibrio del sistema, y esto hace que la pareja tenga un nivel de } \\
\text { exigencia en la distribución de tareas y tiempos de trabajo que } \\
\text { pareciera no permite el disfrute pleno de las actividades, pero como } \\
\text { se ha mencionado hay un límite temporal para esta dinámica y es la } \\
\text { finalización de la carrera de la hija estudiante universitaria. "Nosotros } \\
\text { estamos armados para que todo funcione, cuando quedás con una } \\
\text { pata menos tenés problemas, esa es la realidad". (Enrique, producción }\end{array}$ \\
\hline
\end{tabular}

${ }^{72}$ En el siguiente cuadro se enfatizan algunos conceptos utilizando colores que luego serán adoptados en el esquema conceptual que explica las interacciones de la actividad turística con el resto de las actividades del sistema. Así, con naranja se remarca la interacción entre productos de las distintas actividades; con rojo y azul la interacción de los recursos humanos y sociales y con naranja claro entre recursos físicos, naturales y materiales; con verde la interacción patrimonial; con gris, la temporal; con violeta claro la interacción dada entre el ingreso y el sentido dado al trabajo, y con violeta oscuro, la interacción entre los ingresos que aportan las actividades al sistema. 


\begin{tabular}{|c|l|}
\hline & $\begin{array}{l}\text { y alojamiento en el delta). "Nos dimos cuenta de que todo marcha si } \\
\text { todo funciona". (Irma, producción y alojamiento en el delta). }\end{array}$ \\
& \\
\hline $\begin{array}{c}\text { Interacción ingreso } \\
\text { Se da cuando } 2 \text { o más } \\
\text { actividades aportan a los } \\
\text { ingresos totales disponibles } \\
\text { para la familia. }\end{array}$ & $\begin{array}{l}\text { Todas las actividades aportan al ingreso del sistema familia- } \\
\text { explotación. Estas se complementan y son indispensables en la } \\
\text { actualidad. } \\
\text { "A nosotros esta actividad nos ha aportado un grado de tranquilidad. } \\
\text { No vivimos mal y aparte tenemos una chica estudiando, que todos } \\
\text { estos aportes han significado poder hacerlo. Los del turismo, no } \\
\text { exclusivamente el turismo, pero sí es un aporte importantísimo. } \\
\text { Cuando una actividad no anda, la otra levanta. Pero nosotros } \\
\text { tenemos una cultura del trabajo que no le decimos no a nada. } \\
\text { Hacemos lo del catering también". (Enrique, producción y alojamiento } \\
\text { en el delta). }\end{array}$ \\
\hline
\end{tabular}

\section{D.3.7 Impacto del turismo en el sistema productivo}

La dinámica económica en la zona del Delta ha condicionado dos de las actividades que otrora eran fundamentales en la zona como la actividad forestal y frutícola.

La caída de estas actividades hizo movilizar la actividad turística, como alternativa para seguir viviendo en el delta, proceso beneficiado por la cercanía a la provincia de Buenos Aires.

En el caso de este sistema, el turismo surge como complementario al comercio.

Esta familia sumamente emprendedora contaba con un capital que les dio la posibilidad de invertir en turismo y agregar esta actividad al sistema. Además, esa característica los hizo transitar un camino de diversas tareas sociales y actividades, siempre ligadas al lugar y a la actividad comercial.

\section{D.3.8 Impacto del turismo en la familia, en las personas y en sus estilos de vida}

- El turismo por sí solo no agrega complejidad al sistema. Es la sumatoria de actividades que requieren organización y tiempo, que pueden provocar momentos de tensión al interior de la familia.

- Esta combinación de actividades impacta sobre los tiempos y genera estrés, pero les permite "vivir bien" y sobre todo, les posibilita mantener la carrera universitaria de su hija menor en la ciudad de La Plata.

"Yo hoy por ejemplo estoy levantada desde las 5 de la mañana, para armar el bungalow, dejar las camas hechas y a las 8 de la mañana voy a la tienda. Y mañana ya empiezo haciendo matambre para el servicio del sábado, ya estoy contando las servilletas, estoy contando lo que es mantelería, es mucho. pero él dice. "un servicio de esos te deja". (Irma, producción y alojamiento en el delta).

"Hacés un servicio grande y te embocás 1 mes de la tienda, y significa 2 o 3 meses de la nena estudiando". (Enrique, producción y alojamiento en el delta). 
- Por otro lado, el turismo les da más tranquilidad desde el punto de vista económico, pero aún están trabajando intensamente para que el sistema funcione como un engranaje.

"A mí me gusta esto del turismo, lo que sí veo es que yo antes trabajaba menos que ahora. Porque el bungalow tiene que estar IMPECABLE, con todos los detalles, y yo ando limpiando junto con la que limpia". (Irma, producción y alojamiento en el delta).

- También impacta sobre la proyección de algunos viajes, condicionados con las temporadas altas del turismo en la isla.

"Me gustaría ir a Ushuaia de acá a fin de año pero tenemos mucho turismo en esa época". (Enrique, producción y alojamiento en el delta)

- Prácticamente no tienen descanso pero hoy tienen un "enganche" de actividades y tiempos que les permiten generar los ingresos que les permiten vivir. "Nosotros los domingos para salir de lo otro descansamos atendiendo turismo". (Enrique, producción $y$ alojamiento en el delta)

\section{D.3.9 Percepción del futuro en relación a los hijos y en relación a su resguardo de ingresos}

La idea de "jubilarse" a través del turismo está muy claro en este sistema. El entrevistado no duda respecto a seguir viviendo en el lugar y continuar con turismo. Proyecta completar el complejo hasta hacerlo una actividad rentable que no dependa de otras para mantener a la familia.

"Me gustaría hacer 4/5 bungalows más, cosa de que casi con los mismos gastos por fin de semana tengas un ingreso que te permita en algún momento replegarte y vivir del turismo, más de jubilación. Si nos da la salud y enderezamos los patos con la venta de lotes en un tiempo vas a ver este complejo mucho más completo, con más bungalows, habitaciones con baño privado, con una pileta, tenemos algunas ideas. Yo te dije que me iba a jubilar acá". (Enrique, producción y alojamiento en el delta).

"Yo soy un convencido de que no podemos irnos a otra parte. Acá nosotros sabemos vivir. Irnos a otro lado a hacer qué, es ir y tener que aprender. Y aprender cuesta años y errores, acá todas las macanas que nos teníamos que mandar ya nos la mandamos, es como que ya estás armado. Los proyectos que fracacás son los que abanodnás, porque siempre tenés una posibilidad al menos, o te equivocás y lo corregís". (Enrique, producción y alojamiento en el delta).

Ella demuestra amar el lugar pero que ha sufrido mucho con las crecientes, lo que la condiciona.

"Si vos me das a elegir yo no me muevo de acá. Si me decís nos vamos unos días de vacaciones, yo le digo los días que vas dejame acá en el Sagastume pero sin pensar que tengo que ir a la tienda, sin pensar que tengo que viajar, pero no estar acá sentada, haciendo cosas. Soy feliz". "Yo recién ahora... que empezás a quedarte sola. Después de que se fue el agua yo le decía, otra creciente no me quedo". (Irma, producción y alojamiento en el delta).

A los padres les gustaría que por ejemplo la hija más chica que estudia farmacia pueda instalarse allí, en el local adonde ahora tienen la tienda de ropa. Pero no saben si esos son sus planes. Uno de los hijos tiene su comercio en el pueblo y todo apunta a que siga viviendo allí. No hacen referencia directa a la sucesión de las actividades.

"Somos muy de pensar en ellos nosotros y el gran debate de todo esto es que a veces nos olvidamos de nosotros". (Enrique, producción y alojamiento en el delta). 
El símbolo + representa la importancia relativa del ingreso al sistema de cada actividad

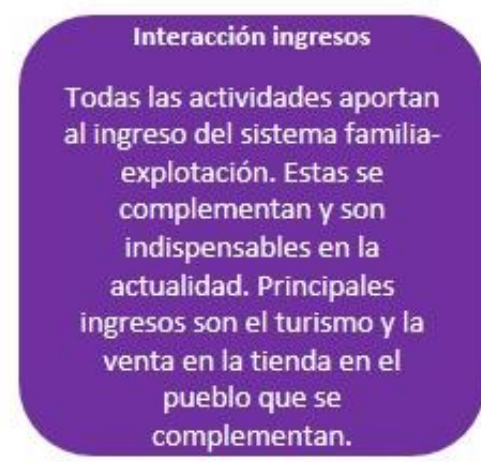

Interacción ingreso/sentido del trabajo

Funcionamiento de todas las actividades colaboran al

equilibrio del sistema. El

turismo es una actividad que agrada por su dimensión social.
Interacción temporal

El turismo surge como

alternativa a la tienda. Cuando hay actividad turística en alza, en el verano, bajan las ventas en la tienda, $y$ viceversa.

Capacidad anticipación del productor (desarrollo de la actividad turística, loteo de campo, venta de lotes como capital para invertir en turismo y reserva para el futuro de la familia) as flechas del esquema central ejemplifican los tipos de interacción del sistema familiaexplotación, con sus respectivos colores identificatorios

\section{Interacción de producto.}

No hay integración de

productos de las diversas actividades que desarrolla la familia.

\section{La pareja es la base de todo e sistema, más la contratación \\ de recursos para tareas especificas en momentos concretos. Empleada fija en la \\ tienda de ropa. Hoy sostienen \\ estas actividades gestionando \\ sus tiempos, recursos y \\ tomando decisiones que les \\ permitan seguir combinando \\ las actividades para obtener el \\ ingreso necesario que sustente \\ su vida y sobre todo garantice \\ el estudio de la hija menor.}

Tipo de interacciones entre recursos.

Los colores utilizados responden al recurso movilizado (humano, en rojo; social, en azu;, espacial, física, material en naranja claro)
Complementariedad entre ganaderia y forestación.

Los ingresos dados por la

venta de lotes han permitido en turismo.

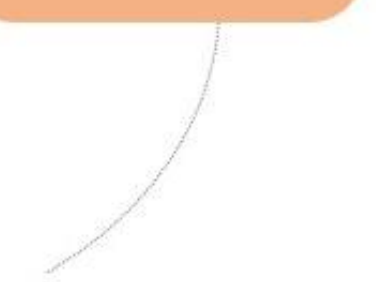




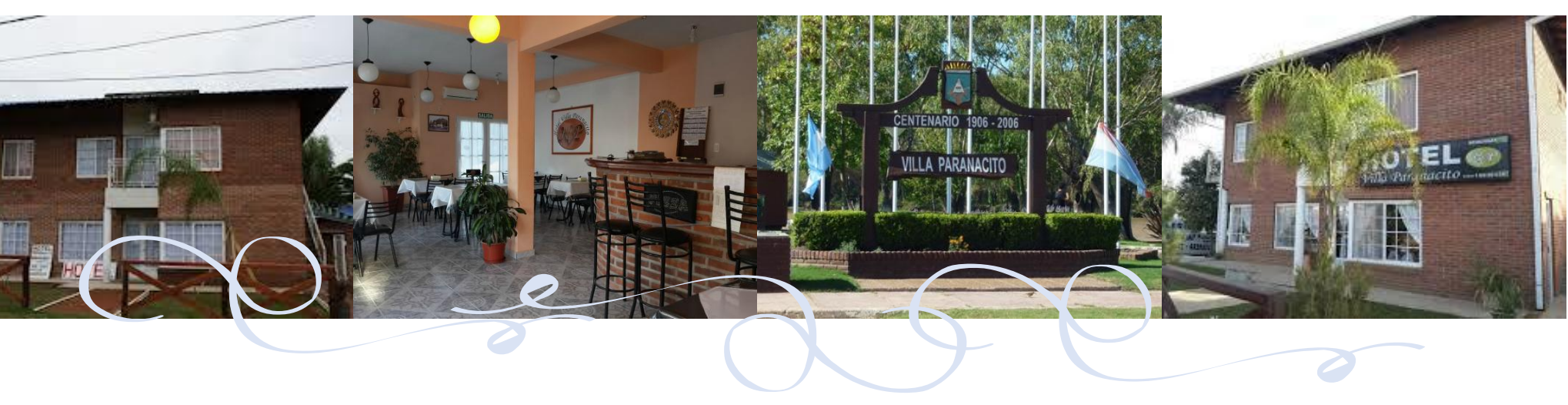

\section{"En el centro de la escena"}

"Yo lo hice como mi jubilación, es una inversión que vos hacés y después esperás". (Pablo, hotel en Villa Paranacito). 


\section{D.4 Caso 12- EN EL CENTRO DE LA ESCENA}

Este sistema tiene como protagonistas a un hombre que fue históricamente productor agropecuario y abandonó esta actividad en el 2016, luego de la última creciente importante, al igual que la parte comercial. Llevan adelante un hotel en el pueblo, manejado por ellos. Contratan empleados solo para la temporada alta y han estado vinculados a instituciones técnicas como INTA y otros productores agropecuarios pero a partir de su vinculación con la ganadería, no con el turismo. Tienen un hijo adolescente.

\section{D.4.1 Presentación general}

Matrimonio de 55 años él y 48 ella con un hijo de 15 años.

El entrevistado nació en Villa Paranacito, la mujer es de Gualeguaychú pero vive allí hace 25 años. Viven en el pueblo.

Él fue productor ganadero hasta el 2016. Tiene un campo en la islas de $\mathbf{2 0 0}$ ha y llegó a tener 500 vaquillonas. Hacía cría, recría y el novillo pesado (de 500/600 k) se exportaba. Integró grupos cambio rural ganadero y trabajó junto a INTA en la resolución de algunas demandas que tenían en el territorio, incluso fue representante del departamento ante la Estación Experimental de su territorio.

Hizo una gran inversión para levantar una porción de terreno lo que le permitió mantener a los animales en época de crecientes. Tenía dos personas trabajando, no era empleados sino que "tienen su propia hacienda, eran propietarios de hacienda, yo les daba parcelas con la condición de que me cuiden los animales". (Pablo, hotel en Villa Paranacito).

Son dueños de un hotel en la avenida principal del centro del pueblo que abrieron al público en el año 2011 con 5 habitaciones. Lo fueron construyendo progresivamente hasta contar en la actualidad con 24 habitaciones con 60 plazas. Además construyeron unos locales comerciales sobre el mismo terreno que alquilan.

Hace un año le anexaron otra modalidad de alojamiento, esto es, 8 habitaciones de apart hotel, 4 de ellas, monoambientes.

Cuentan además con su vivienda familiar y un local, donde históricamente funcionó la librería de la familia del entrevistado, que hace un año pusieron en alquiler.

Dejó definitivamente la ganadería con la última inundación del 2015/2016 y se dedica exclusivamente al turismo. "Me llevaba mucho tiempo el hotel y desatendía la ganadería". Hace 1, 2 años cerraron también la librería y alquilan el local.

"Con la creciente del año pasado vendí todo (los animales). Lo que te satura no es el trabajo si es bienvenido, lo que me saturó a mí es que empecé a trabajar en el hotel, el hotel te lleva mucho tiempo y desatendía el campo. Y en el campo no estando yo, el personal no me rendía. Una cosa es cuando vas 3 veces por semana y cuando vas una vez cada 15 días, y yo no puedo ir más que eso. Y llegó la creciente, con un montón de problemáticas, de falencias. Una cosa es cuando voy todas las semanas y sé que los animales están empotrados en un lugar y en otro y otra cosa cuando iba cada 15 días y los animales estaban desatendidos, vacas trancadas. Tuve muchas bajas de animales, muchos problemas económicos". (Pablo, hotel en Villa Paranacito).

"Es que después de la crecientes y más de esta, cuesta mucho retomar las actividades dentro de la isla porque primero y principal todos quedamos muy noqueados. Invertir nuevamente hasta en pintar tu casa es complicado. Nosotros todavía hoy estamos pintando lo 
que quedó del año pasado porque todavía no se secó. Te desanima". (Pablo, hotel en Villa Paranacito).

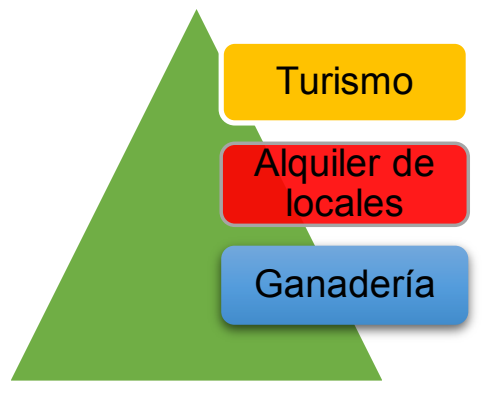

Esta familia cuenta entonces con 2 actividades que les generan ingresos: el hotel (turismo) y el alquiler de locales comerciales. A pesar de que ya no se dediquen a la actividad ganadera, será tenida en cuenta para el análisis, porque es importante entender su relación con el resto de los componentes del sistema.

\section{D.4.2 Recursos de la familia ${ }^{73}$}

\begin{tabular}{|c|c|}
\hline $\begin{array}{l}\text { Recursos } \\
\text { humanos }\end{array}$ & 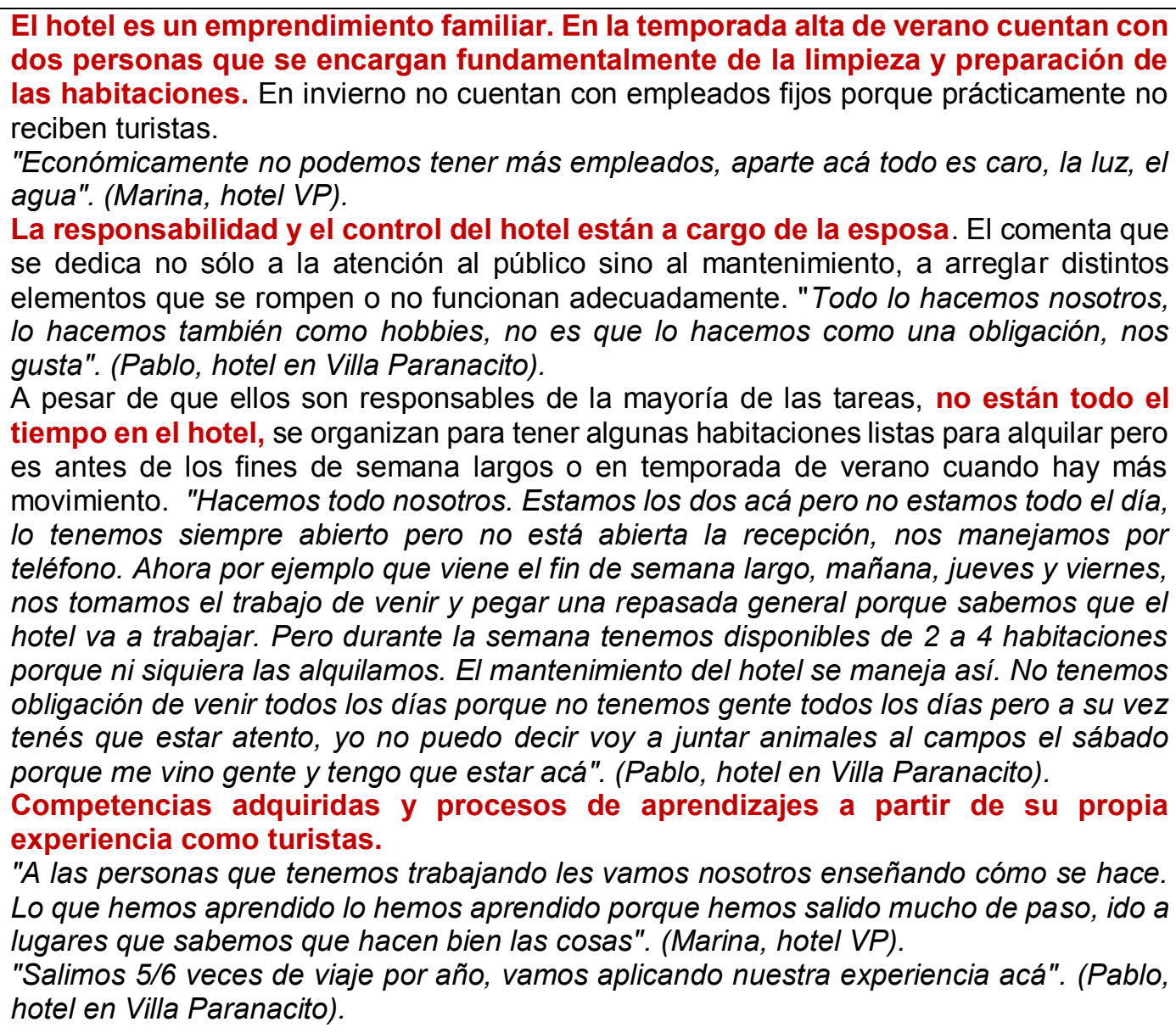 \\
\hline $\begin{array}{l}\text { Recursos } \\
\text { físicos, } \\
\text { materiales } \\
\text { naturales }\end{array}$ & $\begin{array}{l}\text { El hotel se construyó gracias a los aportes de la ganadería. Hoy cuentan con un hotel } \\
\text { totalmente equipado. Han construido además } 4 \text { locales comerciales, además del campo } \\
\text { de } 200 \text { ha y el local en el pueblo. } \\
\text { Las crecientes condicionan las actividades productivas y la vida social de las } \\
\text { familias. }\end{array}$ \\
\hline
\end{tabular}

\footnotetext{
${ }^{73}$ En el cuadro se utilizan colores determinados para resaltar algunos conceptos que luego son recuperados en un esquema conceptual. Los recursos humanos son referidos en color rojo; los físicos, materiales y naturales en naranja; los recursos económicos en violeta; los sociales en azul y los recursos identitarios en verde.
} 


\begin{tabular}{|c|c|}
\hline & $\begin{array}{l}\text { "Lo que pasa en las crecientes es gravísimo. El Estado tendría que apoyar... hay gente } \\
\text { que no sabe que vendiendo } 10 \text { novillos podés hacer un cerro y te olvidás para toda la } \\
\text { vida. Te desanima. los fenómenos atmosféricos son complicados en todo el mundo. } \\
\text { Algunos vienen de un momento a otro como los terremotos, los ciclones, esos te generan } \\
\text { pérdidas de vidas, te genera una pérdida económica. pero vos no tenías la anterior. El } \\
\text { proceso de concientización de tal o cual fenómeno te vino de un momento para el otro. } \\
\text { En el caso nuestro ya sabemos que va a haber creciente, entonces en el proceso es muy } \\
\text { grande el desánimo, el malestar, en un proceso de creciente que son } 6 \text {, } 8 \text { meses. No } \\
\text { dormimos cuando hay sudestada. Psicológicamente te trabaja de una forma muy distinta". } \\
\text { (Pablo, hotel en Villa Paranacito). }\end{array}$ \\
\hline $\begin{array}{l}\text { Recursos } \\
\text { económicos }\end{array}$ & $\begin{array}{l}\text { El turismo tiene una marcada estacionalidad, lo que hace que haya momentos de } \\
\text { suficiente ingresos y otros que no alcanzan. Deciden invertir en la construcción de } \\
\text { unos locales para alquilar y en unos departamentos para alquiler turístico, pensando } \\
\text { en los costos fijos. } \\
\text { "Lo que hicimos fueron locales que están alquilados fijos y hoy hemos tomado la } \\
\text { modalidad por ejemplo de a alguna maestra alquilarle una habitación fija también. Esto } \\
\text { implica una economía más estable, más rentable". (Pablo, hotel en Villa Paranacito). } \\
\text { "Hay meses que con el turismo no sacamos el alquiler de un local y hay meses que } \\
\text { sacamos } 5 \text { meses del alquiler de local. Es muy relativo. En este momento el } 20 \% \text { es } \\
\text { turismo, la mayoría del ingreso es de alquileres fijos". (Pablo, hotel en Villa Paranacito). }\end{array}$ \\
\hline $\begin{array}{l}\text { Recursos } \\
\text { sociales }\end{array}$ & $\begin{array}{l}\text { El entrevistado ha integrado redes técnicas, grupos asociativos y ha sido una } \\
\text { referencia en ganadería en la zona. } \\
\text { "Viene gente y me pregunta qué hice con las vacas y yo les digo que no las saqué... por } \\
\text { la creciente la construcción del cerro donde colocó el corral y evita el traslado de los } \\
\text { animales". (Pablo, hotel en Villa Paranacito). Destaca que de los productores que } \\
\text { integraba el grupo, él era el menor y que aprendía mucho, pero también era innovador. } \\
\text { El turismo les ha ampliado y diversificado el espectro comercial y social ya que a } \\
\text { partir de la librería se relacionaban con gente mayoritariamente del pueblo. Esta apertura } \\
\text { apareja experiencias positivas y experiencias negativas. }\end{array}$ \\
\hline $\begin{array}{l}\text { Recursos } \\
\text { identitarios }\end{array}$ & $\begin{array}{l}\text { Lo más destacable en este aspecto es el sentimiento de arraigo, de profundo amor } \\
\text { por su lugar. } \\
\text { "Yo soy amante de Villa Paranacito y me quiero quedar a morir acá". (Pablo, hotel en Villa } \\
\text { Paranacito). }\end{array}$ \\
\hline $\begin{array}{l}\text { Recursos } \\
\text { territoriales }\end{array}$ & $\begin{array}{l}\text { Es muy crítico con el pueblo y la dinámica turística, en relación a las falencias que } \\
\text { existen. } \\
\text { "Yo estoy decepcionado con la forma de hacer turismo en Villa Paranacito. Nos faltan } \\
\text { capacidades para atender a cierto nivel de gente que necesita servicios, y para eso tiene } \\
\text { que haber ayuda, no solo del estado. No es como una ciudad que tenés } 70 \text { tenedores y } \\
\text { al otro día ya lo vendés porque hay mucha gente. Acá no, de lunes a viernes no vendes } \\
\text { nada. El problema que tenemos es el servicio, vos venis hoy y no tenés lugar para comer, } \\
\text { hay un solo carrito. El pueblo tiene que pensar en una economía que le sume al } \\
\text { pueblo. Yo creo que al pueblo no le sirve la modalidad de camping. Hoy tenés un turismo } \\
\text { y operadores muy básicos. La dirección de turismo tiene un wapp donde se maneja toda } \\
\text { la información pero no le doy bolilla, no tengo mucha relación pero no nos sirve". (Pablo, } \\
\text { hotel en Villa Paranacito). } \\
\text { También destaca la dinámica de segunda residencia para gente de Bs As. } \\
\text { "Se han vendido muchos terrenos a gente de Bs As que tienen su casa de fin de semana } \\
\text { acá, es tipo un barrio privado pero abierto". (Pablo, hotel en Villa Paranacito). }\end{array}$ \\
\hline
\end{tabular}

\section{D.4.3 Trayectoria familiar}

El entrevistado es nacido en la localidad. Hijo de inmigrantes italianos por línea paterna y de alemanes por parte de la madre. Los abuelos maternos que llegaron a la zona escapando de la primera guerra mundial tenían una pensión. 
"En esa época Villa Paranacito era un lugar de posta para el ingreso a la provincia de Entre Ríos o a la Mesopotamia porque no estaba el acceso terrestre, había que cruzar en balsa y los vapores venían de Buenos Aires a Gualeguaychú como trayecto, había muchos hospedajes, hosterías. Mis abuelos vivían de la hostería y de ahí también viene la nostalgia de hacer un emprendimiento hotelero". (Pablo, hotel en Villa Paranacito).

El padre es de Diamante y en el 1940, por su trabajo en gendarmería, se radica en Paranacito y la conoce a su madre. El entrevistado comenta que trabaja desde muy chico allí, que con la creciente del 1983 se instala un par de años en Buenos Aires donde los padres tenían un departamento que habían comprado con la idea de que sus hijos estudien. Son 3 hermanos, uno contador.

"Después de un accidente, me chocaron y volví, además la vida de la ciudad no me asentaba. Al poco tiempo fallece mi padre y yo me hago cargo del comercio, una librería, junto a mi madre". (Pablo, hotel en Villa Paranacito).

Cuando se conocen con su señora, ella se muda a Villa Paranacito y se suma a trabajar en la librería.

Antes de la creciente de 1998, empezó un "éxodo de gente a producir en los campos, se empezó a poblar mucho la isla. En ese momento los propietarios de tierra firme la utilizaban para siembra y la ganadería la llevaban a la isla. Yo no tenía campo ni nada pero me parecía interesante incursionar en la hacienda y abandoné lo del hotel porque el turismo estaba pinchado. A este terreno, donde funciona el hotel lo compré en el 95/96, junto con este terreno compré el campo. En 1998 empecé el hotel y me agarró la creciente. Compré 200 ha de un campo improductivo para forestación y lo convertí en ganadero, lo traté de mejorar, tenía habilitación para la exportación, tenía novillo pesado, novillo gordo. Llegué a tener 500 animales en 250 ha. Esto es tierra buena pero es complicado, tenes que trabajarlo mucho pero la resaca es lo más efectivo que hay. Tenía que sembrar para tener firmeza de gordura. No es un pasto firme pero le podía meter dos animales por ha". (Pablo, hotel en Villa Paranacito).

Mientras tanto el productor se dedicaba a la ganadería la mujer continuaba trabajando con su suegra en la librería.

"El hotel estaba en cero, teníamos las bases, la loza pero cero con el hotel porque el turismo en Paranacito no fue ni es actualmente un beneficio muy importante". (Pablo, hotel en Villa Paranacito).

En todo el tiempo de trabajo con la ganadería tuvo diferentes problemáticas como muerte súbita de los animales, esto fue en 1996, antes de la creciente. En ese momento se contactó con INTA, integró grupo cambio rural con otros productores, era representante del departamento islas en INTA de Concepción del Uruguay. Realizaron estudios en el campo, de suelo, de parasitosis. Trabajó con el asesoramiento de INTA y de otros productores. En algún momento de este periodo, "quiso cambiar la vaca por el novillos. Los últimos que me quedaban eran novillos, los terminé vendiendo en ferias, vendía jaulas que estaban acordes para exportación pero la mayoría eran intermedios" (Pablo, hotel en Villa Paranacito).

"Pasamos todas las crecientes, como grandes las del 83, la del 98 y la última del 2016. Después hubo un montón de creciente donde se nos ha inundado la casa incluso, pero no han sido tan grandes". (Pablo, hotel en Villa Paranacito).

Comienzan nuevamente con el hotel en el 2009.

"Arrancamos con el hotel en el 2009, con el entusiasmo de terminarlo. El turismo estaba empezando a funcionar, la ganadería estaba medianamente organizada, o sea que teníamos los tiempos suficientes, marchaba todo sobre ruedas. Empezamos a invertir y lo terminamos en el 2011". (Pablo, hotel en Villa Paranacito). 
"Empezamos de a poquito, con algunas habitaciones, no es que arrancamos con todo terminado. Nosotros tuvimos una época muy baja de venta de habitaciones, recién ahora estamos repuntando un poco". (Marina, hotel en VP).

"Fuimos muy de a poco, no teníamos el dinero para gastar 200 mil pesos en colchones". (Pablo, hotel en Villa Paranacito).

En el 2016 abandona el campo, deja la ganadería y también deciden cerrar la librería.

\section{D.4.4 Emergencia del turismo rural}

- Invierten en turismo pensando en una jubilación privada a pesar de ser muy críticos con la dinámica y la forma de desarrollo turístico de la localidad. Complementaria a la producción ganadera, que era central en el sistema.

- Hay también una cuota de encanto por la actividad hotelera y la búsqueda de una vida más tranquila en el pueblo, lugar por el que sienten profundo arraigo.

"En ese proceso la idea siempre fue tener un hotel porque a nosotros siempre nos gustó viajar. En ese momento invierto para mi jubilación, como independiente. Empecé a construir este edificio pero veía que turísticamente Villa Paranacito no crecía, había muchas falencias". (Pablo, hotel en Villa Paranacito).

\section{D.4.5 Objetivos, decisiones y estrategias puestas en marcha}

- Apuestan al turismo. A partir de la incorporación del turismo abandonan la actividad ganadera y luego deciden poner el local en alquiler, donde antes funcionaba la librería familiar.

"Estamos tratando de sacar fichas para estar lo más tranquilos posibles nosotros. Y no quiere decir que nos haya ido mal en lo otro o que esto sea mucho mejor. en nuestro caso el por qué de los cambios, no es referencial, es muy particular. No es que me quedé en el turismo porque me conviene más o vamos a renegar menos. Es porque ya estamos embarcados en este busque y en todos los busques quiero llegar a destino, tenga los traspies que tenga. En números el hotel me redituaba mucho menos, económicamente me reditúa mucho menos pero es a lo que estamos apuntando. Las dos cosas no se pueden hacer". (Pablo, hotel en Villa Paranacito).

- Pretenden vender el campo para tener una vida más tranquila.

"Si bien la base de poner este hotel era mi jubilación, yo ya prácticamente quiero jubilarme entonces como tal, al campo lo vendo. Vendo el campo porque no lo voy a utilizar, no me va a rentabilizar, imaginate que arrendando 200 ha de campos es lo mismo que dos departamentos en cualquier lugar, vendo el campo y me hago 4 departamentos, y tengo más rentabilidad, pero no es lo que pienso. Todo lo que venda del campo me lo voy a pasear por el mundo". (Pablo, hotel en Villa Paranacito).

- $\quad$ No piensan seguir invirtiendo en turismo.

"Ya inversiones no pensamos hacer más. Lo que queremos nosotros es tratar de tener una casa como tenemos acá, donde vivimos muy bien, una casa en Gualeguaychú donde estamos edificando y donde vamos a hacer un departamento donde podamos ir a vivir o a pasar unos días tranquilos. Porque ya queremos pensar en la vida tranquilos". (Pablo, hotel en Villa Paranacito). 
Ilustración 29- Esquema del sistema familia/explotación Caso 12

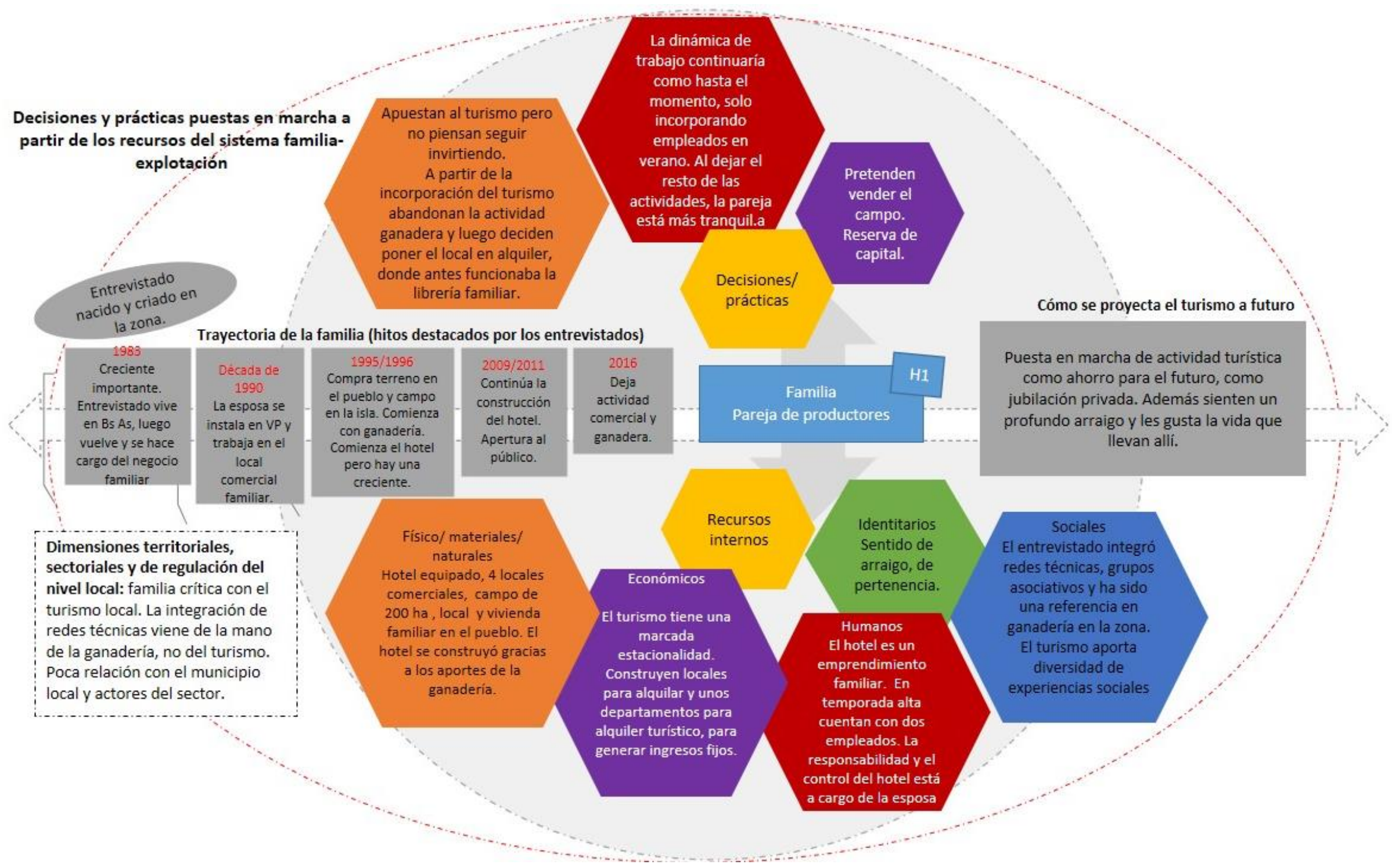




\section{D.4.6 Vinculación del sistema familia-explotación con la actividad de turismo rural $^{74}$}

\begin{tabular}{|c|c|}
\hline $\begin{array}{l}\text { Interacción producto } \\
\text { Explica el flujo de materia } \\
\text { prima de una actividad a otra. }\end{array}$ & $\begin{array}{l}\text { No hay integración de productos de las diversas actividades que } \\
\text { desarrolla la familia. }\end{array}$ \\
\hline $\begin{array}{l}\text { Interacción recursos } \\
\text { Se explica a partir de la } \\
\text { movilización de un mismo } \\
\text { recurso para varias } \\
\text { actividades. }\end{array}$ & $\begin{array}{l}\text { En este sistema se da una movilización de recursos físicos y } \\
\text { materiales en el terreno donde se ubica el hotel. Allí, al afrontar a } \\
\text { importantes gastos fijos deciden construir locales de alquiler mensual. } \\
\text { Además implementan otra modalidad alojamiento como es apart hotel } \\
\text { con monoambientes y ambientes completos con una habitación. } \\
\text { Los recursos humanos que organiza sus tiempos son la pareja, } \\
\text { ellos enseñan a las dos empleadas que tienen fija en base a sus propias } \\
\text { experiencias y aprendizajes como "turistas". Trasladan su experiencia } \\
\text { viajando a la prestación de su servicio turístico. Lo mismo manifiesta el } \\
\text { entrevistado respecto a la ganadería. Es referente de consulta para } \\
\text { otros productores, ha realizado ensayos y estudios con el INTA en su } \\
\text { propio campo y transmite sus aprendizajes a otros productores. Es } \\
\text { importante mencionar que el turismo se capitalizó gracias a la } \\
\text { ganadería. En virtud de esta fueron construyendo progresivamente el } \\
\text { hotel. }\end{array}$ \\
\hline $\begin{array}{l}\text { Interacción temporal } \\
\text { Explica los procesos de } \\
\text { anticipación de un cambio que } \\
\text { está por venir, del abandono o } \\
\text { implementación de una nueva } \\
\text { actividad }\end{array}$ & $\begin{array}{l}\text { En la implementación del turismo se contempla una anticipación a los } \\
\text { ingresos del futuro de la pareja. Ellos mismos lo manifiestan como } \\
\text { una inversión para la "jubilación privada". }\end{array}$ \\
\hline $\begin{array}{l}\text { Interacción ingreso/ sentido } \\
\text { del trabajo } \\
\text { La combinación de actividades } \\
\text { permite asociar actividades } \\
\text { fuertemente remuneradas con } \\
\text { actividades que no son menos } \\
\text { importantes pero proveen otro } \\
\text { tipo de satisfacciones }\end{array}$ & $\begin{array}{l}\text { Por el contrario a combinar actividades, en este caso se da un proceso } \\
\text { de abandono de la actividad que generaba más ingresos, como la } \\
\text { ganadería, pero que aparejaba una vida de mayor sacrificio. } \\
\text { "Prefiero estar atento a esto, tomando unos mates en casa o acá, } \\
\text { esperando que pase algo, aunque gane mucho menos". (Pablo, hotel en } \\
\text { Villa Paranacito). }\end{array}$ \\
\hline $\begin{array}{c}\text { Interacción ingreso } \\
\text { Se da cuando } 2 \text { o más } \\
\text { actividades aportan a los } \\
\text { ingresos totales disponibles } \\
\text { para la familia. }\end{array}$ & $\begin{array}{l}\text { Hasta el } 2016 \text { tenían los ingresos por la venta de productos de librería, } \\
\text { el turismo y los de la ganadería. Actualmente los ingresos de la } \\
\text { familia están dados por el alquiler de locales (local familiar y } \\
\text { nuevos construidos) y el turismo. } \\
\text { La implementación del alquiler fijo mensual alivia los gastos fijos, } \\
\text { que son importantes. Estos ingresos garantizan una buena calidad de } \\
\text { vida de la familia. }\end{array}$ \\
\hline
\end{tabular}

\section{D.4.7 Impacto del turismo en el sistema productivo}

En este caso, a partir de la puesta en funcionamiento del alojamiento se empiezan a reacomodar el resto de las actividades.

El productor decide abandonar la actividad ganadera, aunque sea más redituable que el turismo, y también deciden dejar el comercio que hasta ese momento estaba a su cargo.

\footnotetext{
${ }^{74}$ En el siguiente cuadro se enfatizan algunos conceptos utilizando colores que luego serán adoptados en el esquema conceptual que explica las interacciones de la actividad turística con el resto de las actividades del sistema. Así, con naranja se remarca la interacción entre productos de las distintas actividades; con rojo y azul la interacción de los recursos humanos y sociales y con naranja claro entre recursos físicos, naturales y materiales; con verde la interacción patrimonial; con gris, la temporal; con violeta claro la interacción dada entre el ingreso y el sentido dado al trabajo, y con violeta oscuro, la interacción entre los ingresos que aportan las actividades al sistema.
} 
Además deciden poner en venta el campo, que les resulta más rentable para realizar inversiones que arrendarlo.

El turismo se convierte en la actividad central. Para atenuar el impacto de la estacionalidad implementan alquileres de habitaciones fijas y adicionaron departamentos y monoambientes atentos al perfil de la demanda turística de la localidad.

\section{D.4.8 Impacto del turismo en la familia, en las personas y en sus estilos de vida}

- El turismo genera un reacomodamiento de los tiempos en virtud de que la pareja pueda continuar con su vida de una manera más relajada y tranquila. No genera importantes modificaciones en la rutina pero sí marca el ritmo de las actividades.

"Hace 1/2 años cerramos la librería, fue cuando dije basta, porque yo tenía que estar acá y allá y para mí era demasiado, Ahí pusimos en alquiler el local" (Susana, producción y alojamiento en Villa Paranacito).

"Aunque el negocio nos redituaba, nos llevaba tiempo" (Pablo, hotel en Villa Paranacito).

"No ha impactado en los tiempos de las tareas. No se deja de hacer nada. A lo sumos a los platos no se los lava al mediodía. Las tareas de higiene del hogar si ella no los hace a las 10, los hace a las 11, hay días que se duerme siesta, hay días que no. Es de acuerdo a las circunstancias, no es rutinario". (Pablo, hotel en Villa Paranacito).

"Es un reacomodamiento. Nos ordena, porque por ejemplo si es fin de semana largo, de martes a viernes nos vamos de vacaciones en lugar del viernes al domingo como nos íbamos antes. $A$ estos cambios los tenemos pero no nos afectaron. No quiere decir que no nos vayamos de vacaciones". (Pablo, hotel en Villa Paranacito). "Tratamos de adaptarnos". (Susana, producción $y$ alojamiento en Villa Paranacito).

- El turismo aporta tranquilidad, una vida menos agitada, sobre todo al productor.

"Yo sí siento que he dejado de hacer un trabajo sacrificado como es el del campo. Del campo volvía a las 10 de la noche, embarrado, transpirado, y hoy no lo hago. La vida acá es mucho mejor, hay que reconocer que el campo es sacrificado. En el campo no sabés con qué te vas a encontrar, no es con una discusión, es con un animal enterrado o vos con algún inconveniente con la naturaleza, con la cabeza así picada de abejas. Hoy la vida es mucho más tranquila, menos agitada". (Pablo, hotel en Villa Paranacito).

- Genera otro tipo de intercambios y relaciones sociales, que pueden ser positivas como negativas.

"Comercialmente nos cambió mucho la vida porque nosotros teníamos un habitat que trabajábamos con la gente del pueblo, conocida. Acá no. Comercias con gente que no conocés, tenés un montón de problemas y circunstancias que no pensábamos que pasaban en los hoteles. Acá me pasan cosas que no me imaginaba que pasan en los hoteles. Hay gente que quiere pasar las barreras del sonido con las exigencias. Hay clientes que se van de mambo". (Pablo, hotel en Villa Paranacito).

"No es que el turismo nos da o nos quita. Hemos tenido más diversidad de experiencias. Cuando conocés a una persona como el amplio espectro de la gente de Villa Paranacito, 
sabés con quién te enfrentas, con quién te encontrás. Cuando viene un turista te podés encontrar con una mejor o peor persona". (Pablo, hotel en Villa Paranacito).

- En este caso colabora a que la familia está más unida y más cerca la pareja.

"Estamos más tiempos juntos, cuando él trabajaba en el campo, él vivía para su campo, iba todos los días". (Susana, producción y alojamiento en Villa Paranacito).

\section{D.4.9 Percepción del futuro en relación a los hijos y en relación a su resguardo de ingresos}

Está clara la idea de que comienzan con la propuesta turística pensando en ahorro para el futuro, en un ingreso como jubilación privada. Pero además sienten un profundo arraigo y les gusta la vida que llevan allí.

"Cada día que pasa estoy convencido de que es el mejor lugar del mundo que podría haber elegido, porque veo lo que pasa en otros lugares y no me convence para nada. La inseguridad, las problemáticas de las grandes ciudades. Si le pasa algo en la calle a mi hijo, vienen los vecinos y me avisan. Tenemos muchas dificultades pero la vida que tenemos acá. Yo dejo la camioneta abierta con plata arriba, nuestra casa está abierta de par en par. El imponderante es el agua, si bien te trabaja psicológicamente lo afrontás, sabés las consecuencias". (Pablo, hotel en Villa Paranacito).

"Yo soy de Gualeguaychú y a mí Villa Paranacito me atrapó y me encantó. Voy a Gualeguaychú dos días y ya me quiero volver. Me encanta el lugar, la tranquilidad, la naturaleza". (Susana, producción y alojamiento en Villa Paranacito).

No surge la idea de la sucesión en los procesos de cambio que ha realizado la familia, lo que no quiere decir que el futuro de su hijo no esté en su mente ni horizonte. Tienen un hijo adolescente que aún no tiene definido su futuro.

"Como el 90\% de la población que tiene un chico de 15 años, no sabemos para qué lado va a ir... ahora está embalado que quiere estudiar derecho, ese es el entusiasmo de él ahora". (Pablo, hotel en Villa Paranacito). "Tiene la idea de seguir estudiando". (Susana, producción y alojamiento en Villa Paranacito). 
El símbolo + representa la importancia relativa del ingreso al sistema de cada actividad

\section{Interacción ingresos}

Los ingresos de la familia

están dados por el alquiler de locales $y$ el turismo.

La implementación del

alquiler fijo mensual alivia los

gastos fijos, que son

importantes. Estos ingresos

garantizan una buena calidad$$
\text { de vida de la familia. }
$$

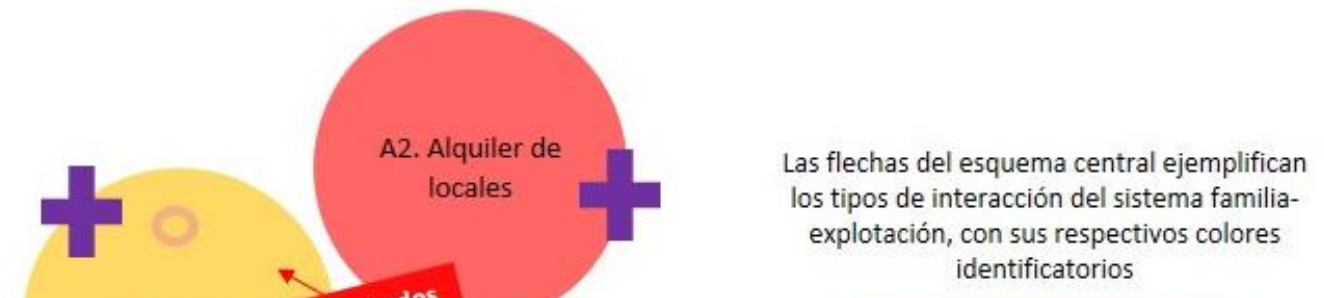

A1. Turismo

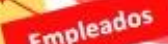

Pareja

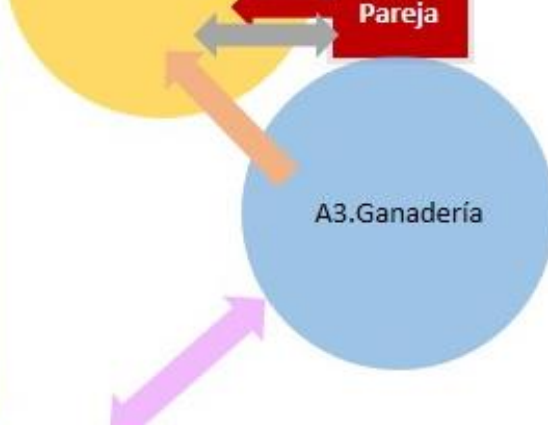

identificatorios

Interacción de productos

No hay integración de productos de las diversas actividades que desarrolla la familia.

La pareja es la base de todo el

sistema, más empleados para

turismo en temporada alta.

En este sistema se da una Movilización de recursos

físicos y materiales en el

terreno donde se ubica el

hotel. Construcción de

locales de alquiler

mensual. El hotel se

Interaccion temporal

En la implementación del

turismo se contempla una

anticipación a los ingresos de

futuro de la pareja, "jubilación privada". construyó a partir de la

$$
\text { ganadería. }
$$

Tipo de interacciones entre recursos.

Los colores utilizados responden al recurso movilizado (humano, en rojo; social, en azu; espacial, física, materia en naranja claro 


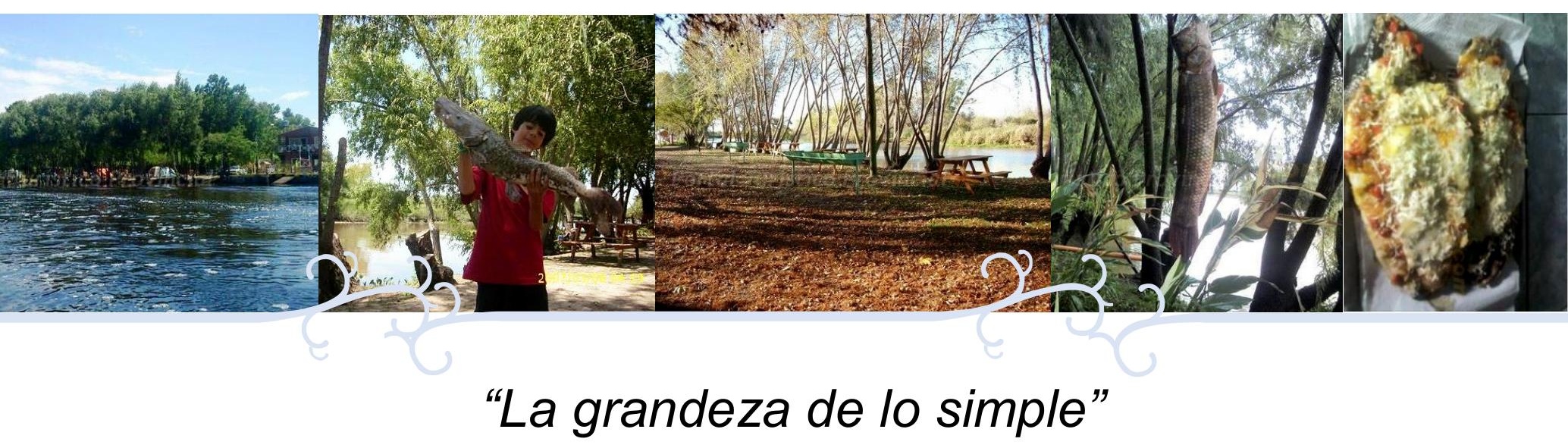

"Para mí es un placer, yo lo tomo más como placer, el trato con la gente". (Antonio, camping). 


\section{D.5 Caso 13- LA GRANDEZA DE LO SIMPLE}

Esta experiencia pone su foco en una familia que en algún tiempo se dedicó a la actividad forestal en la isla. Luego tuvo la oportunidad de vender parte de sus campos e instaló un camping que trabaja con su esposa. Sus hijos son adultos y no se vinculan con esta actividad. El entrevistado nació en Villa Paranacito y vivió muchos años en Buenos Aires. Actualmente además es empleado del hospital local.

\section{D.5.1 Presentación general}

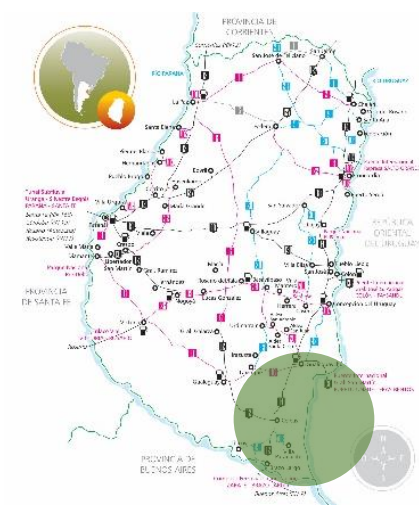

Se trata de una pareja de alrededor de 60 años con $\mathbf{4}$ hijos adultos, que cada uno tiene su familia y actividad económica particular. Tienen 34, 30, 24 y 21 años.

La pareja tiene dos actividades de generación de ingresos. Por un lado el hombre trabaja en el hospital por la mañana y cuentan con un camping en la isla, que trabajan juntos.

El hombre nació en Villa Paranacito pero a los 11 años se va a vivir a Buenos Aires junto a su familia. El padre del entrevistado era productor agropecuario.

"Tenía plantaciones de sauces y álamos, cosecha de limones. Era forestal y frutal. Eran 30 y pico de ha producidas". (Antonio, camping).

En Buenos Aires tuvo un taller mecánico durante muchos años. Producto del estrés tuvo problemas de salud y decidieron volver al pueblo con el objeto de mejorar su calidad de vida.

Realizaron diversas actividades para generar ingresos hasta que en 1998 ingresa en el hospital. De su familia hereda unos campos ubicados en una isla que antes estaba incomunicada vía terrestre, y una casa en el pueblo. Deciden comprar las partes correspondientes a sus hermanas.

"Le compramos esto cuando nos vinimos para acá. Después surgió todo esto del cambio de la isla endicada. Antes era todo campo, uno solo podía venir en lancha". (Antonio, camping).

Hace 3/4 años vendió unos lotes y con eso se capitalizó. Cuentan con 27 ha en el predio donde se sitúa el camping.

En el 2011 comenzaron a trabajar en ese predio con un camping, en el que también ofrecen comidas en base al pescado que él mismo pesca allí. También cuentan con unas casas rodantes que alquilan a los turistas.

En una época se dedicó a la parte forestal. Plantaba 1 o 2 ha "como para tener, pero era

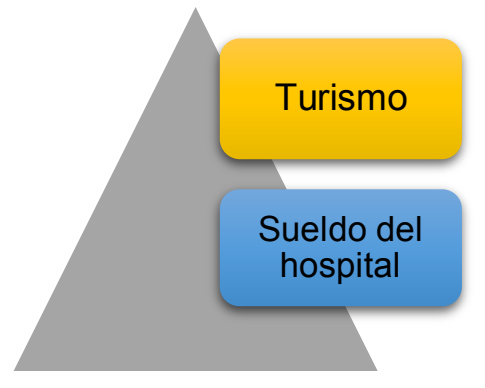
un poco el parate de la madera. La forestación se tomaba como un ahorro. Tenías 2 ha, volteabas y tenías para comprar algo. Si necesitabas comprar algo te hacías de esa madera. En aquel momento no valía la pena comprar una motosierra, era muy cara. Contrataba a alguien. Ahora casi no queda nada ni tampoco hay mucho interés de comprar". (Antonio, camping). Lo que sacaba de madera se vendía a la cooperativa forestal. 


\section{D.5.2 Recursos de la familia ${ }^{75}$}

\begin{tabular}{|c|c|}
\hline Recursos humanos & $\begin{array}{l}\text { Trabajan solo la pareja. El entrevistado continúa trabajando en el hospital de } 7 \\
\text { a } 13 \text { hs. En ese momento queda la esposa en el camping. Vuelve a las } 13 \text { hs y } \\
\text { se queda hasta la noche. A veces duermen allí mismo ya que tienen una } \\
\text { vivienda allí y una en el pueblo. }\end{array}$ \\
\hline $\begin{array}{l}\text { Recursos físicos, } \\
\text { materiales y naturales }\end{array}$ & $\begin{array}{l}\text { Cuenta con un campo de } 27 \text { ha. En este se ubica el camping, que no tiene } \\
\text { una importante infraestructura pero sí un entorno natural único, con salida } \\
\text { al río, una frondosa arboleda, vegetación diversa. En esta zona hay otros } \\
\text { complejos turísticos pero no hay un flujo constante de gente, lo que posibilite que } \\
\text { el lugar conserve el patrimonio natural y paisajístico. Tienen una huerta con } \\
\text { algunos vegetales que utilizan para preparar las comidas que ofrecen en el } \\
\text { camping. Cuentan con algunos árboles de nuez pecán que venden allí mismo } \\
\text { también. }\end{array}$ \\
\hline Recursos económicos & $\begin{array}{l}\text { Tiene dos actividades que generan ingresos al sistema, el hospital y el } \\
\text { turismo. No mencionó el entrevistado el porcentaje de ingresos pero se entiende } \\
\text { que como empleado tiene un sueldo fijo. Además cuenta con un amplio terreno } \\
\text { en la isla, de los cuales vendió } 3 / 4 \text { lotes con los que se fue capitalizando y } \\
\text { mejoró el predio del camping. }\end{array}$ \\
\hline Recursos sociales & $\begin{array}{l}\text { El entrevistado siente reconocimiento y afecto de los visitantes. Con la } \\
\text { mayoría de los clientes se genera un vínculo de familiaridad. } \\
\text { "La gente que viene vuelve todo el tiempo. Me han regalado una cuchilla } \\
\text { especialmente grabada con mi nombre, un cliente que viene hace } 3 / 4 \text { años. Y } \\
\text { como esos un montón de cosas que podés decir es el agradecimiento por lo uno } \\
\text { hace. Tenés contacto permanentemente con la gente que viene. A veces se } \\
\text { reúnen } 4 / 5 \text { familias y comemos todos juntos. Cada uno pone un pedazo de carne". } \\
\text { (Antonio, camping). }\end{array}$ \\
\hline Recursos identitarios & $\begin{array}{l}\text { El entrevistado demuestra ser un hombre simple, sencillo, que priorizó la } \\
\text { tranquilidad y la salud y que vive feliz en su pueblo. } \\
\text { Hizo un cambio de vida que él mismo denomina "brusco" al dejar Bs As para } \\
\text { radicarse a Villa Paranacito. } \\
\text { Su historia familiar está allí. Evidencia un profundo sentido de pertenencia a } \\
\text { su lugar. }\end{array}$ \\
\hline Recursos territoriales & $\begin{array}{l}\text { No se mencionan elementos en la entrevista pero se puede mencionar que } \\
\text { algunos aspectos del contexto como la ubicación privilegiada, el entorno } \\
\text { natural y la misma idiosincrasia del lugareño son un atractivo para el } \\
\text { desarrollo del turismo. }\end{array}$ \\
\hline
\end{tabular}

\section{D.5.3 Trayectoria familiar}

"Yo nací acá" expresa el entrevistado.

"Mi padre era italiano, vino solo cuando tenía 18 años, creo que en el 38. Estuvo en San Isidro, compró unos terrenos con lo que trabajó y después se vino para acá. Era forestal y frutal. No pensaba en el turismo en aquel momento". (Antonio, camping).

A los 11 años la familia se traslada a Bs As y parte de su vida la desarrolla allí.

"Tenía un taller de chapa y pintura y a veces por incumplimiento de la gente, todo eso, me llevó a tener problemas de gastritis, un montón de cosas más que se complican y me dije "la dieta no me va a servir". (Antonio, camping).

Hizo un cambio radical de vida y volvió a vivir a Villa Paranacito.

\footnotetext{
${ }^{75}$ En el cuadro se utilizan colores determinados para resaltar algunos conceptos que luego son recuperados en un esquema conceptual. Los recursos humanos son referidos en color rojo; los físicos, materiales y naturales en naranja; los recursos económicos en violeta; los sociales en azul y los recursos identitarios en verde.
} 
"Optamos por volver, acá estaba la casa vacía (paterna). Vendimos la casa allá y decidimos volver a hacer cualquier cosa. Empezamos a vender yerbas medicinales, Salíamos por el río. lo que era eso, una paz increíble, venir de la locura a esto, nos cambió la vida. Y como es un pueblito de campo, las yerbas medicinales eran el remedio justo. Llevábamos un cajón de naranjas, manzanas, otras cosas para complementar. Teníamos una huerta y lo que no, comprábamos en el verdulero. Volvíamos vacíos. A esto lo hacíamos con mi esposa. Era lindo, como si todos los días estuviésemos de picnic, de aventura. En aquel momento se hacía algo de madera. Había plantación, cortábamos, se renovaba". (Antonio, camping).

En este tránsito de diversas actividades que la familia fue desarrollando, empezaron a vincularse con la actividad turística a través de la venta de comida en el complejo municipal.

"Con el turismo siempre estuvimos. Hacíamos pan casero para vender cuando estaba el complejo turístico municipal, que era el único que había. Llegamos a hacer 90 panes caseros por día. Hacíamos empanadas a la nochecita, había mucha gente, mucho turismo, trabajábamos todos los días. Al verano hay que aprovecharlo, tenía de 15 a 18 docenas de empanadas encargadas por día. Con el tiempo empecé a trabajar en el hospital. Ya era otra tranquilidad. Mi esposa siempre fue ama de casa". (Antonio, camping).

Esto se modificó en 1998 cuando ingresó a trabajar en el hospital. En el año 2011 deciden poner en funcionamiento un camping en la isla 9, a partir de la venta de unos lotes que comenzaron a valorizarse significativamente.

\section{D.5.4 Emergencia del turismo rural}

El turismo surge como una oportunidad cuando endicaron la isla. El entrevistado supo ver esta alternativa y avanzó con la venta de algunos terrenos.

Además, la familia estuvo vinculada con la actividad turística desde la gastronomía, actividad que siempre le gustó realizar y continúa desarrollando.

"Siempre estuve de una manera u otra ligado con el turismo. Hacíamos panes, empanadas. Cuando llegó el momento se hizo un cambio en el complejo (municipal) y ahí no dejaban vender comida. Después de varias charlas arreglé quedarme con la concesión del comedor, era lo único que había". (Antonio, camping).

\section{D.5.5 Objetivos, decisiones y estrategias puestas en marcha}

El entrevistado no menciona cambios a futuro. Como se ha mencionado anteriormente, la forma de vida que lleva la familia es tranquila, relajada, cuentan con dos viviendas, una en el pueblo y una en la isla, sus hijos ya son independientes, están en permanente contacto con la naturaleza, con los turistas que acampan allí.

Además, tienen un capital económico de resguardo. 
Ilustración 31- Esquema del sistema familia/explotación Caso 13

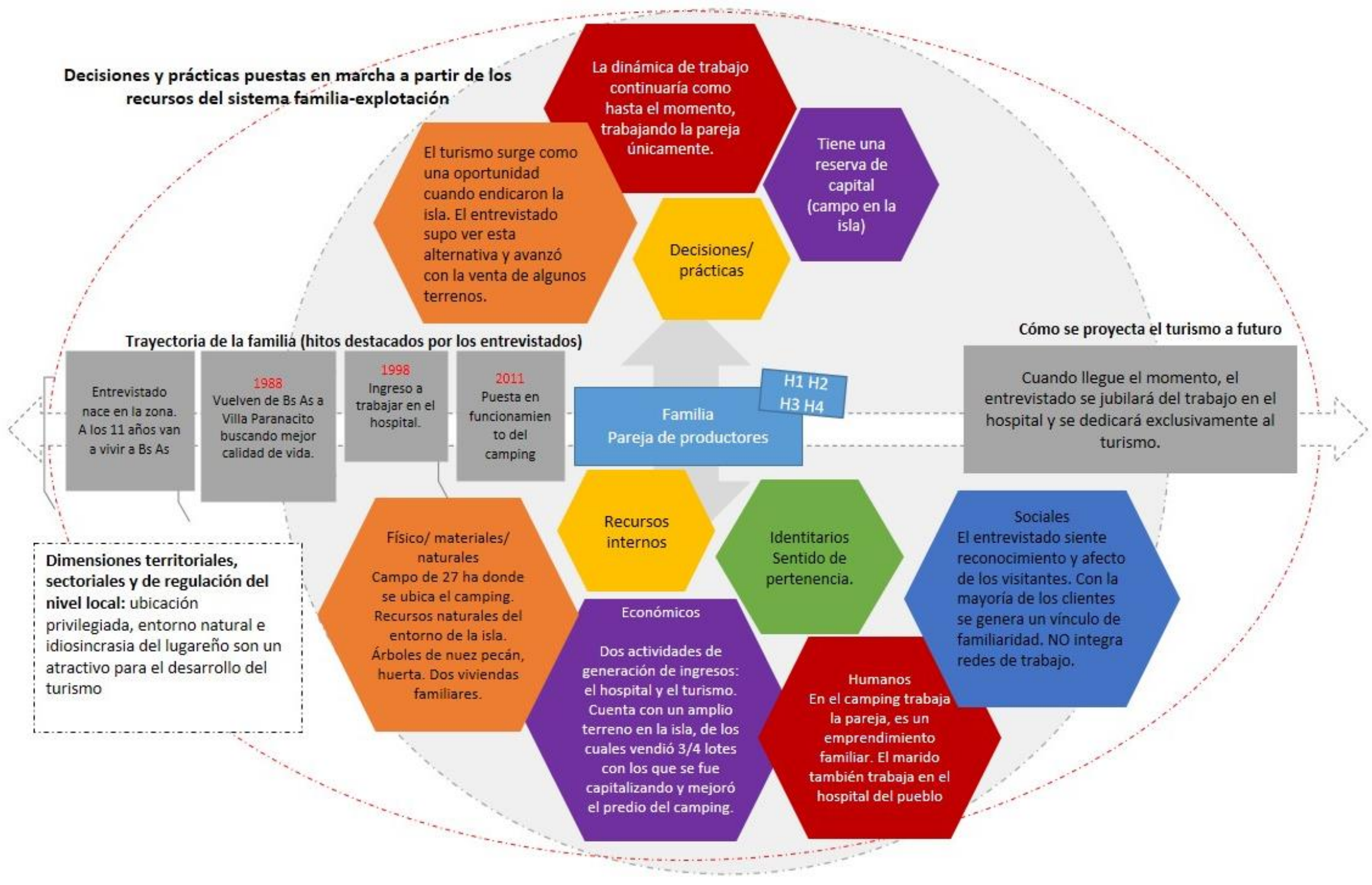




\section{D.5.6 Vinculación del sistema familia-explotación con la actividad de turismo rural $^{76}$}

\begin{tabular}{|c|c|}
\hline $\begin{array}{c}\text { Interacción producto } \\
\text { Explica el flujo de materia } \\
\text { prima de una actividad a } \\
\text { otra. }\end{array}$ & $\begin{array}{l}\text { En el camping se ofrecen menú a base de pescado que él } \\
\text { mismo pesca y su mujer cocina. También venden algo de nuez } \\
\text { pecán de los } 6 / 7 \text { árboles que tiene plantados allí y utilizan } \\
\text { productos de su huerta. }\end{array}$ \\
\hline $\begin{array}{l}\text { Interacción recursos } \\
\text { Se explica a partir de la } \\
\text { movilización de un mismo } \\
\text { recurso para varias } \\
\text { actividades. }\end{array}$ & $\begin{array}{l}\text { El recurso humano es la base de todas las actividades que } \\
\text { desarrollan, que en turismo es un "plus". El valor agregado de la } \\
\text { actividad es él, con su personalidad, su amabilidad, la forma en que } \\
\text { se relaciona con los turistas. Además el entorno en el que se ubica el } \\
\text { camping es naturaleza pura, con el río a unos pasos. El camping } \\
\text { está inmerso en la isla. Los recursos naturales son el principal } \\
\text { atractivo del lugar. }\end{array}$ \\
\hline $\begin{array}{l}\text { Interacción patrimonial } \\
\text { La implementación } \\
\text { actividades simultáneas se } \\
\text { dan en torno al valor } \\
\text { intangible de un patrimonio }\end{array}$ & $\begin{array}{l}\text { El entrevistado supo valorar y aprovechar el patrimonio paisajístico } \\
\text { y natural del lugar para hacer un espacio tranquilo que permita } \\
\text { ser disfrutado apaciblemente. }\end{array}$ \\
\hline $\begin{array}{l}\text { Interacción temporal } \\
\text { Explica los procesos de } \\
\text { anticipación de un cambio } \\
\text { que está por venir, del } \\
\text { abandono o implementación } \\
\text { de una nueva actividad }\end{array}$ & No es una interacción trascendental en el sistema. \\
\hline $\begin{array}{l}\text { Interacción ingreso/ } \\
\text { sentido del trabajo } \\
\text { La combinación de } \\
\text { actividades permite asociar } \\
\text { actividades fuertemente } \\
\text { remuneradas con actividades } \\
\text { que no son menos } \\
\text { importantes pero proveen } \\
\text { otro tipo de satisfacciones }\end{array}$ & $\begin{array}{l}\text { El turismo, además de ser una actividad que permite generar } \\
\text { ingresos, es una actividad que al entrevistado le deleita, la } \\
\text { disfruta. El mismo dice que es como un "hobbies". Complementa el } \\
\text { ingreso que realiza en el hospital. }\end{array}$ \\
\hline $\begin{array}{l}\text { Interacción ingreso } \\
\text { Se da cuando } 2 \text { o más } \\
\text { actividades aportan a los } \\
\text { ingresos totales disponibles } \\
\text { para la familia. }\end{array}$ & $\begin{array}{l}\text { Tiene dos actividades que le generan ingresos, el hospital y el } \\
\text { turismo. No mencionó el entrevistado el porcentaje de ingresos pero } \\
\text { se entiende que como empleado tiene un sueldo fijo. }\end{array}$ \\
\hline
\end{tabular}

\section{D.5.7 Impacto del turismo en el sistema productivo}

El abandono de la actividad forestal que desarrollaba la familia no se da por la irrupción del turismo sino por las condiciones del contexto en general. Lo mismo sucedió con la actividad frutícola que realizaba el padre del entrevistado, al igual que sucedió en otros casos presentados.

En este caso, el turismo funciona como un ingreso económico, que no genera complicaciones en la vida la familia y que se constituye como un canal de venta de algunos productos que la

\footnotetext{
${ }^{76}$ En el siguiente cuadro se enfatizan algunos conceptos utilizando colores que luego serán adoptados en el esquema conceptual que explica las interacciones de la actividad turística con el resto de las actividades del sistema. Así, con naranja se remarca la interacción entre productos de las distintas actividades; con rojo y azul la interacción de los recursos humanos y sociales y con naranja claro entre recursos físicos, naturales y materiales; con verde la interacción patrimonial; con gris, la temporal; con violeta claro la interacción dada entre el ingreso y el sentido dado al trabajo, y con violeta oscuro, la interacción entre los ingresos que aportan las actividades al sistema.
} 
familia elabora, como platos en base a pescado y nueces, aunque el fuerte de la actividad es el alojamiento en un entorno natural extraordinario.

\section{D.5.8 Impacto del turismo en la familia, en las personas y en sus estilos de vida}

Tienen incorporado el turismo a sus vidas. Tienen dos viviendas así que cuando se les hace tarde en el camping duermen allí, si no vuelven a sus casas.

El entrevistado recalcó el impacto en el estilo de vida que implicó dejar Bs As para instalarse en el pueblo. Más allá del esfuerzo y las diversas actividades que desempeñaron para adaptarse al lugar, al parecer nada se compara con las tareas y estrés de la vida anterior.

\section{D.5.9 Percepción del futuro en relación a los hijos y en relación a su resguardo de ingresos}

Cuando llegue el momento, el entrevistado se jubilará del trabajo en el hospital y se dedicará exclusivamente al turismo.

No se vislumbró en la entrevista si el origen del turismo tuvo que ver con una cuestión de sucesión o simplemente como algo que se dio porque vieron la posibilidad, más que la pareja siempre estuvo vinculada con la actividad.

Además el entrevistado claramente deja expuesto su amor por el pueblo y su vida allí.

"Yo no dejaría jamás Villa Paranacito. Es extraordinario. La paz, la tranquilidad..." (Antonio, camping). 


\section{identificatorios \\ Interacción \\ ingreso/sentido del trabajo \\ El turismo, además de ser una actividad que permite generar ingresos, es una actividad que al entrevistado le deleita, la disfruta. El mismo dice que es como un "hobbies".}

Las flechas del esquema central ejemplifican los tipos de interacción del sistema familiaexplotación, con sus respectivos colores

\section{Interacción de productos}

En el camping se ofrecen menú a base de pescado que él mismo pesca y su mujer cocina. También venden algo de nuez pecán de $\operatorname{los} 6 / 7$ árboles que tiene plantados alli y utilizan productos de su huerta

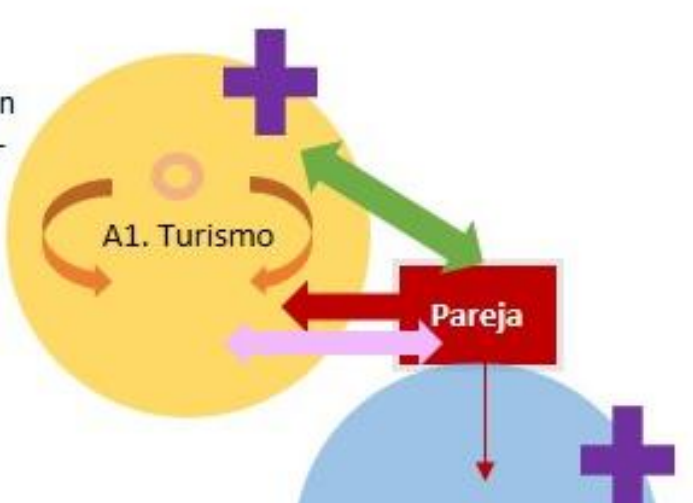

A2. Hospital

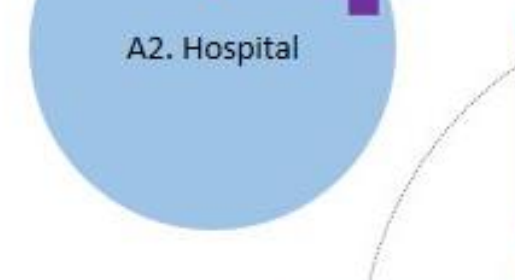

El símbolo + representa la importancia relativa del ingreso al sistema de cada actividad

Tiene dos actividades que le generan ingresos, el hospital y el turismo.

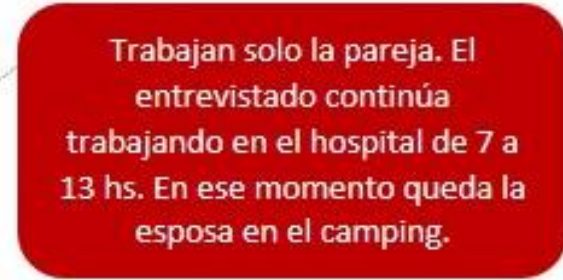

\section{Interacción patrimonial}

Valoración del patrimonio paisajístico y natural del lugar para hacer un espacio tranquilo que permita ser disfrutado apaciblemente.

\section{El camping está inmerso}

en la isla. Los recursos

naturales son el principal

atractivo del lugar.

Tipo de interacciones entre recursos.

Los colores utilizados responden al recurso movilizado

(humano, en rojo; social, en azu; espacial, física, material en naranja claro) 
Capítulo 6- Factores claves que explican la organización del turismo en las familias agropecuarias 


\subsection{Resultados generales}

Como oportunamente se ha presentado al inicio del capítulo anterior, y con motivo de introducir a la exposición de los casos, se ha mencionado concisamente el resultado del primer relevamiento para abordar el universo de análisis, es decir, la oferta de turismo rural del Corredor del río Uruguay en la provincia de Entre Ríos, que en esta investigación llamamos sistemas de actividades (SA) que incorporan la actividad turística en el espacio rural.

Al respecto, cabe mencionar que su objeto no fue la realización de un censo, sino, una forma de aproximarnos al objeto de estudio a partir de la información que referentes técnicos e institucionales, conocedores de la temática y las propuestas de turismo en los territorios, pudieron aportar.

También es trascendente explicar el porqué de las variables que se tomaron como tamices para abordar este objeto.

Al momento de realizar las primeras entrevistas de esta investigación ${ }^{77}$, emergieron inquietudes y reflexiones que consustanciaron nuevas presunciones y que motivaron las dimensiones a tener en cuenta para emprender el camino de búsqueda de elementos de comprensión y análisis.

En primer lugar, se discriminó teniendo en cuenta si la gestión de las propuestas estaban a cargo y/o gestionadas por productores agropecuarios $u$ otras personas que no se dedican a la actividad rural.

Allí encontramos que de las 130 propuestas de turismo rural en el Corredor, 48 son implementadas por productores agropecuarios, es decir un $37 \%$ del total.

De ese porcentaje de establecimientos turísticos en el espacio rural gestionados por productores agropecuarios, se diferenció a partir del tipo de productos y/o servicios turísticos brindados. Entonces se encontraron

$\checkmark$ 8 SA que ofrecen sólo alojamiento, $(16,7 \%)$

$\checkmark 9$ SA que ofrecen gastronomía, ya sea en forma de servicios y/o elaboración de alimentos para venta $(18,75 \%)$

$\checkmark 10$ SA que ofrecen actividades turísticas (recreativas, culturales, deportivas, tareas específicas rurales) $(20,9 \%)$

$\checkmark 21$ SA que combinación más de una categoría (43,75\%)

Para la siguiente variable y teniendo en cuenta que en Entre Ríos, el $72 \%$ de las EAPs utilizan mano de obra familiar ${ }^{78}$ intentamos cotejar si esta tendencia se daba en la situación de los productores que implementan propuestas turísticas.

Tal como se preveía, el $81,25 \%$ del total son productores familiares (39 casos).

Por otro lado, y como se planteó en la hipótesis central de esta investigación, se consideraba que los productores incorporan la actividad turística al SA como una estrategia para posibilitar la permanencia de los hijos en el campo, garantizando la sucesión del patrimonio. Pero también los que han llevado una vida de gran esfuerzo físico y sacrificio, ligados al tipo de actividad históricamente realizada, ven en el turismo una oportunidad para mejorar su calidad de vida, viviendo en su predio y trabajando a futuro en una actividad más "placentera". Es por ello que nos pareció interesante tener en cuenta si la familia tiene o no tiene hijos. Y si éstos intervienen

\footnotetext{
77 Las entrevistas exploratorias fueron desarrolladas en julio de 2016 junto al Director y Codirector de esta investigación, Ing. Agr. MSc .Gustavo Larrañaga y Dr. Pierre Gasselin, respectivamente.

78 Datos expuestos en el capítulo $n^{\circ} 4$.
} 
en alguna de las actividades productivas, son independientes del SA, son niños pequeños, entendiendo que esta variable además puede relacionarse con el ciclo de vida del sistema y ello arrojar elementos de análisis para comprender las estrategias y toma de decisiones de los productores, seleccionados como casos de esta investigación.

Asimismo, veíamos en las primeras entrevistas exploratorias que los productores nacidos o criados la mayor parte de su vida en la zona, le otorgan al turismo un sentido más ligado a la valorización de los recursos territoriales y de su propia historia, lo que a la vez le brinda un mayor reconocimiento/ orgullo, a partir del reconocimiento de la comunidad y del turista. Es por ello que se incluyó la variable sobre la procedencia/origen de los productores.

Aquí nos encontramos con que sólo 2 de las 48 experiencias eran originarios de otras provincias o incluso países, uno de los cuales se ha tomado como caso de estudio. Esto marca a las claras que las propuestas de turismo rural del Corredor son puestas en marcha por familias rurales locales. No se encuentran grandes empresas o personas foráneas que invierten o se interesan por generar este tipo de alternativas, lo que no quita que se de en otras modalidades de turismo a lo largo de este Corredor.

Otras de las cuestiones que emergen en el primer relevamiento en terreno fue que este sentido dado al turismo como herramienta para visibilizar los aspectos personales, familiares y también comunitarios podía verse fortalecido a partir de la integración de los productores, de las familias rurales a redes de trabajo junto a otros referentes de la comunidad. Concretamente se pensó en los grupos asociativos Cambio Rural orientados al turismo que se integraron en la zona de estudio.

En esta línea, 31 propuestas están vinculadas a estas herramientas, que representa el 64,58\%. Más adelante, en este mismo apartado, se intentará interpretar el rol de estos y su vinculación con los SA tomados como base para el análisis.

Las particularidades que presentan cada una de las tres zonas que se contemplan en el Corredor fueron explicitadas en su momento, para fundamentar la selección de casos.

A modo de síntesis se expone un gráfico con la minuciosidad del detalle de esta primera clasificación de propuestas de SA que incorporan el turismo en los espacios rurales, implementados por productores agropecuarios. 


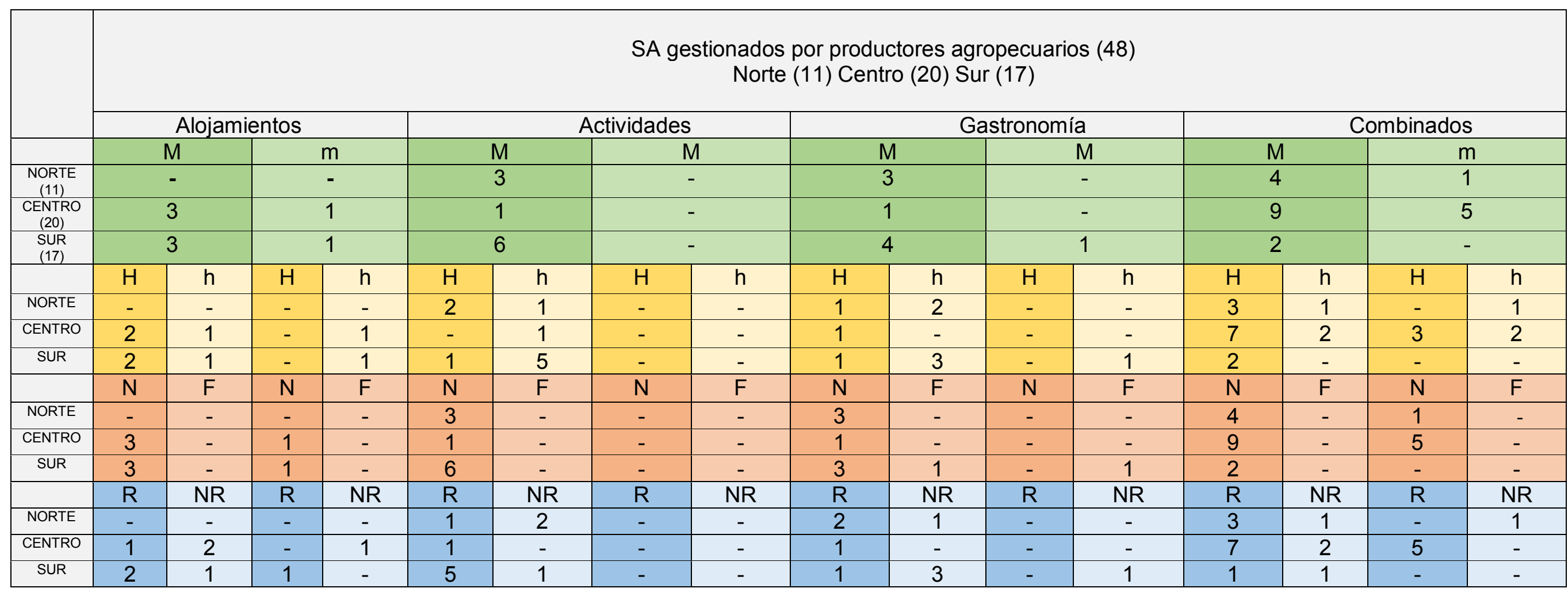

(M) con mayor mano de obra familiar

(m) con mayor cantidad de empleados

(H) con hijos dependientes del SA, que trabajan con titular/es

(h) $\sin$ hijos, con hijos independientes del SA o hijos pequeños

(N) nacidos y/o criados en la zona

(F) personas que están en la zona hace menos de 7 años

$(R)$ que integran redes de trabajo

(NR) que no integran redes de trabajo 


\subsection{Primeros hallazgos}

Comenzando con el análisis, puede observarse que la mayoría de los casos están representados por productores familiares con diverso grado de capitalización, siguiendo la definición de Piñeiro (2003).

La mano de obra es netamente familiar en cuatro de los casos, en tanto que se combina con empleados en seis casos.

La excepción a este tendencia es el caso $n^{\circ} 3$, de Chajarí, que presenta un perfil empresarial, y el $n^{\circ} 2$ y $n^{\circ} 7$ que no se dedican a la producción agropecuaria sino a otros rubros, pero que en las entrevistas han dejado entrever que parte de sus familias han estado vinculadas al trabajo en el campo.

Este aspecto es interesante de destacar porque tal como explica Craviotti (2012)

"aunque las transformaciones ocurridas a partir de los años noventa han provocado un fuerte impacto en materia de reducción de las explotaciones familiares y polarización de la estructura agraria pampeana, la organización laboral de las unidades que logran permanecer sigue siendo predominantemente familiar. En este sentido, un rasgo que destacan es que, durante los periodos clave de producción, todos los miembros participan indistintamente en los requerimientos del proceso". (Craviotti, 2012).

En los 13 casos, que incluye a productores rurales y familias locales no agropecuarias, todos son propietarios de sus tierras, y en algunos casos puntuales arriendan otros predios vecinos. Las dimensiones difieren según el grado de capitalización y la actividad productiva desarrollada.

También puede decirse que la mayoría de los sistemas familia-explotación evidencian explotaciones agropecuarias diversificadas y familias pluriactivas. Algunas de estas familias se dedican a trabajos agrarios dentro y fuera de su predio.

En tres casos, los hijos de la pareja se dedican a realizar trabajos relacionados a su formación profesional u otras actividades fuera de sus explotaciones, como el transporte de granos con camión propio, servicios de carpintería a terceros y trabajo en la municipalidad como empleada. (Caso 5, 6 y caso 9).

\begin{tabular}{|l|l|l|}
\hline \multicolumn{1}{|c|}{ Explotaciones } & $\begin{array}{l}\text { No } \\
\text { diversificadas }\end{array}$ & Diversificadas \\
\hline Monilias & $\begin{array}{l}\text { Caso 2 } \\
\text { Caso 10 } \\
\text { Caso 12 }\end{array}$ & \\
\hline $\begin{array}{l}\text { Pluariactivas } \\
\text { dentro de la } \\
\text { explotación }\end{array}$ & & $\begin{array}{l}\text { Caso 1 } \\
\text { Caso 4 } \\
\text { Caso 8 }\end{array}$ \\
\hline $\begin{array}{l}\text { Pluriactivas } \\
\text { dentro y fuera } \\
\text { de la } \\
\text { explotación }\end{array}$ & Caso 13 & $\begin{array}{l}\text { Caso 3 } \\
\text { Caso 5 } \\
\text { Caso 6 } \\
\text { Caso 9 } \\
\text { Caso 11 }\end{array}$ \\
\hline
\end{tabular}

Lo anterior responde a los aspectos que emergen de la definición pluriactividad que ofrecen Piñeiro y Cardeillac (2010). Estos autores expresan que 
"La pluriactividad es una propiedad de las familias, y no de la explotación. Se puede verificar sólo entre familias que poseen tierra. Se refiere a establecimientos de carácter familiar. Se refiere al trabajo humano, y no a otros conceptos como los ingresos". (Piñeiro y Cardeillac, 2010).

Resultan muy complejos de analizar los casos de la zona sur, ya que allí se evidencia una retracción importante de la actividad productiva que otrora fue principal (como la forestación en tres casos) o el abandono total, separándose de la actividad productiva, en los casos de ganadería y producción tambera quesera en el Uruguay y luego la pesca comercial en Argentina. Más adelante, se volverá sobre esta cuestión cuando se profundice en la interacción del turismo con el resto de las actividades.

Otro elemento tenido en cuenta para la descripción de los casos es la composición familiar y el ciclo de vida del sistema familia- explotación, adoptado de la conceptualización de en López Castro (2009) siguiendo a Bennet (1982).

\begin{tabular}{|c|c|c|c|}
\hline Caso & $\begin{array}{l}\text { Edad de } \\
\text { productores }\end{array}$ & Hijos & Fase \\
\hline 1 & $\begin{array}{l}50 \text { años } \\
\text { aprox. }\end{array}$ & $\begin{array}{l}4 \text { hijos de diversas edades } \\
\text { dependientes económicamente } \\
1 \text { activamente trabajando en la } \\
\text { unidad }\end{array}$ & $\begin{array}{l}\text { De desarrollo (en turismo) y } \\
\text { estabilidad con re desarrollo } \\
\text { por traspaso }\end{array}$ \\
\hline 2 & $\begin{array}{l}50 \text { años } \\
\text { aprox. }\end{array}$ & $\begin{array}{lll}3 & \text { hijos } & \text { dependientes } \\
\text { económicamente. } & \text { Colaboran en } \\
\text { la unidad } & \end{array}$ & De desarrollo \\
\hline 3 & $\begin{array}{l}50 \text { años } \\
\text { aprox. }\end{array}$ & $\begin{array}{l}3 \text { hijos estudiantes universitarios } \\
\text { dependientes económicamente }\end{array}$ & De desarrollo \\
\hline 4 & $\begin{array}{l}\text { Entre } 40 \quad y \\
50 \text { años }\end{array}$ & $\begin{array}{l}2 \text { hijos involucrados en la unidad, } \\
\text { dependientes económicamente. }\end{array}$ & $\begin{array}{ll}\text { De } & \text { estabilidad } \\
\text { (descendiente para re } & \text { re } \\
\text { desarrollo por traspaso } & \end{array}$ \\
\hline 5 & Más de 60 & $\begin{array}{l}3 \text { hijos, } 2 \text { independientes, } 1 \text { que } \\
\text { trabaja activamente en la unidad }\end{array}$ & $\begin{array}{l}\text { De estabilidad y re desarrollo } \\
\text { por traspaso }\end{array}$ \\
\hline 6 & Más de 50 & $\begin{array}{l}4 \text { hijos, } 2 \text { independientes, } 1 \\
\text { dependiente económicamente } \\
\text { que colabora en la unidad, } 1 \\
\text { activamente trabajando en la } \\
\text { unidad con empleo fuera del } \\
\text { predio }\end{array}$ & De desarrollo \\
\hline 7 & Más de 60 & $\begin{array}{l}3 \text { hijos, } 2 \text { independientes del } \\
\text { sistema, } 1 \text { que continúa con la } \\
\text { actividad }\end{array}$ & $\begin{array}{l}\text { De estabilidad con re- } \\
\text { desarrollo por traspaso }\end{array}$ \\
\hline 8 & $\begin{array}{l}\text { Entre } 30 y \\
40\end{array}$ & 2 hijas pequeñas en edad escolar & De desarrollo (en turismo) \\
\hline 9 & $\begin{array}{l}50 \text { años } \\
\text { aprox. }\end{array}$ & $\begin{array}{lll}4 & \text { hijos universitarios, } & 2 \\
\text { trabajando en la unidad } & \end{array}$ & $\begin{array}{l}\text { Re desarrollo por traspaso } \\
\text { en actividades productivas }\end{array}$ \\
\hline 10 & $\begin{array}{l}\text { Entre } 30 \text { y } \\
40 \text { años }\end{array}$ & $\begin{array}{l}2 \text { hijos pequeños y adolescente } \\
\text { dependientes económicamente }\end{array}$ & De establecimiento \\
\hline 11 & Más de 60 & $\begin{array}{l}3 \text { hijos, } 2 \text { independientes, } 1 \\
\text { universitario } \\
\text { económicamente }\end{array}$ & $\begin{array}{l}\text { De desarrollo (en turismo) } \\
\text { estabilidad estática en el resto } \\
\text { de las actividades }\end{array}$ \\
\hline 12 & $\begin{array}{l}\text { Entre } 40 \text { y } \\
50\end{array}$ & $\begin{array}{l}1 \quad \text { hijo } \\
\text { económicamente }\end{array}$ & $\begin{array}{l}\text { De desarrollo (en turismo) } \\
\text { estabilidad descendiente en el } \\
\text { resto de las actividades }\end{array}$ \\
\hline
\end{tabular}




\begin{tabular}{|l|l|l|l|}
\hline 13 & $\begin{array}{l}\text { De } 60 \text { años } \\
\text { aprox. }\end{array}$ & 4 hijos independientes & De estabilidad \\
\hline
\end{tabular}

Los casos circulan mayormente entre las fases de desarrollo y de estabilidad.

En las experiencias en fase de desarrollo, la expansión del sistema familia-explotación viene de la mano de la inversión en turismo. Se vislumbran sistemas en los que se da un proceso de desarrollo por traspaso en las actividades productivas, en los que la pareja de productores piensan dedicarse más a la actividad turística y los hijos al resto de las producciones.

En los casos que transitan la fase de estabilidad, en asociación a las necesidades y edad de los productores, el turismo no es una actividad de fuerte remuneración en el sistema pero provee una significativa satisfacción personal.

Respecto a los tiempos y roles, si bien las distintas tareas vinculadas al sistema se distribuyen entre los miembros de la familia (y empleados si los hubiese), lo que distingue a la atención al turista del resto de las actividades es que se considera una tarea específica de la familia, indelegable e intransferible. Además de lo anterior, esto es, que el trato al turista es dispensado exclusivamente por la familia anfitriona, puede explicitarse que en seis de los 13 casos, es una actividad más desarrollada por las mujeres de la familia.

Este aspecto, la inclusión de mujeres y jóvenes a través del turismo, ha sido resaltado en múltiples caos cuando se analiza su implicancia en el arraigo rural (Guastavino et al, 2012) y como

"complemento (...) que permite el uso de la capacidad instalada ociosa de los establecimientos, así como también la inclusión de mano de obra familiar no ocupada en la producción tradicional, principalmente la de mujeres y jóvenes". (Ferrer et al, 2013).

Frances y Méndez (2001) corroboran lo anterior señalando que en las actividades agroturísticas predomina la presencia de la mujer, tanto como gestora única o compartiendo las responsabilidades con la pareja y familia.

La introducción del turismo implica en la mayoría de los casos (en 8 de 13) una redistribución de tareas, con roles asignados. En las otras experiencias, los entrevistados han manifestado que todos saben hacer todo y que no hay tareas específicas para uno u otro integrante.

Respecto a los recursos económicos generados por el turismo, en siete experiencias significa un ingreso complementario, no siendo la actividad de mayor importancia en términos de generación de ingresos para el sistema familia-explotación. En cuatro se distribuyen entre ésta y otra actividad de importancia relativa similar, y en dos es la actividad económica central.

Estos aspectos han sido valorizados en otros territorios destacándose la diversidad de situaciones dadas:

"El propietario (...) ha visto en el turismo rural una opción para poder poner en valor su propiedad, mantenerla y conseguir unos ingresos extras a las agrícolas. En algunos casos, han abandonado la agricultura y se dedican al turismo rural como principal actividad, en otros compaginan la agricultura y el turismo". (Villarino Pérez et al, 2009).

Un hecho singular y digno de rescatar es que del total de los casos, sólo una propuesta es puesta en marcha por una familia de la cual uno de sus miembros no es nacido y criado en la localidad. Es el caso del productor tambero quesero uruguayo, luego pescador, que contrajo matrimonio con una mujer argentina, pescadora, y que decide radicarse en Villa Paranacito para continuar su vida juntos y en familia. No obstante, ella sí, nació y vivió casi toda la vida en una de las islas de la localidad. 
Esta cuestión, dada la procedencia local de todos los prestadores de propuestas de turismo en espacios rurales, guarda directa relación con el sentido de pertenencia y amor por su terruño, explícitamente expuesto por lo interlocutores en las entrevistas, que intentan dar a conocer a través del turismo. Puntualiza aquellos aspectos identitarios personales y familiares, que los definen a sí mismos y también a los otros. Sentido que es puesto en palabra y acción.

“...sentido (como significado y orientación), el discurso (que legitima y comunica) y la acción (como acción social) que materializa un cierto orden social y simbólico. Acción como actividad, como práctica, como rutina con saber hacer pero también como capacidad de proyectarse, de observarse a sí misma y modificar su desarrollo". (Bustos Cara y Haag, 2010).

Esta impronta, esta necesidad de transmitir el arraigo, la significación dada a la tierra es construida de generación en generación, y transmitida a los hijos, que colabora a pensar en la continuidad de las explotaciones, más allá del valor económico de la tierra en sí, sino desde un valor afectivo.

Como explican Grass y Hernández (2008)

"el patrimonio no se reduce a su sola dimensión económica; por medio de la tierra, el individuo logra inscribirse en la dinámica familiar: el campo se recibe de -y se entrega a - un pariente. No se trata de un mero espacio productivo: constituye también un lugar de construcción simbólica colectiva e individual. Por todo ello, estamos frente a un patrimonio económico, social y afectivo esencial que cristaliza la pertenencia a un linaje. Es un capital que entraña diferentes dimensiones, cuya articulación está ligada de manera directa en las estrategias socio-productivas elaboradas por estos productores".

El turismo es un canal para que eso que los productores hacen, han aprendido, han heredado a la vez de sus padres, pueda mostrarse, y en ese mostrarse se genere un reconocimiento.

\section{Reconocimiento que a la vez refuerza y nutre su identidad, asociado al trabajo en el} campo y la vida allí transitada.

"El trabajo de campo, el ser chacareros, sigue siendo un pilar de la identidad de las personas. Ser productor es mucho más que tener una fuente de ingresos es parte del ser de cada individuo. Lo que pareciera perder cierto peso en la construcción de esa identidad es la tierra. Si bien esta última sigue siendo muy fuerte, en aquellos productores aún activos pareciera ser más relevante la actividad que la tierra en la cual se realiza". (Muzlera Klappenbach, 2007).

En palabras de una productora entrevistada,

"Yo creo que es amor al campo, a transmitir lo que uno vivió, a transmitir una cultura porque si no a mí me ocurriría contarles a los turistas qué es lo que hacían mis abuelos. Es amor a contar lo que vivieron, lo que hicieron, valorar su sacrificio y poderlo transmitir, como me gusta escuchar las historias de otras culturas, de otras familias (...) Creo que es amor al campo y a la zona, recordar lo que ellos hicieron. $A$ veces uno no mira el pasado, pero lo tenemos siempre presente. Lo que hacían los abuelos es lo que hoy podemos contar y ver el sacrifico que tuvieron. Si hoy no lo seguimos contando no nos vamos a acordar...". Parece que llega un momento de la vida en que uno hace un click para acordarse de lo que hicieron los abuelos, los padres, uno recuerda dentro de la infancia cómo era de sacrificado y la falta de tecnología". (Carmen, productora y responsable de alojamiento rural).

El hecho de poner en valor las referencias identitarias, hacia dentro, y pensando en el turismo, no sólo permite capitalizar el ingreso de divisas de la actividad turística, sino que fortalece la imagen que las comunidades poseen de sí mismas, de su historia, cultura, idiosincrasia, recursos naturales, patrimonio rural, intangible, posibilitando sostener y promover la visibilización de un territorio vivo, con sentido, "como espacio de reencuentro del hombre con los lazos comunitarios y como sustento de la identidad y la cultura no uniformizada" (Sili, 2010) ponderando el saber local, lo auténtico y lo identitario (Nogar y Capristo, 2010) frente a un contexto global que tiende a la homogeneización. 
Este anclaje territorial se ve fortalecido por la participación en redes sociales y de trabajo asociativo junto a otras familias rurales de la zona. A través de éstas circula información (técnica, sectorial, de interés común para los miembros), se generan instancias de capacitación y formación, se construyen lazos de confianza y se promueven diversos espacios para el trabajo asociativo, que posibilita la puesta en marcha de proyectos colectivos y espacios de intercambio para el aprendizaje a partir de la puesta en común de los logros y también dificultades de las experiencias vividas, lo que fortalece el capital social y cultural a nivel particular de cada familia pero también a nivel grupal y comunitario. (Piñeiro, 2003, 2004; Craviotti y Palacios, 2012).

En este sentido, el turismo rural

"propicia el fortalecimiento del entramado socioinstitucional, sobre todo porque se fomenta la participación social y la construcción de un proyecto colectivo en el cual es clave la cooperación entre los distintos actores presentes en el territorio". (Guastavino et al, 2012)

Uno de los entrevistados, recalca las fortalezas de estos procesos de construcción y trabajo colectivo:

"Comenzamos con el INTA, con el apoyo de ellos y la información dentro. Fue la principal ayuda e información. Ahí surgió el turismo rural, las reuniones, las enseñanzas y las propuestas y el estudio del lugar. Eso fue lo más importante que si no no estaríamos... Dentro del rubro se trata de ir a las reuniones, de vincularse, de tener experiencias de qué es lo que hace uno y qué es lo que hace el otro, como ser ahora incorporar los dulces de una chica vecina que se los vende en el alojamiento, ella está muy contenta y a nosotros también nos sirve. Después están todos lo que son los productos de la zona también. Creo que es importante dentro de la zona". (Roberto, productor y responsable de alojamiento rural).

\subsection{Objetivos y motivaciones en torno a la actividad turística en las familias agropecuarias}

Lo mencionado en los capítulos anteriores, muestra que los productores rurales interesados en diversificar sus explotaciones a través del turismo, poseen un grado de capitalización que les ha permitido reinvertir en su propio predio pero apostando a la actividad turística.

Ahora bien, no todos los productores familiares capitalizados de la costa del río Uruguay son a su vez prestadores de servicios turísticos en el espacio rural. ¿Qué elementos distinguen a estas familias? ¿Qué los ha motivado a integrar el turismo a sus sistemas familia-explotación?

Puede decirse que existen dos elementos muy marcados que confluyen en la incursión o puesta en marcha del turismo por parte de las familias entrerrianas que se tomaron como casos a analizar. En primer lugar, en algunos casos se asocia a situaciones críticas que movilizan la necesidad de generar cambios al interior del sistema familia- explotación.

Estas crisis pueden estar relacionadas a circunstancias internas (como el fallecimiento de un miembro de la familia, la disociación de una sociedad de trabajo familiar, desgaste físico muy importante debido al trabajo realizado y a los años de dedicación) u obedece a situaciones vinculadas a aspectos del entorno que condicionan y determinan las actividades productivas del sistema, por ejemplo, la caída de las otras actividades dada las dinámicas propias de éstas, la baja en el precio de la materia prima (madera, leche, pescado) o inclemencias climáticas, como inundaciones recurrentes o periodos de sequía, que influyen en la búsqueda de alternativas productivas que colaboren a la estabilidad del sistema.

"Nosotros ya tenemos 50 y pico y el trabajo de la huerta no es para viejos, esto es más para nuestro futuro (...) Pensamos que estamos envejeciendo y teníamos que tener algo un poco más aliviado, un poco más liviano. Pero como siempre se trabajó en familia, uno lo piensa para todos porque también si ellos se quedan a trabajar acá, bueno, ahí tenés dos cosas". (Analía Huerta Chajarí). 
Por otro lado, se ha notado que convergen aspectos asociados a la valorización de recursos y dinámicas territoriales que se visualizan como oportunidades para el desarrollo del turismo.

En este punto se destacan la ubicación estratégica de las establecimientos y de las localidades donde éstos se emplazan, muy próximos a la provincia de Buenos Aires con una conexión vía terrestre sumamente ágil; la existencia de un movimiento turístico que elige los destinos de las zonas que se han presentado, esto es en el norte Federación y Chajarí, en el centro la microrregión Tierra de Palmares, y en el sur la localidad deltaica de Villa Paranacito. Además, la existencia de recursos naturales y paisajísticos y atractivos de jerarquía que motivan los viajes de miles de visitantes anualmente, como los complejos termales, el Parque Nacional El Palmar, o monumentos históricos destacados como el Palacio de Justo José de Urquiza o el Molino Forclaz, entre otros. A esto se suma el patrimonio cultural e histórico de cada propuesta en particular, que es puesto en valor a través de la implementación de las propuestas turísticas en los espacios rurales. Esto se puede ver en los casos donde una casona antigua, un casco de estancia, almacenes de ramos generales de más de 100 años se constituyen en la esencia y fundamento de sendas ofertas.

En algunos casos, la existencia de este patrimonio familiar, heredado o adquirido, y la necesidad de conservar y resguardar estos inmuebles, dado su valor arquitectónico, históricocultural y también afectivo, es una de las principales motivaciones que han llevado a las familias a incursionar en el turismo. Quizás el ingreso que genere la actividad turística no es suficiente y por ello es una alternativa a las que ya vienen realizando, pero sí colabora a este objetivo, que es determinante para el funcionamiento equilibrado del sistema.

"Yo creo que la estancia sin el proyecto de turismo en el tiempo no tiene sustento porque es real, esto se va agravando más el costo de estructura y nosotros lo que al menos pretendemos es ir arreglando de a poco y que se pague con el mismo valor, sino estás permanentemente subsidiando un elefante blanco que algún día te voltea" (Carlos, dueño de la estancia).

"Empezamos a valorar el almacén, a darnos cuenta que no había otro, a mirar con otros ojos qué era lo que teníamos". (Irma, dueña almacén de ramos generales).

Asimismo se evidencia un movimiento de valorización de aquellos recursos intangibles, asociados a la historia de la familia, la historia de las colonias, de las comunidades, representadas en objetos, lugares o anécdotas, historias, cuentos o relatos, que rememoran del pasado aquellas costumbres y prácticas culturales relacionadas con la vida cotidiana, los saberes culinarios, el trabajo y los quehaceres, que quizás si no fuera por la palabra del que los recuerda y exhibe, quedarían subrepticios y olvidados en la remembranza de solo quien los puede recordar.

"A través del turismo empecé a conocer la historia del lugar, de mi papá. Antes no conocía mucho de la familia, no me había metido. A partir del turismo empecé a conocer quienes estaban acá, quiénes allá. Todo ese movimiento de la historia no la conocía". (Pedro, hijo, almacén Chajarí).

Y son éstos, las costumbres, los conocimientos locales, los recursos naturales y paisajísticos que revalorizan "lo cotidiano" del campo y se convierten en objeto de consumo (Nogar, 2008), en los elementos más valorados por el turista, en general habitantes del medio urbano que comienzan a trasladarse hacia los espacios rurales. Y así,

"...el disfrute vacacional, las salidas de observación de la naturaleza, las excursiones de índole culturalrural o histórico-rural, la práctica de deportes-aventura, la organización de degustaciones culinarias en lugares tradicionales del medio rural y un largo etcétera son expresiones del consumo de lo rural". (Nogar, 2008).

Crisis y oportunidad, son entonces como caras de la misma moneda, que pueden converger en las motivaciones que llevan a pensar en el turismo como una alternativa viable para estas familias rurales. 
En algunos casos, surge como una actividad complementaria, ya que el tiempo que se le brinda es menor al resto de las actividades, decisión que impacta en el nivel de ingreso total que esta aporta, que es relativamente menor a las actividades centrales. Pero también se evidencian experiencias en las que las motivaciones giran en torno a objetivos económicos y el turismo rural aparece asociado a una visión de negocio a futuro, a una estrategia de dispersión de riesgo para el productor rural, en el marco de un contexto de incertidumbre y reglas de juego cambiantes para las actividades agropecuarias que propician una alta inestabilidad en el sector.

A lo anterior se suma que desde la génesis, en muchos de los casos, existe una idea de proyecto familiar en el que el turismo se piensa como una alternativa de futuro tanto para los productores y productoras como para sus hijos. El turismo se concibe como una actividad menos desgastante físicamente, más entretenida, que permite continuar viviendo en el campo pero con mayor contacto y vinculación, elemento que se ha expuesto como determinante por muchos entrevistados. Esto se evidencia fundamentalmente en aquellos productores que han llevado una vida de gran esfuerzo físico y sacrificio, ligados al tipo de actividad históricamente realizada, que ven en el turismo una oportunidad para mejorar su calidad de vida, viviendo en su predio y trabajando a futuro en una actividad más "placentera".

El turismo aporta entonces

“...más bienestar a la salud de uno. Nosotros que ya tenemos varios años de tambo, el turismo es algo más tranquilo, más liviano. Mi marido ya está cansado de madrugadas, de lluvias, de frío... con esto (el turismo) te guardás más en la casa para preparar las cosas para el fin de semana". (Ana, productora zona centro).

Es importante mencionar también la tracción hacia la actividad que han promovido determinadas herramientas de política pública como la formación de los grupos Cambio Rural de turismo y la decisión política de los municipios en acompañar este tipo de alternativas. Ambos elementos, de la dimensión pública y del quehacer de las instituciones del estado, han sido impulsores de la actividad y han motivado a familias, que ya venían vislumbrando el movimiento turístico en la zona, pero que no creían en la capacidad de encanto de sus espacios y vidas en el campo para el turismo. Puede decirse que la labor de los técnicos y funcionarios de las oficinas de turismo de los municipios locales y la organización y trabajo asociativo de los grupos cambio rural vinculados a INTA han sido basales para la movilización y fortalecimiento de los capitales cultural y social entre sus miembros y han colaborado en el autoreconocimiento y en los procesos de valorización de los recursos y disposiciones particulares de cada familia, y de los elementos del territorio susceptibles de ser puestos en valor.

\subsection{Sobre las decisiones, las estrategias y las prácticas}

Una de las cuestiones que primeramente sale a la luz del análisis de las estrategias y decisiones puestas en marcha por las familias rurales es que la lógica de poner en práctica y combinar diferentes tipos de actividad en el interior de sus unidades productivas, no siempre responde o a está asociado a la maximización de las ganancias. Tratan de dar solución a sus problemas y necesidades organizando sus recursos dentro de los límites que enfrentan (Craviotti y Palacios, 2012). La generación de ingresos es trascendente pero no es el único objetivo.

En general tienen un manejo de caja única, donde

"... todo es una cadena (...) Es toda una cadena de inversiones, tal vez uno no lo ve, lo trae de otro lado, después lo va recuperando lentamente y no es un libro, una contabilidad exacta". (Carmen, productora y responsable de alojamiento rural).

"No hay una cuenta exacta porque la luz por ejemplo que es uno de los gastos principales está todo junto". (Analía Huerta Chajarí). 
Como explica Muzlera Klappenbach (2007),

"Es de destacar como rasgo distintivo de la empresa familiar que las cuentas de donde sale el dinero es común. Las inversiones y los gastos de la familia salen de la misma cuenta y unas se deciden en función de la otra. No hay un \% de dinero que previamente se destine a la familia y otro a la explotación, ni ningún otro mecanismo por medio del cual se decida cuánto dinero se destina a cada espacio. Tal vez, desde lo material, esta sea la característica más indiscutible de que estas empresas siguen siendo familiares, la imbricación de las esferas de producción con la de reproducción doméstica". (Muzlera Klappenbach, 2007).

En algunos casos, sí, la combinación de actividades es fundamental para garantizar la calidad de vida de la familia y a la vez generar ganancias para seguir invirtiendo en capital patrimonial. En otros casos, permite que la pareja pueda dedicarse a las actividades que más les agrada, distribuyendo sus tiempos y tareas en este sentido. Estas relaciones se evidencian en la interacción ingresos y en la interacción ingresos/sentido del trabajo analizadas en cada uno de los casos.

En todas las experiencias, se vislumbra que el turismo es una actividad que agrada realizarse y que aporta satisfacciones personales que se convierten en concluyentes para continuar con la actividad. Reconocimiento social por las tareas desarrolladas, mayor apertura a nuevas experiencias y desafíos, mayor calidad de vida asociada a la salud, disfrute, contacto con otras culturas y personas son los aspectos más destacados en este sentido por los entrevistados.

En los casos 1, 3, 4 y 8, la actividad turística posibilita procesos de agregado de valor de la producción primaria, siendo un canal para la venta y comercialización de productos artesanales, elaborados por la familia, que se incorporan a los servicios brindados, y que colaboran con la autonomía y sustentabilidad del sistema.

En los casos en los que la propuesta turística se basa esencialmente en la existencia de construcciones de valor histórico-cultural como los almacenes antiguos de campo, el casco de estancia y la casona rural, el turismo es una herramienta que no sólo pone en valor el patrimonio en sí sino que también favorece a su conservación y mantenimiento, a partir de los ingresos que pudiera generar que colabora con los altos gastos de mantención (interacción patrimonial), entendiéndose que forma parte de una estrategia global implementada por la familia, que a la vez se dedica a otro tipo de actividades.

Otra cuestión interesante de mencionarse en este apartado, y fuertemente relacionada con las decisiones puestas en marcha es la vinculada a las estrategias relacionadas a las interacciones temporales entre las diversas actividades. En algunos casos, el turismo surge como complemento a la actividad productiva principal en ciclos de baja producción, esto se da por ejemplo en la experiencia de la familia hortícola, que en momentos donde baja la venta de su producción se dedican más a la prestación turística y de esta manera equilibran sus ingresos.

En muchos de los casos se evidencia una apuesta al turismo en el marco de una estrategia a largo plazo, una estrategia a futuro o de anticipación a determinados períodos del ciclo de vida de la familia-explotación, por ejemplo, el momento en que los hijos abandonan la casa para estudiar, a la edad de los productores, su cansancio y desgaste, a que se convierta en el principal ingreso en forma de jubilación a la hora de abandonar o dejar en mano de los hijos las actividades del campo.

En virtud de lo anterior, y en relación a los proyectos implementados por las familias, vemos que en algunos casos, existe una inyección de inversiones apuntalando la actividad turística que ha provenido o proviene del resto de las actividades, que se entiende si se contempla el funcionamiento del sistema y los objetivos de la familia en términos integrales, esto es, su apuesta como alternativa a futuro. 
La idea presente en la mayoría de los sistemas es no abandonar ninguna actividad, pudiendo dejar algunas en manos de los hijos y la pareja dedicarse de pleno a la actividad turística $o$ también dejar las bases de las propuestas turísticas para su continuidad en manos de los hijos que se profesionalizan en esta rama.

Muchos de los entrevistados lo plantean en términos de proyecto familiar:

"Todo es para ellos en definitiva". (Analía Huerta Chajarí).

"Ellos sabrán el día de mañana si lo van a seguir o no. Techo no tiene esto, se podría ir ampliando con bungalows, con pileta, con más paseos, con más parques". (Eduardo, productor zona centro).

"Posiblemente (el hijo) es el que tome las riendas dentro de un tiempo. Ya se lo va consultando, tira ideas nuevas". (Jorge, productor y dueño almacén de ramos generales).

Tal como explicita López Castro (2009)

"más allá de la fase por la que atraviesan actualmente las familias, todos coinciden en el deseo de que la unidad se transmita a las generaciones más jóvenes y que "todo quede en familia" (...) En este sentido, la relación que se establece entre padres e hijos, la comunicación y el grado de participación real que los más jóvenes tienen efectivamente en la toma de decisiones y en las actividades dentro y fuera de las explotaciones juegan un papel fundamental en la forma en que se organizan las estrategias productivas y se proyecta la sucesión". (López Castro, 2009).

\subsection{Variaciones en la relación de los sistemas familia-explotación con su entorno}

Como se ha venido comentando, los diferentes componentes de lo que configura el contexto de cada sistema, se materializan y dinamizan de forma particular en cada una de las zonas que conforman el territorio de análisis de esta investigación.

La dimensión sectorial específica referida al turismo y sus aspectos regulatorios, las instituciones que integran el sector, las decisiones y definiciones políticas de los gobiernos locales, los instrumentos de política pública llevadas al terreno, el perfil y capacidad de trabajo de los técnicos y funcionarios, la dinámica del sistema en sí, varían según el momento histórico y también según la mirada y opinión de quien los contempla.

En la zona norte, por ejemplo, salvo el caso de la familia de perfil empresarial que pone en valor su vivienda en un casco de estancia restaurada al turismo, cuyas vinculaciones técnicas y referenciales se dan más por el resto de las actividades productivas que por la turística, en los dos casos restantes el impulso dado por la integración de grupos asociativos de trabajo en turismo rural vinculados a Cambio Rural e INTA y el compromiso de acompañamiento asumido y manifiesto por el Municipio local, han sido decisivos para la puesta en marcha de las experiencias turísticas en cuestión.

En palabras de un entrevistado, "a través del grupo de INTA empezamos a aprender de turismo". (Eduardo, productor zona centro).

A partir de estos espacios, fundamentalmente las familias han podido compartir sus aprendizajes y procesos en torno a una actividad nueva para ellos, como fue el turismo. Aprender, compartir, participar de instancias de promoción y comercialización grupales, iniciar sus propias acciones de promoción, acciones que han favorecido, según los mismos entrevistados, a la puesta en marcha y a la mejora de las propuestas turísticas de cada uno de los integrantes. 
Además, es claro por ejemplo en el caso de los productores familiares hortícolas que han sabido aprovechar su red social, de contactos comerciales provenientes de su actividad central, para dar a conocer su emprendimiento turístico, que es recomendado por vecinos y locales.

Procesos similares se dieron con los entrevistados de la zona centro, quienes manifiestan que el acompañamiento técnico y también anímico de los técnicos de las oficinas de turismo de sus municipios locales, se convirtió en fundamental para la implementación de la actividad turística en sus predios.

No se destacan estos procesos en zona sur, en donde por el contrarios, las familias entrevistadas han sido críticas con el sector turístico en su comunidad y con el rol del municipio como dinamizador de la actividad. Puntualmente en Villa Paranacito, a pesar de la larga trayectoria en turismo, que los mismos entrevistados han narrado y contado cómo se desarrolló la zona del delta con los primeros hoteles de lujo y pensiones para viajeros, los prestadores turísticos privados no han conformado una cámara que los nuclee o entes de carácter mixto o asociaciones de alojamientos. Pareciera que es más dificultoso el trabajo mancomunado o asociativo. La entidad con más años de existencia y trabajo es la cooperativa local, que hasta el día de hoy funciona y va abriendo sus puertas a nuevas actividades productivas como la de la nuez pecán, y a partir de esta, una nueva asociación al turismo.

No obstante las diferentes modalidades en que los sistemas familia-explotación se vinculan a sus entornos sectoriales particulares, a las organizaciones que lo integran, a las regulaciones establecidas, a sus territorios, a cómo ponen en valor aquellos aspectos de sus propias realidades, de su historia personal, familiar y comunitaria, y cómo movilizan los recursos de sus territorios para darle visibilización a través de las propuestas concretas y a través de la palabra, lo que atraviesa como eje en común a la totalidad de los casos, es que el turismo, como actividad que se introduce, comienza a permutar la forma en que las personas se fundan y construyen sus lazos con los otros.

El turismo como fenómeno social implica la mirada de otro. La presencia de visitantes provenientes de otros lugares, con otras formas de vida o rasgos socioculturales, que eligen un emprendimiento ubicado en el campo, que eligen conocer y aprender, de la mano de sus anfitriones, cómo se llevan adelante las diferentes tareas rurales, y hasta compartir el momento en que desarrollan sus actividades, permite acercar realidades diferentes y en esta proximidad colabora a reforzar la imagen que las familias rurales tienen de sí mismas, de su trabajo y de su realidad. Este reconocimiento, puesto en palabras de agradecimiento o de valorización de lo que las familias rurales realizan, por parte de los turistas, constituye un aliciente nuevo, que antes del turismo no existía y que a los anfitriones, genera una importante satisfacción. Satisfacción que proviene de esta mezcla de ideas y sensaciones relacionadas a que "la gente se encariñe con el lugar y vea nuestra forma de ser" como expresaba uno de los anfitriones.

Esta construcción de vínculos y de lazos con personas y familias que no son de sus comunidades, el hecho de abrir las tranqueras de sus chacras o campos, el poder compartir sus propias experiencias y brindarse a otro, es también abrirse a las críticas. Pero en este intercambio contribuye a reforzar la idea de sí mismos, su propia identidad.

Seguramente la experiencia es enriquecedora desde este punto de vista también para el visitante, pero no es el objetivo de esta investigación profundizar en este aspecto.

Sí creemos oportuno destacar que el turismo puede ser comprendido como una herramienta de valorización de los recursos particulares y de cada territorio, por parte de oferentes y visitantes; que en esta puesta en valor para el disfrute de otros, también moviliza y robustece la imagen que las familias tienen de su historia, de su patrimonio, de su idiosincrasia y de sus propios terruños; que el turismo es un fenómeno sociocultural que propicia el intercambio genuino de cosmovisiones y pautas culturales, y que en este intercambio se enaltece tanto lo de uno como lo ajeno, que colabora a ampliar los horizontes y búsquedas personales de las 
familias rurales, aportando otros elementos a su vida diaria y a la construcción de sí mismos y a la forma en que se comunican y se brindan a otros.

O en términos de Bustos Cara y Haag (2010)

"se ha constituido en un vector importante de legitimación de acciones e intervenciones patrimoniales y territoriales. En muchos aspectos la forma en que el turismo y particularmente el turismo rural se plantea, recurre a procesos de patrimonialización y anclaje territorial de productos y servicios". (Bustos Cara y Haag, 2010).

\subsection{Las interacciones del sistema de actividades turísticas y agropecuarias}

Intentando aproximarnos a la pregunta central que motivó esta investigación y tal como se ha pretendido plasmar a lo largo del capítulo $n^{\circ} 5$, cada uno de los sistemas de actividades tomados como casos en este trabajo, presentan singularidades que los hacen únicos. Y en estos aspectos radica su riqueza explicativa para aproximar respuestas a la pregunta de esta investigación. No obstante, el esfuerzo de este apartado es intentar elaborar patrones comunes en la trayectoria de estas experiencias que nos permitan comprender de qué forma la actividad turística se relaciona con el resto de las actividades del sistema.

A pesar de que las unidades sociales son complejas y diversas, es posible identificar características comunes en los modos en los que la actividad turística se entrecruza, interactúa, se integra con el resto de las actividades productivas de generación de ingreso de los casos estudiados.

Y en este sentido, una de las primeras cuestiones que interesa profundizar es si el turismo se integra al resto de las actividades desde el punto de vista de la interacción de los productos de éstas, lo que en el marco conceptual expuesto se denomina interacción producto.

Aquí vemos que algunos establecimientos que se abocan al turismo utilizan parte de su producción primaria como insumo para generar nuevos servicios en su predio, lo que agrega valor a la producción, es decir, que hay una integración entre la producción productiva y la actividad turística. En el otro extremo, encontramos casos en los que la actividad turística no guarda ninguna relación con la actividad productiva, esto es, se desarrolla en otro espacio, aprovechando las características naturales o edilicias del mismo, pero no se integran los productos de la producción primaria a los servicios brindados. Entre uno y otro esquema de integración se visualizan grados de integración diversos, en los que el turismo y las actividades productivas de base comparten el mismo espacio de realización, poniéndose en valor los recursos patrimoniales territoriales.

Otro elemento que se suma a lo anterior es que en la mayoría de los casos, la vivienda familiar se emplaza en el mismo predio en el que se realizan las actividades productivas y turísticas.

En un esfuerzo de síntesis, en el siguiente cuadro se pretende establecer las simetrías entre los casos:

\begin{tabular}{|c|c|c|c|}
\hline $\begin{array}{l}\text { Sistemas de } \\
\text { actividades con } \\
\text { alta integración } \\
\text { del turismo }\end{array}$ & $\begin{array}{l}\text { Sistemas de } \\
\text { actividades con } \\
\text { integración media del } \\
\text { turismo }\end{array}$ & $\begin{array}{l}\text { Sistemas de } \\
\text { actividades con } \\
\text { integración baja el } \\
\text { turismo }\end{array}$ & $\begin{array}{l}\text { Sistemas de actividades } \\
\text { sin integración del } \\
\text { turismo }\end{array}$ \\
\hline $\begin{array}{l}\text { El turismo se } \\
\text { desarrolla en el } \\
\text { mismo espacio } \\
\text { donde se realizan } \\
\text { las otras } \\
\text { actividades. }\end{array}$ & $\begin{array}{l}\text { Integración desde lo } \\
\text { espacial, es decir, el } \\
\text { turismo se desarrolla en } \\
\text { el mismo espacio } \\
\text { donde se realizan las } \\
\text { otras actividades. La } \\
\text { actividad principal es la } \\
\text { base del turismo pero }\end{array}$ & $\begin{array}{l}\text { Integración desde lo } \\
\text { espacial, es decir, el } \\
\text { turismo se desarrolla } \\
\text { en el mismo espacio } \\
\text { donde se realizan las } \\
\text { otras actividades. } \\
\text { Se ponen en valor el } \\
\text { patrimonio natural y }\end{array}$ & $\begin{array}{l}\text { No hay integración espacial } \\
\text { ni funcional. El turismo } \\
\text { puede ser una inversión de } \\
\text { la familia que no interfiere } \\
\text { con el resto de las } \\
\text { actividades. }\end{array}$ \\
\hline
\end{tabular}




\begin{tabular}{|l|l|l|l|}
\hline $\begin{array}{l}\text { Integración de la } \\
\text { actividad productiva } \\
\text { y turística. }\end{array}$ & $\begin{array}{l}\text { no hay integración de } \\
\text { productos. Producción y } \\
\text { patrimonio (tangible e } \\
\text { Producción base del } \\
\text { intangible) base del } \\
\text { turismo. Procesos } \\
\text { de agregado de } \\
\text { valor de la } \\
\text { producción primaria. }\end{array}$ & $\begin{array}{l}\text { cultural de la zona y } \\
\text { del predio. } \\
\text { No hay integración de } \\
\text { productos. } \\
\text { producción primaria } \\
\text { para el turismo. }\end{array}$ & $\begin{array}{l}\text { Se ponen en } \\
\text { patrimonio natural y cultural } \\
\text { de la zona y del predio. }\end{array}$ \\
\hline Casos $n^{\circ} 1,3,4,8,9$ & Casos $n^{\circ} 2,5$ & Caso $n^{\circ} 6$ & \\
\hline
\end{tabular}

Respecto a la movilización de los recursos dentro de sistemas con alta interacción entre turismo y el resto de las actividades, se puede observar que:

- El turismo no reemplaza la actividad principal del sistema sino que le otorga más valor a ésta. Agrega valor a la producción primaria por ejemplo en la cosecha de producción hortícola aprovechada como atractivo para los turistas, productos de la huerta, carne bovina y ovina como elementos centrales gastronómicos del casco de estancia puesto en valor; la producción tambera como central del atractivo a lo que se suman propuestas gastronómicas elaboradas por la familia a partir de su propia producción (ganadera, tambera, huerta y granja); producción de quesos y salames como base de la gastronomía de una granja en la que se suma el elemento histórico como esencial; productos derivados de la madera de producción propia, insumos para la construcción de muebles, decks y demás elementos del complejo turístico.

- Se pueden dar casos en los que el turismo ha desplazado la actividad productiva principal en términos del tiempo dedicado a una u otra actividad. Pero esta situación puede estar dada por elementos del contexto que limitan el desarrollo de algunas actividades económicas y productivas (como la producción tambera a partir de la caída en el precio de la leche, o la forestal con la baja de la venta de la madera). Esta retracción de las actividades que han sido basales para el desarrollo del sistema condiciona la necesidad de generar otras estrategias y otras alternativas para garantizar los ingresos necesarios para la producción y reproducción del sistema familiaexplotación.

- El turismo colabora a diversificar los ingresos y dispersar los riesgos. Aporta mayor apertura personal y cultural, espacios de intercambios y contactos sociales.

- La actividad turística puede aportar complejidad desde el punto de vista de la redistribución de las tareas en el caso de los emprendimientos netamente familiares porque se suma como una actividad más en la que hay que pensar para redistribuir los tiempos. Puede generar momentos de tensión o nervios en la familia cuando se ajustan los tiempos en temporadas de mayor afluencia turística. Esto puede ser más o menos tolerable para la familia e incluso incorporar el turismo de una manera muy natural a sus rutinas. También puede impactar sobre los tiempos de ocio, ya que se evidencian casos en los que la familia decide suspender viajes familiares o momentos de encuentros que antes realizaban, fundamentalmente los que están en los primeros años de trabajo en turismo. Los proyectos turísticos más consolidados por el contrario, se plantean estrategias para recuperar el tiempo de disfrute familiar.

En sistemas de actividades con integración media (y de media a baja), se ha advertido que:

- El turismo no genera una importante interdependencia con el resto de las actividades productivas. No modifica el resto de las actividades del sistema. No hay competencia por el uso de los recursos.

\footnotetext{
${ }^{79}$ En este caso se contempla la actividad ganadera que se desarrollaba en otro predio diferente adonde se ubica el hotel.
} 
- Genera ingresos complementarios a la familia, colaboran con la conservación del patrimonio familiar y mantenimiento de las construcciones históricas en las que se sustenta la actividad turística.

- La puesta en marcha de las propuestas turísticas se basa fundamentalmente en el patrimonio arquitectónico o histórico-cultural familiar, más que en las tareas o actividades productivas que la familia desarrolla.

- En dos de los tres casos, es la mujer de la familia la más dedicada al turismo.

- Según el grado de integración de las actividades puede o no generar un impacto importante o grandes modificaciones en la rutina de las tareas familiares implicando una mayor organización para cumplimentar con todas las actividades, pudiendo afectar o no los tiempos de ocio de los miembros de la familia.

En los sistemas con baja integración de las actividades se presentan dos tipos de situaciones:

- una en la que el turismo es una inversión familiar y es una actividad a la que la familia se dedica cuando no se ocupa de su actividad principal, es decir, es una tarea extra, y no hay competencia ya que el turismo se moviliza fundamentalmente los fines de semana. Se realiza en otro predio, en un espacio rural que no es trabajado productivamente por la misma familia sino que se arrienda. Si bien no se generan momentos de gran tensión por los tiempos o las tareas a desarrollar sí existe una preocupación por la atención al turista, su bienestar, por el estado de los caminos, entre otras cuestiones que marcan una atención de parte de la familia.

- Por otro lado, se comprueba que en otros sistemas, existe una baja integración porque el turismo fue desplazando el resto de las actividades productivas. Estas decisiones particulares de cada familia están sujetas a múltiples variables, en las que influyen fuertemente las condiciones del entorno. Los tres casos que responden a este tipo de situación, se sitúan en la zona sur del corredor del Uruguay, en el corazón del delta entrerriano. Allí se ha advertido que las frecuentes crecidas de los ríos e inundaciones pueden afectar durante meses la vida cotidiana de las familias y las actividades que éstas desarrollan. Una de las explicaciones por las cuales los productores han abandonado su actividad productiva (ganadería en islas, pesca comercial, actividad forestal) puede estar relacionada con estos fenómenos y con la caída generalizada de las actividades. No obstante, juegan otras motivaciones tanto personales como familiares que instauran las decisiones a tomar.

- En estos casos se advierte que el turismo genera un reacomodamiento de tiempos y roles, marca una rutina diferente pero aporta una mejora en la calidad de vida y aporta tranquilidad en términos de ingresos generales más estables.

Para finalizar esta sección, se presenta un cuadro síntesis que intenta matizar dos de los tipos de interacciones esbozadas que creemos marcan las semejanzas y diferencias más estratégicas, esto es, la interacción producto (o la forma en que se da la integración de la producción agropecuaria -o base del sistema- con la turística) y la interacción recursos, fundamentalmente la movilización de los recursos humanos, los relacionados a la espacialidad, la interacción dada por los ingresos económicos, y el sentido del trabajo

No es pretensión generar una reducción o tipologías cerradas y esclerosadas sino más bien una realidad por demás dinámica y que presenta esa finitud de gradientes que otorga cada caso en particular. 


\begin{tabular}{|c|c|c|c|c|c|c|c|}
\hline & \multicolumn{2}{|c|}{$\begin{array}{l}\text { Sistemas de actividades con } \\
\text { alta integración del turismo }\end{array}$} & \multicolumn{2}{|c|}{$\begin{array}{l}\text { Sistemas de actividades con } \\
\text { integración media del turismo }\end{array}$} & $\begin{array}{l}\text { Sistemas de actividades con } \\
\text { integración baja el turismo }\end{array}$ & \multicolumn{2}{|c|}{$\begin{array}{l}\text { Sistemas de actividades sin } \\
\text { integración del turismo }\end{array}$} \\
\hline $\begin{array}{l}\text { Integración de la } \\
\text { producción } \\
\text { agropecuaria (o } \\
\text { base del sistema) } \\
\text { con la turística }\end{array}$ & \multicolumn{2}{|c|}{$\begin{array}{l}\text { El turismo agrega valor a la } \\
\text { producción primaria. } \\
\text { Integración de la actividad } \\
\text { productiva y turística. }\end{array}$} & \multicolumn{2}{|c|}{$\begin{array}{l}\text { La actividad principal es la base } \\
\text { del turismo pero no hay } \\
\text { integración de productos. } \\
\text { No hay desplazamiento de la } \\
\text { actividad de base. }\end{array}$} & $\begin{array}{l}\text { No hay integración de productos. } \\
\text { Puesta en valor del patrimonio } \\
\text { natural y cultural de la zona y del } \\
\text { predio. }\end{array}$ & \multicolumn{2}{|c|}{$\begin{array}{l}\text { No hay integración de } \\
\text { productos. }\end{array}$} \\
\hline $\begin{array}{l}\text { Integración de } \\
\text { recursos (espacial } \\
\text { de las actividades } \\
\text { (si se realizan en } \\
\text { el mismo predio) }\end{array}$ & \multicolumn{2}{|c|}{$\begin{array}{l}\text { El turismo se desarrolla en el } \\
\text { mismo espacio donde se realizan } \\
\text { las otras actividades }\end{array}$} & \multicolumn{2}{|c|}{$\begin{array}{l}\text { El turismo se desarrolla en el } \\
\text { mismo espacio donde se realizan } \\
\text { las otras actividades }\end{array}$} & $\begin{array}{l}\text { El turismo se desarrolla en el } \\
\text { mismo espacio donde se realizan } \\
\text { las otras actividades }\end{array}$ & \multicolumn{2}{|c|}{$\begin{array}{l}\text { El turismo se desarrolla en } \\
\text { otro espacio diferente. No hay } \\
\text { movilización de recursos } \\
\text { físicos, materiales y naturales } \\
\text { en común. }\end{array}$} \\
\hline Mano de obra & $\begin{array}{l}\text { Sigue trabajando } \\
\text { la familia. No } \\
\text { contratan } \\
\text { empleados. } \\
\text { Mayor } \\
\text { organización. }\end{array}$ & $\begin{array}{l}\text { En turismo } \\
\text { trabaja la } \\
\text { familia pero } \\
\text { tienen } \\
\text { empleados } \\
\text { para cada } \\
\text { actividad. }\end{array}$ & $\begin{array}{l}\text { Sigue } \\
\text { trabajando la } \\
\text { familia. No } \\
\text { contratan } \\
\text { empleados. } \\
\text { Mayor } \\
\text { organización. }\end{array}$ & $\begin{array}{l}\text { En turismo } \\
\text { trabaja la } \\
\text { familia pero } \\
\text { tienen } \\
\text { empleados } \\
\text { para cada } \\
\text { actividad. }\end{array}$ & $\begin{array}{l}\text { En turismo trabaja la familia pero } \\
\text { tienen empleados para cada } \\
\text { actividad. }\end{array}$ & $\begin{array}{l}\text { Mano de obra } \\
\text { familiar } \\
\text { exclusivamente }\end{array}$ & $\begin{array}{l}\text { Con } \\
\text { empleados }\end{array}$ \\
\hline $\begin{array}{l}\text { Ingresos por } \\
\text { turismo }\end{array}$ & Complementario & $\begin{array}{l}\text { El turismo } \\
\text { ingreso muy } \\
\text { importante en } \\
\text { el sistema. El } \\
\text { resto } \\
\text { complementa }\end{array}$ & Complementario & $\begin{array}{l}\text { El turismo } \\
\text { ingreso muy } \\
\text { importante en } \\
\text { el sistema. El } \\
\text { resto } \\
\text { complementa }\end{array}$ & Complementario & Complementario & $\begin{array}{l}\text { El turismo } \\
\text { ingreso } \\
\text { muy } \\
\text { importante } \\
\text { en el } \\
\text { sistema. EI } \\
\text { resto } \\
\text { compleme } \\
\text { nta }\end{array}$ \\
\hline Casos & \multicolumn{2}{|l|}{$\begin{array}{l}\text { Caso } 1 \\
\text { Caso } 4\end{array}$} & \multicolumn{2}{|c|}{ Caso $2 \quad$ Caso 5} & Caso 6 & \multicolumn{2}{|l|}{ Caso 7} \\
\hline
\end{tabular}




\section{Conclusiones}

Abordando de lleno a la pregunta que dio vida a esta tesis de investigación, puede decirse que los principales cambios se dan en aquellos sistemas de actividades en los que el turismo se fue consolidando en un proceso de varios años como la actividad central, a partir de la cual gira el resto de las actividades y los tiempos de dedicación de la familia a éstas.

Esto se ha evidenciado en aquellos sistemas definidos como con una alta integración de la actividad turística, en los que fundamentalmente el turismo se ha constituido en un canal de venta de la producción primaria a la que se agrega valor en origen para convertirla en un servicio o producto determinado.

En otros casos, la familia ha decidido concentrar sus esfuerzos en el turismo condicionados por determinadas situaciones contextuales que hicieron decaer las actividades productivas a la que históricamente se dedicaban, situación que se repite en la zona del delta entrerriano. En esta zona en particular además influyen otros elementos propios del territorio como las constantes crecidas de los ríos e inundaciones que marcan fuertemente el ritmo de vida familiar y de la comunidad y las actividades que se desarrollan allí, además de una idiosincrasia privativa que los define e identifica de manera especial.

"Con el turismo arrancamos en el 1996. Arrancó como complemento (...) Surgió como para hacer algo más. Y después cambió. Ahora lo del turismo es lo primero (...) Nosotros plantábamos 20 ha y al año lográbamos 18. Todo el tiempo era invertir, invertir y no lográs. Los ciclos del agua de las crecientes se fueron acortando, cada vez la tenemos más cerca. Y después la edad. Uno es mayor. Cuando uno es joven todo te parece que todo lo podés revertir. Cuando te vas poniendo viejo, vas cambiando". (Mario, producción y alojamiento en Villa Paranacito).

No puede decirse que la introducción del turismo haya repercutido en este desplazamiento de la actividad productiva principal, sino por el contrario, que éste ha sido implementado como estrategia innovadora para garantizar el sustento de la familia, sobre todo teniendo en cuenta aspectos que influyen favorablemente en el desarrollo del turismo regional como la ubicación estratégica de la provincia, la existencia de numerosos accesos terrestres, la existencia de una demanda turística importante que se moviliza hacia estos destinos, entre otros a tener en cuenta para comprender la dinámica turística provincial.

Pero más allá de lo anterior, los principales cambios y reconfiguraciones se dan a nivel familiar. Hablamos de una redistribución del tiempo de trabajo de las familias, que deben reorganizar sus rutinas en pos del turismo, actividad que deciden no delegar a sus empleados -si tuviesen- porque consideran esencial transmitir en su atención personalizada, su propia vivencia e historia. Es a partir de esta puesta en palabra y acción de lo que ellos son y hacen, del poder mostrar de manera auténtica cómo son, dónde viven y porqué hacen lo que hacen, que se generan lazos que los mismos entrevistados destacan como especiales con los turistas y que posibilita un alto nivel de repitencia de las visitas.

"Nosotros somos auténticos, somos esto. Y yo creo que el turista lo valora, que estamos dando algo que es auténtico también, lo que tenemos, y el buen trato, sentir que del otro lado hay un ser humano, que estas son las cosas que se han perdido mucho, el dedicarle un ratito de tiempo. Yo creo que eso es lo más valioso que le entregamos". (Irma, dueña almacén de ramos generales).

Como se ha comentado, las familias deben reorganizarse, repensar sus roles, distribuir las distintas tareas para poder dar respuesta a los tiempos que cada una de las actividades que desarrollan demanda. Esta organización puede generar momentos de tensión, de nervios, de disputas familiares, de reclamos, pero, y he aquí un aspecto sumamente interesante, cuando vislumbran que se está llegando a un límite por el cual las tareas dejan de ser agradables, alguna decisión inteligente se toma para relajar la situación y volver a empezar. Esto es, se 
decide no abrir al turismo en determinada fecha o día, dedicar los domingos a la familia, es decir, poner en marcha dispositivos de reorganización que no tensen sino que por el contrario, permitan hacer disfrutable lo que hacen.

"No nos levantamos ni un minuto antes ni un minuto después, a lo mejor nos acostamos más tarde (...) Dificultó algunos tiempos los fines de semana, la salida en familia, las vacaciones en familia (...) Pero sabemos que lo vamos a recuperar en algún momento, no sabemos cuándo ni cómo, pero no nos desespera porque sabemos que es un tiempo". (Analía Huerta Chajarí).

Vemos la importancia que tiene el sentido dado al trabajo, el peso que tiene otro tipo de satisfacciones que van más allá de lo económico y que se relaciona con el bienestar personal y familiar, la salud, el deleite de hacer algo que guste hacer.

Otra de las cuestiones que más contribuyen a responder la pregunta de investigación se asocia a los cambios personales que se dan a partir de la incorporación del turismo en los sistemas. Hay familias que no habían podido salir con frecuencia de paseo y es a partir del intercambio, de la charla con el otro, que incita la búsqueda de nuevos horizontes, de nuevos conocimientos, de nuevos desafíos. Cambios personales que también se traducen en cosas superfluas como el estar más arreglado para atender al turista, sin perder la esencia que los identifica, o aprovechar los espacios ociosos de los predios para hacerlos más lindos, más agradables, más ordenados. Y todas estas dimensiones, sumadas a la mirada de un otro que reconoce como valioso, como interesante, lo que estas familias hacen, operan de manera positiva en la construcción de sus propias imágenes, en la construcción de su personalidad, de su ser.

Respecto a la hipótesis sobre la cual se construyó esta tesis de investigación, puede decirse que en realidad, el turismo rural responde a la estrategia de la pluriactividad en el seno de familias, que en su mayoría ya tienen incorporada esta estrategia. Es decir, algún o algunos miembros de la familia se dedican a más de una tarea dentro o fuera de su predio, ya sea agraria o relacionada a otro tipo de actividad.

Esto también se relaciona con que el perfil de las explotaciones es diversificado. $Y$ en este sentido está dentro de la lógica de estos productores pensar en estrategias que por ejemplo puedan ser complementarias desde el punto de vista económico, que a la vez colaboren a la permanencia de la vida diaria en el campo, con un mayor contacto, no aislados, con desafíos diarios, con la sorpresa de la llegada inminente de algún turista que puede convertirse en una persona sumamente interesante de conocer y poder establecer un diálogo. O pensar en actividades que complementen desde el punto de vista de la temporalidad de los ciclos productivos, o aprovechar la existencia de construcciones de valor histórico para convertirlas en propuestas turísticas de base patrimonial cultural. Más aun en territorios donde es propicio el desarrollo turístico y donde, como se ha visualizado, existe un flujo importante de turistas que llegan a los destinos en los que se ubican estos sistemas.

Podemos decir entonces que es muy interesante analizar el conjunto de factores y elementos que forman parte de las dinámicas de estos sistemas, en los que se movilizan recursos y capitales naturales, físicos, materiales, patrimoniales, identitarios y fundamentalmente humanos, que producen y se reproducen en un contexto socio territorial determinado, y comprender cómo el turismo opera al interior de estos sistemas.

Sistemas que como organización de familia-explotación ha transitado -y transita- un camino de decisiones, de momentos críticos, de buenas rachas, de pérdidas, de caídas y vueltas a levantar y en esta trayectoria, incorporar una actividad como el turismo marca un punto de inflexión, sobre todo en lo que mencionábamos oportunamente respecto a los cambios al interior de las personas y a la redefinición de tiempos y roles que implican reconfiguraciones en las dinámicas familiares. 
Cabe destacarse algunas circunstancias particulares sobre todo en aquellos casos que encarnan a familias que no se desempeñan en la actividad agropecuaria, experiencias que se han sido incluido en el análisis en un intento de profundización mayor pero que no representan acabadamente al objeto central de estudio, que está representado por familias rurales que incorporan el turismo a sus sistemas de actividades.

¿Qué sucede en estos casos?

En este punto pueden diferenciarse dos tipos de situaciones diferentes. Por un lado, vemos una familia que se dedica al rubro de la construcción y venta, que decide invertir en un proyecto turístico en un espacio rural. Por otro, una familia que hereda un almacén de campo de colonia, que funciona como tal, y que deciden abrir al turismo incorporando picadas y venta de productos regionales. ¿Qué tienen en común estas familias con el resto de los casos? En primer lugar, vemos que existe una vinculación afectiva con su zona de residencia y que poseen una relación con la actividad agropecuaria ya que ésta fue desarrollada por sus padres. Ellos decidieron no continuarla específicamente pero sí se evidencia una identificación con el rubro. En ambos casos además, el turismo comienza a partir de un fuerte impulso de sus municipios y la formación de grupos Cambio Rural orientados a esta temática, del que han sido integrantes.

Uno de estos elementos también se repite en el único caso cuyo sistema familia-explotación representa a un productor agropecuario de perfil y escala empresarial. Vemos cómo en las motivaciones de esta familia juega el deseo de vivir en el campo, de conservar y velar por el patrimonio familiar y cómo el turismo se convierte en una estrategia que puede colaborar en este sentido.

"Ahora que ellos ya se están yendo, creo que es una buena manera de mantener esto. No hay manera de subvencionar mucho la casa. Sí o sí si queremos tener esto bien mantenido y lindo hay que mantener la impronta del turismo". (Carla, dueña de la estancia).

Ahora bien ¿el turismo impacta sobre el tradicional estilo de vida de las familias?

Son justamente el estilo de su vida, su idiosincrasia, sus tareas y sus costumbres, los que se ponen en juego como atractivo genuino de sus propuestas. El turismo impacta fundamentalmente sobre los tiempos de la familia, y en todo caso, enriquece, nutre, su estilo de vida al exteriorizarlo, al mostrarlo al otro, y en este intercambio, también se aprende de otros, de otras formas de vida, en otros lugares, con otros tiempos.

"El turismo te permite mostrar lo que uno tiene, cómo uno vive, las particularidades de la gente de la zona a la gente que eligió Villa Paranacito, que viene con una apertura porque justamente quiere absorber de las personas, de los locales. Uno también trata de hacerles un panorama para que se enamoren del lugar..." (Susana, producción y alojamiento en Villa Paranacito).

"Es como que vayas a otro país, te sientes con ellos y te cuenten cómo viven, qué hacen. Ellos vienen y te cuentan. Te vas cultivando, mirás las cosas de ellos con la perspectiva de ellos, es distinto a cuando viajas vos". (Carlos, dueño de la estancia).

"Se vuelve interesante desde toda la gente que viene hasta lo que vas intercambiando. A mi marido le encanta, ustedes ven que parece que no dice nada pero cuando viene gente se hace el ratito para charlar, les arma los cuentos, las anécdotas que las tiene él más que yo". (Irma, dueña almacén de ramos generales).

Respondiendo a la última parte de la hipótesis, en realidad podemos decir que el turismo se pone en marcha como parte de una estrategia hacia el futuro por parte de la familia, integrando un proyecto personal o familiar de cara al futuro. Esto se evidencia sobre todo en sistemas cuyos productores ya están cerca del retiro de la actividad. En estos casos, el turismo se presenta como una alternativa de trabajo para la pareja, quien cede a sus hijos, o a alguno de ellos, la responsabilidad de una o varias de las actividades que desarrolla el sistema, para dedicarse a una actividad que genera ingresos, que colabora a la conservación de su patrimonio, que viabiliza la memoria y que además es placentera, agrada realizarse. 
"Ver que había otras posibilidades que permitían que nos quedáramos en el campo. Pero también por ejemplo él toda la vida viajó, no le gusta la vida monótona. Nos gusta estar relacionados, intercambiar y esto del turismo lo permitió". (Irma, dueña almacén de ramos generales).

Pero no puede entenderse esta inserción del turismo a futuro como una acción estratégica aislada sino en el marco de una serie de operaciones y acciones puestas en marcha pensando en la familia en su conjunto. El hecho de desarrollar varias actividades, entre ellas el turismo, posibilita la integración de los hijos y de la pareja, y su dedicación a la actividad más conveniente y más agrade realizar, a futuro.

“... ya me acordaba de la edad que tenía y los años que lo venía haciendo y es como monótono... Para mi edad, ya el trabajo de andar subiendo y bajando huevos a la camioneta ya no da, yo decía, esto tiene que cambiar, esto tiene que cambiar... porque mi edad no lo va a permitir. Y en esto de que me gusta el diálogo, me gusta todo eso, en el turismo me vino una oportunidad especial". (Carmen, productora y responsable de alojamiento rural).

Éstas y el resto de las familias analizadas pudieron haber decidido tirar abajo las construcciones antiguas que heredaron y empezar de nuevo, o en situaciones de mayor crisis económica, vender el campo e irse a las ciudades como tantas lo han hecho, sin embargo, no lo hicieron. Y siguieron apostando, y sufrieron una y otra caída, y siguieron... Y es en esta mirada histórica de las decisiones que fueron tomando, que los anclan a su territorio, a su colonia, en la que se aprecia un profundo apego a su historia, a sus luchas y a la idea de un futuro con oportunidades. $Y$ es aquí donde el turismo se presenta como una opción que brinda, entre otras cosas, esperanza...

"Tenía la visión de que era una actividad que podía ayudar, yo era el loco del turismo. Visión de a qué nos quedamos? El tema era a qué nos quedamos, y yo vi que esto podía ser (...) Vos te encontrabas de repente que esa actividad decaída de la forestación o la fruta, y te encontrabas en una coyuntura que no sabías qué hacer y que posiblemente tenías que migrar. El turismo, esto te daba una esperanza". (Enrique, producción y alojamiento en el delta).

Existen entonces tres ideas respecto al futuro que nos parecen interesantes de realzar. En primer lugar, parece presentarse muy clara la función del turismo como elemento que moviliza la transmisión de la historia de padres a hijos, los oficios y los saberes aprendidos. Y de esta manera, manteniendo vivo el pasado en la realidad presente, viabilizar un futuro que, al igual que un árbol, pueda tener más raíces más profundas y desarrollarse con más robustez.

Una segunda idea tiene que ver con cómo el turismo puede motivar a que los jóvenes piensen en un futuro en sus propios campos, o a aquellos que tienen pensado emprender experiencias en otros lugares, pueda existir la idea de volver, tal como lo han manifestado dos de los jóvenes.

$Y$ en tercer lugar, vemos a adultos que no quieren dejar sus campos, que buscan alternativas para no irse $y$ en este sentido, como se ha mencionado, el turismo genera expectativa y por qué no, ilusión.

Producto del trabajo realizado, que pretende dar a conocer las distintas realidades de los territorios en torno a una temática relativamente incipiente en la provincia de Entre Ríos pero que ha movilizado procesos muy dinámicos, nos hemos encontrado con complejidades y dinámicas que dan luz sobre la diversidad que hace rico el objeto de estudio.

Se ha aspirado a identificar, caracterizar e interpretar la diversidad de funcionamiento y niveles de integración del turismo en los sistemas de actividades seleccionados, cómo esta integración repercute en el resto de las actividades, en las dinámicas de las familias y en las personas y aquellas señales y procesos que dan cuenta de cómo las familias se prefiguran en el futuro. 
Creemos, con total humildad, que hemos logrado una contribución en el conocimiento existente sobre esta problemática, de manera rigurosa. Sin embargo es tanta y tan rica la información que los casos han aportado, que consideramos pueden abordarse otros aspectos y elementos de análisis en futuras líneas de investigación.

A nivel personal para la autora de este trabajo, ha implicado un proceso apasionante, atiborrado de enseñanzas, signado por un intento de comprender esos cómo y porqué, que han movilizado desde un principio esta exploración, en la que las familias rurales han sido fuente de indagación e inspiración por bucear más profundo en búsqueda de respuestas.

Asimismo, el hecho de estar involucrada en parte del proceso como profesional de INTA en territorio y a la vez tomar distancia del objeto en mi rol como investigadora en el marco de este proceso científico, generó limitantes y dificultades, pero a la vez facilitó el acceso a los entrevistados dada la confianza construida a partir del trabajo compartido. ¿Cómo se minimizaron esas contradicciones y limitaciones? En primer lugar, reconociendo ese doble rol e intentando desdoblar los tiempos de trabajo y de investigación, a los fines de crear un ámbito de familiaridad pero también de confidencialidad, indispensables para avanzar en la búsqueda. Gracias al incondicional acompañamiento de los excelentes profesionales y personas que me acompañaron en esta etapa, se han ido sorteando, paso a paso, los conflictos propios de este tipo de procesos.

Este andar requirió un gran esfuerzo personal por comprender la complejidad en sí misma, interpretar, mirar integralmente, apoyarse en lo que otros ya han observado, analizado e intelectualizado para intentar aportar información y elementos de comprensión a una realidad que atraviesa cada una de las familias y sus actividades, situación que por momentos ha interpelado hasta la fibra más íntima de los conocimientos y hasta de las intuiciones de quien escribe.

Este arduo e intenso camino generó además fuertes movilizaciones internas, la más de las veces generadas por los dichos y experiencias de los hombres y mujeres que abrieron las puertas de sus vidas, que hablaron de sus decisiones, sueños y sacrificios. Escucharlos motivó también pensar en las luchas de los propios padres, en sus esfuerzos silenciosos y en las renuncias que uno hace por sus hijos, como un espiral en el que la vida nos pone en uno y otro lugar, en espacios de reconocimiento, de entrega y escisiones, en forma de microhistoria hecha de retazos de una historia más global y de pequeños pasos personales.

Y si en esos pasos que forman la historia de muchas de las familias rurales que entrevistamos, en el turismo se pueden encontrar formas para resguardar un trecho de pasado, un fragmento de historia para que no se olvide, para que permanezca un poco viva en el contexto de una sociedad que va más rápido de lo que cavila, entonces estamos ante una huella, un mojón en el propio mundo...

Y como expresa Hannah Arendt (2009) no sólo se hace historia sino que queda grabada, perpetua, en ella...

"La tarea y potencial grandeza de los mortales radica en su habilidad en producir cosas -trabajo, actos y palabras- que merezcan ser, y al menos en cierto grado lo sean, imperecederas con el fin de que, a través de dichas cosas, los mortales encuentren su lugar en un cosmos donde todo es inmortal a excepción de ellos mismos. Por su capacidad en realizar actos inmortales, por su habilidad en dejar huellas imborrables, los hombres, a pesar de su mortalidad individual, alcanzan su propia inmortalidad y demuestran ser de naturaleza divina". (Arendt, 2009). 


\section{Bibliografía utilizada}

ACÁMPORA, Teresa y FONTE, María. 2008. Productos típicos, estrategias de desarrollo rural y conocimiento local. En: Revista Opera, núm. 7, pp. 191-212, Universidad Externado de Colombia, Colombia.

ANDRADE, Norma B. 2011. El debate de la multifuncionalidad de la agricultura y nueva ruralidad. Aportes teóricos y evidencias empíricas. En: Realidad, Tendencias y Desafíos en turismo. Año XI. Volumen 9. Neuquén, Argentina.

ARENDT, Hannah. 2009. La condición humana. Paidós. Buenos Aires, Argentina.

ARRÚA MAIDANA, Víctor. 2009. Prólogo. En: ROMAN, Florencia y CICOLELLA, Mariana. 2009. Turismo rural en Argentina. Concepto, situación y perspectivas.IICA. Buenos Aires, Argentina.

ASCANIO, Alfredo. 2004. Turismo y desarrollo de la comunidad: un primer paso para rescatar la identidad cultural. En: PASOS Revista de Turismo y Patrimonio Cultural, vol. 2, núm. 2, junio, 2004, pp. 155-161, Universidad de La Laguna, España.

BARRERA, Ernesto y DACHARY, Alfredo C. 2012. Sobre la situación del turismo rural en la República Argentina. En línea: https://slidex.tips/download/sobre-la-situacion-del-turismo-ruralen-la-republica-argentina

BATTHYÁNY, Karina y CABRERA, Mariana. 2011. Metodología de la investigación en Ciencias Sociales. Apuntes para un curso inicial. Departamento de Publicaciones, Unidad de Comunicación de la Universidad de la República (UCUR), Montevideo, Uruguay,

BOCCHETTO, Roberto. 2008. Innovación, institucionalidad y desarrollo: experiencia y caminos para su integración. Ed. PROCISUR (IICA) / INTA Argentina.

BOURDIEU, Pierre. 1989. La ilusión biográfica. En: Historia y fuente oral, núm.2, Universidad de Barcelona, España.

BOURDIN Gabriel y otros. 2013. Entre Ríos. Aportes hacia un camino de oportunidades y desafíos. $1^{\circ}$ edición Dictum Ediciones, Paraná, Entre Ríos, Argentina.

BOTE GÓMEZ, Venancio. 1979. El turismo rural en España: una estrategia artesanal para un turismo masivo. En: Revista de Estudios Agrosociales, ISSN 0034-8155, Nº. 109, págs. 29-51.

BOTE GÓMEZ, Venancio. 1988. Turismo en espacio rural. Rehabilitación del patrimonio sociocultural y de la economía local. Ed. Popular SA, España.

BRAVO, Gonzalo. 1991. La Diversidad de explotaciones agropecuarias. Marco teórico y metodológico. Boletín técnico n¹- Diciembre 1991, INTA, CR Salta Jujuy.

BRAVO, G; DORADO, G; y CHIA, E. 1995. Funcionamiento de la explotación agraria y análisis de la diversidad en una perspectiva de desarrollo rural. En: Eds. BERDEGUÉ, J. y RAMIREZ, E. Integración con enfoque de sistemas en la agricultura y el desarrollo rural. RIMISP. Chile.

BUSTOS CARA, Roberto. 2001. IDENTIDAD, TURISMO Y TERRITORIOS LOCALES. La permanente construcción de valores territoriales. En Revista APORTES y Transferencias Año 5 Vol. 1, Mar del Plata, Argentina. 
BUSTOS CARA, Roberto. 2004. Patrimonialización de Valores territoriales. Turismo, sistemas productivos y desarrollo local. En: Ensayo Revista Aportes y Transferencias. Año 8, volumen 2, Mar del Plata, Argentina.

BUSTOS CARA, Roberto y HAAG, María Isabel. 2010. Territorialización y Patrimonialización. Convergencias y conflictos en la asignación de recursos patrimoniales en las relaciones producción y consumo. Necesidad de continuar la reflexión. VIII Congreso Latinoamericano de Sociología Rural. 15 al 19 de noviembre de 2010. Puerto de Galhinas. Brasil.

CABRINI, Luigi. 2002. Turismo, desarrollo rural y sostenibilidad. En: VII Congreso AECIT, Jaen, España.

CARACCIOLO de BASCO, Mercedes y otros. 1981. Esquema conceptual y metodología para el estudio de tipos de establecimientos agropecuarios con énfasis en el minifundio. El minifundio en la Argentina 2da parte. Servicio Nacional de Economía y Sociología Rural. SAyG, Ministerio de Economía, Argentina.

CITTADINI, R; MANCHADO, J; y MOSCIARO, M. 1990. Las formas de organización social de la producción: marco conceptual y planteo operativo. Publicación $n^{\circ} 2$ del Área de Economía y Sociología Rural de la Unidad Integrada INTS- FCA.

CHAMPREDONDE, Marcelo y otros. 2007. Culturas migratorias y valores territoriales localizados en la ruralidad y el desarrollo del sudoeste de la provincia de Bs As. En: V Jornadas Interdisciplinarias de Estudios Agrarios y Agroindustriales. Facultad de Ciencias Económicas de la Universidad de Buenos Aires, Argentina.

CLOQUELL, Silvia. 2013. Familias rurales; límites y posibilidades en el escenario de la Región Pampeana Argentina en el nuevo orden mundial de la agricultura. En: Eds. GASSELIN, P; CLOQUELL, S. y MOSCIARO, N. Adaptación y transformaciones de las agriculturas pampeanas a inicios del siglo XXI. 1 edición, Ed CICCUS, CABA, Argentina.

CLOQUELL, S; PROPERSI, P; y ALBANESI, R. 2011. Algunas reflexiones acerca de la producción familiar pampeana. En LÓPEZ CASTRO, N. Y PRIVIDERA, G (Compiladores) "Repensar la agricultura familiar." CICCUS Ediciones. Buenos Aires.

COSTA BEBER, Ana María y BARRETTO, Margarita. 2007. Los cambios socioculturales y el turismo rural: el caso de una posada familiar. En: Revista PASOS, vol 5 n¹. p 45-52.

CRAVIOTTI, Clara. 2002. Actividades turísticas y nueva ruralidad: análisis de experiencias en la Cuenca del Abasto a Buenos Aires. En: Revista de Desarrollo rural y cooperativismo agrario, $n^{\circ} 6$. Universidad de Zaragoza, España, p 89-102.

CRAVIOTI, Clara. 2012. Las explotaciones familiares en el agro pampeano: controversias y perspectivas. En Revista Pueblos y Fronteras Digital, vol. 7, núm. 14. Universidad Nacional Autónoma de México. Distrito Federal, México.

CRAVIOTTI, Clara y PALACIOS, Paula. 2012. Estrategias de productores familiares en contextos socio-productivos adversos: la fruticultura familiar en el noreste de la provincia de Buenos Aires, Argentina. En Revista Trabajo y Sociedad. N²0, Santiago del Estero.

CHIA, E; BRAVO, G; y DORADO, G. 1994. Funcionamiento de las explotaciones agropecuarias: el punto de vista de la economía. En: Seminario INTA- INRA/ Mar del Plata.

DE OLIVEIRA SANTOS, E; GONÇALVES VIANNA, S; y ROSA GULLO, M. 2012. Evolución de la renta, empleo y sueldos en propiedades rurales que ofrecen Agroturismo y Turismo rural 
en la Mitad Sur de Rio Grande do Sul, Brasil (1997 - 2011). En: El Periplo Sustentable, núm. 23, julio-diciembre, 2012, pp. 27-47, Universidad Autónoma del Estado de México, Toluca, México.

DIÉGUEZ-CASTRILLÓN, M; GUEIMONDE-CANTO, A; y SINDE-CANTORNA, A. 2009. Turismo rural como estrategia de diversificación: factores determinantes y resultados en Galicia. Cuadernos de Gestión, vol. 9, núm. 2, 2009, pp. 31-53, Universidad del País Vasco/Euskal Herriko Unibertsitatea, España.

DOMINGUEZ, Néstor y ORSINI, Germán. 2009. Impactos en la estrguctura agraria por la ampliación de la frontera agrícola en base a la expansión del cultivo de soja en la Región Pampeana: la historia reciente de Entre Ríos. Ediciones Cooperativas. Buenos Aires.

ENGLER, Patricia y otros. 2008. Zonas AgroEconómicas Homogéneas Entre Ríos. Descripción ambiental, socioeconómica y productiva. Estudios socioeconómicos de la sustentabilidad de los sistemas de producción y recursos naturales. $\mathrm{N}^{\circ} 6$. INTA, Argentina.

ESTRADA, María Emilia. 2013. Turismo rural y desarrollo local. Distintas miradas sobre la relación. En: VIII Jornadas Interdisciplinarias de Estudios Agrarios y Agroindustriales, Buenos Aires, Argentina.

FERNANDEZ, Guillermina y RAMOS, Aldo. 2000. Innovación y cambio rural: el turismo en el desarrollo local sostenible. En: Scripta Nova. Revista Electrónica de Geografía y Ciencias Sociales $N^{\circ} 69$, Universidad de Barcelona, España.

FERRER, G y otros. 2013. El turismo rural como alternativa para el desarrollo en el norte de la provincia de Córdoba. En: VIII Jornadas Interdisciplinarias de Estudios Agrarios y Agroindustriales. Buenos Aires, Argentina.

FLORES, Murilo. 2007. La identidad cultural del territorio como base de una estrategia de desarrollo sostenible. En: Revista Opera, núm. 7, pp. 35-54, Universidad Externado de Colombia, Colombia.

FLORES RUIZ, David y BARROSO GONZÁLEZ, María de la O. 2011. Desarrollo rural, economía social y turismo rural: un análisis de casos. En: CIRIEC-España, Revista de Economía Pública, Social y Cooperativa, núm. 70, abril, 2011, pp. 55-80.

FULLER, Norma. 2011. Reflexiones sobre el turismo rural como via de desarrollo. El caso de la comunidad de Antioquía, Perú. En: Estudios y Perspectivas en Turismo, vol. 20, núm. 4, pp. 929-942, Buenos Aires, Argentina.

FRANCÈS, Gemma y MÉNDEZ, Marisa. 2001. El turismo rural como estrategia de diversificación de las explotaciones agrarias catalanas. En: IV Congreso Nacional de Economía Agraria, Pamplona, España.

GANGE, M; MOSCIARO, M; IORIO, C. 2013. Análisis de las características que favorecen la persistencia de explotaciones familiares en un distrito del sudeste entrerriano. Ponencia en VIII Jornadas Interdisciplinarias de Estudios Agrarios y Agroindustriales. Centro Interdisciplinario de Estudios Agrarios (CIEA) de la Facultad de Ciencias Económicas de la UBA. 29 de octubre - 1 de noviembre de 2013. Buenos Aires.

GARRA, Lobodón. 1994. Río abajo. El drama de los montes y los esteros de las Islas del Ibicuy. Ediciones de las islas. Ediciones Cinco. Buenos Aires. 
GASSELIN, Pierre. 2009. Flexibilidad de los sistemas de actividades familiares en contextos inciertos. Ponencia en Seminario- taller "La calificación de las capacidades de adaptación de los sistemas en contextos adversos: flexibilidad y resiliencia". INTA- Agriterris, 23/03/2009. Buenos Aires, Argentina.

GASSELIN, Pierre. 2009. Document de travail, actualicé aun 19 nov. 2009.

GASSELIN, Pierre y BATHFIELD, Benjamín. 2013. La flexibilidad de los sistemas de actividad: un marco de análisis de las propiedades y de los procesos adaptativos de las actividades de los agricultores. En: Eds. GASSELIN, P; CLOQUELL, S. y MOSCIARO, N. Adaptación y transformaciones de las agriculturas pampeanas a inicios del siglo XXI. 1 edición, Ed CICCUS, CABA, Argentina.

GASSELIN, P; VAILLANT, M; BATHFIELD, B. 2015. Le système d'activité. Retour sur un concept pour étudier l'agriculture en famille. En Gasselin,P y otros. 2015. J.-P. L'agriculture en famille : travailler, réinventer, transmettre INRA-SAD, 2014 EDP Sciences Francia.

GASSELIN, P; CLOQUELL, S; y MOSCIARO, M. 2013. Adaptarse: entre necesidad y proyecto. En: Eds. GASSELIN, P; CLOQUELL, S. y MOSCIARO, N. Adaptación y transformaciones de las agriculturas pampeanas a inicios del siglo XXI. 1 edición, Ed CICCUS, CABA, Argentina.

GRAS, Carla y HERNANDEZ, Valeria. 2008. Modelo productivo y actores sociales en el agro argentino. 2008. Universidad Autónoma de México. Instituto de Investigaciones Sociales. Revista Mexicana de Sociología 70, núm. 2 (abril-junio, 2008). México.

GUASTAVINO, M; TRIMBOLI, G; y ROZENBLUM, C. 2012. El turismo rural en el INTA". Ensayo de la Coordinación Nacional del PROFEDER (Programa Federal de Desarrollo Rural Sustentable) Disponible en línea: https://inta.gob.ar/documentos/el-turismo-rural-en-el-inta

HAMDAN, Virginia. 1994. Explotaciones familiares: un aporte metodológico. Seminario INTAINRA. Mar del Plata, Argentina.

HERNER, María Teresa. 2010. Agricultura familiar y desarrollo rural. Aportes teóricometodológicos para el trabajo de Extensión Rural. En: XV Jornadas Nacionales de Extensión Rural. AADER, San Luis, Argentina.

INTA Centro Regional Entre Ríos. 2001-2004, 2006- 2009, 2009-2012. PTR Plan de Tecnología Regional.

IORIO, Carlos y MOSCIARO, Mirna. 2013. El comportamiento de los productores del sudeste bonaerense frente a los cambios de contexto. Una mirada económica. En: Eds. GASSELIN, P; CLOQUELL, S. y MOSCIARO, N. Adaptación y transformaciones de las agriculturas pampeanas a inicios del siglo XXI. 1 edición, Ed CICCUS, CABA, Argentina.

LATTUADA, Mario y NOGUIERA, María Elena. 2011. Capacidades estatales y políticas públicas. Una propuesta para el abordaje de las políticas agropecuarias en la Argentina contemporánea (1991-2011). En Estudios Rurales. Publicación de Centro de Estudios de La Argentina Rural. Bernal, Vol 1, nº1.

LEONARDI BRICALLI, Luis Carlos. 2005. Construcción de tipologías para el turismo en áreas rurales. En: Estudios y Perspectivas en Turismo, vol. 14, núm. 3, septiembre, 2005, pp. 263275, Centro de Investigaciones y Estudios Turísticos, Argentina. 
LERA, Carmen y otros. 2007. Trayectorias: un concepto que posibilita pensar y trazar otros caminos en las intervenciones profesionales del Trabajo Social. Revista Cátedra Paralela $n^{\circ} 4$. Facultad de Trabajo Social, Universidad Nacional de Entre Ríos.

LÓPEZ CASTRO, Natalia. 2009. Cuando la persistencia es una cuestión de familia. Relaciones familiares, traspaso y género en explotaciones agropecuarias del Sudoeste bonaerense (19872007). Mundo Agrario, vol. 10, $n^{\circ} 19$, segundo semestre de 2009. Centro de Estudios Histórico Rurales. Facultad de Humanidades y Ciencias de la Educación. Universidad Nacional de La Plata.

MARRADI, A; ARCHENTI, N; y PIOVANI, J.I. 2007. Metodología de las ciencias sociales. Ed. EMECÉ. Bs As. 326 pp.

MARTINEZ F. y MONZONIS, J. 2000. Alojamiento turístico rural. Gestión y comercialización. Ed. Síntesis. España.

MEDINA, Jorge. 2010. Etapas en la planificación espacial del turismo en Entre Ríos. En: Revista Tiempo de Gestión Año VI, N 10. Universidad Autónoma de Entre Ríos (UADER), Entre Ríos.

MILLÁN, René y GORDON, Sara. 2004. Capital social: una lectura de tres perspectivas clásicas. Universidad Nacional Autónoma de México-Instituto de Investigaciones Sociales. En: Revista Mexicana de Sociología, Año 66, № 4, octubre-diciembre, 2004. México, D. F., pp. 711747.

MILLÁN VÁZQUEZ DE LA TORRE, M; LÓPEZ-GUZMÁN GUZMÁN, T; y AGUDO GUTIÉRREZ, E. 2006. El turismo rural como agente económico: desarrollo y distribución de la renta en la zona de Priego de Córdoba. En: CIRIEC-España, Revista de Economía Pública, Social y Cooperativa, núm. 55, pp. 167-192, España.

MUZLERA KLAPPENBACH, José. 2007. La relación familia-empresa en los estratos medios de la producción agropecuaria pampeana. VII Jornadas de Sociología. Facultad de Ciencias Sociales, Universidad de Buenos Aires, Buenos Aires.

NEIMAN, Guillermo; BERGER, Matías y NEIMAN, Melina. 2013. La pluriactividad entre pequeños y medianos productores de la provincia de Buenos Aires. Contextos productivos, familia y trabajo. En: Eds. GASSELIN, P; CLOQUELL, S. y MOSCIARO, N. Adaptación y transformaciones de las agriculturas pampeanas a inicios del siglo XXI. 1 edición, Ed CICCUS, CABA, Argentina.

NEIMAN, Guillermo y CRAVIOTTI, Clara. 2006. Entre el Campo y la Ciudad. Desafíos y estrategias de la pluriactividad en el agro. Ediciones Ciccus. Buenos Aires

NOGAR, Ada Graciela. 2013. Estrategias territoriales complementarias entre las agroindustrias de base rural y el turismo rural a partir del enfoque SIAL. En: VIII Jornadas Interdisciplinarias de Estudios Agrarios y Agroindustriales. Bs. As, Argentina.

NOGAR, Ada Graciela. 2011. Procesos convergentes y contradictorios. Un análisis del turismo rural desde las Ciencias Sociales. En: Realidad, Tendencias y Desafíos en turismo. Año XI. Volumen 9, Neuquén, Argentina.

NOGAR, Ada Graciela. 2008. El turismo rural como estrategia incluyente. Teorización e Investigación Empírica. En: Boletín de Turismo Rural. Disponible en línea http://www.turismoruralbolivia.com/img/GracielaNogar.pdf. Último acceso: febrero, 2015. 
NOGAR, Ada Graciela y JACINTO, Guillermina. 2010. Los espacios rurales. Aproximaciones teóricas y procesos de intervención en turismo rural. Ed. La Colmena, $1^{\circ}$ Edición, Buenos Aires.

PASCIARONI, C; OLEA, M; y SCHROEDER, R. 2010. "Pequeñas localidades, entre el éxodo rural y la urbanización. Evolución de las localidades rurales de la región pampeana argentina: 1960-2001". Ponencia presentada en el VIII Congreso Latinoamericano de Sociología Rural, Porto de Galinhas, Brasil.

PAUL, Jean-Luc y otros. 1995. ¿Qué sistema escoger para tomar en cuenta la racionalidad del agricultor? Del sistema de producción agrícola al sistema de actividad. En: BERDEGUÉ, J. y RAMIREZ, E. Investigación con enfoque de sistemas en la Agricultura y el Desarrollo Rural. RIMISP. Centro Latinoamericano para el Desarrollo Rural, Chile.

PELLIZA, Valeria y ERCOLANI, Patricia. 2013. Gestión Pública del Turismo en el Espacio Rural: Proyecto TERRA. En XII Jornadas Nacionales de Investigación en Turismo. VI Simposio "El tueismo y los nuefos paradigmas educativos". Ushuaia, Tierra del Fuego.

PIÑEIRO, Diego. 2003. Caracterización de la producción familiar. Mimeo, Buenos Aires.

PIÑEIRO, Diego. 2004. El capital social en la producción familiar. INIA, Las Brujas.

PIÑEIRO, Diego y CARDEILLAC, Joaquín. 2010. Influencia de la composición del grupo familiar en la pluriactividad En: EI Uruguay desde la Sociología VIII. Montevideo, Uruguay.

Plan Estratégico de Desarrollo Turístico Sustentable de Entre Ríos 2008.

Plan Estratégico de Desarrollo Turístico Sustentable de Entre Ríos 2020.

Plan Federal Estratégico de Turismo Sustentable de Argentina 2016.

POSADA, Marcelo. 1999. El espacio rural entre la producción y el consumo: algunas referencias para el caso argentino. En Revista eure (Vol. XXV, № 75), Santiago de Chile.

RAMÍREZ PLASCENCIA, Jorge. 2005. Tres visiones sobre Capital social: Bourdieu, Coleman y Putman. En ACTA REPUBLICANA POLÍTICA Y SOCIEDAD. AÑO 4. NúMERO 4, México

ROZENBLUM, C; GUASTAVINO, M; y TRIMBOLI, G.J. 2010. La revalorización de la identidad local como estrategia para el desarrollo territorial en el marco del Programa Federal de Apoyo al Desarrollo Rural Sustentable del INTA. II Congreso Internacional de Desarrollo Local. I Jornadas Nacionales en Ciencias Sociales y Desarrollo Rural. Universidad Nacional de La Matanza. San Justo, Buenos Aires, Argentina.

ROMAN, Florencia y CICOLELLA, Mariana. 2009. Turismo rural en Argentina. Concepto, situación y perspectivas.IICA. Buenos Aires, Argentina. 117 p.

SACCO DOS ANJOS, Flavio y VELLEDA CALDAS Nadia. 2007. Pluriactividad y agricultura familiar en Brasil: el caso de Rio Grande do Sul. En: Revista de la CEPAL n 93, diciembre de 2007.

SARASA, José Luis Andrés. 2000. Aportaciones básicas del turismo al desarrollo rural. En: Cuadernos de Turismo, núm. 6, pp. 45-59.

SARASA, José Luis Andrés. 2014. La utopía del turismo rural como actividad excluyente: sus consecuencias. En Cuadernos de Turismo, núm. 34, pp. 15-32, Universidad de Murcia, España. 
SCALISE, Jorge. 2012. Herramientas técnicas y conceptos claves para el desarrollo del turismo rural. PROSAP. - 1a ed. - Buenos Aires.

SILI, Marcelo. 2007. Fragmentación territorial y desarrollo rural. Nuevas interpretaciones y propuestas para el desarrollo de los territorios rurales en un contexto de globalización. Ed. Banco Mundial.

SILI, Marcelo. 2010. ¿Cómo revertir la crisis y la fragmentación de los territorios rurales? Ideas y propuestas para emprender procesos de desarrollo territorial rural. Ediciones INTA. Buenos Aires, Argentina.

TEUBAL, Miguel y RODRIGUEZ, Javier. 2001. Neoliberalismo y crisis agraria. En: GIARRACA, Norma y otros. La protesta social en la Argentina. Trasformaciones económicas y crisis sociales en el interior del país. Ed. Alianza. Buenos Aires.

TORT M. y ROMÁN M. 2005. Explotaciones familiares: Diversidad de conceptos y criterios operativos. En: Productores Familiares Pampeanos: Hacia la comprensión de Similitudes y Diferenciaciones Zonales. Coord. María del Carmen Gonzáles. Editorial ASTRALIB. Buenos Aires.

VILLARINO PÉREZ, M; de UÑA ALVAREZ,E; y CANOVES VALIENTE, G. 2009. Reflexiones sobre experiencias de diversificación del turismo rural en España. Serie Geográfica 15. España.

WALLINGRE, Noemí. 2008. Evolución del desarrollo del turismo en la provincia de Entre Ríos, Argentina. En: Revista Tiempo de Gestión n 5. Universidad Autónoma de Entre Ríos (UADER), Entre Ríos. 


\section{Anexos}




\title{
ANEXO 1- Formato de cuestionario a informantes clave territoriales para construcción de precaracterización
}

\author{
Datos del entrevistado \\ Nombre y Apellido: \\ Organismo: \\ Cargo / función: \\ Antigüedad en su cargo: \\ Fecha de Entrevista:
}

\section{Preguntas para determinar la pretipología de casos}

¿Cuántas propuestas de turismo rural funcionan en la zona?

De estas propuestas:

I. Cuántas de estas propuestas están gestionadas por productores agropecuarios

II. Cuántas de estas propuestas están gestionadas por otros actores que no son productores agropecuarios

De los emprendimientos gestionados por productores agropecuarios (I):
A. cuántos son alojamientos
B. cuántos ofrecen actividades
C. cuántos ofrecen servicios de gastronomía o venta de productos alimenticios/regionales
D. cuántos combinan estas actividades

De los alojamientos (I.A):

A.1 Cuántos tienen mano de obra mayormente familiar

A.2 Cuántos tienen mano de obra que mayormente no es familiar (empleados, encargados, etc)

A.1.De los alojamientos con más mano de obra familiar

A.1.1 Cuántos de los productores que poseen los alojamientos tienen hijos, y de éstos que trabajen con ellos

A.1.2 Cuántos de los productores que poseen los alojamientos no tienen hijos, y si tienen son independientes económicamente/ no se vinculan con el trabajo de la familia.

A.1.3Cuántos de los alojamientos están a cargo de actores nacidos/ criados en la zona o radicados hace menos de 10 años- antigüedad de la actividad

A.1.4 Cuántos de los alojamientos están a cargo de actores que no han nacido o en la zona o que se radicaron recientemente (menos de 10 años)

A.1.5. Cuántos de los productores que poseen los alojamientos integran redes asociativas para el desarrollo de sus actividades.

A.1.6 Cuántos de los productores que poseen los alojamientos no integran redes asociativas para el desarrollo de sus actividades.

A.2.De los alojamientos con más empleados que mano de obra familiar

A.2.1 Cuántos de los productores que poseen los alojamientos tienen hijos, y de éstos que trabajen con ellos

A.2.2 Cuántos de los productores que poseen los alojamientos no tienen hijos, y si tienen son independientes económicamente/ no se vinculan con el trabajo de la familia.

A.2.3Cuántos de los alojamientos están a cargo de actores nacidos/ criados en la zona o radicados hace menos de 10 años- antigüedad de la actividad

A.2.4 Cuántos de los alojamientos están a cargo de actores que no han nacido o en la zona o que se radicaron recientemente (menos de 10 años)

A.2.5. Cuántos de los productores que poseen los alojamientos integran redes asociativas para el desarrollo de sus actividades. 
A.2.6 Cuántos de los productores que poseen los alojamientos no integran redes asociativas para el desarrollo de sus actividades.

\section{De las propuestas que ofrecen actividades (I.B)}

B.1 Cuántos tienen mano de obra mayormente familiar

B.2 Cuántos tienen mano de obra que mayormente no es familiar (empleados, encargados, etc)

B.1.De los emprendimientos con más mano de obra familiar

B.1.1 Cuántos de estos productores tienen hijos, y de éstos que trabajen con ellos

B.1.2 Cuántos de estos productores no tienen hijos, y si tienen son independientes económicamente/ no se vinculan con el trabajo de la familia.

B.1.3Cuántos de los emprendimientos están a cargo de actores nacidos/ criados en la zona o radicados hace menos de 10 años- antigüedad de la actividad

B.1.4 Cuántos de los emprendimientos están a cargo de actores que no han nacido o en la zona o que se radicaron recientemente (menos de 10 años)

B.1.5. Cuántos de estos productores integran redes asociativas para el desarrollo de sus actividades.

B.1.6 Cuántos de estos productores no integran redes asociativas para el desarrollo de sus actividades.

B.2.De los emprendimientos con más empleados que mano de obra familiar

B.2.1 Cuántos de estos productores tienen hijos, y de éstos que trabajen con ellos

B.2.2 Cuántos de estos productores no tienen hijos, y si tienen son independientes económicamente/ no se vinculan con el trabajo de la familia.

B.2.3Cuántos de los emprendimientos están a cargo de actores nacidos/ criados en la zona o radicados hace menos de 10 años- antigüedad de la actividad

B.2.4 Cuántos de los emprendimientos están a cargo de actores que no han nacido o en la zona o que se radicaron recientemente (menos de 10 años)

B.2.5. Cuántos de estos productores integran redes asociativas para el desarrollo de sus actividades.

B.2.6 Cuántos de estos productores no integran redes asociativas para el desarrollo de sus actividades.

De las propuestas que ofrecen servicios de gastronomía o venta de productos alimenticios/regionales (I.C)

C.1 Cuántos tienen mano de obra mayormente familiar

C.2 Cuántos tienen mano de obra que mayormente no es familiar (empleados, encargados, etc)

C.1.De los emprendimientos con más mano de obra familiar

C.1.1 Cuántos de estos productores tienen hijos, y de éstos que trabajen con ellos

C.1.2 Cuántos de estos productores no tienen hijos, y si tienen son independientes económicamente/ no se vinculan con el trabajo de la familia.

C.1.3Cuántos de los emprendimientos están a cargo de actores nacidos/ criados en la zona o radicados hace menos de 10 años- antigüedad de la actividad

C.1.4 Cuántos de los emprendimientos están a cargo de actores que no han nacido o en la zona o que se radicaron recientemente (menos de 10 años)

C.1.5. Cuántos de estos productores integran redes asociativas para el desarrollo de sus actividades.

C.1.6 Cuántos de estos productores no integran redes asociativas para el desarrollo de sus actividades.

C.2.De los emprendimientos con más empleados que mano de obra familiar

C.2.1 Cuántos de estos productores tienen hijos, y de éstos que trabajen con ellos 
C.2.2 Cuántos de estos productores no tienen hijos, y si tienen son independientes económicamente/ no se vinculan con el trabajo de la familia.

C.2.3Cuántos de los emprendimientos están a cargo de actores nacidos/ criados en la zona o radicados hace menos de 10 años- antigüedad de la actividad

C.2.4 Cuántos de los emprendimientos están a cargo de actores que no han nacido o en la zona o que se radicaron recientemente (menos de 10 años)

C.2.5. Cuántos de estos productores integran redes asociativas para el desarrollo de sus actividades.

C.2.6 Cuántos de estos productores no integran redes asociativas para el desarrollo de sus actividades.

De las propuestas que combinan estas actividades (I.D)

D.1.De los emprendimientos con más mano de obra familiar

D.1.1 Cuántos de estos productores tienen hijos, y de éstos que trabajen con ellos

D.1.2 Cuántos de estos productores no tienen hijos, y si tienen son independientes económicamente/ no se vinculan con el trabajo de la familia.

D.1.3Cuántos de los emprendimientos están a cargo de actores nacidos/ criados en la zona o radicados hace menos de 10 años- antigüedad de la actividad

D.1.4 Cuántos de los emprendimientos están a cargo de actores que no han nacido o en la zona o que se radicaron recientemente (menos de 10 años)

D.1.5. Cuántos de estos productores integran redes asociativas para el desarrollo de sus actividades.

D.1.6 Cuántos de estos productores no integran redes asociativas para el desarrollo de sus actividades.

D.2.De los emprendimientos con más empleados que mano de obra familiar

D.2.1 Cuántos de estos productores tienen hijos, y de éstos que trabajen con ellos

D.2.2 Cuántos de estos productores no tienen hijos, y si tienen son independientes económicamente/ no se vinculan con el trabajo de la familia.

D.2.3Cuántos de los emprendimientos están a cargo de actores nacidos/ criados en la zona o radicados hace menos de 10 años- antigüedad de la actividad

D.2.4 Cuántos de los emprendimientos están a cargo de actores que no han nacido o en la zona o que se radicaron recientemente (menos de 10 años)

D.2.5. Cuántos de estos productores integran redes asociativas para el desarrollo de sus actividades.

D.2.6 Cuántos de estos productores no integran redes asociativas para el desarrollo de sus actividades. 


\title{
ANEXO 2- Cuestionario base de la herramienta para realizar las entrevistas de los casos en territorio
}

\author{
RECORDATORIO- Objetivos de la investigación
}

Comprender las transformaciones operadas al interior del sistema familia/ explotación y en vinculación al entorno, a partir de la incorporación del turismo como estrategia de diversificación de actividades e ingresos.

En tanto los objetivos específicos son:

- Caracterizar la estructura y funcionamiento del sistema de actividad de las unidades productivas seleccionadas, desde una perspectiva global e histórica.

- Analizar los elementos constitutivos del sistema y las interacciones entre éstos y el sistema y el entorno, identificando las variaciones que se dan en la vinculación de los sistemas con el contexto.

- Identificar las tensiones, conflictos y sinergia que se dan al interior del sistema a partir de esta reconfiguración.

- Caracterizar las variaciones en el comportamiento de la familia a partir de las nuevas actividades turísticas en la explotación,

\section{Dimensiones a tener en cuenta para realizar las entrevistas}

\section{DIMENSIÓN TEMPORAL: ubicar la historia de la familia y la unidad}

Historia personal, familiar y de la unidad productiva: son de la zona? Cuándo llegaron? Cómo se hicieron de la tierra, del lugar? Vincular la familia con las actividades a las que se dedican...

\section{DIMENSIÓN DESCRIPTIVA}

Describir: cuántos trabajan y quiénes, las características del predio (hectáreas, características del suelo?)

Con qué herramientas, tecnologías cuentan?

Han recurrido a créditos para invertir?

Quién y cómo toman las decisiones en la unidad? Tienen algún asesoramiento? integran alguna cooperativa o red técnica en algunas de las actividades que realizan?

Sistema familia/ explotación:

- ¿Cómo está compuesta la familia?

- ¿Cuánto hace que viven en este campo?

- ¿Qué actividades realizan en esta explotación? (Datos productivos: cantidad de hectáreas, cantidad de cabezas, tipo cultivos, rendimientos...)

- ¿Quiénes trabajan en el campo? (Cómo distribuyen las tareas? Quién hace qué?) ¿cómo se organizan habitualmente?

- ¿Qué otras actividades realiza la familia?

- A qué actividades se dedican? Si hacen más de una, cómo se distribuyen? A qué se dedica cada miembro de la familia? Contratan empleados?

- Explicar el funcionamiento del sistema de actividades productivas?

\section{INCORPORACIÓN DEL TURISMO RURAL}

- Cuándo incorporan el turismo rural?

- A qué se dedican en turismo? Analizar ¿cómo se vinculan los productos de la producción agropecuaria con la actividad turística? 
- Generó cambios la introducción del turismo? Cómo era antes? Cómo es ahora?

- Sentido dado a la actividad: por qué decidieron vincularse al turismo? Cómo surge la idea?

- Hubo cambios en los roles, en las funciones, en las responsabilidades de la familia?

- Les da más tiempo, menos tiempo? Cómo son los tiempos de ocio, compartidos, de trabajo?

- Qué les aporta o qué les quita el turismo?

- ¿Y porque aparece la actividad del turismo en su explotación?

- Cómo fue la evolución de esta actividad en el campo?

- ¿Qué actividades hacen y brindan al turista?

- y quienes la hacen, como se dividen las tareas?

- Con la incorporación del turismo... ¿se modificó mucho el ritmo de vida de la familia?

- Desde que se dedican al turismo ¿tuvieron que dejar de hacer otras actividades?

- ¿Se ha vuelto más complejo el trabajo en la explotación? ¿Hay momentos de muchos nervios en la semana? Tensiones en algún momento del mes o del año?

- Respecto a sus hijos: se han ido? se dedican a la actividad principal? tienen otras expectativas? incorporan la actividad turística por descarte, porque no hay otras oportunidades...?

- Hay alguna tarea especial que sea sólo para la mujer? Que no pueda hacer el hombre de la familia?

\section{INGRESOS/ MOTIVACIONES/ EXPECTATIVAS}

- ¿Qué porcentaje del ingreso a la explotación le genera el turismo?

- Además de nuevos ingresos, ¿qué otra cosa les aporta el turismo rural?

- Si tuvieran que darles un consejo a otras familias que deseen avanzar con un emprendimiento de turismo rural, que consejos les darían sobre lo que funciona o no funciona, lo que hay que hacer o lo que no hay que hacer

- ¿Cómo ven su chacra/ unidad y emprendimiento de turismo en el futuro? Piensan hacer algún cambio? Incorporar otra actividad?

- ¿Por qué desarrollaron el turismo en lugar de profundizar y desarrollar más una actividad agropecuaria?

- ¿Tienen expectativas que sus hijos se queden en el campo? ¿Si se quedan es también con la actividad turística?

\section{DIMENSIONES TERRITORIALES/ DE REGULACIÓN}

- Han tenido apoyo de algún organismo para comenzar con la actividad turística?

- Integran algún grupo, asociación, cooperativa? Están organizados de alguna manera?

- Tienen algún reglamento, algunas normas de turismo rural en la zona?

- Con qué otras personas de la comunidad (otros emprendedores, municipios, INTA) se vinculan a partir del turismo?

- Qué tienen en común los emprendedores/ familias rurales de la zona que ofrecen turismo?

- Reciben muchos turistas? Cómo se promociona/ difunde la propuesta?

- Cómo se regulan los precios del servicio que se presta?

- Qué condiciones (físicas, paisajísticas, distancias, precios, etc) de la zona favorecen y/o limitan el desarrollo de la actividad?

Dimensión de regulación: políticas, dispositivos de apoyo, reglas, instituciones, herramientas, relaciones de fuerza...

Dimensión sectorial: actores de la cadena, mercados, regulaciones de precios... Dimensión territorial: identidad (historia, cultura, patrimonio, límites espaciales, nombres...), organización social y política (cooperativas, sindicatos...), dimensiones materiales (condiciones biofísicas y ordenamiento); organización reticular (bienes, personas, servicios, saberes, dinero...), proyecto de una sociedad sobre su espacio... 
PRIMERAS PREGUNTAS DISPARADORAS destinadas a los jóvenes hijos de la familia

1. A qué te dedicás vos? Estudiás? Trabajás?

2. En el predio ¿Qué actividades hacen y quienes la hacen, como se dividen las tareas?

3. Con la incorporación del turismo... ¿se modificó mucho tu ritmo de vida? Y el de la familia?

4. Desde que se dedican al turismo ¿tuvieron que dejar de hacer otras actividades?

5. ¿Qué crees que les aporta el turismo rural?

6. Crees que el turismo es la única alternativa laboral que tenés? O pensas que puede haber otras alternativas para tu futuro?

7. ¿Qué pensás hacer en el futuro: seguir trabajando en el campo con el turismo, ir a estudiar, etc. 
Caso $n^{\circ} 1$ - UNA VENTANA AL TRABAJO EN LA HUERTA

Familia integrada por la pareja de productores de 54 años con cuatro hijos de 25, 24, 17 y 9. Los dos mayores son varones y las menores mujeres. Son productores hortícolas que hace aproximadamente 2 años construyeron cuatro cabañas de madera en el predio donde poseen la huerta. A los turistas ofrecen el alojamiento en el campo, la posibilidad de cosechar su propia verdura, recorrer los campos y se les regala frutas y verduras de estación durante los días de pernocte allí. No se les ofrece desayuno pero se les deja una canasta con naranjas de regalo. Poseen 41 ha, 9 en producción. La chacra fue comprada por el abuelo del productor en el año 1957 y era citrícola en sus comienzos "pero daba apenas para vivir" (productora). El productor comenzó la huerta en ese predio hace 40 años solo y luego se sumó una de sus hermanas y su familia. Actualmente, trabajan las dos familias y contratan a un empleado cuando es necesario carpir la tierra. En el predio vive la familia, los abuelos (que ya no trabajan) y la familia de la hermana del productor. Se fueron capitalizando a partir de la producción hortícola. Poseen $4 / 5$ ha de citrus (heredadas del abuelo) pero no se les da cuidado, venden la fruta para jugo. Crian algunos animales de granja (cerdos y vacas) para consumo familiar y para mostrarles a los turistas. "Cuando los turistas quieren ven los animales se los lleva, ahora estamos poniendo 15 ovejas también) (hijo). La comercialización de las verduras se realiza en Chajarí, diariamente hacen el reparto

\section{Caso n²- UN ALMACÉN QUE ES MÁS QUE} DESPENSA

Pareja de comerciantes de 49 y 47 años con 3 hijos Familia de una pareja de 49 años y tres hijos de (2 varones de 14 y 19 y una mujer de 21). Manejan 20, 19 y 17 años. El es productor agropecuario, un almacén de ramos generales que la familia ingeniero agrónomo egresado de la UBA. Ella paterna compró hace 45 años ubicado en un paraje se dedica a la familia y atención del turismo. en las afueras de Chajarí. El ingreso a la unidad se Sus dos hijos estudian en Bs As (agronomía y da a partir de dos actividades: el almacén y la renta veterinaria) y el tercero empezará allí también. de unas casas que construyeron en el predio. El Poseen un casco de estancia antiguo en las almacén de campo funciona como una despensa, se afueras de Chajarí que han recuperado para venden productos de todo tipo además de productos vivienda familiar y hace 6 años reciben turistas. regionales. Funciona también un bar en el que Son dueños de una empresa agropecuaria que ofrecen picadas tanto para los lugareños como para posee una parte productiva y una comercial, turistas. Se ubica a 800 metros del complejo termal con varias unidades de negocio. El $50 \%$ de su de Chajarí, atractivo muy fuerte en la zona y desde producción se exporta. Tienen producción donde recomiendan el almacén. Es un negocio ganadera (feed lot), agricultura y producción de netamente familiar. No venden productos de arroz. Poseen una empresa de insumos en elaboración propia a excepción del pan y algún otro Chajarí "que hace todo lo que es producto de panificación que elabora el hijo del comercialización en general, provisión de medio que estudia gastronomía. Los productos insumos, tecnología, hacemos lo que es regionales (salame, miel, quesos, dulce de leche) los agricultura de precisión en manejo de agua" compran a productores de la colonia. El almacén se (el). Además, tienen una industria arrocera que ubica en un predio de 4 ha donde además se toma como insumos su producción. El predio encuentra la vivienda familiar y una granja con propio de la estancia cuenta con 400 ha. animales. Tienen 25/30 ovejas, vacas, 25/30 Alquilan unos 600 más. Se explotan 1000 ha de gallinas, chajá y avestruces. Son para consumo ganadería y cría de caballos de polo. Respecto familiar y a los huevos los venden en el almacén. a esta última, cuentan con infraestructura y Eventualmente venden algún cordero. En realidad personal idóneo, un club de polo (afiliado a la los padres siempre tuvieron animales pero ellos no Asociación Argentina de Polo (AAP), dos los toman como una actividad productiva que les canchas, pista de vareo, caballerizas, corrales genere un ingreso. "Mi padre también tenía y montureros a disposición de los socios. chanchos, hacía salames, mi madre ordeñaba. Durante los fines de semana se llevan a cabo Cuando faltaron ellos no hicimos más, él era el que prácticas de polo y se realizan torneos. E más sabía". (él). Uno de los hijos comenzó una casco es un alojamiento con 5 habitaciones y pequeña huerta. Pero a entender de la pareja no espacios de recreación. También se alquila 
a los clientes en la ciudad, que son alrededor de $\mid$ tienen mucho tiempo para otra actividad. "Por ahí no para eventos especiales. Ofrecen cabalgatas, 20 supermercados. "Tratamos de cumplir a te dan los tiempos, no se puede, porque en el desayunos camperos, almuerzos de campo, rajatabla con los negocios (productora). "E primer cliente que mi mamá le llevaba la verdura en bicicleta todavía es cliente" (hijo). Los clientes extralocales retiran la producción en la chacra, vienen de Federal, Feliciano, Mocoretá. "Vienen por temporada, cuando nos sobra verdura porque tenemos mucha entonces les decimos que vengan y si no la entregamos a un mayorista que lleva a otras zonas". almacén ténes que estar, haya gente o no" (ella). paseos por el campo, pileta habilitada, "Tenés que tenerlo abierto siempre" (él). Abren bicicletas. "Hay también un turismo especifico todos los días con excepción del domingo, de 7:30 a ligado al polo, nosotros criamos caballos, esto $12: 15 / 30$ hs y de $15: 15$ a 21 hs. Los fines de semana además es un club, se juega, hay torneos, se largos son los que reciben más cantidad de turistas. organizan eventos, clases para gente interesada" (él). Tienen dos modalidades de trabajo, reserva completa o solo alojamiento. "Tenemos dos sistemas, uno con todas las comidas y todo incluido o alojamiento con desayuno. Todo es a medida de la gente" (ella).

1.B.Caracterización del SA Familia/ explotación según los recursos/ capitales

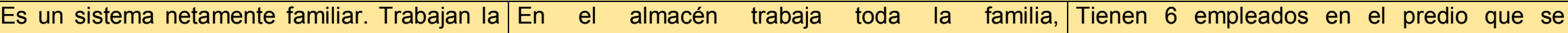
pareja de productores y uno de los hijos, la fundamentalmente la pareja, aunque los 3 hijos dedican 2 a ganadería, 2 a mantenimiento y 2 hermana del productor, su esposo y una hija. Una de las hijas de la pareja y uno de sus primos se suman cuando no van a la escuela. "Ellos trabajan con nosotros, se les da un porcentaje pero esto es todo nuestro, ellos están acá y trabajan con nosotros" (productora). Todas las mañanas cosechan todos y por la tarde realizan el reparto. En turismo trabaja solamente la familia del productor y productora. El hijo que estudia afuera está los fines de semana largos y vacaciones y colabora con las cabañas, al igual que la hija mayor. Tienen repartidas las tareas al interior de la familia para organizar mejor los tiempos entre las dos actividades.

"Todos sabemos todo pero cada uno tiene su puesto. Lo que está bien definido es: a la página y reservas la maneja mi papá. Limpian mamá y mi hermana. Yo corto el patio y todo lo que es el parque" (hijo). "Si no está mi mamá y hay que limpiar una cabaña lo hacemos nosotros, si no está mi papá y hay que contestar, lo sé hacer también, pero para que haya uno que sepa bien cuántas cabañas están ocupadas, etc, nos organizamos así"(hijo). "A los turistas los colaboran, más los varones. Todos hacen todo, a los caballos. ("Mínimo, a veces se contrata si ncluso comparten las tareas domésticas. "Lo que es necesario"). La más dedicada al turismo es hay que hacer, se hace entre todos. Si hay que la mujer que se encarga de las reservas, de la completar las góndolas, despachar, tanto en la logística, la organización general. También despensa como en el bar". (él). Una tarea específica elabora dulces para el consumo familiar y de los del marido es hacer las compras, el contacto con los turistas, no se venden. "Entre todos aportamos roveedores, el resto se comparte. No contratan un poco más allá de que cada uno se ocupa de empleados. Las decisiones se discuten en el seno los suyo. Cuando hay turistas yo trato de de la familia. cocinar a la noche" (el)."Tengo una señora que viene cuando hay gente que es de acá y toda la vida trabajó con nosotros. El también cocina, hace todo lo que es al disco, asados". Trabaja allí el cuñado y se especializa en el tema de los caballos, es contratado part time. En total tiene 35 empleados si se incluye la agroindustria y las otras unidades de negocio. 
La familia vive del almacén. Han reinvertido en el salón para separar el bar de la despensa, sostiene en parte con el resto de las actividades modernizaron heladeras y aberturas. Con parte de pero colabora al sistema. Las las ganancias construyeron dos inmuebles para actividades/unidades se complementan: alquiler. El turismo implica un ingreso más, son "porque los márgenes comerciales son nuevos clientes del almacén. Aunque la mayoría de importantes, el volumen en lo productivo es los clientes son de la colonia, funciona como la menor pero los márgenes son más importantes. despensa de la zona. "La ganancia que te da es para Yo te diría que lo comercial y productivo están vivir, no te da pata invertir mucho, por eso me incliné ahí. El 50\% de la facturación es exportación, lo que es industria es todo exportación. Estamos 


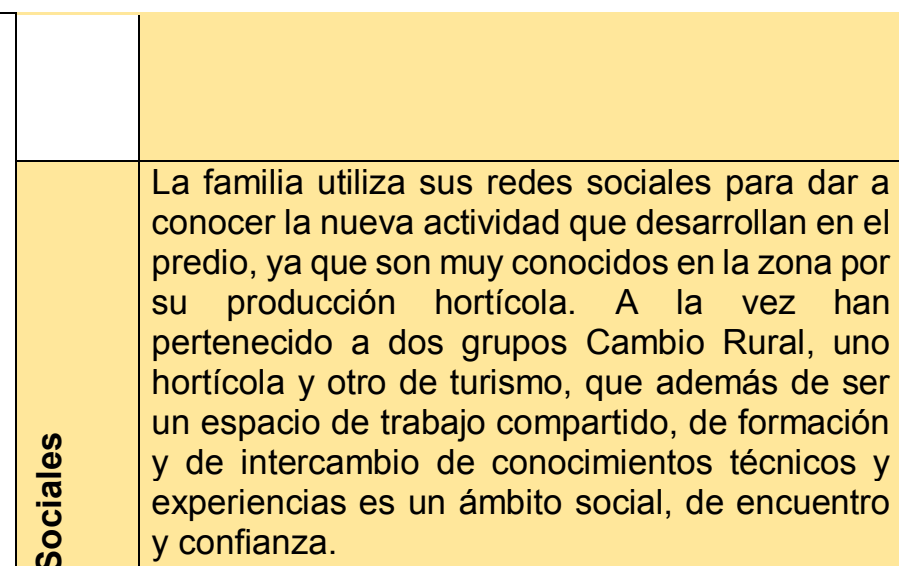

por los departamentitos, ahora estoy arrancando otro" (él)

Al conformar el grupo de turismo rural con otros Se evidencia un importante intercambio prestadores de alojamiento muy cercanos, han cultural con los turistas, que en su gran logrado una relación personal de confianza y mayoría son extranjeros. La idea que recomendación. Cuando eran vecinos no tenían manejan es que los turistas se sientan como en tanta relación como a partir de los grupos. Estos su priopia casa, por lo que se dan y generan dueños de cabañas, cercanos, los recomiendan a espacios para el dialogo y disfrute. Incluso los turistas para sus compras. "Los turistas van y mencionan algunas familias que los han vienen varias veces al día, incluso $\mathrm{M}$ (el dueño de visitado en varias ocasiones y les traen regalos una cabaña) nos avisa si viene alguno fuera de a los hijos. "Se dan esas cosas, comés con

(a)

La familia demuestra sentir mucho orgullo por su
trayectoria como productores hortícolas, destacan que gracias a esa actividad se ha capitalizado y logrado todo lo que tienen. "Cuando arrancamos con las cabañas yo les dije a los dos no descuidemos la huerta porque eso es lo que nos dio todo lo que tenemos" : (productora).Al ser de la zona, haber nacido allí, 늘 da un sentido de pertenencia al lugar y un cariño por su terruño, que pretenden dar a ฮ conocer a través del turismo. Cuando se les - consultó qué tenían en común las familias de la zona que hacen turismo, el hijo contestó "Yo creo que lo económico no es lo que más pesa, a lo mejor es que gusta recibir bien a la gente, que la gente se encariñe con el lugar y vea nuestra forma de ser". (hijo). "Si lo hacés solamente por dinero, no va" (productor). "Mostrarle lo tuyo, lo que tenés, lo que hacés. A la gente le gusta que horario". (hijo)

ellos, a veces te cocinan ellos, hay un ámbito de intercambio" (el). Lo social es muy fuerte en el sistema, de hecho, la pareja plantea que su idea siempre fue vivir en el campo y recibir amigos. Fueron ellos quienes los entusiasmaron para hacer turismo. No trabajan en red con otros productores relaciones con turismo rural tampoco integran redes técnicas. La posibilidad de narrar la historia del lugar refuerza La particularidad del caso se relaciona a la la identidad familiar y de la colonia. Además, genera esencia de la familia y el lugar. Todo indica que orgullo por lo propio y por lo construido imprimen a su propuesta de turismo aquellos históricamente. "Vienen y nos dicen uy mirá... estos aspectos y actividades que disfruta la misma almacenes no se ven más! Esa gente, cuando son familia porque es la familia la que ama vivir en así te da gusto porque son gente dada y sencilla. el campo y ha sido esta su opción. Otra Nos da alegría". (él). Ese reconocimiento es un cuestión es que le dan vital importancia al estímulo. "Te dan ganas de seguir con lo que estás cuidado del ambiente, a la producción de haciendo". (ella) "A la parte de la historia la cuenta alimentos saludables. A esto lo trasladan al mi papá, si lo dejás puede estar una hora y pico turismo. "Todo es casero. Todo es natural, la conversando". (hijo).

carne que comemos es producción de acá y a pasto. La mayoría de la verdura es de la huerta. No se le echa nada. Nosotros comemos esto. (productor). "Yo ni loca fumigo algo que nosotros comemos, que es lo mismo que consume el turista" (ella). "El $90 \%$ de lo que consumimos lo producimos, es una cuestión cultural, toda la vida fue así. Nosotros criamos ovejas asi que hacemos todas las comidas que 
se te ocurran con ovejas" (el) El deporte, la cría de caballos de polo también se vincula con un gusto personal y familiar, una actividad que desarrollan como deporte y comercialmente. Hay gente que ha venido por el polo, otra por turismo pero le gusta el polo. El polo también le suma" (productor).

Se da una importante vinculación con los vecinos y otros productores de la colonia, dada por la actividad comercial a la que se dedican hace tiempo. Además, compran hace años productos elaborados por gente de la zona y dan garantía de la calidad y el sabor. Se evidencia un fuerte sentido de pertenencia y amor por su lugar. "Nosotros vivimos y crecimos en el campo. Esto no es campo campo porque está el pueblo cerca". (ella). "Para e que se crió acá, no hay mejor lugar que este. Por más de que la ciudad sea linda y tenga todo lo que quieras, no es como el lugar en que naciste y te criaste". (él) "Los turistas ven que estamos tranquilos, cuántos vienen y nos dicen qué lindo ugar qué paz, cómo me gustaría tener una casita acá". (él).

).




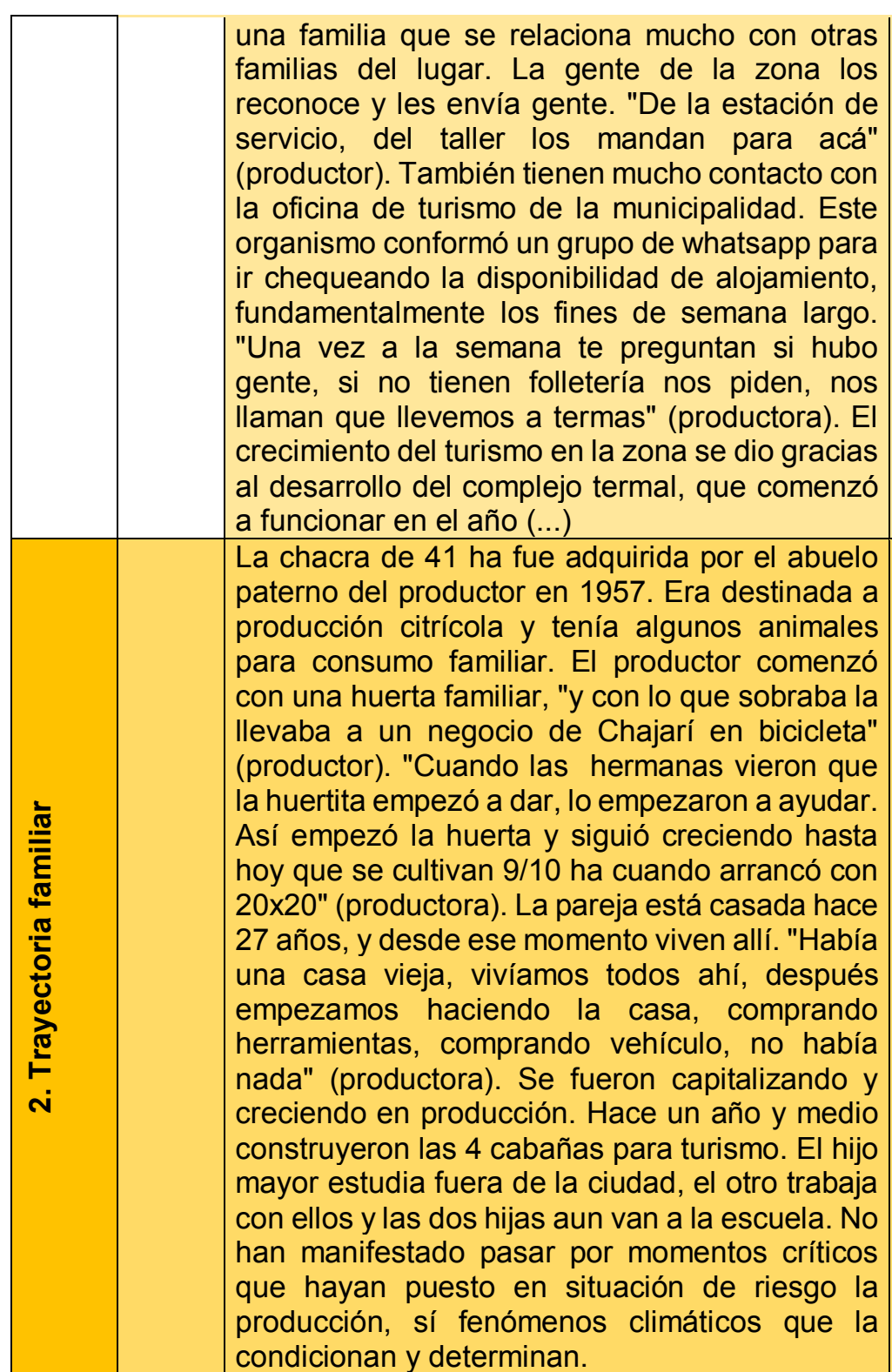

La pareja se conoce hace 30 años. Ella nació en Los La pareja es de Concordia. En el 1996 Consquistadores, pero su abuela vivía en la zona y comienzan su establecimiento en Chajarí, se fue a estudiar allí. El marido nació en la Colonia donde la familia de la mujer era originaria. Su San Ramón, a $30 \mathrm{~km}$ del lugar. Hace 25 años que abuela tenía un campo en la zona. Vivían en la están casados. Los padres compraron el almacén ciudad pero con intenciones de irse a vivir al hace 45 años y luego se lo heredaron a ellos. En el campo. "La idea original era vivir en el campos" 2004 se hace cargo la pareja del almacén. En la (él). Compran el caso de estancia en el año trayectoria no manifiestan grandes crisis ni 2000 a un tío de la familia de la mujer. "Esta contratiempos, hablan de altibajos normales del estancia había sido originariamente de la comercio, épocas en las que les fue mejor y otras no familia que había quedado por división hasta tanto. Abrieron en el turismo en el 2012, cuando que llegó a manos de un tío abuelo", relata el fueron convocados a integrar un primer grupo productor. "El tío abuelo hizo todos los Cambio Rural de turismo rural con otros actores de esfuerzos para que quede en la familia. En ese Chajarí y Villa del Rosario. Aproximadamente, en el momento estaba muy abandonado, la parte de 2013 construyen el primer departamento, a los 2 la estructura, edilicia" (productor). "Otros que años el segundo y están en vías de construir un han venido nos han dicho, a esto hay que tercero. demolerlo" (ella). Se fue haciendo la reparación "despacio y con ganas. Es difícil mantenerlo, es mucho esfuerzo, mucho tiempo y mucha plata" (ella). "Lo empezamos a poner lindo, a arreglar y nos encantaba invitar a amigos, a pasar tiempo con amigos acá. Mucha gente nos decía por qué no hacen turismo acá? Y así empezamos, de a poco" (ella). En el año 2004 


\begin{tabular}{|c|c|c|c|c|}
\hline & & & & $\begin{array}{l}\text { compran un plantel de yeguas pura sangre de } \\
\text { carrera para la cría de caballos de polo. Hace } 6 \\
\text { años aproximadamente B5que arrancaron con } \\
\text { turismo. Fueron creciendo en turismo. "Al } \\
\text { principio era de boca en boca, hace un par de } \\
\text { años empezamos con la página web y } \\
\text { empezamos con booking, ahora se va } \\
\text { conociendo más" (ella) "Al principio teníamos } \\
\text { un poco de miedo porque vienen a tu casa pero } \\
\text { ya está..." (el) . Período de expansión y } \\
\text { crecimiento en turismo: "Tuvimos una época } \\
\text { muy fuerte de turismo extranjero. Venían sin } \\
\text { que los llamen, prácticamente todo el turismo } \\
\text { que teníamos era extranjero. Después se } \\
\text { planchó más el de afuera un poco por el tipo de } \\
\text { cambio y otro porque no había una buena } \\
\text { visualización afuera en el tema de turismo. } \\
\text { Ahora estamos como lanzando un poco de } \\
\text { vuelta, más masivo y nos gusta la idea" (el) }\end{array}$ \\
\hline 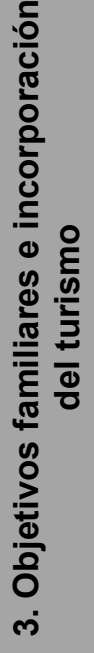 & 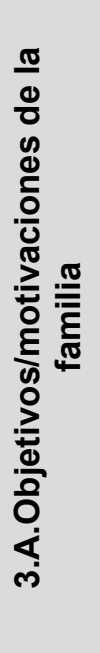 & $\begin{array}{l}\text { En este caso hay un flujo de materia prima de la } \\
\text { producción primaria al turismo, pero se le agrega } \\
\text { otro valor, esto es, a los turistas se les permite } \\
\text { tener la experiencia de cosechar con los } \\
\text { productores, se les regala la verdura que van a } \\
\text { utilizar en los días que permanezcan alojados en } \\
\text { las cabañas, se les regala naranjas. La } \\
\text { producción se integra a la actividad turística, es } \\
\text { parte del recorrido y de la esencia de las } \\
\text { cabañas que tienen vista a la huerta. }\end{array}$ & $\begin{array}{l}\text { Para la pareja, el turismo hoy representa un ingreso } \\
\text { más al generado por el almacén y no altera el ritmo } \\
\text { familiar ni del negocio.Lo han incoporado de manera } \\
\text { natural. "El turista viene y gasta, te compra lo que } \\
\text { son los regionales, seguro te va a llevar salame, } \\
\text { queso y miel porque sabe que es mercadería } \\
\text { casera". (él). "Fuimos creciendo con el turismo, se } \\
\text { vende un } 40 \% \text { más. Los fines de semana largo y } \\
\text { semana santa hay mucho movimiento" (él). Hasta } \\
\text { ahora nunca se pensó en cerrar, se trabajó } \\
\text { regularmente" (él). "Hubo altibajos pero siempre se } \\
\text { trabajó" (ella). Piensan en seguir reinvirtiendo.El jefe } \\
\text { de la familia proyecta además de mantener el } \\
\text { almacén, la construcción de casas de alquiler, } \\
\text { para generar un ingreso más. A mí me gustaría } \\
\text { seguir haciendo casitas para alquilar". (el). Me }\end{array}$ & $\begin{array}{l}\text { En este caso se destaca la preocupación } \\
\text { por el ambiente, por lo natural, por un estilo } \\
\text { de vida personal y familiar ligado al } \\
\text { consumo de alimentos sanos y en contacto } \\
\text { con la naturaleza y el campo, idea que se } \\
\text { transpola al turismo, "Nosotros acá que } \\
\text { tenemos el proyecto de turismo no tenemos } \\
\text { ninguna actividad contaminante. El concepto } \\
\text { que vendemos sin venderlo es que venís a un } \\
\text { lugar auténtico y natural, acá nos podemos dar } \\
\text { el lujo de eso" (el). El turismo colabora en el } \\
\text { mantenimiento del patrimonio familiar. "El } \\
\text { turismo es interesantísimo, primero porque } \\
\text { arraiga, segundo porque mantiene la historia y } \\
\text { además lo que está generando es un poco de } \\
\text { desarrollo en el lugar" (productor). "No hay }\end{array}$ \\
\hline
\end{tabular}




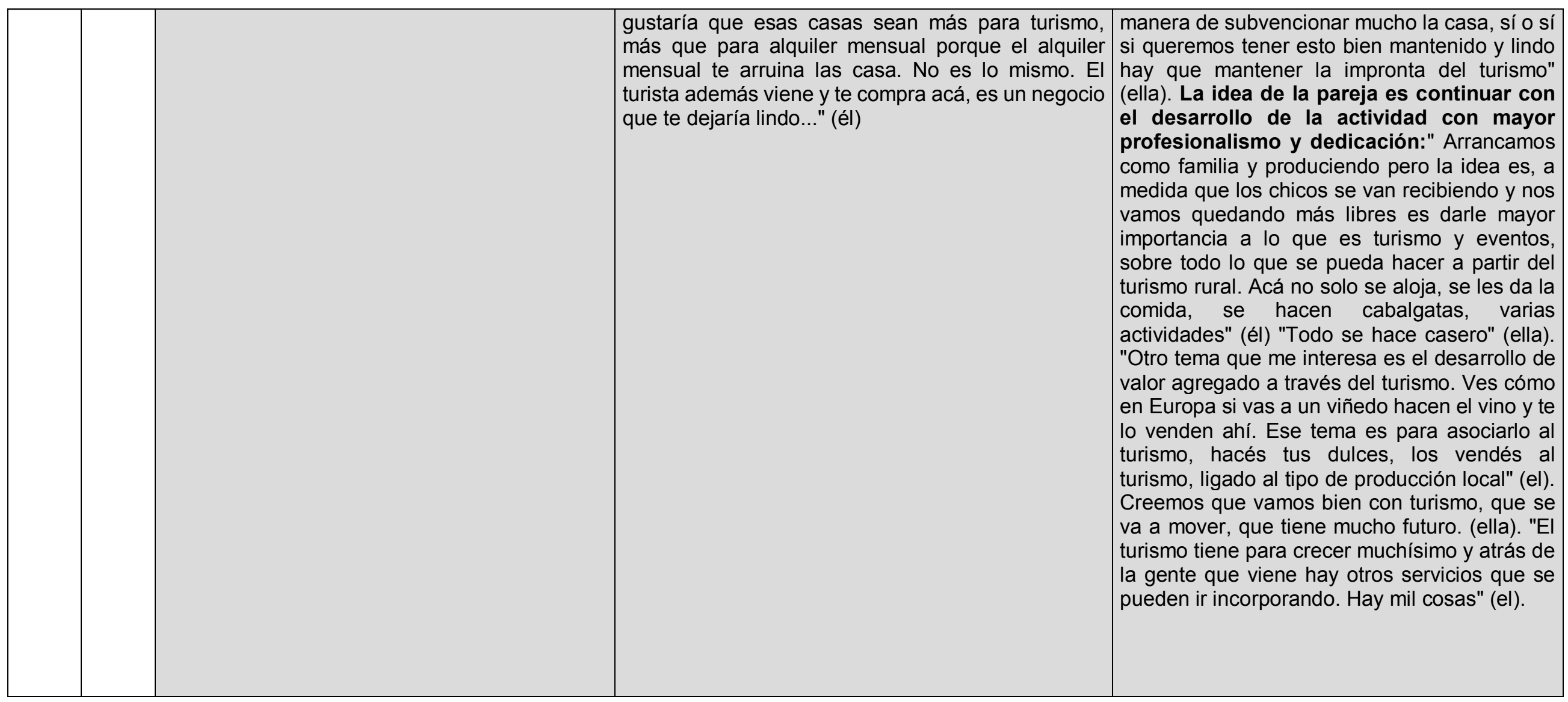




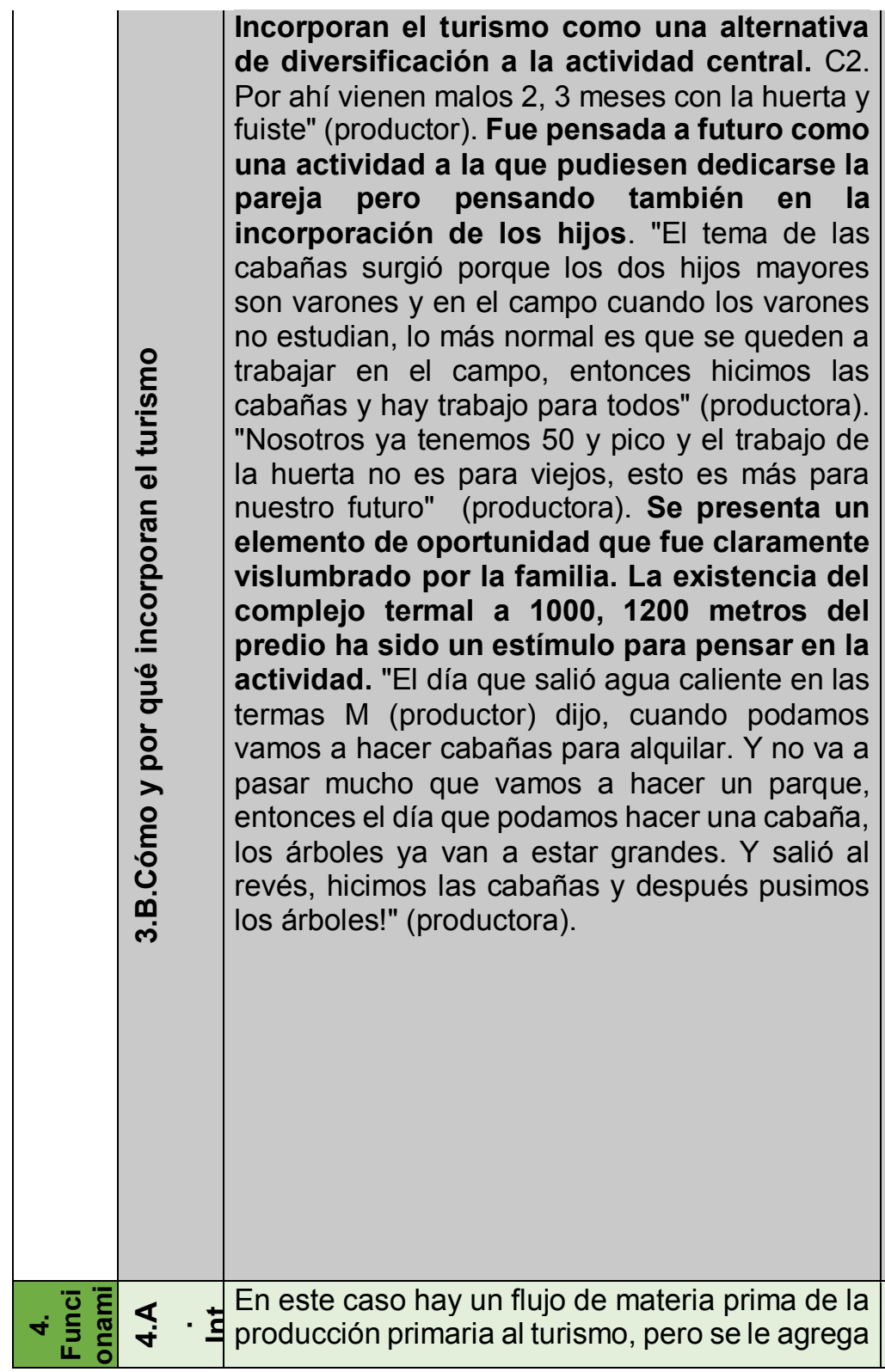

La cercanía a las termas y la ubicación El turismo surge a partir del potencial del privilegiada, a metros de la RN 14 son elementos casco de estancia como alojamiento, el que han movilizado la incorporación de los turistas. entorno, su estética, sus dimensiones y Además, a partir de la integración de un segundo también como una inversión a futuro: "Hoy grupo Cambio Rural de turismo, el vínculo con el se mantiene con las otras actividades, es como municipio y con el complejo termal (que es la inversión en vivienda, y de hecho ha municipal) es más fluido. "Los turistas vienen por el generado ingresos, le da cierta movilidad" (el). plano que les dan en las termas. Vienen a conocer, Necesidad de mantener el edificio y algunos compran, otros vienen, miran y se van". estructura: "Yo creo que LV sin el proyecto de (él).El grupo Cambio Rural orientado al turismo rural turismo en el tiempo no tiene sustento porque que se conformó en la zona fue un impulso para el es real, esto se va agravando más el costo de desarrollo del turismo rural. "Vino gente de termas y estructura y nosotros lo que al menos el técnico a hablarnos para incorporaron en el grupo. pretendemos es ir arreglando de a poco y que Y nosotros dijimos que sí" (él). El turismo significa se pague con el mismo valor, sino estás nuevos clientes y más ventas para el almacén. permanentemente subsidiando un elefante "Es un beneficio que te deja, para nosotros es blanco que algún día te voltea". "Tampoco es positivo". (él) Importante desarrollo del turismo en que las actividades son super rentables y la localidad con un impulso a partir de la creación podés subsidiar una casa con toda esta de las termas. "Las termas son lo principal fue el estructura". Respuesta a una demanda factor inicial para el desarrollo". (él). turística: existe un perfi que nada el extranjero de aprender sobre el campo argentino y compartir las costumbres rurales. Les interesa la tranquilidad del lugar, degustar comidas típicas argentinas. "Lo importante es el concepto de turismo que nosotros hacemos, de que la persona que viene se sienta como en su casa, es muy abierto y a la vez muy exclusivo" (el). Idea de descanso en un entorno rural: "van a pescar, a andar a caballo, y después se quedan, no se les ocurre hacer mucho, agarran un libro, van a la pileta. "Disfrutan de estar acá"(ella). "Los extranjeros se interesan mucho por la producción, se sientan a comer y te preguntan de todo, quieren saber todo. A muchos les apasiona, ven desde su óptica cosas que nosotros damos por hecho" (el)

Como actividades de generación de ingresos se Con respecto a la relación de la actividad pueden mencionar dos: el elmacén y el alquiler de turística con los productos del resto de las 


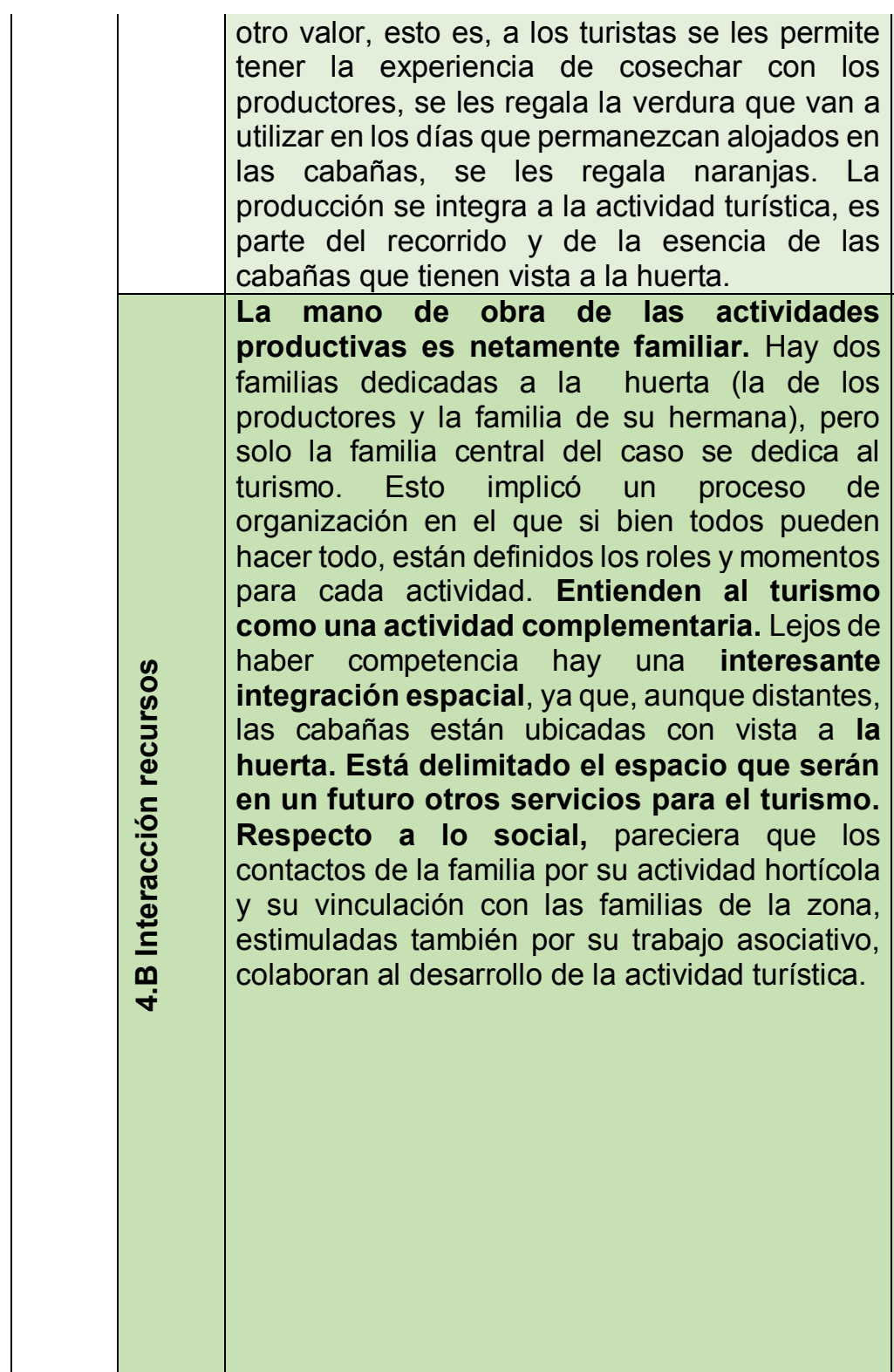

departamentos. Además tienen animales para actividades puede decirse que hay una consumo propio y eventualmente alguna venta integración de los insumos de la producción ocasional en el almacén. No se evidencia una primaria para el consumo familiar y como interacción importante entre productos de servicio gastronómico que se brinda al diferentes actividades. Puede mencionarse la turismo (productos de la huerta, carne vacuna venta en el almacén de huevos de producción y ovina de producción propia) propia.

El capital humano familiar es el sustento de las Respecto al capital humano, en el predio de tareas de generación de ingresos. No hay la estancia cuentan con empleados que contratación de mano de obra extra. No hay desarrollan diversas actividades. En cuanto a tareas especificamente asignadas para los los miembros de la familia, la más dedicada a miembros de la familia sino que todos comparten las la logística y organización de la actividad tareas, incluso las domésticas. El rol más turística es la productora, quien además determinante es el del padre como portador de la elabora dulces y conservas para el consumo. El historia del lugar y del almacén, la madre también productor está más dedicado al resto de las interviene pero en menor medida. Existe una actividades productivas y comerciales, pero se transmisión de los saberes en el manejo del almacén suma a la propuesta turística cocinando y que los padres enseñan a los hijos, compartiendo con los turistas, en lo general por fundamentalmente en lo que es la organización del la noche. El conocimiento, experiencia y saber almacén, la venta y el manejo del bar. Los recursos de los productores en relación a su actividad, al físicos y materiales que se utilizan para la actividad sector turístico dado por su interés y posibilidad comercial y turística son los mismos, ya que se de viajar, idiosincrasia e intereses particulares realizan en el mismo espacio. No se evidencia como el deporte, la alimentación sana, el competencia por su uso por el momento.Desde cuidado del ambiente y del patrimonio hacen el punto de vista económico, las ganancias que la propuesta turística sea lo que es, es permiten mantener a la familia y realizar algunas decir, le imprimen calidad y calidez humana inversiones. Respecto a lo social, la vinculación además de conocimiento técnico. Lo mismo con otros actores de turismo ha incentivado a la sucede con el polo, actividad que además familia a promover el almacén para este sector, practican y disfrutan. En cuanto a los incluso a incorporar productos regionales y realizar recursos naturales y el uso de la tierra, parte picadas. El intercambio social y cultural es uno de los principales aportes que genera la incorporación de los turistas a la dinámica comercial del almacén.

de las actividades productivas que no requieren uso de agroquímicos se desarrollan en el predio de la estancia, donde a la vez vive la familia. Esto ha sido remarcado fuertemente en la entrevista. Además, poseen otros predios donde generan otras actividades productivas. Es importante destacar que se diferencian los sectores de uso 


\begin{tabular}{|c|c|c|c|}
\hline & & & $\begin{array}{l}\text { exclusivo familiar y abierto al turismo, lo que } \\
\text { promueve y propicia la intimidad de la familia y } \\
\text { de los turistas, además se da una distribución } \\
\text { de las actividades productivas en el predio de } \\
\text { la estancia de tal forma que sea ordenada y que } \\
\text { permita el disfrute de los turistas. }\end{array}$ \\
\hline 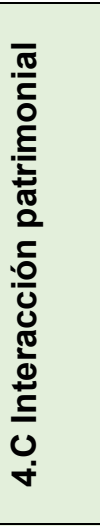 & $\begin{array}{l}\text { La actividad turística, más allá del servicio de } \\
\text { alojamiento prestado, se basa en la historia } \\
\text { familiar, en sus experiencias y en la tarea a la } \\
\text { que se dedican históricamente. El fuerte y } \\
\text { aquello que distingue esta propuesta de otros } \\
\text { alojamientos de la zona es el perfil productivo del } \\
\text { predio y el saber y trabajo de la familia. Esto, que } \\
\text { es reconocido por los turistas y otros vecinos, es } \\
\text { un elemento que genera orgullo a la familia y los } \\
\text { estimula a seguir invirtiendo y apostando por el } \\
\text { turismo. }\end{array}$ & $\begin{array}{l}\text { El patrimonio arquitectónico y cultural representado } \\
\text { en el almacén es la base de la propuesta que ofrecen } \\
\text { en la que la visita a un almacén de ramos generales } \\
\text { se combina con la posibilidad de comprar productos } \\
\text { artesanales de la zona, compartir alguna } \\
\text { picadas,conocer más de la historia y el intercambio } \\
\text { con lugareños. El turismo pone en valor el espacio, el } \\
\text { patrimonio. El turismo refuerza su identidad, } \\
\text { familiar y comunitaria. El reconocimiento de la } \\
\text { tradición, el esfuerzo por resguardar el patrimonio y } \\
\text { continuar con la tarea dada por la mirada de alguien } \\
\text { externo a la colonia es un impulso a continuar con la } \\
\text { tarea. }\end{array}$ & $\begin{array}{l}\text { La implementación de la actividad turística } \\
\text { se basa y surge a partir del potencial del } \\
\text { casco histórico de la estancia. Esto es lo que } \\
\text { le da sustento. A esto se suma el mobiliario } \\
\text { antiguo reciclado y los objetos de valor histórico } \\
\text { que agregan valor y estétiva a la propuesta }\end{array}$ \\
\hline 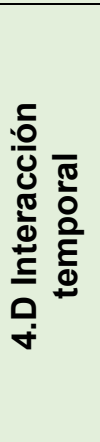 & $\begin{array}{l}\text { Se da claramente en este sistema ya que la } \\
\text { actividad turística complementa a la actividad } \\
\text { hortícola en la temporada en la que esta requiere } \\
\text { menor intensidad de trabajo. "Justo cuando la } \\
\text { huerta se pone más complicada que es verano, } \\
\text { es el fuerte del turismo", explica el productor. } \\
\text { También en esta familia se pudo observar la } \\
\text { visión del potencial que vieron en el turismo, } \\
\text { apenas se comenzó a trabajar en el complejo } \\
\text { termal. Ellos vislumbraron el desarrollo de la } \\
\text { actividad y proyectaron la inversión. }\end{array}$ & $\begin{array}{l}\text { La anticipación no es a largo plazo. La familia preve } \\
\text { que los fines de semana largo o los picos de turismo } \\
\text { en la zona pueden reportar un ingreso extra } \\
\text { importante. Hablan de un } 40 \% \text {. Se anticipan a esta } \\
\text { situación y toman decisiones en función de lo } \\
\text { anterior. }\end{array}$ & $\begin{array}{l}\text { La pareja piensa en el futuro, con hijos que ya } \\
\text { no viven con ellos y ven en el turismo una } \\
\text { alternativa para dedicarse que a la vez colabora } \\
\text { al mantenimiento de una estructura y } \\
\text { patrimonio que piensan heredar a sus hijos. Los } \\
\text { hijos estudian carreras relacionadas al agro y } \\
\text { sienten arraigo por ese espacio en particular ya } \\
\text { que es allí donde han vivido. }\end{array}$ \\
\hline
\end{tabular}




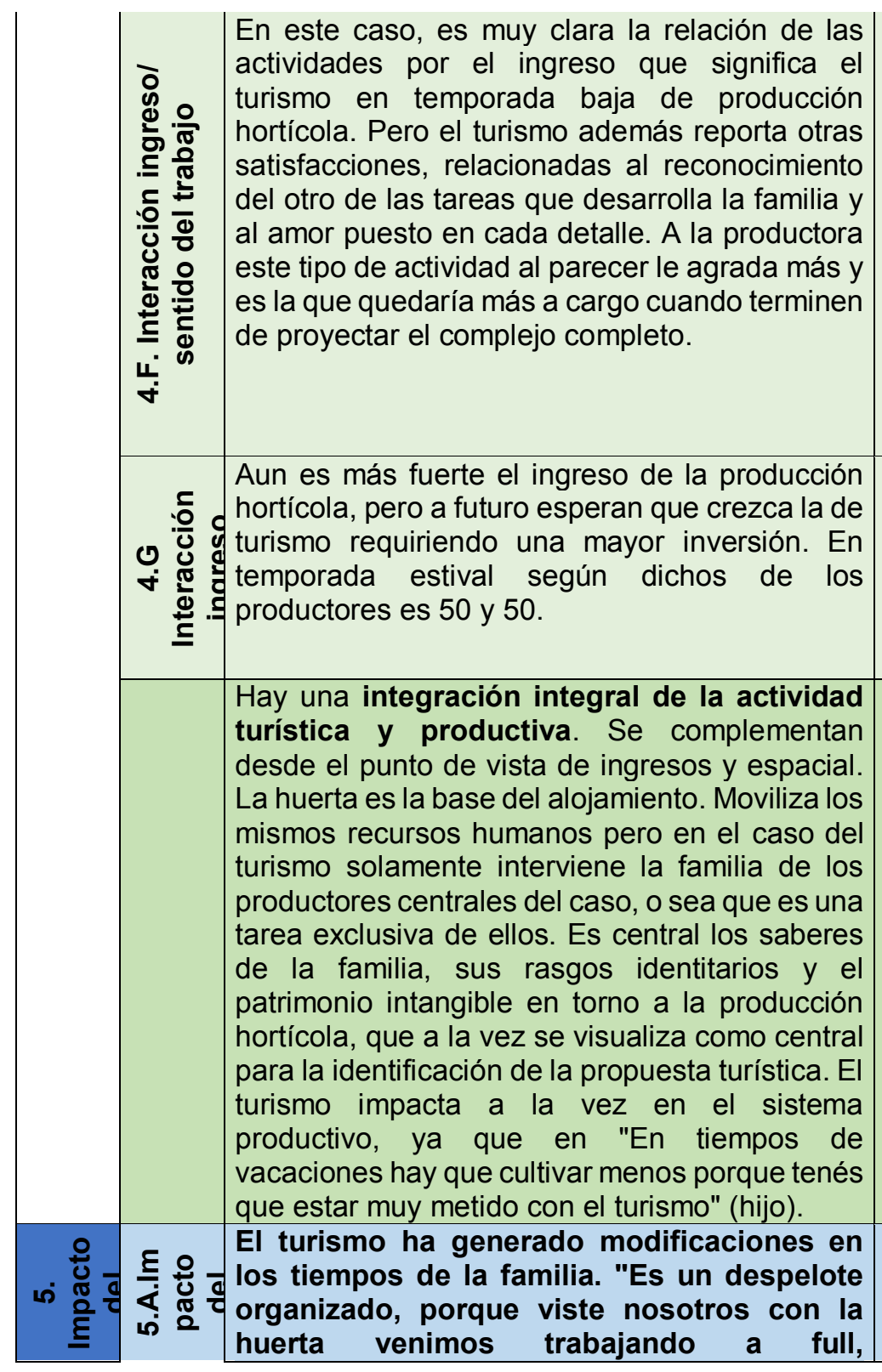

En este caso lo económico es determinante. $Y$ en Hay una apuesta al turismo a futuro por ser una este sentido el turismo aporta más ganancias, más actividad que les agrada desde lo social. movimiento comercial en el almacén, además de Económicamente hoy no implica grandes movilizar otros aspectos vinculados al ingresos pero sí se proyecta a futuro. El turismo reconocimiento social de mantener abierto un no resta. Para ellos la mantención de la almacén de colonia al público, de manera regular, la estancia es fundamental, pero sin el proyecto posibilidad de generar nuevas vinculaciones y de turismo en el tiempo lo ven insustentable a apertura cultural.

futuro.

El ingreso económico para la vida de la familia está dada por el almacén. La integración del turismo apota un $40 \%$ más de ventas. Las ganancias permiten cumplir las necesidades y expectativas de la familia y reinvertir en departamentos para alquiler.

El turismo y mantenimiento de la vivienda se sostiene en gran parte con el resto de las actividades que generan ingreso en el sistema. El ingreso por turismo es menor pero evoluciona. Las actividades productivas y comercial se complementan.

El turismo colabora, no es indispensable para el Al ser la estancia lugar de residencia de la desarrollo del resto de las actividades. No familia, el turismo puede como no existir. compite sino que complementa fundamentalmente Quizás a largo plazo se genere una interacción en términos de ingresos. de mayor sinergia en cuanto los mismos productores consideran al turismo como una alternativa para sostener y conservar el patrimonio. El mismo productor destaca que el campo va a seguir funcionando con o sin la estancia, pero al haber interés y arraigo piensan en el turismo para seguir conservando la propiedad.

La incorporación del turismo no ha generado un La familia vive en la estancia. Tienen una parte impacto mayor en la familia. Lo incorporaron a la que es exclusivamente vivienda familiar y otra rutina. "Para mí sigue todo igual, me gusta el social, para el turismo. Están en contacto con turismo" (hijo). No tuve que dejar de hacer nada. Lo los turistas, los reciben con la intención de que 
implementamos esto y es algo más, tenés que abandonar un poco la huerta o buscar otros tiempos". "En tiempos de vacaciones hay que cultivar menos porque tenés que estar muy metido con el turismo" (hijo). "Hay que "l atenderlos bien y bueno, tenés que estar" (productora). El tiempo que le dedican al turismo es relativo, aunque son concientes de que su presencia y dedicación es el valor agregado que deja más conformes a los turistas: "depende de cómo lo atendés, si vos dejás que estén ahí nomás, pero si uno va le ofrece naranjas, verduras, cuanto más le ofrecés más tiempo te lleva (hijo). A la gente le gusta que vos estés, que converses un rato, que les cuentes cómo vive la gente, que los lleves a recorrer la huerta, que coseches la verdura con ellos. Eso te demanda un poco de tiempo" (productora). "A la gente le gusta eso y va a volver por eso" (hijo). (productor). "7:30 empezamos a trabajar en la huerta hasta las 12. Cortamos y empezamos 13:30, 13:45. Y después hacemos el reparto. Ellos dejan la cosecha como a las 18 hs" (productor). "Ahí voy corto el paso, igual si hay que cortar antes dejo la huerta y voy. (hijo). "Si hay turistas se trata de estar por ahí por si necesitan algo (productor).

La incorporación del turismo impactó sobre os tiempos de ocio de la familia, salidas y vacaciones, aunque tienen claridad respecto a que es momentáneo. "Dificultó algunos tiempos los fines de semana, la salida en familia, las vacaciones en familia" (productora). "No podemos vacacionar en tiempos de vacaciones" (hijo). "Para nosotros era fundamental salir juntos, papá, mamá y los cuatro gurises" (productora). "Eso está cada vez más complicado porque uno está un día el otro está otro. Además vendimos la trafic, pero la idea es incorporamos, hasta la mismas gente del barrio se se sientan en su casa. Los hijos también se acostumbró a los turistas porque por ejemplo llegan relacionan con los turistas. El hijo más grande al almacén y se sigue atendiendo por orden de fue a una escuela rural cerca de allí, pero luego llegada, no importa si es del lugar o turista (hijo). Ios tres fueron a un colegio privado en Chajarí. "Fue algo que se fue dando y nos fuimos adaptando" El productor también tiene la oficina allí. Están (hijo). Mantienen el domingo para la familia, ubicados a 20/25 minutos de la ciudad. "nos descansar y disfrutar. El domingo es sagrado."El hemos organizado bien, té diría que ninguno se día domingo que tenemos libre tratamos de no incluir imagina viviendo de otra manera, es más, nada de eso. Nos quedamos en familia, salimos, nuestros chicos estudian uno veterinaria y el vamos a comer". (ella). Los fines de semana largo otro agronomía" (productor). "Tienen mucho son los momentos de pico de clientes. "Ya se arraigo. Nosotros por ahí en broma les decimos sabe que los turistas andan, entonces nos tenemos ahora que son más grandes vamos a vender que organizar con la mercadería, compramos más todo y viajar. Y ellos dicen no, todo menos La regionales." (él) Se mantiene el mismo horario y el Violeta. No sólo se criaron acá, ellos han hecho almacén continúa funcionando con la misma lógica todo acá, es su lugar" (productor). de atención, por orden de llegada. "Ya es muy Incorporaron el turismo de manera natural. normal que un fin de semana venis a comprar y haya Les gusta la actividad. "El lugar donde muchos turistas) (hijo)

tenemos lo que más nos gusta es acá. Ni siquiera hacemos agricultura. Me parece que el turismo ayuda un poco a querer hacer un ambiente lindo, amigable, te arraiga, te obliga a estar ordenado y te hace mirar las cosas de otra manera. Ha venido gente acá que justamente valora que no haya nada arado, que sea todo campo". (productor)

Apertura personal: según decir del hijo, los padres El principal cambio está dado por la apertura están más abiertos. "No eran tan abiertos porque cultural y posibilidad de educación (no formal) venía gente de acá nomás. Al venir gente de afuera de los hijos: "Los chicos son muy abiertos. El que quiere conocer algo de sus vidas, del pasado, hecho de recibir gente de afuera los hizo muy tuvieron que ir abriéndose de a poco. Eso es abiertos" (productor). Suma muchísimo en esto positivo. A la gente le interesa conocer la historia". del tema de los chicos, les hizo abrir mucho la El turismo colabora con la transmisión de la cabeza, sino imaginate que los chicos viven en historia familiar y local de generación en el campo y no es tan fácil. A eso lo veo como generación. "A través del turismo empecé a conocer un punto muy importante. Los educa sí o sí" la historia del lugar, de mi papá. Antes no conocía (el). Destacan lo interesante del intercambio mucho de la familia, no em había metido. A partir del con personas de otros países. "Es como que turismo empecé a conocer quienes estaban acá, vayas a otro país, te sientes con ellos y te 
comprar algo para salir en familia. Saldremos en temporada baja que aquí no ha nadie o casi nadie" (productor). "Sabemos que lo vamos a recuperar en algún momento, no sabemos cuándo ni cómo, pero no nos desespera porque sabemos que es un tiempo. No sé cómo nos vamos a arreglar más adelante, a lo mejor viajemos no en familia, saldremos con las nenas y ellos aparte (refiriéndose a los hijos varones" (productora). "Serán uno o dos años" (productor). El turismo no generó grandes cambios en la rutina. "No nos levantamos ni un minuto antes ni un minuto después, a lo mejor nos acostamos más tarde porque en turismo por ejemplo a alguien se le ocurrió llegar a las 3 de la mañana y en vez de llegar a las 3 llegó a las 5. A esas cosas no las teníamos pero lo otro, no nos vamos a levantar antes porque si no terminás siendo esclavo del trabajo" (productora). "Tratamos de seguir con lo que siempre se hizo, si ellos hacen deporte que lo sigan por ejemplo" (productora). Les aporta mayor apertura mental y cultural: "a mí me encanta recibir gente, conversar con la gente" (productor). "Es como innovador para nosotros este trabajo. Te abre un montón la mente, eso de tener que trabajar en la huerta, con la tierra y venir a charlar con la gente y ver que la gente esté contenta, es lindo"'" (productora). Sienten reconocimiento a las tareas que dedican y eso refuerza su autoestima. "Es placentero abrir la páginas y ver que te están agradeciendo por la fruta que les dejaste que a nosotros no nos cuesta nada". (productora). quiénes allá. Todo ese movimiento de la historia no cuenten cómo viven, qué hacen. Ellos vienen y conocía". (hijo). Es una actividad que les te cuentan. Te vas cultivando, mirás las cosas gusta.Los complace el trato con los turistas, con de ellos con la perspectiva de ellos, es distinto gente que provenga de otros lugares. "Hay turistas y a cuando viajas vos." (el).

turistas, gente y gente, hay algunos que son más calladitos" "El trato con la gente de afuera, conocer escuchar porque escuchar también es importante" (ella). "A mí me gusta conversar con ellos y más cuando son gente dada, que te hacen preguntas. A veces si no tengo gente que atender puedo seguir conversando un rato más" (él). 


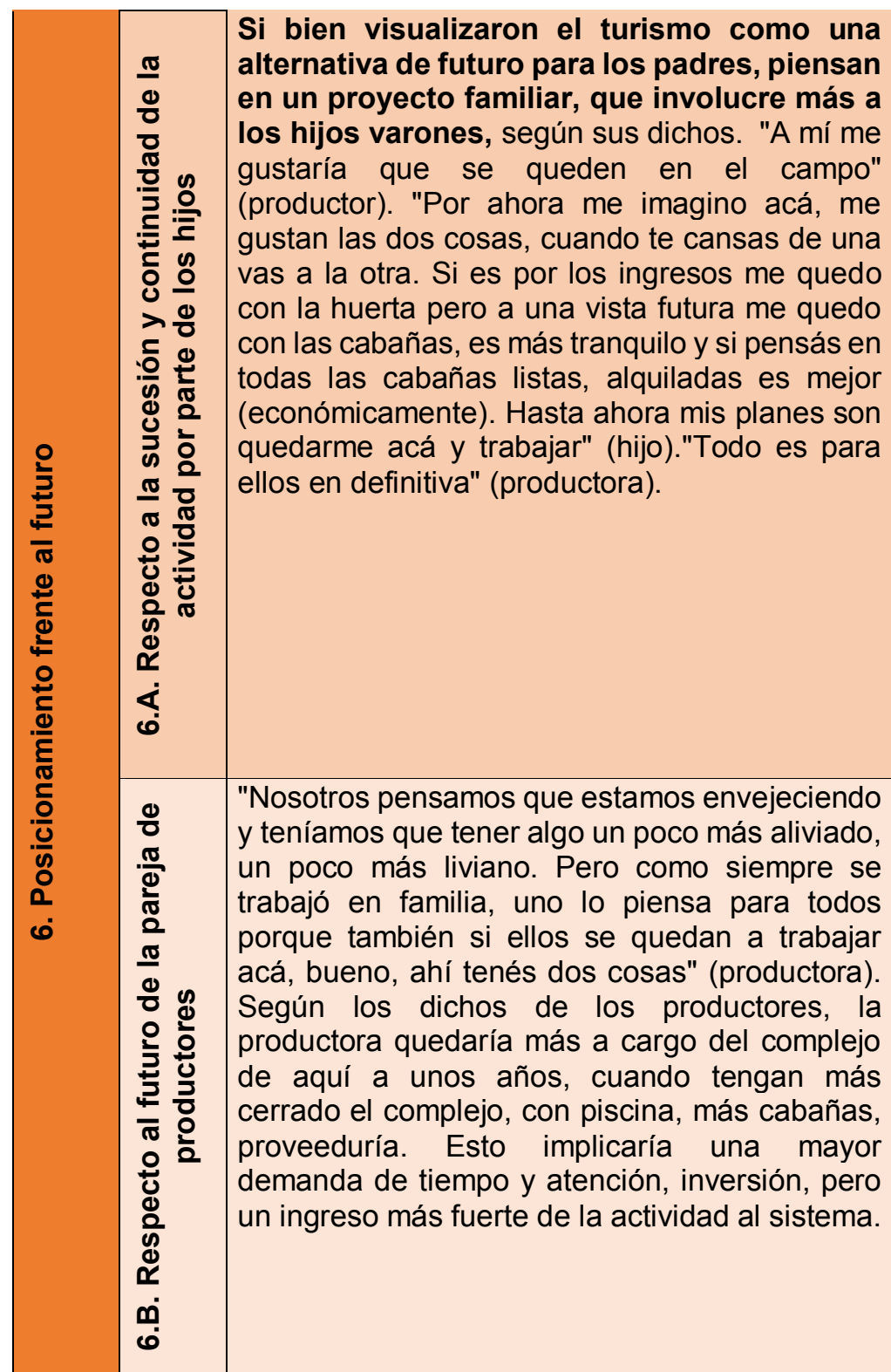

Piensan en el turismo como un ingreso extra y a largo plazo para que quede para los hijos. "A medida que va pasando el tiempo te vas dando cuenta que es una entrada más y les va a quedar a ellos". (él) "La idea es que sigan. No se sabe pero entusiasmados por lo menos están" (ella). "Pienso que los hijos se van a quedar en el campo. Hasta ahora el proyecto de lo que se viene haciendo es para el más chico, el que quedaría en el almacén porque no le gusta estudiar" (él). La idea es que el chico termine la escuela secundaria y trabaje con ellos. La hija tiene un retraso y hace otro tipo de tareas. Uno de los hijos está estudiando para ser chef. Los padres piensan que el lugar tiene potencial para trabajarlo desde el punto de vista gastronómico, además evaluan el costo de salir a alquilar o comprar un local en el centro de la ciudad. La limitante estaría dada, para ellos, por estar lejos del centro. La idea de volver. Su idea es "llegar lo más lejos posible, viajar, y después de grande (adulto), volver acá al campo". "No me gusta mucho el campo, porque mi crié acá, pero siempre está la idea de volver". (hijo)

Piensan en seguir reinvirtiendo. Lo que es de ellos es un resguardo para su futuro y a la vez queda para los hijos. También apuestan a seguir construyendo otras casas para alquilar y que puedan tener otro ingreso de las rentas. "Si nos queda algún restito de plata lo que queda es mejorar el almacén o seguir haciendo cosas que te den en el futuro. A mí mer gustaría seguir haciendo casitas para alquilar" (El) Me gustaría que esas casas sean más para turismo, más que para alquiler mensual porque el alquiler mensual te arruina las casas. No es lo mismo. E turista además viene y te compra acá, es un negocio que te dejaría lindo..." (él) "Pensamos seguir hasta que podamos" (ella)
"No es menor cuando hablamos de recursos, el turismo no es la más importante pero porque tampoco no es la actividad a la que más tiempo y recursos le hemos dado. Pero sí creemos que es un desarrollo a futuro. También hay un tema sucesional acá". potencial. El turismo autóctono, regional, local está cada vez más fuerte. Va de la mano para el lado que va el mundo. La gente que viene acá es gente que ya ha hecho todo y te das cuenta porque valoran cosas que en otro momento no se valoraban como lo natural, lo ambiental. $Y$ esto tiene un fuerte contenido relacionado, es un turismo netamente ambiental. De hecho nosotros lo queremos enfocar a un turismo netamente ecológico" (EI) "Ahora que ellos ya se están yendo, creo que es una buena manera de mantener esto. No hay manera de subvencionar mucho la casa, sí o sí si queremos tener esto bien mantenido y lindo hay que mantener la impronta del turismo (ella). "Algún día tengo 

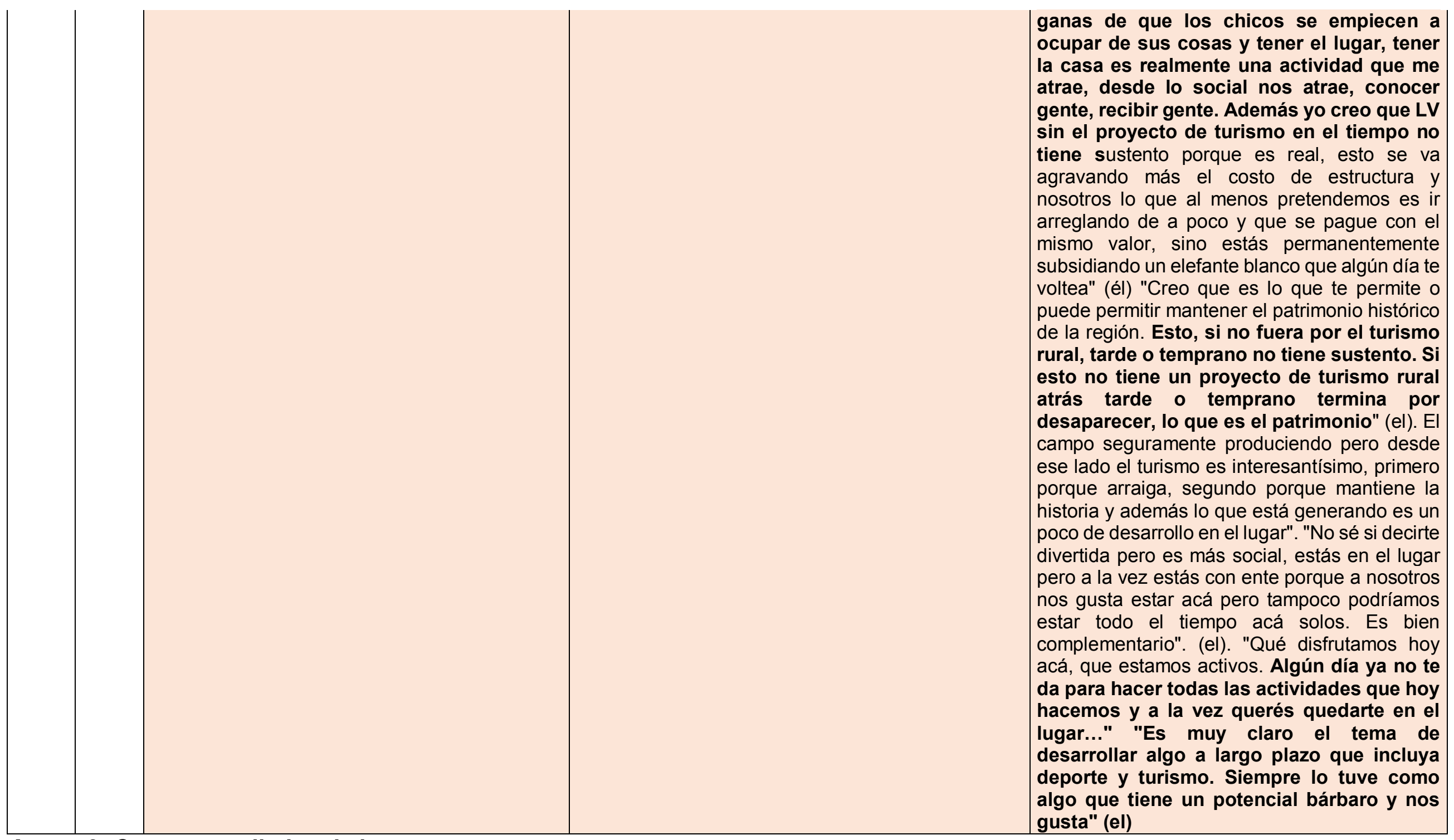

Anexo 3- Casos compilados de la zona no 


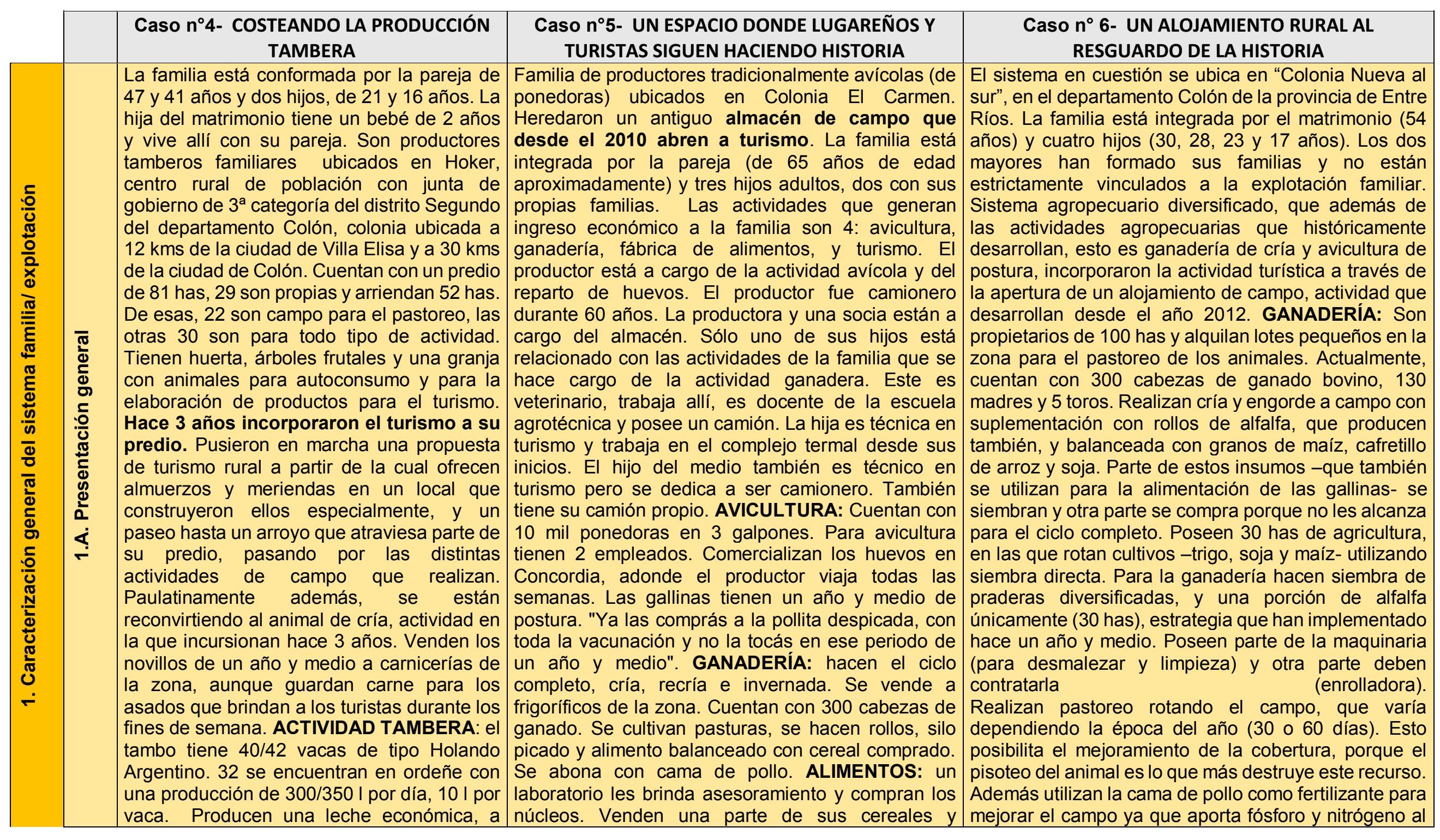


sabiendas de que es baja la producción, alimento fabricado. Producen 40 toneladas para uso estrategia que responde a la lentitud de los propio y 10 para la venta. TURISMO: El almacén de pagos y el bajo precio de la leche cruda. ramos generales de 1907 se encuentra en un predio Poseen un toro (Pampa negro). Ordeñan de de 12 ha. Abre de lunes a sábado desde las 8 hs manera mecánica 2 veces al día, con una hasta el mediodía, y luego por la tarde hasta las máquina de 4 bajadas, con la que arrancaron 19:30 hs. Además de la presentación de la historia hace $\mathrm{C} 11$ casi 2 décadas. Compraron una del lugar se ofrecen picadas y meriendas. Funciona más grande (de 6 bajadas) cuando pensaban como almacén al público y además se venden llegar a 100 vacas, pero no la utilizaron. En productos regionales elaborados en la zona. Son su predio producen el silaje de maíz. y propietarios de 180 ha que fueron comprando para la además compran alimento para cada actividad ganadera. $Y$ alquilan unas 150 ha más categoría de a una fábrica de Villaguay. La Estos campos se alquilan para que sea más rentable. leche se vende a la Cooperativa COTAPA

(Cooperativa Tamberos de Paraná) desde hace $7 / 8$ años con un pago a 120 días aproximadamente y a un precio muy bajo. De la parte sanitaria se encarga un veterinario. Cuentan con vacunación de brucelosis y aftosa (a cargo de FUCOFA). GANADERÍA DE CRÍA: hace 3 años empezaron con la cría. Hasta ahora van reservando comprando y cambiando vientres de Holando Argentino por vacas de color (Pampa Negro/ Pampa Colorado) para hacer vientres de animales de color. Venden novillos de menos de 1 año y medio (380/400 k) a carnicerías de San José o Colón. Tratan de quedarse con alguna manta de asado para ofrecer a turismo que llega al predio durante los fines de semana.

TURISMO RURAL: en el establecimiento ofrecen: Almuerzos: asado con ensalada y picada con quesos y embutidos. Paseo en "El Costerito": es una excursión guiada por el productor, en un carro tirado a tractor, con capacidad para 17 personas. En el recorrido se muestra el trabajo en el campo y se llega a un arroyo (Arroyo Mármol) y se visita un viejo puente ferroviario. Dura aproximada 1 suelo. Canales de comercialización de hacienda: se entre a los carniceros una vez que está terminado por medio de frigoríficos (320, $350 \mathrm{k}$ macho y hembra). Se trabaja con un solo frigorífico. Ellos venden a carniceros directamente (son 2), al menos cuando hay que hacer un recambio, ahí se va a remate, es otro mercado. La cama de pollo va al suelo, como fertilizante, aporte de fosforo y nitrógeno. En agricultura tienen 30 has, con pasturas hay otras 30 has, y apuntan producir con alfalfa pura (es otra de las cosa que anda muy bien con mejor resultado). Se hace el rollo y se da luego a la hacienda. Parte tiene maquinarias, están por comprar la enrolladora. AVICULTURA: se desarrolla en un predio a $5 \mathrm{kms}$ de donde se localiza el alojamiento turístico, en el que se ubica la casa familiar. En éste se encuentra la granja con 12 mil gallinas de postura. Poseen dos galpones, uno para la cría y otro para la postura. Para alimentar las gallinas se utiliza balanceado con granos de maíz, soja, harina de carne y núcleos. Como se ha mencionado, los productores incorporaron la agricultura para suplir estos insumos, pero parte debe adquirirlos por fuera del sistema (vacunas, vitaminas, reposición de pollitos).

Respecto a la salida de los productos, lo conciben como un negocio cerrado, con venta directa a los comercios. La hacienda - terneros con $320 / 350$ ks- se entrega a carnicerías por medio de un frigorífico. El recambio de vacas se canaliza por otro tipo de mercado como remates de la zona. La venta de huevos es directa a minoristas y mayoristas -supermercados y despensas de Colón, San José y Concepción del Uruguay). TURISMO: se añade al sistema en el año 2006/2007-por necesidad de contar con campos para pastorear en época de sequía- pero se pone en funcionamiento como alojamiento en el año 2012. El alojamiento se brinda en una casona antigua (construida en el año 1909) originariamente habitada por una familia de origen suizo (del Cantón de Vallais) 
hora 10'. Se comparte la alimentación de animales, se ofrece la visita al tambo (exclusivamente en el horario de ordeñe (17 horas). Meriendas. Actividades recreativas en el parque: juegos de tejo y canchita de fútbol. Productos elaborados por la familia: quesos de campo, licores, dulces B15artesanales, budines, huevos de campo. Al turismo abren los fines de semana y feriados. Los horarios son los siguientes: 12 hs Visita guiada (rodeo y granja); 13 hs Almuerzo (asado o picadas; 15 hs Paseo en "El Costerito"; 16.30 hs Visita guiada (rodeo, granja, tambo, alimentación animales); $17 \mathrm{hs}$ Paseo en "El Costerito". A partir 17 horas Meriendas. El asado es con reserva previa. La mayoría de los productos y alimentos que ofrecen al turismo lo elaboran ellos. La carne que sirven es de su producción, al igual que el chorizo parrillero que elaboran ellos. Solo un $20 \%$ del total de verduras que utilizan para las ensaladas las compran a productores vecinos. Utilizan las frutas para los budines. A la elaboración del pan la hace la productora. Procesan los chorizos secos cuando hacen las carneadas de invierno, que también ponen a la venta del turismo. GRANJA Y HUERTA: en su predio tienen una huerta de $10 \mathrm{~ms} \times 30 \mathrm{~ms}$ en la que producen verduras para autoconsumo y para abastecer al turismo; alrededor de 30 árboles frutales (limones, naranjas, higos, mandarinas, manzanas), plantaciones de frutillas y zanahorias. Poseen además con un vivero con plantas aromáticas, cactus (para la venta, en macetas de barro). Cuentan con una granja de animales con vizcachas, terneros, conejos, chanchos (4/5), gallinitas, perdices, cordero, patos. Su destino es el que se dedicaban a la avicultura y la producción de quesos. Con el correr de los años y el fallecimiento de Don Fellay, primer propietario, se fueron vendiendo campos y solo quedaron unas pocas hectáreas alrededor de la propiedad. Específicamente, el predio donde se ubica la casona es de 20 has -18 has dedicadas a la ganadería y 2 has al turismo -casona y predio para los paseos en caballos y sulkys. Ofrecen actividades recreativas como bicicletas y cañas de pescar, ya que a 1000 metros de la casa se encuentra un arroyo, que aunque no está dentro del predio y es de un vecino, se ofrece como alternativa de entretenimiento y descanso. Las épocas del año con mayor afluencia de turistas son de diciembre hasta semana santa, vacaciones de invierno y fines de semana largos. La ocupación es del 75 al $100 \%$ y solo se abre el alojamiento cuando se tienen reservas previas.

También comparten las tareas rurales a las que se dedican, invitando a los turistas a compartir fundamentalmente las relacionadas a la ganadería (yerra, enlazar terneros, curaciones). No hay gran capacidad de carga, porque el alojamiento es pequeño, posee 4 habitacio+B3nes con una capacidad de 17 a 20 plazas. Una de las salidas que posee el sistema teniendo en cuenta esta actividad, es la comisión del $17 \%$ a Despegar por las reservas mensuales, estrategia que están implementando hace poco tiempo. 


\begin{tabular}{|c|c|c|}
\hline & $\begin{array}{l}\text { autoconsumo y a partir del turismo se } \\
\text { incorporan como un atractivo y producen } \\
\text { alimentos a partir de estos. Tienen } 5 / 6 \\
\text { colmenas. La miel es para la venta y para } \\
\text { endulzar los productos que elaboran para el } \\
\text { turismo. }\end{array}$ & \\
\hline 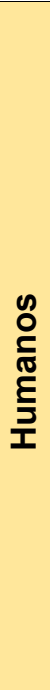 & $\begin{array}{l}\text { Son productores familiares, no cuentan con } \\
\text { empleados sino que se dedican los } \\
\text { integrantes de la familia al trabajo en el } \\
\text { campo. }\end{array}$ & $\begin{array}{l}\text { En relación con la unidad productiva trabajan el } \\
\text { productor, la productora, una socia, el hijo y tienen } 1 \\
\text { empleado para la ganadería y } 2 \text { para avicultura. El } \\
\text { hijo tiene un sueldo y un porcentaje de lo que se } \\
\text { produce. El productor se dedica a las gallinas y al } \\
\text { reparto. Una vez a la semana viaja a hacer el reparto. } \\
\text { El Almacén "es un emprendimiento más de ella y la } \\
\text { empleada". (productor). Respecto a la toma de } \\
\text { decisiones, en ganadería el manejo es a criterio del } \\
\text { hijo. "Consulta pero el manejo es suyo. Siempre } \\
\text { estamos en contacto en las decisiones y sabemos } \\
\text { qué es lo que hace". (productor). En avicultura el } \\
\text { productor gestiona pero en consulta con el hijo. La } \\
\text { productora y socia/empleada son responsables } \\
\text { además de la parte administrativa. Producen algunas } \\
\text { conservas, dulces y mantienen la limpieza del } \\
\text { almacén. }\end{array}$ \\
\hline 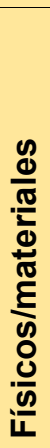 & $\begin{array}{l}\text { Para el desarrollo de la actividad turística } \\
\text { vendieron aproximadamente } 35 \text { novillos y } \\
\text { fueron adquiriendo cocina industrial, } \\
\text { construcción del local, baños, } 2 \text { heladeras, } 3 \\
\text { freezer. }\end{array}$ & $\begin{array}{l}\text { El productor dio a uno de sus hijos el camión y éste } \\
\text { lo renovó, el otro hijo también tiene camión. Poseen } \\
\text { galpones donde crian a las ponedoras, silo y máquina } \\
\text { para fabricar el alimento. Poseen un almacén de más } \\
\text { de } 100 \text { años. } 180 \text { ha propias, } 150 \text { arrendadas, } 10 \text { mil } \\
\text { gallinas ponedoras, } 300 \text { cabezas de vacunos, } 2 \\
\text { galpones, silo y máquina para producción de } \\
\text { alimento.B17 }\end{array}$ \\
\hline
\end{tabular}

Mano de obra familiar y empleados. El productor se dedica a la ganadería; la productora a la atención al turista y la avicultura (producción y comercialización). Los dos hijos menores trabajan en la unidad productiva: uno de ellos, más activamente en la atención al turista, las reservas y comunicación del emprendimiento, además trabaja en la oficina de turismo de una municipalidad de la zona; el más joven colabora en las actividades agropecuarias y en el mantenimiento del predio de la casona. Cuentan además con dos empleados permanentes para el trabajo en la granja avícola y el mantenimiento de los campos para la ganadería. Tiempos y distribución de roles: género - es indistinto. "Está bueno que toda la familia trabaje en turismo rural. No tiene por qué ser uno u otro que trabaje atendiendo a la gente" (productor)

El sistema familia-explotación responde a la categoría de productor familiar capitalizado. Siguiendo a Piñeiro (...) es "aquel que aun utilizando trabajo familiar predominantemente (pero contratando asalariados) consigue generar y guardar excedentes de un ciclo agrícola para el próximo. Suele reinvertir sus ganancias en maquinarias y otras mejoras tecnológicas que ahorran fuerzas de trabajo, aunque la explotación crezca en tamaño y en producción, se sigue manejando la unidad productiva con trabajo familiar. Poseen parte de la maquinaria (para desmalezar y limpieza) y otra parte deben contratarla (enrolladora). Poseen dos galpones, uno para la cría y otro para la postura. En uno de sus predios cuentan 


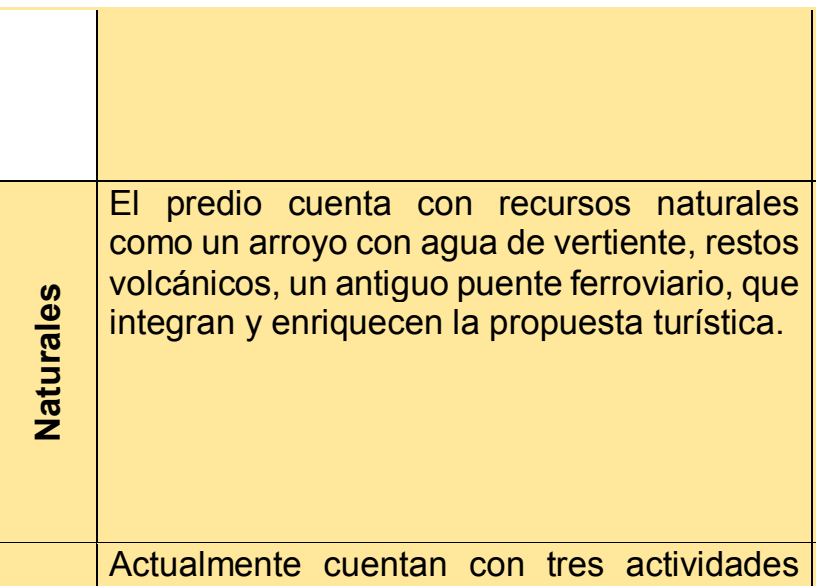

productivas que les generan los ingresos a la $h$ familia: el tambo, el animal de cría y el turismo.

Manejan sus ingresos como una caja única, en la que el tambo representa el ingreso más sólido y estable. No llevan un registro sistemático de su flujo de ingresos y egresos. La familia integra los flujos d ingresos de las tres actividades. a "Sacamos de uno y lo metemos en el otro" ¿ (productor) aunque la actividad que más ह ingresos le genera es el tambo. "Lo sólido es - el tambito: hay que venir a buscar bebidas a ¿ Villa Elisa, paga el tambito; la comida de las vacas se paga con cheques a la liquidación de la leche". (productor)

"Al ser sólido el tambito, las otras actividades dan". "No podemos dejar ninguna actividad, pero la idea es achicar el tambito lo más que se pueda. (productor)A partir de los ingresos del tambo se mantienen las otras actividades, pero a la vez no se puede dejar ninguna actividad, ya que todas generan un ingreso económico. con una casona de más de 100 años, que ha sido restaurada como alojamiento rural.

Los campos son muy ricos en biodiversidad. Poseen montes de reparo de especies típicas de la zona (Espinillos, Ñandubay, Cincina, Talas) donde abundan diferentes especies de aves, insectos y roedores (cuices, comadrejas), zorros entre otras especies. A 1 $\mathrm{km}$ del predio donde se haya la casona, y en el mismo predio donde se ubica la vivienda familiar, hay arroyos, ecosistema de peces y diversidad de plantas y animales acuáticos.

El Almacén no implica un ingreso importante. "S hacés un balance se te cae la estantería" (productor).

Las otras actividades son el principal sustento. "Es un conjunto de cosas. Con la avicultura, la ganadería que vendés algo de cereales, de molido o algo de balanceado, hacés girar la rueda" (productor). "Viene un cliente a buscar el huevo, te lleva el alimento, pero te compra la galletita. Son varias patas" (productora).

Manejan como caja única las cuentas de las diversas actividades.

Turismo actividad con menor peso en el ingreso total: "La avicultura y ganadería bastante parecido hablando de ingreso, no así los gastos, la avicultura genera más ingresos pero tiene más gastos (alimentación, reposición de los pollitos bebes, vacunas, calefacción, mano de obra), que son números importantes. Igual es rentable. La ganadería es mucho más lento el negocio, pero a su vez es más seguro, más estable. Si bien te lleva nueve meses tener un ternero de gestación, una vaca, 9 meses para sacarlo de la madre y otros 9 meses para engordarlo y venderlo. 27 meses lleva todo el proceso, a logra el ternero una vez que la vaca está servida. En cambio la avicultura es un ingreso de todos los días (aunque la pollita lleva 5 meses para que comience la postura de huevos chicos y eso todavía no es rentable hasta que sea un huevo mediano y grande. La vida útil es de 2 años de postura). Porcentaje de Ingresos HOY- $45 \%$ y $45 \%$, avicultura y ganadería. Turismo 10\%" (productor). Esperan que eso cambie, piensan que el turismo le va a generar más ingresos. "Somos nuevos" (productor) Idea de caja única y de turismo como inversión: "Es una caja única, es todo una cadena. La ganadería contribuye con la avicultura, la avicultura contribuye con la ganadería, también se ha hecho algo de siembra de pastura que también va contribuyendo, 
Para esto se despliegan una serie de acciones estratégicas:

1. El turismo es un canal de comercialización de los productos que elaboran con la materia prima que brinda su campo (huerta, frutales, granja), que de otra manera serían para autoconsumo solamente.

2. Elaboración de todos los productos que ofrecen al turismo con una alta calidad, lo que les da confianza en sus servicios. Intentan comprar insumos para el turismo lo menos posible.

3. No tienen empleados. Es empleo familiar, y todos hacen todo.

4. Elaboran una leche económica. Son conscientes de que es bajo el rendimiento "pero es la única forma de hacer una leche económica". "Por lo rápido que nos pagan tampoco nos desesperamos por hacer leche". "Si no cobramos, no queremos invertir. La leche se levanta con dinero, con más alimento, con más silaje, con más alfalfa". (productor)
Se vinculan con la oficina de turismo de Villa Elisa, integran un grupo Cambio Rural y el proyecto de la Ruta de Turismo Rural del

\& Corredor del Río Uruguay. Se relacionan con productores, articulación que potencia
Tienen una activa relación con las familias de la zona "Acá somos 6/7 familias, da cuenta de que somos una familia grande, nos damos mucha bolilla, nos llevamos bien, es una familia grande, estamos muy acompañados" (productora). Se genera un vínculo intercambios, aprendizajes y muy especial con los turistas que llegan al almacén. comunicación de su propuesta turística. "Nos Algunas familias han vuelto más de 10 veces. cruzamos con otros productores en ferias, Muchos visitantes les regalan objetos que integran cursos. "Entre INTA y Villa Elisa nacimos el patrimonio del museo. "Cuando vienen y vamos nosotros". "A través del grupo de INTA y el turismo está también dentro del mismo paquete, que no lo separamos. Es toda una cadena de inversiones, tal vez uno no lo ve, lo trae de otro lado, después lo va recuperando lentamente y no es un libro, una contabilidad exacta. Aparte, yo creo que una inversión que venga de otra actividad acá no estaría mal porque en algún lugar tener que ir invirtiendo que te quede dentro del campo" (productora) Turismo, ingreso complementario. "Es un ingreso complementario.

Por lo general me parece en los casos de acá de la zona, en la mayoría no es el mayor ingreso, sino que complementan o ayuda a la actividad principal que tienen. Vas complementando con el resto de las actividades. No ponen todos los huevos en la misma canasta, como dice el dicho... Yo creo que es el tema este de procurar que los jóvenes queden en el campo, involucrar a toda la familia, le enseñan a los jóvenes a trabajar en sí, lo que es el trabajo, lo que es la responsabilidad. Mucho surge de eso. El balance es positivo. Es otro ingreso más, si bien es bastante desgastador pero como no es de todos los días... es estacionario, hay temporadas (alta) donde se trabaja mucho y después es un ingreso extra que tenés todos los meses que antes no se contaba, que ayuda a reforzar los gastos de otras actividades. Capaz que con la avicultura no te está yendo muy bien, tenés el turismo y compensás con eso. O al revés".(hija)

\section{Integración técnica y generación de redes: Integran} grupos asociativos (Cambio Rural) de ganadería y turismo rural. A través del turismo venden productos que fabrican vecinos y compañeros de los grupos (dulces, masas, panificación, salames). Además recomiendan alternativas de turismo de otros emprendimientos rurales. Se vinculan con los municipios de la microrregión Tierra de Palmares, INTA y otros organismos del sector. "Después de que se compra la casa, a los 2 años, arrancó el INTA con 


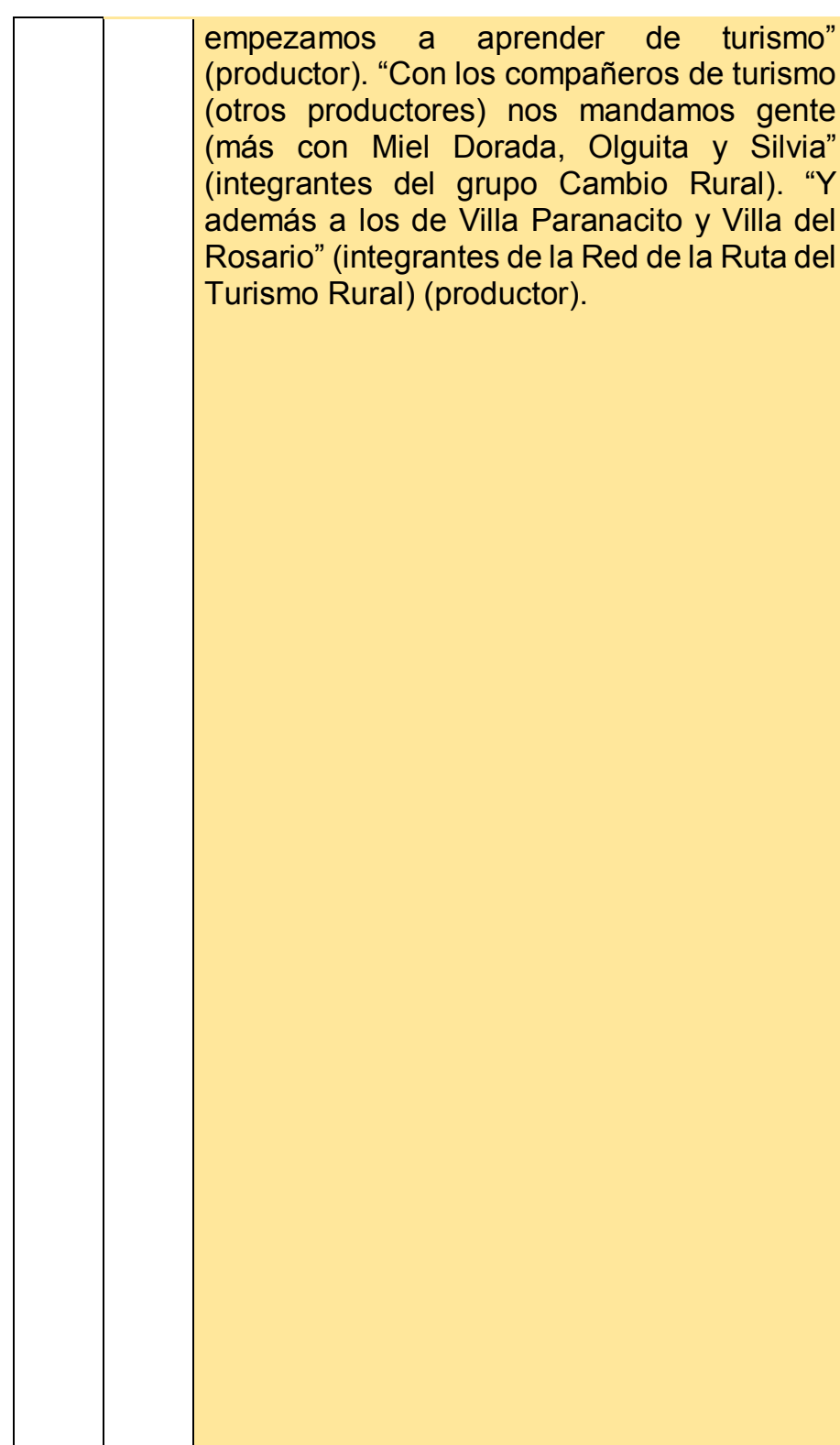
mostrando se van mezclando con much
con muchas emociones" (productora) además a los de Villa Paranacito y Villa de Rosario" (integrantes de la Red de la Ruta de

Turismo Rural) (productor) el tema de los grupos cambio rural de turismo rural, y fue ahí que la técnica conoce a papi, porque papi ya formaba parte de los grupos cambio rural de los ganaderos, a través de eso le comentó que tenía una casa como para hacer algo y empezó a surgir lo de turismo rural. Empezamos a participar del grupo de turismo, pero sin estar trabajando con la casa, era como un proyecto todavía muy a futuro y sin saber bien qué hacer. Después yo hice el curso en la UBA y todos los que conocían la casa iban tirando ideas de lo que se podía hacer y demás, y fue cuando decidimos hacer el alojamiento" (hija)

Rol técnico de los municipios y del INTA: "es una gran ayuda. Los municipios ven una alternativa para cuando no es verano, no están las playas, en el invierno por ejemplo, es una salida de decir adonde los mandamos a los turistas... el día que llueve, un día van a las termas.... Se ve como una alternativa para los destinos" (productor). "Comenzamos con el INTA, con el apoyo de ellos y la información dentro. Fue el principal ayuda e información. Ahí surgió el turismo rural, las reuniones, las enseñanzas y las propuestas y el estudio del lugar. Eso fue lo más importante que si no no estaríamos... Dentro del rubro se trata de ir a las reuniones, de vincularse, de tener experiencias de qué es lo que hace uno y qué es lo que hace el otro, como ser ahora incorporar los dulces de una chica vecina que se los vende en el alojamiento, ella está muy contenta y a nosotros también nos sirve. Después están todos lo que son los productos de la zona también. Creo que es importante dentro de la zona". "Cada vez se está agrupando más la gente que permite, que está bueno también como productor vender los productos del otro, que te manden gente, que la gente vaya por chacinados a un lado, y por otra cosa a otro, que lo mandes a conocer a otro lado o tener el dulce que hace un vecino o un colega, y creo que habría que intensificarlo más. Que cada uno tuviera que tener el producto del otro en cada 


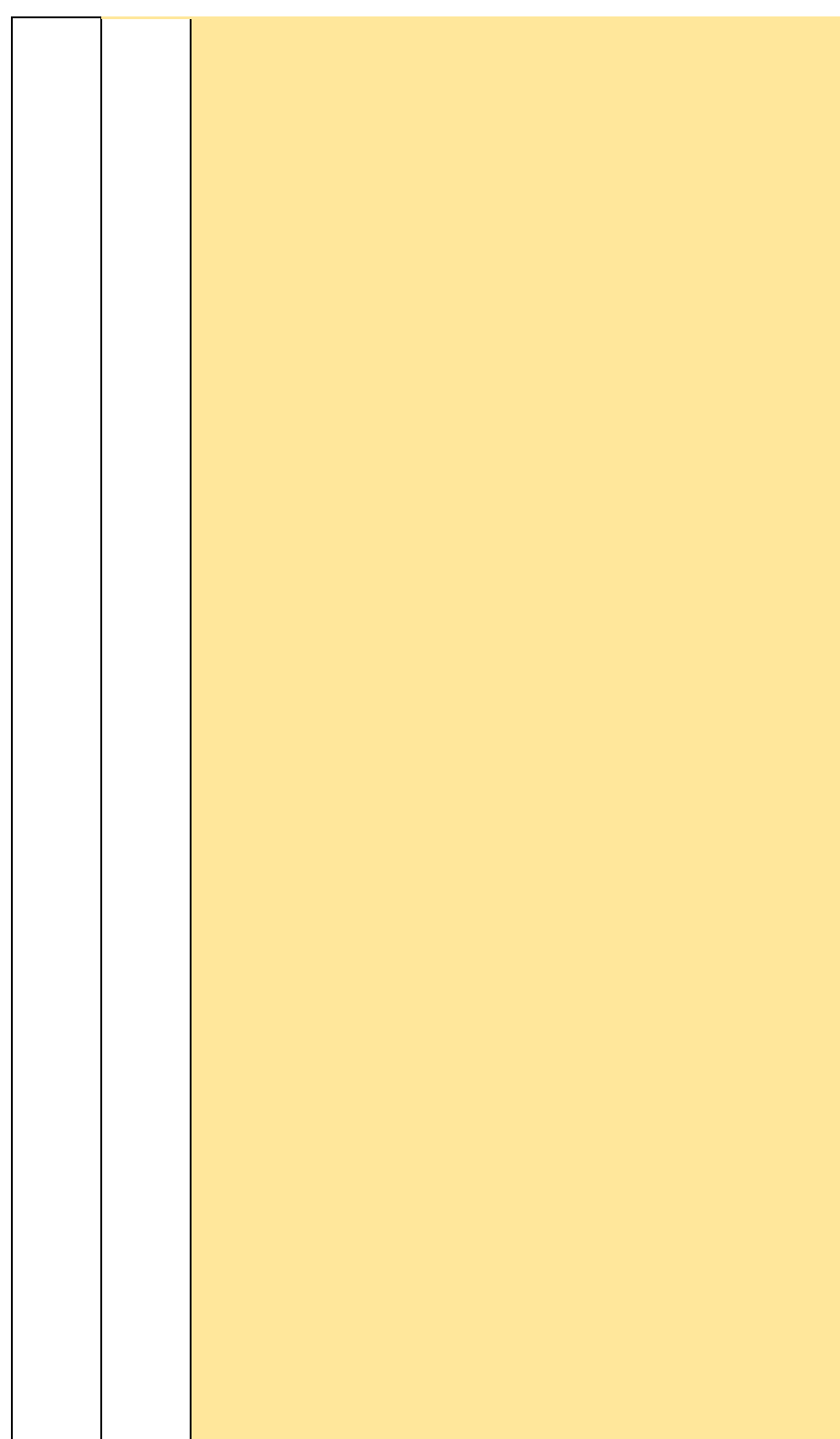

alojamiento o visita de turismo, saber qué ofrece, que productos tiene el otro" (productor). Reconocimiento social: "Cuando arrancamos éramos "los locos estos que van a hacer turismo", quién va a venir al campo a hacer turismo? Decían. Al turismo rural lo veían muy lejos. Y después les llamaba mucho la atención a los vecinos, "mirá cuántos autos hay, cuántos autos van para Victoria del Campo". Los vecinos de la zona son ganaderos más que nada y avicultores de pollo (integración). Tratamos de sumarlos. Los dulces que ponemos en el desayuno y para la venta son de una vecina de cerquita del alojamiento, tenemos otro vecino que hace carne, chorizo de campo así que le compramos a él o le recomendamos a los turistas si quieren ir a comprar. Hay otra vecina que hace masas dulces y ese tipo de cosas, así que cuando tenemos fines de semana largos o vacaciones de invierno, o sea que sabemos que vamos a tener gente, le compramos como para la venta". Intercambio cultural con turistas: "Es super rico, por el intercambio de la gente, te permite eso. Estas en contacto con gente que viene de toda la Argentina y conocés otras culturas, otras formas de vida, es super enriquecedor."(hija) Se destaca lo vincular: "El turismo, en la parte vínculos, es mucho más fuerte que las otras. En la ganadería hay vínculos, en la avicultura también pero es distinto" (productora). "La gente viene a desenchufarse, y a contarnos sus cosas. En su trabajo o en las cosas diarias de ellos uno ve que ni tiempo tienen de dialogar con alguien. Es algo que nos agradece la gente es el tiempo que nosotros les dedicamos. Para ellos es importante el tiempo que uno le dedica, en la atención, en conversar, en explicarles, en contarles la historia de la casa, de nosotros. Y agradece mucho". "Nos ha cambiado el trabajo... creo que está bueno de que nos lleguen los turistas, y en el caso mío, por ejemplo no sabemos si es obrero, si es juez... un diputado, si es doctor (que han venido mucho)... por ahí te llega la gente y no sabés con qué tipo de gente estás tratando. 


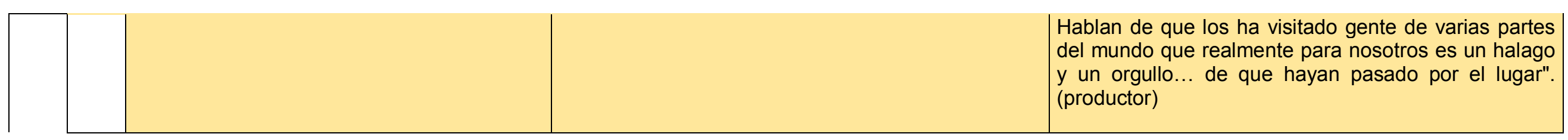


Un aspecto interesante es que esta La propuesta turística se basa en la esencia de un diversificación productiva también está almacén de campo, en sus rasgos identitarios. "No pensada como una manera de continuar con queríamos perder la esencia de un almacén de el tambo. A primera vista podría pensarse campo, porque acá viene la gente a tomar copas que el turismo está desplazando esta viene el correo, la correspondencia. Todo eso no lo actividad productiva principal, pero a la vez, queríamos perder, la esencia del lugareño, entonces la razón de ser del turismo es el tambo, no lo que hicimos fue, al almacén de campo le sólo desde el punto de vista de la producción agregamos turismo" (productora). "Seguimos con el de materia prima para los productos que sistema del almacén porque si no nos convertíamos elaboran para los visitantes, sino también en restaurante de campo y eso es más fácil de desde una mirada identitaria. El tambo, encontrar. En cambio, la esencia del almacén de además de ser la actividad económica más campo es lo que se ha ido perdiendo" (productora). "sólida", es la que más los representa como Intentan dar a conocer las costumbres del hombre de familia, por su historia en la actividad, por su campo de antaño, sus herramientas y estilo de vida. origen y por las características que le "Vamos poniendo lo viejo con lo nuevo. Sobre la imprimen como familia que a su vez viene de familia tambera.

El emprendimiento se localiza en el centro de una de las micoregiones más turísticas de la provincia, a pocos kilómetros de uno de los principales destinos turísticos del país pro heladera por ejemplo hay bebidas que ya no estan a

la venta. Tratamos de comparar cómo era en otro tiempo y cómo es ahora". "Se acuerdan de cuando e baño estaba afuera a partir de la pelela". El almacén posibilita la convivencia de lugareños y turistas, y esa gente del lugar con sus historias también forma parte del patrimonio local. "A los lugareños no les molesta el turismo. Eso es lo lindo, ese era el gran desafío que vengan los turistas pero también los lugareños, lograr eso. Hay un paisano que se instala en aque rincón y les dice si quieren me pueden sacar una foto (productora). "Nosotros somos auténticos, somos esto. Y yo creo que el turista lo valora, que estamos dando algo que es auténtico también, lo que tenemos, y el buen trato, sentir que del otro lado hay un ser humano, que estas son las cosas que se han perdido mucho, el dedicarle un ratito de tiempo. Yo creo que eso es lo más valioso que le entregamos". (productora)

"Economía de lo cercano y lo lejano". En el almacén venden productos elaborados por productores de la zona. "Vendemos todos los productos que hace la gente del lugar, por ejemplo es una particularidad que le otorga autenticidad. La
El turismo permite rescatar la tradición oral y la historia familiar, que son a la vez esencia del atractivo turístico: "Yo creo que es amor al campo, a transmitir lo que uno vivió, a transmitir una cultura porque si no a mí me ocurriría contarles a los turistas qué es lo que hacían mis abuelos. Es amor a contar lo que vivieron, lo que hicieron, valorar su sacrificio y poderlo transmitir, como me gusta escuchar las historias de otras culturas, de otras familias. Sí, creo que es amor, porque si no no me acordaría de los abuelos B23cuando hacemos los cuentos, cómo trabajaban, los desayunos que se levantaban temprano para ir a arar. Creo que es amor al campo y a la zona, recordar lo que ellos hicieron. A veces uno no mira el pasado, pero lo tenemos siempre presente. Lo que hacían los abuelos es lo que hoy podemos contar y ver el sacrifico que tuvieron. Si hoy no lo seguimos contando no nos vamos a acordar...". Parece que llega un momento de la vida en que uno hace un click para acordarse de lo que hicieron los abuelos, los padres, uno recuerda dentro de la infancia cómo era de sacrificado y la falta de tecnología" (productora). "Ofrecemos el alojamiento, con la historia de la casa, porque no es un alojamiento común, desde la historia que vendríamos a traerlos a la historia de los abuelos, ya desde la estructura de la casa traemos la historia de los abuelos, no el servicio de los abuelos porque dentro de eso tenemos la tecnología de hoy en día". (productora)

Cercanía a destinos turísticos favorecen el desarrollo: "Las que favorecen, el lugar, porque estamos en un punto muy estratégico dentro de Colón, Villa Elisa y San José. Lo que nos limita, los caminos" 


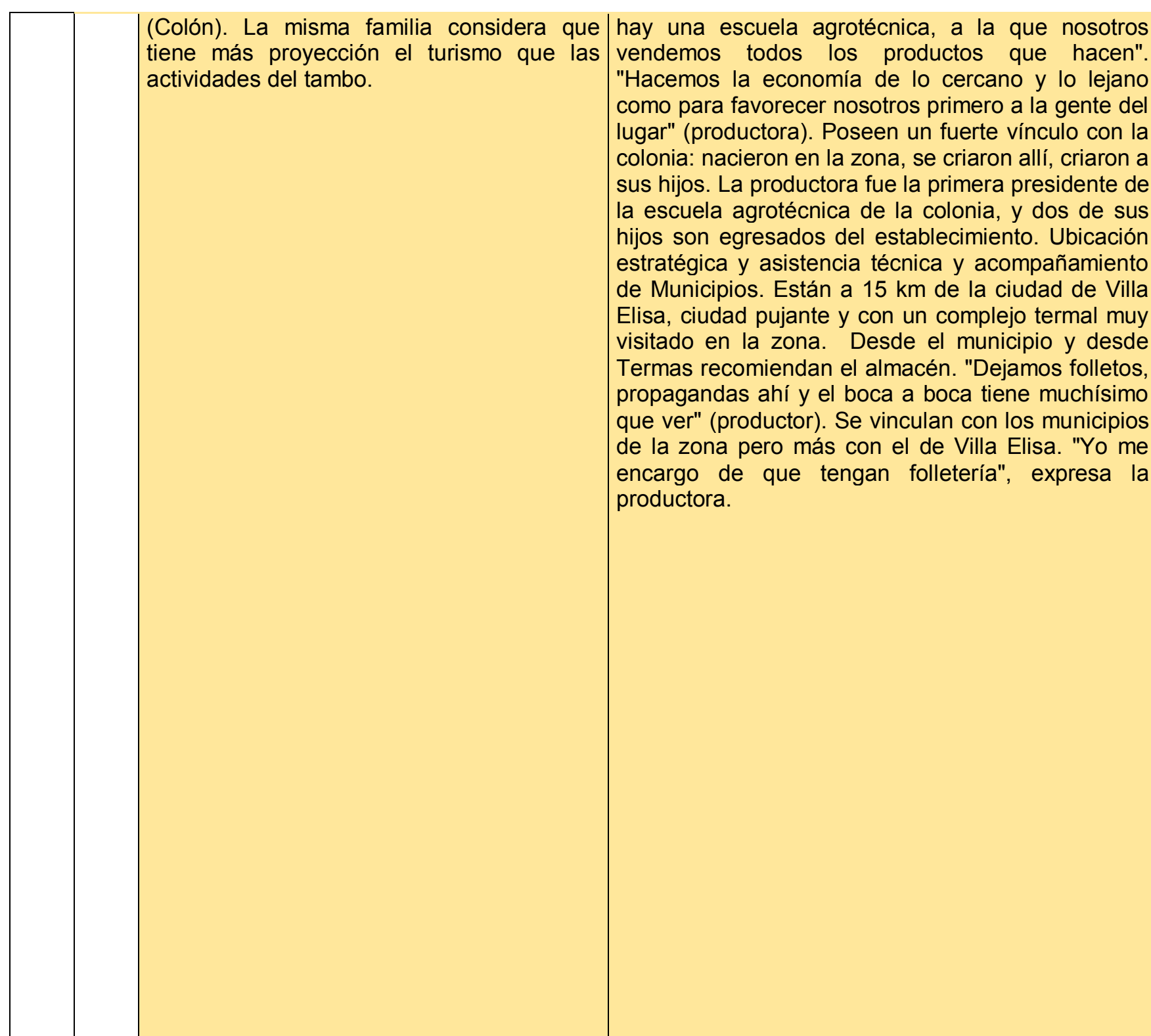

(productora). Limitantes relacionados al estado de los caminos: "El camino que nosotros tenemos es muy transitado y es una angustia pensar que va a llover y que el turista no va a poder salir o no va a poder entrar si hay una reserva porque los autos no serían lo ideal para entrar a un camino rural. A eso lo pedimos ya desde el comienzo, siempre se pide el camino, otra cosa la colonia o el campo no pide para sacar productos, en este caso, el producto sería el turista. Lo estamos peleando dentro de lo que se puede que nos den bolilla con todo (porque limita todas las actividades). Ese sería el problema, el lugar es el ideal porque estamos a $7 \mathrm{kms}$ de la autovía, la autovía hoy es muy rápida (desde Bs As son 2 horas y media/3) que para ellos es una sencillez, pero entrar, venir de una ciudad que están acostumbrados al asfalto a un camino rural es una limitante. Hoy en día es nuestro "sufrir" (productora). "En esta zona hay mucha gente viviendo en el campo". En otros lugares es más agricultura y campos más grandes, que están alquilados. Acá se ha quedado la gente por la avicultura. En la colonia de nosotros hay muchas casas nuevas en el campo, y se sigue construyendo. Es una de las colonias que más se ha construido en el campo" (productor).Contexto provincial propicio: "Creo que al haber tanta gente en la zona, es una de las cosas que a cualquiera se le da por poner algo a la venta para el turismo. La gente uno la tiene, más en la época fuerte de turismo, verano, invierno, fines de semana largo" (productor) El campo se revaloriza: hace 4 años no era lo mismo que hoy, es muy distinto, hoy la gente lo pide. A mí al principio me costó entender por qué la gente iba a querer venir al campo y cómo lo iban a elegir, pero gracias a toda la tecnología que hay, de ver en internet, hoy lo compruebo que sí, que la gente lo elige... por la tranquilidad, por muchas cosas que uno al tenerlos no lo valora. Unos chicos me decían "ay las estrellas!" y como yo las veo todas las noches no me llaman la atención. Ese cambio es muy importante 


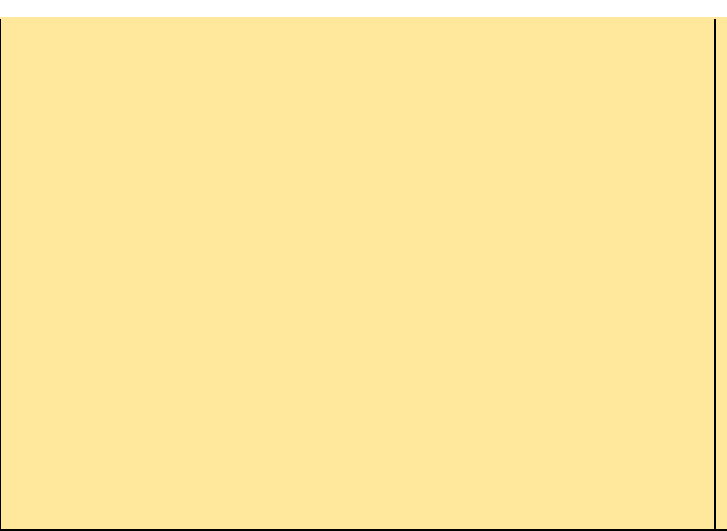

Ambos productores nacieron en la zona, y Los productores son nacidos en la zona. Ella de una ambos provienen de familias tamberas. colonia ubicada a $20 \mathrm{~km}$ de donde se sitúa el Comenzaron con su tambo hace 19 años a almacén y viven. El almacén es de 1907, fecha en la partir de la venta de 15 has del terreno por que llega el tren. El abuelo del productor comienza la parte de un familiar de Ricardo, adonde sociedad. "Uno pone el local, el otro la mercadería y fueron a vivir a los 5 años de casados. Luego, el abuelo ingresa como dependiente, con la idea de reciben en herencia otra cantidad de vendérselo" (productor). En aquella época había tres hectáreas con la que llegan al arroyo Mármol, almacenes en la colonia. En 1909 el abuelo queda eje del atractivo de turismo rural. En su con el $33 \%$ y en 1919 con el $100 \%$. Se convierte en trayectoria como productores tamberos han único dueño. El predio siempre fueron 12 ha. Hasta sufrido 3 grandes crisis, producto de la caída el 2010 funcionó solo como almacén de campo. La de las grandes empresas a las que familia del productor lo hereda y luego ellos se hacen entregaban su leche cruda -1998/1999- 2003 cargo en el año 2004 cuando se disuelve la sociedad y fines del 2015. En los 2000, producto de la con los hermanos.

situación de crisis económica e institucional Testigos de la migración del campo a la ciudad: del país, que repercutió directamente en el "Hasta el año 60/61 se trabajaba un montón. Llegó a sector, comenzaron a hacer queso de haber 120 clientes, abarcaba un radio de 20/30 km colonia, actividad a la que se dedicaron unos porque ya se habían cerrado otros almacenes. Este $3 / 5$ años. Como productores tamberos funcionaba como acopio de aves, acopio de huevos, vienen retrocediendo en la producción. Hace de cereales, pero a partir de esa fecha se vino una 3 años atrás estaban ordeñando 70/75 vacas ola que me parece que la gente grande se empezó a y con intenciones de llegar a 100 (para lo cual ir al pueblo, porque veía que la juventud migraba a hicieron inversiones) pero a partir de la crisis otro lado. Acá las parcelas son todas chiquitas, de 25 de las industrias lácteas en el país, el bajo ha, pero había 70/80" (productor)

precio de la leche y el pago diferido de la Destacan que las condiciones del lugar tampoco misma, han decidido achicarse y lentamente alentaban la vida allí: "no había luz, faltó pasar al animal de cría. También hace 3 comunicación, el camino era grave. Además, la dentro de la zona porque me parece que antes el turismo buscaba más la costa del río, la ciudad... porque la cuidad era más pequeña y menos ruidosa, ahora dicen vamos al campo, y lo que menos haya de gente, mejor. Creo que sí, en mi caso, de proponerles dormir en el campo, amanecer en el campo, estar un rato desayunando mirando lo que es la naturaleza y luego sí, ir a pasear, conocer otros lugares, degustar las comidas y platos de nuestra zona que son muy ricas, y después volver al campo. Esa es la propuesta ideal. Otros dicen nos quedamos a descansar.

El matrimonio de productores nació y vivió toda la vida en la zona. "Somos nacidos, criados, siempre vivimos acá en el campo, en la zona, los dos somos vecinos, las dos familias, mi familia y la de los papás de Luis, vecinos de años. De los abuelos, de los inmigrantes, ya vienen siendo una generación que creció acá" (productora). Cuando emprenden su proyecto familiar, centran sus actividades productivas en la ganadería de cría y posteriormente la avicultura de postura (hace 28 años). La actividad turística es la más reciente. Cuando se casaron se dedicaron a la gallina de postura, actividad que continúan hasta el día de hoy. La Ganadería siempre vigente desde los padres en ambas familias. Forma parte de una de las actividades que desarrollan también hoy. Siempre hicieron avicultura. Alrededor de 1992 dejaron la cría de pollo parrillero y se integraron, pero por poco tiempo porque empezó una enfermedad ("cabeza hinchada") que se atribuía a las granjas que combinaban parrilleros y de postura. Se prohibieron este tipo de granjas combinadas. Siguieron con la de postura, crecieron en esta actividad, construyendo galpones. En la década del 90/95 les fue bien. De tener una hiperinflación a un dólar estable, fue bueno. En los 90 que hubo estabilidad, igual la ganancia era "muy chiquita". Mencionan como crítica la enfermedad y las nuevas normativas que prohibían la combinación de granjas. 
años, la familia construyó el local que fueron mamá se iba con los chicos que estudiaban y ya no armando bajo directrices de accesibilidad volvía" (productor). La familia nunca cerró el (baños accesibles, rampas). Construyeron almacén, estuvo abierto al público desde sus también un acoplado al que paulatinamente orígenes. La productora comenta que en 2015 se fueron agregando techo, rampa para inundaron y producto del agua se cayó una pared del personas con discapacidad, que ofrecen a sótano, donde se hace una visita. "En ese momento los turistas para hacer un recorrido por el mi marido había viajado con mis hijos, entonces yo predio y hasta un arroyo cercano. dije lo cierro y me quedo tranquila. Y cuando llegó el momento dije no, nosotros nos llenamos la boca diciendo que nunca se cerró, yo no lo voy a cerrar. Pusimos el mostrador tapando y atendimos por una sola puerta, pero no cerramos". "Cuestión de orgullo", dice el productor. Comienzan con la avicultura en la década de 1960, continuando con la producción familiar (padre del productor). Hacían producción integrada pero tuvieron un problema financiero y no continuaron. "No se pudo reponer, nos costó mucho pero logramos salvar el patrimonio" (productor) "Nosotros siempre hicimos avicultura, producción de parrillero y huevos. Con el pollo allá en el 2001/2002 dejamos" (productor). "Y si no, nos dejaba a nosotros, todavía nos quedan manchas de esa época" (productora). "Con avicultura de ponedora seguimos en menor escala y el hijo veterinario nos empuja a tener algo de hacienda. Eso nos lleva diversificar" (productor).Hace 20 años que hacen ganadería. El fue camionero hasta el 2000/2001. Sufrieron la crisis del 2001 que afectó fundamentalmente la producción avícola. "Decayó todo. Esto se fue todo abajo, entonces nos planteamos ¿seguimos o lo cerramos y nos vamos? Pero también irte adónde, si estaba todo el mundo igual. Si resistimos a esa época, hoy por hoy estamos chochos" (Roberto). "Y después llegó el pavimento, y nos fue cambiando" (productor). Les llevó 15 años pagar las deudas para salvar el campo (productora). Se fueron reduciendo en la parte de la producción avícola. Eran una sociedad con los hermanos de productor, desde el 1972. Cuando se disuelve y
Cambios en la avicultura: antes habian productores particulares, se compraba y criaba el pollito bebé alimentos en bolsa, y se hacía la venta por su lado. Ahora se da la integración, desaparecieron los productores chicos por las crisis de la avicultura. Destaca que ahora también hay crisis, pero "a otra escala". "A la avicultura ya la teníamos incorporada porque esta zona fue muy de avicultura en pollo y ya con mis padres nosotros ya vivimos la avicultura criando pollo, después surge que se van agrandado las empresas y como éramos pequeños productores, desaparece el productor pequeño de pollo, y ahí empezamos con la gallina para ser dueños de un emprendimiento propio, después vos tenes el de pollo que se integra que ya viene a ser como empleado. Para seguir siendo dueños propios de manejar nuestro negocio pasamos a la gallina. Los años te van haciendo aprender como todo, como es, y ahí lo manejamos directamente. También somos vendedores directos al público, del productor al comerciante, sin intermediarios, también por una razón del momento, de cómo surge, no porque lo hayamos buscado sino que se presentó porque venían antes a buscar el huevo a la granja de bs as los camiones, y eso se fue cortando porque era poca cantidad, por el centro, porque no se podía estacionar el camión, etc, y automáticamente nos fuimos buscando otros mercados acá en la zona para hacerlo directo" (productora). Crecieron. En 2000/2001 hubo un periodo de seca muy grande con más de 6 meses con poca lluvia. B33Fue un año muy difícil para la ganadería y la agricultura. En todos estos años experimentaron un proceso de capitalización: lentamente pudieron comprar "algunos pedacitos de tierra" para desarrollar la ganadería. "Cuando yo era chica recuerdo cómo mis padres cómo se trabajaban en el campo progresando con mucho esfuerzo. Eso lo fuimos aplicando desde chicos en la familia viniendo de los abuelos que ya tenían campo. Yo me caso en los 80 , era muy jovencita también trabajando en el campo 


\begin{tabular}{|c|c|c|c|}
\hline & & & $\begin{array}{l}\text { quedan solos, se retrae. "Yo fui } 32 \text { años a Buenos } \\
\text { Aires con huevos, la mayoría de producción propia. } \\
\text { Acopiábamos } 500 / \text { c } 600 \text { cajones por semana. } \\
\text { Después se terminó la integración". Con el mismo } \\
\text { camión que llevaba los huevos a Bs As iba a Córdoba } \\
\text { o Rosario y buscaba cereales para hacer el alimento } \\
\text { de las gallinas y la hacienda. Hoy producen ellos el } \\
\text { alimento y venden a otros particulares. Uno de los } \\
\text { hijos continúa con esta forma de trabajo con el } \\
\text { camión. "Tiene unos viajes especiales porque hizo } \\
\text { un arreglo con unos molinos de San Salvador. Les } \\
\text { retira cafrechillo de arroz y desparrama. Tiene sus } \\
\text { clientes en la zona. Y en la época de cosecha de } \\
\text { arroz también transporta. El otro hijo solo hace } \\
\text { transporte para terceros. Transporta cereales más } \\
\text { que nada a Rosario, también lleva implementos para } \\
\text { cría de cerdos, arma la vuelta completa. Ellos ya son } \\
\text { rancho aparte" (productor). Cuando se hicieron cargo } \\
\text { del almacén tuvieron que trabajar mucho para darle } \\
\text { vida nuevamente. "Nosotros encontramos un } \\
\text { almacén totalmente despoblado. En } 10 \text { años lo dimos } \\
\text { vuelta. Hoy tenemos más de } 3000 \text { visitas al año. }\end{array}$ \\
\hline 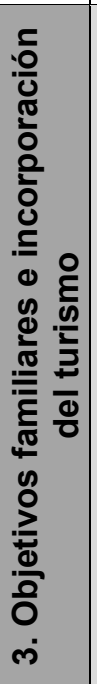 & 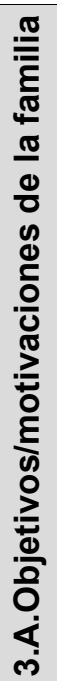 & $\begin{array}{l}\text { Ante contextos de alta incertidumbre y } \\
\text { volatilidad como es el sector tambero en } \\
\text { Argentina, la familia busca incorporar otras } \\
\text { actividades económicas, que colaboren y } \\
\text { posibiliten su permanencia en el campo, } \\
\text { actividades que son pensadas asimismo } \\
\text { como una posibilidad de empleo y } \\
\text { continuidad de los hijos en actividad y en la } \\
\text { colonia. } \\
\text { Reducción del tambo: sus objetivos } \\
\text { productivos son: reducir el tambo a } 7 / 10 \\
\text { vacas, } 100 \text { Is de leche a día para } \\
\text { autoconsumo y para el turismo); cambio por } \\
\text { animales de cría. Aun no tienen determinado } \\
\text { si van a hacer recría; seguir apostando por el } \\
\text { turismo; continuar con las tres actividades }\end{array}$ & $\begin{array}{l}\text { Se desprende de las entrevistas que el objetivo de la } \\
\text { familia es continuar con las } 4 \text { actividades, que son las } \\
\text { partes que necesitan para que el engranaje } \\
\text { económico funcione. Tienen empleados para la } \\
\text { ganadería y la avicultura. Están pensando en } \\
\text { modernizar la granja. Tienen aceitado el esquema de } \\
\text { la fábrica de alimentos y el almacén seguiría a cargo } \\
\text { de la productora y su socia. El almacén les estaría } \\
\text { aportando más satisfacciones personales y de } \\
\text { vinculación que económica pero al compensarse con } \\
\text { el resto de las actividades, no habría nada que } \\
\text { alterar. }\end{array}$ \\
\hline
\end{tabular}

y buscando progresar en el campo, queriendo hacer, siempre en la tarea del campo, nunca se nos ocurrió salir del campo, progresar. Hoy me doy cuenta lo que se pudo lograr en esos 30 años, 35 años en el campo que trabajamos juntos. Tuvimos crisis, cambios de gobierno, mucho más sacrificado, a veces tal vez no tanto, pero siempre con esfuerzos. Años de más progreso, años de menos pero gracias a Dios para adelante, despacito, para adelante" (productora).

Continuar con las actividades del sistema, si es necesario contratando empleados, no para turismo porque entienden que en esta actividad deben estar ellos. "El turismo rural es una entrada más de dinero, si bien todavía no estamos a full todavía porque "somos nuevos". En el caso de necesitar piensan tomar algún empleado más pero para la avicultura, no para el turismo "porque es muy importante que sea personalizado". El resto, lo demás, hay trabajos que se pueden hacer con personal "si bien el patrón es el patrón", son cosas que se pueden lograr. Dejar algunas de las actividades no es mi idea".(productor). Mayor integración: Su idea es incorporar la granja al turismo (llevar a la gente a ver las gallinas, juntar los huevos) o la de llevar al turista a ver a los animales (enlazar un ternero, curabicheras, yerra). "Para ellos es toda una novedad". Por la parte de atractivos creo que la 


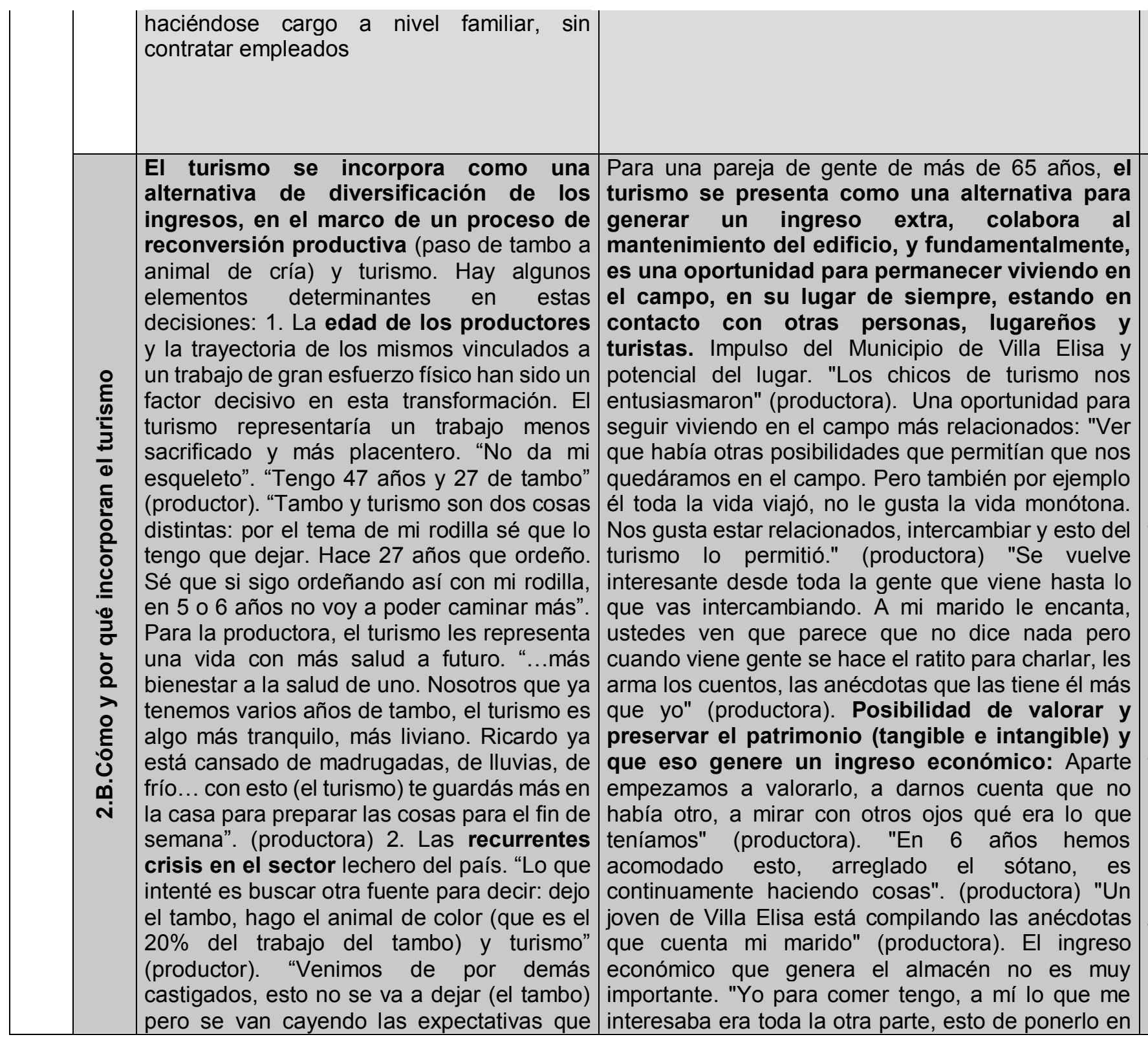

ganadería es un atractivo más y que fuera la parte de avicultura incorporarla". (productor)

Elemento de crisis en el origen: En el año 2007, afectados por una sequía, la familia decide alquilar campos cercanos para el pastoreo del ganado. Les ofrecen la compra de un campo de 20 has que incluía una casona de más de 100 años, que había quedado deteriorada por el abandono y reparto de las tierras originales. Su origen estaba vinculado a una familia de colonos suizos de apellido Felay, radicados en tierras entrerrianas desde principios del siglo XX. "En el año 2006/7 por una sequía importante -ajustados con el pasto- sale la compra por buscar un alquiler de campo para llevar los animales a otro lugar que estaba haciendo falta. Sale lo de la casona" (productor). Conocían la casa porque eran vecinos. "No fue fácil tampoco". Había financiaciones para comprar y además vendieron un campo más alejado, que no tenía luz" (productor). Mirada empresarial: El lo vio como "un gran negocio, desde el primer momento". El pensó en comprar la casa para restaurarla, "en ese momento nadie pensaba en turismo rural". Pasan 4 años hasta que la compran. Forman parte de un grupo ganadero desde el 2000, estando en ese grupo se enteran de la convocatoria de turismo rural. Luego entran al grupo de turismo rural (2009). 2010 se empieza a restaurar. Se decide hacer 4 habitaciones- con baños privados. "Fue bastante fácil dentro de todo, no se hicieron grandes reformas a la casa. Arrancamos así sin experiencia, sin nada, sin tener página de internet solamente amigos que nos empezaban a mandar gente" (productor). Abren en el año 2012. Victoria termina el secundario y empieza a estudiar turismo. Destacan la compra de la casona "como una gran oportunidad, y que abrió la alternativa de turismo. Que vino por la sequía, fue el destino! Luis es el innovador. Cuando fue todo esto de 


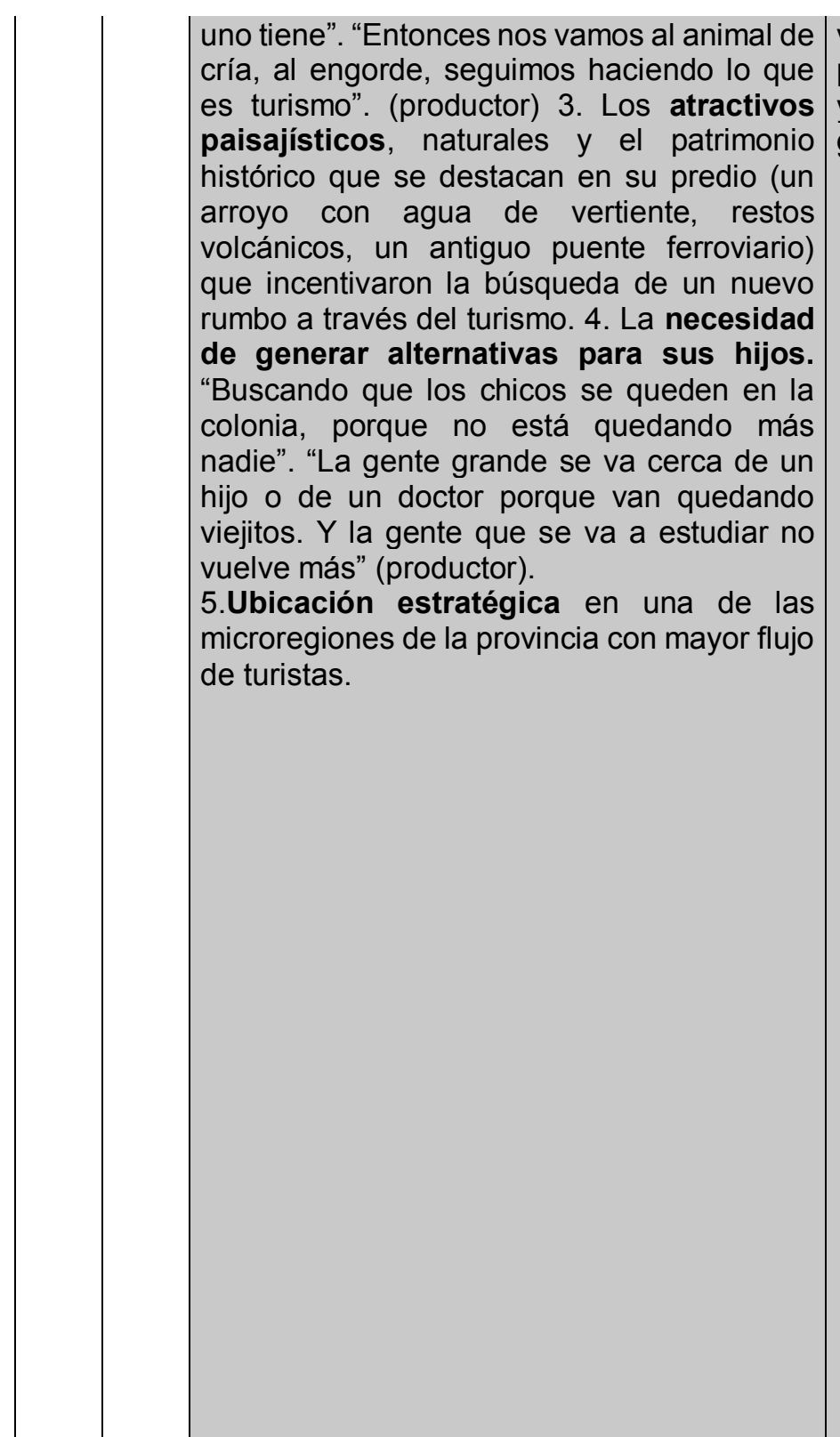

valor, de las charlas, poder disfrutarlo en una y comés, pero a nosotros las otras actividades nos genera más ingresos". (productora)

histórico que se destacan en su predio (un

arroyo con agua de vertiente, restos

, un antiguo puer

de generar alternativas para sus hijos.

"Buscando que los chicos se queden en la

colonia, porque no está quedando más

La gente grande se va c viejitos. Y la gente que se va a estudiar no microregiones de la provincia con mayor flujo de turistas. la sequía él salió a consultar, sin preguntarme porque si no yo le hubiera dicho "nooo, déjalo, vamos a hacer otra cosa". Y surgió de la casona. Yo creo que es una inversión". (productora) "Daba pena dejar caer la casa por todo lo que había, entonces ahí se comienza a revertir esto, pero era más una inversión en ese momento, y hoy, todos los días pienso que es una inversión, que es un logro, es así" (productora). Opción de futuro para los jóvenes pero también alternativa de agrado para los padres: "cuando Victoria termina su secundaria no tenía ninguna vocación a seguir estudiando qué. Y ahí yo tenía la visión de que el turismo es el fuerte nuestro acá en la zona... nuevo, porque para contadores tenemos un montón, todas las otras profesiones tenemos un montón, y sobre el turismo me parecía que estaba ideal. Aparte tenía la experiencia de mi mamá, que tiene departamentos en Colón que siempre alquiló, y sin estudio, sin conocimiento lo fue llevando, y yo le decía, eso, con estudio, sabiendo, con la experiencia de ser técnicos en turismo, me parecía que era una profesión ideal para ella. Por suerte a ella le gustó y arrancamos ahí, y desde ahí entonces viene el turismo a nuestra familia. Luego aparece la compra de este terreno con la casa antigua que yo no la quería refaccionar porque me parecía que era una locura. En ese momento no se hablaba tanto de turismo rural como es hoy, pero bueno, el ímpetu de mi marido de querer hacerlo y viendo el futuro para mis hijos sobre todo, de que sea un futuro para Victoria, y si no hubiera sido para Victoria para el que fuera de ellos, me gustó seguir en esa parte, ponerle la potencia ahí. Yo pensaba, sí, que sea para ellos pero que a mí me guste. Y le encontraba una cuota de que a mí me iba a gustar, lo que era la parte del dialogo, aprendizaje en otras en otras culturas, en otras vidas, porque todos traen una historia distinta, y yo sabía que esa parte me iba a gustar. Y por eso llegó. Acá parecía cuando nosotros comenzamos con esto, que no era el momento. Otra persona hubiera hecho otra inversión, 


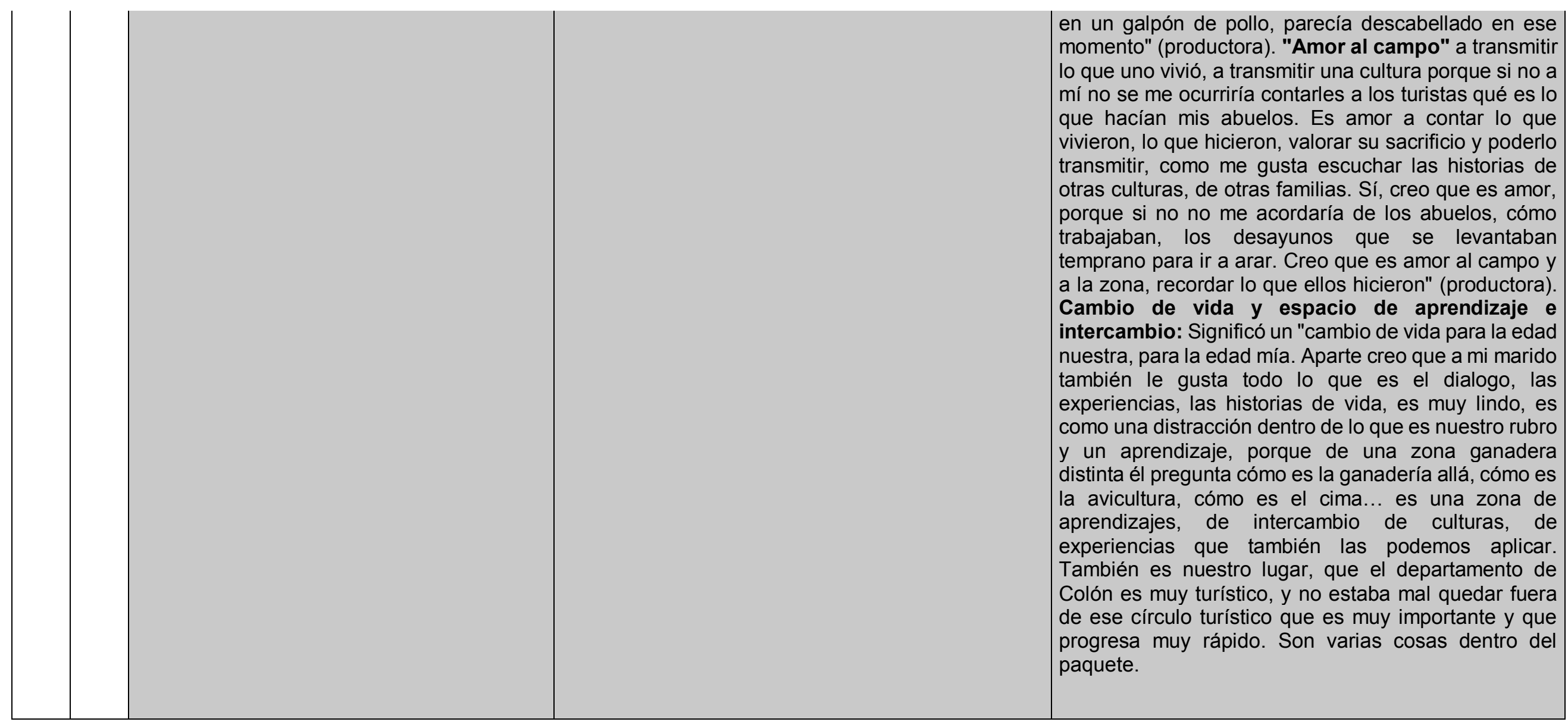


Este tipo de integración del turismo en el sistema se da muy claramente en este caso en el que los productos de la producción primaria son insumos para la elaboración de los alimentos que sustentan una segunda actividad como es el turismo: carne y chorizo para el asado, verduras para ensaladas, frutas para budines y meriendas. Este circuito in de materia prima (producción primaria) productos elaborador (turismo) colabora a la sustentabilidad del proyecto familiar. Se da también entre la agricultura y ganadería ya que ellos mismos producen el maíz que alimenta a los animales de cría.

El capital humano familiar es la base del En este caso se combina mano de obra familiar con

trabajo de todas las actividades: el turismo asalariada. Están bien divididas las funciones de los rural viabiliza una reorganización de tareas potenciando las capacidades y gustos emr personales de los miembros de la familia. al reparto y cuenta con 1 empleado La productora Aunque "todos sepan hacer todo" y "todos 1 socia/empleada atienden el almacén y son hagan todo", hay tareas que corresponden - responsables además de la parte administrativa. por empatía y capacidad de trabajo- a cada Además producen algunas conservas, dulces y productora: granja y cocina; hija: granja y empleados se hacen cargo de la ganadería. Para la ayudante en cocina; hijo: manejo de fábrica de alimentos compran los núcleos y en la maquinaria mozo y ayudante en parrilla; máquina se elabora el alimento, que atienden padre

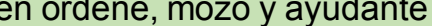
en parrilla). Por otro lado, la base de las propuestas de turismo rural está dada por el

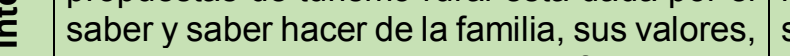
$\emptyset$ y aquellos aspectos que la identifican con el entorno. La distribución de tareas se da de una manera organizada y coordinada, tanto para las tareas que desarrollan durante la po semana, que mayoritariamente están pie asignadas a la alimentación y cuidado de los tur animales y mantenimiento del predio, como las del fin de semana, que dedican un $80 \%$ la preparación del asado, comidas, visitas
En este caso, si bien el sistema funciona como una animales, producen el a alimento balanceado para las gallinas, con la cama del pollo se fertiliza el campo donde se siembra, no se contempla integración de sumos de la actividad turística. miembros de la familia y cada actividad tiene a la vez hijo una vez por semana según el resto de las actividades. La tarea que más requiere presencia es la avicultura. En el caso de que la pareja deba viaja se aseguran de que uno de los hijos quede a cargo de esa actividad. Es fundamental el conocimiento específico que tiene la pareja de productores de la historia del lugar, la familia y la colonia, son los portadores de la historia, lo que los convierte en pieza clave para el desarrollo de la actividad turística. Físico: la principal movilización se da en el almacén de campo, que es además de almacén de venta para la colonia fue abierto al turismo como almacén de campo, con la posibilidad de hacer pasturas y se hacen rollos para alimentar los
No se evidencia integración de los productos de las actividades productivas como insumos de la actividad turística. Sí se da entre ganadería, agricultura y avicultura ya que producen los rollos de alfalfa, soja, trigo y maíz para el engorde de la haciendo. Además, utilizan la cama de pollo para fertilizar el campo. Eventualmente, utilizan huevos de su producción para preparar alguna comida a pedido de los turistas.

Para que se puedan cumplir todas las actividades hay una organización compleja, con consensos y diálogo. La incorporación de turismo ha complejizado las tareas y hay actividades de ocio que han dejado de practicarse. También genera reclamos en el resto de los miembros de la familia que no integran la unidad económica. Los tiempos son ajustados, más en temporada alta de turismo. Respecto a las competencias, lo+E16s productores toda su vida han vivido en el campo y han aprendido los oficios de sus padres, y con ellos han trabajado también. Enseñan su saber a sus empleados e hijos. Hay intercambio de opiniones con la hija respecto a decisiones en la casona, que aporta una mirada más técnica. Los padres apuestan a la profesionalización de las actividades productivas a través de la formación profesional de sus hijos menores. Si bien todos los días la familia organiza su rutina de trabajo en función de las actividades impostergables y la llegada de los turistas, hay roles que están claramente E13asignados. El productor está dedicado a la ganadería y eventualmente al mantenimiento y arreglo de la casona para turismo. La productora a avicultura (es la que más sabe de la actividad) y al reparto de huevos, pero también es la que más presencia tiene en 
guiadas y atención al turistas. Las mujeres se meriendas o almorzar, con base en la historia y dedican al aseo de la casa, atención a dinámica particular del lugar. Natural-tierra: tienen animales de granja, alimentan a los terneros organizadas las actividades en predios separadas y producen alimentos. Tareas campos propios y arrendados. No hay competencia impostergables: El ordeñe y la comida a los por el uso porque cada actividad se realiza en predios novillos (se dan en horas fijas, con turistas diferentes. Respecto al capital económico, aunque también). Físico: se utilizan equipamientos han sufrido un proceso de retracción en la avicultura, para varias actividades del sistema, por han diversificado sus actividades productivas $e$ ejemplo el tractor, utilizado por las invertido para recapitalizarse. Han sufrido una crisis actividades típicas del campo, es el motor de importante pero han logrado mantener su patrimonio. "El Costerito", una de las patas de la mesa de Hoy están capitalizados. Aunque el almacén no la propuesta de turismo rural. Esto muestra a implica un ingreso importante, colabora con el las claras la creatividad y la eficiencia en el mantenimiento del patrimonio. Actualmente son las uso de los recursos de la familia. Respecto al otras actividades el principal sustento de la familia. uso de la tierra, no se vislumbra En lo social, el turismo ha reforzado el vínculo con las competencia en el uso de los suelos, ya familias de la colonia, se revalorizan los productos que las actividades están claramente bien elaborados por gente de la zona que se venden en e distribuidas en todo el predio. No se da almacén, y a través de estos sus saberes. El almacén competencia por el espacio. Se aprovecha posibilita además la convivencia de lugareños y cada espacio del predio y están claramente turistas, y esa es una particularidad que le otorga diferenciadas las actividades. El turismo ha autenticidad.

movilizado una puesta en valor del espacio

su orden, mantenimiento y una puesta más estética. Desde el punto de vista económicofinanciero, el turismo ha sido capitalizado $-\mathrm{y}$ sigue siendo en su mayoría financiado por la actividad tambera. No obstante, se piensa que en un futuro, va a tener otro rendimiento económico, en el marco de una estrategia productiva global. Manejan sus ingresos como una caja única, en la que el tambo representa el ingreso más sólido y estable. No llevan un registro sistemático de su flujo de ingresos y egresos. La familia integra los flujos de ingresos de las tres actividades. Respecto a lo social, a diferencia de las otras actividades económicas de la familia, el turismo vincula a la familia con las comunidades de la zona, con referentes municipales, técnicos y con otros la casona. Limpia y ordena las habitaciones y atiende a los turistas cuando la hija de la familia trabaja en la oficina de turismo. Además se dedica a las tareas de su hogar. Tienen dos empleados (gente de la zona) para el trabajo en ganadería y avicultura. El hijo menor colabora con el corte de pasto de la casa y ayuda al padre en las tareas con la hacienda. Natural-tierra: tienen organizado el pastoreo rotativo en campo propio y arrendado. No hay competencia por el uso porque cada actividad se realiza en predios diferentes. En el predio ganadero donde se ubica la casona rural, está bien delimitado el espacio para el uso turístico alrededor del alojamiento. Del análisis del capital económico, se desprende que se invirtió en turismo como una oportunidad de negocio "dentro del campo". Permite a la vez diversificar más los ingresos, es complementario pero tiene una buena proyección económica a futuro. La familia se ha ido capitalizando en su trayectoria productiva. Poseen una caja única y funciona según los productores como una cadena de inversiones. "La ganadería contribuye con la avicultura, la avicultura contribuye con la ganadería, también se ha hecho algo de siembra de pastura que también va contribuyendo, y el turismo está también dentro del mismo paquete, que no lo separamos".

Desde el punto de vista social, el turismo es vinculante. Posibilita el intercambio sociocultural con los turistas, a quienes se transmite la historia familiar y de la colonia (porque la casona originariamente perteneció a una familia suiza que arribó a la zona a principios del siglo $X X$ ). A la vez, este intercambio posibilita un enriquecimiento personal y cultural, que ha estimulado a la familia a viajar y conocer otras culturas. También permite el intercambio con vecinos de la zona, venden productos elaborados por familias vecinas. Comparten experiencias y opiniones con otros productores que integran junto a ellos grupos asociativos de turismo rural y el asesoramiento técnico y acompañamiento de los municipios de la microregión. 
productores

generando

mayores

oportunidades

intercambio

experiencias y aprendizajes, en los que productores dan y reciben, son transmisores de sus propias experiencias y conocimientos, en los que lo central es su saber, saber hacer y su ser.

La propuesta turística se basa en dos pilares: el patrimonio natural y paisajístico que se encuentran dentro del predio y que a la vez

. misma familia; y la tarea rural que desarrolla la familia, son sus saberes, experiencias y forma de transmitirla a los turistas, que a la vez tiene la posibilidad de participar de la actividad.

El turismo se integra al sistema como una aternativa de trabajo a futuro concretamente para la pareja de productores. La estrategia es que paulatinamente se vaya convirtiendo en su actividad principal para los próximos .․ años, dado el desgaste físico que caracteriza la actividad tambera y que, dada la edad del productor y su mala salud, pareciese imposible de continuar. Esta decisión implica transformaciones y un esfuerzo mayor en e presente, pero pensando en una mayor calidad de vida a futuro.

Los productores destacan el reconocimiento de los vecinos de la zona al ver turistas en el campo, idea que les parecía inverosímil en sus principios.

La implementación de la actividad turística no solo se basa en el patrimonio tangible, en el almacén de más de 100 años y sus objetos, sino y fundamentalmente es a partir de la movilización y puesta en valor de historias, sucesos, costumbres de las épocas, de la herencia cultural de la familia y familias de la colonia. Es un rasgo muy fuerte en el sistema.

Se evidencia una apuesta a las 4 actividades que realizan a futuro. Existe una expectativa de continuidad de las actividades a partir del involucramiento de los hijos, fundamentalmente de uno de ellos. calidad de vida a futuro. arquitectónico e infraestructura que brinda la casona antigua de campo. Además de ser atractiva a la vista cuenta con espacios y detalles que evidencian la historia y un estilo propio de as primeras familias colonas que arribaron a la zona. La familia se interesó y estudió la vida de la familia, con mucho esfuerzo recuperó los espacios, los aggiornaron, recuperaron muebles y objetos de antaño para recrear lo más posible la casa familiar como era originalmente. Además del patrimonio tangible, la tradición oral, el transmitir la historia familiar, cómo vivían y trabajaban sus abuelos y cómo fue modificándose la vida en el campo ha sido destacado por los productores como vital. El patrimonio paisajístico y el entorno rural natural integra el atractivo de la propuesta. a partir de la continuidad de las actividades que se desarrollan, fundamentalmente ganadería (con cabañas) y turismo. También surge de las entrevistas la idea de la pareja de productores de dedicarse más al turismo a futuro. Vislumbran en la actividad una alternativa con proyección a futuro y más placentera, menos desgastante físicamente y más agradable por el intercambio con los turistas y la gente.
Existe una expectativa de arraigo de los hijos al campo 
Además de los ingresos económicos, aporta La combinación de las actividades permite sostener ฮ a la familia otro tipo de "ganancias", la propuesta turística del almacén que genera más vinculadas con satisfacciones personales y satisfacciones que ingresos. "Las pocas gananc : aportes a la salud de los miembros de la del almacén son más satisfacciones que ganancias". familia; refuerza la autoestima personal y es (productora) Yo no sé qué es más rentable, si el un vehículo para reforzar la identidad y su contacto con la gente y la tranquilidad que la plata ¿ propia idea de quiénes son, de dónde vienen, que va y viene" (productor) que hacen y por qué hacen lo que hacen.

Complementa los ingresos familiares, es Las actividades en su conjunto contribuyen al ingreso

¿ \& niven de sinergia entre actividades y

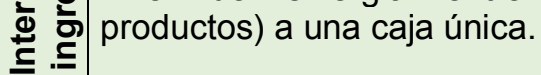

Existe un tipo de relación funcional opcional A la altura del ciclo de vida familiar, la combinación respecto a la incorporación del turismo. El de actividades permite a la pareja de productores sistema seguiría funcionando esté o no la dedicarse a lo que más les gusta, incluso mantene actividad turística, aunque su integración el patrimonio familiar que es el almacén, a través de colabora al engranaje de los productos de las la puesta en funcionamiento de la propuesta turística. diversas actividades. Además, es Existe una relación entre la existencia del patrimonio, competitiva, compite al interior del sistema, del almacén para la existencia de la actividad turística en términos del uso de la fuerza de trabajo el turismo reporta una serie de capitales que son porque es la familia la responsable de la vitales para la pareja de productores gestión y ejecución de las actividades. No fundamentalmente relacionados a la satisfacción obstante, con una buena organización en la personal y a lo vincular. Sin el patrimonio no sería distribución del tiempo de tareas diario y una propuesta viable. Desde el punto de vista semanalmente, no agrega en sí una dificultad económico no es obligatoria la interacción porque difícil de sortear, si: se respetan los tiempos es menor el ingreso respecto al resto de las de las tareas impostergables (ordeñe, actividades. El ingreso del turismo es opcional. A alimentación, tiempos del asado para el parecer no hay competencia al interior del sistema, e turista); en los momentos de mayor visita, el turismo es complementario, tienen bien "equipo de trabajo" responde rápidamente a diferenciadas las actividades en el uso de los la hora de asumir nuevas tareas y funciones, recursos. y se complementan en los roles.
El turismo es comprendido como una inversión, como una oportunidad de negocio y genera ingresos, no tan importantes como el resto de las actividades pero con proyección a mejorar en un futuro. Además de lo económico moviliza otros sentidos, que permiten poner en valor la historia personal, familiar y del territorio. Moviliza a la vez el reconocimiento de los vecinos de la zona y la propia comunidad lo que refuerza la autoestima familiar y visión innovadora de los productores.

El turismo es una actividad con menor peso en el ingreso total $(10 \%$ aproximadamente, respecto a la ganadería y avicultura, a las que corresponde un 45 y $45 \%$ según dichos del productor). Las actividades se complementan y equilibran: la avicultura genera un ingreso diario con la venta de huevos y la ganadería es más lenta (27 meses el proceso), pero más segura. Se organizan con la idea de una caja única y en cadena. Para entender la sustentabilidad del sistema es clave el tipo de relación que se da entre las distintas actividades productivas: se aprecia una relación de complementariedad y obligatoriedad en las relaciones funcionales de las 3 actividades principales (agricultura, ganadería y avicultura). Se maneja el sistema de forma integrada y esto le da mayor autonomía. Los productos de una actividad son insumo para otra (asimetría). No sucede lo mismo con el turismo. No se vislumbra una interdependencia con el resto de las actividades, no hay competencia, pero cumple otras funciones dentro del sistema: genera ingresos complementarios, los ingresos permiten mantener el patrimonio (si no existiese el patrimonio sería muy difícil la puesta en marcha de una propuesta turística con lo cual hay un lazo de obligatoriedad entre patrimonio y turismo) moviliza otro tipo de capitales relacionados a la valorización de la historia personal, familiar, los recursos paisajísticos, culturales y territoriales, es una opción para el futuro de los 


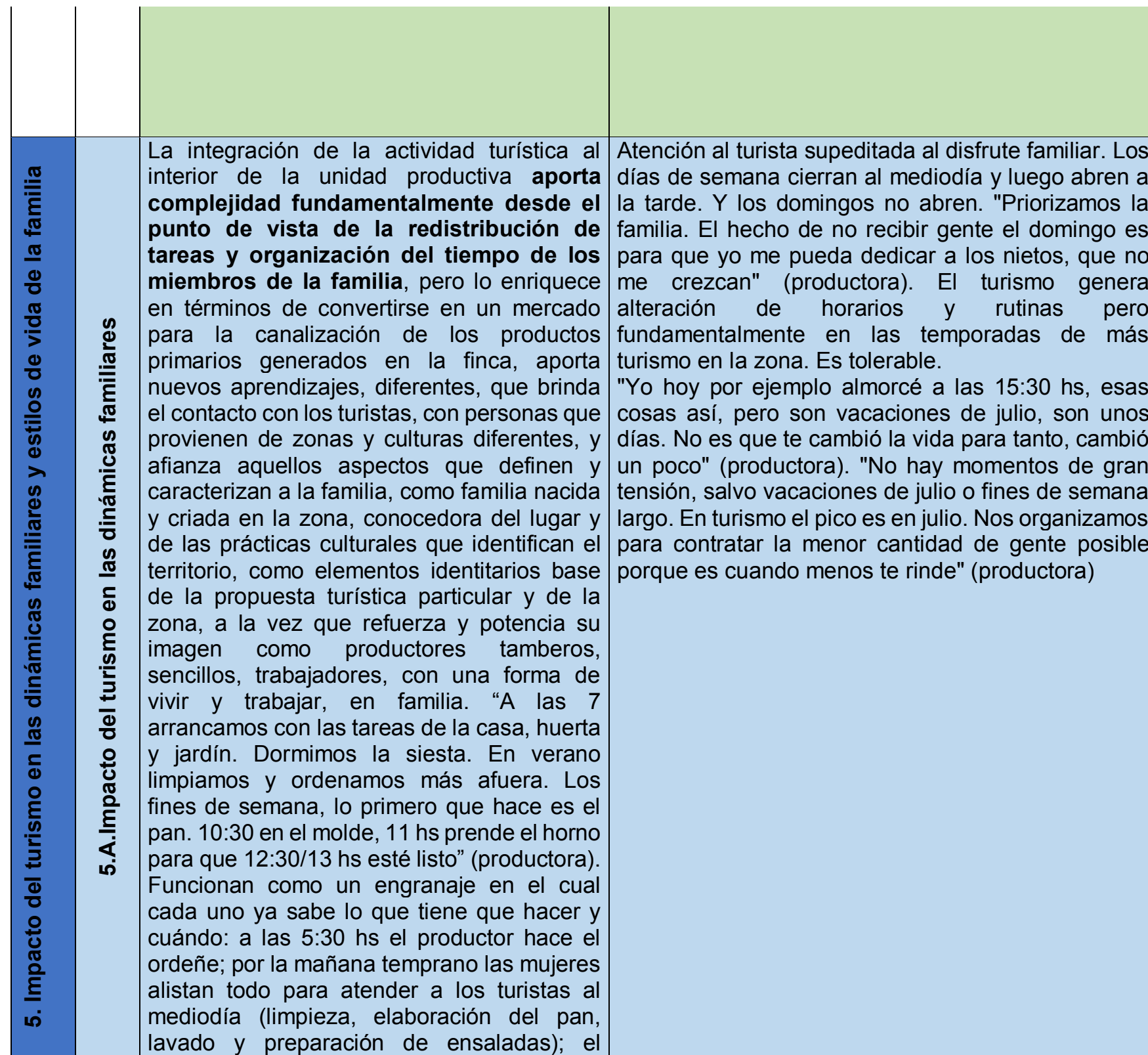

padres y una alternativa más para el futuro de los hijos (reciprocidad)

Cambios en el rol de la mujer/ se dejan actividades para dedicarse al turismo: Sí, ha cambiado, totalmente. Van mis vecinos, mi hermana y me dicen "no te encontramos más acá" (por su casa), "no, me cambié de domicilio, estoy en el alojamiento". Fue un cambio muy importante porque yo me puse la camiseta, más yo, porque Victoria con el tema de su estudio, su trabajo está trayendo todas las experiencias y la compartimos, pero como que las horas libres que hay que tomar, las tomo yo, me hice dueña de las horas libres para el turismo. Antes me dedicaba más a mi casa y a estar más dentro de controlar o de ayudar dentro lo que es la avicultura. En la ganadería participaba poco, pero en la avicultura era más la presente. Ahora dejé esa presencia, la tuve que delegar más a los empleados para ponerme más en el alojamiento, porque acá en el turismo... una que me gusta más, un cambio, otra, me parece que la presencia del dueño es más importante... en todos los emprendimientos, en lo otro también+B2 es importante el dueño pero con los años que tengo, con la experiencia como que lo puedo manejar más mandando al empleado. Y como esto es nuevo... me gustaría que el día de mañana esto surja, tal vez podamos ir haciendo... gente capacitada para ir dejando, poder manejarlo distinto, pero estoy yo porque me parece más importante estar acá. Específicamente, en la crianza de una pollita es muy especializado, hay que estar, ver si tomó agua, las vacunas, todo lo que hay que hacer. Después también el control de la postura, cómo están, cuánto ponen, mirar dentro de la granja, los resultados de lo que vos estás haciendo, si lo estás haciendo bien o no. Ya eso lo tuve que dejar... pregunto pero no lo puedo hacer más, es imposible. A esas horas las trasladé 
productor comienza con el trabajo en la parrilla; los 2 varones (hijo y yerno) mantienen la parrilla mientras Ricardo hace la visita guiada (a las $12 \mathrm{hs);} \mathrm{a} \mathrm{las} 15$ hs paran la parrilla, Ricardo hace una nueva visita y Carina queda a cargo del local. Los dos varones preparan los animales para que a las 17 hs hagan el segundo ordeñe. Mie+C28ntras tanto son mozos. "A las 12 les contamos cómo hacemos el ordeñe, a las 17 hs les mostramos" (cómo se da leche a los terneros, cómo se ordeña)" (productor). De los 7 días de la semana, 2 son destinados al turismo, aunque en temporada alta, son 4. Por día del fin de semana el $80 \%$ es dedicado al turismo. Durante la semana, la mayor parte del tiempo se dedica a las actividades con animales. acá (alojamiento) a venir acá, a decir, bueno, falta esto, hago esto, y cuando hay gente por supuesto, estar atender acá" (productora). "El turismo apareció sin pensarlo, y se agregó una cosa más. Uno no lo buscó. En lo demás, Estela es una de las que quiere dejar la avicultura. "Si fuera por ella quedarían pocas gallinas!". Para mí es una entrada importante, si bien genera su tiempo y todo, si fuera ella quedarían pocas gallinas" (productor). Requerimiento de mayor organización para cumplir con todas las actividades "Se modificó muchísimo mi ritmo de vida. Porque yo me vengo a trabajar a la oficina y cuando yo me vengo a trabajar, mi mamá va al alojamiento, y cuando yo salgo, mi mamá vuelve para la casa a hacer las actividades cotidianas suyas. A veces incluso se queda todo el día en el alojamiento trabajando. Entonces nos vamos rotando para ir cubriendo para que los turistas no queden solos. Pero aparte las veces que tenemos gente yo me voy a instalar allá. Si bien todos hacemos un poco de todo y colaboramos entre todos, mi papá está más con el tema de ganadería, la parte de avicultura la maneja más mi mamá. $Y$ yo estoy con el turismo, y a la vez ellos dos me ayudan a mí. Mi hermano, el más chico, está estudiando en Colón, y mis otras hermanas ya están casadas y tienen sus familias, una vive en Colón y la otra en Villa Elisa. No participan de estas actividades".(hija). Reclamos familiares: "cuando tenemos gente los fines de semana largos olvídate porque mis hermanas empiezan "ay mamá qué estás todo el día allá, que no te vimos, que te cansás, que estás todo el día trabajando..."A ella le gusta... se cansa, trabaja, por ahí más de la cuenta lo que debería, pero porque le gusta, se pone a arreglar las plantas, habla con la gente..." (hija) El turismo, una actividad femenina: Sí... en nuestro caso, sí. En nuestro emprendimiento, sí, lo llevamos más mi mamá y yo, más que mi papá. 


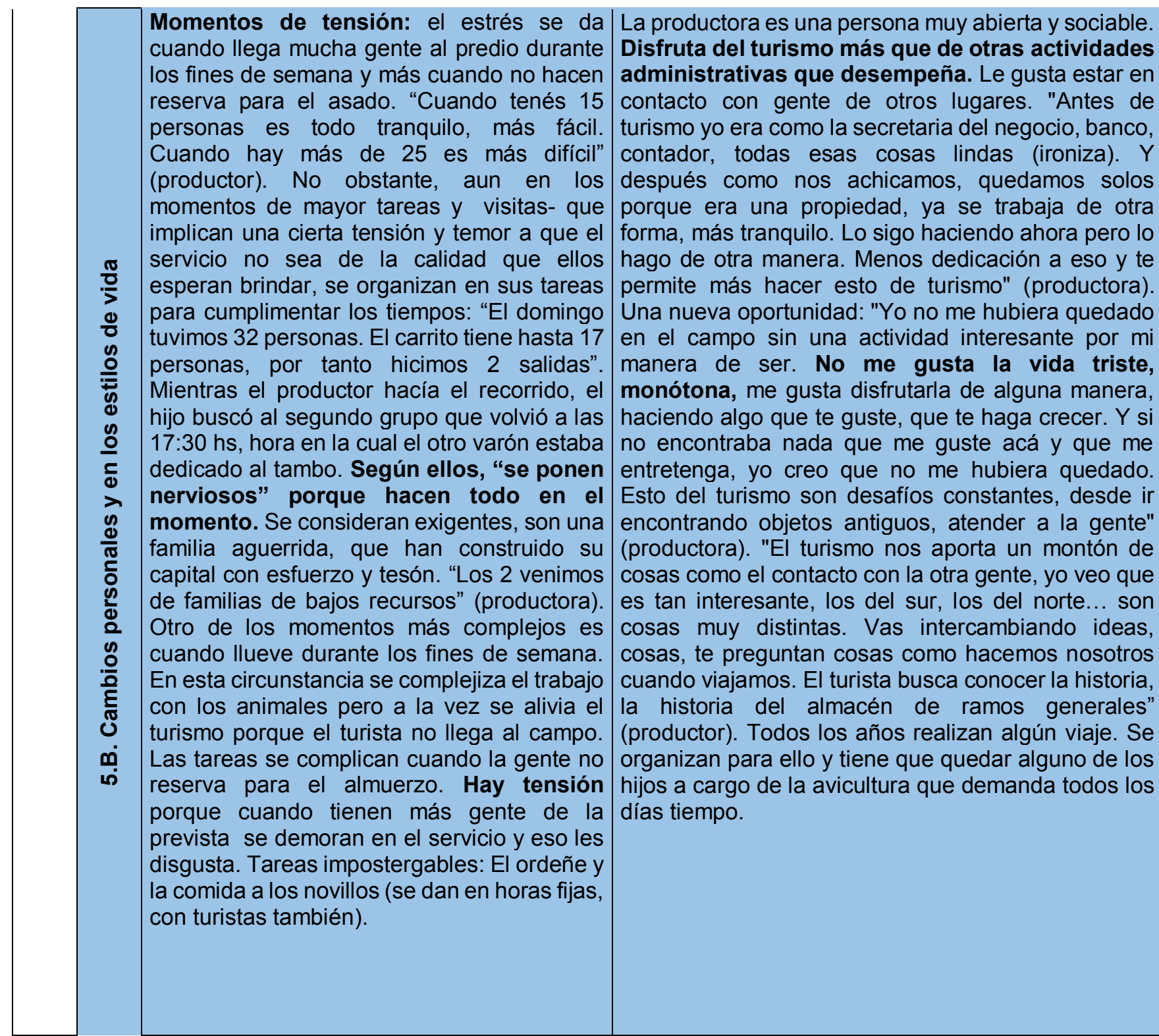

Posibilidad de formación profesional: "Antes cuando era más chica sí me involucraba con el resto de las actividades. Ahora muy poco. Ayudaba si había que encerrar animales para cargar, juntar el huevo, clasificarlos. Sigo ayudando pero menos. Por ejemplo si hay que llevar a repartir huevos a Colón o Concepción la B5acompaña a mi mamá y la ayudo con eso. Yo además trabajo en el área de turismo en la Municipalidad de San José. Empecé en el 2010 haciendo el curso de la UBA (postgrado de turismo rural), después hice otro curso de gestión turística, y en el 2012 arranqué con la carrera (tecnicatura en turismo)" (hija). "Victoria termina el secundario y empieza a estudiar turismo. Hace la carrera en la UBA, hemos ido "aprendiendo a través de ella" (productor). La oportunidad que le brinda el turismo. "Lo hago por elección, porque me gusta. Porque igual dentro del turismo tenés un montón de alternativas, pero este es el que más me gusta. Porque yo sigo trabajando, sin dejar de irme de mi lugar, donde nací, donde me crié, donde están mis vecinos, mis parientes. Eso tira. No, no creo irme de acá, y si me iría, volvería". (hija). Cambio positivo vinculado a la edad y las posibilidades: $Y$... el cambio me gustó. El cambio me gustó. Porque lo otro... ya me acordaba de la edad que tenía y los años que lo venía haciendo y es como monótono... nunca dije un trabajo me aburre ni nada pero es como monótono. Para mi edad, ya el trabajo de andar subiendo y bajando huevos a la camioneta ya no da, yo decía, esto tiene que cambiar, esto tiene que cambiar... porque mi edad no lo va a permitir. Y en esto de que me gusta el diálogo, me gusta todo eso (que no se puede negar) en el turismo me vino una oportunidad especial. El lo dice: vos que no querías ir y ahora no salís de allá. Y bueno, es que ahí está el tema, de que yo no quisiera que fracase, si yo no vengo no se podría sostener todo. El otro día me decía, y bueno, poné a otra persona. Y no es lo mismo, así no sea por una cuestión de campo, lo dice el dicho de campo "el ojo 

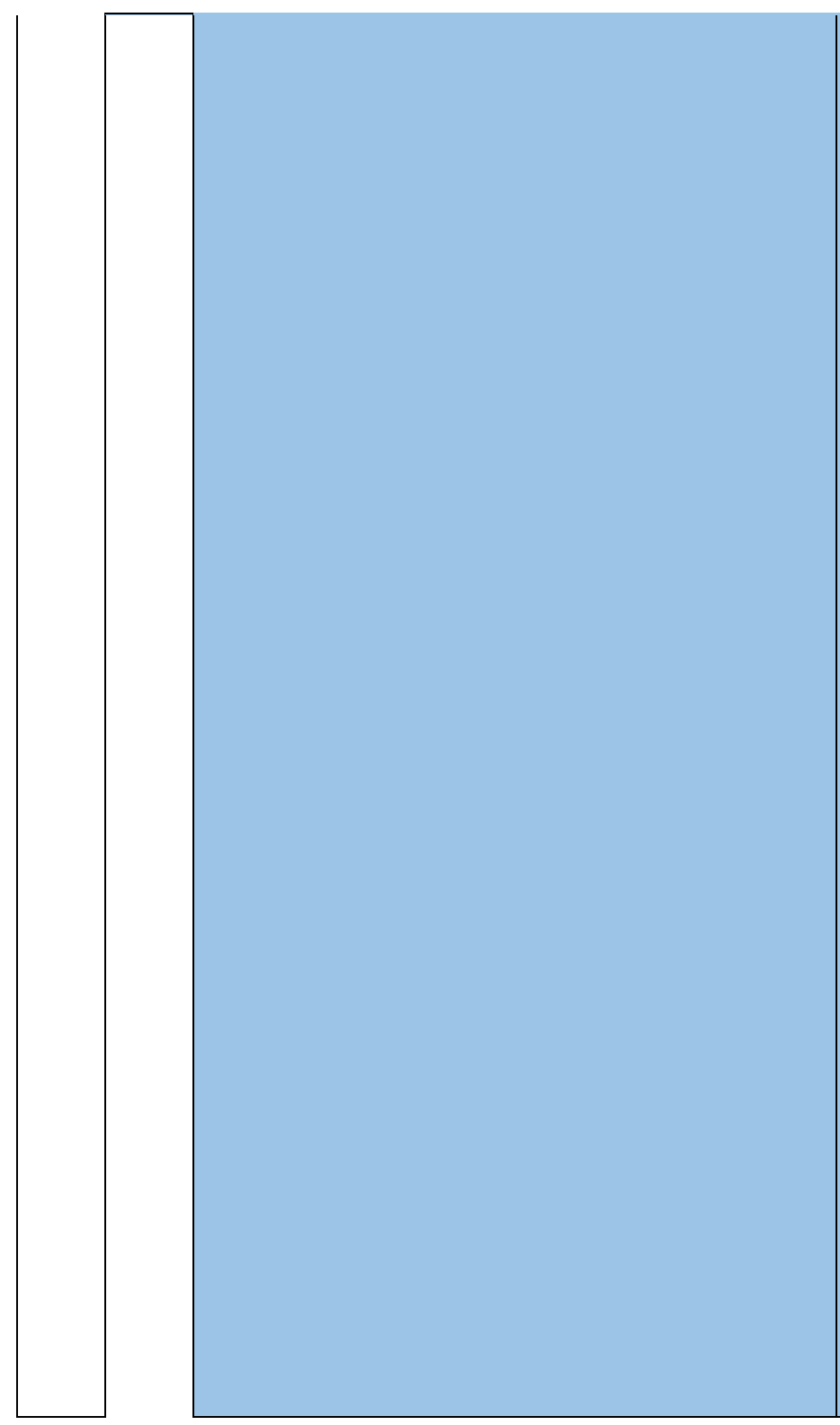

del dueño engorda el ganado". El ojo del dueño acá va a tener la sencillez y el entendimiento hacia el turista. Nosotros somos los dueños, y si te dicen, nos podés dar tal cosa? Pero sí... tomá, llevá, vení... y tal vez un empleado se limitaría! Nunca salí 5 veces de vacaciones en 6 meses. Esto es nuevo para mí. Pero a partir del turismo es algo que estoy anexando. Lo aprendí y me gustó. A luis no le gusta salir porque no probó! Es un dulce del que no abrió el frasco y no sabe degustarlo así que cuando abra el frasco pobre de él. Viajar... Ese era un sueño del futuro. Cuando Victoria estudie, la primera que la voy a acompañar, y va a ser un motivo de salida, es ese. Ese fue mi primer ideal, adonde Victoria tenga que viajar yo me engancho. Era un ideal de la vida que tenía guardadito cuando llegue esta edad. Dentro del trabajo que había hecho, de lo que la vida me acompañó que junté ahorros, poder disfrutar de esa forma. Es un cambio que me está generando y recién comienza! Ese es el sueño. Cuando fuimos a Mendoza y estábamos en la Cordillera nunca pensé que podía estar ahí! Pensá que ya sueño con viajar a Roma, que nunca se me había ocurrido! (productora). Actividad desestructurante: creo que a nosotros se nos dieron muchas oportunidades, muchas condiciones: el estudio de Victoria, el lugar que nos tocó y tal vez, una forma nueva de salir de la estructura que teníamos en la vida, esto fue desestructurante, porque es una cosa que descompagina lo otro, en el sentido de que es totalmente diferente. Porque vos te imaginas al ganadero, con las vacas, al productor que vende los huevos, con su venta y no te lo imaginas en el turismo. Es como salir a pasear dentro de tu casa trabajando. Te da dinero, y le da otro sentido. Viajes: El salir a otros lugares, ahora no me da. Pero nunca salí 5 veces de vacaciones en 6 meses, porque en enero fui a Punta del Este, en marzo a Brasil, en julio fui a Carlos Paz.. lo junto a los días que no me tomo, y cierro la página y me voy! Creo que se fue dando solo el cambio... no se 


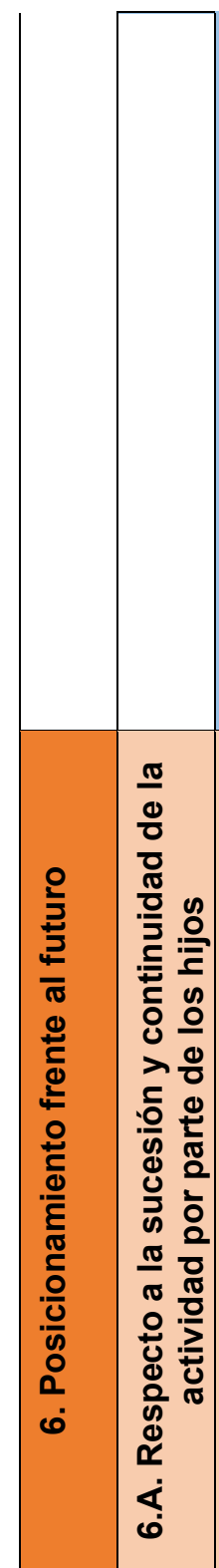

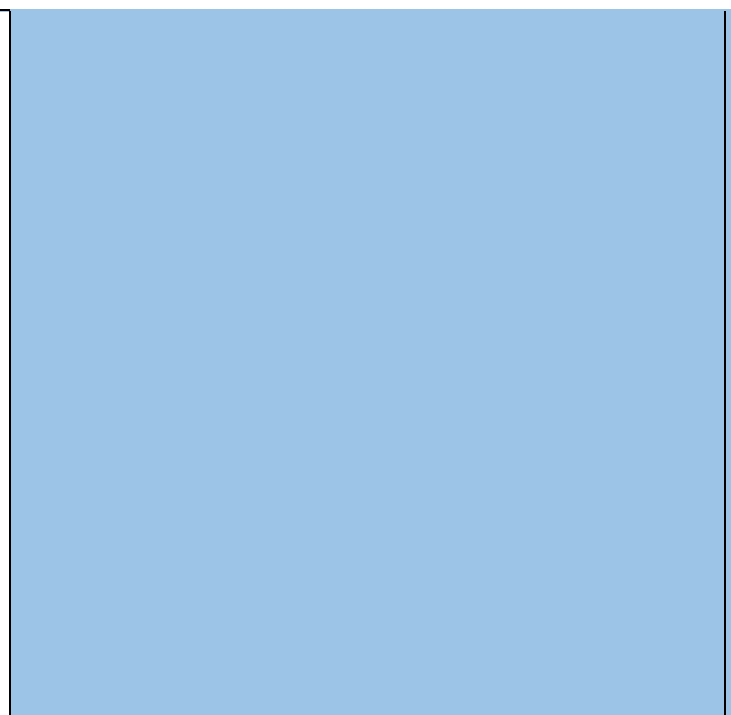

En particular a esta familia, se ha decidido que los hijos no continúen con su estudio secundario, en principio porque se les hacía pesado desde el punto de vista económico.

También afectan las experiencias personales

de los padres en esta decisión, bien porque han tenido que despegarse de sus familias de jóvenes y porque entienden que es muy dificultoso finalizar la escuela. $Y$ además pone a las claras una lógica -y necesidad- de trabajo con mano de obra familiar, y de "garantía" de continuidad del patrimonio a familiar en manos de los hijos. "Se tienen que ir para hacer el secundario... es bravo para una persona del campo ir a un internado" (productor). El hijo dijo que quiere estudiar para poner un taller "se lo apoyará si así lo deciden pero no creo que se vayan" (productor). "No sé si es una deuda que nos va a quedar pendiente o no porque en general los chicos de la colonia empezaron
Si bien los hijos no trabajan en el almacén están muy vinculados afectivamente $y$ aparentemente la pareja tiene esperanzas de que continúe en la familia. "El día que se cayó la pared estaban los tres acá. Se vinieron los tres a darnos ánimo, a apuntalarnos. Y los nieto también. Vienen y les encanta contar la historia" (productora). "Cuando les pregunto si piensan si van a seguir con el almacén me dicen que no saben". "Lo que sea mejor para ellos. Yo pienso que esto tiene mucha fuerza, mucho valor, valor afectivo, pero no vas a hipotecar el futuro de nadie por esto porque no podés. Será lo que deba ser. El abuelo hace noventa y pico de años que murió, fijate si él iba a pensar que su almacén iba a ser esto" (productora). "Surgen cosas, hay que esperar, mientras tanto lo estamos disfrutando nosotros" (productora). Con respecto a la sucesión todo indica que queda en mano de uno de sus hijos. "Posiblemente (hijo) es el que tome las riendas dentro de un tiempo. Ya se lo va consultando, tira ideas nuevas" (productor). La productora dice que no lo pregunto, pero le quedó... el cambio ya está. Porque ya surgió el cambio. La familia se transformó en otra cosa, totalmente. Creo que va a ser positivo. Primero chocó muy fuerte, como que no gustaba, ese cambio como que les fue rotundo, no encontrar a mamá en el lugar donde tenía que estar, que para ellos era lo normal. $Y$ ahora despacito, lo que son mis nietos ya lo tienen incorporado, ya les gusta venir. $Y$ a las hijas mayores estoy tratando de que les guste venir, pedirles opiniones que también me las dan, que las aplico, como un turista más pero con la ventaja de que son de la familia, una opinión de la familia. NO existen tiempos de ocio. Lamentablemente. Eso es lo que quiero anexar, no el ocio, pero sí por ejemplo comer un asado, que los nenes paseen en caballo. Ese sería el momento de disfrute. Antes del turismo íbamos a pasear a la costanera a Colón, por ejemplo, a eso ahora no lo hago (productora).

Los protutores tienen expectativas de que los hijos continúen con las tareas del sistema. "Sí, tengo expectativas, porque eso siempre se los digo fundamentalmente a los que no están, o sea la mayor que está en la ciudad, le digo que el día de mañana cuando tenga mi edad, o antes, sea ella la que pueda seguir continuando este emprendimiento. Pueden ser los nietos..." A Agustín le gusta el campo pero tb le gusta el estudio, sueña con ser ingeniero, primero dijo que quería ser arquitecto, el padre se quería morir porque él pensaba que iba a ser agrónomo, y bueno, le digo yo, vamos a ver... el campo a él le gusta, apare el nació con mucha diferencia, con mucha más tecnología, ama lo que es la tecnología para el campo. En ganadería el progreso en todo lo que es cabañas... le digo, bueno Agustín está bien, nosotros hicimos los pasos con los abuelos, los pasos nuestros, los pasos de nuestros padres como fueron y veo que miro para atrás en el pasado cómo progresó todo eso, así que pienso que el sí, que él va a llegar con más tecnología y más progreso en el campo. Muy distinto porque con 


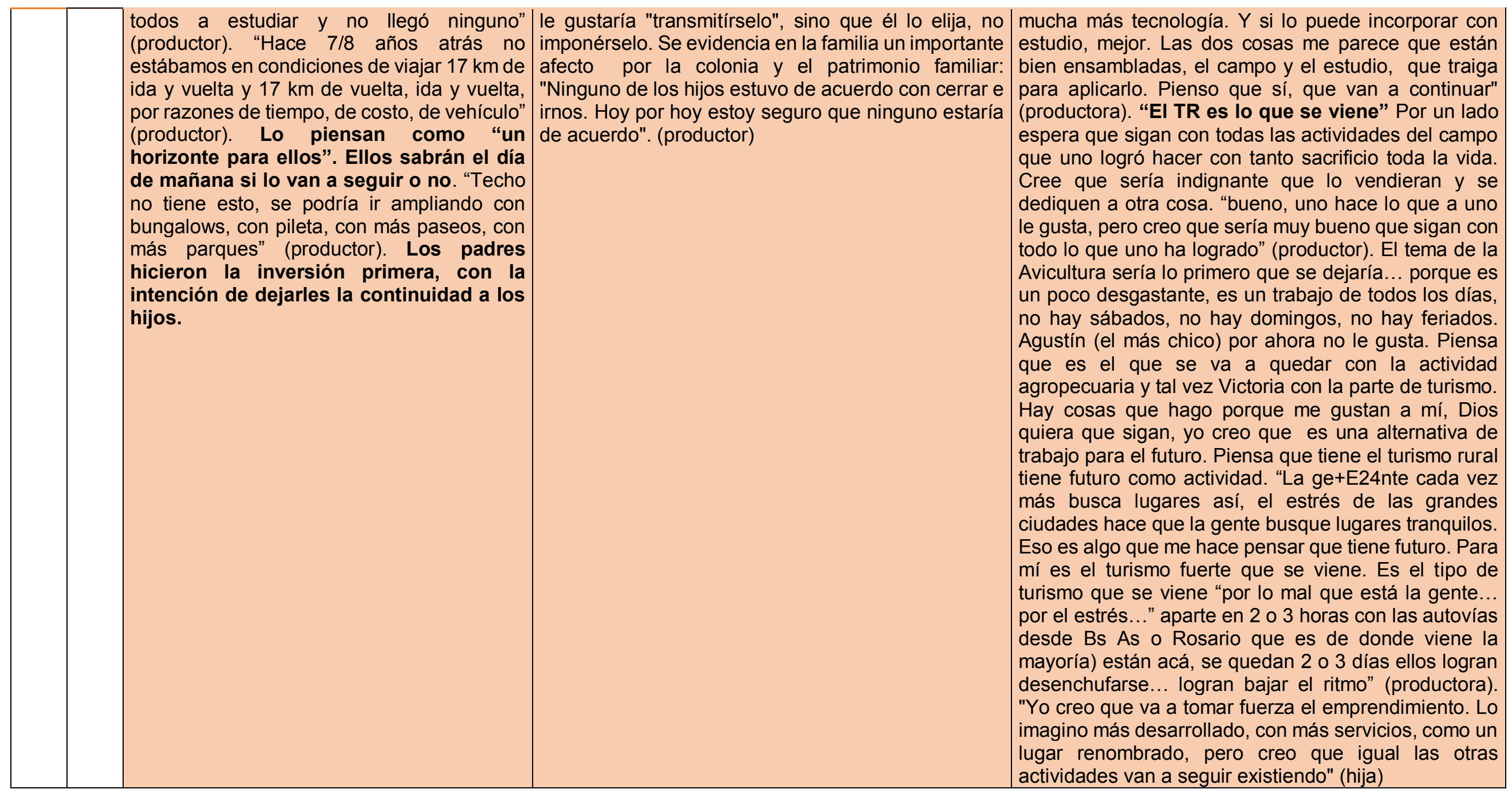




\begin{tabular}{|c|c|c|c|}
\hline 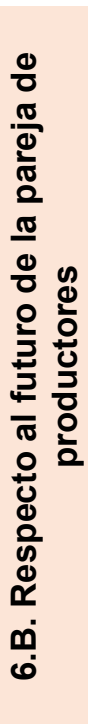 & $\begin{array}{l}\text { La idea de la familia es vivir del turismo, } \\
\text { dedicar el trabajo de la semana a la } \\
\text { elaboración de productos (quesos, } \\
\text { escabeches, nueces para vender al } \\
\text { turismo que se recibe durante los fines de } \\
\text { semana. "Con el tiempo me gustaría, en } \\
\text { parte a los animales que siempre van a estar, } \\
\text { pero de trabajar para el turismo. Trabajar y } \\
\text { vivir de eso" (productor). A eso le quieren } \\
\text { agregar venta de artesanías y souvenirs, que } \\
\text { responde a un anhelo personal del productor. } \\
\text { "Mi gran ilusión es trabajar con la madera, me } \\
\text { gustaría algún día tener una mini carpintería } \\
\text { para poder hacer recuerdos, platos, } \\
\text { adornos..." (productor) }\end{array}$ & $\begin{array}{l}\text { Es una actividad que ya desarrollan y todo indica } \\
\text { que a ella se van a dedicar, fundamentalmente la } \\
\text { productora, aunque el productor también ha } \\
\text { demostrado interés por el intercambio social y } \\
\text { cultural que se da en el espacio. El desarrollo de las } \\
\text { distintas actividades productivas y la integración de } \\
\text { uno de los hijos en el manejo y gestión, permite a la } \\
\text { pareja de productores dedicarse a lo que más les } \\
\text { gusta, incluso mantener el patrimonio familiar que es } \\
\text { el almacén, a través de la puesta en funcionamiento } \\
\text { de la propuesta turística. No se irían a vivir a otro } \\
\text { lugar. "El nació acá, tiene toda su vida acá. Hay un } \\
\text { refrán que dice "a loro viejo no se le cambia la jaula". } \\
\text { Lo llevas a este hombre a una ciudad y qué hace..." } \\
\text { (productora) }\end{array}$ & $\begin{array}{l}\text { Proyecto para la pareja con mayor intervención en } \\
\text { el futuro: "Tal vez instalarme más en Victoria del } \\
\text { Campo. Es como un hobbies. Uno de los mini } \\
\text { proyectos es en el galpón hacer un salón de juego } \\
\text { (ping pong, metegol, como para que la gente, o a la } \\
\text { noche, o el día que llueva tener un entretenimiento } \\
\text { más). Pensar en un comedor, algo gastronómico, lo } \\
\text { ven como algo rentable, pero sería ya tomar algo de } \\
\text { personal. Si bien hay gente que pegunta y pide, hay } \\
\text { gente que le gusta hacer sus asados, sería algo } \\
\text { importante económicamente pero desde lo laboral } \\
\text { sería más complicado" (productor). "Creo que con el } \\
\text { tiempo se van a ir organizando mejor, creo que igual } \\
\text { mis papás van a seguir trabajando pero en algún } \\
\text { momento van a tener que pensar en jubilarse, dejar de } \\
\text { trabajar tanto! Y ahí me los imagino más en el } \\
\text { alojamiento, porque es como más liviano el trabajo, no } \\
\text { es tanto físico el trabajo sino más el estar".(hija) }\end{array}$ \\
\hline
\end{tabular}

Anexo 4- Casos compilados de la zona centro 


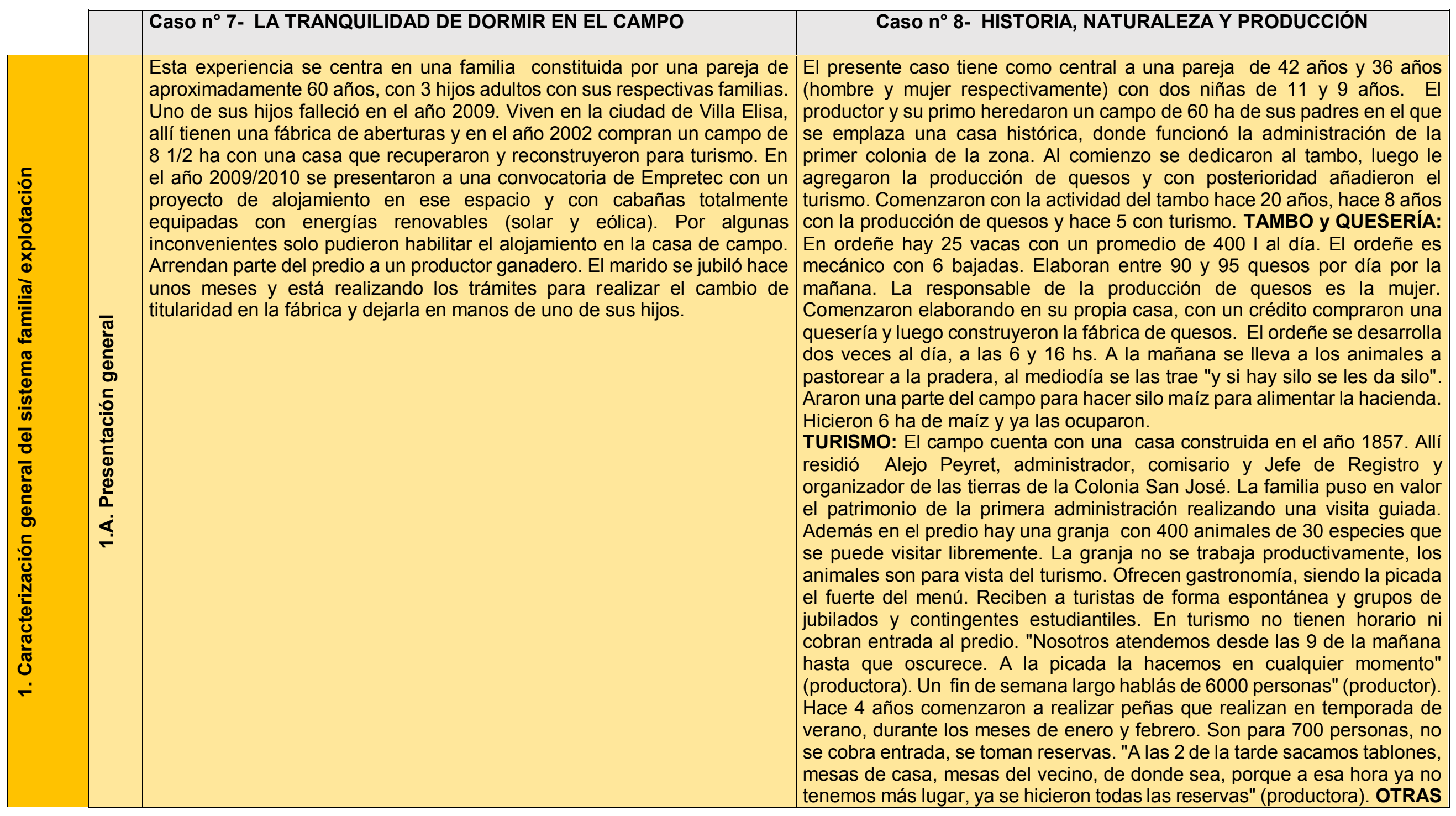




\begin{tabular}{|c|c|c|}
\hline & & $\begin{array}{l}\text { ACTIVIDADES PRODUCTIVAS QUE REALIZAN EN EL CAMPO: } \\
\text { Recientemente incorporaron producción de lechones. Tienen } 20 \text { madres y } \\
\text { venden lechones todo el año, aproximadamente } 750 \text {. Crían terneros para } \\
\text { vender. Actualmente están limpiando otra parte del monte para hacer } \\
\text { animales de cría. "Antes a los terneros los vendíamos, ahora criamos y } \\
\text { vendemos novillos } 2 \text { veces al año. Vamos aun tambo cerca de San Miguel, } \\
\text { compramos terneros guachos y criamos. Entonces juntas } 30 / 40 \text { terneros de } \\
200 \mathrm{~kg} \text { y los vendemos". Actualmente tienen } 30 \text { para vender. }\end{array}$ \\
\hline 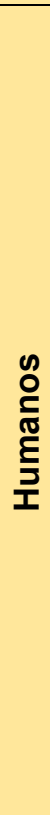 & $\begin{array}{l}\text { El emprendimiento turístico y la fábrica son atendidos por la familia. El padre } \\
\text { e hijo trabajan juntos en la fábrica. La madre se encarga de la parte } \\
\text { administrativa. En la actividad turística ella maneja las páginas y reservas, } \\
\text { el marido es "el jardinero", realiza el mantenimiento y ella y el hijo y su } \\
\text { esposa la limpian para alquilar. }\end{array}$ & $\begin{array}{l}\text { La mano de obra es familiar pero además cuentan con una tambera y } \\
\text { dos empleados fijos. Trabajan el productor, la productora y el socio } \\
\text { (primo). Tienen una rutina durante la semana y otra para los fines de } \\
\text { semana. La productora y una señora elaboran el queso y preparan las } \\
\text { picadas que venden al turista durante los fines de semana. Durante la } \\
\text { semana ella atiende al turismo y el productor y el primo con otros empleados } \\
\text { se dedican a lo productivo. Todos atienden a los turistas, productor, } \\
\text { productora y el primo, más el padre que los fines de semana. Durante los } \\
\text { fines de semana se suma el padre del productor que es profesor de historia. } \\
\text { Realiza las visitas y da las charlas en la casa. El primo y el productor } \\
\text { atienden al turista. } \\
\text { "Yo me desenvuelvo mejor en la cocina y ellos atienden, me gusta más" } \\
\text { (productora). "A veces hacemos bondiolas pero capaz que tenés que hacer } \\
1000 \text { para ese fin de semana " (productor). Todos sabemos hacer quesos, } \\
\text { si ella se tiene que ir (la esposa) todos podemos hacer, que es lo más difícil" } \\
\text { (productor). "Hay tareas que no se delegan, por ejemplo, no delegan la } \\
\text { elaboración de la picada y la atención al público. Son una familia muy } \\
\text { emprendedora, año a año van generando propuestas nuevas. "Yo soy } \\
\text { el que tiro las ideas, tengo las ideas en la cabeza para hacer de aquí a un } \\
\text { tiempo pero a veces lo económico no te da" (productor). }\end{array}$ \\
\hline
\end{tabular}




\begin{tabular}{|c|c|c|}
\hline 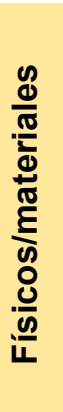 & $\begin{array}{l}\text { Para comprar el predio del campo y la casona hicieron una especie de } \\
\text { intercambio por la que en ese momento era su vivienda familiar. } \\
\text { Construyeron sobre el galpón donde fabrican las aberturas y allí viven. El } \\
\text { alojamiento fue en parte financiado por un crédito al que se presentaron (con } \\
\text { una tasa muy subsidiada) pero han tenido que invertir mucho dinero y } \\
\text { mucho tiempo de la familia para habilitar el alojamiento. Hoy lo que ingresa } \\
\text { por turismo colabora al mantenimiento del alojamiento, pago de impuestos } \\
\text { y luz. Están construyendo un galpón en el parque industrial para continuar } \\
\text { y fortalecer la fábrica de aberturas. }\end{array}$ & $\begin{array}{l}\text { Para iniciar con la quesería pidieron un crédito a CAFESG, pero a la hora } \\
\text { de comprar les faltó dinero porque demoró mucho la entrega del dinero. } \\
\text { Primero construyeron la quesería, luego la vivienda familiar. "Las primeras } \\
\text { personas que venían a visitarnos les decíamos qué queríamos hacer y hoy } \\
\text { esa gente nos dicen pensábamos que estaban locos, pero ya lo hiciste!" } \\
\text { (productora). } \\
\text { "Después construimos el quincho pero sin las paredes y después los baños" } \\
\text { (productor). "A los corrales los cambiamos } 3 \text { veces hasta los que hicimos } \\
\text { los que están ahora" (productor). "A veces los frenamos nosotros, lo } \\
\text { traemos a la realidad" (productora) }\end{array}$ \\
\hline$\frac{\substack{\frac{0}{N} \\
\frac{N}{2}}}{\frac{\pi}{\pi}}$ & & $\begin{array}{l}\text { En el predio del campo hay una zona que no ha sido desmontada y que } \\
\text { conduce a un arroyo donde hay agua de vertiente, vegetación especies } \\
\text { nativas de monte. Piensan que en algún momento esa parte se puede } \\
\text { añadir para realizar paseos y caminatas. }\end{array}$ \\
\hline
\end{tabular}


La familia cuenta actualmente con tres ingresos: la venta de aberturas, el alojamiento y el alquiler del campo. El turismo hoy no les reporta grandes ingresos aunque ven que hay mayor movimiento en los últimos tiempos. "Es mínimo el ingreso por turismo pero este es el primer año que enero se alquiló durante todo el mes" (entrevistado). Se va incrementando el ingreso por la actividad. La ganancia por turismo, que es mínima se va reinvirtiendo. "Se usa para mantener el capital" (entrevistada). $\begin{array}{ll}\text { \& } & \text { No se consideran una familia sociable, no tienen mucha relación con los } \\ \frac{\text { ț }}{0} & \text { turistas. Quedan a disposición pero tampoco quieren "invadir". Tampoco }\end{array}$ al $100 \%$ dedicados entonces no están todo el tiempo en el lugar como para establecer una relación de más intercambio con los pasajeros.
El principal ingreso del sistema actualmente proviene del turismo. Los uristas no pagan entrada al predio pero ganan de las picadas que ofrecen con productos de elaboración propia y los que compran a otros productores. Compran dulces, escabeches, miel, salames a 10 productores de la zona, "ahora hay cuatro panaderos que nos traen pan" (productor). Elaboran quesos y bondiolas para los fines de semana largos. "El ingreso más grande que tenemos es la picada. Después cuando prueban se llevan las cosas" (productor). Hay una estacionalidad bien marcada con temporadas altas y bajas. "Abril y mayo es malísimo en turismo. Semana Santa el año pasado y este llovió y fue desastroso para todos iguales (porque acá cuando anda gente anda para todos). Nosotros tenemos la suerte de que durante los fines de semana viene gente de la región, de Concordia, Concepción del Uruguay, Gualeguaychú" (productor).

El problema nuestro es cuando llueve, nos llueve 4 fines de semana seguidos y vos tenés que pagarle igual a los empleados, tenés que pagar los impuestos, la luz, y no te entra nadie, y ahí no tenemos ingresos" (productor). "Las épocas de malaria son abril y mayo, ya sabés, ahora ya sabés que no tenés que agarra ninguna deuda para esa época. Y nos damos cuenta que cada vez viene más gente" (productor). Se fueron capitalizando gracias al turismo. Van realizando inversiones todos los años. "Nos vamos adaptando a las circunstancias, a la plata que entra. Sabemos que ahora en octubre tenemos 30 excursiones y buen+G8o, vos sabes que podés traer albañiles, estamos por agrandar la cocina porque en verano hacemos peñas los jueves de noche, para 700 personas" (productor). En el verano desarrollan peñas. Esta estrategia fue implementada porque en verano tienen menos turistas. "Se trabaja menos, trabajamos pero no es la locura porque hace mucho calor entonces la gente viene de mañana o de tardecita, pero con las peñas cubrimos" (productor). El fuerte de las excursiones es de septiembre a noviembre. Se hace por reserva y se les ofrece almuerzo o merienda con chocolatada y tortas fritas con dulce de leche. Trabajan también con grupos de jubilados. "El 2015 fue el mejor año, teníamos una empresa de Bs As que traía grupos día por medio. Con eso terminamos el quincho, y de julio a diciembre una excursión por día" (productor). No llevan registro, va todo a la misma caja.

Se genera un vínculo muy especial con los turistas. "Nadie los atiende como los atendés vos. Viene gente que vino como hace 4 años y te abrazan, te dan un beso, hay gente que se pone a llorar". (productor). "Un $80 \%$ de la gente que viene te dice, me manda uno que es re conocido tuyo, uno medio 


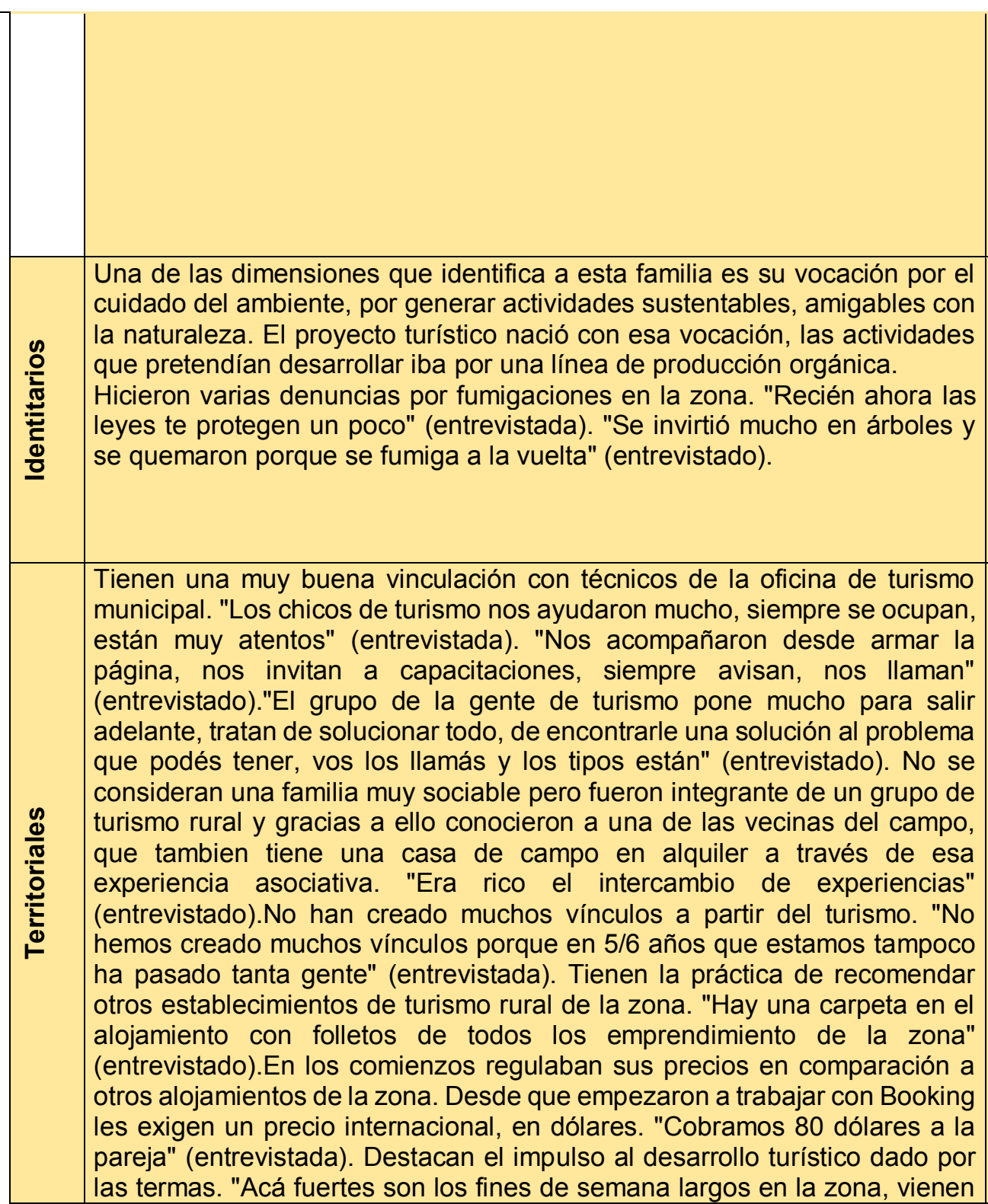

gordito... yo les digo ah sí, y es un turista que vino. Así gente que nos manda gente, que nos ha traído cosas de regalo... millones! aparte del que menos te esperás" (productor). Hay un reconocimiento del trabajo y el progreso del lugar por parte de la comunidad local, la oficina de turismo y los mismos visitantes. "La mayoría de la gente que viene es por boca a boca". "Yo soy fanática de Estudiantes, viene uno y me regaló un banderín" (productora). "Hay gente que ya somos amigos. Cuando vamos a Bs As algunos te dicen no viniste a mi casa, y se enojan si no vas!" (productor).

Tienen claridad respecto a quiénes son y qué hacen. Son auténticos.

"Por ahí de turismo nos recomiendas que nos vistamos todos se gauchos,

y nosotros no lo sentimos, no nos sentimos cómodos, aparte a la gente lo que más le gusta es cómo la tratás" (productor). Se evidencia arraigo, amor a la historia y resguardo del patrimonio familiar. "Al campo lo compró mi abuelo y nunca quiso vender el campo. También lo cuidamos por mis abuelos. Y nos damos cuenta que la casa tiene valor histórico, fue lo primero que se hizo en la zona, capaz que vas adentro y por ahí anduvo Urquiza. Por eso lo que queremos hacer es darle más valor, hacer algo lindo"(productor).

La dinámica turística de la zona es muy favorable al desarrollo del turismo. "Tenemos la suerte de estar entre San José y Colón. De San José estamos a 20 cuadras" (productora). "Aparte los dueños de los bungalows se han portado re bien con nosotros, el $80 \%$ de los bungalows nos recomiendan. Por ejemplo llega un turista antes de la hora que tiene que ingresar y les dicen, vayan a la granjita a desayunar, es barato y es lindo" (productor). Poseen un vínculo muy estrecho con la Municipalidad de San José. "El Municipio de San José nos da bolilla, el de Colón no. Para pagar impuestos somos de Colón pero como atractivo somos de San José" (ella). "Pero el $80 \%$ de los turistas vienen de Colón, están parando allá" (productor). No integran redes asociativas. "No podemos ir a reuniones, son en horarios que estamos trabajando, no podemos salir" (productora). "Capaz que un día de semana son las 11 y no hay nadie y a las 12:30 tenés 15 autos y tenés que hacer picadas" (productor). 
por las termas" (entrevistada). "Algunos vienen ara conocer la zona, Colón, el palacio, San José, el Parque Nacional" (entrevistado).

La mujer de la pareja es de Villa Elisa, sus padres continúan siendo productores ganaderos y siguen viviendo en el campo. El es oriundo de Villaguay. Se conocen hace más de 40 años, desde cuando eran bien jóvenes. Estudiaron en Rosario. Ella no se alcanzó a recibir de farmacéutica. El iba a estudiar ingeniería pero no finalizó, trabajó para mantenerse allí. "Fue en la época mala del país, en la dictadura. Las cosas no se dieron y tuve que trabajar para mantenerme en ese momento muy difícil" (entrevistado). Por lo que comenta el entrevistado vivió algunos momentos complejos en esa época aun sin pertenecer a ningún movimiento ni espacio político. En aquel momento, ella se volvió a Villaguay estudió magisterio y trabajó en una escuela rural. El se volvió a trabajar a Villaguay, trabajó en Chaco, Corrientes y le fue mal. Después se fue a San Lorenzo a la casa de un tío a buscar trabajo. Y consiguió, el es técnico mecánico. En 1979 entró a trabaja en SOMISA. "En ese momento SOMISA era seguro" (ella). "Cuando nos casamos (1981) nos fuimos a vivir a San Nicolás por el trabajo de él. Allá estuvimos 12 años hasta que se acató al retiro voluntario en el 1992 y nos vinimos" (entrevistada). "Habíamos planificado tres cosas; o poner una librería mayorista en Concepción del Uruguay o una fábrica o una tornería -yo soy tornero- acá" (él). Y se decidieron por lo segundo. "Esto era de mis suegro, un galpón viejo que se caía, se lo alquilamos" (el). "El galpón era un pedazo, nos instalamos en el fondo en un mini departamento con los 4 chicos" (ella). Ese mismo año abrieron la fábrica y no cerraron hasta ahora. Luego se construyeron su casa. En el 2002, hicieron el cambio de su casa por un campo que tenía una casona abandonada. "El sueño de él siempre fue tener una chacra" (ella). Hicieron el cambio sin saber lo deteriorada que estaba la casa, tuvieron que tirarla prácticamente abajo y remodelarla. En un principio la idea del campo era cultivar aromáticas, tener pollos orgánicos. Pero no se fueron dando las cosas. "La compramos en parte por una situación personal difícil que estaba atravesando la dueña y un deseo personal, pero una persona cuerda no lo hace!" (entrevistado)

En ese momento no pensaban en turismo. "Era para tener un campo y sin demasiada proyección" (entrevistada). Era difícil concretar lo productivo porque ellos estaban dedicados a la fábrica. Con los hijos durante los fines de semana se dedicaorn a reconstruir la casa. "Con mucho sacrificio, mucho amor reconstruimos todo en $3 / 4$ años" (productor). Sufrieron 5 grandes crisis de la mano de la historia económica del país. La del 2000/2001 fue muy fuerte. "Esta crisis (actual) no agarró sin deudas en las otras estábamos
El y la productora son nacidos y criados en la zona. Se casaron en el 2005 El productor entrevistado y el primo heredan este campo que había comprado su abuelo, hace 54 años. El campo luego queda abandonado. De manos del abuelo pasó a su padre y su tío. "Y ellos nos regalaron el campo a nosotros. Lo único que existía era la casa y un galpón, donde ahora está la quesería. Hace 20 años me metí con el tambo, no tenía ni idea de lo que era el tambo. Gracias a Dios me llevó a tener todo esto. Empecé porque no quería estudiar ni nada" En el 2008 compran una quesería. "Y viste como es el tambo, si entregás la leche te va un año bien y tres mal entonces después compramos lo que era una quesería en San Anselmo". Empezamos con una olla a hacer quesos porque no pagaban nada la leche" (productor). Comenzaron vendiendo los quesos en Colón. En el año 2010 hubo una creciente importante. "Y ahí, por accidente porque no había actividad, no había playas, empezaron a venir acá. Y empezamos a vender los quesos a la gente que venía y así surgió lo del turismo" (productor). En ese momento la Dirección de Turismo de la Municipalidad los impulsó a seguir trabajando en turismo. EI INTI también los asesoró. En el 2010/11 hicieron la quesería actual. "En el 2012 hicimos la inauguración de la casa como museo" (productor)."En aquel momento nosotros vivíamos en la casa. Empezamos todo desorganizado, pero el fuerte de turismo empezó en el 2013/2014 y nos tuvimos que venir acá" (productor). La familia en ese entonces habían arreglado una casa en San José pero nunca se instalaron, vivían en la casa histórica. "El chico que estaba con el tambo.

Luego construyeron su vivienda a unos metros, en el mismo predio. Hasta ese momento "se nos complicaba, como la casa es histórica mostrábamos el sótano, pero vivíamos también ahí, era un lío. No era museo toda la casa. Esto hasta el 2013. Y llegó un momento en que no podíamos más porque venía mucha gente" (productor). "Las nenas tenían 1 y 3 años. Sacábamos todo lo del comedor y lo llevábamos a la pieza donde estábamos nosotros, entonces mostrábamos el sótano y el comedor. El hacía las visitas y las nenas abrían la puerta para ir al baño! La gente entendía, se reían porque eran chiquitas" (productora). "Elaborábamos queso en la casa y los sábados yo me iba a vender a Colón" (productora). Su primo jugaba al basquet y prácticamente no estaba allí, se radica en el 2014. Con la puesta en marcha del museo los ayudó el padre del productor que es profesor de historia, y una historiadora local muy reconocida (Celia Berna). "Creció mucho, primero no queríamos de la vergüenza mostrar lo que teníamos. Después 


\begin{tabular}{|c|c|c|}
\hline & & $\begin{array}{l}\text { creciendo..." (entrevistado). En el } 2009 \text { fallece uno de los hijos y esto } \\
\text { moviliza la necesidad de poner la cabeza en otra cosa. "Hace } 2 \text { o } 3 \text { años } \\
\text { atrás estuvimos a punto de venderlo, hubo gente que lo quiso comprar. } \\
\text { Cuando les dije a mis hijos me dijeron 'rompiste tanto que querías tener el } \\
\text { campo y ahora lo querés vender?"" (entrevistado). "Se opusieron los hijos" } \\
\text { (entrevistada) }\end{array}$ \\
\hline 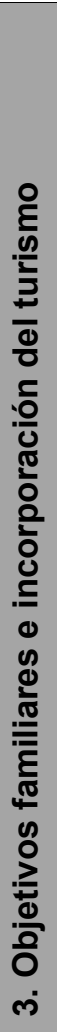 & 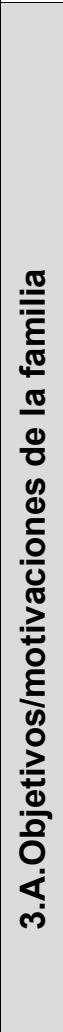 & $\begin{array}{l}\text { Actualmente la prioridad es finalizar la construcción del galpón en el área } \\
\text { industrial. La idea de la pareja es ceder la fábrica a mano de uno de sus } \\
\text { hijos y ellos continuar con el emprendimiento turístico "sin enloquecernos", } \\
\text { a disfrutar la familia y al disfrute personal." (entrevistada) } \\
\text { "Yo creo que ya cumplí mi ciclo, estoy para acompañar. Quiero ahora } \\
\text { disfrutar, poder salir a pasear. Quiero dedicarme a varias cosas que no hice } \\
\text { en mi vida por no darme permisos, por traer el dinero a la casa. Me gusta } \\
\text { tallar, pintar, hago artesanías, muebles" (entrevistado). "Y por eso se va a ir } \\
\text { para el campo" (entrevistada). } \\
\text { Hoy están evaluando el negocio familia ya que quieren diversificar. Están } \\
\text { analizando el mercado y pensando de qué manera pueden diversificar la } \\
\text { venta, ya que hay mucha competencia. } \\
\text { Respecto al turismo, proyectan continuar, seguir invirtiendo y piensan en } \\
\text { algunas alternativas para el complejo. Les gustaría construir las cabañas } \\
\text { algún día, así "podés tener más gente" que valga la pena poder incorporar } \\
\text { más servicios. Otras de las ideas es hacer paseos por la colonia en un } \\
\text { camioncito } 4 x 4 \text { pero "sin desesperarnos, ir haciendo sin desesperación" } \\
\text { (entrevistada). } \\
\text { Ven el alojamiento en el campo como una alternativa. "No dejarlo caer y si } \\
\text { le podemos ir agregado cosas hacerlo, porque lo vamos usando nosotros } \\
\text { también" (entrevistado) }\end{array}$ \\
\hline
\end{tabular}

mi viejo tiene un amigo con cosas antiguas y nos las prestó" (productor). Según e el mejor año de trabajo fue el 2017.

Su objetivo es fortalecer la oferta de servicios que le ofrecen al turista, no agregar más servicios. Mejorar también la puesta en funcionamiento del museo en la casona. "Ahora estamos haciendo una fabriquita de salames". Nosotros vamos haciendo según lo que va entrando, ahora queremos reformar la granja, estamos comprando unos loritos. En algún momento pensamos en hacer del quincho una parrilla pero tampoco queremos agrandarnos para enloquecernos"(productor). "Decidimos no abrir la parrilla y fortalecer la picada, hacerla mejor" (productora). "El año que viene queremos hacer la peña en invierno, agrandar el salón para 200 personas (ahora es para 130). Hacerla una vez por mes en invierno" (productor). "Pagas lo que consumis y ponemos un sobre para los músicos" (productora). "Va todo aparejado de lo económico, para hacer cosas hay un montón pero no nos queremos enloquecer" (productor). "Ahora la idea es desarmarlo entero, nos van a ayudar la gente del Museo de San José. Queremos hacer luces y sonido, algo diferente" (productor). Tienen una estrategia de precios que los hace muy accesibles. "Son muy accesibles, los hacemos bien populares, una picada para 4, que comen los 4 te sale $\$ 250$, con $\$ 190$ comen dos personas con una gaseosa grande". "Yo la voy peleando de no aumentar, los trato de aguantar hasta que me doy cuenta que es muy barato"(productor). No se comparan con otros lugares: "yo me voy manejando en base a la plata que me va entrando, lo que puedo hacer" (productor). Apuestan también a la producción de ganadería de cría "Hoy dependemos del turismo, por ahí 2 veces al año te dan un empujón los terneros. Lo que queremos hacer es tener más terneros de cría. Queremos tener aberdeen angus. Podés tener dos ventas de 60, por eso estamos limpiando el campo que está sucio. Aparte agarra valor el campo, lo estamos limpiando. El día de mañana se puede hacer un paseo en carro, hay agua de vertiente, hay 70/80 pinos, es muy lindo" (productor). 


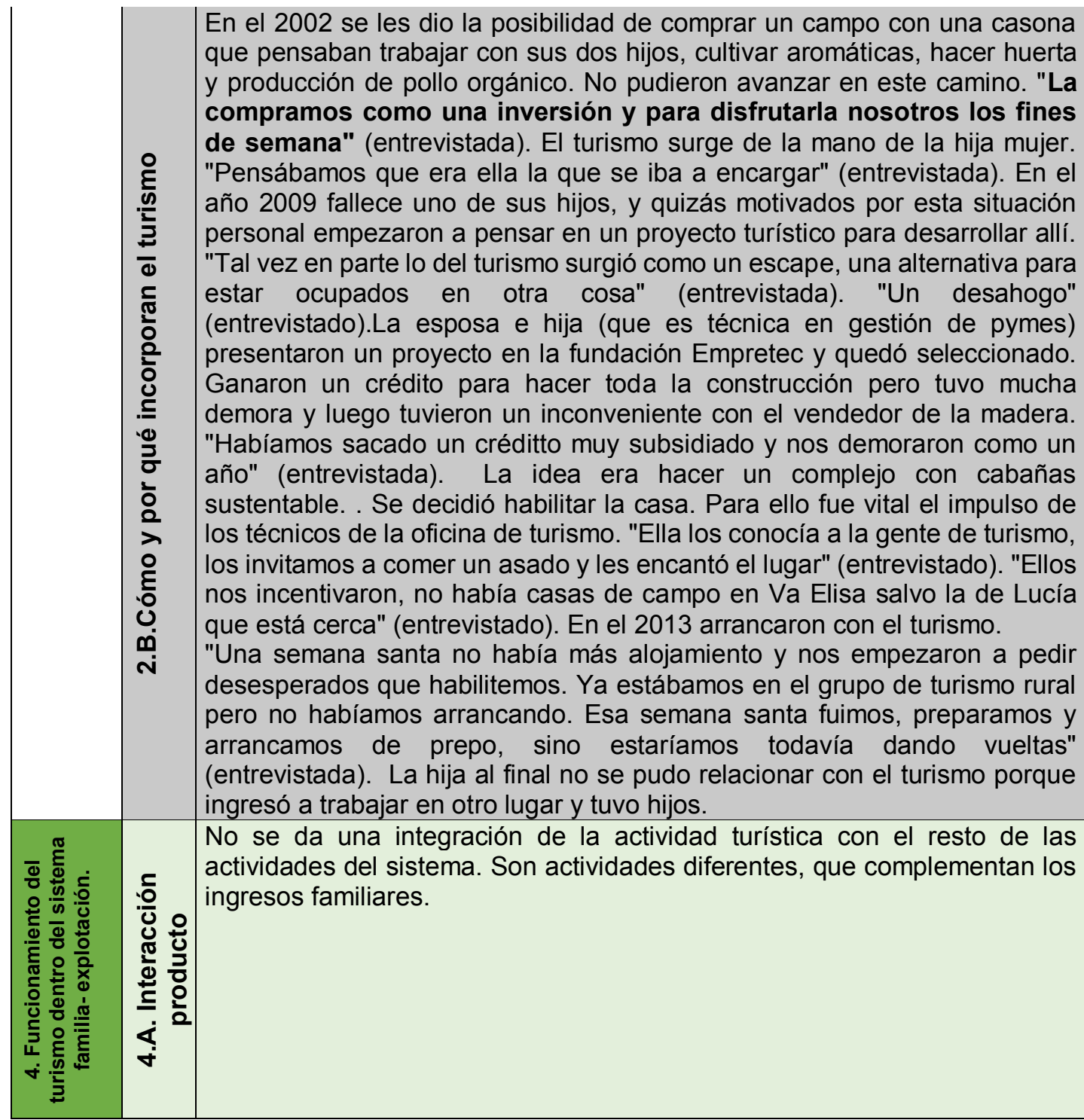

Incorporaron el turismo como una alternativa económica ligado el la oportunidad que le brinda la zona y su ubicación estratégica. "como una alternativa, por la cantidad de turistas que vienen, tenemos el Molino Forclaz cerca, es una zona turística y eso es una ventaja" (productor).

\& $\quad$ "Pensábamos que era ella la que se iba a encargar" (entrevistada). En el año 2009 fallece uno de sus hijos, y quizás motivados por esta situación personal empezaron a pensar en un proyecto turistico para desarrollar allí.

ब $\quad$ Tal vez en parte lo del turismo surgió como un escape, una alternativa para

Estar ocupados en otra cosa" (entrevistada). "Un desahogo"

" (entrevistado).La esposa e hija (que es técnica en gestión de pymes)

늘 presentaron un proyecto en la fundación Empretec y quedó seleccionado.

- Ganaron un crédito para hacer toda la construcción pero tuvo mucha $\leqq \quad$ demora y luego tuvieron un inconveniente con el vendedor de la madera. "J- "Habíamos sacado un créditto muy subsidiado y nos demoraron como un - año" (entrevistada). La idea era hacer un complejo con cabañas sustentable. . Se decidió habilitar la casa. Para ello fue vital el impulso de $\lambda$ los técnicos de la oficina de turismo. "Ella los conocía a la gente de turismo, los invitamos a comer un asado y les encantó el lugar" (entrevistado). "Ellos . nos incentivaron, no había casas de campo en Va Elisa salvo la de Lucía U. que está cerca" (entrevistado). En el 2013 arrancaron con el turismo.

i "Una semana santa no había más alojamiento y nos empezaron a pedir desesperados que habilitemos. Ya estábamos en el grupo de turismo rural pero no habíamos arrancando. Esa semana santa fuimos, preparamos y arrancamos de prepo, sino estaríamos todavía dando vueltas" (entrevistada). La hija al final no se pudo relacionar con el turismo porque ingresó a trabajar en otro lugar y tuvo hijos.

No se da una integración de la actividad turistica con el resto de las

En esta experiencia se vislumbra una fuerte integración de la producción primaria a la actividad turística. Primero decidieron elaborar quesos por el poco ingreso que percibían vendiendo la leche. El turismo alentó un segundo proceso de agregado de valor del queso, elaborando picadas para la venta. A la vez, a partir de la venta de las picadas, venden los quesos. Por otro lado, utilizan maíz de su propia producción para alimentar a los animales. 


\begin{tabular}{|c|c|c|}
\hline 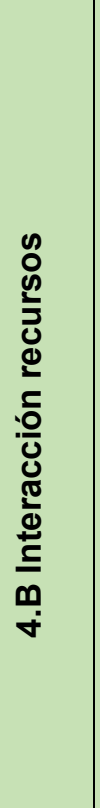 & $\begin{array}{l}\text { No hay relación de la actividad turística con las actividades productivas que } \\
\text { se desarrollan en el campo que alquilan. Son espacios diferentes y no se } \\
\text { combinan ni comunican. Los recursos que movilizan es el capital humano } \\
\text { familiar, que se distribuye entre las dos actividades, los saberes y } \\
\text { conocimientos de la familia sobre todo en lo que es construcción. }\end{array}$ & $\begin{array}{l}\text { Los principales recursos que se movilizan en común para las actividades } \\
\text { son: la mano de obra que es familiar y a la vez tienen } 3 \text { empleados. En este } \\
\text { sentido, el turismo aportó complejidad pero se distribuyen las tareas } \\
\text { relacionadas al turismo entre el productor, la productora y el socio. Hay } \\
\text { dinámicas de distribución de roles y tiempos durante las semanas y los fines } \\
\text { de semana o fines de semana largos. Suelen contratar algún empleado para } \\
\text { hacer de mozo durante las peñas y fines de semana largos, que es cuando } \\
\text { reciben mayor cantidad de gente. Hay tareas que no delegan como la } \\
\text { atención al turista y la elaboración de picadas. Hay una movilización de } \\
\text { recursos físicos y materiales en común, ya que también en los límites del } \\
\text { espacio del campo las familias han construido sus viviendas familiares y en } \\
\text { el predio combinan la actividad turística con la producción tambera, la } \\
\text { elaboración de quesos artesanales, la ganadería de cría, y la producción de } \\
\text { lechones, agricultura para alimentar los animales y pasturas. En este caso, } \\
\text { los recursos económicos provenientes del turismo están financiando } \\
\text { la diversificación de actividades y la capitalización familiar. La familia } \\
\text { se ha ido capitalizando gracias al turismo. Invierten las ganancias de esta } \\
\text { actividad -y venta de terneros- principalmente en mejorar y ampliar la } \\
\text { infraestructura con la que cuentan, poniendo en valor a la vez el campo. } \\
\text { Manejan sus ingresos como caja única }\end{array}$ \\
\hline 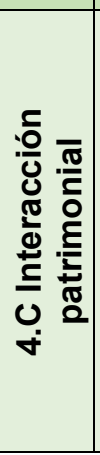 & & $\begin{array}{l}\text { La propuesta turística tiene un fuerte contenido histórico y de } \\
\text { naturaleza, ligada a los dos atractivos fuertes del lugar. Combinan el } \\
\text { patrimonio de la casona donde funcionó la primera administración y donde } \\
\text { habitó uno de los responsables de la organización de los colonos en esas } \\
\text { tierras, con la posibilidad de disfrutar en un torno campestre, rodeados de } \\
\text { animales y naturaleza prístina. También es fundamental el rol del padre del } \\
\text { productor que es profesor de historia, y el conocimiento que ha podido } \\
\text { transmitir a su familia que es retransmitido a los turistas que visitan el lugar. } \\
\text { A partir de esta combinación de actividades turísticas logran dar respuestas } \\
\text { a diversas demandas y segmentos, tanto a estudiantes, familias y gente } \\
\text { mayor con diferentes intereses y gustos. }\end{array}$ \\
\hline
\end{tabular}


No pareciera destacarse alguna movilización temporal entre las actividades, solo que la familia se dedica al turismo fundamentalmente los fines de semana, no generando una gran tensión que genere incompatibilidad con la fábrica de aberturas. tendriamos que dedicar mucho más tiempo. No podemos estar en las dos partes, si está mucho allá abandonás acá" (entrevistada). Actividad que va creciendo: "cada vez hay más demanda de gente que quiere lugares aislados como el campo, porque el campo es ideal para desconectarse" (entrevistada).

La familia actualmente prioriza el ingreso dado por las actividades que otra tipo de satisfacciones. Incluso, la familia disfruta el lugar cuando no hay turismo los fines de semana. "En este momento priorizamos el ingreso porque se necesita" (entrevistado) El objetivo es económico. "Lo co que nos va sobrando lo estamos guardando para irnos de vacaciones en familia y poder disfrutar" Eso y tratar de mantener la casa. (entrevistado)
"Si es por ingresos esto no es lo más rentable. Para hacerlo más rentable le

En este caso hay una interesante puesta en marcha de estrategias ligadas la temporalidad de la actividad turística. Por un lado, se continúan diversificando productivamente y desde lo turístico buscan equilibrar los ingresos que son disímiles durante el año. Hay dos meses que son de temporada baja como abril y mayo. En ese periodo no toman deudas ni hacen una fuerte movilización de recursos económicos. Generaron peñas durante el verano teniendo en cuenta que los momentos de mayor movimiento de turistas se dan a la tardecita, noche, Los fines de semana comunes apuntan a un turismo regional y los fines de semana largos y vacaciones de invierno al turista que circula por la zona. Desde septiembre a noviembre trabajan con grupos de jubilados y excursiones de estudiantes.

Al parecer, la combinación de actividades en esta experiencia se da motivadas por lo económico, para diversificarse. Pero a la vez el turismo genera satisfacciones que van más allá de lo económico, que el resto no presenta como el reconocimiento de la comunidad, el vínculo con los turistas que en su gran mayoría suelen repetir las visitas y a los que los mismos productores destacan a algunos como "amigos" y el contacto social.

Este caso presenta una combinación de actividades que genera ingresos, aunque la principal sea el turismo: el tambo es la base de la producción de quesos que a la vez son insumo para el turismo, producen lechones que también venden y ganadería de cría que están buscando fortalecer. 


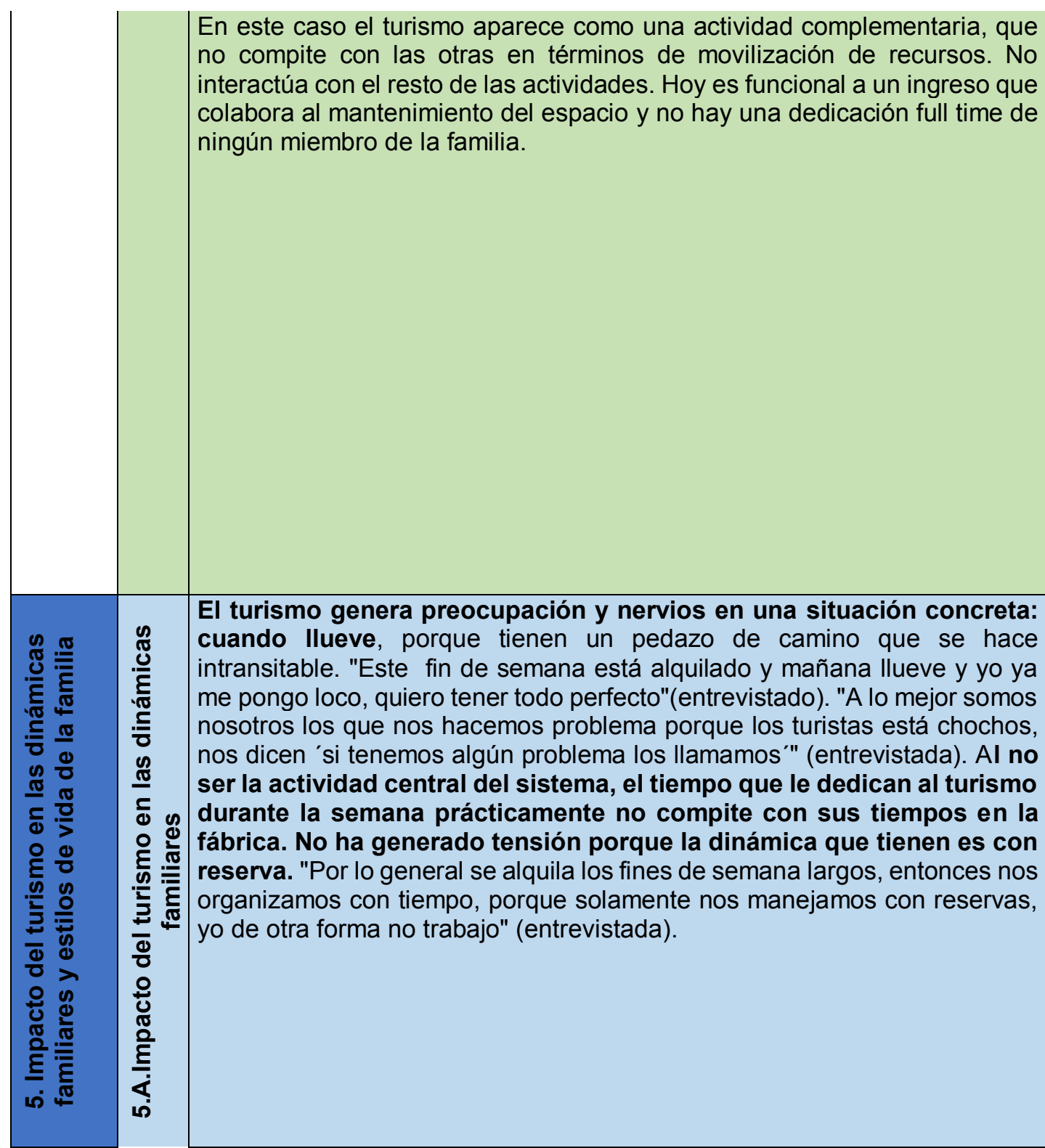

En este caso, la familia se fue reconvirtiendo. De ser productores tamberos pasaron a producir quesos para la venta directa al público. Luego, a partir de la incorporación del turismo, el resto de las actividades y los tiempos de trabajo comenzaron a girar en torno a la actividad turística, hoy la más importante en términos de ingresos, satisfacciones personales y proyección a futuro. No obstante, con el correr de los años se fueron diversificando productivamente, añadiendo cría de terneros y producción de lechones, generando una cadena entre agricultura, la producción de pasturas y ganadería. Sería insustentable el sistema sin el turismo? Aparentemente sí, tal como se presenta, más dada la cercanía del predio a dos ciudades turísticas como Colón y San José, y a un monumento histórico muy visitado en la zona como el Molino Forclaz. Esta familia está en un momento de crecimiento personal, familiar y en el establecimiento. Piensan en diversas alternativas para incorporar a futuro pero siguen apostando a fortalecer las actividades que hoy desarrollan, turística y productivamente. En este caso, pareciera que lo patrimonial no es lo más fuerte, o que el turismo pudiese existir sin el eje histórico, ya que en el marco del turismo también están diversificados.

A partir de un mayor ingreso de gente y de añadir comidas, los productores redujeron la producción de quesos pero mejoraron el ingreso económico dando valor a su producción a través de la elaboración de picadas. Antes del turismo producían más cantidad de quesos. "Antes producíamos más que ahora a la mañana y a la tarde, íbamos a comprar leche, pero tampoco era vida. Eso nos llevaba a hacer cosas. Después empezaron a venir las excursiones, compramos unos fardos y los atendimos a los nenes ahí, les servimos la merienda" (productora). "Estamos re contentos con como fuimos creciendo, no esperábamos esto" (productor). Solamente producen queso por la mañana. "Al principio cuando empezamos con turismo hacíamos a la mañana y a la tarde, hacíamos más litros, $1000 \mathrm{I}$, comprábamos leche, pero ahora hacemos 400 , porque no te da el tiempo, no tenés vida. Im+G10aginate que a las 8 tirábamos la leche, terminábamos 11:45, sacábamos los trapos, teníamos que prensar, y volvés a tirar la leche a las 5 de la tarde, terminábamos a la 1 de la mañana." (productora). A ese ingreso lo suplen con turismo. "Antes no hacíamos picada, nada, hacíamos el recorrido por la granja y les vendíamos los quesos y algún salame" (productor). Hay momentos de nervios y gran tensión, sobre todo los fines de semana 


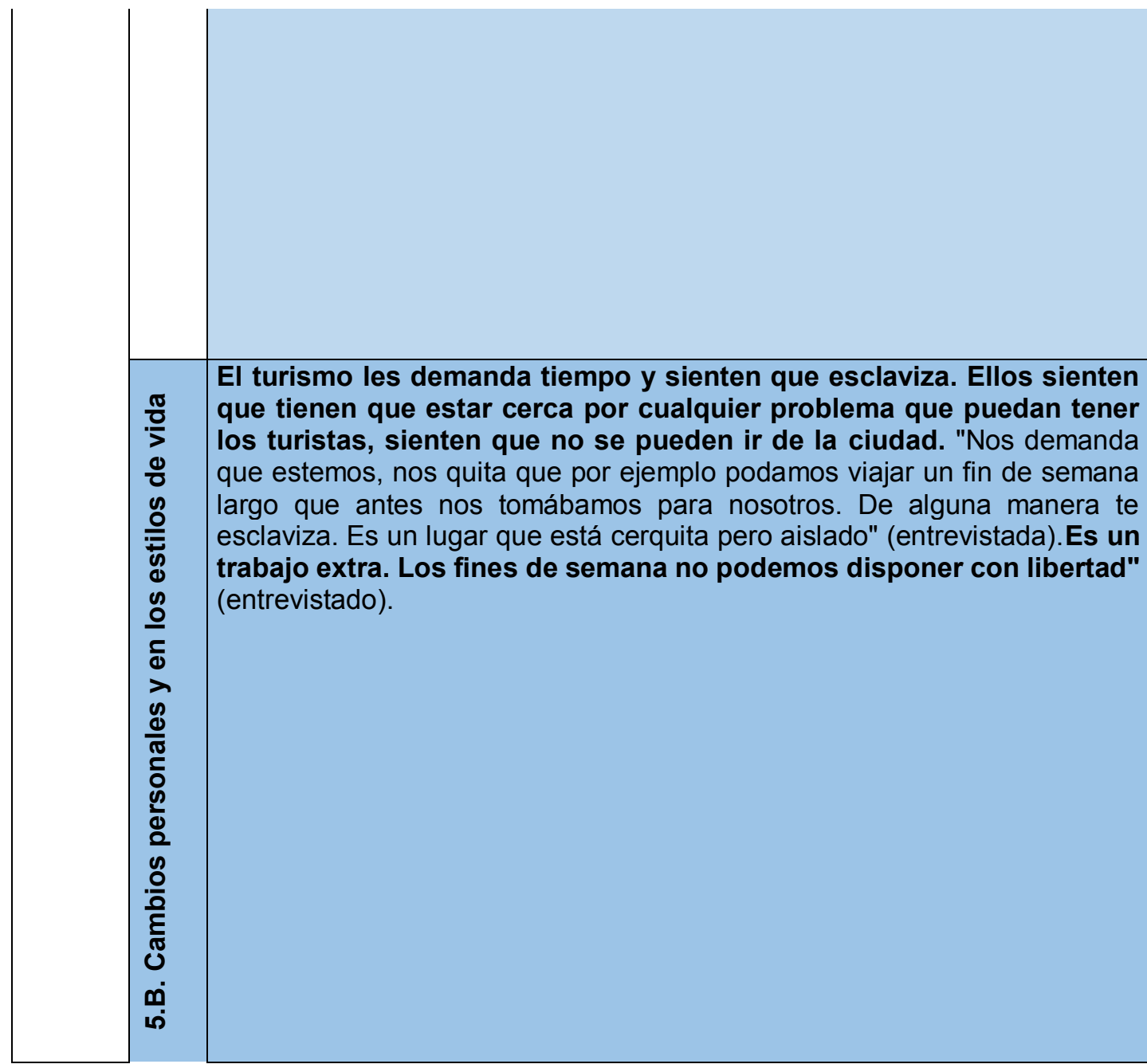

largo y cuando organizan las peñas. "A veces nos enloquecemos. Somos 2 en la cocina, él atiende en el mostrador y el primo y otra chica hacen de mozos" (productora). "Yo me enloquezco. Un fin de semana largo teníamos 30 pedidos y en el bolsillo tenía otros 30 pedidos. Capaz que la demora es de 20 minutos, es rápido, y mi primo es una luz de mozo, y tenemos una chica que es una fenómeno, te atienden 120 mesas ellos 2. Entonces yo anoto a lo mejor "rubia remera gris" porque no puedo poner números en las mesas, las corren! Vienen y me dicen, mirá que vos me dijiste 20 minutos y van 22, y yo ya me empiezo a rascar la cabeza. Es una locura pero no hay forma, no les podés decir que no. Te dicen me recomendaron la picada, me vine hasta acá..." (productor).

Se modificó mucho el ritmo de la familia. La familia necesita un tiempo para el descanso. A partir del turismo, "nos tomamos un domingo por medio hace un año. Por ahí nos vamos, yo tengo campeonatos de paddle y nos vamos el fin de semana" (productor). "Necesitás tiempo libre para la familia porque te das cuenta que te pasan los años y tenés que vivir" (productor). El turismo les da mayor apertura, más contacto. "Yo por ejemplo para hablar con las personas, te relacionas mucho más. Si tenés producción te peleas con una vaca, porque vos estás ordeñando, te pagan poco, vivís rabioso, acá nosotros tenemos la suerte de que la gente viene buena onda. Esa es la gran diferencia que tenés, que tenés mucho más contacto" (productora). Reconocimiento por el crecimiento que estimula a la familia. "El $90 \%$ de la gente te dice, yo vine cuando no tenían nada, qué espectacular todo... eso es lindo" (productor). Para la productora el turismo significa "trabajo, trabajo y trabajo, pero me gusta" (productora). "Ella tiene menos relación porque está en la cocina, atiende durante los días de semana pero lo que pasa es que cuando empieza a hablar no para" (productor). "Me encanta charlar, capaz que hay 5 esperándome y yo sigo hablando con uno, le explico, le muestro" (productora). "Yo tomo todo positivo al turismo, porque digo que el turista es el que nos da de comer" (productor). "Las nenas se adaptaron, a la más chiquita le gusta el campo, interactúa con los turistas, me ayuda, junta la mesa, a la más grande no le gusta" (productora). 
Si bien no hay claridad respecto al rumbo que va a tomar el proyecto

co hijos se opusieron a la venta del campo y casona. Hoy también

la disfrutan ellos como casa quinta. Hay líneas de proyectos en los cuales

án involucrados los hijos pero hasta ahora no se han concretado. Uno de

los hijos, el que hoy está trabajando con el padre en la fábrica es el que va

hijo y su esposa son los más involucrados. "Siguen la fábrica y si quieren hacer algo allá lo pueden hacer".

La idea de la pareja es continuar con el alojamiento "un par de años más, - 4 o 5 años más, pero medio light, sin enloquecernos".

"Es grande la casa, a veces vamos el día entero para ponerla en orden y no
nos alcanza" (entrevistada). El tema es que estamos viejitos. Nosotros ahora queremos disfrutar. Yo seguir disfrutando de los nietos, quiero \& empezar a viajar, tuvimos una época que pudimos viajar pero después las 은 otras crisis nos agarraron mal" (entrevistado). Siempre ronda la idea de vender "Si yo estoy cansado no tengo problema, se la tengo que vender la vendo"(entrevistado) pero también el afecto y el esfuerzo puesto hace que cueste el desapego. "Cuesta desprenderse porque uno puso mucho y 을 dentro de todo es lindo" (entrevistada). "Lo emocional no tiene valor porque si le tuvieras que poner precio al tiempo que estuvimos ahí...." (entrevistado). En él es más firme la idea de ir a vivirse al campo, en la mujer no. Ella vivió en el campo y piensa que es muy desgastante. "Me deprimiría vivir todo el tiempo en el campo, es muy aislado" (entrevistada). "Mirá que la charlo pero no..." (entrevistado).

"No queremos que las nenas se vayan a estudiar lejos". En las entrevistas no se profundizó mucho en el futuro y las dinámicas de sucesión. Al parecer una de las hijas presenta un perfil más ligado al turismo y es la que más colabora con los padres actualmente en tareas sencillas. Presenta interés por aprender y escuchar las visitas en la casona, le gusta atender a los turistas, a los niños y es más sociable. La niña mayor es más intelectual, reservada y según los padres no demuestra interés por las actividades que desarrolla la familia. No obstante son muy pequeñas y es muy difícil proyectar su inserción al sistema. Lo que sí queda claro es que el patrimonio y capital del campo es importante y que incluso existe la posibilidad a futuro de lotearlo, resguardando el espacio turístico. "El día de mañana hablamos con mi primo de guardar $5 / 6$ ha para esto y el resto lotearlo porque vos acá de 1 ha sacás 15/20 lotes" (productor).

\section{La pareja de muestra estar muy dispuesta a continuar con la actividad}

a futuro. Les gusta la actividad y les gusta la vida allí. "Queremos seguir con esto, nos gusta lo que hacemos por ahí nos enloquecemos y rabiamos pero nos gusta. Es lindo, a mí me gusta personalmente" (productora). No se ha mencionado si vivirían en otro lugar pero eligieron construir su hogar allí, teniendo posibilidades de realizarlo en la ciudad. "A mí me encanta, podríamos vivir en San José porque vamos todos los días, capaz que estamos hasta las 11 de la noche, pero querés volver" (productor). 


\section{Anexo 5- Casos compilados de la zona sur}

\begin{tabular}{|c|c|c|}
\hline & & 0 \\
\hline ป็ & 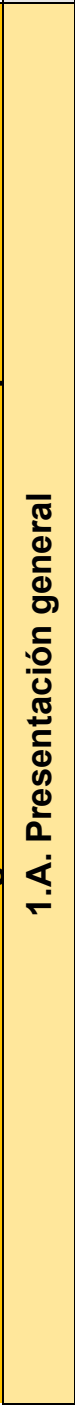 & $\begin{array}{l}\text { Pareja de } 50 \text { años con cuatro hijos. Los dos } \\
\text { hijos varones actualmente están trabajando con } \\
\text { ellos, uno es ingeniero electrónico y el otro a } \\
\text { punto de recibirse de agrónomo. Tienen una hija } \\
\text { contadora y la más chica estudia turismo rural } \\
\text { en la UBA y es chef. Tienen 27, 25, } 23 \text { y } 21 \\
\text { años. Actividad forestal: Históricamente se } \\
\text { han dedicado a la actividad forestal pero hoy no } \\
\text { están renovando sus árboles. En la isla cuentan } \\
\text { con un predio de } 340 \text { ha: "Teníamos } 200 \text { ha en } \\
\text { producción, quedarán } 60 \text { ha. Hace como } 6 \text { años } \\
\text { hicimos la última plantación" } \\
\text { (entrevistado)."Éramos forestales, seguimos } \\
\text { trabajando lo que nos queda pero no volvemos } \\
\text { a plantar" (entrevistado). Tienen un aserradero } \\
\text { móvil. "Lo del aserradero es muy chico. } \\
\text { Vendemos la producción de por ejemplo } \\
\text { eucalipto colorado que acá es una madera que } \\
\text { no se trabaja. La trabajamos nosotros, } \\
\text { vendemos tirantería, tablas, se vende } \\
\text { localmente" (entrevistado). Asociado a la } \\
\text { forestación/ servicio a terceros: con las } \\
\text { máquinas que fueron comprando para mejorar, } \\
\text { endicar, levantar su campo en la isla } \\
\text { comenzaron a hacer trabajos a terceros, no sólo } \\
\text { en VP sino en otras localidades de la zona. } \\
\text { Actualmente es uno de sus principales ingresos. } \\
\text { Asociado a la forestación/ carpintería: Los } \\
\text { hijos tienen una carpintería. "Con mi hermano } \\
\text { empezamos una carpintería y ahí hacemos } \\
\text { otros trabajos, construir muebles, estamos } \\
\text { viendo si en un futuro no podemos hacer } \\
\text { cabañas también, y muebles pero no sólo con } \\
\text { la madera que producimos nosotros sino } \\
\text { también compramos" (hijo). }\end{array}$ \\
\hline
\end{tabular}

Caso 10- DE RIOO Y CAMPO

Este sistema tiene como familia a una pareja de 38 años él y 31 ella, con una hija del primer matrimonio de la mujer y un niño de 9 años en común. El es uruguayo y ella nacida en Villa Paranacito. Se conocieron en el río ya que ambos son pescadores comerciales, él de la costa uruguaya, ella del lado argentino. Además, él y su familia son productores tamberos queseros en Uruguay. Este es un caso muy particular porque la actividad del tambo y quesería no es en Argentina, no es una actividad que genere ingresos a la familia pero parte de las decisiones que se tomaron están en relación directa a su desarrollo. Si bien el entrevistado no trabaja diariamente en la producción, está relacionado desde la toma de decisiones familiares. TAMBO QUESERÍA: "La actividad mía de toda la vida fue el campo: tambo y quesería toda la vida. La quesería cumplió 40 años y yo tengo 38. Mi viejo sigue con la actividad en un predio chico, de 55 ha" (entrevistado). La familia posee este predio lindero al río Uruguay, entre Nueva Palmira y Dolores. En el año 2000 por una crisis económica tuvieron que cerrar el tambo y quesería, pero continuaron con ganado de carne y comenzaron a trabajar en la pesca comercial en el río Uruguay. El entrevistado continúa relacionado con la producción agropecuaria de su familia en Uruguay, aunque no esté diariamente en el campo. "No trabajo allá pero siempre estoy con mi padre en lo que son las ideas, nos estamos consultando todo el día lo que es siembra, pasturas, compra de animales, se vaquillonas todos los años, terneros. Hoy ya se está con 51 vacas y 1320 litros, 25 litros
promedio por vaca. Se ordeña dos veces al día y

\section{Caso 11- UNA POSTA EN EL SILENCIO}

Sistema que tiene por familia a una pareja de 61 años él y 59 ella, con 3 hijos (38, 35 y 20). Los dos más grandes tienen sus actividades y familia, la menor estudia en La Plata. La pareja cuenta con un complejo de 4 bungalows y camping para 40/50 personas lindero al Arroyo Sagastume en Villa Paranacito en un predio de 2 ha. Además tienen una tienda de ropa en el pueblo y hacen servicios de catering en eventos. Por otro lado, cuentan en otro campo en una isla con un predio de 20 ha. Alli poseen una casa para 12 personas en alquiler. Una parte de este terreno se ha loteado para la venta de terrenos y otra la arrendan para ganadería. Allí todavía poseen una plantación de árboles para sacar madera. "Algo de forestación nos queda, algo le sacamos. En el caso mío yo tengo una parte en Arroyo Las Tintas, unas 20 ha que por ahí arrendo para vacas y hay alguito de forestación. En ese predio hice un proyecto medio náutico adelante, que eso fue lo que posibilitó mejorar, hacer buenos baños. Vendimos lotes y eso nos dio un respiro porque el turismo es muy lindo pero tenés que invertir y no siempre se está en condiciones de acceder a los créditos"(entrevistado). Comenzaron a trabajar en turismo como un complemento al trabajo en la tienda. Tienen 3 bungalows con capacidad para 4 personas cada uno y tro para 2 pasajeros. La familia del entrevistado era productora forestal, y fruteros. La actividad frutícola se abandonó y luego se fue retrayendo la forestal por varias condiciones del contexto.

"Tenemos algunos destellos de la actividad. Lo que pasó es que el porcentaje de la tierra acá en el Delta es de pequeños productores. Las unidades económicas para $20 / 30$ ha en la forestación empezaron a ser inviables, además de que los precios 
Ganadería: Hace aproximadamente 8 años se elaboran quesos 2 veces al día" (entrevistado). comenzaron a incorporar ganadería, primero Producen queso cáscara colorada que en Uruguay con el objetivo de mantener limpio el campo, se llama queso de colonia "que es muy similar al actualmente están apostando a esta actividad. queso Mar del Plata de acá". El $60 \%$ de la "En un momento la isla se fue despoblando, casi producción se vende a una cadena de no había gente y a las plantaciones tenés que supermercados en Montevideo al que le vendieron mantenerlas limpias entonces $\mathrm{mi}$ es poco desde los inicios. Además, tienen vendedores en empezó a comprar animales y pasa a un Paysandú, Fray Bentos y la madre tiene un puesto sistema silvopastoril, se sigue con los árboles y de venta en su casa. "Estuvimos 12 años sin el ganado que limpia el terreno. El ganado al producir esa calidad de queso. Hace dos años servicio de los árboles y para autoconsumo. logramos el permiso de exportación" Uno siempre piensa en el ahorro, cada tanto (entrevistado). Forma parte de un grupo quesero matamos un animal y comemos todos" con 11 empresas locales, "más chicos". "Toda la (entrevistada). "Hay algo de animales que en un principio se tenían para autoconsumo y para mantener limpio el campo por el tema de los incendios y para que sea más fácil recorrer, pero uno ve que es más atractivo eso desarrollarlo desde el punto de vista de la rentabilidad". "Cría pero siempre ajustando al ciclo de las crecientes. Ahora tenemos 40 animales. Pero hay cosas que no tenemos definido, no tenemos parámetros aun (de destete, qué porcentaje de preñez se obtiene) como para decir con este número podemos vivir de la ganadería" (hijo) "Teniamos ganas de meternos con ganadería porque si hay hacer maíz, y se trata de hacer más temprano, creciente, arrendás algún campo y llevás los entre 10/14 ha, no más". PESCA COMERCIAL: E animales y podés seguir con eso" objetivo de diversificar a través de la pesca (entrevistado).Turismo: "arrancamos con 4 siempre fue recuperar el tambo y la quesería. La cabañas y ahora tenemos 8 con distinta actividad tuvo un buen desempeño desde el 2003 capacidad. Por más de que nos beneficia la y con esos ingresos lograron reactivar el campo. cercanía a Bs As es muy temporal. En verano En el 2007 decide radicarse en Villa Paranacito tenemos prácticamente ocupación completa. para formar su familia y continúa con la pesca é En mayo, junio, julio se trabaja poco, muy poco. desde el lado argentino y su padre del uruguayo. Cuando hay mal tiempo no viene gente. Al no Continúan hasta el 2015 y en ese momento dejan tener actividades turísticas en VP la gente viene la actividad. Por esos años comienzan a elabora 2 o 3 días nomás" (entrevistada). "Por un lado y vender comidas caseras desde su propia casa, crecimos en cantidad de bungalows pero para contrarrestar la caída de la producción no acompañaban los requerimientos de la evolución de las demandas familiares. La gente empezó a vivir mejor y empezó a requerir que los chicos estudiaran por ejemplo. Antes las familias producían lo que consumían, tenían desde su fruta, su vaca, su leche, su cerdo que carneaban, la huerta... Era gente que no necesitaba prácticamente nada y de repente se encontraba con el ahorro de la forestación que la plantaba y esperaba 11, 12 años. Ahí tenés las versiones de que con 2 ha que cortaban por año vivían en el contexto de esas economías". Respecto al catering, ellos cotizan el servicio y el cliente contrata alquiler de mesas y sillas, el servicio de mozos, la comida.

grupos CREA, ahora solo estamos en el grupo de queseros". Venden un queso de muy buena Allá pasa lo mismo que en Argentina: la leche vale poco entonces hay momentos en que muchos la leche. Te saturan el mercado" (entrevistado). El padre además utiliza el suero para producir chanchos o terneros. Tiene entre 150/200 echones. Utilizan el sistema de feed lot "para la aquillona que está por parir". Producen el silo

s, la comida.


reducimos actividades. Mi esposo antes hacía pesquera en invierno. TURISMO: En el 2014 salidas de pesca embarcada, cuando le deciden emprender un establecimiento quedaba un tiempo libre. El trabajaba toda la gastronómico del estilo food truck, es decir un semana en el monte y los fines de semana carrito fijo donde se elabora y venden diversos hacía las salidas, incluso después compramos menú. Comenzaron con un carro más pequeño, otra embarcación y llamábamos a un guía. En prestado, y luego lograron construir el que tienen el 2000/2001 lo dejamos. No tenía ni 1 día libre, actualmente, completamente instalado. Es hasta los sábados se levantaba a las 4 de la mañana el día de hoy que se dedican exlusivamente a la y a las 7 salían. Nosotros vendíamos carnadas, gastronomía, han logrado capitalizarse y atienden artículos de pesca. Lo hacés un tiempo, ganás tanto a turistas como lugareños. Fueron plata pero después uno se cansa. Como 5 años diversificando sus propuestas de platos, lo hicimos. Y yo hacía paseos en lancha. Yo era adaptándose a la clientela local y visitantes. la que recibía, atendía, limpiaba y después Ofrecen desde comidas rápidas, bebidas hasta hacía paseos de una hora. Los dejaba a los platos más elaborados como pastas o guisos. chicos a cargo, que eran chicos."(entrevistada)

Dejaron la actividad pesquera para dedicarse exclusivamente a la gastronomía y el turismo. Hoy están dedicados al $100 \%$

Tratan de organizarse para mantener el trabajo Actualmente la única actividad de generación de familiar. En el tema forestal y servicio a terceros, ingresos es la gastronómica. En esta trabaja la ocasionalmente contratan jornaleros. El marido pareja y un empleado. Por el momento es un está más dedicado a la actividad forestal y el trabajo muy intensivo, con jornadas de más de servicio, la mujer al turismo, dos de los hijos se $12 / 13$ hs durante el años y en verano, que es están sumando al sistema a partir la carpintería temporada alta turística, más de $18 \mathrm{hs}$. Abren a las y el agronónomo vinculado a la gastronomía. La 11 de la mañana y trabajan de corrido hasta la hija menor que estudia turismo rural, aporta noche. Ella se retira antes del carrito para estar ideas y proyectos a la parte turística. "El hace con los hijos. "Vamos, hacemos tarea, comemos y \% todo solo, no tiene empleados. Lo que estaba haciendo en vez de cortar lo propio es hacer este servicio a terceros". En turismo "siempre Trabajan todos los días juntos y los dos hacen las que nunca parás, estás todos los días a full". "Yo lo hago con gusto, a mi esposo no le gusta atender, a eso lo hago yo. Le gusta que esté todo en orden, eso sí, pero no el trato directo con la gente. A él le gusta la actividad tranquila del campo, y a mí lo contrario, me gusta el trato con la gente" (entrevistada)". La parte comercial la maneja ella, nosotros hacemos todo el maneja las reservas y la atención al turista en general Ella se encarga de los detalles, de la limpieza de los bungalows y de que todo esté "impecable". Además contratan personal de limpieza y de mantenimiento, pero no de forma estable. "En turismo no tenemos a nadie fijo, contratamos a gente esporádicamente, es muy irregular" (entrevistado). "Nosotros contratamos generalmente para la limpieza de los bungalows a gente que se dedica a eso, cobran por hora y lo hacemos, ella está en la parte estética, decoración, de las plantas, que el bungalow esté impecable" (entrevistado). A la mujer también le gusta el cuidado del jardín. La responsable de la tienda es principalmente ella. Si tienen reserva de bungalows ella se queda por la mañana a prepararlo y él se va a la tienda, donde además tienen una empleada y luego se vuelven a rotar. "De lunes a sábado atendemos la tienda, si hay que limpiar algún bungalow yo me quedo y él a a la tienda con la chica, cuando se termina todo mantenimiento, la construcción. Cuando ella no gusta comer bien, y eso hemos tratado de volcarlo 


\begin{tabular}{|c|c|c|c|}
\hline & $\begin{array}{l}\text { está lo podemos hacer nosotros. Como no } \\
\text { cerramos nunca, siempre alguien queda } \\
\text { (entrevistado). "Si está ella, hace las reservas, } \\
\text { cobra ella" (hijo). "En general nosotros } \\
\text { hablamos todo, todo lo que hacemos en lo } \\
\text { productivo lo hacemos en conjunto (con los } \\
\text { hijos), menos la parte turística" (entrevistado). }\end{array}$ & $\begin{array}{l}\text { a los clientes, y con eso hemos andado } \\
\text { bien".(entrevistado) }\end{array}$ & $\begin{array}{l}\text { (entrevistada). En el servicio de catering, el } \\
\text { entrevistado es el encargado de la logística general y } \\
\text { la mujer con otras } 3 / 4 \text { señoras preparan la comida. } \\
\text { Toman gente para el servicio de mozos para cada } \\
\text { evento. La atención al turista es indelegable. "Al } \\
\text { turismo no lo delegamos, no es fácil, yo soy un fanático } \\
\text { de controlar el buen ambiente y soy celoso de que se } \\
\text { vayan contentos. La gente vuelve por los detalles, la } \\
\text { tranquilidad y el ambiente familiar". "En el camping } \\
\text { tenés que estar mucho encima, nosotros hacemos un } \\
\text { ambiente familiar y de descanso, eso requiere de la } \\
\text { percepción de que sí y que no, no es discriminar pero } \\
\text { tenés que tener cuidado". "Yo creo que en turismo un } \\
\text { gran porcentaje es el prestador y cómo atiende al que } \\
\text { viene" (entrevistado). }\end{array}$ \\
\hline 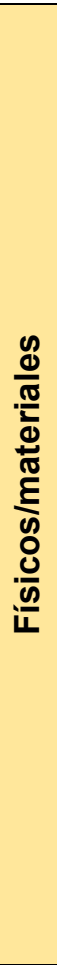 & $\begin{array}{l}\text { Es una familia que está capitalizada, cuentan } \\
\text { con el predio donde se ubica el complejo } \\
\text { turístico y la vivienda familiar y la quinta forestal } \\
\text { en la isla, donde apuntan a la ganadería. Allí } \\
\text { también tienen una casa que en un tiempo } \\
\text { alquilaron para turismo, y hoy está más } \\
\text { desmejorada por la última creciente. Comentan } \\
\text { que el turismo surgió por la venta de un barco } \\
\text { que el esposo heredó y luego fueron invirtiendo } \\
\text { en turismo a partir de la venta de la madera. } \\
\text { "Fuimos invirtiendo en turismo vendiendo } \\
\text { maderas. "Con el tema de la creciente (del 98) } \\
\text { nadie trabajaba. Había demanda de madera } \\
\text { pero nadie cortaba por las condiciones de la } \\
\text { creciente. Y bueno, mi esposo cortaba sobre } \\
\text { pontones, cortaba hasta donde se podía, era } \\
\text { todo incómodo pero eso te permitía vivir porque } \\
\text { eran muchos meses sin ingresos, se pagaba } \\
\text { bien". Han hecho inversiones importantes en } \\
\text { mejorar la calidad de la isla y del terreno en VP. } \\
\text { "Se ha invertido en un dique para que no esté } \\
\text { constantemente inundado porque las crecientes } \\
\text { vienen cada vez más seguidas. Llegó a comprar } \\
\text { una retroexcavadora y empezamos a hacer un }\end{array}$ & $\begin{array}{l}\text { La familia del entrevistado ha logrado capitalizarse } \\
\text { a partir de la pesca. De hecho la actividad } \\
\text { gastronómica/turística se generó a partir de la } \\
\text { pesca. Para construir el carrito vendieron una } \\
\text { embarcación, más la venta que en la época de la } \\
\text { inundación fue buena. "La inundación es una } \\
\text { desgracia porque le pasa a todo el mundo. A } \\
\text { nosotros nos favoreció porque estábamos arriba } \\
\text { del cerro. Se trabajó más que nunca. Se compró } \\
\text { todo nuevo" (entrevistado). Las ganancias se } \\
\text { reinvierten en mercadería fundamentalmente. } \\
\text { Tienen varios freezers en el carrito y en el hogar } \\
\text { donde stockean mercadería. }\end{array}$ & $\begin{array}{l}\text { En una parte del campo de } 20 \text { ha que poseen en otra } \\
\text { zona de la isla hicieron un loteo. Con la venta de esos } \\
\text { terrenos ampliaron y mejoraron el complejo turístico. } \\
\text { "El turismo requiere inversión, si haces un camping } \\
\text { tenés que tener buenos baños. Hoy el más o menos no } \\
\text { existe, hay cosas que ya no se discuten } \\
\text { más"(entrevistado). Tenían } 27 \text { ha de las cuales el } \\
\text { padre le había regalado una parte y él compró lo otro. } \\
\text { Todavía tiene lotes para vender allí. Y con el predio de } \\
11 \text { ha que lindan al complejo tienen el proyecto de } \\
\text { hacer otro loteo, a futuro. El predio donde se ubican los } \\
\text { bungalows y el camping tiene } 2 \text { ha. Además, la mujer } \\
\text { es dueña de la tienda en el pueblo, que proviene de } \\
\text { línea familiar. }\end{array}$ \\
\hline
\end{tabular}




\begin{tabular}{|c|c|c|c|}
\hline & $\begin{array}{l}\text { dique para tratar de preservar la plantación con } \\
\text { un sistema de compuertas para que el agua no } \\
\text { entre en el campo si hay una creciente "normal" } \\
\text { (entrevistada). }\end{array}$ & & \\
\hline 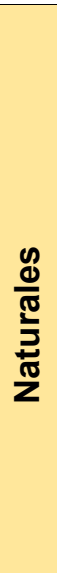 & $\begin{array}{l}\text { Las crecientes condicionan y marcan el rumbo } \\
\text { de las decisiones familiares. }\end{array}$ & & $\begin{array}{l}\text { Idiosincrasia definida por la dinámica del agua. "En la } \\
\text { última creciente fuimos verduleros porque estuvimos } 8 \\
\text { meses sin trabajar el año pasado, ni tienda ni turismo. } \\
\text { Yo iba al mercado de Escobar, traía verdura con la } \\
\text { camioneta hasta el Sagastume y de ahí la cargábamos } \\
\text { arriba de la lancha y la vendíamos". "El gran afectado } \\
\text { de las crecientes es el que se las arregla solo, porque } \\
\text { el que tiene un sueldo mal que mal sigue viviendo del } \\
\text { sueldo, y el indigente... Paranacito tuvo una avalancha } \\
\text { de donaciones. A nosotros no nos perdonaron ni los } \\
\text { impuestos. Los gastos fijos los seguís teniendo, yo } \\
\text { tengo una hija estudiando afuera... todo un } \\
\text { drama"(entrevistado). "Con la creciente esto era un } \\
\text { caos, teníamos dos metros de agua..." (entrevistada). }\end{array}$ \\
\hline 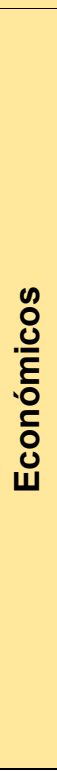 & $\begin{array}{l}\text { Según los entrevistados tienen } 2 \text { ingresos } \\
\text { fuertes: el turismo y el servicio a terceros. "La } \\
\text { forestación es lo que más aporta, no sólo la } \\
\text { forestación sino el servicio que él hace a } \\
\text { terceros, en eso se gana. Eso es lo que } \\
\text { posibilitó el ingreso mayor porque en la quinta } \\
\text { vos invertís, invertís, invertís y el día que querés } \\
\text { cortar tenés } 1000 \text { problemas. Lo que más sirve } \\
\text { es el servicio, manteniendo lo propio. Es el } \\
\text { ingreso mayor". "Con lo de turismo yo no } \\
\text { recuperé nada de lo que invertí. Obviamente } \\
\text { que en temporada estás más holgado pero si } \\
\text { sacás los números yo no recuperé, pero } \\
\text { tampoco han pasado tantos años" } \\
\text { (entrevistada). "Mezclamos todo, por ahí él saca } \\
\text { mucho de un trabajo decimos bueno, vamos a } \\
\text { hacer una cabaña" (entrevistada). "El servicio a } \\
\text { terceros te permite la inversión. Lo que se gana } \\
\text { se invierte } \quad \text { en las dos }\end{array}$ & $\begin{array}{l}\text { Hoy el único ingreso con que cuenta la familia es } \\
\text { la gastronomía pero apuestan a su sostenibilidad } \\
\text { en el tiempo a pesar de las dificultades. "Está } \\
\text { complicado los últimos meses pero venimos } \\
\text { zafando. Los impuestos y la luz han subido } \\
\text { bastante" (entrevistado). Ellos destacan que es } \\
\text { una actividad que genera ingresos todos los días. } \\
\text { Esta característica, más orden y organización en } \\
\text { los gastos y reservas de insumos le dan } \\
\text { tranquilidad y sustentabilidad en el tiempo. "Con la } \\
\text { gente del pueblo trabajás todos los días, los } \\
\text { precios son bastante accesibles porque uno se } \\
\text { tiene que acomodar al lugar donde vive. Trabajás } \\
\text { todos los días, algo laburás" (entrevistado). "Creo } \\
\text { que es uno el que tiene que emprolijar los gastos } \\
\text { fijos. Yo lo hice toda la vida en el campo y acá pasa } \\
\text { lo mismo. No endeudarse, si no tenés deudas la } \\
\text { vas acomodando, si no tenés créditos o no } \\
\text { malgastas la plata. Gracias a Dios si vas a mi casa }\end{array}$ & $\begin{array}{l}\text { Los principales ingresos están dados por el } \\
\text { turismo y la venta en la tienda en el pueblo que se } \\
\text { complementan dada la marcada estacionalidad del } \\
\text { turismo. "Nosotros tenemos divididas las cosas, } \\
\text { cuando está floja una cosa tenemos la otra. De } \\
\text { septiembre en adelante trabajamos bien con turismo y } \\
\text { la tienda empieza a aliviarse, la preparamos para el } \\
\text { invierno que es cuando cae el turismo y levanta la } \\
\text { tienda". El catering colabora, pero no es tan estable } \\
\text { el ingreso. Respecto a la forestación, "sacamos } \\
\text { madera de lo que había, y en los campos esos que se } \\
\text { están quedando sin madera apuntan a la ganadería. } \\
\text { Los arrendamos porque la forestación grande permite } \\
\text { que haya vacas abajo. Quedan } 7 / 8 \text { ha de árboles, muy } \\
\text { poco. Cuando tenés algo que cortar contratás a alguien } \\
\text { y lo saca hasta la costa del río, ahí lo llevan a papel } \\
\text { prensa la mayoría" (entrevistado). Los entrevistados } \\
\text { manifiestan que tienen altos gastos fijos de servicios y } \\
\text { por la hija que estudia afuera. "No vivimos mál, vivimos }\end{array}$ \\
\hline
\end{tabular}




\begin{tabular}{|c|c|c|c|}
\hline & $\begin{array}{l}\text { actividades"(entrevistada). "Yo hago trabajos a } \\
\text { teceros con las máquinas que tenemos, esa } \\
\text { entrada también es importa. Eso y el turismo } \\
\text { están más o menos equilibradas" } \\
\text { (entrevistado). }\end{array}$ & $\begin{array}{l}\text { tenés } 40 \text { mil pesos en gaseosas, hay } 3 \text { freezers } \\
\text { llenos de mercadería, eso te da tranquilidad. No } \\
\text { tenés dinero en el bolsillo pero la tenés invertida } \\
\text { (entrevistado). }\end{array}$ & $\begin{array}{l}\text { bien, pero eso implica un enganche muy particular" } \\
\text { (entrevistado). }\end{array}$ \\
\hline $\begin{array}{l}\frac{\mathscr{d}}{\pi} \\
\frac{\pi}{0} \\
\text { ळ }\end{array}$ & $\begin{array}{l}\text { Son una familia que ha integrado redes } \\
\text { históricamente y están muy vinculados a } \\
\text { actividades de la comunidad. Integran } \\
\text { Federación Agraria desde el 2008. "Más que } \\
\text { nada nos juntamos por la madera, hicimos una } \\
\text { filial". Forman parte de la Cooperativa que } \\
\text { primero era forestal y luego fueron incluyendo } \\
\text { otras actividades productivas. La entrevistada } \\
\text { comenta que se sumó a un grupo de pecaneras } \\
\text { que se armó en la cooperativa. "Yo ingresé al } \\
\text { grupo pecanero hace } 4 \text { años, empezamos con } \\
\text { un grupo Cambio Rural. Hay muchos } \\
\text { productores forestales que tenían árboles de } \\
\text { pecán, que los abuelos habían plantado. Hoy } \\
\text { son otro ingreso más para la familia. Yo estoy } \\
\text { en el grupo pero no vendo nada, ayudo en la } \\
\text { comercialización, estoy en las ferias, se hace } \\
\text { todo ad honorem para sacar el grupo de la } \\
\text { cooperativa adelante" (entrevistada). También } \\
\text { ella integra la comisión de la Biblioteca Popular } \\
\text { desde sus inicios. Respecto a lo social que } \\
\text { ofrece el turismo, destacan que muchos de sus } \\
\text { amigos datan de sus inicios en turismo, que la } \\
\text { mayoría de los turistas vuelven muchas veces y } \\
\text { se genera un vínculo más que especial. }\end{array}$ & & $\begin{array}{l}\text { No se profundizó en la entrevista sobre este aspecto } \\
\text { pero por dichos del entrevistado, él es muy sociable, le } \\
\text { gusta interactuar con los turistas, ha formado parte de } \\
\text { espacios políticos, liderado procesos de } \\
\text { transformación local, ocupado cargos públicos e } \\
\text { integrado redes de trabajo asociativo en turismo. }\end{array}$ \\
\hline 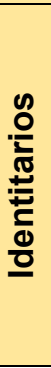 & $\begin{array}{l}\text { Uno de los rasgos que más distingue a esta } \\
\text { familia es un fuerte sentido de pertenencia al } \\
\text { lugar y de cooperación y asociativismo. "Por } \\
\text { mi formación o lo que sea, creo que es muy } \\
\text { importante agruparse, poderse ayudar } \\
\text { mutuamente y no importa si tenés beneficios } \\
\text { personales porque ayudás a la comunidad } \\
\text { entera. También estoy en la biblioteca popular } \\
\text { desde que se fundó. Estoy en distintas }\end{array}$ & $\begin{array}{l}\text { Hay algunos rasgos claros que definen a esta } \\
\text { pareja, que tiene que ver con sus origenes y estilo } \\
\text { de vida elegida. El es un hombre de campo y río, } \\
\text { que decidió comenzar una actividad diferente a la } \\
\text { que venía desarrollando para cambiar su presente } \\
\text { dos veces. Primero para salvar el campo de la } \\
\text { familia en Uruguay, segundo para tener una vida } \\
\text { diferente con su nueva familia en Argentina, lo que } \\
\text { lo define como un hombre emprendedor y }\end{array}$ & $\begin{array}{l}\text { Hay elementos que identifican a la familia y su vínculo } \\
\text { con la comunidad. Son una familia emprendedora y } \\
\text { sumamente trabajadora, comprometida y que participó } \\
\text { activamente de la construcción y crecimiento del lugar, } \\
\text { desde diferentes roles. "Nosotros estamos } \\
\text { convencidos de que el que soluciona algo o deja de } \\
\text { solucionar es cada uno con su propio esfuerzo. Partís } \\
\text { de eso. El único artífice de lo que sos, sos vos. Podés } \\
\text { tener circunstancias de mala suerte, una creciente }\end{array}$ \\
\hline
\end{tabular}


actividades. No sirve el aislado, no se logra sumamente trabajador. En ambos casos, el valor nada. Uno solo no llega a nada y la comunidad de la familia ha sido central. Ella una mujer nacida no c+F7recer. El ejemplo que tuvimos: cuando y criada en la isla, con una vida alejada de las se empezó a formar esta zona de islas, no VP, grandes urbes, que también se adaptó a las había una cooperativa eléctrica, acá en la isla vueltas de la vida y que tuvo que salir a pescar tenían la luz antes que en Bs As, había con el riesgo y el sacrificio que implica- para vivir y cooperativa de agua potable. Se hacía todo a mantener a su hija.

partir de la unión de la gente, por eso prosperó" (entrevistada). "Yo estoy muy metida con lo de la cooperativa porque al insertarse lo del pecán se inserta más la mujer. Ahora se cumplen dos años de la feria isleña que también surge por la necesidad de vender la nuez y la miel al turista,

y a su vez agregarle más personas, mujeres que hacen artesanías, cestería, cerámica. Son como 14 mujeres. Yo participo ayudando, no vendo, ayudo a cómo presentar las cosas, los stands. Son personas que necesitan ánimo porque no se valoran así mismos, al estar en la isla son también muy retraídas. Yo les aporto en eso y apoyo moral" (entrevistada). Por otro lado es muy notorio el vínculo afectivo, por la historia familiar, que los une a esas tierras.

El impacto de las inundaciones. "Allá en la Villa Paranacito tiene una dinámica particular, isla es como que se está más organizados para social y naturalmente hablando. La vida de las las crecientes, de por sí tenés movimiento en personas, las actividades comerciales, el turismo, lancha, escuela había, pasaba la lancha de alguna manera está condicionada por el agua escuela, nuestra casa se inundó toda pero por los ríos y arroyos, sus crecientes y sudestadas. \& teníamos dos piecitas en alto y un baño y ahí estábamos los 6 . La vida continúa, hay que lavar ropa por ejemplo, entonces mi marido me hizo una base afuera pa+F12ra lavar ropa, después me hizo una terracita. Para colgar la ropa lo hacía desde el bote. Con los chicos en ese momento jugábamos mucho a juegos de mesa. Después vino el invierno, un frio hacía, pusimos una salamandra en el pasillito. La cuestión era que esté la familia junta, yo me
Eso impregna las decisiones de las familias. Esta localidad tiene la particularidad de estar muy próxima a la ciudad de Bs As, a 3 horas en auto, lo que se presenta como una oportunidad para el desarrollo del turismo. Una dinámica que se está observando los últimos años es la compra de terrenos para la construcción de casas de fin de semana, segunda residencia por parte sobre todo el "porteño" le decimos nosotros, vienen a invertir, de gente de Buenos Aires. "Desde hace 4/5 años esas cosas, pero a lo largo de la vida es la garra que vos le pongas. $Y$ en ese sentido, sí, somos emprendedores" (entrevistado). Además, el haberse criado en la isla les da una particularidad como isleños un amor por su lugar que permite contrarrestar las limitaciones y coyunturas varias que presenta el ambiente y la misma sociedad.

"El isleño es muy particular, celoso de su lugar, muy aislado. Esta irrupción del foráneo, del "porteño" tiene algunos que lo aceptan y otros que no". Los entrevistados así como destacan las ventajas de estar en un lugar cercano al principal centro emisor de turistas como es Buenos Aires remarcan las imitantes del pueblo. "Nos faltan servicios, falta gastronomía, y aparte qué puede hacer la familia, el hombre pesca y el resto? Esas cosas para mí se van dando de a poco, va mejorando Villa Paranacito, hay servicios que hace un tiempo atrás no se ofrecían. Redes, ahora por whatsapp. Esta familia ha integrado grupos de turismo, tienen relación con otros actores del turismo. "Ahora es por wapp, es fantástico tenemos un grupo de turismo que todo el tiempo se 
podría haber ido a Bs As que estaban mis padres, pero separar la familia no. Estuvimos como 8 meses, fue duro.

"La creciente te paraliza mucho" (entrevistada). "Uno se adapta a la vida con agua. Lo peor es cuando baja, el desastre, quedan como 20 centímetros de barro, que la correntada deja depositada el lino sobre todo. Te desanimás porque parece que nunca vas a componerte." Falta de apoyo del estado. Uno eligió vivir en un lugar que sabés que se va a inundar. Si estás acá, aguantátelo pero el tema impositivo para mí es importante que sea automático cuando hay creciente. Eso lo estamos trabajando con FA, hay que insistir en eso". Isleños vs locales de VP. "Hay mucha diferencia entre la gente que vive en la isla y la que vive acá, no es la misma gente, es totalmente diferente en "su ser". El de la isla es de unirse, de colaborar, de tratar de lograr algo, el del pueblo no, no es gente acostumbrada, no es gente isleña, es agregada, no es de espíritu isleño, pero no es de ahora. Mi esposo que hizo la secundaria acá (porque en la isla hay escuela primaria nomás) él siempre decía que el isleño quedaba aparte, el del pueblo era como el vivo, el urbano, el isleño era como el pobrecito. $Y$ los chicos se agrupaban así. Ellos los de la isla no venían a gusto a VP, no se juntaban, y ahora pasa lo mismo" (entrevistada). Pocas organizaciones en VP."No hay otras organizaciones en VP. La biblioteca se fundó en el 1998, no depende del gobierno, vos tenés un grupo de personas que se hacen socias, tiene personería jurídica. Se hacen asambleas, se eligen autoridades. No es municipal, se recibe el apoyo de nación y de provincia. La biblioteca fue muy boicoteada, siempre insistiendo que tenía que ser municipal. Se han querido hacer otras cosas pero quedan compran tierra y hoy esa tierra ya tiene o una casilla o una terrible casa. Hay mucha demanda de terrenos, cualquier terreno te sale entre 30 y 50 mil dólares" (entrevistado). El turismo aumenta. "La gente cada vez frecuenta más. En verano hay más movimiento pero este año en invierno y primavera nosotros tuvimos mucho turismo, todos los días tenemos turistas" (entrevistado). Al principio tuvieron resistencia del Municipio y algunos locales para establecer el carrito. "A carrito en sí no lo querían pero yo pienso que eso fue cambiando, la mayoría de la gente viene hoy a consumir. En las reuniones de turismo que puedo ir que se hacen cada 15 o 20 días siempre aporto, ayudo a los otros. Las mismas empresas de alojamiento nos mandan gente para acá. Creo que estamos haciendo las cosas bien, si no no pasaría eso" (entrevistado). "Al principio no teníamos un lugar fijo, nos cambiaban de un lado a otro". Crecidas e inundación, crisis y oportunidad. En la época de la inundación les permitieron instalar el carrito (el más pequeño, el primero) en le cerro, que es una zona alta de la localidad. En esos meses lograron finalizar el carrito en el que hoy trabajan. En ese momento, la vivienda familiar tuvo 2,60 de agua, y durante más de 20 días vivieron en la planta alta. "Esta fue la primera inundación de él, yo ya estoy acostumbrada" (entrevistada) Pese a las dificultades, haber sufrido la inundación, que por un lado afectó y por otro colaboró al negocio familiar, la pareja no cambiaría de lugar para vivir. "Nos aporta tranquilidad, hasta ahora. Por supuesto que vos vas viendo que viene gente, que hay movimiento, que hay gente que no conocés, eso puede perjudicar en algún momento, ojalá que no" (entrevistado). está chequeando quién tien lugar, se dice tengo lugar para 3, una familia de 4 busca alojarse... Eso que nosotros intentamos hacer con reuniones, lo solucionó el wapp" (habla de la coordinación). Esto lo centraliza la Dirección de Turismo de la Municipalidad, con la misma dinámica se coordinan las salidas en lancha, los guías de pesca. "Esto es realmente una satisfacción porque el turismo funciona así, el que se encapsula y se hace una isla no funciona" (entrevistado). Reflexionan sobre el haber participado de un grupo asociativo de turismo rural. "Hicimos un intercambio con turismo en Tigre. Y esas cosas para qué sirvieron? Nos dimos cuenta que lo que teníamos servía y era tan bueno como aquello para hacer turismo porque nosotros teníamos algún grado de... esto servirá para hacer turismo? Si bien yo tenía fe, no sabía si era una locura mía..." (entrevistado) 
truncas. Te lo impiden. 20 años en turismo y todavía no tenés ni una cámara, y no es que no nos hemos reunido. Por lo menos la cooperativa funciona..." (entrevistada). "Se los ve muy individualistas, muy en lo suyo y no vamos a adelantar así. VP podría estar mucho mejor. Yo no veo apoyo al isleño, a la gente que vive en la isla. No lo tenés que apartar de todo. No hay apoyo al productor, al que todavía insiste en llevar una vida en la isla, porque acá en el pueblo no se produce nada, son la mayoría empleados" (entrevistada). Turismo \& pecán: "varios de los productores que integran la cooperativa están haciendo turismo. Lo que estamos tratando de hacer es unir el turismo con la nuez para hacer algo que nos destaque - que nos de cierta particularidad" (entrevistada). Trabajo en red con asesoramiento de INTA. "Trabajamos con el INTA para presentar un proyecto para conseguir fondos para mejorar la infraestructura de la feria, unificar todos los puestos. También se había pensado en ofrecer circuitos para recorrer las plantaciones, cosechar y después cerrar con la venta de algun producto. Brenda lo quería hacer en casa, hacer un circuito, llevarlos en lancha a la quinta, hacer un recorrido y ofrecer un té, un café con alguna torta de pecán y volver en lancha" (entrevistada). "Cuando no hay agua, el ingreso que genera el turismo en el pueblo es impresionante, es muchísimo. Un fin de semana con turismo es totalmente diferente al que llovío y no entró ninguno. En todo el pueblo se nota, si viene gente es otro movimiento, se vende más. Si son pocas las familias que se benefician con el turismo, es una pena". La entrevistada insiste en que se podrían generar más actividades. "Si al turismo lo tenés, hacé que vuelva, que gaste más en la 
comunidad. Tenés que incentivar el desarrollo, hay que aprovechar el desarrollo del turismo" (entrevistada).

La historia familiar narrada por la El entrevistado comenta que toda su vida estuvo entrevistada se sitúa en la isla. $Y$ también en dedicado al campo ya que colaboraba con el padre este caso, la dinámica de la isla va marcando en el tambo quesería que tiene 40 años de la historia familiar. Tanto la familia del marido existencia. En los 2000 les fue "muy mal" y como la de ella son de la zona. La familia del tuvieron que cerrar el establecimiento quesero entrevistado se instaló en Brazo Chico y la de la pero continuaron con ganadería de carne. En esa entrevistada tenía una pensión en Brazo Largo. época el entrevistado comenzó la actividad "Mi abuelo vino después de la primera guerra pesquera "para ayudar a la empresa. Con la pesca mundial. El empezó con la forestación y con se pagaron algunas deudas que estábamos frutales (tenía 2 ha) y un almacén. Después complicados". "En el 2003 el pescado empezó a siguió mi papá con el almacén y la parte forestal valer muchísimo dinero. En Uruguay empezó a y como parte principal. $Y$ después seguimos haber mucha demanda de sábalo desde la parte nosotros, el almacén dejó de funciona" brasilera y Uruguay le empezó a vender a Nigeria (entrevistado). "Cada arroyo era como un y otros países africanos y a un precio terrible. E barrio", narra la entrevistada, "Brazo Chico tenía $60 \%$ del pescado fresco se vende a Brasil y el $40 \%$ más inmigración dinamarquesa, Brazo Largo a 8 países" (entrevistado). Ellos trabajaban todo el era de alemanes, suizos, austríacos. Mis padres día y lo obtenido se vendía a acopiadores. La y los padres de mi esposo se conocían de joven. mujer también era pescadora del lado argentino. Todos los inmigrantes comenzaron a dedicarse "El padre de mi primera hija era pescador, yo a la actividad forestal (sauce y álamo) y en empecé a trabajar con él cuando ella era chiquita, aquella época, el cítrico también era fuerte, eran tenía meses. Después la familia fracasó y yo seguí plantaciones de cítricos que iban al Mercado de trabajando con mi cuñado. Yo tenía que Frutos de Tigre. Las crecientes se ve que no mantenerla a ella, todo era por ella. Mi familia me eran tan fuertes porque los cítricos aguantaban. Todos se dedicaban a esta actividad, eran mantenerla a ella, todo era por ella. Mi familia me
ayudaba a cuidarla" (entrevistada). La
entrevistada nació y vivió hasta hace 10 años en
"Nosotros tenemos la vida aquí". Así comienza el diálogo sobre la historia familiar del entrevistado que se mezcla inevitablemente con la dinámica e historia de la isla. "Siempre estuve relacionado con el campo, con la producción. Mis abuelos vinieron de Europa, de pasarla muy mal por la posguerra, para ellos acá era todo divino". "El abuelo llegó en 1906. Los padres de ella llegaron en el 40/50 en una época floreciente de la isla en términos de actividad productiva y también de turismo. Había mucho turismo en esa zona, en el delta en general había muchas hosterías a las que se arribaba en lancha. Antes del boom de Mar del Plata, el Delta de Tigre con el Tigre Hotel era el lugar de veraneo de toda la gente de zona norte y Buenos Aires, después con las rutas el lugar de verano fue Mar del Plata. Acá en el medio de una actividad productiva fenomenal con la fruta y la forestación, era un combo que se hacía, hubo gente que vino, sobre todo muchos inmigrantes que hicieron hosterías con turismo de buen nivel. Era un delta que tenía 18/20 mil personas distribuidas dentro de las islas o sea que la actividad terrestre que hoy conocemos no existía. La organización del delta estaba en los arroyos, distinta a la forma normal de un pueblo como vos estás acostumbrado en cualquier lugar. En el medio de esa 
productores chicos que veían la necesidad de la isla. Su padre "siempre trabajó en el monte". La unirse para vender sus productos, por eso la pareja se conoce trabajando. "El río es cooperativa de productores tiene más de 78 compartido y hay pescadores argentinos y años. El europeo quería educación para sus uruguayos, en ese interín a los pescadores hijos y los del vecino, eran muchos chicos. argentinos se le complican las exportaciones y Empezó un sistema de educación privada que empiezan a llevar pescado para allá. Nos después pasa a manos del estado. "Había conocemos todos porque andamos todo el día en mucho progreso porque el inmigrante trabajaba el agua. Ahí fue cuando la conocí a ella que su tierra pero también hacía cosas para la pescaba con el cuñado, la misma actividad. Lo que comunidad, por ejemplo, hacían canales es desde Paranacito que es el kilómetro 0 del río hechos a pala entre todos" (entrevistada). "La hasta el km 40 hay 138 pescadores, entre actividad forestal empieza con los inmigrantes argentinos y uruguayos. En un tramo corto europeos, comienza a crecer la zona. La conviven muchas familias" (entrevistado). La creación de la organización del pueblo es pareja logró crecer y lograron capitalizarse en la mucho posterior. Acá era más que nada campo. pesca, ya que las condiciones para la venta eran Después se empiezan a instalar turcos, óptimas y la demanda de pescado estaba en alza. españoles, italianos y se empiezan a hacer otro "Nos fue recontra bien, y cuando empezamos a tipo de actividades, más comercial" (entrevistada). "Yo me crié en Bs As, nací allá por más de que toda las vacaciones obligado era venir acá. Estudié en una escuela alemana y después administración de empresas alemanas. Me vine a vivir acá cuando me casé en 1987. Vivimos en la isla muchos años" (entrevistada).F10"El abuelo de mi esposo empezó con forestación pero también tenían un almacén de ramos generales, todos se surtían de ahí, combustible, las primeras máquinas, alimentos... empezó a adquirir más tierras, hacer más producción y empiezan a vender a Bs As que había más aserraderos y necesitaban más producción, que se traslada en barcos. Mi suegro se hace de un barco, era épocas muy buenas, la madera valía mucho... Estos barcos se cargaban a pulso. Todo eso sufrió una transformación muy grande. E marido hereda el barco, lo utilizan mucho tiempo y luego lo venden. Con ese dinero ya llegamos a tener un rodeo de 30 y pico de vacas
compran las tierras en el pueblo donde ahora y las usábamos como nodrizas porque no había actividad se armaron 16 escuelas dentro del delta, clubes, hay banco desde el 1935 o sea que algo pasó acá como para que hubiera banco. Había 3 servicios diarios de lancha, desde San Fernando y Campaba que recorrían el delta, y esas grandes lanchas pasajeras llevaban correspondencia, llevaban de todo. Y traían turismo. Esto era Islas del Ibicuy, Villa Paranacito era el centro" (entrevistado). "Después de la creciente del 83, ahí empieza la bisagra, viene a ser el inicio del turismo contemporáneo a nuestra edad". "En 1984 se crea el departamento Islas, se crea para atender una zona especial del delta que no tenía nada que ver con Gualeguaychú". En ese momento el entrevistado formaba parte del grupo político que ganó las elecciones en el 83 y trabajaron para crear el departamento. "Hicimos alguna presentación porque entendíamos que nuestra idiosincracia, nuestra forma de vida no tenía nada que ver con una ciudad "normal" de la provincia. Esto era diferente. Incluso los reclamos eran distintos. Cuando ibas a pedir presupuesto para una lancha para que los chicos vayan a la escuela, no te entendían" (entrevistado). La creciente del 83 según el entrevistado marca un antes y un después en la isla. "Después de la creciente del 83 se produce un fenómeno, se empieza a despoblar el delta interior y se empieza a concentrar mucha gente en los servicios del pueblo, en Paranacito, fenómeno que se da también en otros lugares". "Se empieza a incrementar la actividad ganadera porque al abandonarse un poco la actividad forestal empezaron a quedar campos que, manejando el agua, se transforman en campos ganaderos y en los lugares donde empiezan a llegar caminos que antes no llegaban (por ejemplo acá) se empieza a visualizar la posibilidad del turismo. Se empieza a ver la necesidad de abrir caminos donde antes se llegaba solo con lancha. En ese momento se habían perdido los servicios de lancha que te comentaba porque a despoblarse el delta interior dejaron de funcionar. No 
funciona el complejo turístico y vive la familia.

"Al barco lo tuvimos bastante tiempo hasta que llegó una tecnificación mayor que fue en los 80 y pico que se empezó a poner pluma. El barco se armó para cargar 90 toneladas, se alarga. Después lo vendimos. Con ese capital en 1995 compramos la tierra que está en VP donde está el complejo y dijimos vamos a hacer otra cosa. Vamos a volcarnos al rubro turístico. Desde que compramos se modificó mucho porque había una parte de bañado. Lo que se vendían eran en total como 16 ha de las cuales 1 era utilizable. Todo el resto ahora estamos haciendo una inversión importante para aprovecharla, está entre la ruta y otro arroyo. Cuando compramos acá estuvimos un año rellenando porque era muy bajo el terreno, ahí vivíamos en la isla, todavía nuestro domicilio está ahí. En la isla teníamos básicamente forestación, solo forestación. Al barco lo utilizábamos para hacer fletes, transportábamos nuestra madera y la de otros". En 1996 arrancan con el turismo. "Empezamos arreglando una construcción vieja existente. Empezamos con 4 módulos, había un piso arriba y otro abajo. Cuando veníamos ocupábamos uno y el resto lo alquilábamos. El equipamiento y todo eso lo hicimos con un trato con un corralón, era un trueque, cambiábamos madera por material de construcción. Le compramos todos los muebles, era la única manera de hacernos de algo. Así empezamos con esas primeras cabañas". "Después I agregamos el camping. La gente que venía VP en un principio era como muy tipo pescador y requería pocas instalaciones. Desde el inicio yo teniendo chicos apunté a un turismo familiar nuestro equipamiento fue siempre para la familia" (entrevistada). "Estábamos iniciando máquina para ordeñar, no estaba la quesería|había gente en el delta". Con nuestra familia yo armada, entonces se compraban terneros en los campos cercanos y se tenían 3/4 terneros por vaca y se juntaban dos veces al día. En el 2012 fue que empezamos con el ordeñe a máquina, ya con la quesería instalada, y desde esa fecha hasta ahora se sigue". Respecto a la pesca, "fueron años buenos para la pesca. Del 2000 al 2007 en Uruguay, y del 2009 al 2015 fue parejo, hubo buenos precios en los dos países". En abril de 2015 dejaron la pesca. "Hay pocos compradores de pescado y hay 68 familias como patrones de embarcaciones, a eso lo tenés que multiplicar por 3 o 4 que son los que trabajan por embarcación. A fines del 2014 vivían 277 pescadores artesanales en Villa Paranacito" (entrevistado). "Nosotros dejamos en el 2015 por no tener mercado. El 70\% de los pescadores acá en Paranacito se dedicó a otra cosa, madera, algunos están cuidando animales en estancias, que la inundación perjudicó mucho". "En julio del 2014 arrancamos con la comida antes de que se cortara lo de pescado. Arrancamos con un carrito más chico que nos prestamos y haciendo panchos y hamburguesas. No sabíamos ni hace hamburguesas. Habíamos arrancado en casa haciendo torta frita, empanadas, churros y hacíamos reparto, pedidos. La idea era abrir los fines de semana pero nos salía más caro así el impuesto municipal. Hoy hace 3 años que estamos, y vendemos hasta pasta. En invierno hacemos buseca, guisos, nos adaptamos a la gente del pueblo, al turismo".

estuve hasta los 80 , con la actividad forestal. Después de los 80 nosotros nos volcamos un poco más a la parte del comercio, sin llegar a abandonar del todo porque siempre algo de madera tenemos. El entrevistado además participó de la vida política de la comunidad. . "Yo participé en política, estuve en la actividad pública, en las dos primeras intendencias de la democracia como concejal, secretario de gobierno y en una etapa fui diputado provincial. Cuando volví, volví pobrísimo. Eran otras épocas" (entrevistado). "Recibimos la intendencia arriba de un barco porque estaba recién creada y estaba la creciente. La intendencia no tenía ni donde funcionar. Éramos nosotros, un par de palas y unas carretillas". El entrevistado destaca la pasión que sentían por e trabajo en la comunidad, cómo trabajaban juntos todos los políticos más allá de las banderas políticas. "Era como la comisión de un club". Luego de la política comenzaron con la actividad gastonómica. "Del 96 al 2001 tuvimos dos parrillas en la ruta. Siempre me gustó la parte gastronómica. Ahí agarramos una empresa en la ruta y le dábamos de comer a Pentamar, a 100 por día". "Nosotros vivíamos acá, teníamos el predio, a esto se lo compré a un hermano que en la creciente del 83 se acobardó y se fue. Teníamos la casa que después ampliamos, hace 2 años" (entrevistado)."En ese momento teníamos la concesión del Club Isleño" (entrevistada). "Teníamos la concesión, hacíamos servicios de catering ahí que es una actividad que todavía tenemos. Hace unos días hicimos un cumpleaños de 160 personas, después uno de 100 y pico, el sábado tenemos otro de 220, después uno de 300" (entrevistado). El fuerte del turismo arrancó en el 2005. "Empezamos a hacer los bungalows a fines de los 90 . Acá abajo que era un galpón hicimos el primer bungalow. "El turismo surge como una cosa aleatoria a lo que teníamos. Arrancamos trabajando fuerte en el 2005 cuando 
todo bien y en el 98 vino un agua peor que esta (2016), todavía más meses que esta. Todo lo que habíamos empezado.... Subimos todo, teníamos poquito, el agua pasó la altura de la toma de la luz. Cortamos todo y nos quedamos en la isla también inundados.... Allá bajó antes que acá, primero acomodamos allá y después acá. El parque había quedado mal, habíamos plantado un montón de árboles que se secaron. Fue muy deprimente, pero bueno, arrancamos de nuevo. Fue un golpe duro porque recién estábamos arrancando. Después hicimos el quincho, otra cabaña más, parrillas en alto..." (entrevistada). Hace algunos años comenzaron a incorporar la ganadería, primero para limpiar los campos forestados, en un sistema silvopastoril.

Actividad forestal en retraimiento:

"Forestadores quedan muy pocos, la madera no vale mucho. Los valores los fija papel prensa, se han fundido la mayoría de los aserraderos. Vino toda una consecuencia lógica de progreso, se reemplazó la madera por el plástico". "Es su actividad, le gusta mucho. La semana pasado recorrimos la quinta y ya me dijo que no va a volver a plantar, son ciclos de 10 años si todo va bien, para tener una madera de corte, pero una creciente así te seca, te impide que lleguen a desarrollarse. No tiene ganas de seguir, aparte por la edad, ya tenemos más de 50 . Esta forestación se va a seguir cuidando, lo que se pueda cortar se va a cortar pero se requiere mucha inversión para plantar" (entrevistada). La forestación les implica una gran inversión que no les genera tanta rentabilidad. Está asociada a la tradición. "Nosotros plantábamos 20 ha y al año lográbamos 18. Todo el tiempo era invertir invertir y no lográs. Los ciclos del agua de las

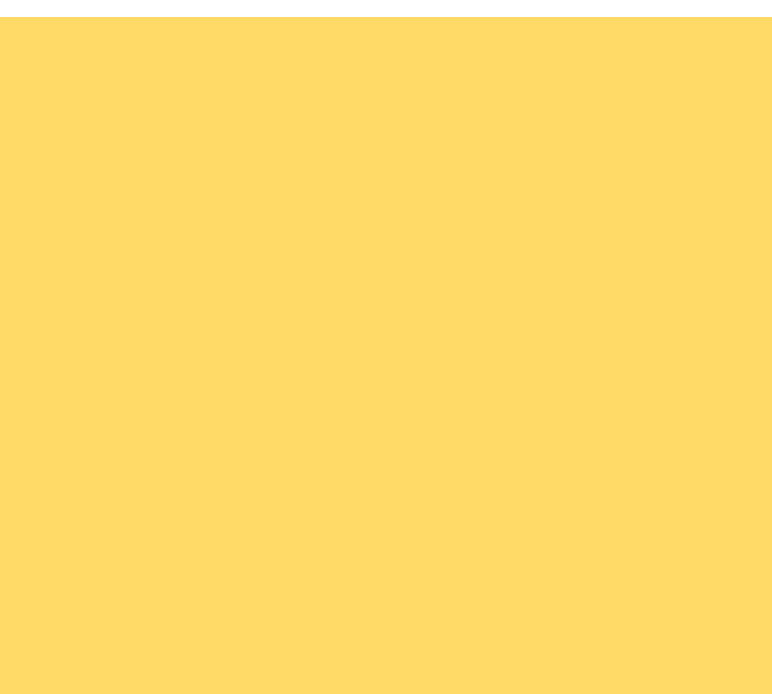
capitalizandose pero a través de la compra de insumos, de mercadería que es su forma de ahorrar y lo que les da más tranquilidad pensando en el futuro. "Para mí el turismo no va a parar de crecer, por lo que ando viendo año a año hay cada vez más gente de afuera en el río. Y al pescador eso le viene en contra porque el desarrollo del turismo genera mucho movimiento en el río, mucho alboroto y el pescado no está tranquilos" (entrevistado). "Invertir más en esto no creo, esto nos salió mucha guita más lo que hay en casa de infraestructura (freezer, heladera). Uno iene que tener mucha mercadería" (entrevistado) "Si seguís invirtiendo acá pasas a otro nivel, tenés que poner más gente, ya después te estás obligando a trabajar con un presupuesto fijo que te armaste. No da para complicarse tanto" (entrevistado). "Yo la tengo clara de que de acá en adelante uno va a trabajar más que menos, por Vos tenés un gran porcentaje de gente que antes empezamos con un bungalow. Alquilábamos esta casa y nos íbamos a vivir a Villa Paranacito, teníamos la casa paterna de ella. Después yo venía y algunos días me encontraba con gente acampando acá y les decía amablemente que no era camping, pero venían por el lugar tan lindo. En una creciente, como la casa tenía agua, empezamos a alquilar para camping con un baño abajo, para pasar el día. Después sí vimos que el camping era un buen servicio y sirve también. Lo único, no es derivable, tenés que estar mucho encima". "Hace más de 10 años que tenemos la tienda, antes de eso yo era ama de casa"(entrevistada).

Al día de hoy la pareja trabaja intensamente en las tres actividades que requieren su presencia y mano de obra: la tienda, el turismo y el servicio de catering. Pero el límite temporal de esta organización es "hasta que la hija termine de estudiar en La Plata".. Apuestan al turismo. A futuro, aparentemente la idea es dejar la tienda. Respecto a lo productivo, "la idea no es seguir plantando árboles". "Dentro de la actividad productiva yo estoy más cerca de irme a la parte ganadera que a la forestal, si tendría que salir para eso. Antiguamente en casa tenían vacas, pero porque tenía otra explicación, era por los fuegos. Las quintas estaban forestadas $1000 \mathrm{~m}$ desde la costa, y en e fondo había albardones, que son la parte más alta. En esos albardones se tenían vacas porque adonde hay vacas está limpio. A vos te permitía que si alguien prendía fuego no se te metía el fuego en la parte forestada. Y la ganadería a partir de las lecheras que también servían. Si cambiaran las políticas de gobierno, volvería a hacer frutales. "Yo creo que esas unidades económicas que no sirven para la 
crecientes se fueron acortando, cada vez la salía mucho más lejos a gastar plata, hoy salen forestación, hoy si esto cambiara y hubiera coherencia tenemos más cerca. Y después la edad. Uno es más cerca" (entrevistado). "Y además hay que en algunas políticas se podría volver al tema de las mayor. Cuando uno es joven todo te parece que hacer las cosas bien para vender, trabajar con todo lo podés revertir. Cuando te vas poniendo buena calidad, ser muy higiénico, muy prolijo. viejo, vas cambiando" (entrevistado). "Nosotros, Mucha gente de afuera nos recalca eso, que la idea de la vida antes era forestar. No somos muy prolijos" (entrevistado) En pesca no pensábamos otra cosa y después te vas dando tienen pensado continuar a corto plazo al cuenta que con eso no lográs. Si vos no vivís de menos la pareja. Cuentan con el capital, que no eso es distinto porque vos decís dentro de 12 quieren vender, para una posible integración años voy a cosechar lo que plantás hoy" de miembros de la familia. "Están las (entrevistado). "La forestación está más embarcaciones, está todo, y está un hermano de relacionada a la tradición que a la inversión" ella y mi sobrino. No lo quisimos vender porque no (hijo). Piensan apostar a la ganadería como me armo nunca más de eso. Una de las alternativa de diversificación. "Pensamos embarcaciones vale 500 mil pesos, y si le echas algo ganadero, probar con eso, hay que ver si las herramientas para salir a pescar te sale 120 mil funciona. Pensábamos hacer algo de cría, es pesos más. Si la vendíamos podríamos haber una prueba porque hay que empezar a terminado la casa, pero no me hago nunca más de aprender de vuelta" (entrevistado). "La idea es, esas cosas. Hoy se hace algo de flete, algún viaje teniendo el campo acá, no abandonarlo. Qué se de pesca, mi sobrino viene todos los días a la puede puede producir para aprovecharlo escuela... es mejor que el motor esté andando y porque es una zona endicada, que es una inversión muy grande, y ya a las crecientes chicas, los repuntes, ya con eso tenemos con qué atajarlos" (hijo). "Tampoco es que abordamos las actividades de forma brusca. No decimos vamos a hacer ganadería y compramos 500 madres. Siempre es de a permisos. No podés hacer las dos cosas" poquito y nos vamos repartiendo con otras (entrevistado). Además, el entrevistado manifesto cosas y siempre organizándonos y viendo cómo no gustarle la pesca deportiva, con caña.

marcha" (hijo). "Siempre con el esquema de tener varias actividades diferentes, cosa de que uno sabe si falla algo, uno tiene de donde sostenerse, siempre hay una salida laboral aunque falle la otra" (hijo). Para la ganadería van invirtiendo de a poco, pero lo ven "como una forma de ahorro" (hijo). Tienen 40 animales y "compramos 40 más, van 20 en enero, 20 en abril y así vamos a seguir despacito a ver qué pasa" (entrevistado). Respecto a las actividades comunitarias que desarrolla la

frutas, con el manejo de aguas y con los diques. 20 ha de frutas es una cosa diferente a 20 ha de forestación". "Yo creo que hay bisagras y estas son bisagras en la historia. Ahora están llegando los caminos adentro de la isla, las balsas, entonces por ejemplo en una isla como la 9 que yo tengo el lugar que me permitió e loteo, te permite que salir con un camión y eso te posibilitaría hacer otro tipo de actividades. No piensan diversificar las propuestas de turismo. "A mí me gusta la gastronomía pero cada cosa que le agregás a la actividad es una tortura, es más tiempo y estamos solos. Es complicado sumarle algo" (entrevistado). E entrevistado cree en el Delta y cree en el turismo. "Villa Paranacito ha crecido turísticamente, hay mucha oferta de bungalows, hay quien habilitó la costa e hizo un bungalow. Hoy está informal pero el isleño no abandonó la isla, que ya es bueno. Y le vio la veta a quedarse y hacer algo, ahí es útil y tienen \begin{tabular}{ll|l} 
no parado" (entrevistado). Se les consultó si les & fundamentalmente la dignidad de decir lo que hago, lo \\
interesaba hacer otro tipo de actividad & hago por mí." "Yo soy un optimista, el delta tiene futuro,
\end{tabular} \begin{tabular}{ll|l} 
no parado" (entrevistado). Se les consultó si les & fundamentalmente la dignidad de decir lo que hago, lo \\
interesaba hacer otro tipo de actividad & hago por mí." "Yo soy un optimista, el delta tiene futuro,
\end{tabular} vinculado al turismo y no se sienten tiene futuro turístico, hablan de una conexión con motivados. "Las salidas de pesca están muy Nueva Palmira que le va a dar un manijazo grande" controladas, tenés que abrir como otra empresa y (entrevistado). No pensaron en irse pero ella manifiesta ciertas dudas ahora que "están solos" y que la creciente afectó tanto. "Dentro de unos años pienso a lo mejor en comprar alguna casa o departamento en Gualeguaychú, cosa de si viene el agua ella se pueda instalar ahí. A nosotros no nos sorprenden las crecientes pero aun con toda la experiencia no pensábamos que esta iba a ser tan grande, nos comimos el garrón. Yo siempre soy optimista de que vamos a andar mejor. Ella se irá a alguna casa o con la hija hasta que baje el agua" (entrevistado). Tienen una reserva de capital con unos lotes para vender en las hectáreas de la isla Le quedarían $13 / 14$ lotes de $500 \mathrm{~m} 2$. Tienen el proyecto para hacer otro loteo a futuro en el predio de 


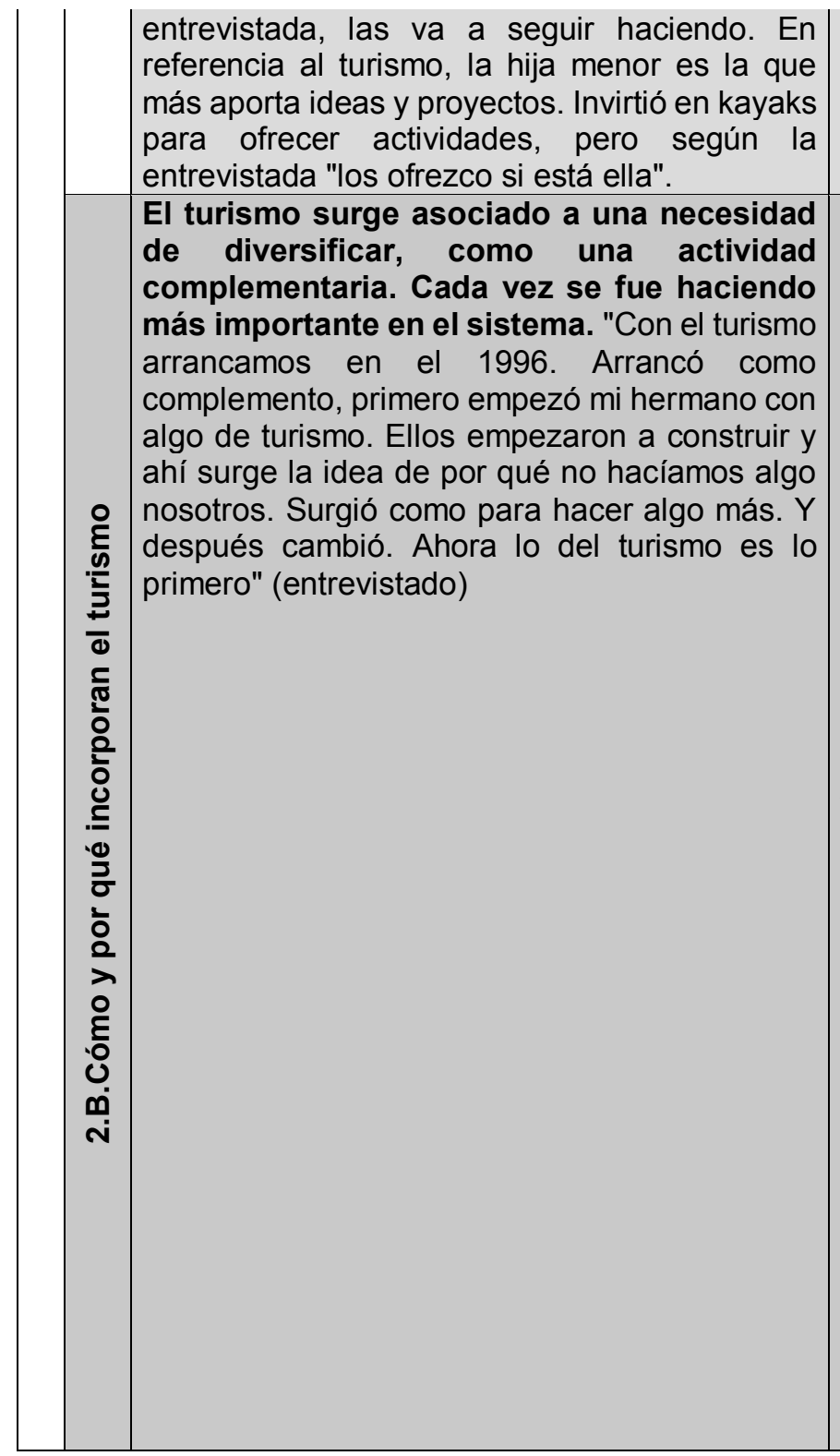

11 ha lindero al complejo, "un canal central navegable y terrenos con salida a ese canal" (entrevistado)

Incorporan el turismo de la mano de la gastronomía, para complementar los ingresos de la pesca, pero luego se convirtió en su actividad central. "Como la pesca es fuerte en verano, en invierno nos quedábamos medio pelados. Todo el peso que se juntaba en verano era para sobrevivir en invierno. O bien te endeudabas y salías a flote en verano, así que había que hacer algo en invierno cuando no había pesca" (entrevistada). "No había mucha opción" (entrevistada). "Lo que saldría para hacer se iba a hacer. Yo tenía la opción de volverme a Uruguay a seguir con el campo, pero elegí la familia, no iba a volverme" (entrevistado). El cambio de la actividad pesquera al turismo les da más estabilidad y tranquilidad desde lo económico y es menos riesgoso "porque eso es todos los días y algo entra. Con la actividad pesquera dependes mucho del clima, hoy podés estar sacando mucho pescado pero se levanta un viento y tenés que parar, te podés ir a pique en el río. Esos son los riesgos que tenés en el río".
"El turismo es un complemento, no es para todos, no todos tienen la vocación del servicio turístico yo tengo la convicción de que es el futuro de la zona..." (entrevistado).

El turismo surge como una actividad complementaria a la que desarrollaban. EI entrevistado tenía la visión de que era una actividad con futuro. "El turismo fue una cosa paso a paso, incipiente como una cosa aleatoria a lo que hacíamos". "A mí siempre me gustó, siempre tuve la idea del turismo, primero porque a mí me gusta lo social, segundo porque la venía venir. Ya cuando estaba en el municipio, dábamos una mano a gente porque yo decía que el que pudiera brindar una pieza, un baño y algo de costa podía tener un ingreso extra que le permitirá quedarse. Yo les decía, vos hacelo que en algún momento se va a dar..." "Vos te encontrabas de repente que esa actividad decaída de la forestación - la futa, y te encontrabas en una coyuntura que no sabías que hacer y que posiblemente tenías que migra unar. El turismo, esto te daba una esperanza". "Tenía la visión de que era una actividad que podía ayudar, yo era el loco del turismo. Visión de... a qué nos quedamos? El tema era a qué nos quedamos, y yo vi que esto podía ser" (entrevistado). La incorporación del turismo además obedece a la caída de las otras actividades. "Hoy con $20 / 30$ ha no podés vivir, la madera te puede ayudar pero no vivís. Los precios de la madera no son buenos, hoy a un productor forestal no le quedan ni $\$ 500$ por una tonelada de madera" (entrevistado). La cercanía a Buenos Aires para el entrevistado es un punto a favor para el desarrollo del turismo. "Nosotros tenemos mercado de 13/14 millones de personas a 2 horas. $Y$ creo que no es 


\begin{tabular}{|c|c|c|c|c|}
\hline & & & & $\begin{array}{l}\text { menor lo que le podemos ofrecer si les damos } \\
\text { infraestructura y servicios. Alguien que sale a las } 6 \text { de } \\
\text { Buenos Aires, a las } 8,8: 30 \text { ya está acá. El ámbito de } \\
\text { tranquilidad, de verde y de cercanía a nosotros nos da } \\
\text { una ventaja" (entrevistado). }\end{array}$ \\
\hline 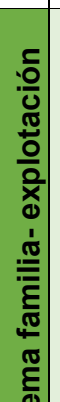 & 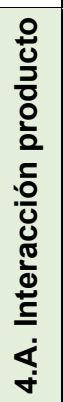 & $\begin{array}{l}\text { Si bien la vinculación más importante entre las } \\
\text { actividades es la económica, su } \\
\text { complementariedad, se vislumbra el uso de las } \\
\text { propias maderas para la construcción de decks } \\
\text { y estructuras dentro del predio del turismo. "El } \\
\text { hace sus propias tablas. Tratamos de } \\
\text { autoproveernos de esas cosas" (entrevistada). }\end{array}$ & $\begin{array}{l}\text { No hay integración de la actividad } \\
\text { gastronómica/turística con el resto de las } \\
\text { actividades, no se utilizan insumos de otras } \\
\text { actividades en ésta. Puede verse una mayor } \\
\text { integración en la actividad tambera/ quesera en } \\
\text { Uruguay pero no guarda relación tampoco con las } \\
\text { desarrolladas en Argentina. }\end{array}$ & $\begin{array}{l}\text { No hay integración de productos de las diversas } \\
\text { actividades que desarrolla la familia. }\end{array}$ \\
\hline 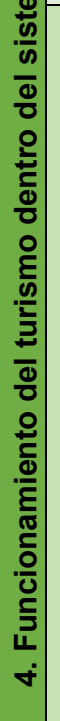 & 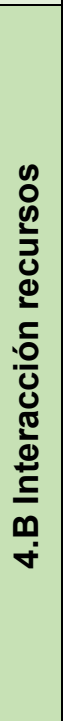 & $\begin{array}{l}\text { En este caso, la fuerza del trabajo es familiar, } \\
\text { que se organiza para cumplimentar con las } \\
\text { tareas de las distintas actividades. Se ve un uso } \\
\text { compartido de las maquinarias que fueron } \\
\text { adquiridas para hacer mejoras en el campo y } \\
\text { también se ofrecen como servicios a terceros. } \\
\text { Cuentan con un tractor, una guía cargadora, el } \\
\text { año pasado compró un aserradero móvil. } \\
\text { "Cuando uno pudo decir tengo para comer, } \\
\text { entonces invertí en maquinarias". Con esos } \\
\text { recursos que fueron utilizados primeramente } \\
\text { para mejorar los campos propios, hacen } \\
\text { trabajos de desmonte, canales, desagües, } \\
\text { diques, a terceros. En turismo, el capital social } \\
\text { de la familia, nacida y criada allí es puesto en } \\
\text { juego para que los visitantes conozcan de } \\
\text { manera genuina la esencia y estilo de vida de } \\
\text { los isleños y lugareños. }\end{array}$ & $\begin{array}{l}\text { Hoy el sistema contempla una sola actividad de } \\
\text { generación de ingresos que es la } \\
\text { gastronomía/turismo, esta ha ido desplazando la } \\
\text { actividad pesquera que fue durante años el } \\
\text { principal sostén de la familia. Durante un corto } \\
\text { plazo, la familia combinó ambas actividades pero } \\
\text { luego la abandonaron para dedicarse a la actual. }\end{array}$ & $\begin{array}{l}\text { Cómo se movilizan los recursos dentro de este } \\
\text { sistema. En referencia a lo espacial, hay dos predios y } \\
\text { en estos se generan la actividad turística, la venta de } \\
\text { lotes, lo que queda de la actividad forestal y lo que se } \\
\text { arrenda para ganadería. Como no están plantando } \\
\text { árboles para seguir con la actividad forestal se da un } \\
\text { complemento entre ésta y la ganadería, en término de } \\
\text { uso de recursos. La pareja es la base de todo el } \\
\text { sistema, más la contratación de recursos para tareas } \\
\text { específicas en momentos concretos. La única } \\
\text { empleada fija es la que está en la tienda de ropa. Hoy } \\
\text { sostienen estas actividades gestionando sus tiempos, } \\
\text { recursos y tomando decisiones que les permitan seguir } \\
\text { combinando las actividades para obtener el ingreso } \\
\text { necesario que sustente su vida y sobre todo garantice } \\
\text { el estudio de la hija menor. }\end{array}$ \\
\hline
\end{tabular}


$\overline{\widetilde{\sigma}}$ En este caso la actividad forestal no se abandonó por un apego a las tradiciones, al patrimonio familiar, al saber que transmitieron los abuelos, que continuaron los padres, continúan los entrevistados y piensan continuar los hijos. También el turismo es un motor para poner en valor el patrimonio intangible que rodea al "ser isleño".

En la lógica de los productores el tema de las La familia supo aprovechar o adaptarse a un crecientes hace que estén por ejemplo momento de crisis en la actividad pesquera para previendo reservas, o pensando en mover generar otra actividad que genere ingresos en $\bar{\sigma}$ animales a la zona alta o moverlos a oro campo. Los ciclos de las crecientes condicionan los actividad forestal, y las diferentes inversiones el lugar como es el estilo food truck.

que se van realizando, además del ánimo de la familia y sus expectativas a futuro.

El turismo surge como una alternativa a la tienda, ya que está muy marcada la estacionalidad de ambas. Cuando hay actividad turística en alza, en el verano, bajan las ventas en la tienda, y viceversa, lo que permite concentrar los esfuerzos y organizar los tiempos familiares. En este sistema se ve cómo la visión del productor respecto al desarrollo de la actividad turística, sumado a la caída de la actividad forestal dados los precios de la madera hicieron que sumen el turismo a su sistema, actividad que hoy está fortalecida. Esta capacidad de anticipación del productor también se evidencia en la toma de decisión de lotear un predio en una isla a la que solo se podía acceder en lancha que gracias a las obras tiene acceso terrestre. La venta de estos lotes fue el capital para invertir en turismo y es una reserva para el futuro de la familia. 
- Hay un involucramiento en actividades relacionadas con la comunidad, que no generan ingresos pero que les otorga muchas satisfacciones personales y sentido político.

"Por ahí descuido las actividades propias por las

o que hago afuera. Me han reclamado mucho pero me da satisfacción. Cuando hay que trabajar, trabajo, pero por ahí descuido de mi actividad personal, por ahí me disperso pero siempre lo he hecho así y mal no me fue. Igual, creo que sirve, a la larga, para que todo el entorno crezca hay que ser así" (entrevistada). El esposo encuentra satisfacciones en lo

Con la forestación la familia expresó que no se puede vivir exclusivamente, fundamentalmente

por el bajo precio de la madera y porque las plantaciones están muy condicionadas por las crecientes. Por ello surge el turismo, como una actividad complementaria que hoy genera uno

\& de los ingresos más importantes y estables. "E turismo es un ingreso más seguro, más constante. Es un ingreso fijo, teniendo la estructura, uno lo tiene que hacer trabajar simplemente" (entrevistado). "Es constante porque la cercanía a Buenos Aires hace que casi todos los fines de semana haya turistas" (hijo). "De la madera no es una actividad de la cual se pudiese vivir exclusivamente" (entrevistado). "El servicio a terceros te permite la inversión. Lo que se gana se invierte en las dos actividades"(entrevistada). "Yo hago trabajos a terceros con las máquinas que tenemos, esa entrada también es importa. Eso y el turismo están más o menos equilibradas" (entrevistado)
La actividad gastronómica/ turismo genera gresos que permiten garantizar la vida de la familia, invertir en mercadería e insumos y a la vez es menos desgastante físicamente que la pesca.

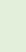

Hoy el sistema cuenta con un único ingreso pero:

mercadería, invierten en mercadería.

"El

\section{Todas las actividades aportan al ingreso del sistema familia-explotación. Estas se} complementan $y$ son indispensables en la actualidad. "A nosotros esta actividad nos ha aportado un grado de tranquilidad. No vivimos mal y aparte tenemos una chica estudiando, que todos estos aportes han significado poder hacerlo. Los del turismo, no exclusivamente el turismo, pero sí es un aporte importantísimo. Cuando una actividad no anda, la otra levanta. Pero nosotros tenemos una cultura del trabajo que no le decimos no a nada. Hacemos lo del catering también" (entrevistado). "Nos dimos cuenta de que todo marcha si todo funciona" (entrevistada). "Nosotros estamos armados para que todo funcione, cuando quedás con una pata menos tenés problemas, esa es la realidad" (entrevistado). 


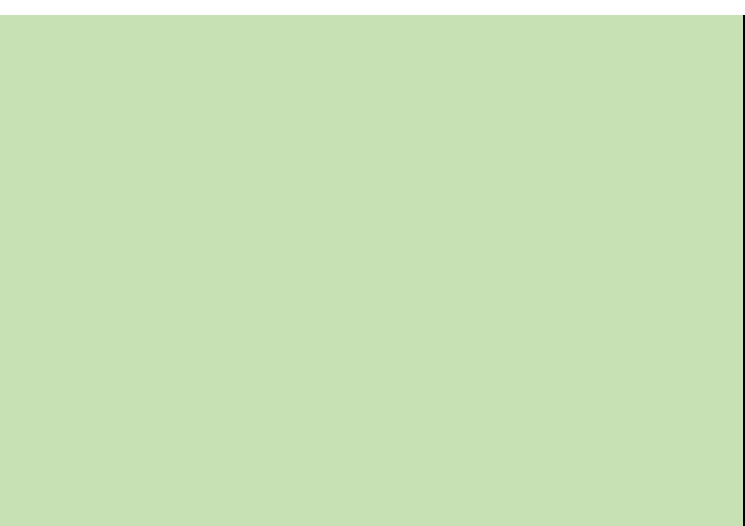

Ya tienen incorporado el turismo a sus tiempos y roles. "Es como que tenés asumido todo. Si tenés mucho trabajo, trabajás todos los días y tratas de cumplir con todas las cosas. Acá lo que tiene prioridad es el turismo porque la persona que viene quiere estar bien y encontrar todo en condiciones. Vos al campo si lo dejás un día no sería tan grave" (entrevistado). "Estamos bien organizados con las actividades. Acá vamos bien con todo pero tenés que trabajar todos los días, no es fácil decir corto, me voy... todos los días es hacer algo, es como la vida del campo" (entrevistado).

"El tema del turismo me gusta mucho. Te Aunque los entrevistados dicen que "el cuerpo permite mostrar lo que uno tiene, cómo uno nos pasa factura" respecto a las jornadas tan vive, las particularidades de la gente de la zona, a gente que eligió VP, que viene con una apertura porque justamente quiere absorber de las personas, de los locales. Uno también trata de hacerles un panorama para que se enamoren del lugar. A mí el trato con la gente me gusta mucho, yo disfruto, aparte la gente

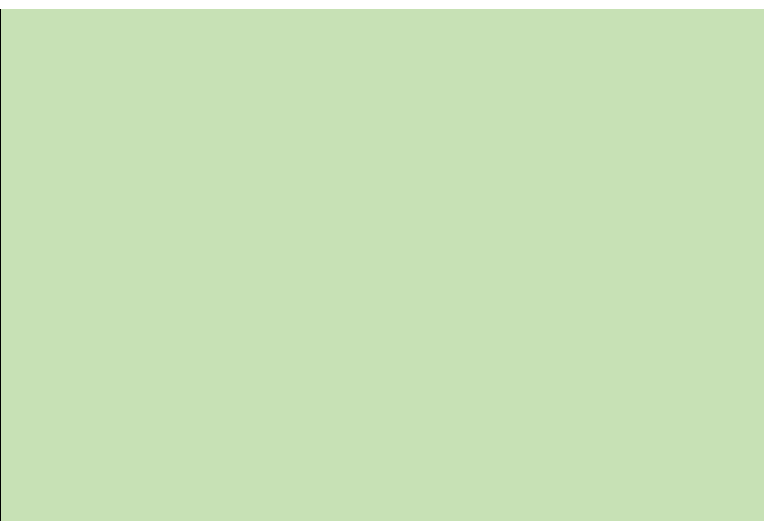

Las largas jornadas de trabajo tienen su impacto en un desgaste de la pareja y a nivel familiar. La necesidad de generar ingresos para seguir capitalizando el negocio y garantizar la vida de la familia hace que tengan que estar abiertos 12 o 13 horas. "El descuido a

los niños, a eso sí lo he notado mucho, de parte de los dos. Eso se nota más porque los niños crecen". intensas de trabajo, nada se equipara en agotador y riesgoso a la tarea de la pesca en e río. El cambio pasa por una mejora en la calidad de vida. "Es mucho más sacrificada la vida del pescador. Ahora estamos bastante más tranquilos, el río es complicado. Se gana bien cuando el pescado sale pero arriesgas mucho,
La dinámica económica en la zona del Delta ha condicionado dos de las actividades que otrora eran fundamentales en la zona como la actividad forestal y frutícola. La caída de estas actividades hizo movilizar la actividad turística, como alternativa para seguir viviendo en el delta. En el caso de este sistema, el turismo surge como complementaria a la del comercio. Esta familia sumamente emprendedora contaba con un capital que les dio la posibilidad de invertir en turismo y agregar esta actividad al sistema, además, esa característica los hizo transitar un camino de diversas actividades, siempre ligadas al lugar y a la actividad comercial.

El turismo por sí mismo no agrega complejidad, hay ciertos momentos de tensión por la sumatoria de actividades, que requieren mucha organización y tiempo. "Yo hoy por ejemplo estoy levantada desde las 5 de la mañana, para armar el bungalow, dejar las cmas hechas y a las 8 de la mañana voy a la tienda. $Y$ mañana ya empizo haciendo matambre para el servicio del sábado, ya estoy contando las servilletas, estoy contando lo que es mantelería, es mucho..." (entrevistada). "Pero él dice "un servicio de esos te deja..." (entrevistada). "Hacés un servicio grande y te embocás 1 mes de la tienda, y significa 2 o 3 meses de la nena estudiando"(entrevistado). Hoy esta combinación de actividades impacta sobre los tiempos y genera estrés, pero les permite "vivir bien" y sobre todo, les posibilita mantener la carrera universitaria de su hija menor en la ciudad de La Plata.

El turismo les da más tranquilidad desde el punto de vista económico, pero aun están trabajando intensamente para que el sistema funcione como un engranaje.

"A mí me gusta esto del turismo, lo que sí veo es que yo antes trabajaba menos que ahora. Porque el bungalows tiene que estar IMPECABLE, con todos los detalles, y yo ando limpiando junto con la que limpia" (entrevistada). También impacta sobre 
que viene es re buena, incluso uno traba incluso la vida" (entrevistado). "Nosotros amistades. Muchos de mis amigos actuales trabajábamos todos los días, todo el día, no había datan de los inicios del turismo mío, los chicos horariio, llegábamos a andar 21 horas en el río. Se jugaban juntos, van creciendo, se una situación laburaba todos los días, hacíamos ranchadas en particular porque acá es un turismo más cualquier lado, terminabas muerto... si te ponés a familiar".(entrevistada) "Tenés la gente que hablar de la pesca... te deja desecho, los riesgos viene una vez y no vuelve porque no le gustó. Y que hay" (entrevistado). "Yo iba y venía, pero no tenés la de siempre, porque a varios de los que tenés horario para volver, para comer, son horas estamos en turismo nos pasa esto de tener al sol, horas al frío, mojados..." (entrevistada). clientes que son los mismos, que se repiten" "Volver al río no, yo estoy desecho de la cintura (entrevistada). "No te cambia mucho la vida. La sufro un montón, no es fácil, cuando sos joven es vida en el campo puede ser más tranquila que una cosa, es muy castigador"(entrevistado). La acá. Acá muchas veces tenés que salir apurado entrevistada hace referencia al desgaste físico, a a hacer las cosas, en el campo no, en el campo los problemas de salud que trae aparejado el lo manejás distinto. No hay quien te apure, acá trabajo en el río. "la lama (el verdín del pescado) se rompe algo a las 10 de la noche y lo tenés te llaga todas las manos, te deja a carne viva las que arreglar" (entrevistado). manos.. la cintura, las rodillas, cortes en las proyección de algunos viajes, condicionados con temporadas altas del turismo en la isla. "Me gustaría ir a Ushuaia de acá a fin de año pero tenemos mucho turismo en esa época" (entrevistado) Prácticamente no tienen descanso pero hoy tienen un "enganche" de actividades y tiempos que les permiten generar los ingresos que les permiten vivir. Nosotros los domingos para salir de lo otro descansamos atendiendo turismo" (entrevistado) piernas". El turismo les aporta mayor interacción social, sobre todo a la mujer que solo hace 10 años vive en el pueblo. "El turismo es otra cosa, a veces llegan, les buscás conversación de alguna manera, intentás entablar una charla con ellos. La gente de afuera viene, se sienta y están acostumbrados a que los atiendan. Nosotros no tenemos mozos así que cocinamos hacemos de mozos... y esto de estar todo el tiempo amables, yo soy más cerrada pero después te acostumbrás. A la clientela uno ya la tiene as que ya la conocés, ya sabés, ya charlas" (entrevistada). "En mi caso, yo allá en el Uruguay, el $90 \%$ del queso que se producía ya en el 94 yo decía "lo bolicheaba", hacía comercio, 300 ventas al comercio, ahí tenía más contacto con la gente en ese sentido tenía más dialogo. En el caso de ella se tuvo más que hacer" (entrevistado). 


\begin{tabular}{|c|c|c|c|c|}
\hline 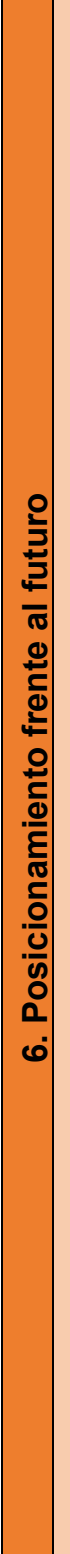 & 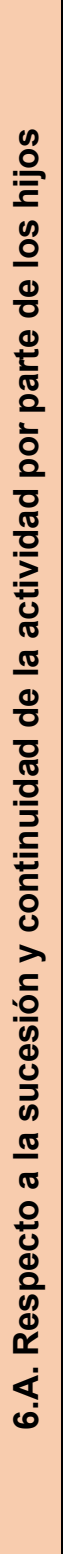 & $\begin{array}{l}\text { Los hijos están muy involucrados con las } \\
\text { actividades que realiza la familia y se evidencia } \\
\text { una clara continuidad por parte de los hijos. "El } \\
\text { agrónomo es el más entusiasta con el tema de } \\
\text { la forestación y la ganadería. Yo pienso que el } \\
\text { va a seguir con esto, a él es al que más le gusta } \\
\text { ir a Brazo Chico. La que hace turismo rural } \\
\text { estudió gastronomía y ahí metiéndose en eso } \\
\text { dijo voy a estudiar turismo rural, que es una } \\
\text { carrera bastante nueva. Su intención era ya } \\
\text { insertarse con el tema de las cabañas, venía } \\
\text { con muchas ideas. Ella dice que nosotros no } \\
\text { tenemos ninguna actividad, vamos a poner } \\
\text { bicicletas, canotaje... Ella me está diseñando } \\
\text { una web con cosas nuevas, me manda } \\
\text { proyectos. Mi otro hijo me está rediseñando el } \\
\text { parque porque se secó todo, es como empezar } \\
\text { de nuevo tratando de mejorar } \\
\text { todo"(entrevistada) "A mi hijo le gusta la } \\
\text { carpintería, les empezamos a comprar las } \\
\text { máquinas, en Bs As ya hizo un par de muebles } \\
\text { para vender y para las cabañas ha hecho } \\
\text { también". (entrevistada)El que estudió } \\
\text { ingeniería eléctrica suela con dejar de ser } \\
\text { empleado, dejar la empresa, inclusive la idea } \\
\text { del aserradero portátil fue de él. El piensa } \\
\text { volver, hacer algo tipo de mecanización" } \\
\text { (entrevistada). "Por el momento pensamos } \\
\text { quedarnos. A uno le gusta el lugar y tiene más } \\
\text { facilidades para trabajar acá, conocés más el } \\
\text { lugar por haberte criado, ya sabés como } \\
\text { manejarte" (hijo). "Uno intenta seguir con lo que } \\
\text { se venía haciendo, no perder las producciones } \\
\text { o lo que uno siempre aprendió a hacer de chico. } \\
\text { Pero viendo de incorporar, tanto mi hermano } \\
\text { como yo, ir haciendo algo de la actividad } \\
\text { privada en el ámbito profesional pero no como } \\
\text { actividad principal y no abandonar todo lo otro" } \\
\text { (hijo). }\end{array}$ & $\begin{array}{l}\text { Aunque no hay una referencia directa al futuro } \\
\text { vinculado a los hijos y las actividades de la familia, } \\
\text { todo indica que el hijo menor es el que demuestra } \\
\text { mayor empatía con las actividades productivas de } \\
\text { la familia. "La idea de la nena mayor es irse a } \\
\text { estudiar afuera. Y para trabajar el día de mañana } \\
\text { no sé tampoco. El nene tiene } 9 \text { años y es el que } \\
\text { está esperando terminar las clases para irse al } \\
\text { campo, allá a Uruguay" (entrevistado). "Son sus } \\
\text { vacaciones, el viernes termina las clases y } \\
\text { marcha, él se va para allá, la nena no" } \\
\text { (entrevistada). }\end{array}$ & $\begin{array}{l}\text { A los padres les gustaría que por ejemplo la hija más } \\
\text { chica que estudia farmacia pueda instalarse allí, en el } \\
\text { local adonde ahora tienen la tienda de ropa. Pero no } \\
\text { saben. "No sé si se va a venir porque le gusta la } \\
\text { investigación" (entrevistada). Uno de los hijos tiene su } \\
\text { comercio en el pueblo y todo apunta a que siga } \\
\text { viviendo allí. No hacen referencia directa a la sucesión } \\
\text { de las actividades. "Somos muy de pensar en ellos } \\
\text { nosotros y el gran debate de todo esto es que a veces } \\
\text { nos olvidamos de nosotros" (entrevistado). }\end{array}$ \\
\hline
\end{tabular}


El turismo rural y las transformaciones de los sistemas productivos familiares del corredor del Uruguay

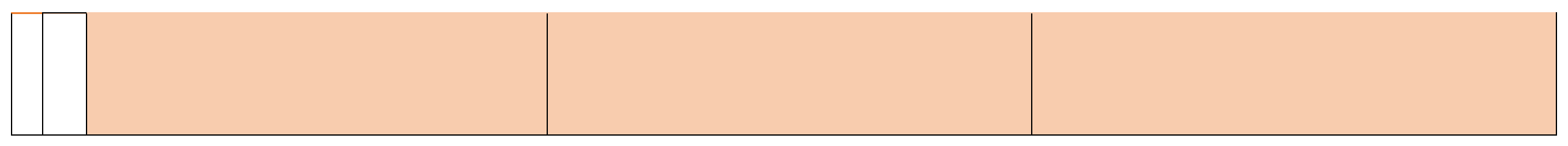




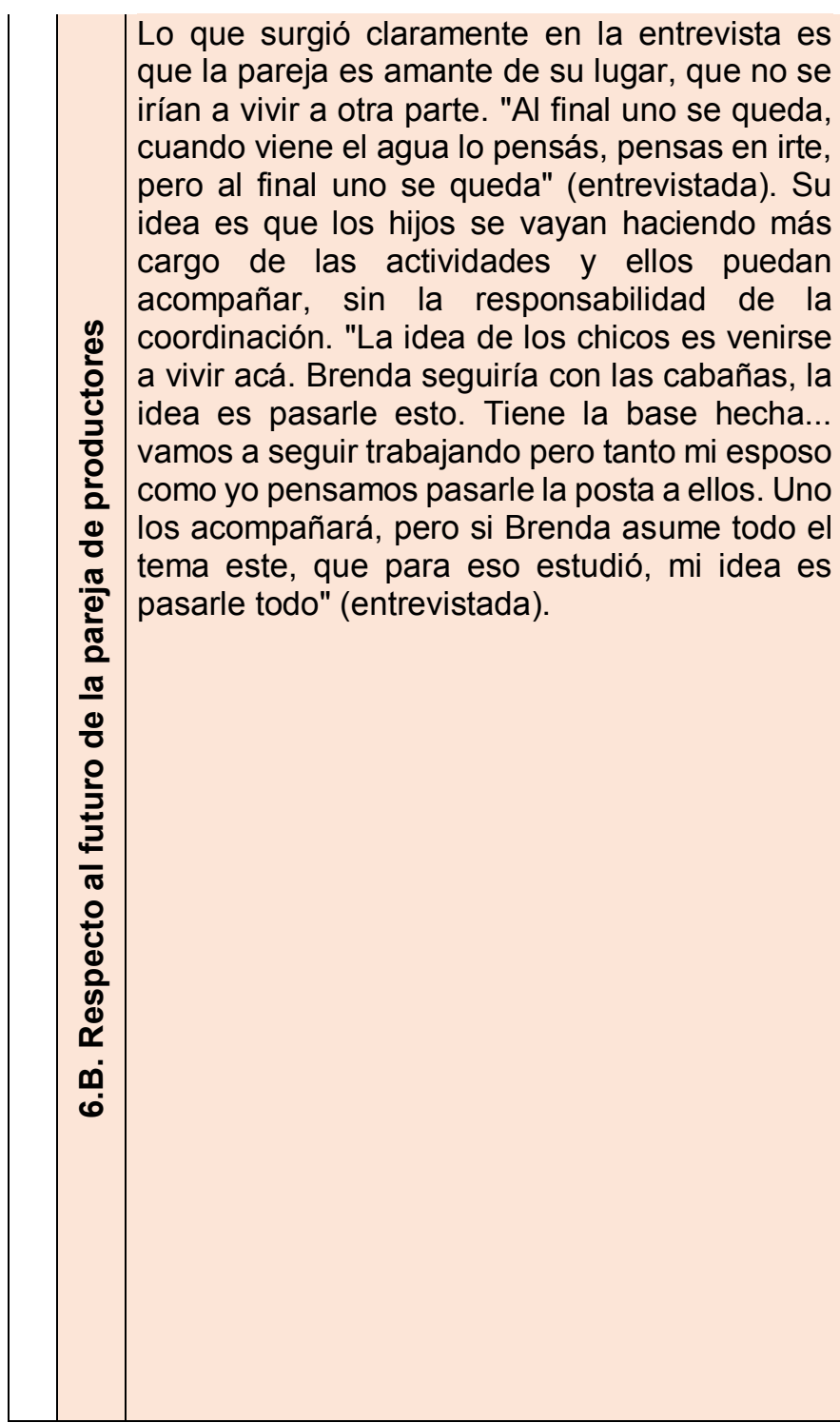
los acompañará, pero si Brenda asume todo el tema este, que para eso estudió, mi idea es pasarle todo" (entrevistada)

A futuro ellos se ven trabajando en la actividad gastronómica pero más tranquilos. "Esto pero (a) $\begin{array}{lll}\text { que la pareja es amante de su lugar, que no se } & \text { gastronómica pero más tranquilos. "Esto pero } \\ \text { iŕan a vivir a otra parte. "Al final uno se queda, } & \text { trabajarlo más tranqui porque nos desgasta mucho } \\ \text { cuando viene el agua lo pensás, pensas en irte, } & \text { y a veces conflictos en casa tenemos. Laburamos } \\ \text { pero al final uno se queda" (entrevistada). Su } & \text { tres años buenos, ahora tomarlo más tranqui. } \\ \text { idea es que los hijos se vayan haciendo más } & \text { Logramos armar esto. Y después trabajar un poco } \\ \text { cargo de las actividades y ellos puedan } & \text { más para disfrutar uno" (entrevistado). "Tener más } \\ \text { acompañar, sin la responsabilidad de la } & \text { momento de familia" (entrevistada). }\end{array}$

$\begin{array}{lll}\text { que la pareja es amante de su lugar, que no se } & \text { gastronómica pero más tranquilos. "Esto pero } \\ \text { iŕan a vivir a otra parte. "Al final uno se queda, } & \text { trabajarlo más tranqui porque nos desgasta mucho } \\ \text { cuando viene el agua lo pensás, pensas en irte, } & \text { y a veces conflictos en casa tenemos. Laburamos } \\ \text { pero al final uno se queda" (entrevistada). Su } & \text { tres años buenos, ahora tomarlo más tranqui. } \\ \text { idea es que los hijos se vayan haciendo más } & \text { Logramos armar esto. Y después trabajar un poco } \\ \text { cargo de las actividades y ellos puedan } & \text { más para disfrutar uno" (entrevistado). "Tener más } \\ \text { acompañar, sin la responsabilidad de la } & \text { momento de familia" (entrevistada). }\end{array}$

$\begin{array}{lll}\text { que la pareja es amante de su lugar, que no se } & \text { gastronómica pero más tranquilos. "Esto pero } \\ \text { iŕan a vivir a otra parte. "Al final uno se queda, } & \text { trabajarlo más tranqui porque nos desgasta mucho } \\ \text { cuando viene el agua lo pensás, pensas en irte, } & \text { y a veces conflictos en casa tenemos. Laburamos } \\ \text { pero al final uno se queda" (entrevistada). Su } & \text { tres años buenos, ahora tomarlo más tranqui. } \\ \text { idea es que los hijos se vayan haciendo más } & \text { Logramos armar esto. Y después trabajar un poco } \\ \text { cargo de las actividades y ellos puedan } & \text { más para disfrutar uno" (entrevistado). "Tener más } \\ \text { acompañar, sin la responsabilidad de la } & \text { momento de familia" (entrevistada). }\end{array}$

$\begin{array}{lll}\text { que la pareja es amante de su lugar, que no se } & \text { gastronómica pero más tranquilos. "Esto pero } \\ \text { iŕan a vivir a otra parte. "Al final uno se queda, } & \text { trabajarlo más tranqui porque nos desgasta mucho } \\ \text { cuando viene el agua lo pensás, pensas en irte, } & \text { y a veces conflictos en casa tenemos. Laburamos } \\ \text { pero al final uno se queda" (entrevistada). Su } & \text { tres años buenos, ahora tomarlo más tranqui. } \\ \text { idea es que los hijos se vayan haciendo más } & \text { Logramos armar esto. Y después trabajar un poco } \\ \text { cargo de las actividades y ellos puedan } & \text { más para disfrutar uno" (entrevistado). "Tener más } \\ \text { acompañar, sin la responsabilidad de la } & \text { momento de familia" (entrevistada). }\end{array}$

$\begin{array}{lll}\text { que la pareja es amante de su lugar, que no se } & \text { gastronómica pero más tranquilos. "Esto pero } \\ \text { irían a vivir a otra parte. "Al final uno se queda, } & \text { trabajarlo más tranqui porque nos desgasta mucho } \\ \text { cuando viene el agua lo pensás, pensas en irte, } & \text { y a veces conflictos en casa tenemos. Laburamos } \\ \text { pero al final uno se queda" (entrevistada). Su } & \text { tres años buenos, ahora tomarlo más tranqui. } \\ \text { idea es que los hijos se vayan haciendo más } & \text { Logramos armar esto. Y después trabajar un poco } \\ \text { cargo de las actividades y ellos puedan } & \text { más para disfrutar uno" (entrevistado). "Tener más } \\ \text { acompañar, sin la responsabilidad de la } & \text { momento de familia" (entrevistada). }\end{array}$

$\begin{array}{lll}\text { que la pareja es amante de su lugar, que no se } & \text { gastronómica pero más tranquilos. "Esto pero } \\ \text { iŕan a vivir a otra parte. "Al final uno se queda, } & \text { trabajarlo más tranqui porque nos desgasta mucho } \\ \text { cuando viene el agua lo pensás, pensas en irte, } & \text { y a veces conflictos en casa tenemos. Laburamos } \\ \text { pero al final uno se queda" (entrevistada). Su } & \text { tres años buenos, ahora tomarlo más tranqui. } \\ \text { idea es que los hijos se vayan haciendo más } & \text { Logramos armar esto. Y después trabajar un poco } \\ \text { cargo de las actividades y ellos puedan } & \text { más para disfrutar uno" (entrevistado). "Tener más } \\ \text { acompañar, sin la responsabilidad de la } & \text { momento de familia" (entrevistada). }\end{array}$ a vivir acá. Brenda seguiría con las cabañas, la idea es pasarle esto. Tiene la base hecha... vamos a seguir trabajando pero tanto mi esposo como yo pensamos pasarle la posta a ellos. Uno

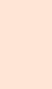

La idea de "jubilarse" a través del turismo está muy claro en este sistema. El entrevistado no duda respecto a seguir viviendo en el lugar y continuar con turismo. "Proyecta completar el complejo hasta hacerlo una actividad rentable que no dependa de otras para mantener a la familia. "Me gustaría hacer $4 / 5$ bungalows más, cosa de que casi con los mismos gastos por fin de semana tengas un ingreso que te permita en algún momento replegarte y vivir del turismo, más de jubilación". "Durante la semana podés estar más light, con un comercio tenés horarios, tenés que viajar". "Acá podemos poner pileta, algunos bungalows más o habitaciones con baño privado". "Si nos da la salud y enderezamos los patos con la venta de lotes en un tiempo vas a ver este complejos mucho más completo, con más bungalows, habitaciones con baño privado, con una pileta, tenemos algunas ideas... Yo te dije que me iba a jubilar acá..." (entrevistado). Yo soy un convencido de que no podemos irnos a otra parte. Acá nosotros sabemos vivir. Irnos a otro lado a hacer qué, es ir y tener que aprender. Y aprender cuesta años y errores, acá todas las macanas que nos teníamos que mandar ya nos la mandamos, es como que ya estás armado. Los proyectos que fracasas son los que abandonas, porque siempre tenés una posibilidad al menos, o te equivocás y lo corregís". (entrevistado). Ella demuestra amar el lugar pero que ha sufrido mucho con las crecientes, lo que la condiciona.

"Si vos me das a elegir yo no me muevo de acá... si me decís nos vamos unos días de vacaciones, yo le digo los días que vas dejame acá en el Sagastume pero sin pensar que tengo que ir a la tienda, sin pensar que tengo que viajar, pero no estar acá sentada, haciendo cosas. Soy feliz...". "Yo recién ahora... que empezás a quedarte sola... Después de que se fue el agua yo le decía, otra creciente no me quedo" (entrevistada). 


\section{Caso 12- EN EL CENTRO DE LA ESCENA}

Matrimonio de 55 años él y 48 ella con un hijo de 15 años. El entrevistado nació en Villa Paranacito, la mujer es de Gualeguaychú pero vive en allí hace 25 años en el pueblo. El fue productor ganadero hasta el año pasado. Tiene un campo en la islas de 200 ha y llegó a tener 500 vaquillonas. Hacía cría, recría y el novillo pesado (de 500/600 k) iba para exportación. Lo vendía a un frigorífico en Santa Fe en algún momento, después a un consignatario, una o dos veces llevé al mercado central.
Integró grupos cambio rural ganadero, trabajó junto a INTA en la resolución de algunas demandas que tenían en el territorio. Hizo una gran inversión para levantar una porción de terreno, "hice un cerro ahí, nunca tuve que sacar una vaca en creciente" (entrevistado). Tenía dos personas trabajando, no era empleados, "Ellos tienen su propia hacienda, eran propietarios de hacienda, yo les daba parcelas con la condición de que me cuiden los animales. TURISMO: son dueños de un hotel en el centro del pueblo, en la avenida principal que abren al público en el 2011 con 5 habitaciones. Lo fueron construyendo progresivamente hasta contar en la $\circlearrowleft$ actualidad con 24 habitaciones para 60 plazas. Además construyeron unos locales comerciales sobre el mismo terreno que alquilan. Hace un año le anexaron al hotel otra modalidad de alojamiento, 8 habitaciones de apart hotel, 4 de ellas son monoambientes. Cuentan con su vivida familiar y un local, donde históricamente funcionó la librería de la familia del entrevistado, que hace un año alquilan. Dejó definitivamente la ganadería con la última inundación del 2015/2016 y se dedica $\varangle$ exclusivamente al turismo. "Con la creciente del año pasado vendí todo (los animales). Lo que te satura no es el trabajo si es bienvenido, lo que me saturó a mí es que empecé a trabajar en el hotel, el hotel te lleva mucho tiempo y desatendía el campo. Y en el campo no estando yo, el personal no me rendía. Una cosa es cuando vas 3 veces por semana y cuando vas una vez cada 15 días, y yo no puedo ir más que eso. Y llegó la creciente, con un montón de problemáticas, de falencias..." (entrevistado). "Una cosa es cuando voy todas las semanas y sé que los animales están empotrados en un lugar y en otro y otra cosa cuando iba cada 15 días y los animales estaban desatendidos, vacas trancadas... Tuve muchas bajas de animales, muchos problemas económicos" (entrevistado). "Es que después de la crecientes y más de esta, cuesta mucho retomar las actividades dentro de la isla porque primero y principal todos quedamos muy noqueados. Invertir nuevamente hasta en pintar tu casa es complicado. Nosotros todavía hoy estamos pintando lo que quedó

\section{Caso 13- LA GRANDEZA DE LO SIMPLE}

Se trata de una pareja de alrededor de 60 años con 4 hijos adultos, que cada uno tiene su familia y actividad económica particular. Tienen 34,30 24 y 21 años. La pareja tiene dos actividades de generación de ingresos por un lado le trabaja en el hospital por la mañana y el camping en la isla. El hombre nació en Paranacito pero a los 11 años se van a vivir en Buenos Aires. Allá tenía un taller mecánico pero por estrés tuvo problemas de salud y decidieron volver a VP para mejorar su calidad de vida. Realizaron diversas actividades para generar ingresos hasta que en 1998 ingresa en el hospital. De su familia tenía unos campos y una casa en el pueblo. Él le compra las partes a sus hermanas, en una isla que antes estaba incomunicada vía terrestre. "Le compramos esto cuando nos vinimos para acá. Después surgió todo esto del cambio de la isla endicada. Antes era todo campos, uno solo podía venir en lancha" (entrevistado). Hace 3/4 años vendió unos lotes y con eso se capitalizó. Tienen 27 ha allí. En el 2011 comenzaron a trabajar en ese predio con un camping, en el que también ofrecen comidas en base al pescado que él mismo pesca allí. También cuentan con unas casa rodantes que también alquilan En una época se dedicó a la parte forestal. Plantaba 1 o 2 ha "como para tener". Vendía la madera a la cooperativa forestal. E padre del entrevistado era productor agropecuario. "Tenía plantaciones de sauces y álamos, cosecha de limones. Era forestal y frutal. Eran 30 y pico de ha producidas". Cuando volvió de Bs As "era un poco el parate de la madera. La forestación se tomaba como un ahorro. "Tenías 2 ha volteabas y tenías para comprar algo. Si necesitabas comprar algo te hacías de esa madera. En aquel momento no valía la pena comprar una motosierra, era muy cara. Contrataba a alguien". "Ahora casi no le queda nada ni tampoco hay mucho interés de comprar". 
del año pasado porque todavía no se secó... Te desanima" (entrevistado).

"Me llevaba mucho tiempo el hotel y desatendía la ganadería". Hace

1,2 años cerraron también la librería y alquilan el local. 
El hotel es un emprendimiento familiar. En la temporada alta, de verano cuentan con dos personas que la ayudan, fundamentalmente con la limpieza y prepara+E2ción de las habitaciones. En invierno no cuentan con empleados fijos. "No hay casi gente ni los fines de semana" aparte acá todo es caro, la luz, el agua..." (entrevistada). "Tenemos 3 empleados y perdemos plata" (entrevistado). "Hacemos todo nosotros. Estamos los dos acá pero no estamos todo el día, lo tenemos siempre abierto pero no está abierta la recepción, nos manejamos por teléfono" (entrevistado). La entrevistada se dedica a la limpieza. La responsabilidad y el control de todo es de ella. "Si bien no lo hace todo ella, tiene un gran porcentaje de responsabilidad, está detrás. Es muy puntillosa con esas cosas" (entrevistado). El entrevistado comenta que se dedica no sólo a la atención al público sino al mantenimiento, a arreglar distintos elementos que se rompen o no funcionan adecuadamente. "Todo lo hacemos nosotros, lo hacemos también como hobbies, no es que lo hacemos como una obligación, nos gusta". "En

\& cualquier lugar del mundo, el dueño del hotel levanta el teléfono para llamar a un plomero, a un gasista, a la lavandería, pero acá todo lo hago yo, yo soy el que atajo, tiro al centro y si puedo hago el gol, pero no es 구 porque quiero hacerlo si no porque es muy difícil no hacerlo". Se refiere a la falta de gente capacitada. "Tenés que estar atento a todas estas cosas y te absorben mucho tiempo, incluso hasta el día de hoy hay cosas que las estamos haciendo nosotros porque no da para decir voy a comprar el mobiliario de 10 habitaciones... no, yo hago los respaldares de la cama, ella hace algún cuadrito..." (entrevistado). A pesar de que ellos tienen que hacer todo, no están todo el tiempo en el hotel, se organizan para tener algunas habitaciones listas para alquilar pero es antes de los fines de semana largos o en temporada de verano cuando hay más movimiento. "Acá no tenemos ni vamos a tener nunca una obligación de trabajar, lo que sí tenemos es solucionar los problemas que van apareciendo. Ahora por ejemplo que viene el fin de semana largo, mañana, jueves y viernes, nos tomamos el trabajo de venir y pegar una repasada general porque sabemos que el hotel va a trabajar. Pero durante la semana tenemos disponibles de 2 a 4 habitaciones porque ni siquiera las alquilamos. El mantenimiento del hotel se maneja así. No tenemos obligación de venir todos los días porque no tenemos gente todos los días pero a su vez tenés que estar atento, yo no puedo decir voy a juntar animales al campos el sábado porque me vino gente y tengo que estar
Trabajan solo la pareja. El entrevistado continúa trabajando en el hospital de 7 a 13 hs. En ese momento queda la esposa en el camping. Vuelve a las 13 hs y se queda hasta la noche. A veces duermen allí mismo ya que tienen una vivienda allí y una en el pueblo. 
acá." (entrevistado). Competencias adquiridas y procesos de aprendizajes. "A las personas que tenemos trabajando les vamos nosotros enseñando cómo se hace. Lo que hemos aprendido lo hemos aprendido porque hemos salido mucho de paso, ido a lugares que sabemos que hacen bien las cosas" (entrevistada). "Salimos 5/6 veces de viaje por año, vamos aplicando nuestra experiencia acá" (entrevistado).

E El hotel se construyó gracias a los aportes de la ganadería. Hoy cuentan \& con un hotel totalmente equipado. Han construido además 4 locales तs comerciales.

Las crecientes condicionan las actividades productivas y la vida social de las familias. "Lo que pasa en las crecientes es gravísimo. El Estado tendría que apoyar... hay gente que no sabe que vendiendo 10 novillos podés hacer un cerro y te olvidás para toda la vida" (entrevistado). "Te \& mundo. Algunos vienen de un momento a otro como los terremotos, los ciclones, esos te generan pérdidas de vidas, te genera una pérdida económica... pero vos no tenías la anterior... El proceso de concientización de tal o cual fenómeno te vino de un momento para el otro. En el caso nuestro ya sabemos que va a haber creciente, entonces en el proceso es muy grande el desánimo, el malestar, en un proceso de creciente que son 6, 8 meses. No dormimos cuando hay sudestada. Psicológicamente te trabaja de una forma muy distinta" (entrevistado).

El turismo tiene una marcada estacionalidad, lo que hace que haya momentos de suficiente ingresos y otros que no alcanzan. Deciden invertir en la construcción de unos galpones para alquilar y en unos

\& departamentos para alquiler turístico, pensando en los costos fijos. "Lo

que hicimos fueron locales que están alquilados fijos y hoy hemos tomado la modalidad por ejemplo de a alguna maestra alquilarle una habitación

fija también. Esto implica una economía más estable, más rentable"

u (entrevistado)."Hay meses que con el turismo no sacamos el alquiler de un local y hay meses que sacamos 5 meses del alquiler de local. Es muy relativo. En este momento el $20 \%$ es turismo, la mayoría del ingreso es de alquileres fijos.E12
Cuenta con un campo de 27 ha. En este se ubica el camping, que no tiene una importante infraestructura pero sí un entorno natural único, con salida al río, una frondosa arboleda, vegetación diversa.

Tienen una huerta con algunos vegetales que utilizan para preparar las comidas que ofrecen en el camping. Cuentan con algunos árboles de nuez pecán que venden allí mismo también.

Tiene dos actividades que le generan ingresos, el hospital y el turismo. No mencionó el entrevistado el porcentaje de ingresos pero se entiende que como empleado tiene un sueldo fijo. Además cuenta con un amplio terreno en la isla, de los cuales vendió $3 / 4$ terrenos con los que se fue capitalizando y mejoró el predio del camping. 


\begin{tabular}{|c|c|c|}
\hline 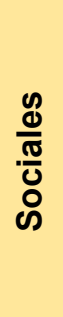 & $\begin{array}{l}\text { El entrevistado ha integrado redes técnicas, grupos asociativos y ha sido } \\
\text { una referencia en ganadería en la zona. "Viene gente y me pregunta qué } \\
\text { hice con las vacas y yo les digo que no las saqué" (por la creciente la } \\
\text { construcción del cerro donde colocó el corral y evita el traslado de los } \\
\text { animales). Destaca que de los productores que integraba el grupo, él era } \\
\text { el menor y que aprendía mucho, pero también era innovador. }\end{array}$ & $\begin{array}{l}\text { El entrevistado siente reconocimiento y afecto de los visitantes. La } \\
\text { gente que viene vuelve todo el tiempo. Me han regalado una cuchilla } \\
\text { especialmente grabada con mi nombre, un cliente que viene hace } 3 / 4 \\
\text { años. Y como esos un montón de cosas que podés decir es el } \\
\text { agradecimiento por lo uno hace". Se genera un vínculo de familiaridad } \\
\text { con los clientes. "Tenés contacto permanentemente con la gente que } \\
\text { viene. A veces se reúnen } 4 / 5 \text { familias y comemos todos juntos. Cada uno } \\
\text { pone un pedazo de carne..." }\end{array}$ \\
\hline 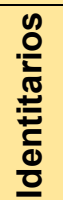 & $\begin{array}{l}\text { Lo más destacable en este aspecto es el sentimiento de arraigo, de } \\
\text { profundo amor por su lugar. } \\
\text { "Yo soy amante de Villa Paranacito y me quiero quedar a morir acá" } \\
\text { (Entrevistado). }\end{array}$ & $\begin{array}{l}\text { El entrevistado demuestra ser un hombre simple, sencillo, que priorizó la } \\
\text { tranquilidad y la salud y que vive feliz en VP. Hizo un cambio de vida que } \\
\text { él mismo denomina "brusco" al dejar Bs As para venir a VP. Su historia } \\
\text { familiar está allí. }\end{array}$ \\
\hline 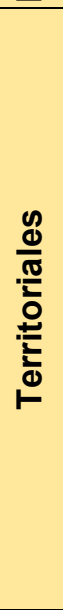 & $\begin{array}{l}\text { Es muy crítico con el pueblo y la dinámica turística. "Yo estoy } \\
\text { decepcionado con la forma de hacer turismo en VP. Nos faltan } \\
\text { capacidades para atender a cierto nivel de gente que necesita servicios, } \\
\text { y para eso tiene que haber ayuda, no solo del estado. No es como una } \\
\text { ciudad que tenés } 70 \text { tenedores y al otro día ya lo vendés porque hay } \\
\text { mucha gente. Acá no, de lunes a viernes no vendes nada. El problema } \\
\text { que tenemos es el servicio, vos venís hoy y no tenés lugar para comer, } \\
\text { hay un solo carrito". "El pueblo tiene que pensar en una economía que le } \\
\text { sume al pueblo. Yo creo que al pueblo no le sirve la modalidad de } \\
\text { camping. Hoy tenés un turismo y operadores muy básicos". "La dirección } \\
\text { de turismo tiene un wapp donde se maneja toda la información pero no le } \\
\text { doy bolilla, no tengo mucha relación pero no nos sirve. Segunda } \\
\text { residencia para gente de Bs As. "Se han vendido muchos terrenos a } \\
\text { gente de Bs As que tienen su casa de fin de semana acá, es tipo un barrio } \\
\text { privado pero abierto" (entrevistado). }\end{array}$ & \\
\hline
\end{tabular}


El entrevistado es nacido en la localidad. Hijo de inmigrantes italianos por línea paterna y de alemanes por parte de la madre. Los abuelos maternos que llegaron a la zona escapando de la primer guerra mundial tenían una pensión. "En esa época VP era un lugar de posta para para el ingreso a la provincia de Entre Ríos o a la Mesopotamia porque no estaba el acceso terrestre, había que cruzar en balza y los vapores venían de Buenos Aires a Gualeguaychú como trayecto, había muchos hospedajes, hosterías. Mis abuelos vivían de la hostería y de ahí también viene la nostalgia de hacer un emprendimiento hotelero" (entrevistado). El padres es de Diamante y en elaño 40 por su trabajo en gendarmería se radica en Paranacito y la conoce a su madre. El entrevistado comenta que trabaja desde muy chico allí, que con la creciente del 1983 se instala un par de años en Buenos Aires donde los padres tenían un departamento que habían comprado con la idea de que sus hijos estudien. Son 3 hermanos, uno contador. "Después de un accidente, me chocaron y volví, además la vida de la ciudad no me asentaba. Al poco tiempo fallece mi padre y yo me hago cargo del comercio, una librería, junto a mi madre" (entrevistado). Cuando se conocen con su señora, ella se muda a VP y se suma a trabajar en la librería. Antes de la creciente de 1998, empezó un "éxodo de gente a producir en los campos, se empezó a poblar mucho la isla. En ese momento los propietarios de tierra firme la utilizaban para siembra y la ganadería la llevaban a la isla. Yo no tenía campo ni nada pero me parecía interesante incursionar en la hacienda y abandoné lo del hotel porque el turismo estaba pinchado. A este terreno, donde funciona el hotel lo compré en el 95/96, junto con este terreno compré el campo. En 1998 empecé el hotel y me agarró la creciente. Compré 200 ha de un campo improductivo para forestación y lo convertí en ganadero, lo traté de mejorar, tenía habilitación para la exportación, tenía novillo pesado, novillo gordo. Llegué a tener 500 animales en 250 ha, esto es tierra buena pero es complicado, tenés que trabajarlo mucho pero la resaca es lo más efectivo que hay. Tenía que sembrar para tener firmeza de gordura. No es un pasto firme pero le podía meter dos animales por ha." (entrevistado). Mientras tanto el productor se dedicaba a la ganadería la mujer continuaba trabajando con su suegra en la librería. "El hotel estaba en cero, teníamos las bases, la loza pero cero con el hotel porque el turismo en VP no no fue ni es actualmente un beneficio muy importante". En todo el tiempo de trabajo con la ganadería tuvo diferentes problemáticas "tuve muerte súbita de los animales, no fui el primero pero acá no se conocí, nadie hacía el estudio" (esto fue en el 96, antes de la creciente). En ese
"Yo nací acá" expresa el entrevistado. "Mi padre era italiano, vino solo cuando tenía 18 años, creo que en el 38. Estuvo en San Isidro, compró unos terrenos con lo que trabajó y después se vino para acá. Era forestal y frutal. No pensaba en el turismo". A los 11 años se fue a Bs As y volvió por un problema de salud en ese momento. "Tenía un taller de chapa y pintura y a veces por incumplimiento de la gente, todo eso, me llevó a tener problemas de gastritis, un montón de cosas más que se complican y me dije "la dieta no me va a servir" (entrevistado). Hizo un cambio radical de vida y volvió a vivir a VP. "Optamos por volver, acá estaba la casa vacía. Vendimos la cas allá y decidimos volver a hacer cualquier cosa. Empezamos a vender yerbas medicinales, Salíamos por el río... lo que era eso, una paz increíble, venir de la locura a esto, nos cambió la vida... Y como es un pueblito de campo, las yerbas medicinales eran el remedio justo. Llevábamos un cajón de naranjas, manzanas, otras cosas para complementar. Teníamos una huerta y lo que no, comprábamos en el verdulero. Volvíamos vacíos. A esto lo hacíamos con mi esposa (entrevistado). "Era lindo, como si todos los días estuviésemos de picnic, de aventura. En aquel momento se hacía algo de madera. Había plantación, cortábamos, se renovaba" "Con el turismo siempre estuvimos. Hacíamos pan casero para vender cuando estaba el complejo turístico municipal, que era el único que había. Llegamos a hacer 90 panes caseros por día. Era un cambio brusco". "Hacíamos empanadas a a nochecita, había mucha gente, mucho turismo, trabajábamos todos los días. Al verano hay que aprovecharlo, tenía de 15 a 18 docenas de empanadas encargadas por día". En el 1998 ingresó a trabajar en el hospital. "Con el tiempo empezó a trabajar en el hospital. Ya era otra tranquilidad. Mi esposa siempre fue ama de casa". Con el camping arrancan en el 2011. 
momento se contactó con INTA, integró grupo cambio rural con otros productores, era representante del departamento islas en INTA de Concepción del Uruguay. "Hicimos estudios en el campo, de suelo, de parasitosis" (entrevistado). Trabajó con el asesoramiento de INTA y de otros productores. En algún momento de este periodo, "quiso cambiar la vaca por el novillos. Los últimos que me quedaban eran novillos, los terminé vendiendo en ferias, vendía jaulas que estaban acordes para exportación pero la mayoría eran intermedios" (entrevistado). En el 2016 abandona el campo, deja la ganadería. Las crecienten marcando la historia. "Pasamos todas las crecientes, como grandes las del 83, la del 98 y la última del 2016. Después hubo un montón de creciente donde se nos ha inundado la casa incluso, pero no han sido tan grandes" (entrevistado). Comienzan nuevamente con el hotel en el 2009. "Arrancamos con el hotel en el 2009, con el entusiasmo de terminarlo. El turismo estaba empezando a funcionar, la ganadería estaba medianamente organizada, o sea que teníamos los tiempos suficientes, marchaba todo sobre ruedas. Empezamos a invertir y lo terminamos en el 2011" (entrevistado). "Empezamos de a poquito, con algunas habitaciones, no es que arrancamos con todo terminado" (entrevistada). Nosotros tuvimos una época muy baja de venta de habitaciones, recién ahora estamos repuntando un poco" (entrevistada). "Fuimos muy de a poco, no teníamos el dinero para gastar 200 mil pesos en colchones" (entrevistado). El año pasado también decidieron cerrar la librería. 
Apuestan al turismo. A partir de la incorporación del turismo abandonan la actividad ganadera y luego deciden poner el local en alquiler, donde antes funcionaba la librería familiar. "Estamos tratando de sacar fichas para estar lo más tranquilos posibles nosotros. Y no quiere

decir que nos haya ido mal en lo otro o que esto sea mucho mejor... en nuestro caso el porqué de los cambios, no es referencial, es muy particular....No es que me quedé en el turismo porque me conviene más o vamos a renegar menos. Es porque ya estamos embarcados en este busque y en todos los busques quiero llegar a destino, tenga los traspiés que tenga" (entrevistado). "En números el hotel me redituaba mucho menos, económicamente me reditúa mucho menos pero es a lo que estamos apuntando. Las dos cosas no se pueden hacer..." Pretenden vender el campo para tener una vida más tranquila. "Si bien la base de poner este hotel era mi jubilación, yo ya prácticamente quiero jubilarme entonces como tal, al campo lo vendo. Vendo el campo porque no lo voy a utilizar, no me va a rentabilizar, imaginate que arrendando 200 ha de campos es lo mismo que dos departamentos en cualquier lugar, vendo el campo y me hago 4 departamentos, y tengo más rentabilidad, pero no es lo que pienso. Todo lo que venda del campo me lo voy a pasear por el mundo". NO piensan seguir invirtiendo en turismo. "Ya inversiones no pensamos hacer más. Lo que queremos nosotros es tratar de tener una casa como tenemos acá, donde vivimos muy bien, una casa en Gualeguaychú donde estamos edificando y donde vamos a hacer un departamento donde podamos ir a vivir o a pasar unos días tranquilos. Porque ya queremos pensar en la vida tranquilos.

\% Invierten en turismo pensando en una jubilación privada. "En ese proceso ㅎํㄴ la idea siempre fu tener un hotel porque a nosotros siempre nos gustó viajar. En ese momento invierto para mi jubilación, como independiente. Empecé a construir este edificio pero veía que el turísticamente VP no ๙ crecía, había muchas falencias" (entrevistado). "Yo lo hice como mi ¿. jubilación, es una inversión que vos hacés y después esperás" (entrevistado)
El entrevistado no hace comentarios sobre cambios a futuro. Se lo nota tranquilo y satisfecho con su vida.

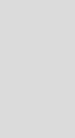




\begin{tabular}{|c|c|c|c|}
\hline 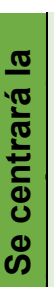 & 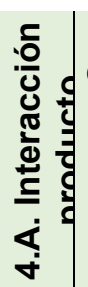 & $\begin{array}{l}\text { No hay integración de productos de las diversas actividades que } \\
\text { desarrolla la familia. }\end{array}$ & $\begin{array}{l}\text { En el camping se ofrecen menú a base de pescado que él mismo pesca } \\
\text { y su mujer cocina. También venden algo de nuez pecán de los } 6 / 7 \text { árboles } \\
\text { que tiene plantados allí. }\end{array}$ \\
\hline 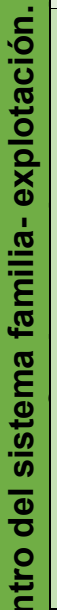 & 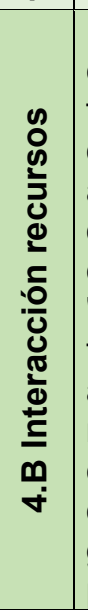 & $\begin{array}{l}\text { En este sistema se da una movilización de recursos físicos y materiales } \\
\text { en el terreno donde se ubica el hotel. Allí, al afrontar a importantes gastos } \\
\text { fijos deciden construir locales de alquiler mensual. Además implementan } \\
\text { otra modalidad alojamiento como es apart hotel con monoambientes y } \\
\text { ambientes completos con una habitación. Los recursos humanos que } \\
\text { organiza sus tiempos son la pareja, ellos enseñan a las dos empleadas } \\
\text { que tienen fija en base a sus propias experiencias y aprendizajes como } \\
\text { "turistas". Trasladan su experiencia viajando a la prestación de su servicio } \\
\text { turístico. Lo mismo manifiesta el entrevistado respecto a la ganadería, } \\
\text { actividad que abandonó el último año con la creciente del } 2016 \text {. Es } \\
\text { referente de consulta para otros productores, ha realizado ensayos y } \\
\text { estudios con el INTA en su propio campo y transmite sus aprendizajes a } \\
\text { otros productores. Es importante mencionar que el turismo se capitalizó } \\
\text { gracias a la ganadería. En virtud de esta fueron construyendo } \\
\text { progresivamente el hotel, abierto al público desde el } 2011 \text {. }\end{array}$ & $\begin{array}{l}\text { El recurso humano es la base de todas las actividades que desarrollan, } \\
\text { que en turismo es un "plus". El valor agregado de la actividad es él, con } \\
\text { su personalidad, su amabilidad, la forma en que se relaciona con los } \\
\text { turistas. Además el entorno en el que se ubica el camping es naturaleza } \\
\text { pura, con el río a unos pasos. El camping está inmerso en la isla. Los } \\
\text { recursos naturales son el principal atractivo del lugar. }\end{array}$ \\
\hline 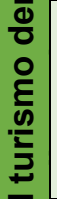 & 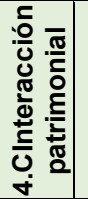 & & $\begin{array}{l}\text { El entrevistado supo comprender y aprovechar el patrimonio paisajístico } \\
\text { y natural del lugar para hacer un espacio tranquilo que permita ser } \\
\text { disfrutado apaciblemente. }\end{array}$ \\
\hline 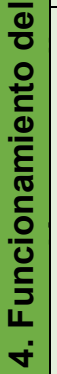 & 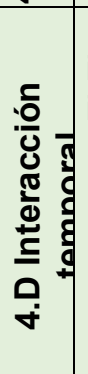 & $\begin{array}{l}\text { En la implementación del turismo se contempla una anticipación a los } \\
\text { ingresos del futuro de la pareja. Ellos mismos lo manifiestan como una } \\
\text { inversión para la "jubilación privada". }\end{array}$ & No es una interacción trascendental en el sistema. \\
\hline
\end{tabular}


Por el contrario a combinar actividades, en este caso se da un proceso de abandono de la actividad que generaba más ingresos, como la ganadería, pero que aparejaba una vida de mayor sacrificio. "Prefiero estar atento a esto, tomando unos mates en casa o acá, esperando que pase algo, aunque gane mucho menos".

Hasta el 2016 tenían los ingresos por la venta de productos de librería o el turismo y los de la ganadería. Actualmente los ingresos de la familia ¿ g están dados por el alquiler de locales (local familiar y nuevo construidos) đ y el turismo. La implementación del alquiler fijo mensual alivia los gastos g fijos, que son importantes. Estos ingresos garantizan una buena calidad - de vida de la familia.

A partir del trabajo en el turismo deciden cerrar la librería. "Hace 1/2 años cerramos la librería, fue cuando dije basta, porque yo tenía que estar

acá y allá y para mí era demasiado, Ahí pusimos en alquiler el local"

(entrevistada). "Si hablamos de los cambios, el porqué de los cambios, yo son todos circunstanciales y de acuerdo a cada uno. Las economías acá no son de decir saco las fichas acá y las pongo allá. Son pruebas. Eso es - lo que nosotros hicimos, teníamos voluntades, hasta que llega un ๘. momento de decir de esta ficha saco esto, de esta, esto. Aunque el \& negocio nos redituaba, nos llevaba tiempo" (entrevistado). Luego de ese cambio, el turismo no ha impactado en los tiempos de la familia pero है sí marca el ritmo de actividades. "No ha impactado en los tiempos de * las tareas. No se deja de hacer nada. A lo sumos a los platos no se los ¿ lava al mediodía Las tareas de higiene del hogar si ella no los hace a las ㅇ 10 , los hace a las 11 , hay días que se duerme siesta, hay días que no. Es ¿ de acuerdo a las circunstancias, no es rutinario" (entrevistado). "Es un reacomodamiento. Nos ordena, porque por ejemplo si es fin de semana largo, de martes a viernes nos vamos de vacaciones en lugar del viernes al domingo como nos íbamos antes. A estos cambios los tenemos pero no nos afectaron. No quiere decir que no nos vayamos de vacaciones" (entrevistado). "Tratamos de adaptarnos" (entrevistada).
El turismo, además de ser una actividad que permite generar ingresos, es una actividad que al entrevistado le gusta mucho, la disfruta. El mismo dice que es como un "hobbies". Complementa el ingreso que realiza en el hospital

Tiene dos actividades que le generan ingresos, el hospital y el turismo. No mencionó el entrevistado el porcentaje de ingresos pero se entiende que como empleado tiene un sueldo fijo. Además cuenta con un amplio terreno en la isla, de los cuales vendió $3 / 4$ terrenos con los que se fue capitalizando y mejoró el predio del camping.

Tienen incorporado el turismo a sus vidas. Tienen dos viviendas así que cuando se les hace tarde en el camping duermen allí, si no vuelven a sus casas. 


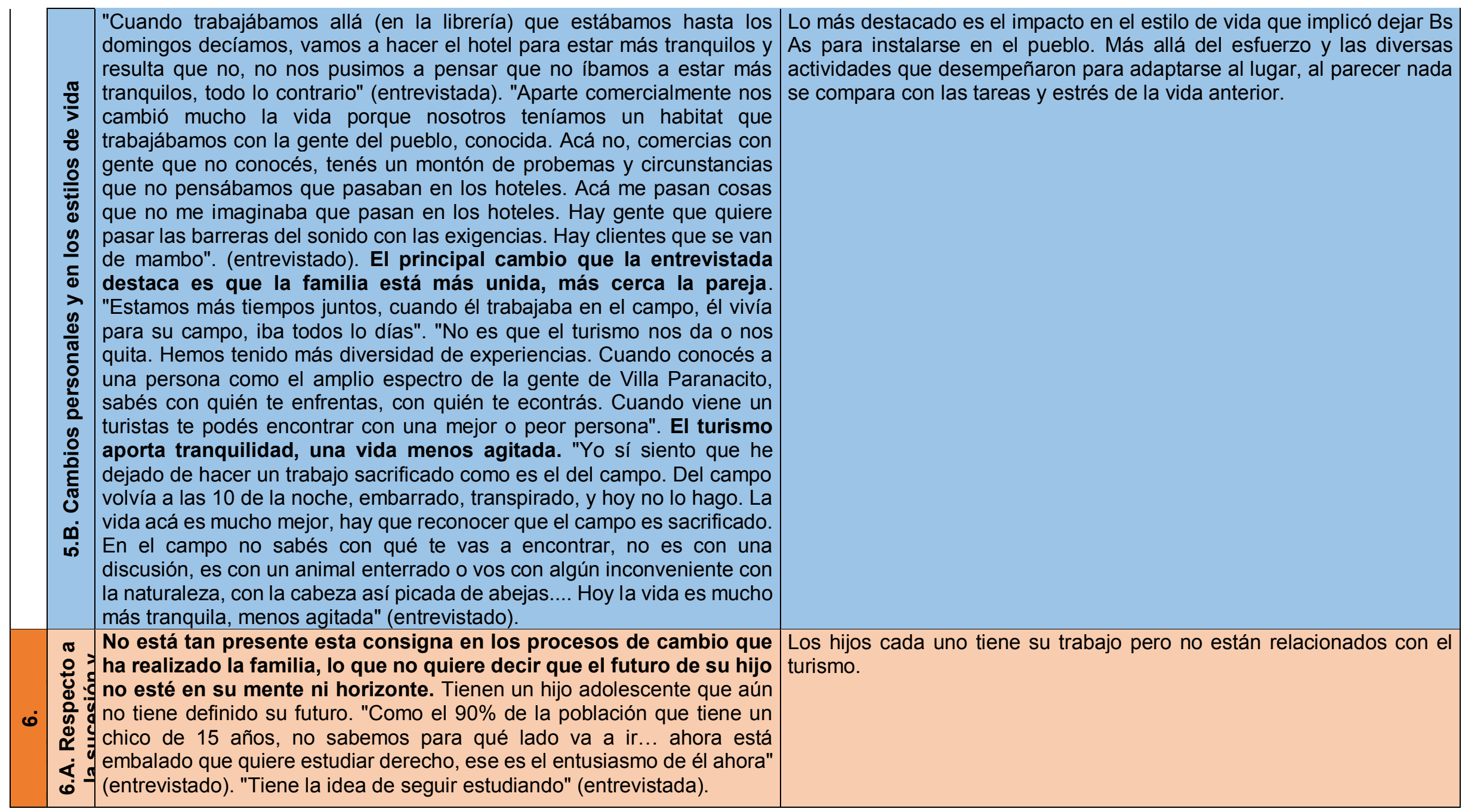


Está clara la idea de que comienzan con la propuesta turística pensando en ahorro para el futuro, en un ingreso como jubilación privada. Pero además sienten un profundo arraigo y les gusta la vida que llevan allí. "Yo ㅇ soy amante de VP y me quiero quedar a morir acá. Cada día que pasa ○ y estoy convencido de que es el mejor lugar del mundo que podría haber o elegido, porque veo lo que pasa en otros lugares y no me convence para t nada. La inseguridad, las problemáticas de las grandes ciudades. Si le $z$ pasa algo en la calle a mi hijo, vienen los vecinos y me avisan... tenemos $\overline{\widetilde{\sigma}}$ muchas dificultades pero la vida que tenemos acá... Yo dejo la camioneta o abierta con plata arriba, nuestra casa está abierta de par en par. El ¿ imponderante es el agua, si bien te trabaja psicológicamente lo afrontás, sabés las consecuencias" (entrevistado). "Yo soy de Gualeguaychú y a ฯ mí VP me atrapó y me encantó. Voy a Gualeguaychú dos días y ya me m quiero volver. Me encanta el lugar, la tranquilidad, la naturaleza" (entrevistada).
Cuando llegue el momento, el entrevistado se jubilará del trabajo en el hospital y se dedicará exclusivamente al turismo. No se vislumbró en la entrevista si el origen del turismo tuvo que ver con una cuestión de sucesión o simplemente como algo que se dio porque vieron la posibilidad, más que la pareja siempre estuvo vinculada con la actividad. Además el entrevistado claramente deja expuesto su amor por el pueblo y su vida allí. "Yo no dejaría VP. Porque es extraordinario. La paz, la tranquilidad". 


\section{Anexo 6- Síntesis de casos según ejes de análisis transversal}

\begin{tabular}{|c|c|c|c|c|c|}
\hline & $\begin{array}{l}\text { Caso 1- Producción } \\
\text { hortícola + alojamiento en } \\
\text { cabañas }\end{array}$ & $\begin{array}{l}\text { Caso 2- Actividad } \\
\text { comercial en almacén de } \\
\text { campo que abren al } \\
\text { turismo. }\end{array}$ & $\begin{array}{l}\text { Caso 3- Producción } \\
\text { agrícola, ganadera, } \\
\text { servicios e insumos + } \\
\text { alojamiento en estancia }\end{array}$ & $\begin{array}{l}\text { Caso 4- Producción } \\
\text { tambera y ganadería de } \\
\text { cría + prestación de } \\
\text { actividades turísticas } \\
\text { (paseos y gastronomía) }\end{array}$ & $\begin{array}{l}\text { Caso 5- Producción } \\
\text { avícola, ganadera, } \\
\text { agrícola y fábrica de } \\
\text { alimentos + turismo en } \\
\text { almacén de campo }\end{array}$ \\
\hline $\begin{array}{l}\text { Composición } \\
\text { familiar }\end{array}$ & $\begin{array}{l}\text { Pareja de } 50 \text { años } \\
\text { Hijos jóvenes (universitario, } \\
\text { secundario, primario) } \\
\text { Integración de un hijo en la } \\
\text { producción (más } \\
\text { activamente) }\end{array}$ & $\begin{array}{l}\text { Pareja de casi } 50 \text { años } \\
\text { Hijos jóvenes (terciario, } \\
\text { secundario) } \\
\text { Integración de un hijo en } \\
\text { comercio (más } \\
\text { activamente) }\end{array}$ & $\begin{array}{l}\text { Pareja de casi } 50 \text { años con } \\
\text { tres hijos universitarios. }\end{array}$ & $\begin{array}{l}\text { Pareja de entre } 40 \text { y } 50 \\
\text { años con dos hijos de } 21 \text { y } \\
16 \text { años. No estudian, } \\
\text { trabajan allí. }\end{array}$ & $\begin{array}{l}\text { Pareja de más de } 60 \text { años } \\
\text { con hijos adultos } \\
\text { independientes. Solo uno } \\
\text { está involucrados al } \\
\text { sistema. }\end{array}$ \\
\hline $\mathrm{RRHH}$ & $\begin{array}{l}\text { Netamente familiar } \\
\text { Todos saben hacer todo } \\
\text { pero se reparten las tareas. } \\
\text { Rol diferencial de la mujer. }\end{array}$ & $\begin{array}{l}\text { Netamente familiar. Todos } \\
\text { hacen todo, incluso } \\
\text { comparten las tareas } \\
\text { domésticas. }\end{array}$ & $\begin{array}{l}\text { Gestión familiar pero con } \\
\text { importante mano de obra } \\
\text { asalariada. } \\
\text { El turismo a cargo de la } \\
\text { mujer de la pareja. El } \\
\text { colabora. }\end{array}$ & $\begin{array}{l}\text { Netamente familiar. } \\
\text { Distribución de tareas se da } \\
\text { de una manera organizada } \\
\text { y coordinada }\end{array}$ & $\begin{array}{l}\text { Combinación de mano de } \\
\text { obra familiar y asalariada. }\end{array}$ \\
\hline $\begin{array}{l}\text { Físicos } \\
\text { materiales } \\
\text { Naturales }\end{array}$ & $\begin{array}{l}\text { Productores familiares } \\
\text { capitalizados. Tierra y } \\
\text { maquinaria en posesión. } \\
\text { Heredan tierra adquirida por } \\
\text { los abuelos. }\end{array}$ & $\begin{array}{l}\text { No son productores } \\
\text { agropecuarios. Sí lo era el } \\
\text { padre del dueño del } \\
\text { almacén, ellos solo } \\
\text { siguieron con la actividad } \\
\text { comercial. }\end{array}$ & $\begin{array}{l}\text { Productores empresariales. } \\
\text { Tierra y maquinaria en } \\
\text { posesión. Compran la } \\
\text { tierra, que integraba el } \\
\text { patrimonio familiar de la } \\
\text { mujer. }\end{array}$ & $\begin{array}{l}\text { Productores familiares } \\
\text { (pequeños). } \\
\text { Porción de tierra en } \\
\text { posesión ( } 29 \text { ha) y la } \\
\text { mayoría arrendada. }\end{array}$ & $\begin{array}{l}\text { Productores familiares } \\
\text { capitalizados. Han } \\
\text { atravesado crisis } \\
\text { importantes pero lograron } \\
\text { mantener su patrimonio. } \\
\text { Tierra y maquinaria en } \\
\text { posesión. }\end{array}$ \\
\hline Económicos & $\begin{array}{l}\text { Turismo financiado por } \\
\text { actividad productiva. } \\
\text { No es la actividad más } \\
\text { importante en generación } \\
\text { de ingresos. }\end{array}$ & $\begin{array}{l}\text { Turismo complementa el } \\
\text { ingreso principal. No es la } \\
\text { actividad más importante en } \\
\text { términos de ingresos (es } \\
\text { más bien estacional). } \\
\text { Posibilita la inversión en } \\
\text { inmuebles para alquilar (en } \\
\text { un principio pensado para } \\
\text { turismo) }\end{array}$ & $\begin{array}{l}\text { El turismo no es la actividad } \\
\text { más importante en términos } \\
\text { de ingresos. Colabora con } \\
\text { el mantenimiento edilicio. } \\
\text { Se ha arreglado la estancia } \\
\text { con los ingresos de las } \\
\text { otras actividades. }\end{array}$ & $\begin{array}{l}\text { El tambo es la actividad que } \\
\text { genera ingresos de forma } \\
\text { sólida y estable. Es la que } \\
\text { permite el resto de las } \\
\text { actividades. El turismo es } \\
\text { complementario, no } \\
\text { actividad principal. }\end{array}$ & $\begin{array}{l}\text { El turismo no es la actividad } \\
\text { más importante en términos } \\
\text { de ingresos. Colabora con } \\
\text { el mantenimiento edilicio. }\end{array}$ \\
\hline Sociales & $\begin{array}{l}\text { Utilizan sus redes sociales } \\
\text { para potenciar el turismo. } \\
\text { Integraron grupos Cambio } \\
\text { Rural. }\end{array}$ & $\begin{array}{l}\text { Las redes sociales permiten } \\
\text { generar redes de } \\
\text { intercambio de productos } \\
\text { en el almacén. }\end{array}$ & $\begin{array}{l}\text { No integran redes sociales } \\
\text { ni técnicas de turismo. } \\
\text { Están más relacionados } \\
\text { con otras instituciones y }\end{array}$ & $\begin{array}{l}\text { Interacción con otros } \\
\text { productores a través de } \\
\text { grupo cambio rural. As } \\
\text { Integración de redes }\end{array}$ & $\begin{array}{l}\text { Utilizan sus redes sociales } \\
\text { para potenciar el turismo. } \\
\text { Integraron grupos Cambio } \\
\text { Rural. Importante vínculo }\end{array}$ \\
\hline
\end{tabular}




\begin{tabular}{|c|c|c|c|c|c|}
\hline & & & $\begin{array}{l}\text { referentes del sector } \\
\text { agropecuario pero no } \\
\text { turístico. }\end{array}$ & $\begin{array}{l}\text { técnicas y sociales a través } \\
\text { del turismo. }\end{array}$ & $\begin{array}{l}\text { con los turistas y con } \\
\text { familias del lugar. }\end{array}$ \\
\hline Identitarios & $\begin{array}{l}\text { Familia nacida en la zona. } \\
\text { Orgullo y sentido de } \\
\text { pertenencia. Turismo } \\
\text { vehículo para mostrar y dar } \\
\text { a conocer la idiosincrasia } \\
\text { de la zona. }\end{array}$ & $\begin{array}{l}\text { Familia nacida en la zona. } \\
\text { Orgullo y sentido de } \\
\text { pertenencia. } \\
\text { Turismo pone en valor la } \\
\text { historia familiar y } \\
\text { comunitaria. }\end{array}$ & $\begin{array}{l}\text { Familia que tiene arraigo en } \\
\text { el lugar, eligieron vivir en el } \\
\text { campo y aman ese estilo de } \\
\text { vida. Preocupación legítima } \\
\text { por el cuidado del ambiente } \\
\text { y la alimentación saludable, } \\
\text { que transpolan al turismo. }\end{array}$ & $\begin{array}{l}\text { Familia que heredó de sus } \\
\text { familias el oficio del } \\
\text { tambero y continúan en la } \\
\text { actividad. Nacidos en la } \\
\text { zona. Orgullo y sentido de } \\
\text { pertenencia. }\end{array}$ & $\begin{array}{l}\text { La propuesta turística se } \\
\text { basa en la esencia del } \\
\text { almacén de campo. } \\
\text { Familia nacida en la zona. } \\
\text { Orgullo y sentido de } \\
\text { pertenencia. }\end{array}$ \\
\hline $\begin{array}{l}\text { Aspectos } \\
\text { territoriales }\end{array}$ & $\begin{array}{l}\text { Destacan el rol técnico y } \\
\text { formativo de las } \\
\text { experiencias asociativas. } \\
\text { Asesoramiento de INTA y } \\
\text { Municipalidad. } \\
\text { Mayor interacción con } \\
\text { familias de la zona gracias } \\
\text { al turismo. }\end{array}$ & $\begin{array}{l}\text { Experiencia asociativa de la } \\
\text { zona impulsa la inclusión } \\
\text { del turismo al almacén. } \\
\text { Mejora el vínculo con el } \\
\text { Municipio. } \\
\text { Se da una importante } \\
\text { vinculación con los vecinos } \\
\text { y otros productores de la } \\
\text { colonia (venden sus } \\
\text { productos). Vinculación con } \\
\text { otros actores de turismo ha } \\
\text { incentivado a la familia a } \\
\text { promover el almacén }\end{array}$ & $\begin{array}{l}\text { No tienen una activa } \\
\text { relación con el municipio y } \\
\text { otros actores del sector } \\
\text { turístico local u otras } \\
\text { estancias de la provincia, sí } \\
\text { en relación a las otras } \\
\text { actividades productivas. }\end{array}$ & $\begin{array}{l}\text { Experiencia asociativa de la } \\
\text { zona impulsa la inclusión al } \\
\text { turismo. Muy fuerte vínculo } \\
\text { con municipio local. } \\
\text { Se ubican en una de las } \\
\text { zonas más turísticas de la } \\
\text { provincia. }\end{array}$ & $\begin{array}{l}\text { Experiencia asociativa de la } \\
\text { zona impulsa la inclusión al } \\
\text { turismo. Muy fuerte vínculo } \\
\text { con municipio local. } \\
\text { Se ubican en una de las } \\
\text { zonas más turísticas de la } \\
\text { provincia. }\end{array}$ \\
\hline
\end{tabular}

\begin{tabular}{|c|c|c|c|c|c|}
\hline & $\begin{array}{l}\text { Caso 6- Producción } \\
\text { avícola, ganadera + } \\
\text { alojamiento en casona de } \\
\text { campo }\end{array}$ & $\begin{array}{l}\text { Caso } 7 \text { - fabricantes y } \\
\text { vendedores de aberturas + } \\
\text { alojamiento turístico en el } \\
\text { campo }\end{array}$ & $\begin{array}{l}\text { Caso 8- Tambo y } \\
\text { quesería, producción } \\
\text { porcina + turismo } \\
\text { (historia, granja y } \\
\text { gastronomía) }\end{array}$ & $\begin{array}{l}\text { Caso } 9 \text { - Producción } \\
\text { forestal (en retracción), } \\
\text { servicios a terceros con } \\
\text { maquinaria propia, } \\
\text { producción ganadera + } \\
\text { turismo (alojamiento) }\end{array}$ & $\begin{array}{l}\text { Caso 10- Tambo y } \\
\text { quesería en Uruguay + } \\
\text { gastronomía }\end{array}$ \\
\hline $\begin{array}{l}\text { Composición } \\
\text { familiar }\end{array}$ & $\begin{array}{l}\text { Pareja de } 54 \text { años con } 4 \\
\text { hijos. Dos de ellos } \\
\text { independientes, un joven } \\
\text { estudiante de secundario y } \\
\text { una mujer con formación } \\
\text { terciaria que trabaja con } \\
\text { ellos en el alojamiento. }\end{array}$ & $\begin{array}{l}\text { Pareja de } 60 \text { años con } 3 \\
\text { hijos adultos con sus } \\
\text { respectivas familias. Uno de } \\
\text { ellos más vinculado a la } \\
\text { actividad familiar. }\end{array}$ & $\begin{array}{l}\text { Pareja de entre } 30 \text { y } 40 \\
\text { años con dos niñas } \\
\text { pequeñas. } \\
\text { Esta familia está en un } \\
\text { momento de crecimiento } \\
\text { personal, familiar y en el } \\
\text { establecimiento. }\end{array}$ & $\begin{array}{l}\text { Pareja de } 50 \text { años } \\
4 \text { Hijos jóvenes } \\
\text { (universitarios). } \\
\text { Integración de dos hijos en } \\
\text { la producción (más } \\
\text { activamente) }\end{array}$ & $\begin{array}{l}\text { Pareja de entre } 30 \text { y } 40 \\
\text { años con dos hijos } \\
\text { pequeños. }\end{array}$ \\
\hline
\end{tabular}




\begin{tabular}{|c|c|c|c|c|c|}
\hline RRHH & $\begin{array}{l}\text { Gestión y trabajo familiar } \\
\text { pero con mano de obra } \\
\text { asalariada. Distribución de } \\
\text { tareas de una manera } \\
\text { organizada y coordinada. } \\
\text { Roles asignados. }\end{array}$ & $\begin{array}{l}\text { Las actividades son de } \\
\text { gestión y trabajo con mano } \\
\text { de obra familiar. El turismo } \\
\text { se realiza por reservas, lo } \\
\text { que permite organizarse con } \\
\text { tiempo y sin generar } \\
\text { complicaciones en el } \\
\text { sistema. }\end{array}$ & $\begin{array}{l}\text { Gestión y trabajo familiar } \\
\text { pero con mano de obra } \\
\text { asalariada. Distribución de } \\
\text { tareas de una manera } \\
\text { organizada y coordinada. } \\
\text { Roles asignados. }\end{array}$ & $\begin{array}{l}\text { El sistema se basa en la } \\
\text { mano de obra familiar y la } \\
\text { organización y distribución } \\
\text { de las tareas se da para } \\
\text { mantener el sistema bajo } \\
\text { esta modalidad de trabajo. } \\
\text { El turismo a cargo de la } \\
\text { mujer de la pareja. }\end{array}$ & $\begin{array}{l}\text { La mano de obra es } \\
\text { familiar con un empleado. } \\
\text { No hay un rol diferencial. }\end{array}$ \\
\hline $\begin{array}{l}\text { Físicos } \\
\text { materiales } \\
\text { Naturales }\end{array}$ & $\begin{array}{l}\text { Productores familiares } \\
\text { capitalizados. Tierra y } \\
\text { maquinaria en posesión. } \\
\text { Además arriendan. }\end{array}$ & $\begin{array}{l}\text { No son productores } \\
\text { agropecuarios. Están } \\
\text { capitalizados. }\end{array}$ & $\begin{array}{l}\text { Productores familiares } \\
\text { capitalizados. Tierra, } \\
\text { infraestructura y } \\
\text { equipamiento. }\end{array}$ & $\begin{array}{l}\text { Productores familiares } \\
\text { capitalizados. Tierra y } \\
\text { maquinaria en posesión. }\end{array}$ & $\begin{array}{l}\text { No son productores } \\
\text { agropecuarios en Villa } \\
\text { Paranacito. Tampoco } \\
\text { continúan la pesca. Se } \\
\text { equiparon a partir de la } \\
\text { venta de una embarcación. } \\
\text { Tienen vivienda propia y el } \\
\text { espacio gastronómico } \\
\text { equipado. El ahorro es } \\
\text { stock de mercadería. }\end{array}$ \\
\hline Económicos & $\begin{array}{l}\text { El turismo no es la } \\
\text { actividad más importante } \\
\text { en términos de ingresos. } \\
\text { Es un ingreso } \\
\text { complementario. Colabora } \\
\text { con el mantenimiento } \\
\text { edilicio. Se ha arreglado la } \\
\text { casona con los ingresos de } \\
\text { las otras actividades. Fue } \\
\text { pensado como una } \\
\text { inversión. }\end{array}$ & $\begin{array}{l}\text { El turismo no es la actividad } \\
\text { más importante en términos } \\
\text { de ingresos. Es un ingreso } \\
\text { complementario. Colabora } \\
\text { con el mantenimiento edilicio } \\
\text { y los gastos fijos. }\end{array}$ & $\begin{array}{l}\text { El turismo es la actividad } \\
\text { central. Posibilita la } \\
\text { capitalización. Colabora } \\
\text { con el mantenimiento } \\
\text { edilicio. Otras actividades } \\
\text { complementan dada la } \\
\text { estacionalidad del turismo. }\end{array}$ & $\begin{array}{l}2 \text { ingresos importantes: el } \\
\text { turismo y el servicio a } \\
\text { terceros. Los otros son } \\
\text { complementarios. } \\
\text { El servicio a terceros } \\
\text { posibilita la inversión }\end{array}$ & $\begin{array}{l}\text { Un solo ingreso al sistema: } \\
\text { la gastronomía. }\end{array}$ \\
\hline Sociales & $\begin{array}{l}\text { Interacción con otros } \\
\text { productores a través de } \\
\text { grupo cambio rural. } \\
\text { Integración de redes } \\
\text { técnicas y sociales a través } \\
\text { del turismo y las otras } \\
\text { actividades. Intercambio } \\
\text { cultural con turistas y con } \\
\text { productores de la zona. }\end{array}$ & $\begin{array}{l}\text { Interacción con otros } \\
\text { productores a través de } \\
\text { grupo cambio rural. No es un } \\
\text { elemento que se destaque } \\
\text { en este caso. }\end{array}$ & $\begin{array}{l}\text { Intercambio cultural con } \\
\text { turistas y con productores } \\
\text { de la zona. } \\
\text { No integran redes. }\end{array}$ & $\begin{array}{l}\text { Interacción con otros } \\
\text { productores a través de } \\
\text { grupo cambio rural. } \\
\text { Integración de redes } \\
\text { técnicas y sociales a través } \\
\text { del turismo y las otras } \\
\text { actividades. Muy } \\
\text { vinculados a actividades de } \\
\text { la comunidad. Intercambio }\end{array}$ & $\begin{array}{l}\text { Mayor contacto social a } \\
\text { partir del trabajo en } \\
\text { gastronomía. }\end{array}$ \\
\hline
\end{tabular}




\begin{tabular}{|c|c|c|c|c|c|}
\hline & & & & $\begin{array}{l}\text { cultural con turistas y con } \\
\text { productores de la zona. }\end{array}$ & \\
\hline Identitarios & $\begin{array}{l}\text { Familia nacida en la zona. } \\
\text { Orgullo y sentido de } \\
\text { pertenencia. } \\
\text { La propuesta turística se } \\
\text { basa en la casona de } \\
\text { campo y su historia } \\
\text { (patrimonio tangible e } \\
\text { intangible). } \\
\text { Turismo pone en valor la } \\
\text { historia familiar y } \\
\text { comunitaria. }\end{array}$ & $\begin{array}{l}\text { La familia de la mujer es de } \\
\text { la zona, son productores } \\
\text { ganaderos. El marido es } \\
\text { entrerriano, de una localidad } \\
\text { a } 70 \mathrm{~km} \text {. Su preocupación } \\
\text { pasa por el tema ambiental. }\end{array}$ & $\begin{array}{l}\text { Familia nacida en la zona. } \\
\text { Orgullo y sentido de } \\
\text { pertenencia. } \\
\text { La propuesta turística se } \\
\text { basa en la casona de } \\
\text { campo y su historia } \\
\text { (patrimonio tangible e } \\
\text { intangible). } \\
\text { Turismo pone en valor la } \\
\text { historia familiar y } \\
\text { comunitaria. }\end{array}$ & $\begin{array}{l}\text { Familia nacida/criada en la } \\
\text { zona. Sentido de } \\
\text { pertenencia al lugar, el } \\
\text { vínculo afectivo, por la } \\
\text { historia familiar, que los } \\
\text { une a esas tierras. } \\
\text { Por otro lado es muy } \\
\text { notoria la noción del trabajo } \\
\text { mancomunado, la } \\
\text { integración y colaboración } \\
\text { en actividades } \\
\text { comunitarias. }\end{array}$ & $\begin{array}{l}\text { No hay características que } \\
\text { se destaquen } \\
\text { particularmente. }\end{array}$ \\
\hline $\begin{array}{l}\text { Aspectos } \\
\text { territoriales }\end{array}$ & $\begin{array}{l}\text { Experiencia asociativa de } \\
\text { la zona impulsa la inclusión } \\
\text { al turismo. Muy fuerte } \\
\text { vínculo con municipio local. } \\
\text { Se ubican en una de las } \\
\text { zonas más turísticas de la } \\
\text { provincia. }\end{array}$ & $\begin{array}{l}\text { Buen vínculo con municipio } \\
\text { local. } \\
\text { Destacan el impulso al } \\
\text { desarrollo turístico dado por } \\
\text { las termas. } \\
\text { Tienen la práctica de } \\
\text { recomendar otros } \\
\text { establecimientos de turismo } \\
\text { rural de la zona. }\end{array}$ & $\begin{array}{l}\text { Muy fuerte vínculo con } \\
\text { municipio local. } \\
\text { Se ubican en una de las } \\
\text { zonas más turísticas de la } \\
\text { provincia. } \\
\text { No integran redes. }\end{array}$ & $\begin{array}{l}\text { Idiosincracia marcada por } \\
\text { las crecidas de los ríos e } \\
\text { inundaciones. } \\
\text { Ubicación estratégica. } \\
\text { Insuficiente desarrollo del } \\
\text { sector turístico. } \\
\text { Trabajo en red con } \\
\text { asesoramiento de INTA. }\end{array}$ & $\begin{array}{l}\text { Ubicación estratégica. } \\
\text { Flujo de turistas. } \\
\text { Nuevos clientes en el } \\
\text { pueblo a partir de la } \\
\text { construcción de segundas } \\
\text { residencias. }\end{array}$ \\
\hline
\end{tabular}

\begin{tabular}{|c|c|c|c|}
\hline & $\begin{array}{l}\text { Caso 11- turismo (alojamiento) + comercio } \\
+ \text { servicio de catering + ingresos por venta } \\
\text { de terrenos y alquiler para ganadería }\end{array}$ & $\begin{array}{l}\text { Caso 12- hacían producción ganadera + } \\
\text { hotel en el pueblo + alquiler de locales }\end{array}$ & $\begin{array}{l}\text { Caso } 13 \text { - Fue productor forestal + } \\
\text { empleado hospital + camping }\end{array}$ \\
\hline Composición familiar & $\begin{array}{l}\text { Pareja de alrededor de } 60 \text { años con } 3 \text { hijos, } \\
\text { dos de ellos independientes y una } \\
\text { estudiando en la universidad. }\end{array}$ & $\begin{array}{l}\text { Pareja de entre } 40 \text { y } 50 \text { años con un hijo } \\
\text { adolescente. }\end{array}$ & $\begin{array}{l}\text { Pareja de alrededor de } 60 \text { años con } 4 \text { hijos } \\
\text { adultos independientes. }\end{array}$ \\
\hline $\mathrm{RRHH}$ & $\begin{array}{l}\text { La mano de obra es familiar con roles bien } \\
\text { diferenciados. Contratan mano de obra para } \\
\text { tareas específicas según el trabajo que } \\
\text { haya. Un empleado fijo en la tienda. }\end{array}$ & $\begin{array}{l}\text { La mano de obra es familiar con roles bien } \\
\text { diferenciados. Contratan mano de obra en } \\
\text { temporada alta. }\end{array}$ & $\begin{array}{l}\text { La mano de obra es familiar. No contratan } \\
\text { empleados. Se organizan cuando el hombre } \\
\text { trabaja en el hospital. }\end{array}$ \\
\hline $\begin{array}{l}\text { Físicos materiales } \\
\text { Naturales }\end{array}$ & $\begin{array}{l}\text { La familia está capitalizada. No se dedican } \\
\text { prácticamente a la producción agropecuaria, }\end{array}$ & $\begin{array}{l}\text { Productor capitalizado. El hotel se construyó } \\
\text { gracias a los aportes de la ganadería. Las }\end{array}$ & $\begin{array}{l}\text { No sé si están capitalizados o no. Tienen } 27 \\
\text { ha. Entorno natural único en la isla. }\end{array}$ \\
\hline
\end{tabular}




\begin{tabular}{|c|c|c|c|c|c|c|c|c|}
\hline & & \multicolumn{2}{|c|}{$\begin{array}{l}\text { la actividad forestal fue retrayéndose. Tiene } \\
\text { varios terrenos en posesión. }\end{array}$} & \multicolumn{3}{|c|}{$\begin{array}{l}\text { crecientes condicionan las actividades } \\
\text { productivas y la vida social de las familias. }\end{array}$} & & \\
\hline \multicolumn{2}{|l|}{ Económicos } & \multicolumn{2}{|c|}{$\begin{array}{l}\text { Los principales ingresos están dados por el } \\
\text { turismo y la venta en la tienda. Son } \\
\text { complementarios. El servicio de catering } \\
\text { varía. El alquiler del campo complementa. } \\
\text { Altos gastos fijos. }\end{array}$} & \multicolumn{3}{|c|}{$\begin{array}{l}\text { Los principales ingresos están dados por el } \\
\text { turismo y el alquiler de locales (que colaboran } \\
\text { con los costos fijos). La ganadería posibilitó la } \\
\text { inversión. }\end{array}$} & \multicolumn{2}{|c|}{$\begin{array}{l}\text { Dos ingresos complementarios, sueldo de } \\
\text { empleado e ingresos por turismo (no deben } \\
\text { ser altos porque es un camping). }\end{array}$} \\
\hline \multicolumn{2}{|l|}{ Sociales } & \multicolumn{2}{|c|}{$\begin{array}{l}\text { Interacción con otros productores a través } \\
\text { de grupo cambio rural. Integración de redes } \\
\text { técnicas y sociales a través del turismo y las } \\
\text { otras actividades. Intercambio cultural con } \\
\text { turistas y con productores de la zona. }\end{array}$} & \multicolumn{3}{|c|}{$\begin{array}{l}\text { Integración de redes técnicas pero por la } \\
\text { ganadería. En turismo, no interactuán con } \\
\text { otros referentes del sector. Turismo amplió los } \\
\text { contactos comerciales y sociales. }\end{array}$} & \multicolumn{2}{|c|}{$\begin{array}{l}\text { Importante intercambio social con los } \\
\text { turistas. }\end{array}$} \\
\hline \multicolumn{2}{|l|}{ Identitarios } & \multicolumn{2}{|c|}{$\begin{array}{l}\text { Familia nacida/criada en la zona. Sentido de } \\
\text { pertenencia al lugar, el vínculo afectivo, por } \\
\text { la historia familiar, que los une a esas } \\
\text { tierras. Sentido político muy marcado en el } \\
\text { entrevistado. }\end{array}$} & \multicolumn{3}{|c|}{$\begin{array}{l}\text { Hombre nacido en la zona. Sentido de } \\
\text { pertenencia al lugar, vínculo afectivo, por la } \\
\text { historia familiar, que los une a esas tierras }\end{array}$} & \multicolumn{2}{|c|}{$\begin{array}{l}\text { Hombre nacido en la zona. Sentido de } \\
\text { pertenencia al lugar, vínculo afectivo, por la } \\
\text { historia familiar, que los une a esas tierras }\end{array}$} \\
\hline \multicolumn{2}{|c|}{ Aspectos territoriales } & \multicolumn{2}{|c|}{$\begin{array}{l}\text { Idiosincracia marcada por las crecidas de } \\
\text { los ríos e inundaciones. } \\
\text { Ubicación estratégica. } \\
\text { Insuficiente desarrollo del sector turístico. } \\
\text { Trabajo en red con asesoramiento de INTA. }\end{array}$} & \multicolumn{3}{|c|}{$\begin{array}{l}\text { Idiosincracia marcada por las crecidas de los } \\
\text { ríos e inundaciones. } \\
\text { Ubicación estratégica. } \\
\text { Insuficiente desarrollo del sector turístico. }\end{array}$} & \multicolumn{2}{|c|}{$\begin{array}{l}\text { Ubicación privilegiada, el entorno natural y la } \\
\text { misma idiosincrasia del lugareño son un } \\
\text { atractivo para el desarrollo del turismo. }\end{array}$} \\
\hline & \multicolumn{2}{|r|}{ Caso 1} & \multicolumn{2}{|l|}{ Caso 2} & Caso 3 & \multicolumn{2}{|c|}{ Caso 4} & Caso 5 \\
\hline $\begin{array}{l}\text { Causas para } \\
\text { la } \\
\text { incorporación } \\
\text { del turismo }\end{array}$ & \multicolumn{2}{|c|}{$\begin{array}{l}\text { Alternativa de } \\
\text { diversificación } \\
\text { Alternativa de futuro para la } \\
\text { pareja e hijos } \\
\text { Elemento de oportunidad } \\
\text { relacionado a cercanía a } \\
\text { termas y ubicación } \\
\text { estratégica. }\end{array}$} & \multicolumn{2}{|c|}{$\begin{array}{l}\text { Elemento de oportunidad } \\
\text { relacionado a cercanía a } \\
\text { termas y ubicación } \\
\text { estratégica. } \\
\text { Integración en red promovida } \\
\text { por política pública como } \\
\text { punto de partida. } \\
\text { Incentivo por parte de la } \\
\text { Municipalidad. } \\
\text { Actividad complementaria: } \\
\text { nuevos clientes y más ventas } \\
\text { para el almacén }\end{array}$} & $\begin{array}{l}\text { Potencial del casco de } \\
\text { estancia como alojamiento. } \\
\text { El turismo es a la vez una } \\
\text { inversión en vivienda. } \\
\text { Colabora a la conservación } \\
\text { del patrimonio familiar. } \\
\text { Demanda turística. } \\
\text { Oportunidad vivir en el } \\
\text { campo pero más } \\
\text { relacionados. }\end{array}$ & \multicolumn{2}{|c|}{$\begin{array}{l}\text { Alternativa de } \\
\text { diversificación de los } \\
\text { ingresos, en el marco de un } \\
\text { proceso de reconversión } \\
\text { productiva. } \\
\text { Crisis del sector tambero. } \\
\text { Desgaste físico de la } \\
\text { pareja. } \\
\text { Oportunidad dada por la } \\
\text { ubicación estratégica. } \\
\text { Oportunidad de trabajo } \\
\text { para los hijos. }\end{array}$} & $\begin{array}{l}\text { Alternativa de } \\
\text { diversificación. } \\
\text { Elemento de oportunidad } \\
\text { relacionado a cercanía a } \\
\text { termas y ubicación } \\
\text { estratégica. } \\
\text { Incentivo por parte de la } \\
\text { Municipalidad. } \\
\text { Potencial del almacén } \\
\text { como atractivo turístico. } \\
\text { Colabora a la conservación } \\
\text { del patrimonio familiar. }\end{array}$ \\
\hline
\end{tabular}




\begin{tabular}{|c|c|c|c|c|c|}
\hline & & & & $\begin{array}{l}\text { Incentivo por parte de la } \\
\text { Municipalidad. }\end{array}$ & $\begin{array}{l}\text { Oportunidad seguir } \\
\text { viviendo en el campo pero } \\
\text { más relacionados. }\end{array}$ \\
\hline $\begin{array}{l}\text { Interacción } \\
\text { productos }\end{array}$ & $\begin{array}{l}\text { Sí. Integración de } \\
\text { productos de la huerta y } \\
\text { citrus para el turismo. } \\
\text { Productos de la huerta se } \\
\text { ofrecen al turismo. Ofrecen } \\
\text { naranjas. } \\
\text { Paseos en el campo. }\end{array}$ & $\begin{array}{l}\text { Relativa (sólo venta de } \\
\text { huevos). No hay una } \\
\text { interacción importante entre } \\
\text { productos de diferentes } \\
\text { actividades. }\end{array}$ & $\begin{array}{l}\text { Sí. Hay integración de los } \\
\text { insumos de la producción } \\
\text { primaria para el consumo } \\
\text { familiar y como servicio } \\
\text { gastronómico que se brinda } \\
\text { al turismo }\end{array}$ & $\begin{array}{l}\text { Sí. Hay integración de los } \\
\text { insumos de la producción } \\
\text { primaria para el consumo } \\
\text { familiar y como servicio } \\
\text { gastronómico que se brinda } \\
\text { al turismo. Esto colabora a } \\
\text { la sustentabilidad del } \\
\text { sistema. (decisión y } \\
\text { necesidad) }\end{array}$ & $\begin{array}{l}\text { No se contempla } \\
\text { integración de los } \\
\text { productos de las } \\
\text { actividades productivas } \\
\text { como insumos de la } \\
\text { actividad turística, sí se da } \\
\text { entre el resto de las } \\
\text { actividades. }\end{array}$ \\
\hline $\begin{array}{l}\text { Interacción } \\
\text { RR }\end{array}$ & $\begin{array}{l}\text { Mismos recursos humanos } \\
\text { para todas las actividades. } \\
\text { Mayor organización y } \\
\text { distribución de roles. } \\
\text { Integración espacial. } \\
\text { Fundamental el rol de los } \\
\text { productores para transmitir } \\
\text { la esencia del lugar a los } \\
\text { turistas. }\end{array}$ & $\begin{array}{l}\text { Mismos recursos humanos } \\
\text { para todas las actividades. } \\
\text { Transmisión de saberes del } \\
\text { padre a los hijos. No hay } \\
\text { roles específicos. } \\
\text { Mismos recursos físicos y } \\
\text { materiales para las dos } \\
\text { actividades. }\end{array}$ & $\begin{array}{l}\text { Más empleados que mano } \\
\text { de obra familiar. } \\
\text { Están bien divididas las } \\
\text { funciones de los miembros } \\
\text { de la familia y cada } \\
\text { actividad tiene a la vez } \\
\text { empleados. } \\
\text { Hay roles específicos: la } \\
\text { mujer es la responsable del } \\
\text { turismo. Sus conocimientos } \\
\text { y posibilidad de viajar } \\
\text { aporta profesionalismo a la } \\
\text { actividad. } \\
\text { Uso del espacio } \\
\text { diferenciado: parte de las } \\
\text { actividades productivas que } \\
\text { no requieren uso de } \\
\text { agroquímicos se } \\
\text { desarrollan en el predio de } \\
\text { la estancia, donde a la vez } \\
\text { vive la familia }\end{array}$ & $\begin{array}{l}\text { Mismos recursos humanos } \\
\text { para todas las actividades. } \\
\text { Reorganización de tareas } \\
\text { que potencia las } \\
\text { capacidades y gustos } \\
\text { personales de los } \\
\text { miembros de la familia. } \\
\text { Integración espacial, de } \\
\text { maquinarias y } \\
\text { equipamientos para varias } \\
\text { actividades del sistema, por } \\
\text { ejemplo el tractor. } \\
\text { Fundamental el rol de los } \\
\text { productores para transmitir } \\
\text { la esencia del lugar a los } \\
\text { turistas. }\end{array}$ & $\begin{array}{l}\text { En este caso se combina } \\
\text { mano de obra familiar con } \\
\text { asalariada. } \\
\text { Están bien divididas las } \\
\text { funciones de los miembros } \\
\text { de la familia y cada } \\
\text { actividad tiene a la vez } \\
\text { empleados. } \\
\text { Fundamental el rol de los } \\
\text { productores para transmitir } \\
\text { la esencia del lugar a los } \\
\text { turistas. } \\
\text { No hay competencia por el } \\
\text { uso de la tierra porque cada } \\
\text { actividad se realiza en } \\
\text { predios diferentes. } \\
\text { Refuerzo del vínculo con las } \\
\text { familias de la colonia, se } \\
\text { revalorizan los productos } \\
\text { elaborados por gente de la } \\
\text { zona que se venden en el } \\
\text { almacén. }\end{array}$ \\
\hline $\begin{array}{l}\text { Interacción } \\
\text { patrimonial }\end{array}$ & $\begin{array}{l}\text { Revalorización del } \\
\text { patrimonio intangible } \\
\text { vinculado a la historia } \\
\text { familiar y saberes de la }\end{array}$ & $\begin{array}{l}\text { Revalorización del } \\
\text { patrimonio tangible } \\
\text { (arquitectónico, histórico y } \\
\text { cultural) e intangible. }\end{array}$ & $\begin{array}{l}\text { Revalorización del } \\
\text { patrimonio tangible } \\
\text { (arquitectónico, histórico y } \\
\text { cultural). El sustento del }\end{array}$ & $\begin{array}{l}\text { Puesta en valor del } \\
\text { patrimonio natural y paisaje } \\
\text { Revalorización del } \\
\text { patrimonio intangible }\end{array}$ & $\begin{array}{l}\text { Revalorización del } \\
\text { patrimonio tangible } \\
\text { (arquitectónico, histórico y } \\
\text { cultural) e intangible. El }\end{array}$ \\
\hline
\end{tabular}




\begin{tabular}{|c|c|c|c|c|c|}
\hline & $\begin{array}{l}\text { familia en torno al perfil } \\
\text { productivo. } \\
\text { Reconocimiento que } \\
\text { refuerza la autoestima. }\end{array}$ & $\begin{array}{l}\text { El turismo refuerza su } \\
\text { identidad, familiar y } \\
\text { comunitaria. }\end{array}$ & $\begin{array}{l}\text { turismo es el patrimonio } \\
\text { (caso de estancia). } \\
\text { Colabora a su } \\
\text { conservación y } \\
\text { mantenimiento. }\end{array}$ & $\begin{array}{l}\text { vinculado a los saberes de } \\
\text { la familia en torno al perfil } \\
\text { productivo. } \\
\text { Reconocimiento que } \\
\text { refuerza la autoestima }\end{array}$ & $\begin{array}{l}\text { sustento del turismo es el } \\
\text { patrimonio (almacén). } \\
\text { Colabora a su } \\
\text { conservación y } \\
\text { mantenimiento. }\end{array}$ \\
\hline $\begin{array}{l}\text { Interacción } \\
\text { temporal }\end{array}$ & $\begin{array}{l}\text { Sí. Complementa la } \\
\text { actividad principal en ciclos } \\
\text { de baja de producción. } \\
\text { Visión anticipada a futuro } \\
\text { en relación al desarrollo } \\
\text { local del turismo. }\end{array}$ & $\begin{array}{l}\text { No es a largo plazo. } \\
\text { Anticipación a momentos de } \\
\text { mayor flujo de visitantes. }\end{array}$ & $\begin{array}{l}\text { Sí. Anticipación de la } \\
\text { pareja a momento en que } \\
\text { los hijos no vivan en la } \\
\text { casa. Necesidad de } \\
\text { generar otra actividad que } \\
\text { colabore al mantenimiento } \\
\text { del edificio. }\end{array}$ & $\begin{array}{l}\text { Sí. El turismo se integra al } \\
\text { sistema como una } \\
\text { alternativa de trabajo a } \\
\text { futuro concretamente para } \\
\text { la pareja de productores. } \\
\text { La estrategia es que } \\
\text { paulatinamente se vaya } \\
\text { convirtiendo en su actividad } \\
\text { principal para los próximos } \\
\text { años }\end{array}$ & $\begin{array}{l}\text { No es a largo plazo. } \\
\text { Anticipación a momentos } \\
\text { de mayor flujo de } \\
\text { visitantes. }\end{array}$ \\
\hline $\begin{array}{l}\text { Interacción } \\
\text { ingreso/ } \\
\text { sentido del } \\
\text { trabajo }\end{array}$ & $\begin{array}{l}\text { Turismo reporta } \\
\text { satisfacciones en torno al } \\
\text { reconocimiento social. } \\
\text { Actividad que agrada } \\
\text { realizarse. }\end{array}$ & $\begin{array}{l}\text { Turismo reporta } \\
\text { satisfacciones en torno al } \\
\text { reconocimiento social. } \\
\text { Actividad que agrada } \\
\text { realizarse. }\end{array}$ & $\begin{array}{l}\text { Turismo, actividad social, } \\
\text { reconocimiento por el } \\
\text { resguardo patrimonial. }\end{array}$ & $\begin{array}{l}\text { Turismo reporta } \\
\text { satisfacciones en torno al } \\
\text { reconocimiento social y } \\
\text { aportes a la salud de los } \\
\text { miembros de la familia; } \\
\text { refuerza la autoestima } \\
\text { personal y es un vehículo } \\
\text { para reforzar la identidad }\end{array}$ & $\begin{array}{l}\text { La combinación de las } \\
\text { actividades permite } \\
\text { sostener la propuesta } \\
\text { turística del almacén que } \\
\text { genera más satisfacciones } \\
\text { que ingresos. }\end{array}$ \\
\hline $\begin{array}{l}\text { Interacción } \\
\text { ingreso }\end{array}$ & $\begin{array}{l}\text { Hay complementariedad. } \\
\text { Hoy más importante el } \\
\text { ingreso por producción } \\
\text { hortícola. }\end{array}$ & $\begin{array}{l}\text { Complementariedad. } \\
\text { El ingreso económico para la } \\
\text { vida de la familia está dada } \\
\text { por el almacén y alquileres } \\
\text { (entrada fija mensual). La } \\
\text { integración del turismo } \\
\text { aporta un } 40 \% \text { más de } \\
\text { ventas (en temporada). }\end{array}$ & $\begin{array}{l}\text { Complementariedad. El } \\
\text { ingreso por turismo es } \\
\text { menor pero el proyecto de } \\
\text { la estancia sin el proyecto } \\
\text { de turismo en el tiempo es } \\
\text { insustentable. }\end{array}$ & $\begin{array}{l}\text { Hay complementariedad. } \\
\text { La familia integra los } \\
\text { ingresos de las tres } \\
\text { actividades y el tambo es el } \\
\text { más sólido y estable. }\end{array}$ & $\begin{array}{l}\text { Hay complementariedad. } \\
\text { Las actividades en su } \\
\text { conjunto contribuyen al } \\
\text { ingreso total que permite } \\
\text { cumplir las necesidades y } \\
\text { expectativas de la familia. }\end{array}$ \\
\hline & Caso 6 & Caso 7 & Caso 8 & Caso 9 & Caso 10 \\
\hline $\begin{array}{l}\text { Causas para } \\
\text { la } \\
\text { incorporación } \\
\text { del turismo }\end{array}$ & $\begin{array}{l}\text { Elemento de crisis en el } \\
\text { comienzo (sequía) } \\
\text { Elemento de oportunidad y } \\
\text { visión de negocio a futuro. }\end{array}$ & $\begin{array}{l}\text { Elemento de crisis familiar } \\
\text { (fallecimiento de uno de los } \\
\text { hijos). }\end{array}$ & $\begin{array}{l}\text { Elemento de oportunidad y } \\
\text { visión a futuro. }\end{array}$ & $\begin{array}{l}\text { Elemento de crisis en el } \\
\text { comienzo asociado a la } \\
\text { baja del precio de la } \\
\text { madera. }\end{array}$ & $\begin{array}{l}\text { Incorporan el turismo de la } \\
\text { mano de la gastronomía, } \\
\text { para complementar los } \\
\text { ingresos de la pesca, pero }\end{array}$ \\
\hline
\end{tabular}




\begin{tabular}{|c|c|c|c|c|c|}
\hline & $\begin{array}{l}\text { Alternativa de futuro para la } \\
\text { pareja e hijos. } \\
\text { Herramienta para valorizar } \\
\text { el campo. }\end{array}$ & $\begin{array}{l}\text { Integración en red promovida } \\
\text { por política pública como } \\
\text { punto de partida. } \\
\text { Incentivo por parte de la } \\
\text { Municipalidad. } \\
\text { Compra del campo como } \\
\text { inversión, como negocio, que } \\
\text { a la vez ayuda al } \\
\text { mantenimiento de los gastos } \\
\text { fijos de la casa en el campo. }\end{array}$ & $\begin{array}{l}\text { Alternativa de ingresos. } \\
\text { Herramienta para valorizar } \\
\text { el campo. }\end{array}$ & $\begin{array}{l}\text { El turismo surge asociado a } \\
\text { una necesidad de } \\
\text { diversificar, como una } \\
\text { actividad complementaria. } \\
\text { Elemento de oportunidad } \\
\text { asociado a la cercanía a Bs } \\
\text { As. } \\
\text { Cada vez se fue haciendo } \\
\text { más importante en el } \\
\text { sistema. }\end{array}$ & $\begin{array}{l}\text { luego se convirtió en su } \\
\text { actividad central. } \\
\text { Elemento de crisis } \\
\text { relacionado con la baja del } \\
\text { precio del pescado. } \\
\text { Continúan con esta } \\
\text { actividad que les da más } \\
\text { tranquilidad y estabilidad } \\
\text { económica. }\end{array}$ \\
\hline $\begin{array}{l}\text { Interacción } \\
\text { productos }\end{array}$ & $\begin{array}{l}\text { No se contempla } \\
\text { integración de los } \\
\text { productos de las } \\
\text { actividades productivas } \\
\text { como insumos de la } \\
\text { actividad turística, sí se da } \\
\text { entre el resto de las } \\
\text { actividades. }\end{array}$ & $\begin{array}{l}\text { No hay integración entre las } \\
\text { actividades. Espacialmente } \\
\text { se desarrollan en diferentes } \\
\text { lugares. }\end{array}$ & $\begin{array}{l}\text { Fuerte integración de la } \\
\text { producción primaria a la } \\
\text { actividad turística. }\end{array}$ & $\begin{array}{l}\text { No es tan fuerte. Hay } \\
\text { integración de los } \\
\text { productos de la producción } \\
\text { primaria para la } \\
\text { construcción de cabañas. }\end{array}$ & $\begin{array}{l}\text { No hay integración porque } \\
\text { la gastronomía desplazó a } \\
\text { la pesca como actividad de } \\
\text { la familia. }\end{array}$ \\
\hline $\begin{array}{l}\text { Interacción } \\
\text { RR }\end{array}$ & $\begin{array}{l}\text { Mayor organización y } \\
\text { distribución de roles. } \\
\text { Integración espacial. Uso } \\
\text { del espacio diferenciado. } \\
\text { Fundamental el rol de los } \\
\text { productores para transmitir } \\
\text { la esencia del lugar a los } \\
\text { turistas. } \\
\text { El turismo es vinculante. } \\
\text { Refuerzo del vínculo con } \\
\text { las familias de la colonia, } \\
\text { se revalorizan los } \\
\text { productos elaborados por } \\
\text { gente de la zona que se } \\
\text { venden allí. }\end{array}$ & $\begin{array}{l}\text { No hay relación de la } \\
\text { actividad turística con las } \\
\text { actividades productivas que } \\
\text { se desarrollan en el campo } \\
\text { que alquilan. Son espacios } \\
\text { diferentes y no se combinan } \\
\text { ni comunican. } \\
\text { Los recursos que movilizan } \\
\text { es el humano familiar, que se } \\
\text { distribuye entre las dos } \\
\text { actividades. }\end{array}$ & $\begin{array}{l}\text { Principales recursos que se } \\
\text { movilizan en común para } \\
\text { las actividades son la mano } \\
\text { de obra que es familiar y } \\
\text { los recursos físicos y } \\
\text { materiales. } \\
\text { Mayor organización y } \\
\text { distribución de roles. } \\
\text { Integración espacial. }\end{array}$ & $\begin{array}{l}\text { Principales recursos que se } \\
\text { movilizan en común para } \\
\text { las actividades son la mano } \\
\text { de obra que es familiar. } \\
\text { Integración espacial, de } \\
\text { maquinarias y } \\
\text { equipamientos para varias } \\
\text { actividades del sistema. } \\
\text { Fundamental el rol de los } \\
\text { productores para transmitir } \\
\text { la esencia del lugar a los } \\
\text { turistas. }\end{array}$ & $\begin{array}{l}\text { Los recursos materiales } \\
\text { con los que cuenta hoy la } \\
\text { actividad gastronómica son } \\
\text { producto de las ganancias } \\
\text { de la actividad pesquera. Y } \\
\text { gracias a esta actividad } \\
\text { también se pudo reactivar } \\
\text { el tambo y quesería en } \\
\text { Uruguay. }\end{array}$ \\
\hline $\begin{array}{l}\text { Interacción } \\
\text { patrimonial }\end{array}$ & $\begin{array}{l}\text { Revalorización del } \\
\text { patrimonio tangible } \\
\text { (arquitectónico, histórico y } \\
\text { cultural) e intangible. El } \\
\text { sustento del turismo es el } \\
\text { patrimonio de la casona. }\end{array}$ & No aparece & $\begin{array}{l}\text { Revalorización del } \\
\text { patrimonio tangible } \\
\text { (arquitectónico, histórico y } \\
\text { cultural) e intangible. Parte } \\
\text { del sustento del turismo es } \\
\text { el patrimonio de la casona. }\end{array}$ & $\begin{array}{l}\text { Valorización del patrimonio } \\
\text { intangible (actividad } \\
\text { forestal que no se } \\
\text { abandona) por un apego a } \\
\text { las tradiciones, al } \\
\text { patrimonio familiar. }\end{array}$ & $\begin{array}{l}\text { No es trascendental en } \\
\text { este sistema. }\end{array}$ \\
\hline
\end{tabular}




\begin{tabular}{|c|c|c|c|c|c|c|c|}
\hline & $\begin{array}{l}\text { Colabora a su } \\
\text { conservación y } \\
\text { mantenimiento. } \\
\text { El turismo refuerza su } \\
\text { identidad, familiar y } \\
\text { comunitaria. }\end{array}$ & & & $\begin{array}{l}\text { Colabora a su } \\
\text { conservación y } \\
\text { mantenimiento. } \\
\text { El turismo refuerza su } \\
\text { identidad, familiar y } \\
\text { comunitaria. Propuesta } \\
\text { turística con un fuerte } \\
\text { contenido histórico y de } \\
\text { naturaleza, ligada a los dos } \\
\text { atractivos fuertes del lugar. }\end{array}$ & \multicolumn{2}{|c|}{$\begin{array}{l}\text { El turismo refuerza su } \\
\text { identidad, familiar y } \\
\text { comunitaria. }\end{array}$} & \\
\hline $\begin{array}{l}\text { Interacción } \\
\text { temporal }\end{array}$ & $\begin{array}{l}\text { La pareja invierte en } \\
\text { turismo porque vislumbran } \\
\text { en la actividad una } \\
\text { alternativa con proyección } \\
\text { a futuro y más placentera. }\end{array}$ & \multicolumn{2}{|c|}{$\begin{array}{l}\text { La familia se dedica al } \\
\text { turismo sobre todo los fines } \\
\text { de semana de forma de no } \\
\text { interferir con los tiempos de } \\
\text { su actividad principal. }\end{array}$} & $\begin{array}{l}\text { Puesta en marcha de } \\
\text { estrategias ligadas a la } \\
\text { temporalidad de la } \\
\text { actividad turística. }\end{array}$ & \multicolumn{2}{|c|}{$\begin{array}{l}\text { Los ciclos de las crecientes } \\
\text { condicionan los procesos } \\
\text { de anticipación. }\end{array}$} & $\begin{array}{l}\text { La gastronomía surge } \\
\text { como estrategia ligada a la } \\
\text { temporalidad de la pesca } \\
\text { comercial. }\end{array}$ \\
\hline $\begin{array}{l}\text { Interacción } \\
\text { ingreso/ } \\
\text { sentido del } \\
\text { trabajo }\end{array}$ & $\begin{array}{l}\text { Turismo reporta } \\
\text { satisfacciones en torno al } \\
\text { reconocimiento social. } \\
\text { Actividad que agrada } \\
\text { realizarse. }\end{array}$ & \multicolumn{2}{|c|}{$\begin{array}{l}\text { El objetivo es más } \\
\text { económico pero el turismo } \\
\text { aporta a un objetivo mayor } \\
\text { que tiene que ver con el } \\
\text { disfrute familiar. }\end{array}$} & $\begin{array}{l}\text { La combinación de } \\
\text { actividades se da } \\
\text { motivadas por lo } \\
\text { económico pero a la vez, el } \\
\text { turismo genera } \\
\text { satisfacciones personales: } \\
\text { reconocimiento de la } \\
\text { comunidad, el vínculo con } \\
\text { los turistas, contacto social. } \\
\text { Actividad que agrada } \\
\text { realizarse. }\end{array}$ & \multicolumn{2}{|c|}{$\begin{array}{l}\text { Involucramiento en } \\
\text { actividades comunitarias } \\
\text { que generan sentido } \\
\text { político y satisfacciones } \\
\text { personales. }\end{array}$} & $\begin{array}{l}\text { La actividad gastronómica/ } \\
\text { turismo implica menor } \\
\text { desgaste físico que la } \\
\text { pesca, condición que ha } \\
\text { sido determinante para } \\
\text { dejar esta actividad y } \\
\text { dedicarse a la gastronomía. }\end{array}$ \\
\hline $\begin{array}{l}\text { Interacción } \\
\text { ingreso }\end{array}$ & $\begin{array}{l}\text { Complementariedad. El } \\
\text { ingreso por turismo es } \\
\text { menor. La familia integra } \\
\text { los ingresos de todas las } \\
\text { actividades. }\end{array}$ & \multicolumn{2}{|c|}{$\begin{array}{l}\text { Complementariedad. El } \\
\text { ingreso por turismo es } \\
\text { menor. La familia integra los } \\
\text { ingresos de todas las } \\
\text { actividades. }\end{array}$} & $\begin{array}{l}\text { Una combinación de } \\
\text { actividades que genera } \\
\text { ingresos, aunque la } \\
\text { principal sea el turismo. }\end{array}$ & \multicolumn{2}{|c|}{$\begin{array}{l}\text { Una combinación de } \\
\text { actividades que genera } \\
\text { ingresos, aunque la } \\
\text { principal sea el turismo y el } \\
\text { servicio a terceros. }\end{array}$} & $\begin{array}{l}\text { Una sola actividad de } \\
\text { generación de ingresos. }\end{array}$ \\
\hline & \multicolumn{2}{|c|}{ Caso 11} & \multicolumn{3}{|c|}{ Caso 12} & \multicolumn{2}{|c|}{ Caso 13} \\
\hline $\begin{array}{l}\text { Causas para } \\
\text { la } \\
\text { incorporación } \\
\text { del turismo }\end{array}$ & \multicolumn{2}{|c|}{$\begin{array}{l}\text { El turismo surge como una actividad } \\
\text { complementaria a la que desarrollaban. } \\
\text { Visión de que es una actividad con futuro. } \\
\text { Obedece a la caída de las otras actividades. }\end{array}$} & \multicolumn{3}{|c|}{$\begin{array}{l}\text { El turismo surge como una actividad } \\
\text { complementaria a la que desarrollaban. } \\
\text { Inversión a futuro (jubilación privada). } \\
\text { Elemento de oportunidad y visión a futuro. }\end{array}$} & \multicolumn{2}{|c|}{$\begin{array}{l}\text { Elemento de oportunidad cuando endicaron la } \\
\text { isla. } \\
\text { Actividad que les agrada realizar. }\end{array}$} \\
\hline
\end{tabular}




\begin{tabular}{|c|c|c|c|c|c|c|c|}
\hline & \multicolumn{5}{|c|}{ Ubicación estratégica que favorece su desarrollo. } & & \\
\hline $\begin{array}{l}\text { Interacción } \\
\text { productos }\end{array}$ & \multicolumn{2}{|c|}{$\begin{array}{l}\text { No hay integración entre las actividades. } \\
\text { Espacialmente se desarrollan en diferentes lugares. }\end{array}$} & \multicolumn{3}{|c|}{ No hay integración entre las actividades. } & \multicolumn{2}{|c|}{$\begin{array}{l}\text { Hay integración a partir de la gastronomía isleña } \\
\text { en base a los pescados que ellos pescan. }\end{array}$} \\
\hline $\begin{array}{l}\text { Interacción } \\
\text { RR }\end{array}$ & \multicolumn{2}{|c|}{$\begin{array}{l}\text { La pareja es la base de todo el sistema, más la } \\
\text { contratación de recursos para tareas específicas en } \\
\text { momentos concretos. Roles y tiempos bien } \\
\text { marcados. }\end{array}$} & \multicolumn{3}{|c|}{$\begin{array}{l}\text { La pareja es la base de todo el sistema, } \\
\text { más la contratación de recursos. } \\
\text { Espacialmente hay uso de recursos en } \\
\text { común ya que en el mismo predio del hotel } \\
\text { han construido otros espacios comerciales. }\end{array}$} & \multicolumn{2}{|c|}{$\begin{array}{l}\text { La pareja es la base de todo el sistema. } \\
\text { Los recursos naturales son el principal atractivo } \\
\text { del lugar. }\end{array}$} \\
\hline $\begin{array}{l}\text { Interacción } \\
\text { patrimonial }\end{array}$ & \multicolumn{2}{|c|}{$\begin{array}{l}\text { Valorización del patrimonio natural de la zona, } \\
\text { intangible (en torno a lo cultural y social). } \\
\text { El turismo refuerza su identidad, familiar y } \\
\text { comunitaria. }\end{array}$} & & & & \multicolumn{2}{|c|}{$\begin{array}{l}\text { Valorización del patrimonio natural de la zona e } \\
\text { intangible (en torno a lo cultural y social). }\end{array}$} \\
\hline $\begin{array}{l}\text { Interacción } \\
\text { temporal }\end{array}$ & \multicolumn{2}{|c|}{$\begin{array}{l}\text { Puesta en marcha de estrategias ligadas a la } \\
\text { temporalidad de la actividad turística. Visión de } \\
\text { futuro respecto al desarrollo del turismo. Capacidad } \\
\text { de anticipación. }\end{array}$} & \multicolumn{3}{|c|}{$\begin{array}{l}\text { Anticipación a los ingresos del futuro de la } \\
\text { pareja. Puesta en marcha de estrategias } \\
\text { ligadas a la temporalidad de la actividad } \\
\text { turística. }\end{array}$} & & \\
\hline $\begin{array}{l}\text { Interacción } \\
\text { ingreso/ } \\
\text { sentido del } \\
\text { trabajo }\end{array}$ & \multicolumn{2}{|c|}{$\begin{array}{l}\text { Es más fuerte el engranaje económico con un plazo } \\
\text { de tiempo determinado. }\end{array}$} & \multicolumn{3}{|c|}{$\begin{array}{l}\text { Se da un proceso de abandono de la } \\
\text { actividad que generaba más ingresos, } \\
\text { como la ganadería, pero que aparejaba una } \\
\text { vida de mayor sacrificio. }\end{array}$} & \multicolumn{2}{|c|}{$\begin{array}{l}\text { Actividad que además de generar ingresos les } \\
\text { agrada, la disfruta. }\end{array}$} \\
\hline $\begin{array}{l}\text { Interacción } \\
\text { ingreso }\end{array}$ & \multicolumn{2}{|c|}{$\begin{array}{l}\text { Una combinación de actividades que genera } \\
\text { ingresos, aunque la principal sea el turismo y el } \\
\text { comercio. Complementariedad dada la } \\
\text { estacionalidad. }\end{array}$} & \multicolumn{3}{|c|}{$\begin{array}{l}\text { Una combinación de actividades que } \\
\text { genera ingresos, aunque la principal sea el } \\
\text { turismo y los alquileres fijos. } \\
\text { Complementariedad dada la } \\
\text { estacionalidad. }\end{array}$} & \multicolumn{2}{|c|}{ Dos ingresos complementarios. } \\
\hline & Caso 1 & \multicolumn{2}{|l|}{ Caso 2} & Caso 3 & \multicolumn{2}{|c|}{ Caso 4} & Caso 5 \\
\hline $\begin{array}{l}\text { Decisiones, } \\
\text { objetivos y } \\
\text { estrategias }\end{array}$ & $\begin{array}{lrr}\text { Apuesta } & \text { al turismo. } \\
\text { Proyecto } & \text { ampliar } & \text { y } \\
\text { completar el } & \text { complejo para } \\
\text { generar mayor rentabilidad y } \\
\text { que un miembro de la familia } \\
\text { se dedique exclusivamente } \\
\text { a esta } & \text { actividad } \\
\text { productora) } & & \\
\end{array}$ & $\begin{array}{l}\text { El turismo hoy repres } \\
\text { ingreso más al gener } \\
\text { el almacén y no a } \\
\text { ritmo familiar ni del } n \\
\text { Lo han incorpora } \\
\text { manera natural. }\end{array}$ & $\begin{array}{l}\text { enta un } \\
\text { ado por } \\
\text { tera el } \\
\text { egocio. } \\
\text { do de }\end{array}$ & $\begin{array}{l}\text { Continuar con el desarrollo } \\
\text { de la actividad con mayor } \\
\text { profesionalismo y } \\
\text { dedicación. Apuestan al } \\
\text { crecimiento de la actividad } \\
\text { y en ir agregando servicios } \\
\text { vinculados con la } \\
\text { producción local. }\end{array}$ & $\begin{array}{l}\text { El turis } \\
\text { comer } \\
\text { produc } \\
\text { la mat } \\
\text { su car } \\
\text { Elabol } \\
\text { produc } \\
\text { turism }\end{array}$ & $\begin{array}{l}\text { smo es un canal de } \\
\text { cialización de los } \\
\text { ctos que elaboran con } \\
\text { eria prima que brinda } \\
\text { npo. } \\
\text { ran todos los } \\
\text { ctos que ofrecen al } \\
\text { o. }\end{array}$ & $\begin{array}{l}\text { El turismo reporta una serie } \\
\text { de satisfacciones que son } \\
\text { vitales para la pareja de } \\
\text { productores, } \\
\text { fundamentalmente } \\
\text { relacionados a la bienestar } \\
\text { personal y a lo vincular. }\end{array}$ \\
\hline
\end{tabular}




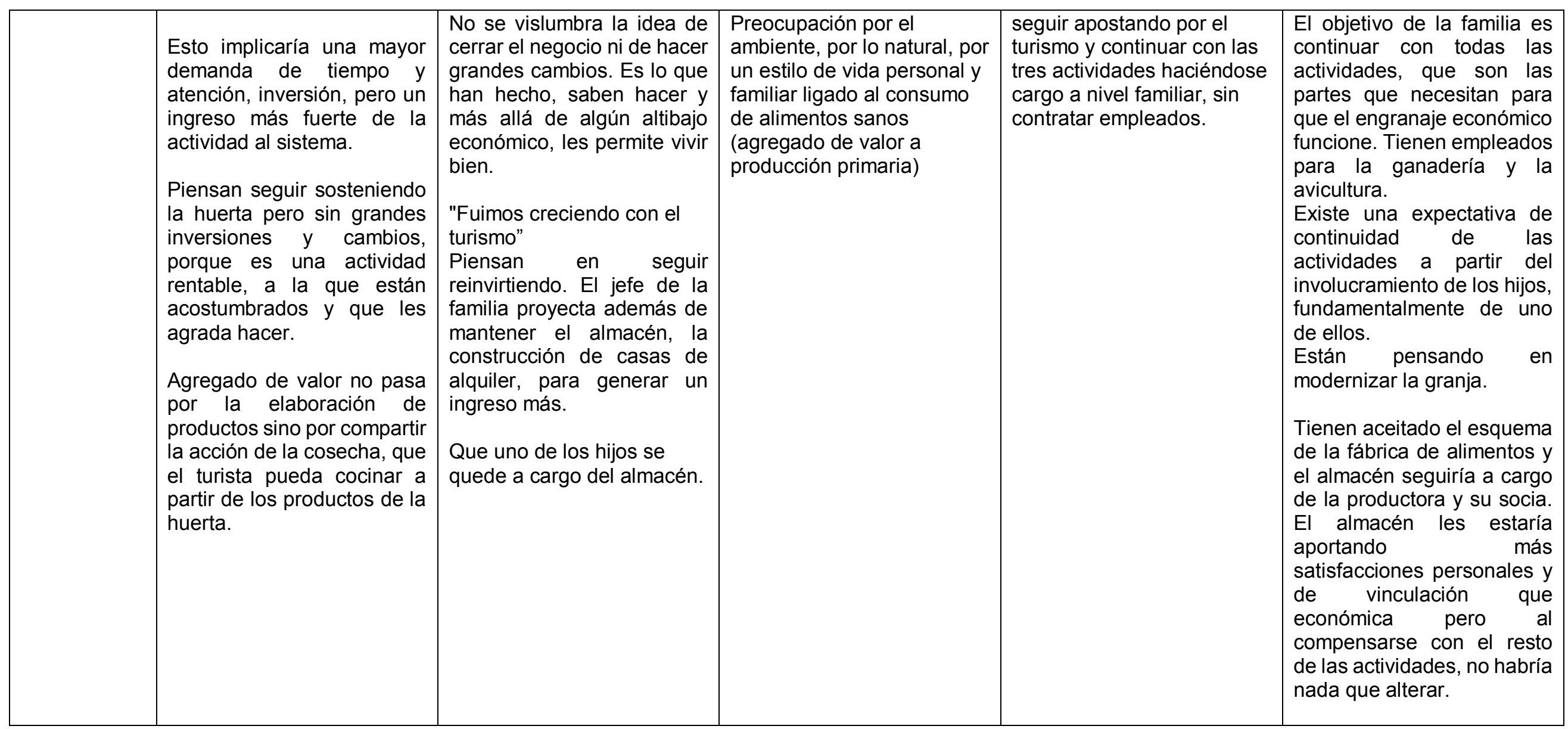

\begin{tabular}{|c|c|c|c|c|c|}
\hline & Caso 6 & Caso 7 & Caso 8 & Caso 9 & Caso 10 \\
\hline $\begin{array}{l}\text { Decisiones, } \\
\text { objetivos y } \\
\text { estrategias }\end{array}$ & $\begin{array}{l}\text { Continuar con las } \\
\text { actividades del sistema, si } \\
\text { es necesario contratando } \\
\text { empleados, no para turismo } \\
\text { porque entienden que en }\end{array}$ & $\begin{array}{l}\text { Actualmente la prioridad es } \\
\text { finalizar la construcción del } \\
\text { galpón en el área industrial. } \\
\text { La idea de la pareja es } \\
\text { ceder la fábrica a mano de } \\
\text { uno de sus hijos y ellos }\end{array}$ & $\begin{array}{l}\text { Su objetivo es fortalecer la } \\
\text { oferta de servicios que le } \\
\text { ofrecen al turista, no agregar } \\
\text { más servicios. Mejorar } \\
\text { también la puesta en }\end{array}$ & $\begin{array}{lr}\text { Actividad forestal } & \text { en } \\
\text { retraimiento. Les implica } & \text { Les } \\
\text { una gran inversión } & \text { que no } \\
\text { les genera r tanta } & \text { Su } \\
\text { rentabilidad. } & \text { Su }\end{array}$ & $\begin{array}{l}\text { Apuestan a la gastronomía y } \\
\text { el turismo. Creen en el } \\
\text { turismo. En pesca no tienen } \\
\text { pensado continuar a corto } \\
\text { plazo al menos la pareja. } \\
\text { Cuentan con el capital, que }\end{array}$ \\
\hline
\end{tabular}




\begin{tabular}{|c|c|c|c|c|}
\hline $\begin{array}{l}\text { esta actividad deben estar } \\
\text { ellos. } \\
\text { "El turismo rural es una } \\
\text { entrada más de dinero" } \\
\text { Apuestan por el turismo. } \\
\text { Piensan que tiene el turismo } \\
\text { rural tiene futuro como } \\
\text { actividad. }\end{array}$ & $\begin{array}{l}\text { continuar con } \\
\text { emprendimiento turístico } \\
\text { "sin enloquecernos, a } \\
\text { disfrutar la familia y al } \\
\text { disfrute personal". } \\
\text { Respecto al turismo, } \\
\text { proyectan continuar, seguir } \\
\text { invirtiendo y piensan en } \\
\text { algunas alternativas para el } \\
\text { complejo. Les gustaría } \\
\text { construir las cabañas }\end{array}$ & $\begin{array}{l}\text { funcionamiento del museo } \\
\text { en la casona. }\end{array}$ & $\begin{array}{l}\text { sostenimiento está más } \\
\text { asociada a la tradición. } \\
\text { Piensan apostar a la } \\
\text { ganadería como alternativa } \\
\text { de diversificación de manera } \\
\text { progresiva. Van invirtiendo } \\
\text { de a poco, pero lo ven } \\
\text { "como una forma de ahorro". } \\
\text { En referencia al turismo, la } \\
\text { hija menor es la que más } \\
\text { aporta ideas y proyectos. } \\
\text { Invirtió en kayaks para } \\
\text { ofrecer actividades, pero } \\
\text { según la entrevistada "los } \\
\text { ofrezco si está ella". De otra } \\
\text { manera le genera } \\
\text { complicaciones. }\end{array}$ & $\begin{array}{l}\text { no quieren vender, para una } \\
\text { posible integración de } \\
\text { miembros de la familia. }\end{array}$ \\
\hline
\end{tabular}

\begin{tabular}{|c|c|c|c|}
\hline & Caso 11 & Caso 12 & Caso 13 \\
\hline $\begin{array}{l}\text { Decisiones, } \\
\text { objetivos y } \\
\text { estrategias }\end{array}$ & $\begin{array}{l}\text { Apuestan al turismo y a } \\
\text { futuro, aparentemente la } \\
\text { idea es dejar la tienda. } \\
\text { Al día de hoy la pareja } \\
\text { trabaja intensamente en las } \\
\text { tres actividades que } \\
\text { requieren su presencia y } \\
\text { mano de obra: la tienda, el } \\
\text { turismo y el servicio de } \\
\text { catering. Pero el límite } \\
\text { temporal de esta } \\
\text { organización es "hasta que } \\
\text { la hija termine de estudiar } \\
\text { en La Plata". Creen en el } \\
\text { turismo y en el crecimiento } \\
\text { de su zona. }\end{array}$ & $\begin{array}{l}\text { Apuestan al turismo. A partir } \\
\text { de la incorporación del } \\
\text { turismo abandonan la } \\
\text { actividad ganadera y luego } \\
\text { deciden poner el local en } \\
\text { alquiler, donde antes } \\
\text { funcionaba la librería } \\
\text { familiar. } \\
\text { No piensan seguir } \\
\text { invirtiendo en turismo. } \\
\text { Pretenden vender el campo } \\
\text { para tener una vida más } \\
\text { tranquila. }\end{array}$ & $\begin{array}{l}\text { No menciona cambios a futuro. } \\
\text { Como se ha mencionado } \\
\text { anteriormente, la forma de vida } \\
\text { que lleva la familia es tranquila, } \\
\text { relajada, cuentan con dos } \\
\text { viviendas, una en el pueblo y } \\
\text { una en la isla, sus hijos ya son } \\
\text { independientes. } \\
\text { Además, tienen un capital } \\
\text { económico de resguardo. }\end{array}$ \\
\hline
\end{tabular}




\begin{tabular}{|c|c|c|c|c|c|}
\hline & Caso 1 & Caso 2 & Caso 3 & Caso 4 & Caso 5 \\
\hline $\begin{array}{l}\text { Cambios } \\
\text { más } \\
\text { importantes } \\
\text { en el sistema } \\
\text { productivo }\end{array}$ & $\begin{array}{l}\text { No reemplaza la actividad } \\
\text { principal. No la desplaza. } \\
\text { Apuesta e inversión al } \\
\text { turismo, no a la producción } \\
\text { principal. } \\
\text { Integración de las dos } \\
\text { actividades. } \\
\text { La huerta es la esencia del } \\
\text { turismo. Agrega valor a la } \\
\text { producción primaria. }\end{array}$ & $\begin{array}{l}\text { El turismo no es la actividad } \\
\text { principal. Complementa la } \\
\text { comercial. Es un ingreso } \\
\text { complementario. Moviliza la } \\
\text { inversión de la familia (2013 } \\
\text { en adelante construcción de } \\
\text { departamentos). Integración } \\
\text { de las dos actividades. El } \\
\text { almacén es la esencia del } \\
\text { turismo. No altera el ritmo del } \\
\text { almacén que opera de igual } \\
\text { manera que siempre. }\end{array}$ & $\begin{array}{l}\text { No modifica el resto de las } \\
\text { actividades productivas del } \\
\text { sistema. } \\
\text { Agrega valor a la } \\
\text { producción primaria. } \\
\text { Complementa } \\
\text { económicamente. Colabora } \\
\text { al mantenimiento del } \\
\text { patrimonio. } \\
\text { Es una actividad a la que la } \\
\text { pareja piensa dedicarse en } \\
\text { un futuro. }\end{array}$ & $\begin{array}{l}\text { Su integración colabora al } \\
\text { engranaje de los productos } \\
\text { de las diversas actividades. } \\
\text { Decisión de los productores } \\
\text { de retraer la actividad } \\
\text { tambera. } \\
\text { El tambo es la esencia del } \\
\text { turismo. Agrega valor a la } \\
\text { producción primaria. }\end{array}$ & $\begin{array}{l}\text { No reemplaza la actividad } \\
\text { principal. No la desplaza. } \\
\text { No modifica el resto de las } \\
\text { actividades productivas del } \\
\text { sistema. }\end{array}$ \\
\hline $\begin{array}{l}\text { Cambios en } \\
\text { las personas } \\
\text { y familia }\end{array}$ & $\begin{array}{l}\text { Mujer a futuro más dedicada } \\
\text { al turismo. } \\
\text { Modificaciones en los tiempos } \\
\text { de la familia pero con } \\
\text { posibilidad de organización. } \\
\text { Más actividades en las cuales } \\
\text { distribuir los tiempos. } \\
\text { Impacto negativo sobre } \\
\text { tiempos de ocio. Temporal. } \\
\text { Refuerza la autoestima. } \\
\text { Apertura mental y cultural. }\end{array}$ & $\begin{array}{l}\text { No ha generado un impacto } \\
\text { mayor en la familia. } \\
\text { Continúan cerrando los } \\
\text { domingos. } \\
\text { Mayor apertura personal. } \\
\text { Actividad que agrada por el } \\
\text { contacto con gente foránea. }\end{array}$ & $\begin{array}{l}\text { Mujer más dedicada al } \\
\text { turismo. } \\
\text { Se incorporó de manera } \\
\text { natural. No generó cambios } \\
\text { en la rutina, o si lo ha } \\
\text { hecho es positivo. } \\
\text { Aporta mayor apertura } \\
\text { mental, cultural y de } \\
\text { formación general sobre } \\
\text { todo a los hijos. }\end{array}$ & $\begin{array}{l}\text { Aporta complejidad desde } \\
\text { el punto de vista de la } \\
\text { redistribución de tareas y } \\
\text { organización del tiempo de } \\
\text { los miembros de la familia. } \\
\text { Más actividades en las } \\
\text { cuales distribuir los tiempos. } \\
\text { Refuerza la autoestima. } \\
\text { Apertura mental y cultural. } \\
\text { Momentos de tensión. }\end{array}$ & $\begin{array}{l}\text { Mujer a futuro más } \\
\text { dedicada al turismo. } \\
\text { Modificaciones en los } \\
\text { tiempos de la familia pero } \\
\text { con posibilidad de } \\
\text { organización. } \\
\text { No alteró los tiempos de } \\
\text { familia (domingos) o viajes } \\
\text { familiares. }\end{array}$ \\
\hline
\end{tabular}

\begin{tabular}{|c|c|c|c|c|c|}
\hline & Caso 6 & Caso 7 & Caso 8 & Caso 9 & Caso 10 \\
\hline $\begin{array}{l}\text { Cambios } \\
\text { más } \\
\text { importantes } \\
\text { en el sistema } \\
\text { productivo }\end{array}$ & $\begin{array}{l}\text { Se maneja el sistema de } \\
\text { forma integrada y esto le da } \\
\text { mayor autonomía. } \\
\text { Los productos de una } \\
\text { actividad son insumo para } \\
\text { otra. } \\
\text { En turismo no se vislumbra } \\
\text { una interdependencia con el }\end{array}$ & $\begin{array}{l}\text { Actividad complementaria. } \\
\text { No compite con las otras en } \\
\text { términos de movilización de } \\
\text { recursos. No interactúa con el } \\
\text { resto de las actividades. } \\
\text { Es funcional a un ingreso que } \\
\text { colabora al mantenimiento } \\
\text { del espacio y no hay una }\end{array}$ & $\begin{array}{l}\text { Con la incorporación del } \\
\text { turismo, el resto de las } \\
\text { actividades y los tiempos de } \\
\text { trabajo comenzaron a girar } \\
\text { en torno a esta. Hoy es la } \\
\text { más importante en términos } \\
\text { de ingresos, satisfacciones }\end{array}$ & $\begin{array}{l}\text { El turismo colabora a } \\
\text { diversificar los ingresos y } \\
\text { dispersar los riesgos. } \\
\text { Mermó la actividad forestal. } \\
\text { Este desplazamiento no fue } \\
\text { a causa del turismo. }\end{array}$ & $\begin{array}{l}\text { La gastronomía/ turismo } \\
\text { desplazó la actividad } \\
\text { pesquera. }\end{array}$ \\
\hline
\end{tabular}




\begin{tabular}{|c|c|c|c|c|c|c|c|c|}
\hline & \multicolumn{2}{|c|}{$\begin{array}{l}\text { resto de las actividades, no } \\
\text { hay competencia, pero } \\
\text { cumple otras funciones } \\
\text { dentro del sistema: genera } \\
\text { ingresos complementarios, } \\
\text { los ingresos permiten } \\
\text { mantener el patrimonio (si no } \\
\text { existiese el patrimonio sería } \\
\text { muy difícil la puesta en } \\
\text { marcha de una propuesta } \\
\text { turística con lo cual hay un } \\
\text { lazo de obligatoriedad entre } \\
\text { patrimonio y turismo }\end{array}$} & \multicolumn{2}{|c|}{$\begin{array}{l}\text { dedicación full time de ningún } \\
\text { miembro de la familia. }\end{array}$} & $\begin{array}{l}\text { personales y proyección a } \\
\text { futuro. } \\
\text { Redujeron la producción de } \\
\text { quesos pero mejoraron el } \\
\text { ingreso económico dando } \\
\text { valor a su producción a } \\
\text { través de la elaboración de } \\
\text { picadas. }\end{array}$ & & & \\
\hline $\begin{array}{l}\text { Cambios en } \\
\text { las personas } \\
\text { y familia }\end{array}$ & \multicolumn{2}{|c|}{$\begin{array}{l}\text { La incorporación de turismo } \\
\text { complejizó las tareas. Los } \\
\text { tiempos son ajustados. } \\
\text { Se requiere de mayor } \\
\text { organización para cumplir con } \\
\text { todas las actividades. } \\
\text { Actividades de ocio que han } \\
\text { dejado de practicarse. } \\
\text { Reclamos en el resto de los } \\
\text { miembros de la familia que no } \\
\text { integran la unidad económica. } \\
\text { Cambio de vida y espacio de } \\
\text { aprendizaje (sobre todo para } \\
\text { la mujer). Oportunidad de } \\
\text { formación para los más } \\
\text { jóvenes. }\end{array}$} & \multicolumn{2}{|c|}{$\begin{array}{l}\text { El tiempo que le dedican al } \\
\text { turismo no compite con sus } \\
\text { tiempos en la fábrica. No ha } \\
\text { generado tensión. Es un } \\
\text { trabajo extra y pierden } \\
\text { libertad. } \\
\text { Preocupaciones en torno al } \\
\text { estado del camino. }\end{array}$} & $\begin{array}{l}\text { Hay momentos de nervios y } \\
\text { tensión. } \\
\text { Se modificó mucho el ritmo } \\
\text { de la familia. La familia } \\
\text { necesita un tiempo para el } \\
\text { descanso. } \\
\text { El turismo les da mayor } \\
\text { apertura, más contacto. } \\
\text { Reconocimiento } \\
\text { estimula a la familia. }\end{array}$ & \multicolumn{2}{|c|}{$\begin{array}{l}\text { Los tiempos son ajustados, } \\
\text { condicionados por el tiempo } \\
\text { y demanda de los turistas. } \\
\text { No genera tensión. Es } \\
\text { tolerable. } \\
\text { Actividad que agrada } \\
\text { realizarse. }\end{array}$} & $\begin{array}{l}\text { Si bien hay desgaste en la } \\
\text { pareja y la familia, el } \\
\text { cambio aportó una mejora } \\
\text { en la calidad de vida. } \\
\text { Mayor interacción social. }\end{array}$ \\
\hline & & \multicolumn{2}{|c|}{ Caso 11} & \multicolumn{3}{|c|}{ Caso 12} & & Caso 13 \\
\hline \multicolumn{2}{|c|}{$\begin{array}{l}\text { Cambios más } \\
\text { importantes en el } \\
\text { sistema productivo }\end{array}$} & \multicolumn{2}{|c|}{$\begin{array}{l}\text { El turismo colabora a diversificar los ingresos y } \\
\text { dispersar los riesgos. Mermó la actividad } \\
\text { forestal y eso llevó a la incorporación del } \\
\text { turismo. Este desplazamiento no fue a causa } \\
\text { del turismo. }\end{array}$} & \multicolumn{3}{|c|}{$\begin{array}{l}\text { Desplazamiento de la actividad productiva por } \\
\text { el turismo. }\end{array}$} & \multicolumn{2}{|c|}{$\begin{array}{l}\text { El turismo colabora al ingreso familiar. } \\
\text { Mermó la actividad forestal y eso llevó a la } \\
\text { incorporación del turismo. Este } \\
\text { desplazamiento no fue a causa del turismo }\end{array}$} \\
\hline
\end{tabular}




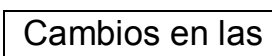

personas y familia
El turismo por sí solo no agrega complejidad al sistema. Es la sumatoria de actividades que requieren organización y tiempo, que pueden provocar momentos de tensión al interior de la familia. No tienen descanso.
Reacomodamiento de tiempos y roles.

El turismo marca la rutina.

Aporta tranquilidad.

Nuevos y diferentes contactos sociales.

Colabora con la unión filial.
Mejora en la calidad de vida.

El turismo por sí solo no agrega complejidad al sistema.

\begin{tabular}{|c|c|c|c|c|c|}
\hline & Caso 1 & Caso 2 & Caso 3 & Caso 4 & Caso 5 \\
\hline $\begin{array}{l}\text { Percepción del } \\
\text { futuro }\end{array}$ & $\begin{array}{l}\text { Proyecto familiar. Seguir } \\
\text { invirtiendo en turismo. } \\
\text { Idea de incorporación de los } \\
\text { hijos. } \\
\text { Actividad menos desgastante } \\
\text { para la pareja. }\end{array}$ & $\begin{array}{l}\text { Proyecto familiar. Seguir } \\
\text { invirtiendo. } \\
\text { La pareja vislumbra el turismo } \\
\text { como un ingreso extra y a } \\
\text { largo plazo como una } \\
\text { actividad que pueden } \\
\text { desarrollar los hijos. }\end{array}$ & $\begin{array}{l}\text { Proyecto para la pareja. } \\
\text { Actividad a la que piensan } \\
\text { dedicarse exclusivamente } \\
\text { en su retiro de la actividad } \\
\text { agropecuaria. } \\
\text { Hay un interés de la } \\
\text { pareja por mantener el } \\
\text { patrimonio familiar. } \\
\text { Los hijos no estarían de } \\
\text { acuerdo con vender la } \\
\text { estancia. }\end{array}$ & $\begin{array}{l}\text { Proyecto familiar. Actividad } \\
\text { menos desgastante para la } \\
\text { pareja. } \\
\text { Piensan en el turismo } \\
\text { además como "un horizonte } \\
\text { para ellos", para los hijos }\end{array}$ & $\begin{array}{l}\text { El desarrollo de las } \\
\text { distintas actividades } \\
\text { productivas y la } \\
\text { integración de uno de los } \\
\text { hijos en el manejo y } \\
\text { gestión, permite a la } \\
\text { pareja de productores } \\
\text { dedicarse a lo que más } \\
\text { les gusta, manteniendo el } \\
\text { patrimonio familiar. }\end{array}$ \\
\hline
\end{tabular}

\begin{tabular}{|c|c|c|c|c|c|}
\hline & Caso 6 & Caso 7 & Caso 8 & Caso 9 & Caso 10 \\
\hline $\begin{array}{l}\text { Percepción del } \\
\text { futuro }\end{array}$ & $\begin{array}{l}\text { Proyecto familiar. Actividad a } \\
\text { la que piensan dedicarse } \\
\text { exclusivamente en su retiro } \\
\text { de la actividad agropecuaria. } \\
\text { Expectativa de continuidad } \\
\text { de las actividades de mano } \\
\text { de los hijos. Idea de } \\
\text { incorporación de los hijos. }\end{array}$ & $\begin{array}{l}\text { La pareja dedicada más al } \\
\text { turismo un tiempo más pero } \\
\text { de forma relajada. Lo central } \\
\text { es el disfrute personal. } \\
\text { Ceden la titularidad de la } \\
\text { fábrica a uno de los hijos } \\
\text { (están realizando inversiones } \\
\text { para ello). } \\
\text { Su idea es que los hijos se } \\
\text { vayan haciendo más cargo } \\
\text { de las actividades. Ellos } \\
\text { acompañar. } \\
\text { La familia también disfruta } \\
\text { del lugar como casa quinta. }\end{array}$ & $\begin{array}{l}\text { Las niñas son muy } \\
\text { pequeñas, no aparece la } \\
\text { preocupación por la } \\
\text { continuidad de la } \\
\text { actividad. }\end{array}$ & $\begin{array}{l}\text { Los hijos están muy } \\
\text { involucrados con las } \\
\text { actividades que realiza la } \\
\text { familia y se evidencia una } \\
\text { clara continuidad de las } \\
\text { mismas en sus manos. } \\
\text { Su idea es que los hijos se } \\
\text { vayan haciendo más cargo } \\
\text { de las actividades. Ellos } \\
\text { acompañar. }\end{array}$ & $\begin{array}{l}\text { La pareja se proyecta en } \\
\text { la actividad gastronómica/ } \\
\text { turística. No aparece muy } \\
\text { fuertemente el tema } \\
\text { sucesional. }\end{array}$ \\
\hline
\end{tabular}




\begin{tabular}{|l|l|l|l|l|}
\hline \multicolumn{2}{|l|}{} & $\begin{array}{l}\text { Los hijos no lo quieren } \\
\text { vender. }\end{array}$ & \multicolumn{1}{|c|}{ Caso 12 } & \multicolumn{1}{|c|}{ Caso 11 } \\
\hline \multicolumn{2}{|c|}{ Caso 13 } \\
\hline Percepción del futuro & $\begin{array}{l}\text { No hay una referencia a la continuidad del } \\
\text { turismo en los hijos. Sí está presente la idea } \\
\text { de que es su jubilación privada. Piensan } \\
\text { seguir invirtiendo hasta convertirlo es su única } \\
\text { actividad. }\end{array}$ & $\begin{array}{l}\text { No aparece muy fuertemente el tema } \\
\text { sucesional. Sí está presente la idea de que es } \\
\text { su jubilación privada. }\end{array}$ & $\begin{array}{l}\text { No aparece muy fuertemente el tema } \\
\text { sucesional. Estilo de vida que agrada y } \\
\text { que piensan continuar (la pareja). }\end{array}$ \\
\hline
\end{tabular}




\section{Anexo 7- Algunas imágenes del trabajo en terreno}

Las que a continuación se presentan son algunas fotografías capturadas por el Dr. Pierre Gasselin en el recorrido realizado en el mes de julio de 2016. Representan algunas de las situaciones compartidas junto al Ing. Gustavo Larrañaga y quien suscribe, que se guardarán en la memoria como anécdotas y aventuras en el marco de parte del trabajo en terreno realizado.

Ilustración 34- Conociendo y aprendiendo de la mano de los entrevistados.

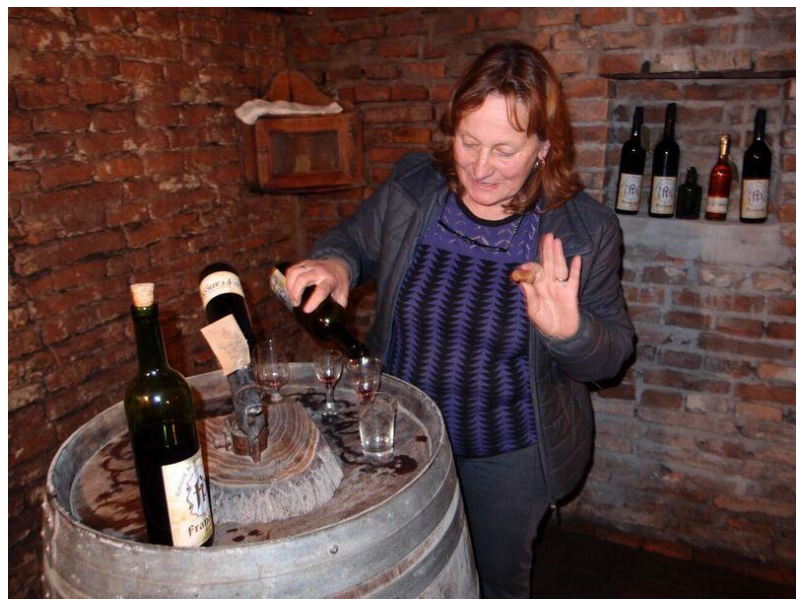

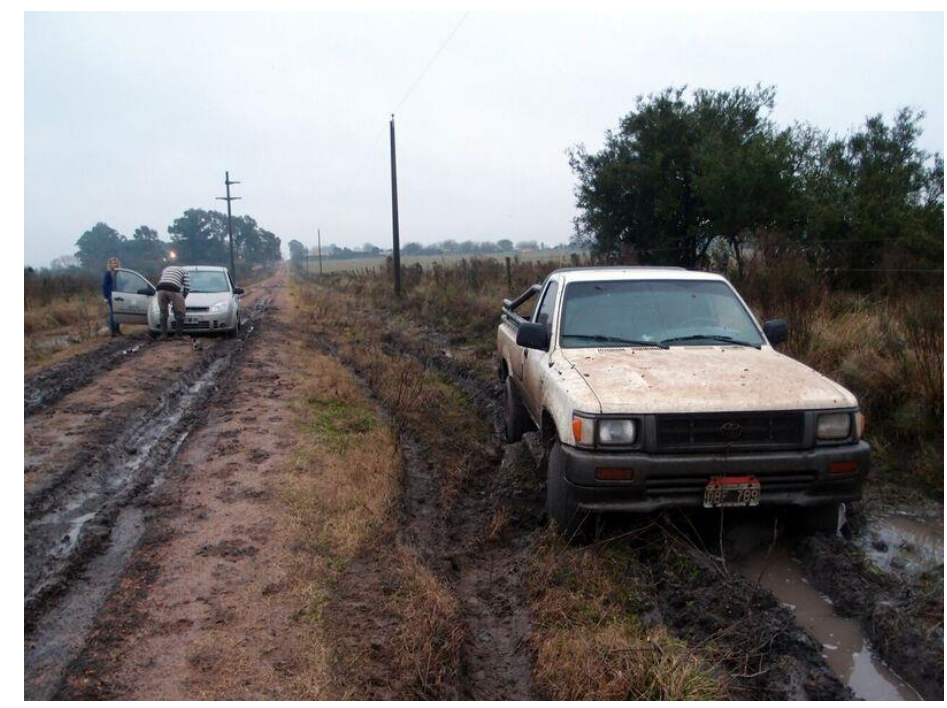

Ilustración 33- Algunas de las dificultades de transitar por caminos rurales en días de lluvia

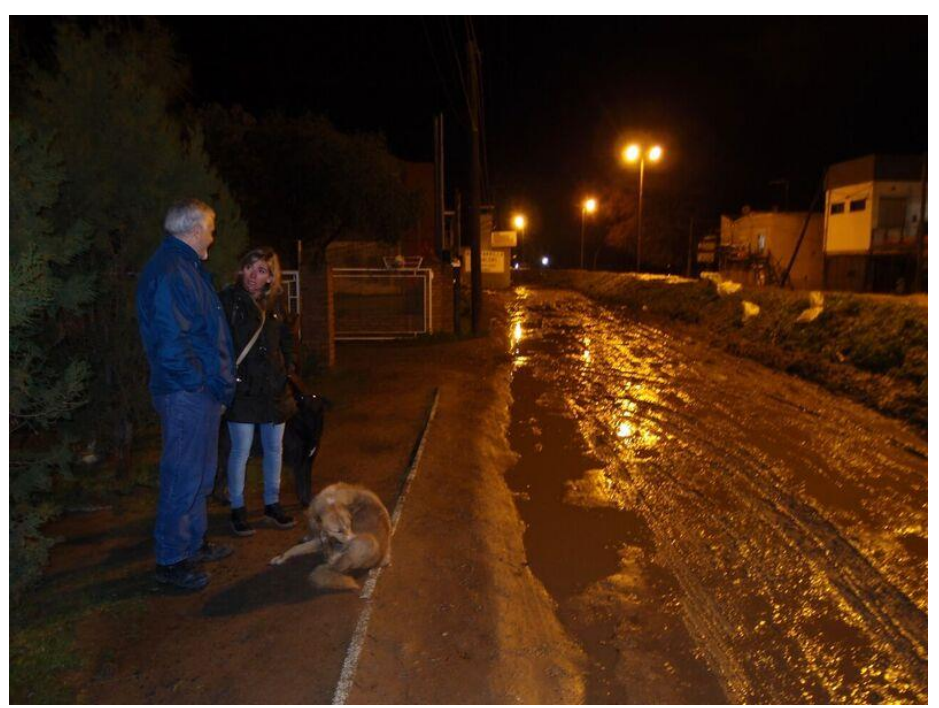

Ilustración 36- Villa Paranacito a pocos días de una de las crecidas más importantes de la historia (2016)

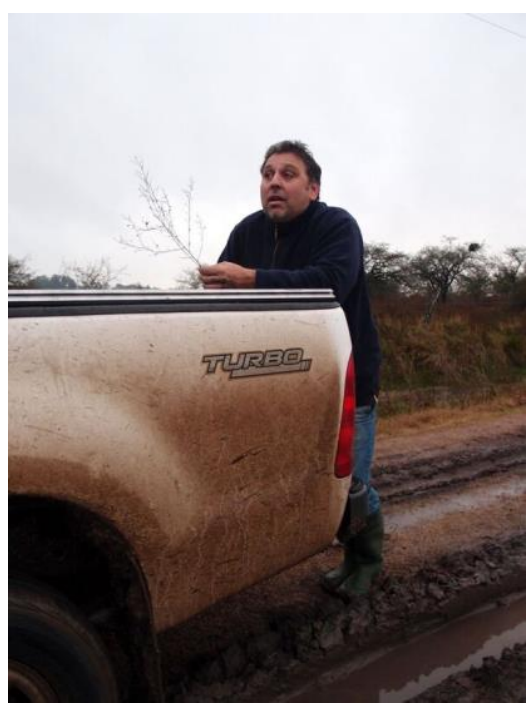

Ilustración 35- Personajes de la colonia que se acercan a ayudar y curiosear 

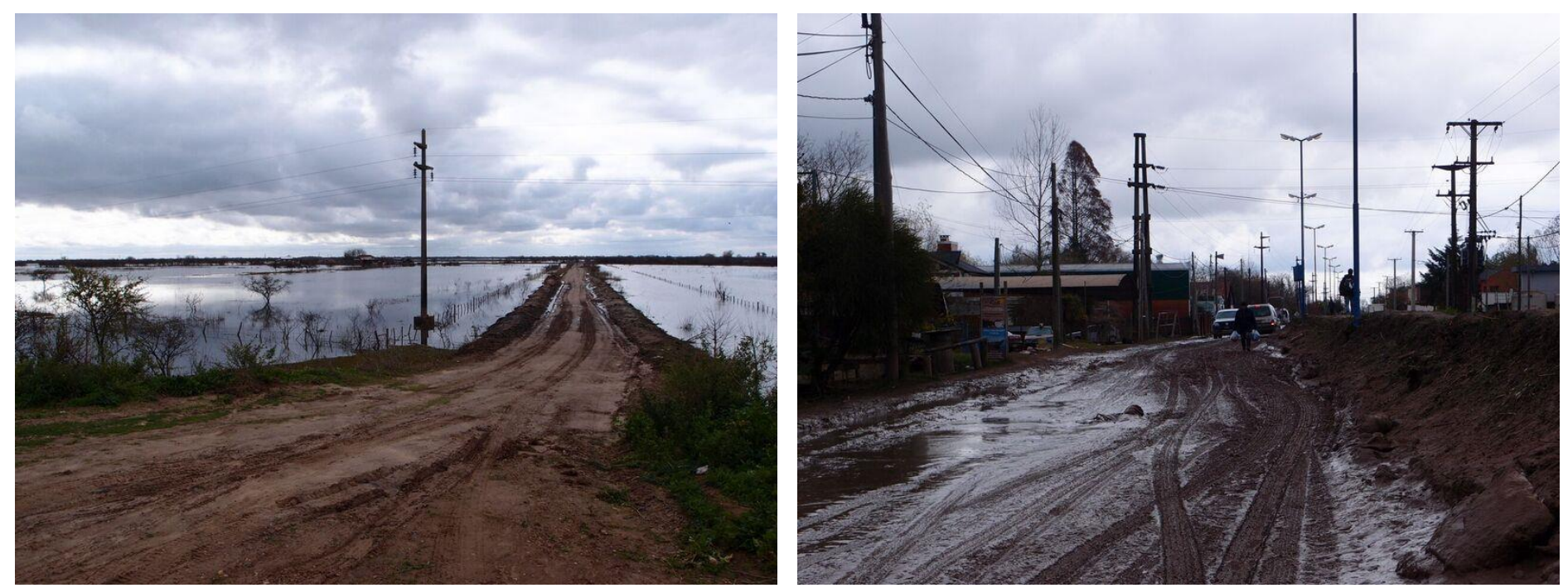

Ilustración 37 y 37- Ingreso a la localidad de Villa Paranacito y entrada al pueblo, a pocos días de retirarse el agua. 